\title{
Geology and Geochemistry of the 25 Ma Underdown Caldera Tuffs and the Tuff of Clipper Gap, Western Nevada Volcanic Field, North- Central Nevada
}

\author{
Kathryn J. Little
}

\begin{abstract}
A thesis submitted to the Faculty of Graduate and Post Doctoral Affairs in partial fulfillment of the requirements for the degree of:

Master of Science

in

Earth Sciences
\end{abstract}

Carleton University, Ottawa

(C) 2020

Kathryn J. Little 


\begin{abstract}
The Underdown Caldera Complex is a 25.0 Ma caldera in the Western Nevada Volcanic Field formed during the mid-Cenozoic Ignimbrite Flare-up, one of the largest expressions of continental volcanism in geological time. Intracaldera and associated outflow tuffs are characteristically crystal-poor, except for one crystal-rich intracaldera tuff representing a later stage of explosive volcanism. Outflow tuffs extend to the east and west of the caldera, representing multiple phases of intracaldera tuffs. Postdeposition alteration of ignimbrites has altered $\mathrm{Sr}$ isotopic ratios, and caused rare earth element enrichment in the Tuff of Clipper Gap. Sr and Nd isotopic compositions of the ignimbrites show a relation to lavas collected from the margins of the caldera, and trace element ratios suggest similar origins of the lavas and ignimbrites from a mixture of mantle and crustal sources. $\mathrm{Pb}$ isotopes plot on mixing lines formed by a mantle-derived source and either a local sedimentary or granitoid unit.
\end{abstract}




\section{Acknowledgements}

Firstly, I would like to acknowledge my supervisor, Brian Cousens, for giving me a wonderful opportunity to learn research skills with an interesting project in an exciting field environment. Without your guidance and support, this thesis would not have been possible.

I would like to thank Dr. Christopher Henry for his invaluable help and insight in the field and throughout this project, and Evelyn Tennant for being a fantastic field partner. Thank you to Tim Mount in the Carleton University Rock Preparation Lab for preparing over one hundred thin sections and helping to prepare samples for geochemical analyses. As well, thank you to Dr. Shuangquan Zhang for all of your help in and out of the geochemistry and mass spectrometry labs. Finally, thank you to Kim Klausen for collecting and preparing samples from 2016, and thank you to Zach Pearse for geochemical work on the anomalous REE samples.

I would also like to thank the "Spice Geologists" Dr. Chris Rogers, Dr. Nico Kastek, Dr. Sarah Davey, and Matthew Trenkler for invaluable insight and advice, as well as great office memories. Thank you to all of my other close friends who have supported me throughout my time at Carleton University.

Thank you to my parents, Sue and Pat Little, and my siblings Emily and Matthew for your constant encouragement. A special thank you to Lucas Brewster, the support and patience you've given me the past two and a half years helped me to finish the project I 
thought I never could. Finally, to my Nana, Betty McCulloch, and Grandma, Liisa Little whom we said goodbye to in the last year of work. Without you I would not be where I am today, and I will be forever grateful for all of the lessons you taught me outside of the classroom. 


\section{Table of Contents}

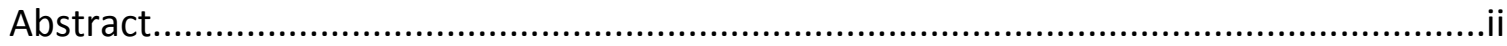

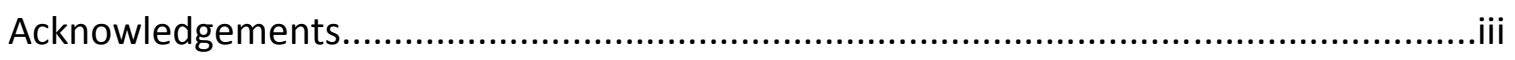

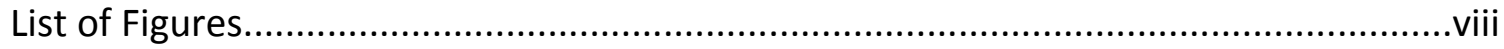

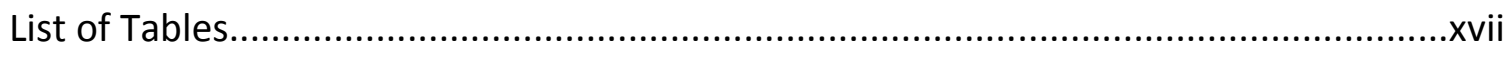

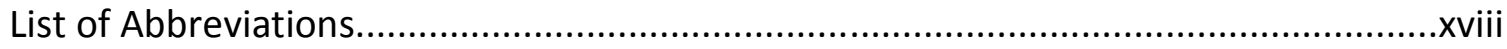

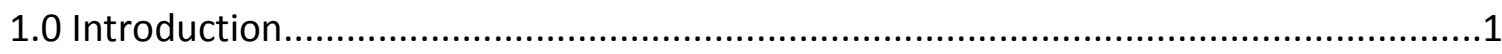

2.0 Geological History of the Southwestern United States..........................................3

2.1 Tectonic and Associated Magmatic Activity..................................................

2.2 Flat Slab Subduction...........................................................................

2.3 The Mid-Cenozoic Ignimbrite Flare-up.................................................... 5

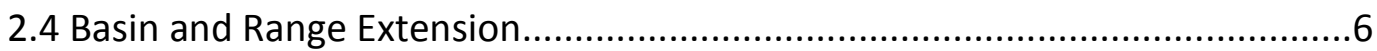

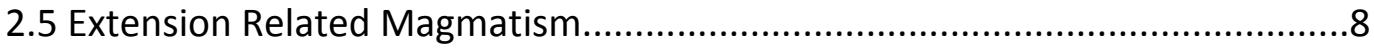

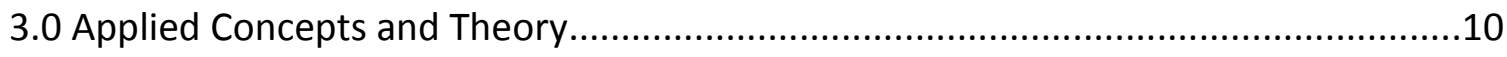

3.1 Generation of Felsic Magma.................................................................10

3.2 Caldera Formation and Pyroclastic Flow Deposits.....................................14

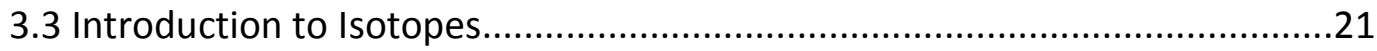

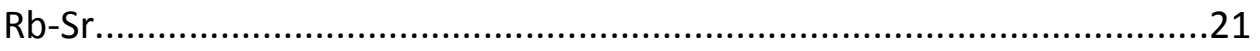

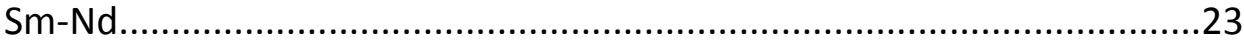

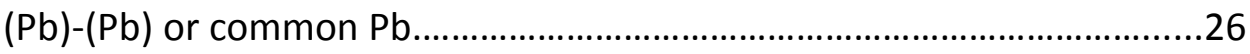

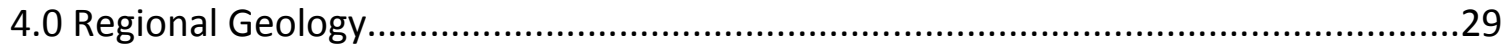

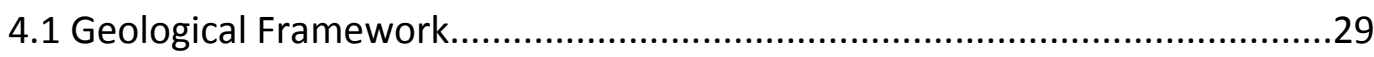

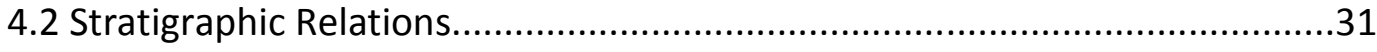

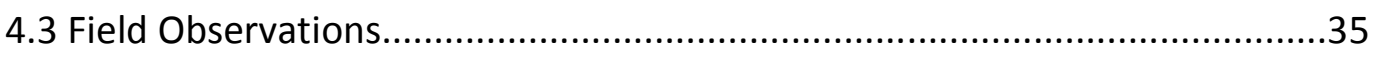

Intracaldera tuffs and the tuff of Clipper Gap......................................35

Other tuffs and potential outflow tuff..............................................40

Megabreccia blocks...................................................................44

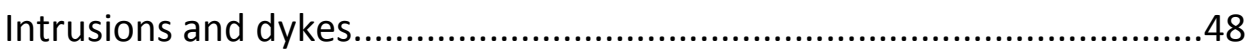


5.0 Methods

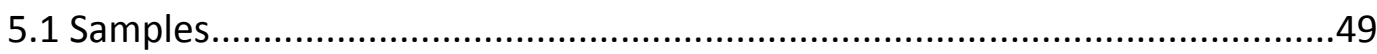

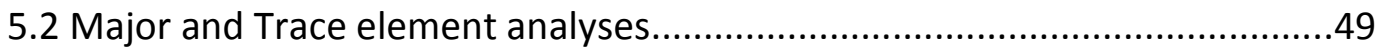

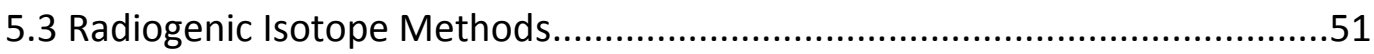

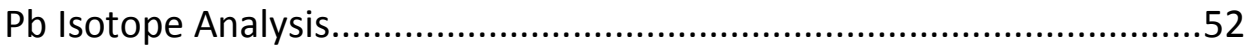

Sr Isotope Analysis..............................................................................53

Nd Isotope Analysis...............................................................................54

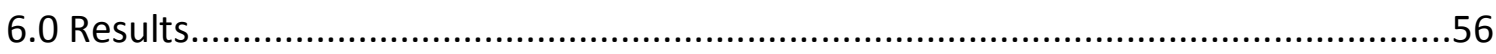

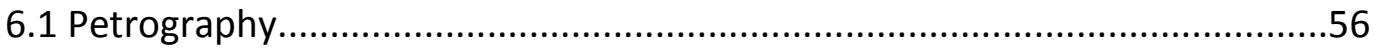

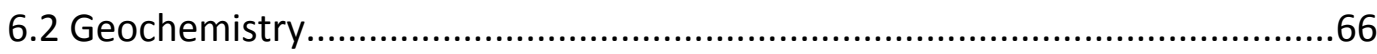

6.2.1 Major element geochemistry...........................................................68

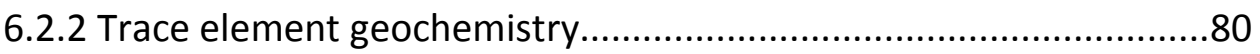

6.2.3 Isotope geochemistry.................................................................93

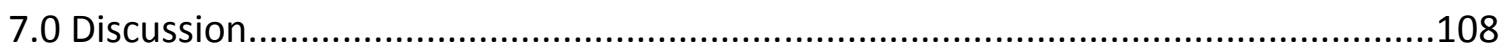

7.1 Establishing Primary Characteristics......................................................108

7.1.1 Petrographic characteristics.......................................................108

7.1.2 Geochemical characteristics......................................................109

7.1.3 Potential alteration of isotopic ratios............................................114

7.1.4 Potential sources of the Oligocene tuffs........................................121

7.1.5 Relationship of the Underdown Tuff, tuff of Clipper Gap, and Bonita

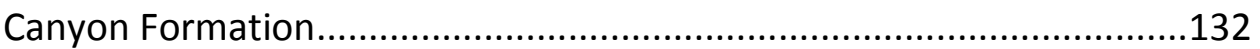

7.1.6 Identity of the Unnamed tuff.......................................................133

7.2 Cerium Anomalies in the tuff of Clipper Gap.............................................141

7.2.1 REE chemistry of the anomalous samples.......................................141

7.2.2 Major element geochemistry of the anomalous samples...............143

7.2.3 Trace element geochemistry of the anomalous samples...............146

7.2.4 Effects of acid washing on anomalous REE samples......................149

7.2.5 Potential sources of Ce anomalies and REE enrichment................160

7.3 Other potentially related exposures.............................................................167 
7.3.1 The tuff of Gabbs Valley................................................................167

7.3.2 The tuff of Arc Dome....................................................................175

7.3.3 The tuff of Brunton Pass................................................................176

7.3.4 The Terrill Mountains tuffs..........................................................181

7.3.5 Young Sierra Nevada tuffs........................................................187

7.4 The Origin of Porphyritic Pumice in the Underdown Tuff.............................197

7.4.1 Field Observations and Petrography.............................................197

7.4.2 Major Element Geochemistry.....................................................199

7.4.3 Trace Element Geochemistry.......................................................202

7.4.4 Source of the Porphyritic Pumice.................................................206

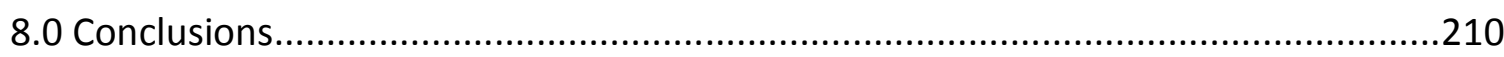

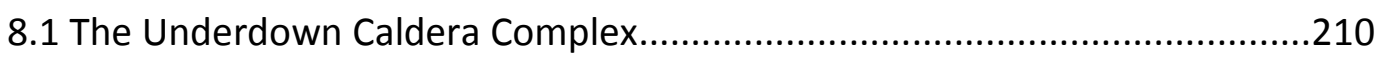

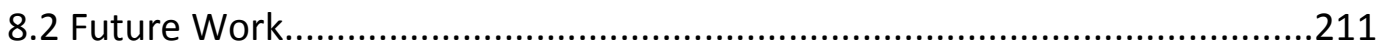

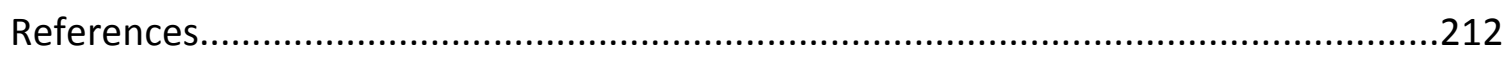

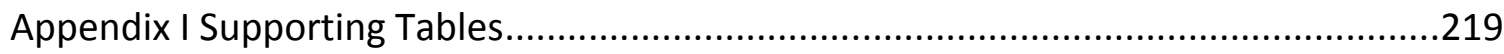

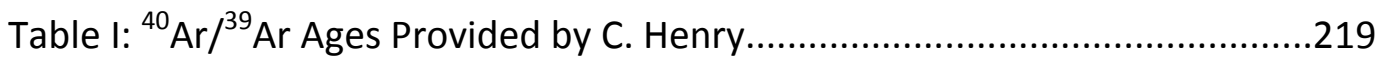

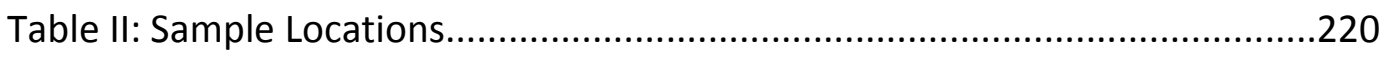

Table III: Thin Section Descriptions...............................................................224

Table IV: Major Element Oxide Abundances.......................................................248

Table V: Precision of Major Element analyses..................................................253

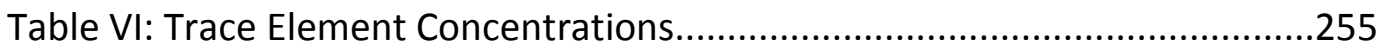

Table VII: Precision of Trace Element analyses................................................267

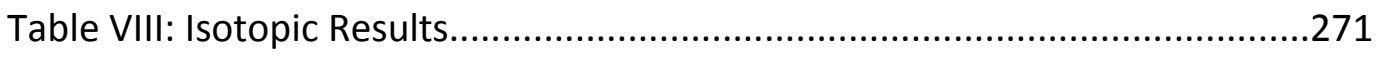

Table IX: Sr Isotopic Precision.......................................................................274

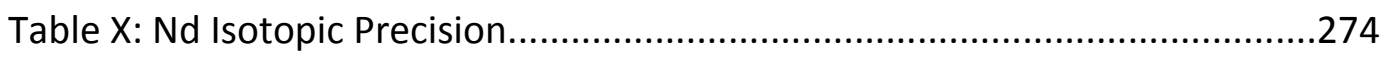

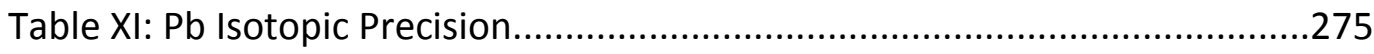

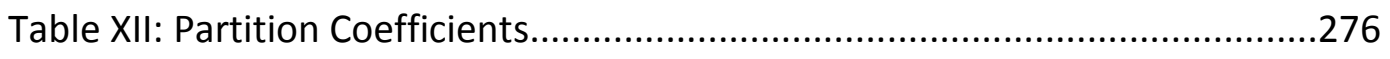




\section{List of Figures}

Figure 2.1: Rollback of the subducting Farallon slab can be traced using geochronology from the north east to the southwest of Nevada. 6

Figure 3.1: A Deep Crustal Hot Zone (DCHZ) by Annen, 2006 .13

Figure 3.2: The evolution and collapse of a dacitic magma system and caldera over an approximately 1 million year time period (modified after Christiansen, 2005)...... 16

Figure 3.3: Schematic of an idealized ignimbrite deposit, after Sparks et al., 1973......20

Figure 3.4: Sr vs. Nd isotopic correlation. .26

Figure 3.5: $\mathrm{A}{ }^{206} \mathrm{~Pb} /{ }^{204} \mathrm{~Pb}$ vs. ${ }^{207} \mathrm{~Pb} /{ }^{204} \mathrm{~Pb}$ diagram showing the differences in isotopic value of the oceanic basalt (mantle) and granites and gneiss (continental crust)..........28

Figure 4.1: Map of the western United States showing the location of the Underdown Caldera (UC) in the Western Nevada Volcanic Field (modified from Henry and John, 2013) 30

Figure 4.2: The Underdown Caldera complex as mapped by H. F. Bonham (1970)......33

Figure 4.3: The eastern and southern extent of the tuff of Clipper Gap, an outflow tuff from the Underdown Caldera 34

Figure 4.4: Field photos of cooling joints of the Underdown Tuff from Barrett Canyon (A) and a cross section slab of a cooling joint (B)....

Figure 4.5: The tuff of Clipper Gap exposed at Moore's Canyon Road..... .38

Figure 4.6: (A) A large outcrop of Bonita Canyon Formation in Barrett Canyon...........39

Figure 4.7: (A) The Unnamed tuff showing its highly porphyritic texture.....................40

Figure 4.8: (A) Outcrop photo of the tuff of Gabbs Valley (geologists for scale)..........42

Figure 4.9: Hand sample and outcrop photographs of TgV2 and TgV3 from Fissure Ridge. .43

Figure 4.10: (A) The Terrill Mountains tuffs are exposed as a lower, grey, poorly to moderately welded unit, and an upper, brown, moderately welded cooling unit, separated by a vitrophyre. 
Figure 4.11: (A) A Pablo Formation outcrop in Barrett Canyon (geologists for scale).

Figure 4.12: (A) Large spires of a quartz-feldspar-biotite tuff deposited on the Bonita Canyon Formation which are megabreccia blocks of the tuff of Arc Dome from the caldera wall that fell inwards into the caldera during collapse. .47

Figure 6.1: Photomicrographs of major ignimbrites showing commonly observed textures. .64

Figure 6.2: Photomicrographs of major ignimbrites showing hydrous phases (hornblende and biotite). .65

Figure 6.3: Total alkalis-silica diagram (Le Maitre et al., 1989) of all data from the Underdown Caldera Complex...... .67

Figure 6.4: Average chondrite normalized rare earth element patterns of the Tuff of Clipper Gap samples with no Ce anomalies and those with Ce anomalies (normalization factors of Sun and McDonough, 1989). 68

Figure 6.5: Total alkalis-silica diagram (Le Maitre et al., 1989) showing the fields of all units collected within and outside of the Underdown Caldera..... .74

Figure 6.6: Total alkalis-silica diagram (Le Maitre et al., 1989) showing the major ignimbrite units (Underdown Tuff, tuff of Clipper Gap, Bonita Canyon Formation, and Unnamed tuff - without Ce anomaly or high LOI samples), mafic to intermediate basement rocks (Pablo Formation), dacite dyke, and rhyolite intrusions collected from the Underdown Caldera. .75

Figure 6.7: Total alkalis-silica diagram (Le Maitre et al., 1989) showing the other ignimbrite units (tuff of Gabbs Valley, tuff of Arc Dome, tuff of Brunton Pass) and the Terrill Mountains tuffs that are close in age to the Underdown tuff..............................76

Figure 6.8: Major element variation diagrams of the Pablo Formation.......................77

Figure 6.9: Major element variation diagrams of the major ignimbrites and the rhyolite intrusions of the Underdown Caldera complex .78

Figure 6.10: Major element variation diagrams of the other tuffs (tuff of Gabbs Valley, tuff of Arc Dome, and tuff of Brunton Pass) and the Terrill Mountains tuffs .79 
Figure 6.6: Trace element variation diagrams of the Pablo Formation and the dacite dyke. 84

Figure 6.12: Trace element variation diagrams of the major ignimbrites and the rhyolite intrusions of the Underdown Caldera complex .85

Figure 6.13: Trace element variation diagrams of the other tuffs (tuff of Gabbs Valley, tuff of Arc Dome, and tuff of Brunton Pass) and the Terrill Mountains tuff...... .86

Figure 6.14: Chondrite normalized (Sun and McDonough, 1989) rare earth element diagrams for the Pablo Formation and the dacite dyke.

Figure 6.15: Chondrite normalized (Sun and McDonough, 1989) rare earth element diagrams for the major ignimbrites of the Underdown Caldera complex (Underdown Tuff, tuff of Clipper Gap, Bonita Canyon Formation and the Unnamed tuff) and the rhyolite intrusions. .88

Figure 6.16: Chondrite normalized (Sun and McDonough, 1989) rare earth element diagrams for the slightly older Oligocene tuffs (tuff of Gabbs Valley, tuff of Arc Dome, tuff of Brunton Pass) and the Terrill Mountains tuffs.

Figure 6.17: Primitive mantle normalized (Sun and McDonough, 1989) trace element diagram for the Pablo Formation and dacite dyke.....

Figure 6.18: Primitive mantle normalized (Sun and McDonough, 1989) trace element diagram for the major ignimbrites of the Underdown Caldera complex (Underdown Tuff, Tuff of Clipper Gap, Bonita Canyon Formation, and Unnamed tuff) and the rhyolite intrusions

.91

Figure 6.19: Primitive mantle normalized (Sun and McDonough, 1989) trace element diagram for the other tuffs (tuff of Gabbs Valley, tuff of Arc Dome, and tuff of Brunton Pass) and the Terrill Mountains tuff....

Figure 6.20: (A) $\varepsilon N d$ versus ${ }^{87} \mathrm{Sr} /{ }^{86} \mathrm{Sr}$ with all Underdown Caldera complex data. (B) Same as in (A), but samples with negative $C e$ anomalies have been removed. (C) Same as in (B), but high LOI (> 6\%) samples have been removed. (D) Same as in (C), but acidwashed tuff of Clipper Gap samples are plotted for comparison. .96

Figure 6.21: "Fresh" and acid-washed data plotted on an initial $\varepsilon N d$ versus ${ }^{87} \mathrm{Sr} /{ }^{86} \mathrm{Sr}$ diagram without the Pablo Formation. .99 
Figure 6.22: Initial ${ }^{87} \mathrm{Sr} /{ }^{86} \mathrm{Sr}$ versus $1 / \mathrm{Sr}$ (ppm) plot showing the relation between $\mathrm{Sr}$ concentration and ${ }^{87} \mathrm{Sr} /{ }^{86} \mathrm{Sr}$ isotopic ratios.

Figure 6.23: Initial ${ }^{87} \mathrm{Sr} /{ }^{86} \mathrm{Sr}$ versus $\mathrm{SiO}_{2}$ content showing the relationship between $\mathrm{Sr}$ isotopic values and increasing $\mathrm{SiO}_{2}$ content.

Figure 6.24: Initial $\varepsilon N d$ versus $1 / \mathrm{Nd}(\mathrm{ppm})$ showing the relation between epsilon $\mathrm{Nd}$ values and $\mathrm{Nd}$ concentration

Figure 6.25: Initial $\varepsilon N d$ versus $\mathrm{SiO}_{2}$ weight percentage showing the comparison between epsilon $\mathrm{Nd}$ values and increasing $\mathrm{SiO}_{2}$ content.

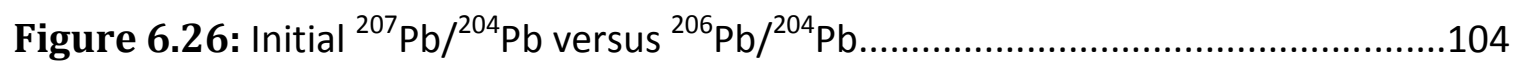

Figure 6.27: Initial ${ }^{208} \mathrm{~Pb} /{ }^{204} \mathrm{~Pb}$ versus ${ }^{206} \mathrm{~Pb} /{ }^{204} \mathrm{~Pb}$ showing the correlation between increasing ${ }^{206} \mathrm{~Pb} /{ }^{204} \mathrm{~Pb}$ and increasing ${ }^{208} \mathrm{~Pb} /{ }^{204} \mathrm{~Pb}$ 105

Figure 6.28: Initial ${ }^{208} \mathrm{~Pb} /{ }^{204} \mathrm{~Pb}$ versus $\mathrm{SiO}_{2}$ weight percentage showing the comparison between ${ }^{208} \mathrm{~Pb} /{ }^{204} \mathrm{~Pb}$ and increasing $\mathrm{SiO}_{2}$ content......

Figure 6.29: Initial ${ }^{208} \mathrm{~Pb} /{ }^{204} \mathrm{~Pb}$ versus $\mathrm{Pb}(\mathrm{ppm})$ showing the comparison between $\mathrm{Pb}$ isotopic values and $\mathrm{Pb}$ concentration

Figure 7.1: Initial Sr and $\mathrm{Nd}$ isotopic data showing the comparison between the high LOI samples and the "fresh" samples....

Figure 7.2: Initial $\mathrm{Pb}$ isotopic diagrams showing the comparison between the high LOI samples and the "fresh" samples....

Figure 7.3: Initial $\mathrm{Sr}$ and $\mathrm{Nd}$ isotopic diagrams showing the comparison between the anomalous REE samples, their acid-washed equivalents, and the "fresh" samples.......119

Figure 7.4: Initial $\mathrm{Pb}$ isotopic diagrams showing the comparison between the anomalous REE samples, their acid-washed equivalents, and the "fresh" samples.......120

Figure 7.5: Age corrected ${ }^{87} \mathrm{Sr} /{ }^{86} \mathrm{Sr}$ vs. primitive mantle normalized Gd/Yb comparing the "fresh" Oligocene tuffs and the acid-washed tuff of Clipper Gap samples with the Miocene lavas.

Figure 7.6: $\varepsilon N d$ vs. ${ }^{87} \mathrm{Sr} /{ }^{86} \mathrm{Sr}$ after Allègre (2008) showing the "fresh" samples, acidwashed tuff of Clipper Gap samples, and Miocene lavas. 
Figure 7.7: Primitive mantle normalized (Sun and McDonough, 1989) Th/La versus $\mathrm{SiO}_{2}$ content of the "fresh" Oligocene tuffs, acid-washed tuff of Clipper Gap samples, and Miocene lavas showing potential crustal addition with increasing magma evolution .126

Figure 7.8: Initial ${ }^{207} \mathrm{~Pb} /{ }^{204} \mathrm{~Pb}$ versus ${ }^{206} \mathrm{~Pb} /{ }^{204} \mathrm{~Pb}$ diagram modified after Allègre (2008). .128

Figure 7.9: Initial ${ }^{207} \mathrm{~Pb} /{ }^{204} \mathrm{~Pb}$ vs. ${ }^{206} \mathrm{~Pb} /{ }^{204} \mathrm{~Pb}$ for the Underdown Caldera ignimbrites compared to mixing between a Miocene lava (red square) (17-SML-11) and an average of selected Paleozoic sedimentary rocks (blue square) (Stepner, 2017).

Figure 7.10: Initial ${ }^{207} \mathrm{~Pb} /{ }^{204} \mathrm{~Pb}$ vs. ${ }^{206} \mathrm{~Pb} /{ }^{204} \mathrm{~Pb}$ for the Underdown Caldera ignimbrites compared to mixing between a Miocene lava (red square) (17-SML-11) and a late Eocene pluton from the Northern Shoshone Range (blue square) (Cousens et al., 2019).

131

Figure 7.11: Total alkalis-silica diagram (Le Maitre et al., 1989) of the Unnamed tuff and the Tuff of Toiyabe (with data from John, 1974). 134

Figure 7.12: Major element variation diagrams comparing the Unnamed tuff with the Tuff of Toiyabe (with data from John, 1974), as well as the Underdown Tuff and Bonita Canyon Formation for reference. 135

Figure 7.13: Trace element variation diagrams comparing the Unnamed tuff with the Tuff of Toiyabe (with data from John, 1974), as well as the Underdown Tuff and Bonita Canyon Formation for reference.

Figure 7.14: Primitive mantle normalized trace element diagram (Sun and McDonough, 1989) of the average trace element concentrations of the Tuff of Toiyabe, Unnamed tuff, Unnamed pumice, and Underdown Tuff, using a limited amount of trace element data available from John (1974) 138

Figure 7.15: Initial ${ }^{87} \mathrm{Sr} /{ }^{86} \mathrm{Sr}$ versus $1 / \mathrm{Sr}$ concentration (A) and $\mathrm{SiO}_{2}$ content (B) showing the $\mathrm{Sr}$ isotope data for the Tuff of Toiyabe and Unnamed tuff (with isotope data from John, 1974).

Figure 7.16: (A) Chondrite normalized rare earth element diagram for the anomalous REE samples 
Figure 7.17: Total alkalis-silica diagram (Le Maitre et al., 1989) of the anomalous-REE samples from the Tuff of Clipper Gap shows the samples plotting in a trend from the rhyolite to trachyte fields, with the whole rock samples plotting exclusively in the rhyolite field and the porphyritic pumice samples plotting in both the trachyte field and rhyolite field.

Figure 7.18: Major element oxides plotted versus $\mathrm{SiO}_{2}$ show that the trachyte samples plot as a cluster in half of the comparisons $\left(\mathrm{CaO}, \mathrm{K}_{2} \mathrm{O}\right.$, and $\left.\mathrm{Na}_{2} \mathrm{O}\right)$ and a scatter in the other half $\left(\mathrm{Al}_{2} \mathrm{O}_{3}, \mathrm{Fe}_{2} \mathrm{O}_{3}, \mathrm{P}_{2} \mathrm{O}_{5}\right.$, and $\left.\mathrm{TiO}_{2}\right)$ 145

Figure 7.19: Trace element variation diagrams for the anomalous REE samples from the tuff of Clipper Gap, as well as the non-anomalous Underdown Tuff and tuff of Clipper Gap samples for comparison.... 148

Figure 7.20: A line diagram showing the effect of acid washing on the major element oxides of the anomalous REE samples and non-anomalous REE samples. .151

Figure 7.21: Chondrite normalized REE diagrams for the acid-washed samples before (A) and after acid washing (B)..... .153

Figure 7.22: A line diagram showing the change in trace element concentration after the acid washing process. 154

Figure 7.23: Initial ${ }^{87} \mathrm{Sr} /{ }^{86} \mathrm{Sr}$ ratios plotted against $\mathrm{Sr}$ concentration for acid-washed and unwashed anomalous REE samples. 156

Figure 7.24: Initial $\varepsilon N d$ plotted against $\mathrm{Nd}$ concentration for the acid-washed and unwashed anomalous REE samples from the tuff of Clipper Gap. .157

Figure 7.25: Initial ${ }^{208} \mathrm{~Pb} /{ }^{204} \mathrm{~Pb}$ vs. ${ }^{206} \mathrm{~Pb} /{ }^{204} \mathrm{~Pb}$ showing the change in isotopic ratio after acid washing. .158

Figure 7.26: Initial ${ }^{208} \mathrm{~Pb} /{ }^{204} \mathrm{~Pb}$ isotopic ratios plotted against $\mathrm{Pb}$ concentrations showing the change in isotopic ratio and $\mathrm{Pb}$ concentrations of the anomalous $\mathrm{REE}$ samples after acid washing...... .159

Figure 7.27: The fractionation of amphibole before and after the acid washing process. $\mathrm{Dy} / \mathrm{Yb}$ is used to represent the formation of amphibole as amphibole preferentially partitions Dy into its structure, but takes in much less $\mathrm{Yb}$. .162 
Figure 7.28: (A) Chondrite normalized REE and (B) primitive mantle normalized trace element diagrams comparing TgV2 ("tuff of Gabbs Valley") and the tuff of Arc Dome.

Figure 7.29: (A) Chondrite normalized REE and (B) primitive mantle normalized trace element diagrams comparing all samples from TgV2 ("tuff of Gabbs Valley") and two samples (17-SM-14, 16-SM-09) from the tuff of Arc Dome 170

Figure 7.30: (A) Chondrite normalized REE and (B) primitive mantle normalized trace element diagrams comparing TgV3 ("tuff of Gabbs Valley" porphyritic pumice) to the Underdown porphyritic pumice samples.

Figure 7.31: Chondrite normalized rare earth element plot $(A)$ and primitive mantle normalized trace element plot (B) comparing TgV3 with the Bonita Canyon Formation and the Underdown Tuff (porphyritic pumice).

Figure 7.32: $\mathrm{Nd}$ isotopic diagrams showing the difference in initial $\varepsilon N d$ values between TgV2 and TgV3. 174

Figure 7.33: Chondrite normalized rare earth element diagram (A) and primitive mantle normalized trace element diagram (B) showing the comparison between the Tuff of Arc Dome and the megabreccia block sampled from the Underdown Caldera.........176

Figure 7.34: Chondrite normalized REE $(A)$ and primitive mantle normalized trace element (B) diagrams showing similar patterns in both the Underdown Tuff and the tuff of Brunton Pass.

Figure 7.35: Chondrite normalized REE diagram showing the comparison between the anomalous REE Clipper Gap whole rock and porphyritic pumice samples to the tuff of Brunton Pass.

Figure 7.36: Primitive mantle normalized Th/La vs. $\mathrm{SiO}_{2}$ content indicating crustal addition into the Oligocene tuffs and Miocene lavas.

Figure 7.37: (A) Chondrite normalized REE and (B) primitive normalized trace element diagrams showing the comparison between the Underdown Tuff (whole rock samples), the Terrill Mountains tuffs and the Terrill Mountains pumice 182

Figure 7.38: Primitive mantle normalized $\mathrm{Th} / \mathrm{La}$ vs. $\mathrm{SiO}_{2}$ content indicating crustal addition into the Oligocene tuffs and Miocene lavas. 
Figure 7.39: (A) Initial $\varepsilon N d$ versus ${ }^{206} \mathrm{~Pb} /{ }^{204} \mathrm{~Pb}$ and $\left(\mathrm{B}\right.$ ) initial ${ }^{208} \mathrm{~Pb} /{ }^{204} \mathrm{~Pb}$ versus ${ }^{206} \mathrm{~Pb} /{ }^{204} \mathrm{~Pb}$ showing the comparison between the Terrill Mountains tuffs and the other Oligocene tuffs from the Underdown Caldera complex. 185

Figure 7.40: Total alkalis-silicate diagram (Le Maitre et al., 1989) comparing the Young Sierra Nevada tuffs to the Underdown Tuff. 188

Figure 7.41: Major element variation diagrams comparing the Young Sierra Nevada tuffs with the Underdown Tuff 189

Figure 7.42: Trace element bivariate diagrams comparing the Young Sierra Nevada tuffs to the Underdown Tuff. 191

Figure 7.43: (A) Chondrite normalized REE and (B) primitive mantle normalized trace element diagrams comparing the Young Sierra Nevada tuffs with the Underdown Tuff.

Figure 7.44: Primitive mantle normalized $\mathrm{Th} / \mathrm{La}$ vs. $\mathrm{SiO}_{2}$ content indicating crustal addition into the Oligocene tuffs and Miocene lavas.

Figure 7.45: (A) Chondrite normalized REE and (B) primitive mantle normalized trace element diagrams showing the comparison between the Young Sierra Nevada tuffs and the Bonita Canyon Formation

Figure 7.46: Map of the Western Great Basin, showing the location of the Underdown Tuff (light blue dashed circle) and the placement and flow direction of paleovalleys...196

Figure 7.47: Field photograph of a porphyritic pumice from the Underdown Tuff.....198

Figure 7.48: Total alkalis-silica diagram (Le Maitre et al., 1989) of the Underdown Tuff, porphyritic pumice and white pumice. 200

Figure 7.49: Major element oxide versus $\mathrm{SiO}_{2}$ content diagrams for the Underdown Tuff. 201

Figure 7.50: Trace element bivariate diagrams showing the compatibility of trace elements in the Underdown Tuff whole rock, porphyritic pumice and white pumice...204

Figure 7.51: (A) Chondrite normalized rare earth element plot and (B) primitive mantle normalized trace element plot of the average Underdown Tuff whole rock, average porphyritic pumice, and white pumice samples (normalizing data from Sun and McDonough, 1989). 205 
Figure 7.52: (A) Chondrite normalized rare earth element plot and (B) primitive mantle normalized trace element plot of the average Underdown Tuff whole rock sample, most evolved porphyritic pumice sample (16-SM-29A), least evolved porphyritic pumice sample (17-SM-17C), and white pumice sample (16-SM-29B) (normalizing data from Sun

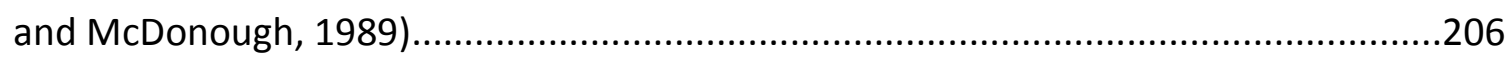

Figure 7.53: Porphyritic pumice in the Tuff of Campbell Creek. The observation of porphyritic pumice in a crystal poor ash flow tuff outside of the Underdown Caldera suggests that the presence of porphyritic pumice in the Western Nevada Volcanic Field may be more common than previously thought.....................................................209 


\section{List of Tables}

Table 7.1: Samples selected for the acid washing process, including porphyritic pumice, white pumice, whole rock and vitrophyre samples....................................................149 


\section{List of Abbreviations}

HREE: Heavy rare earth element

LREE: Light rare earth element

MASH: melting, assimilation, storage, and homogenization

REE: Rare earth element

TAS: Total alkalis-silica

WNVF: Western Nevada Volcanic Field 


\subsection{Introduction}

Western North America was shaped by a complex history of subduction, extension, and magmatism through geologic time. One of the largest expressions of continental volcanism in geological history (Best et al., 2013; Best et al., 2016, and references therein), the mid-Cenozoic Ignimbrite Flare-up, formed an extensive field of caldera complexes and outflow tuffs which, in western Nevada, remain largely unstudied. Recent work to understand the petrogenesis of these large volume caldera forming ignimbrites is providing a better understanding of their origins (Henry and John, 2013;

Best et al., 2013; Watts et al., 2016; Stepner, 2017; Cousens et al., 2019).

The 36-18 Ma Ignimbrite Flare-up is responsible for the formation of the Western Nevada Volcanic field (WNVF), a belt of calderas extending across the state of Nevada, USA. The belt was formed as a result of a sweep of magmatic activity caused by the rollback of the shallowly subducting Farallon plate beneath North America (Best et al., 2013; Henry and John, 2013; Best et al., 2016; Timmermans, 2015). During rollback, intrusions of mantle-derived magmas stalled in the thick continental crust, partially melting the continental crust, and ultimately erupting as caldera forming ignimbrite magmas (Hildreth and Moorbath, 1988; Annen and Sparks, 2002; Clemens and Stevens, 2012). The currently accepted model for the generation of subduction-related arc magmas begins with the intrusion of mantle-derived basaltic magmas into the lower crust. Mixing of the mantle-derived magmas and partial melts from the continental crust, followed by fractional crystallization and segregation of remaining melt, results in 
the generation of felsic magma (Smith, 1979; Hildreth 1981; Hildreth and Moorbath, 1988; Annen et al., 2006; de Silva, 2008). The input of mantle and crustal components into the final magma can be modelled using radiogenic isotopes, providing more information on the petrogenesis of evolved magmas (Davidson, 1985; Aitcheson et al., 1995; Siebel et al., 2001).

The Great Basin Ignimbrite province, formed as a result of the Ignimbrite Flare-up, is divided into three fields which are delineated by the limit of exposed outflow tuffs (Henry and John, 2013; Best et al., 2016). From west to east these fields are the Western, Central, and Indian Peak-Caliente volcanic fields, of which the WNVF is the least studied in terms of geochemistry and petrology. This study focuses on the Underdown Caldera complex, a 25.0 Ma caldera in the WNVF which was mapped for the Nevada Bureau of Mines (Bonham, 1970), but has no petrographic or geochemical analyses of the intracaldera and extracaldera tuffs. The aim of this work is to utilize petrographic analyses, as well as major element, trace element, and radiogenic isotope data to characterize the intracaldera and extracaldera tuffs from the Underdown Caldera complex. The use of $\mathrm{Sr}, \mathrm{Nd}$, and $\mathrm{Pb}$ isotopic data in comparison with Miocene lavas from the margins of the Underdown Caldera will be used to identify potential melt source(s) for the Underdown Caldera ignimbrites. 


\subsection{Geological History of the Southwestern United States}

The Underdown Caldera is one of many caldera complexes in the Southwestern United States that formed during the mid-Cenozoic Ignimbrite Flare-up, one of the largest Mesozoic-Cenozoic ignimbrite events unrelated to continental breakup (Best et al., 2013; Best et al., 2016, and references therein). An overview of the tectonic and magmatic history of the southwestern United States will be discussed in this section.

\subsection{Tectonic and Associated Magmatic Activity}

The basement of the western United States consists of Precambrian basement to the east (Dickinson, 2006) and Phanerozoic oceanic terranes to the west, forming the basement of the future WNVF (DeCelles, 2004; Henry and John, 2013, Best et al., 2016).

Prior to the Mesozoic, a plate boundary existed along the western edge of North America where the Mezcalera plate bordered the continental plate, but changed to a subduction zone by the Late Jurassic (DeCelles, 2004). In the early Late Jurassic, the Farallon plate was subducting underneath consolidated accreted terranes along the Pacific margin of the North American Plate (DeCelles, 2004). Continental arc magmatism and periods of east-vergent shortening formed the Cordilleran orogeny as the slab continued to subduct beneath North America (DeCelles, 2004), culminating in the Laramide orogen (McKee, 1971). At the end of the Mesozoic, subduction of the Farallon Plate beneath North America became more rapid, and changed geometry from a typical dipping subduction zone to flat slab subduction (DeCelles, 2004; Humphreys, 2009; 
Henry and John, 2013; Best et al., 2013; Best et al., 2016). Magmatism ceased where the slab came in full contact with the underside of North America, and the arc shifted into more central regions of the North American continent (Lipman, 1992).

\subsection{Flat Slab Subduction}

Flat-slab subduction began as the dip of the subducting slab shallowed between $90-50$ Ma, which replaced the asthenospheric mantle wedge with a relatively cold oceanic lithospheric plate, and prevented melting within the asthenosphere (Henry and John, 2013; Best et al., 2016, and references therein). Shallowing of the Farallon slab dip is hypothesized to have been caused by a number of factors including: (1) rapid convergence between North America and the Farallon slab (Engebretson et al., 1985; Jarrad, 1986; van Hunen et al., 2002), (2) buoyancy of the young subducting slab (Cadek and Fleitout, 2003; O'Driscoll et al., 2009), and/or (3) suction between the oceanic slab and the continental plate (Cadek and Fleitout, 2003; O'Driscoll et al., 2009). The interaction of the flat-subducting Farallon slab with the overlying continent hydrated the mantle lithosphere, and caused crustal thickening and the formation of the Nevadaplano on which the Central Nevada and Indian-Peak Caliente volcanic fields would eventually form (Best et al., 2016). During the hiatus of arc magmatism in what is now the Great Basin, magmatic activity consisted of the emplacement of S-type granitic plutons, partially melted from meta-sedimentary rocks from the miogeoclinal wedge (Best et al., 1974; Lee and Christiansen, 1983; Farmer and DePaolo, 1983). 


\subsection{The Mid-Cenozoic Ignimbrite Flare-up}

Steepening, or rollback, of the Farallon slab beneath the continent triggered a sweep of magmatic activity from the northeast to the southwest of Nevada between 45 and $3 \mathrm{Ma}$ (Henry and John, 2013; Cousens et al., 2008). The interaction of the re-established hot mantle wedge with the hydrated, fertile mantle lithosphere generated large volumes of basaltic magma through partial melting. This was the driving force behind calderaforming explosive silicic volcanism, with the most voluminous silicic volcanism occurring between 36 - 18 Ma (Best et al., 2016). The sweep of magmatic activity followed the northeast to southwest rollback of the Farallon slab which can be traced using geochronological data (Henry and John, 2013; Best et al., 2016) (Fig. 2.1). This magmatic event, recognized by Lipman et al. (1972) and Noble (1972), was termed the Ignimbrite Flare-up by Coney (1978). The sweep of large volume silicic magmatism stopped at the Walker Lane, a zone of transpressional strike-slip deformation located on the southwestern edge of Nevada, while mafic to intermediate magmatism including stratovolcanoes and lava domes continued across the Walker Lane into the Sierra Nevada Mountains (Henry and John, 2013). While silicic and andesitic volcanism dominated the Ignimbrite Flareup, basaltic magmatism occurred after $20 \mathrm{Ma}$ (Best et al., 2016). 


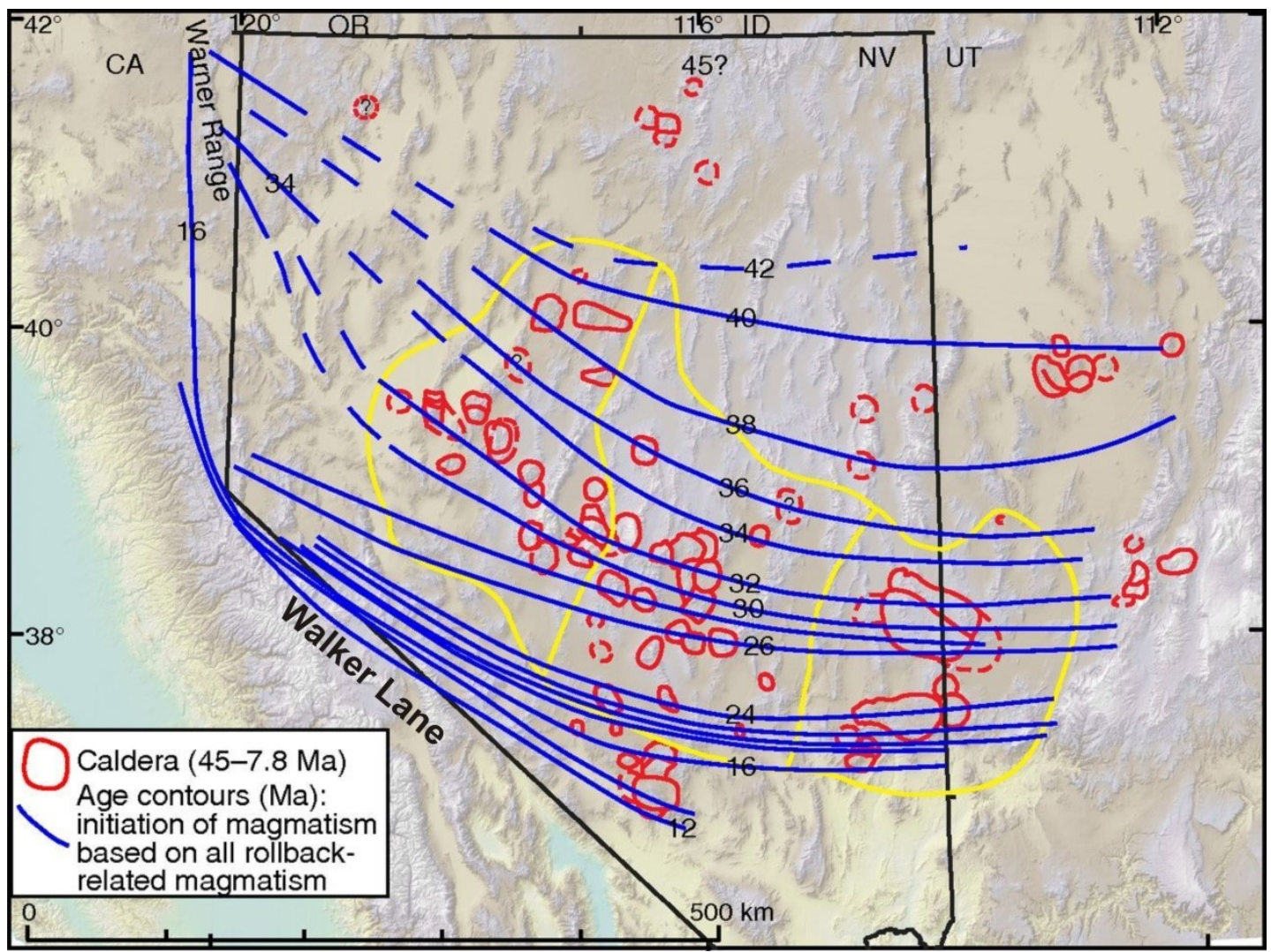

Figure 2.1: Rollback of the subducting Farallon slab can be traced using geochronology from the northeast to the southwest of Nevada. Migration of magmatism began in the northeast of Nevada and tracked to the southwest over time before stopping at the Walker Lane (Henry and John, 2013).

\subsection{Basin and Range Extension}

In the late Cenozoic, widespread high angle normal faulting and resulting crustal extension formed the Basin and Range Province which consists of alternating elongate mountain ranges and alluvial basins (McKee, 1971). While the terms Basin and Range Province and Great Basin are often used interchangeably when describing the NorthSouth trending mountain ranges in Nevada, it is important to note the differences between these two terms. The Great Basin is an endoheric watershed which drains 
internally, as it has no connection to an ocean, and is contained within the Basin and Range Province which extends from the Pacific Northwest to Mexico for almost 2500 $\mathrm{km}$. The Basin and Range Province is characterized by faulted mountain chains and flat, alluvial valleys which were formed from extensional processes. Subsequent to the Ignimbrite Flare-up, the Great Basin underwent two extensional events (Dickinson, 2006).

Rapid Miocene extension in the Basin and Range Province began at 17-16 Ma and continued only a few million years until 12-10 Ma. Until this time, the Basin and Range province was believed to be held together by the fully subducted Farallon slab beneath the continent. The collapse of the Nevadaplano is thought to have occurred after the last piece of the Farallon slab delaminated from beneath the continent (Armstrong and Ward, 1991; Colgan and Henry, 2009). The mechanisms aiding in the extension in the mid Miocene were potentially a combination of (1) shear along the transform San Andreas Fault system, (2) gravitational collapse of the Nevadaplano, and/or (3) magmatic activity including mantle upwelling of the Yellowstone plume, formation of the northern Nevada Rift, and the main phase of the Columbia River flood basalt eruption (Atwater, 1970; Camp et al., 2015). The San Andreas transform fault system was present along the continental margin by the Early Miocene (Dickinson, 2006) and it is believed that shear interaction along the fault system caused transtensional motion of the Sierra Nevada continental block. The Basin and Range region accommodated for the movement of the Sierra Nevada block to the northwest by extension (Atwater, 1970). 
Contrary to extension in the Basin and Range Province, Cenozoic extension in the Great Basin is believed to be unrelated to the formation of the transform fault system, as the subduction of the Farallon slab was still occurring during the time of extension (Dickinson, 2006). The first stage of Cenozoic extension in the Great Basin involved the denudation of metamorphic core complexes which were subjected to $50-100 \%$ strain (Parsons et al., 1996; Colgan and Henry, 2009; Camp et al., 2015). The second extensional event involved high angle block faulting which produced the basin and range topography characteristic of the Basin and Range Province. The second event began around $17 \mathrm{Ma}$ and involved $100 \%$ extension along normal faults which resulted in stacked, tilted fault blocks separated by valleys in between where sedimentation could occur (Proffett, 1977; Chamberlin, 1983). Tilting of the fault blocks was varied, but was between 5-8 degrees in the southern Shoshone range, the field area for this project.

\subsection{Extension Related Magmatism}

Some have postulated that the deformation of the continental block and formation of the Basin and Range Province during the Miocene triggered the rejuvenation of magmatism in the Great Basin, particularly basaltic-andesitic magmatism (Dickinson, 2006). However, after the inception of the Great Basin at ca. $17 \mathrm{Ma}$, rollback continued through the late Miocene, Pliocene, and Quaternary, producing mostly basalts to andesites rather than calderas, and no clear distinction between extension-related lavas and arc-related lavas has been determined (Cousens et al., 2012). The arrival of the Yellowstone plume is believed to have formed the large volume Columbia River flood 
basalts. Presently, the plume is centred beneath Yellowstone (Colgan and Henry, 2009, and references therein), however the plume arrived in northern Nevada between 16-17 Ma and early volcanic activity consisted of caldera formation and the eruption of rhyolitic tuffs (Geist and Richards, 1993) and emplacement of mafic dykes and felsic domes of the northern Nevada rift (John et al., 2000; Camp et al., 2015). Large volume, middle Miocene basaltic magmatism occurred during a volcanic maximum for the Yellowstone hotspot with the eruptions of the Steens and Columbia River basalts which cover a large portion of Oregon, Washington, and northwestern Nevada. The relation of the Yellowstone plume to the extension in the Basin and Range Province has been debated by some authors who believe the beginning of Basin and Range extension predates the arrival of the Yellowstone plume (e.g., Colgan et al., 2013). 


\subsection{Applied Concepts and Theory}

\subsection{Generation of Felsic Magma}

The generation of basaltic magma from partial melting of the mantle is a known and accepted concept. However, the process by which an evolved magma is formed has been under debate, as its origins are far more complex. Multiple processes are believed to occur to evolve from a basaltic magma to a rhyolitic or granitic magma end member. This section will discuss these potential magma forming processes as well as an accepted model for felsic magma generation.

Hutton (1794) first proposed that the intrusion of mafic magma and fusion of preexisting rocks formed silicic melts, however further research into the generation of felsic magmas in arc settings has resulted in a more complex picture of the mechanisms of felsic magma generation in subduction zones, including the interactions between mantle and crustal material, and crustal anatexis (Perry et al., 1993; Annen and Sparks, 2002; de Silva, 2008; Clemens and Stevens, 2012). In a continental arc setting, a combination of partial melting and mixing of a variety of sources can contribute to the generation of silicic magma, including the subducted oceanic crust and sediments, the mantle wedge, the continental crust, crustal underplates, and the subcontinental lithospheric mantle (Winter, 2001). In a subduction zone, the dehydration of the subducting oceanic plate releases volatiles which induce flux melting of the lithospheric mantle to produce mafic magma. The mafic magma ascends and pools at the mantle- 
crust boundary where it partially melts the continental crust and is believed to assimilate crustal material.

De Paolo (1981) proposed that the assimilation of crustal rocks by a basaltic magma was an important factor in the generation of felsic magmas, and mathematically demonstrated the combined effects of assimilation of wall rock and fractional crystallization (AFC). While other authors also believe that the assimilation of wall rock plays a role in the generation of silicic magmas, it is not believed to be a large contributor to pluton-wide compositional variations due to energy constraints and the inevitable crystallization and cooling of the intruding magma during assimilation (Clemens and Stevens, 2012). In addition, partial melting of a basaltic parent and/or the extensive fractional crystallization of a primitive, tholeiitic melt does yield felsic magma. However, this process would produce a volume of magma too small to form the large volume silicic volcanism observed in the Ignimbrite Flare-up. Therefore, pure crustal melting and pure fractional crystallization from a basaltic parent are discounted as major mechanisms behind the production of an evolved magma (Perry et al., 1993; Clemens and Stevens, 2012).

It is proposed that felsic magmas found in arc systems are likely formed by a combination of fractional crystallization of a mantle wedge derived magma, and partial melting of older crust (Annen and Sparks, 2002; Clemens and Stevens, 2012). In this model basaltic magma is fluxed into the crust episodically over time. Heat and volatiles transferred from the crystallizing basaltic magma induces partial melting of the pre- 
existing crust. Melt generation in the crust is controlled by multiple factors including the magma intrusion rate, the water content and composition of the pre-existing crust, and the water content and temperature of the intruding basalt. For example, a dry basaltic magma intrusion into fertile crustal rocks is capable of producing a large volume of melt (Annen and Sparks, 2002).

It is in this deep crustal area that a combination of magma modification processes occurs simultaneously to produce large volumes of intermediate to felsic magma (Annen and Sparks, 2002; Clemens and Stevens, 2012). This zone was proposed by Hildreth and Moorbath (1988) as the MASH (melting, assimilation, storage, and homogenization) zone. Basaltic magma is intruded into the deep crust in a MASH zone where it undergoes differentiation by crystallization and crustal anatexis to produce a variety of magma compositions. Annen et al. $(2006,2008)$ and Solano et al., (2012) expanded the idea of the MASH zone model and proposed a Deep Crustal Hot Zone (DCHZ) at 20-50 $\mathrm{km}$ depth where episodic intrusions of basaltic magma through sills progressively elevates the temperature of the lower crust (Fig. 3.1). Basaltic injections that remain partially molten due to the increased temperature are able to mix with residual melts as they accumulate in the hot zone. Crustal melting and re-melting of intrusions will occur with the increasing temperature of the lower crust provided by the injection of basaltic magma. The resulting andesite-dacite magma will evolve to a more silicic melt through differentiation after cooling and degassing during ascent. 


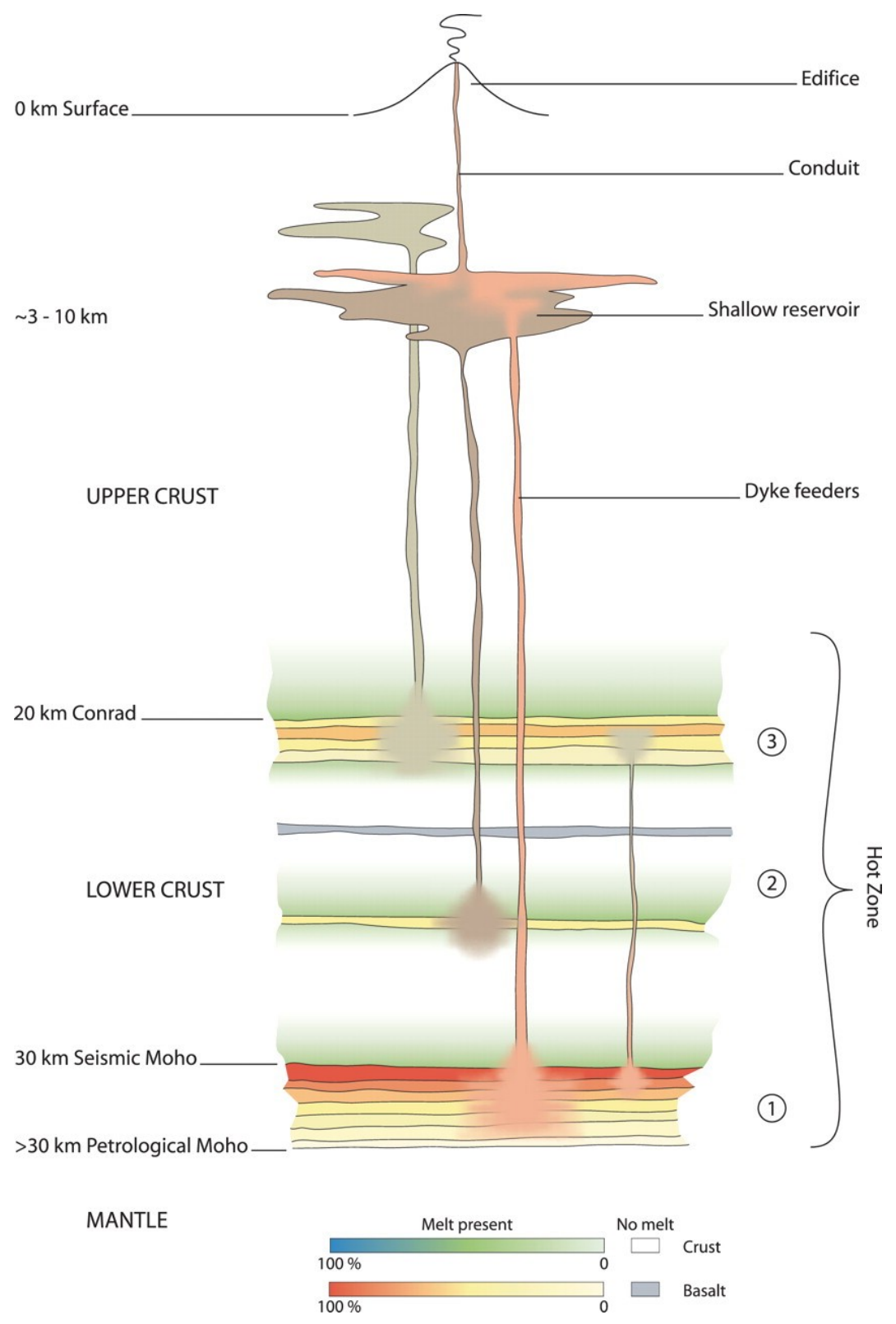

Figure 3.1: A Deep Crustal Hot Zone (DCHZ) by Annen, 2006. Basaltic magma is intruded at depth in episodic injections which heat the surrounding crust. The heated crust allows later injections of basaltic magma to accumulate and mix with other melts in the hot zone. Crustal melting and magma mixing produces an intermediate magma which differentiates into a silicic magma as it is ascending. 


\subsection{Caldera Formation and Pyroclastic Flow Deposits}

A caldera is a volcanic depression which is formed during volcanic eruptions. Two mechanisms for caldera formation include the collapse of a volcano into an emptying magma chamber below or the removal of the top of a volcano by exploding volcanic gases, the former of which will be discussed in more detail. The collapse of a basaltic caldera involves the foundering of caldera blocks into an underlying lava lake, displacing the magma upwards. The formation of a silicic caldera can be much more violent, as fractures through the overlying blocks reach down to the magma chamber, reducing pressure in the magma chamber by rapid vesiculation, and allowing for the escape of magma. As support for the overlying roof disappears with the emptying of the magma chamber, the roof blocks collapse into the void below. Magma escaping through the fractures and the formation of gas bubbles causes a violent eruption that produces pyroclastic materials and caldera-filling ignimbrites. 
Very large volume

outflow tuff ignimbrite fills caldera
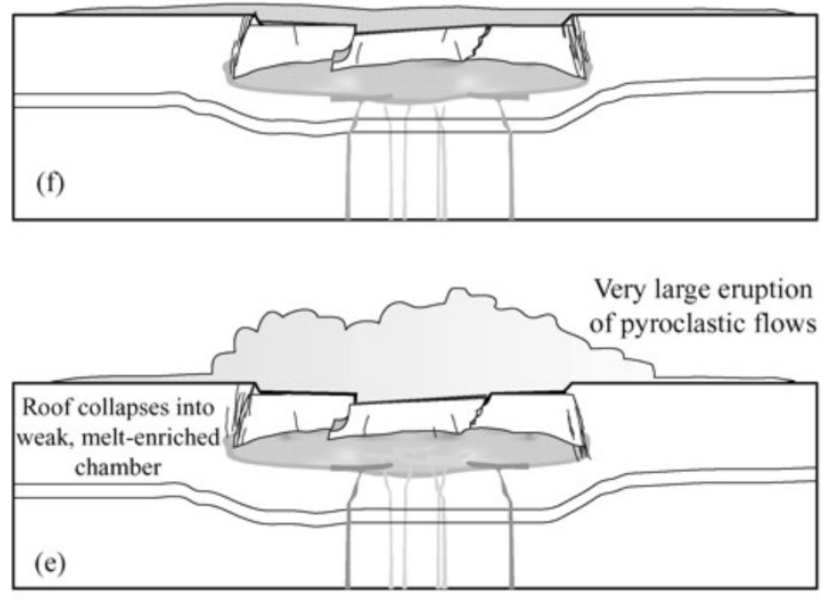

Fractures form and support of roof drops

Continued uplift

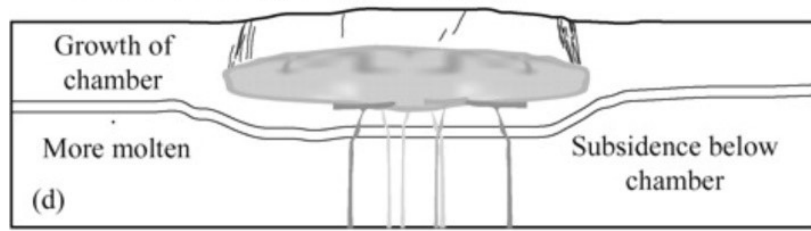

Uplift of surface

\begin{tabular}{|l|c|}
\hline & \\
\hline & \\
\hline & $\begin{array}{c}\text { Continued growth of } \\
\text { mushy magma chamber } \\
\text { More molten }\end{array}$ \\
\hline
\end{tabular}

\begin{tabular}{|l|c|}
\hline $\begin{array}{c}\text { Magma nearly stagnant } \\
\text { Little differentiation }\end{array}$ & $\begin{array}{c}\text { Continued growth of } \\
\text { mushy magma chamber } \\
\text { More molten }\end{array}$ \\
\hline (b) & Evolution of a large-volume dacitic magma system \\
\hline
\end{tabular}

Small chamber, cools quickly, mostly solid

(a)

Rising mafic recharge and silicic magma from lower crustal MASH zone 
Figure 3.2: The evolution and collapse of a dacitic magma system and caldera over an approximately 1 million year time period (modified after Christiansen, 2005). (A) Basaltic magma pools in a lower crustal MASH zone where it forms a small, quickly crystallized magma chamber. (B) and (C) Repeated injection of basaltic material into the lower crust allows the growth of the magma chamber and the change from a crystallized to a mushy state. (D) Fractures form in the roof of the caldera over a large magma chamber. Fractures allow a conduit for the magma to travel upwards as it rapidly degasses and explosively erupts. (E) Support for the roof fails as the magma chamber is emptied and the roof collapses downwards as an explosive pyroclastic eruption occurs. (F) Large volume silicic ignimbrites fill the caldera. 
A main product of these caldera forming eruptions are pyroclastic deposits which are formed from the fragmented material exploded from the vent during the eruption. Pyroclastic deposits are composed of pyroclasts (hot fragments) and can be divided into three categories; pyroclastic falls, pyroclastic flows, and surge deposits (sometimes considered flow deposits). Pyroclastic fall deposits are formed from the fallout of ash from a vertical eruption column, formed from a plinian-style eruption. During these highly explosive eruptions, pyroclasts (hot fragments) are propelled upwards by explosion and/or buoyant convecting gases from the vent and are carried by wind. As the forces carrying the particles dissipate, they fall back down to the Earth and form pyroclastic fall deposits. Ash particles are held the longest in air; however denser particles will fall sooner, resulting in fall deposits that are well sorted and are graded. Grain size of a fall deposit fines upwards and away from the vent. Because they are formed by fallout of relatively cool particles, pyroclastic fall deposits mantle topography and rarely become welded after deposition. The size, shape, and particle size of a pyroclastic fall deposit depends on multiple factors including the rate of explusion, the volume of erupted material, the force of the pyroclastic eruption, and the speed and direction of prevailing winds which carry the eruption column and pyroclasts.

Pyroclastic flow deposits are commonly formed from the collapse of a plinian eruption column due to the density of the suspended material and volcanic gases. However, they can also be formed by a lateral blast from a volcano (e.g. Mount St. Helens), the boiling over of a gas rich magma from a vent, or the collapse of a lava dome. Pyroclastic flows 
are composed of ash, pumice, crystals and lithic fragments that have been blasted off of surrounding rock during an explosive volcanic eruption. Trapped gases within and below the pyroclastic flow cause it to be fluidized. Pyroclastic flows are hot and fast moving, flowing downwards with topography and travelling far away from their source vent in some cases. As the flow loses momentum, the hot pyroclasts suspended in the flow will be deposited, with concentrated deposits occurring in topographic lows. Pyroclastic deposits are referred to as ignimbrites, which have varied textures depending on the nature of the flow and eruption. When sorting does occur in an ignimbrite, it can be characterized by the concentration of dense, lithic fragments at the base of the flow, and lighter blocks of pumice at the top of the flow (Fig. 3.3). Heat of the deposited pyroclasts and weight of overlying material can cause lower parts of the ignimbrite deposit to become welded and foliated. Pumice blocks from these welded sections are flattened, turning the pumice into black obsidian which is then referred to as fiamme.

Pyroclastic surge deposits are erupted from the vent at a very high velocity and contain fewer particles than a pyroclastic flow. The speed and low density of a surge deposit causes the deposits to both mantle topography and concentrate in topographic lows as the deposit hugs the ground when it is erupted from the vent. Surge deposits lose momentum quickly and therefore are deposited close to the vent. Typically, surge deposits show stratification and are cross bedded. A deposit from a pyroclastic eruption may be a product of all three deposit types, based on factors such as the distance from the vent and magnitude of the eruption. In addition, pyroclastic eruptions often occur in 
distinct episodes which can be reflected by the nature of the pyroclastic deposit (Winter, 2001). 


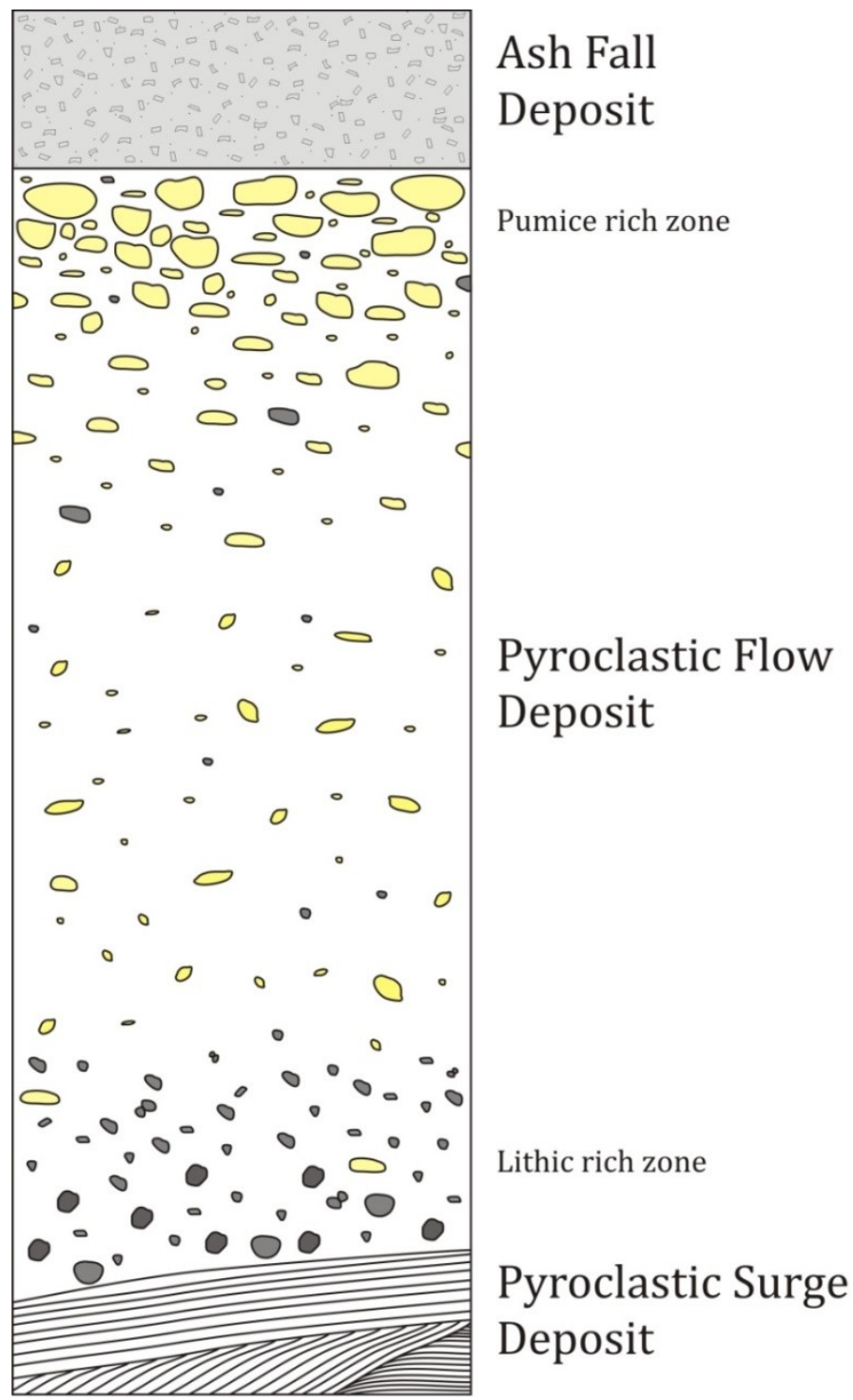

Figure 3.3: Schematic of an idealized ignimbrite deposit, after Sparks et al., 1973. The base of the ignimbrite deposit marks a high velocity, low density eruption of fine material called a pyroclastic surge deposit. The deposit can often display cross-bedding structures indicative of its eruption energy. The pyroclastic flow deposit is characterized by a concentration of dense lithic fragments at the base of the deposit and lighter pumice blocks at the top of the deposit. The pyroclastic flow deposit commonly occurs after the collapse of the plinian eruption column and concentrates in topographic lows. The ash fall deposit lies on top of the pyroclastic flow deposit and is composed of the lightest material (ash, lapilli, and pumice) which fall back down to Earth from the ash cloud and settle on the land surface last. Ash fall deposits mantle topography and extend in the direction of the prevailing winds. 


\subsection{Introduction to isotopes}

\section{$\mathbf{R b}-\mathrm{Sr}$}

The basic radioactive decay equation used in radiogenic isotopic analysis is:

$$
D=D_{0}+N\left(e^{\lambda t}-1\right)
$$

Where $D$ is the number of daughter isotope atoms, $D_{0}$ is the initial number of daughter atoms, $\mathrm{N}$ is the number of parent isotope atoms, $\mathrm{t}$ is the amount of time passed, and $\lambda$ is the decay constant. Based on this equation, the amount of daughter isotope in a closed system is a function of the amount of time passed $(\mathrm{t})$ and the ratio of parent to daughter isotopes in the system at the time of closure (Dickin, 2005).

The rubidium $(\mathrm{Rb})$ - strontium $(\mathrm{Sr})$ isotopic system was one of the first isotopic systems originally developed for geochronometry, but is now commonly used in source identification of igneous rocks, due to the behavioural differences of the parent and daughter isotopes during partial melting. Rb has two naturally occurring isotopes, ${ }^{85} \mathrm{Rb}$ and ${ }^{87} \mathrm{Rb}$, whose abundances are 72.1654 and 27.8346 percent, respectively. While ${ }^{85} \mathrm{Rb}$ is a stable isotope, ${ }^{87} \mathrm{Rb}$ is radioactive. Strontium has four isotopes ${ }^{84} \mathrm{Sr},{ }^{86} \mathrm{Sr},{ }^{87} \mathrm{Sr}$, and ${ }^{88} \mathrm{Sr}$. Of these four, ${ }^{87} \mathrm{Sr}$ is the only radiogenic isotope and is produced by the beta decay of ${ }^{87} \mathrm{Rb}$ with a half-life of ${ }^{87} \mathrm{Rb}\left(\mathrm{t}_{1 / 2}\right)=4.88 \times 10^{10} \mathrm{y}$, and a decay constant of $\lambda=1.42 \times 10^{-}$ ${ }^{11} \mathrm{y}^{-1}$. Sr isotopic data are reported as ${ }^{87} \mathrm{Sr} /{ }^{86} \mathrm{Sr}$ ratios; a comparison of the radiogenic daughter, ${ }^{87} \mathrm{Sr}$, relative to a stable non-radiogenic isotope, ${ }^{86} \mathrm{Sr}$, whose abundance does 
not change. Thus, when considering the $\mathrm{Rb}-\mathrm{Sr}$ isotopic system, the radioactive decay equation becomes:

$$
{ }^{87} \mathrm{Sr} /{ }^{86} \mathrm{Sr}={ }^{87} \mathrm{Sr} /{ }^{86} \mathrm{Sr} r_{t=0}+{ }^{87} \mathrm{Rb} /{ }^{86} \mathrm{Sr} *\left(e^{\lambda t}-1\right)
$$

Therefore, in a system of cogenetic samples which crystallized at the same time, the variation in ${ }^{87} \mathrm{Sr} /{ }^{86} \mathrm{Sr}$ will only be a function of the time since closure, or crystallization, and the parent to daughter ratio at the time of crystallization.

Rubidium is typically a highly incompatible element in igneous rocks, due to its large ionic radius and +1 charge, and is found in micas, amphibole and $\mathrm{K}$-feldspar in minor amounts. In contrast, $\mathrm{Sr}$ has a smaller ionic radius and +2 charge, and is relatively compatible in felsic igneous systems as it readily replaces $\mathrm{Ca}^{2+}$ in plagioclase. The chemical differences between the parent, $\mathrm{Rb}$, and the daughter, $\mathrm{Sr}$, can result in large differences in the $\mathrm{Rb} / \mathrm{Sr}$ ratio in rocks and minerals which can vary by several orders of magnitudes. In addition to its usefulness in dating, the $\mathrm{Rb}-\mathrm{Sr}$ isotopic system is particularly useful when inferring the source of a melt and magmatic differentiation processes, as the mantle has a relatively low, uniform ${ }^{87} \mathrm{Sr} /{ }^{86} \mathrm{Sr}$ ratio and the continental crust has a higher, more variable ${ }^{87} \mathrm{Sr} /{ }^{86} \mathrm{Sr}$ ratio. These differences can result in magmatic reservoirs that have distinctly different isotopic ratios (Dickin, 2005).

However, isotopic systems can reopen and the isotopic values can be changed, particularly for relatively mobile $\mathrm{Rb}$ and Sr. Weathering and hydrothermal activity can cause affected rocks to become contaminated with $\mathrm{Rb}$ and $\mathrm{Sr}$ removed from other 
rocks, altering the isotopic values in the rocks after crystallization. Opening of the isotopic system can also occur during metamorphic events, when the temperature exceeds the closure temperature of the $\mathrm{Rb}-\mathrm{Sr}$ system which will cause isotopic rehomogenization (Dickin, 2005).

${ }^{87} \mathrm{Sr} /{ }^{86} \mathrm{Sr}$ isotopic ratios can be used to determine the source of a melt, as the continental crust and mantle have different isotopic ratios. This can be attributed to the previously mentioned chemical differences in $\mathrm{Rb}$ and $\mathrm{Sr}$. As $\mathrm{Rb}$ is more incompatible than $\mathrm{Sr}$, it will partition into a melt more than $\mathrm{Sr}$ during a differentiation event. This results in reservoirs that are enriched in incompatible elements which, over time, will evolve to have a higher ${ }^{87} \mathrm{Sr} /{ }^{86} \mathrm{Sr}$ ratio than reservoirs with depleted incompatible elements. Characteristically, the continental crust has higher ${ }^{87} \mathrm{Sr} /{ }^{86} \mathrm{Sr}$ and $\mathrm{Rb} / \mathrm{Sr}$ ratios, while the mantle has a lower ${ }^{87} \mathrm{Sr} /{ }^{86} \mathrm{Sr}$ and $\mathrm{Rb} / \mathrm{Sr}$ ratios (Dickin, 2005).

\section{Sm-Nd}

Samarium $(\mathrm{Sm})$ and Neodymium $(\mathrm{Nd})$ are both light rare earth elements, as well as lithophile and refractory elements. ${ }^{143} \mathrm{Nd}$ is produced by the alpha decay of ${ }^{147} \mathrm{Sm}$ with a half-life of $1.06 \times 10^{11} y$ and a decay constant $\lambda=6.54 \times 10^{-12} y^{-1}$. Nd has a slightly larger ionic radius than $\mathrm{Sm}$, and as a result is slightly more incompatible than $\mathrm{Sm}$. This results in higher $\mathrm{Sm} / \mathrm{Nd}$ ratios in reservoirs that are depleted in incompatible elements, such as the mantle, as $\mathrm{Nd}$ is preferentially removed during partial melting. This enrichment of Sm relative to $\mathrm{Nd}$ results in a higher ${ }^{143} \mathrm{Nd} /{ }^{144} \mathrm{Nd}$ ratio in the mantle than in the crust. Isotopic studies using the Sm-Nd system must be done precisely, as the elements are 
chemically similar and little fractionation occurs between them, such that the isotopic difference between mantle and crust are smaller than in the Rb-Sr system. Despite this, $\mathrm{Nd}$ and $\mathrm{Sm}$ are relatively immobile which makes them less susceptible to the effects of weathering and metamorphic events, unlike the Rb-Sr system. Using the isochron-type decay equation, the age can be determined using:

$$
{ }^{143} N d /{ }^{144} N d={ }^{143} N d /{ }^{144} N d_{t=0}+{ }^{147} S m /{ }^{143} N d *\left(e^{\lambda t}-1\right)
$$

Conventionally, $\mathrm{Nd}$-isotopes are reported as a ${ }^{143} \mathrm{Nd} /{ }^{144} \mathrm{Nd}$ ratio, which is the ratio of the radiogenic daughter isotope ${ }^{143} \mathrm{Nd}$, to a non-radiogenic, stable isotope ${ }^{144} \mathrm{Nd}$. Epsilon $(\varepsilon)$ notation, more commonly used to report $\mathrm{Nd}$ isotopes, is the measure of deviation of ${ }^{143} \mathrm{Nd} /{ }^{144} \mathrm{Nd}$ from the Earth's chondritic ${ }^{143} \mathrm{Nd} /{ }^{144} \mathrm{Nd}$ ratio, and is calculated using:

$$
\varepsilon N d T=\left[\frac{\frac{{ }^{143} N d}{144} T_{\text {sample }}}{\frac{143 N d}{{ }^{144} N d} T_{C H U R}}-1\right] \times 10^{4}
$$

where CHUR represents the Chondritic Uniform Reservoir assuming a chondritic Nd isotopic composition for the bulk silicate Earth at time T. The present day values for CHUR are ${ }^{143} \mathrm{Nd} /{ }^{144} \mathrm{Nd}=0.51263$ and ${ }^{147} \mathrm{Sm} /{ }^{144} \mathrm{Nd}=0.196$ (Bouvier et al., 2008). The $\varepsilon \mathrm{Nd}$ value can be used as an indicator of source, as positive $\varepsilon N d$ indicates a depleted source and a negative $\varepsilon N d$ indicates an enriched source. Most terrestrial rocks have an $\varepsilon N d$ value between -20 and +10 , while chondritic meteorites have an $\varepsilon N d$ of 0 (Dickin, 2005). 
$\mathrm{Sr}$ and $\mathrm{Nd}$ isotopic data can be used together as a useful way to determine the source for a suite of rocks due to the differences between the isotopic systems. This includes inverse parent-daughter compatibility which results in differences in their presence in crustal and mantle source reservoirs. On an $\varepsilon N d$ versus ${ }^{87} \mathrm{Sr} /{ }^{86} \mathrm{Sr}$ diagram, source can be inferred using the known isotopic values of other important reservoirs, such as midocean ridge basalts (MORB), ocean island basalts (OIB), and the isotopic value of the bulk Earth (Fig. 3.4). In this diagram, the mantle array is defined by the location of MORB at the top of the array which represents the melting product of the modern depleted mantle, and has the highest $\varepsilon N d$ and lowest ${ }^{87} \mathrm{Sr} /{ }^{86} \mathrm{Sr}$ values of all young igneous rocks. OIBs are the melting product of a more enriched mantle and have lower $\varepsilon N d$ values than MORB, but can have ${ }^{87} \mathrm{Sr} /{ }^{86} \mathrm{Sr}$ values verging towards continental rocks. Continental granites characteristically have low $\varepsilon N d$ and high ${ }^{87} \mathrm{Sr} /{ }^{86} \mathrm{Sr}$ values; however these values are much more variable (Dickin, 2005). 


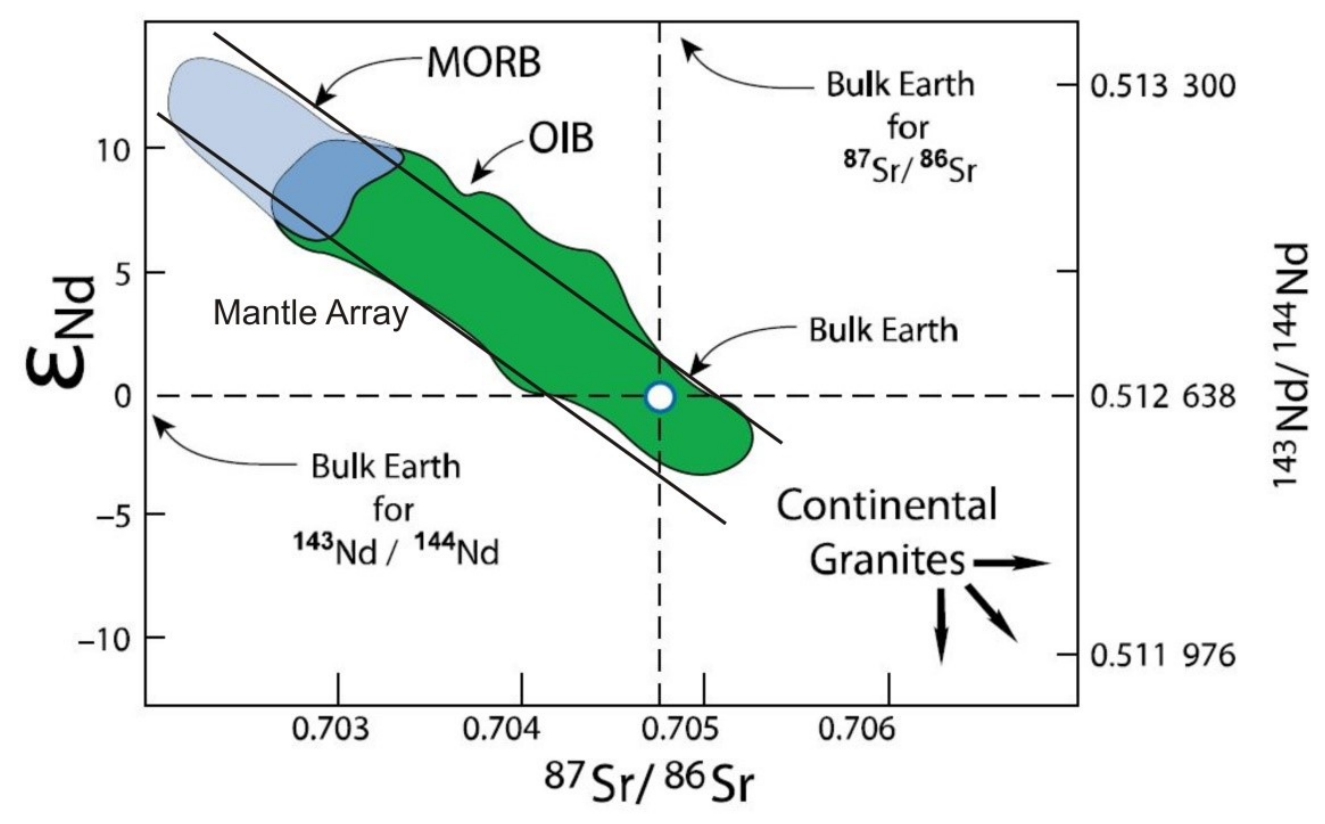

Figure 3.4: $\mathrm{Sr}$ vs. $\mathrm{Nd}$ isotopic correlation. MORB and OIB define a tightly trending correlation referred to as the mantle array. Continental granites have $\varepsilon N d$ values $<0$, and have a much wider range in isotopic values than MORB and OIB. Modified after Stepner (2017) and Allègre (2008).

\section{(Pb)-(Pb), or common $\mathrm{Pb}$}

Lead $(\mathrm{Pb})$ is a volatile, chalcophile element that is present as a trace element throughout the Earth. The $\mathrm{Pb}$ isotopic system is a much more complex decay system than $\mathrm{Rb}-\mathrm{Sr}$ and $\mathrm{Sm}-\mathrm{Nd}$, and begins with the decay of radioactive uranium (U) and thorium (Th). These radioactive decay chains begin with ${ }^{238} \mathrm{U},{ }^{235} \mathrm{U}$, and ${ }^{232} \mathrm{Th}$, and end in the production of radiogenic daughter isotopes ${ }^{206} \mathrm{~Pb},{ }^{207} \mathrm{~Pb}$, and ${ }^{208} \mathrm{~Pb}$, respectively. Intermediate members of the decay chain series are short lived and therefore will not be discussed. The half-lives of the radioactive $U$ and Th parents vary. Whereas the half-life of ${ }^{238} U$ is $\sim 4.47 \mathrm{Ga}$ (comparable to the age of the Earth) and the half-life of ${ }^{232} \mathrm{Th}$ is $14.01 \mathrm{Ga}$ 
(comparable to the age of the universe), the half-life of ${ }^{235} \mathrm{U}$ is $0.704 \mathrm{Ga}$ (Dickin, 2005). Thus, little ${ }^{207} \mathrm{~Pb}$ is produced today compared to ${ }^{206} \mathrm{~Pb}$ and ${ }^{208} \mathrm{~Pb}$. Conventionally, the radiogenic $\mathrm{Pb}$ isotopes are measured relative to ${ }^{204} \mathrm{~Pb}$, a stable, non-radiogenic $\mathrm{Pb}$ isotope (Dickin, 2005).

Due to the high incompatibility of the radioactive parents, $\mathrm{U}$ and Th, compared to $\mathrm{Pb}$, the $\mathrm{Pb}$ isotopic system is arguably the best indicator of a crustal source in a rock. The incompatibility of $U$ and Th has caused these elements to concentrate in melts which primarily become incorporated in the crust. As a result, high $\mathrm{Pb}$ isotopic ratios and high concentrations of $\mathrm{Pb}$ exist in the continental crust relative to the mantle (Fig. 3.5). The isotopic signature of the crust is easily picked up during the assimilation of crustal rocks by mantle derived magma, and can therefore be a strong indicator of crustal contamination (Dickin, 2005). 


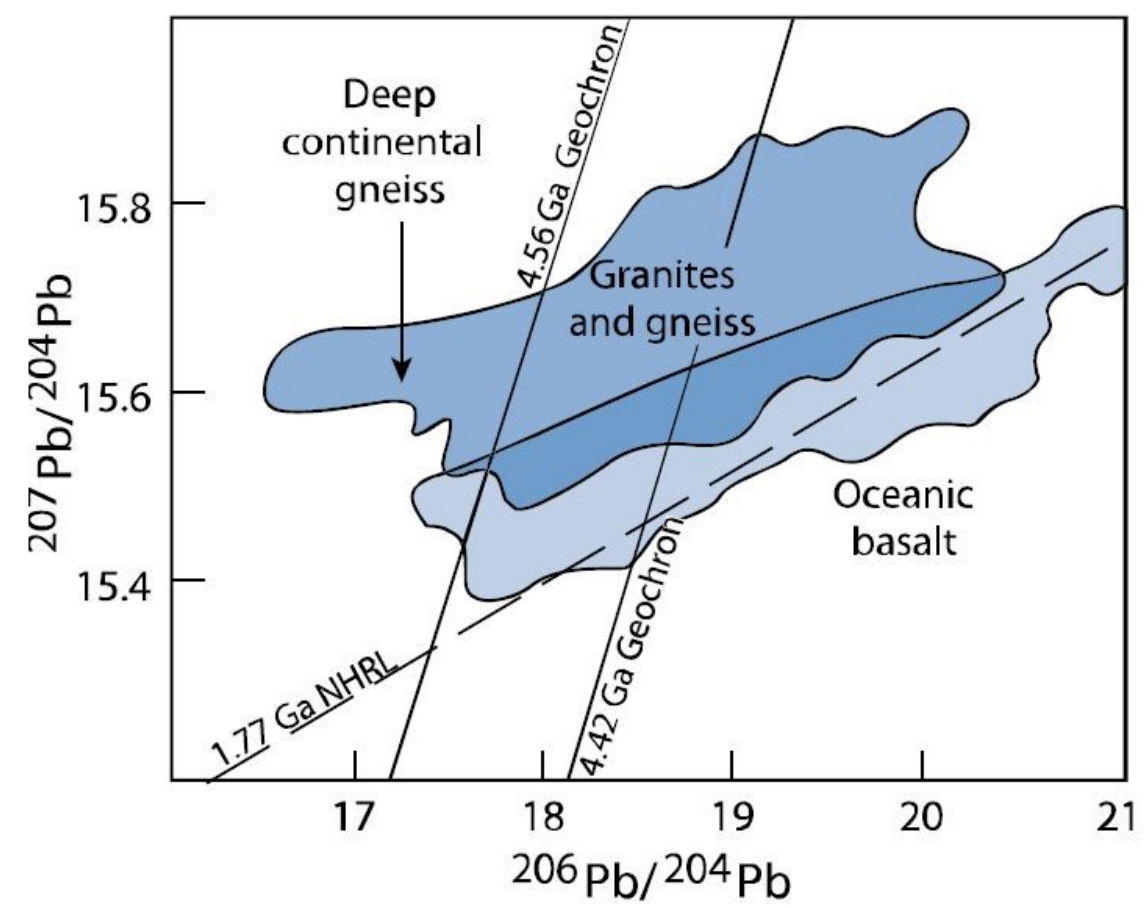

Figure 3.5: $\mathrm{A}{ }^{206} \mathrm{~Pb} /{ }^{204} \mathrm{~Pb}$ vs. ${ }^{207} \mathrm{~Pb} /{ }^{204} \mathrm{~Pb}$ diagram showing the differences in isotopic value of the oceanic basalt (mantle) and granites and gneiss (continental crust). ${ }^{207} \mathrm{~Pb} /{ }^{204} \mathrm{~Pb}$ isotopic values for the continental crust are typically higher than the mantle, which can be used as a good indicator of crustal source. The Northern Hemisphere Reference Line (NHRL) represents the isotopic evolution of the conducting mantle beneath the northern hemisphere. The slope of the NHRL is equal to an age of $1.77 \mathrm{Ga}$. Two geochrons, 4.56 and $4.42 \mathrm{Ga}$, represent the approximate evolution of the $\mathrm{Pb}$ isotopic evolution of the bulk Earth over time. From Stepner (2017), modified after Allègre (2008). 


\subsection{Regional Geology}

\subsection{Geological Framework}

The Underdown Caldera is one of 37 calderas located within the WNVF of the Great Basin, 23 of which are well identified and 14 of which are hypothesized based on dated outflow tuffs (Fig. 4.1) (Henry and John, 2013). More specifically, the Underdown Caldera is located in the Shoshone Mountains of north-central Nevada. The intracaldera tuffs of the Underdown Caldera are confined to the Shoshone Mountain range; however outflow tuff has previously been identified extending to the east of the caldera, stretching nearly to the Nevada-Utah border (Best et al., 2013). Our work indicates that at least two outflow units exist west of the Underdown Caldera. The Underdown Tuff, the main intracaldera tuff in the Underdown Caldera, has $23 \mathrm{~km}$ of exposure along the eastern edge of the Shoshone Mountains which indicates a minimum length of the caldera; however the entire north-south extent of the caldera has not been mapped. The Underdown Caldera is located just to the west of the initial ${ }^{87} \mathrm{Sr} /{ }^{86} \mathrm{Sr}=0.706$ isopleth in central Nevada, and separates the Precambrian basement to the east from the Phanerozoic igneous and sedimentary basement to the west (Henry and John, 2013; Best et al., 2013). 


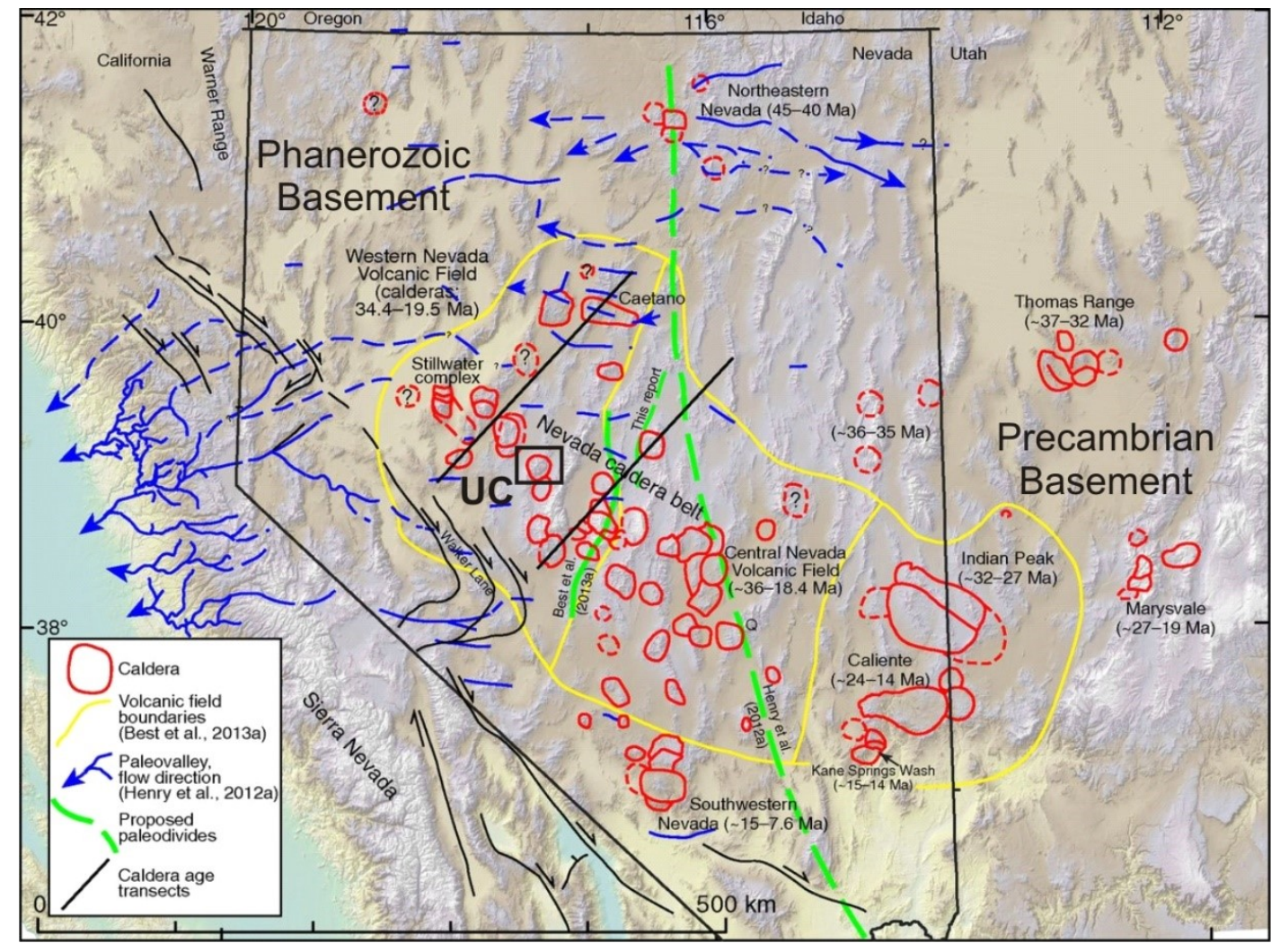

Figure 4.1: Map of the western United States showing the location of the Underdown Caldera (UC) in the Western Nevada Volcanic Field (modified from Henry and John, 2013). Dashed green lines represent proposed paleodivides that mark the highest elevation during the Eocene. Blue lines are paleovalleys (eroded channels) that outflow tuffs commonly follow. Yellow outlines separate the Western Nevada Volcanic Field, Central Nevada Volcanic Field, and Indian Peak-Caliente Volcanic Field. 


\subsection{Stratigraphic Relations}

The Underdown Caldera is contained within a single, mildly ( $<10$ degrees) west-tilted fault block. In 1970, H. F. Bonham mapped the Underdown Caldera complex, identifying andesite basement rocks (the Pablo Formation), three Oligocene rhyolitic tuff packages (the Underdown Tuff, the Bonita Canyon Formation, and the Tuff of Toiyabe), rhyolite to intermediate intrusions, and basaltic lava flows (Fig. 4.2). According to Bonham (1970), the Underdown Tuff is at least $490 \mathrm{~m}$ thick and was deposited against a ridge of basement rocks of the Pablo Formation. The thick exposure has two cooling units, the lower of which exhibits columnar jointing and laminar flow structures (including stretched, folded and lineated pumice) in densely welded sections. The Underdown Tuff is overlain by an epi- and volcaniclastic unit up to 500 m thick; the Bonita Canyon Formation. Overlying the Bonita Canyon Formation, a similarly thick $(460 \mathrm{~m})$ unit of phenocryst rich tuff was identified by Bonham as the Toiyabe Quartz Latite (or Tuff of Toiyabe). The $960 \mathrm{~m}$ thick deposit of reworked and welded tuffs above the Underdown Tuff is interpreted as post-collapse fill of the caldera after the eruption of the Underdown Tuff (Best et al., 2013).

The rocks of the Underdown Caldera area have been dated by ${ }^{40} \mathrm{Ar}-{ }^{39} \mathrm{Ar}$ dating of bulkrock (mafic lavas), plagioclase crystals (Pablo Formation) and sanidine crystals (felsic rocks) (Appendix I, Table I). The oldest unit sampled in the Underdown Caldera is the andesite basement rocks of the Pablo Formation which have a metamorphic age of 87.6 \pm 0.06 Ma (likely Mesozoic in age; C. Henry, pers. comm., 2018). The stratigraphically 
lowest Oligocene tuff unit, the Underdown Tuff, has ages of $24.90 \pm 0.04-0.07 \mathrm{Ma}$, and $24.96 \pm 0.05 \mathrm{Ma}$ (C. Henry, pers. comm., 2018; Best et al., 2013, respectively). The $24.999 \pm 0.043$ Ma Bonita Canyon Formation (C. Henry, pers. comm., 2018) unconformably overlies the Underdown Tuff, and is overlain by a densely welded tuff unit, believed by Bonham to be the Tuff of Toiyabe (Best et al., 2013; Henry and John, 2013). However, this unit is likely misidentified by Bonham (1970) due to differences between the age of this tuff and the true Tuff of Toiyabe exposed elsewhere in the Western Nevada Volcanic Field, as well as differences in the paleomagnetic polarity (Best et al., 2013). This unit will henceforth be referred to as the Unnamed tuff. The Unnamed tuff is dated as $24.755 \pm 0.037 \mathrm{Ma}$ (C. Henry, pers. comm., 2018) while the Tuff of Toiyabe is dated at $23.31 \pm 0.05 \mathrm{Ma}$ (Henry and John, 2013). The intermediate and rhyolitic intrusions within the caldera have been dated at $24.954 \pm 0.043 \mathrm{Ma}$ and $24.774 \pm 0.051 \mathrm{Ma}$ respectively (C. Henry, pers. comm., 2018). Basaltic lava flows located on the margin of the caldera have been dated at ca. 18.4 Ma (Tennant, 2018).

The tuff of Clipper Gap, the outflow tuff from the Underdown Caldera, is exposed primarily to the east of the caldera and has been dated at $24.87 \pm 0.10 \mathrm{Ma}$ and $24.981 \pm$ $0.036 \mathrm{Ma}$ (Henry and John, 2013; C. Henry, pers. comm., 2018, respectively). Exposures of the tuff of Clipper Gap extends across Nevada nearly to the Utah border (Fig. 4.3) and crosses the topographic barrier in central Nevada where most of the outflow tuffs of the Central Nevada volcanic field terminate. The total estimated volume of the Underdown Tuff and tuff of Clipper Gap is at least $180 \mathrm{~km}^{3}$ (Best et al., 2013). 


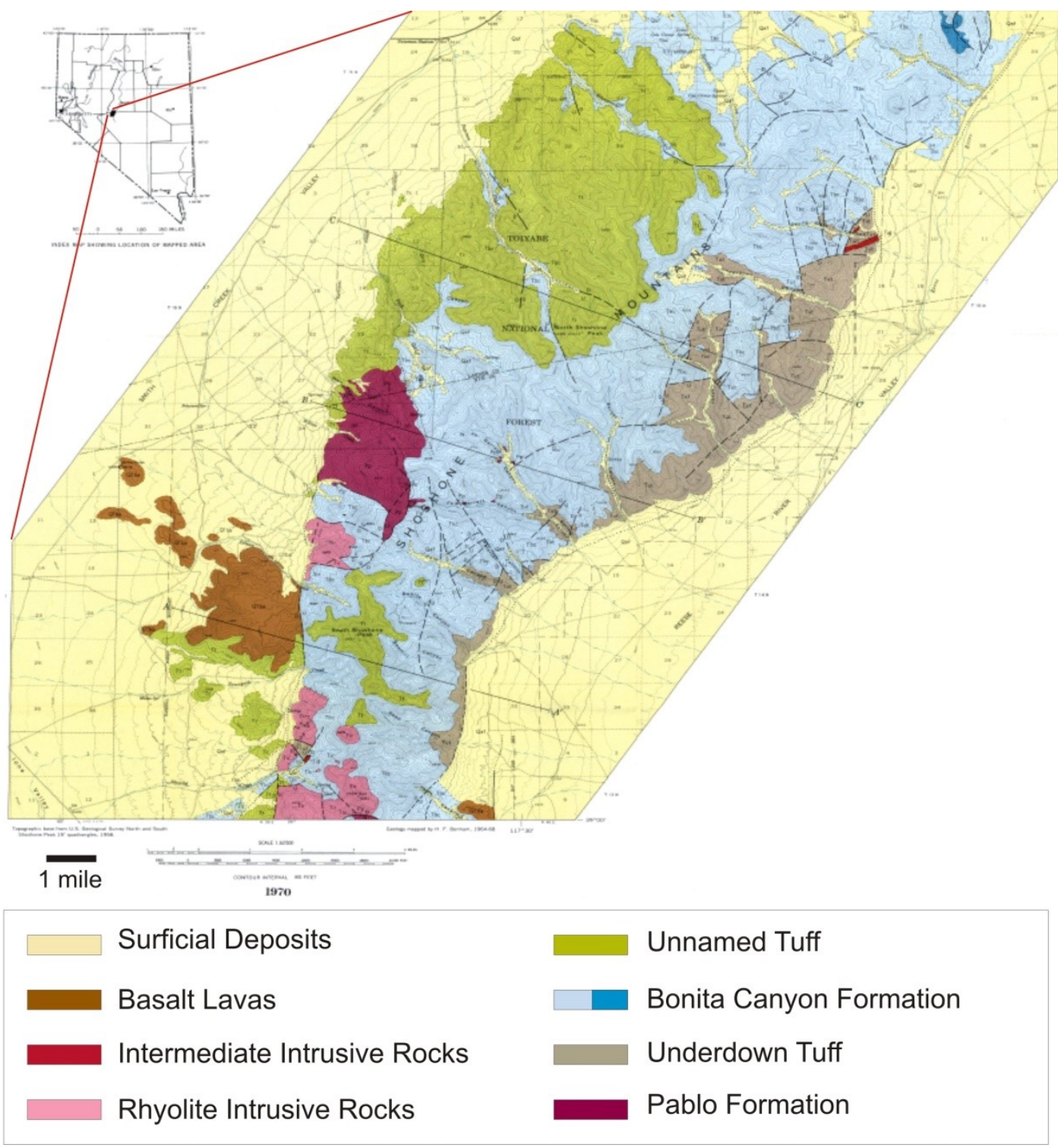

Figure 4.2: The Underdown Caldera complex as mapped by H. F. Bonham (1970). Bonham mapped three Oligocene rhyolitic tuff packages; the Underdown Tuff, the Bonita Canyon Formation, and the Tuff of Toiyabe. The Tuff of Toiyabe will henceforth be referred to as the Unnamed tuff, as this unit was incorrectly assumed to be correlative with the true Tuff of Toiyabe. Bonham also mapped andesite basement rocks (the Pablo Formation), rhyolite and intermediate intrusive rocks, and basaltic lavas. 


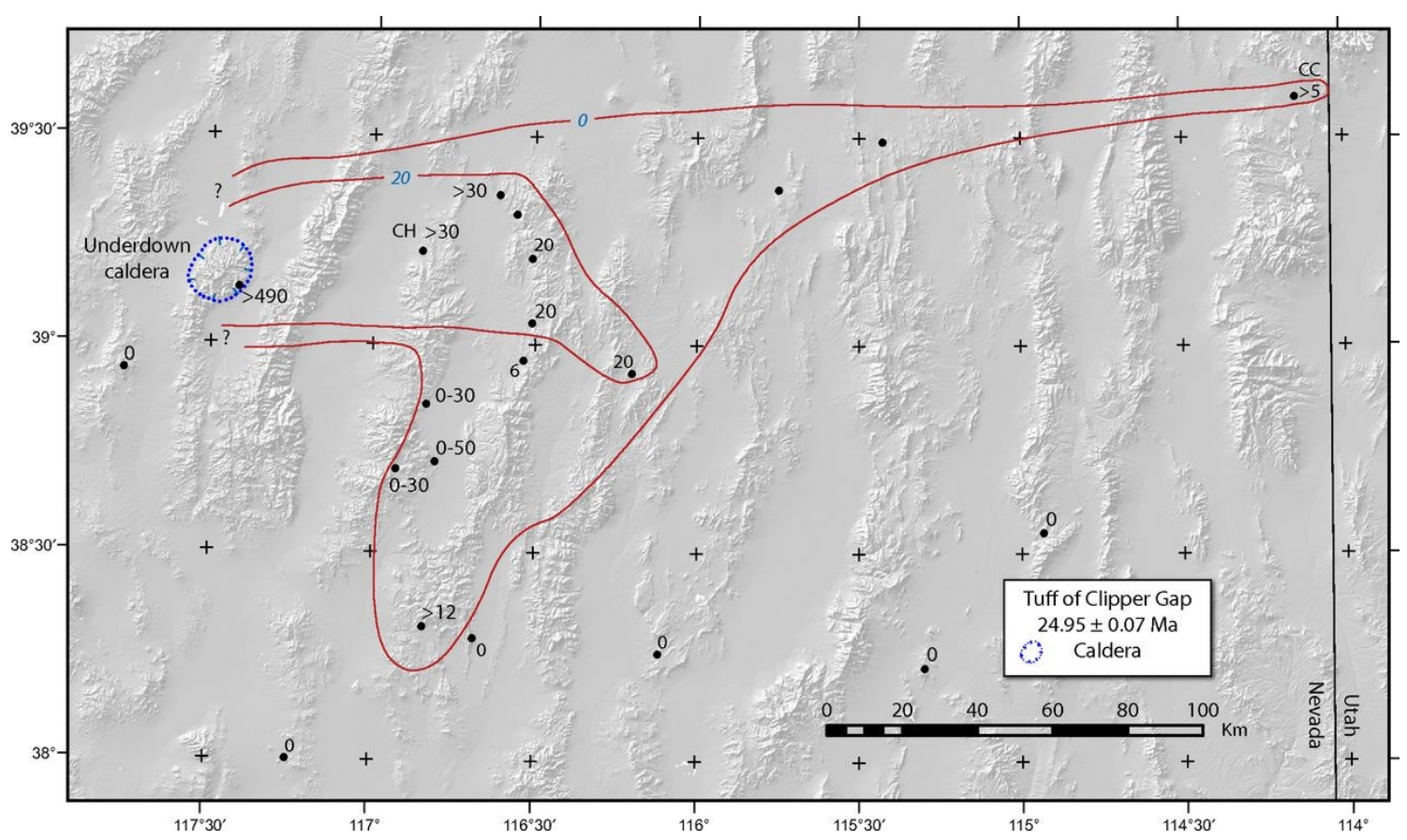

Figure 4.3: The eastern and southern extent of the tuff of Clipper Gap, an outflow tuff from the Underdown Caldera. The extent of the tuff of Clipper Gap is outlined in red. Numbers on the map represent thicknesses of the tuff of Clipper Gap in metres (Best et al., 2013). 


\subsection{Field Observations}

Sample locations of the Underdown Caldera complex samples are listed in Appendix I, Table II.

\section{Intracaldera tuffs and the tuff of Clipper Gap}

The main caldera forming tuff, the Underdown Tuff, was identified in the field by its crystal poor texture and phenocryst assemblage of two feldspars, quartz and minor biotite. Exposures of Underdown Tuff typically consisted of two main cooling units; a poorly welded base, and a moderately to densely welded upper unit. Thick sections of the Underdown Tuff in Barrett and Underdown Canyons exhibited cooling joints in the moderately welded middle of the section (Fig. 4.4). Two types of pumice were observed in the Underdown Tuff; rare large purple porphyritic pumice and common small, white aphyric pumice. The identification of the tuff of Clipper Gap was aided by its similarities to the Underdown Tuff in phenocryst assemblage, crystal poor texture, and the two pumice types. Columnar jointing was also observed in the tuff of Clipper Gap at Butler Ranch in Monitor Valley. This section had a lower poorly welded unit and a moderately welded upper unit separated by a vitrophyre. However, in a section of tuff of Clipper Gap on Moore's Canyon Road most of the section was unwelded and porphyritic pumice was only found in a small welded section at the very top of the exposure (Fig. 4.5).

The Bonita Canyon Formation was distinguishable from the Underdown Tuff by its local sedimentary textures, as well as its poorly welded, light coloured matrix. The base of the 
Bonita Canyon Formation contains abundant lithic material ranging in size from $\mathrm{cm}$-size fragments to large blocks, and some lithics in the base of the formation were identified as possible Underdown Tuff and tuff of Arc Dome (Fig. 4.6). Megabreccia blocks of older tuff units (Tuff of Arc Dome) and Pablo Formation are found in the Bonita Canyon Formation. Moving up section, the Bonita Canyon Formation grades into a pumice rich tuff, where lithic material is rare. Pumice in the Bonita Canyon Formation is brown and aphyric, and no porphyritic pumice was observed. The poorly to unwelded matrix typically contained a small proportion of quartz and feldspar phenocrysts, however no biotite was observed in the field in this unit.

The Unnamed tuff was easily distinguished from the Underdown Tuff and tuff of Clipper Gap by its highly porphyritic texture, despite their similar phenocryst assemblages (Fig. 4.7). Pumice in the Unnamed tuff was typically grey and phyric, but no purple porphyritic pumice characteristic of the Underdown Tuff and tuff of Clipper Gap were observed. Both columnar jointing and rosette jointing were observed in a thick section of Unnamed tuff in Gold Park Canyon. No vitrophyre was found in Peterson Canyon, War Eagle Canyon, or Gold Park Canyon where the Unnamed tuff was also sampled. 


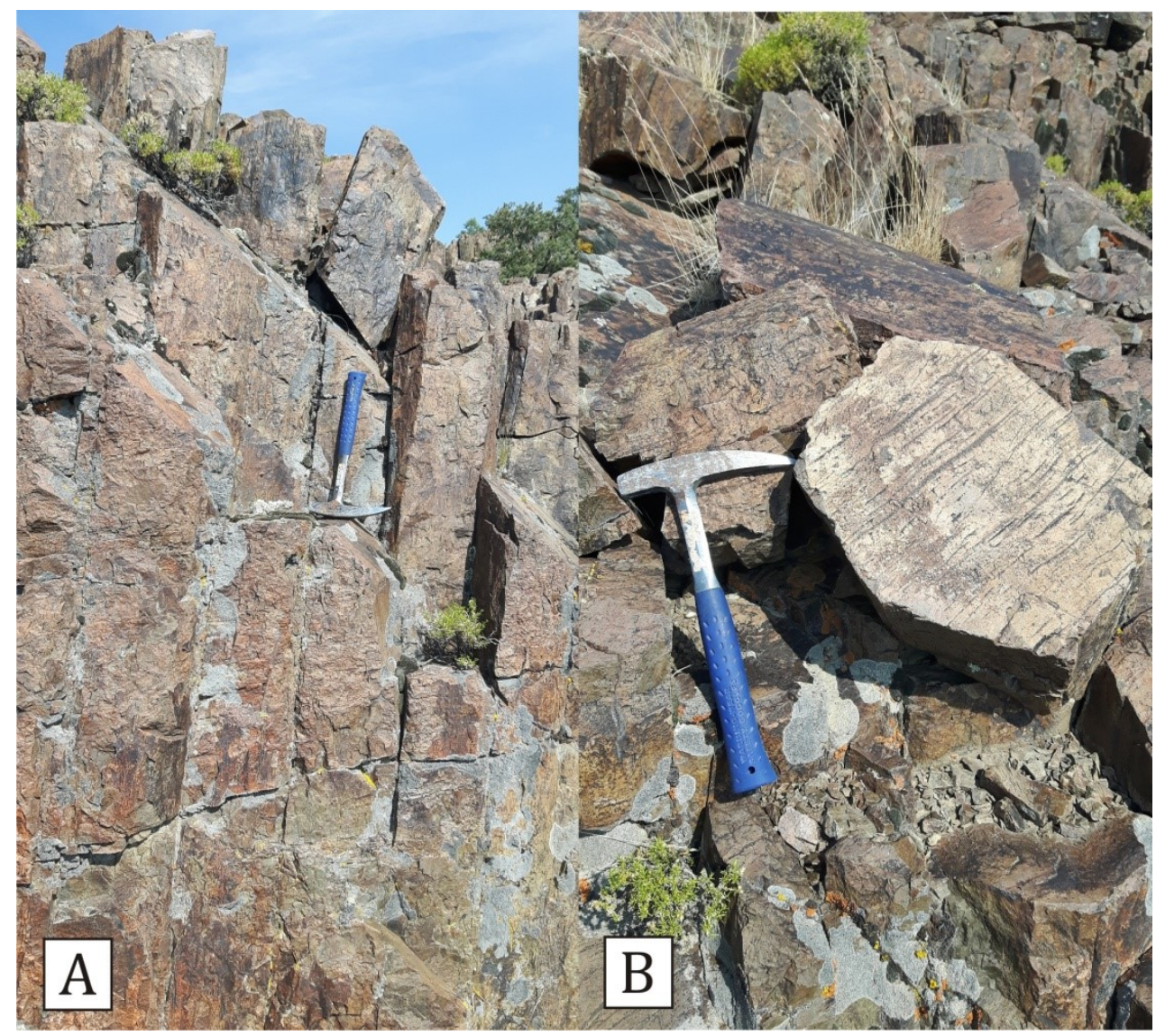

Figure 4.4: Field photos of cooling joints of the Underdown Tuff from Barrett Canyon (A) and a cross section slab of a cooling joint (B). Black streaks in the slab are flattened pumice propagating perpendicular to the elongation of the cooling joint (hammer for scale). 


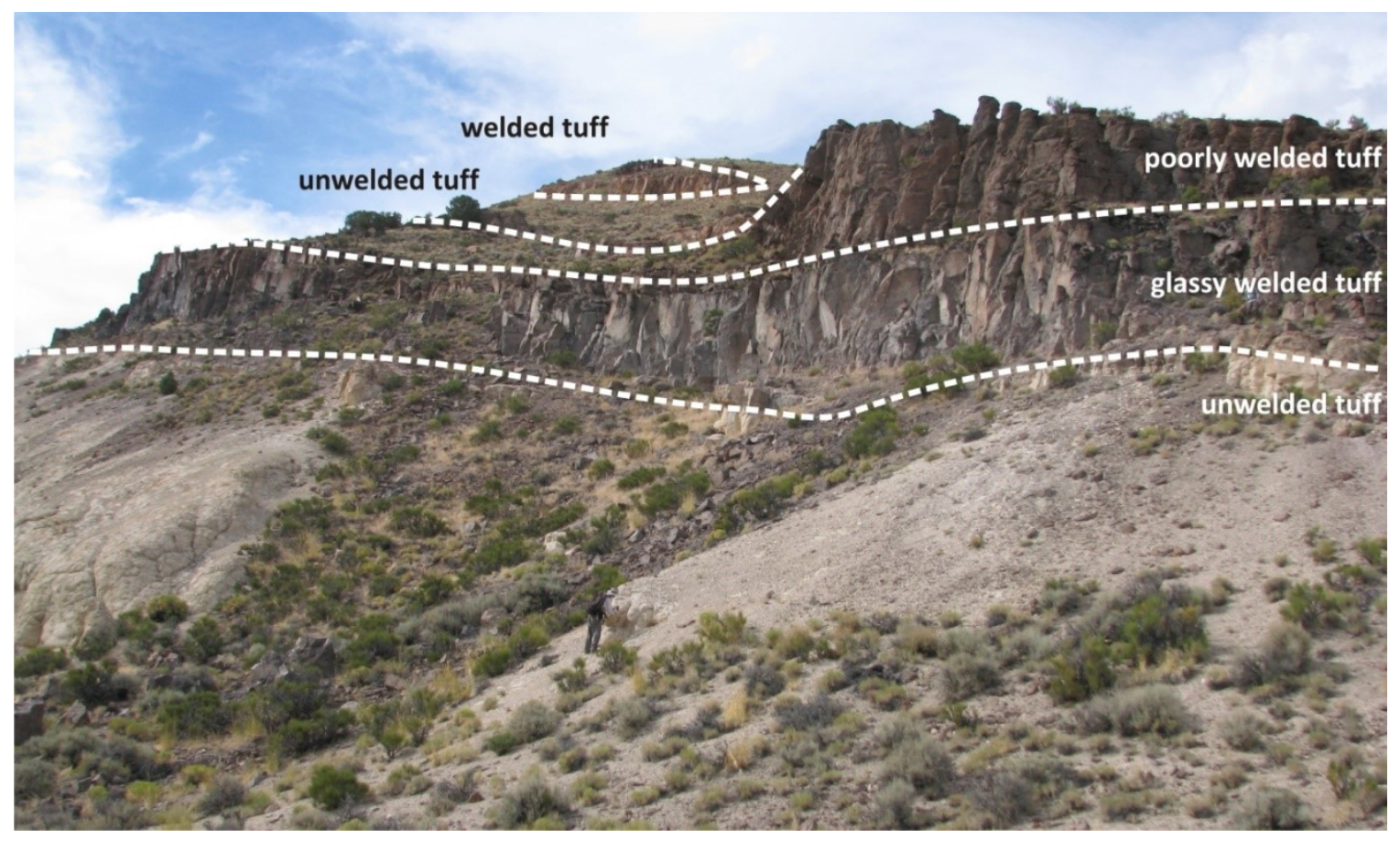

Figure 4.5: The tuff of Clipper Gap exposed at Moore's Canyon Road. The exposure of tuff of Clipper Gap was unusual based on its thick sections of unwelded to poorly welded material. A section of glassy, welded tuff separates the basal unwelded section from the poorly welded section in the upper section of the cliff. Unwelded tuff sits on top of the poorly welded unit, and welded tuff is exposed at the very top of the section (geologist for scale in lower centre of the photo). 


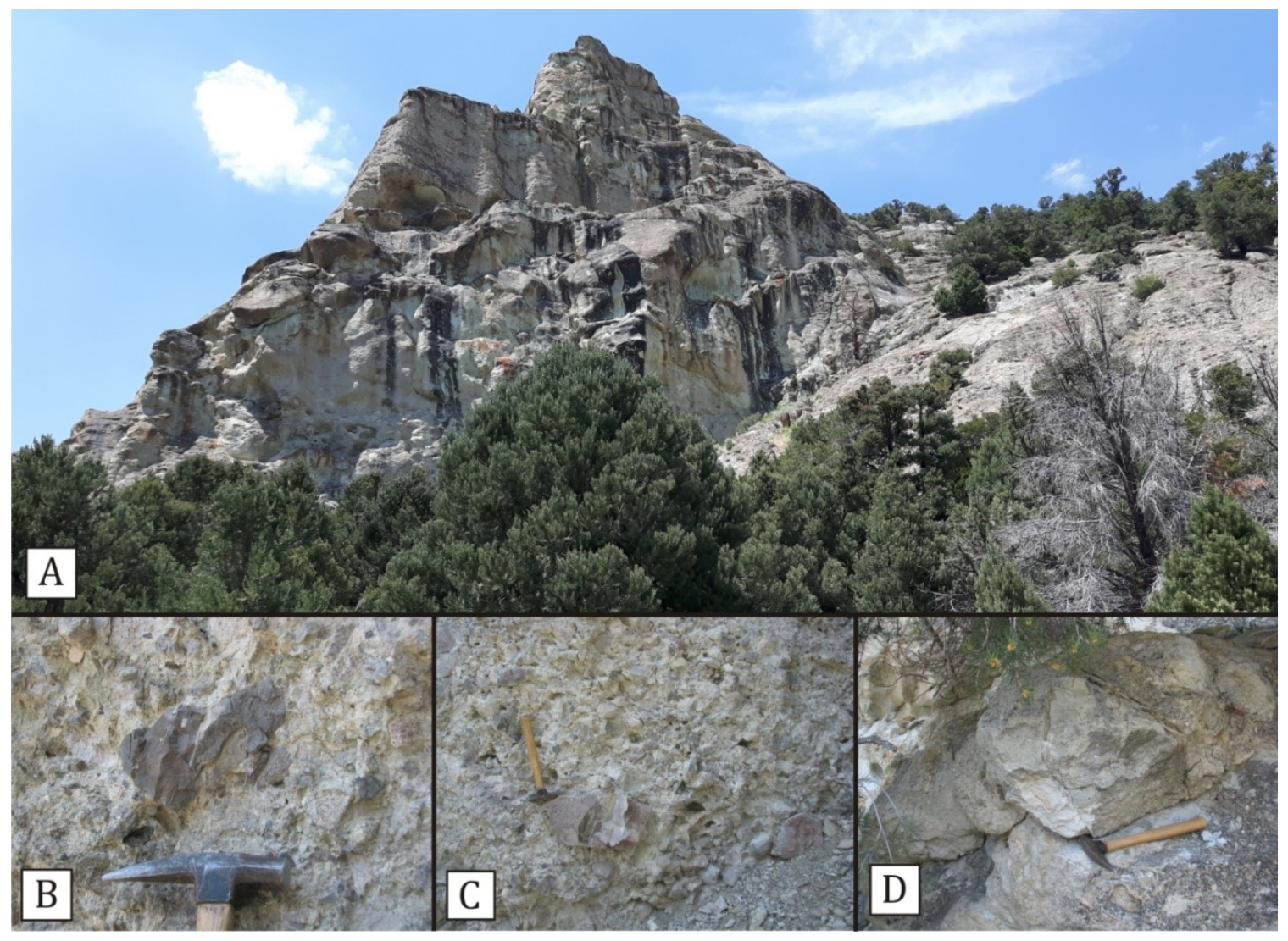

Figure 4.6: (A) A large outcrop of Bonita Canyon Formation in Barrett Canyon. (B) A lithic fragment of Underdown Tuff in the lithic rich base of the Bonita Canyon Formation (hammer for scale). (C) The lithic rich base of the Bonita Canyon Formation and a large tuff of Arc Dome lithic fragment (hammer for scale). (D) The lithic poor upper section of the Bonita Canyon Formation (hammer for scale). 


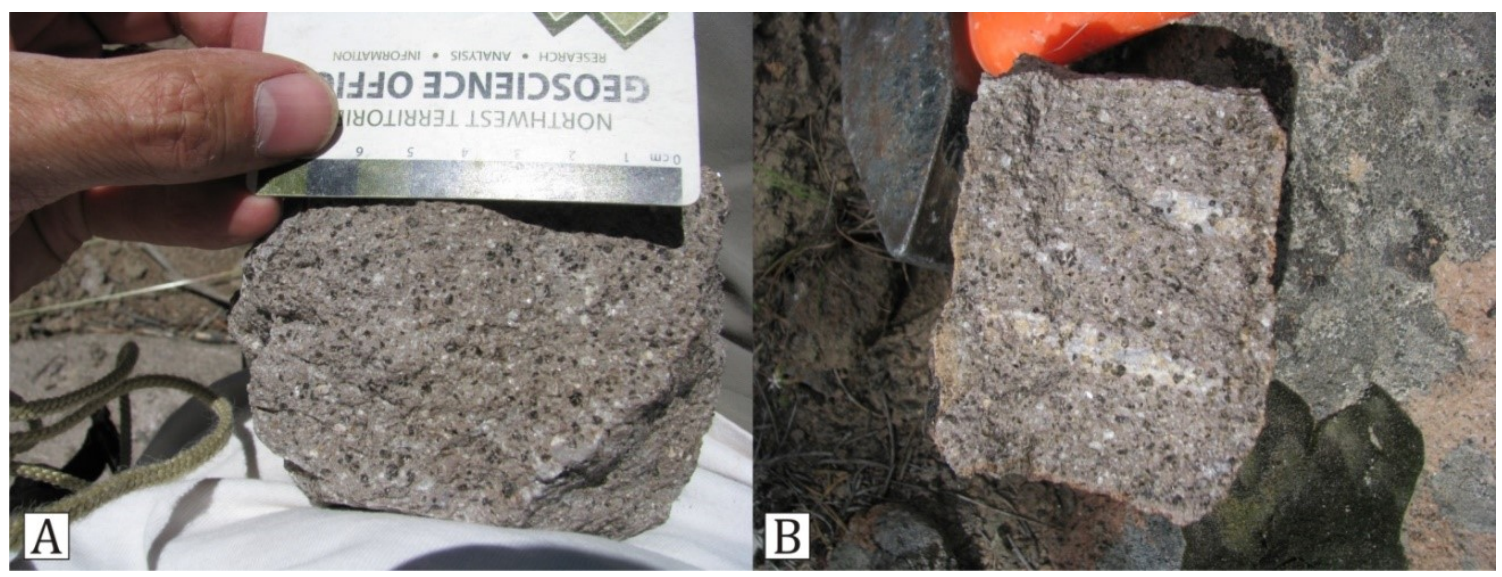

Figure 4.7: (A) The Unnamed tuff showing its highly porphyritic texture. (B) The Unnamed tuff with small grey fiamme (photos from Brian Cousens, hammer for scale).

\section{Other tuffs and potential outflow tuff}

Other units such as the tuff of Gabbs Valley (25.15 $\pm 0.06 \mathrm{Ma}$; Henry and John, 2013), the tuff of Arc Dome (25.18 $\pm 0.06 \mathrm{Ma}$; Henry and John, 2013), and the tuff of Brunton Pass (24.89 $\pm 0.05 \mathrm{Ma}, 25.12 \pm 0.06 \mathrm{Ma}$; C. Henry, pers. comm., 2018; Henry and John, 2013, respectively) were sampled outside of the Underdown Caldera. Similar to the Underdown Tuff, the tuff of Gabbs Valley was crystal poor; however the unit contained three different types of pumice; white, dark, and banded, all of which were crystal poor (Fig. 4.8). At Fissure Ridge, previously mapped tuff of Gabbs Valley was sampled as potentially being tuff of Clipper Gap. This exposure consisted of three different tuff units of differing ages, the top two of which are similar in age to the Underdown Caldera magmatic event. The first of these two units, TgV2 (25.11 $\pm 0.08 \mathrm{Ma}$; C. Henry, pers. comm., 2018), had a poorly welded base with large banded pumice and a phenocryst assemblage of quartz, feldspar and biotite. Welding of the unit increased moving up 
section as the tuff became highly porphyritic and pumice disappeared. The uppermost unit, TgV3 (24.875 \pm 0.048 ; C. Henry, pers. comm., 2018), was separated from TgV2 by the basal vitrophyre of TgV3 (24.898 \pm 0.009 ; C. Henry, pers. comm., 2018). The crystal poor texture of TgV3 made it more similar in appearance to the Underdown Tuff and tuff of Clipper Gap. TgV3 was densely welded and contained very large porphyritic pumice (Fig. 4.9).

A similar aged ash flow tuff to the tuff of Gabbs Valley is the tuff of Arc Dome which was identified outside of the Underdown Caldera by its crystal rich texture, and phenocryst assemblage of quartz, feldspar and biotite. A highly porphyritic vitrophyre sampled from the Reese River Butte contained $\sim 50 \%$ feldspar and quartz phenocrysts. The tuff of Arc Dome is separated by a fault from the tuff of Brunton Pass at the Brunton Pass locality. The tuff of Brunton Pass was identified by its tan matrix and abundant grey fiamme, as it has a crystal poor texture and phenocryst assemblage of quartz, feldspar and biotite, similar to the other Oligocene tuff units.

Potential Underdown Caldera outflow tuff was collected west of the caldera in the Terrill Mountains. Similar to the tuff of Clipper Gap, these tuffs are exposed in two distinct cooling units separated by a vitrophyre. The poorly to moderately welded basal unit is grey in colour, crystal poor, and contains three different types of pumice; white, banded, and black fiamme (Fig. 4.10). The basal unit was observed to have a gradational contact with the overlying basal vitrophyre of a moderately welded upper cooling unit. 
The brown, upper tuff unit is also crystal poor, contains small black and white pumice, and contains minor amounts of quartz and feldspar.

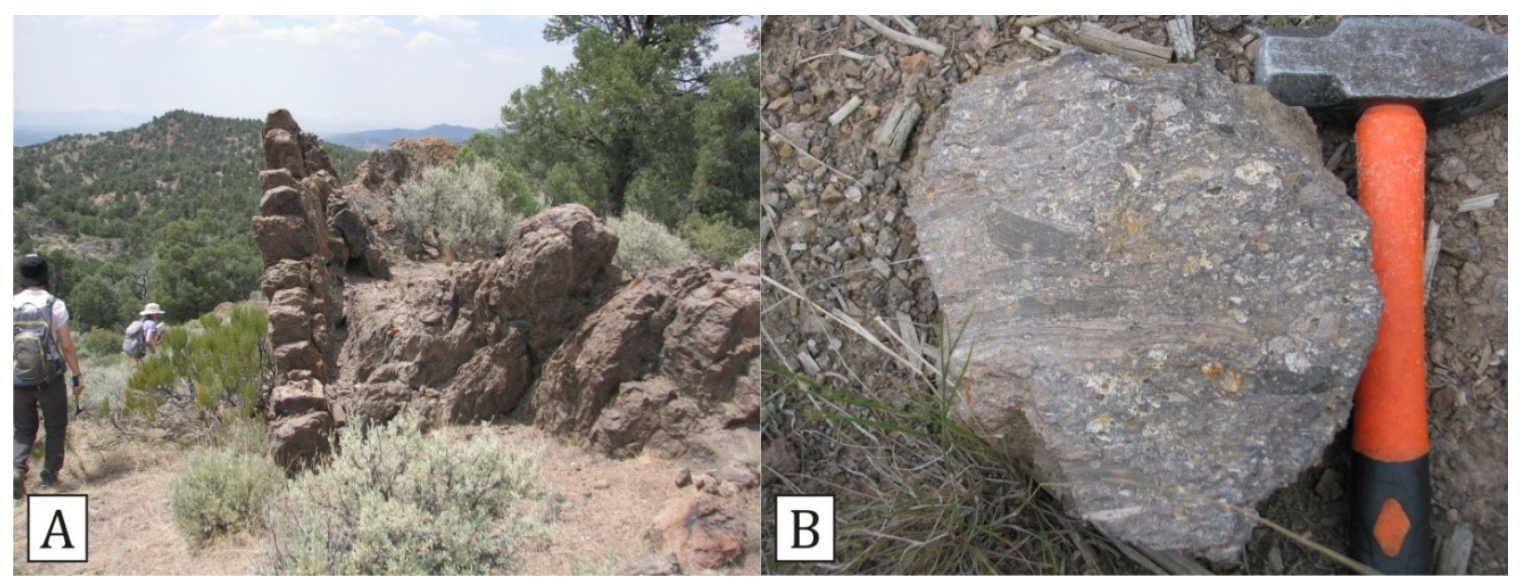

Figure 4.8: (A) Outcrop photo of the tuff of Gabbs Valley (geologists for scale). (B) Hand sample photograph of the tuff of Gabbs Valley showing the large banded pumice typical of the unit (photos from Brian Cousens, hammer for scale). 


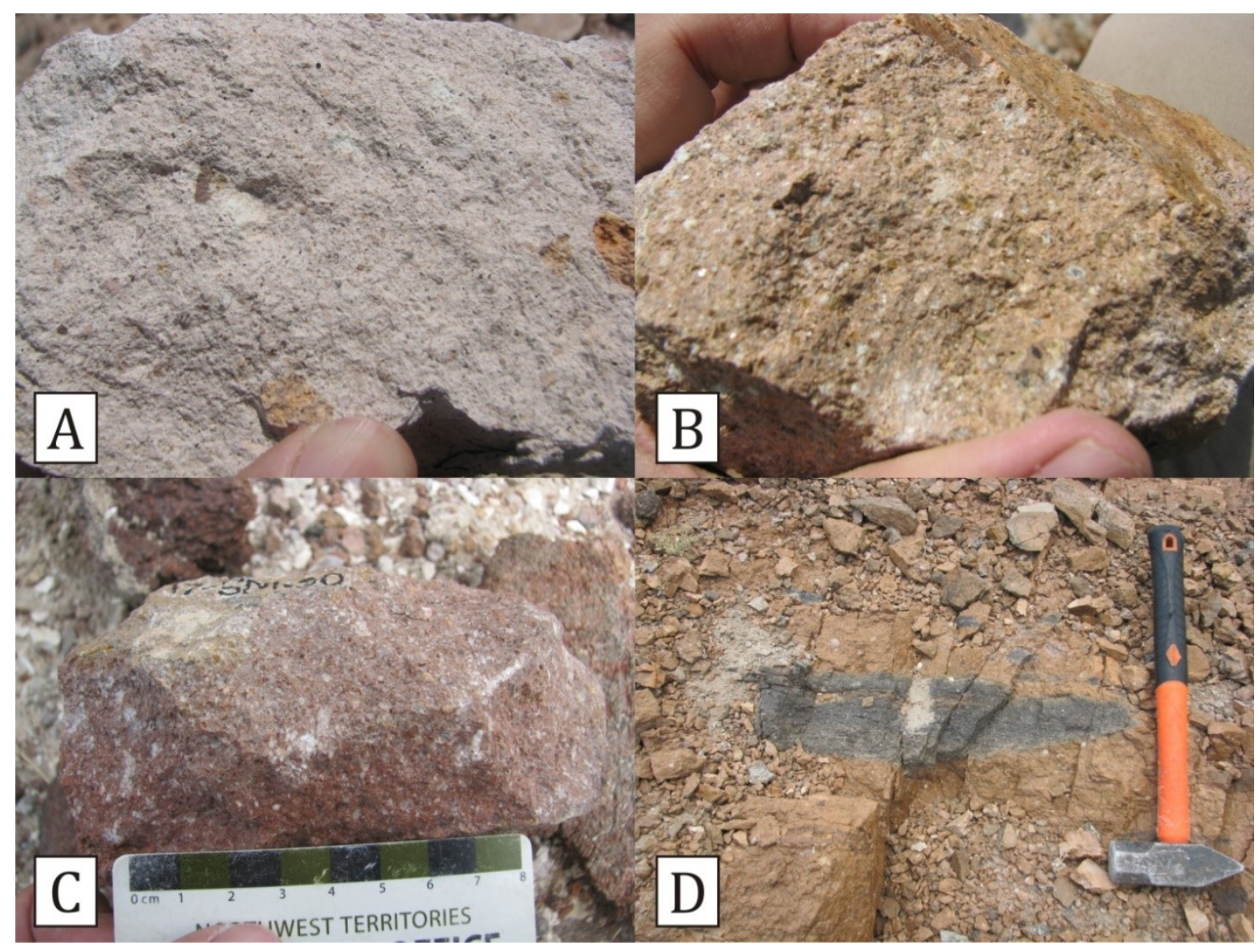

Figure 4.9: Hand sample and outcrop photographs of TgV2 and TgV3 from Fissure Ridge. (A) Hand sample photograph of the poorly welded TgV2 base (thumb for scale). (B) Hand sample photograph of the moderately welded middle of TgV2 (thumb for scale). (C) Hand sample of the densely welded top of TgV2. (D) Outcrop photograph of a large, porphyritic pumice in TgV3 (photos from Brian Cousens, hammer for scale). 


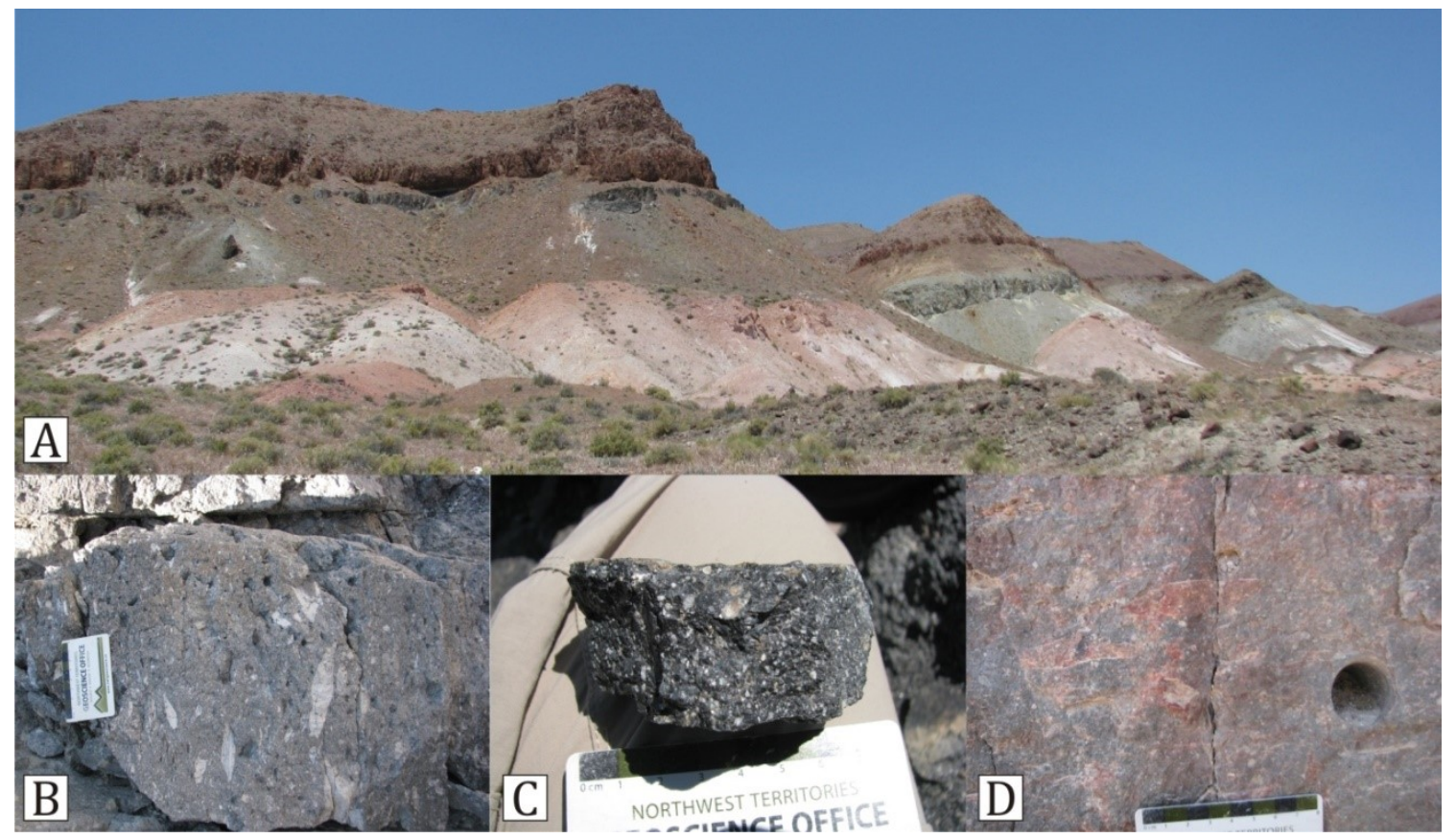

Figure 4.10: (A) The Terrill Mountains tuffs are exposed as a lower, grey, poorly to moderately welded unit, and an upper, brown, moderately welded cooling unit, separated by a vitrophyre. (B) A sample of the lower cooling unit showing the white pumice and black fiamme. (C) A hand sample of the porphyritic vitrophyre. (D) An outcrop shot of the upper cooling unit and paleomagnetic drill hole (photos from Brian Cousens).

\section{Megabreccia blocks}

The Pablo Formation is commonly exposed as large blocks in the Underdown Caldera

(Fig. 4.11). These large blocks sit unconformably on top of the Bonita Canyon Formation in Barrett and War Eagle Canyon. The Pablo Formation was easily distinguishable from other units within the caldera by its dark grey colour and plagioclase-hornblende matrix. Large blocks of the Pablo Formation typically appear to be brecciated and some have epidote alteration. Some of the large blocks mapped as Pablo Formation in Barrett 
Canyon by Bonham (1970) were targeted during field work to verify their identity. While all of these blocks in Barrett Canyon were mapped as Pablo Formation by Bonham, one block near the base of a large exposure of Bonita Canyon Formation was determined to be a large conglomerate block containing cobble to boulder sized material. The tuff of Arc Dome was also found in large blocks and spires in canyons within the caldera margin. Similar to the Pablo Formation, spires of the tuff of Arc Dome unconformably lie on the Bonita Canyon Formation. These spires of megabreccia material were identified as possible tuff of Arc Dome by their phenocryst assemblages (quartz-feldspar-biotite) and crystal rich texture (Fig. 4.12). 


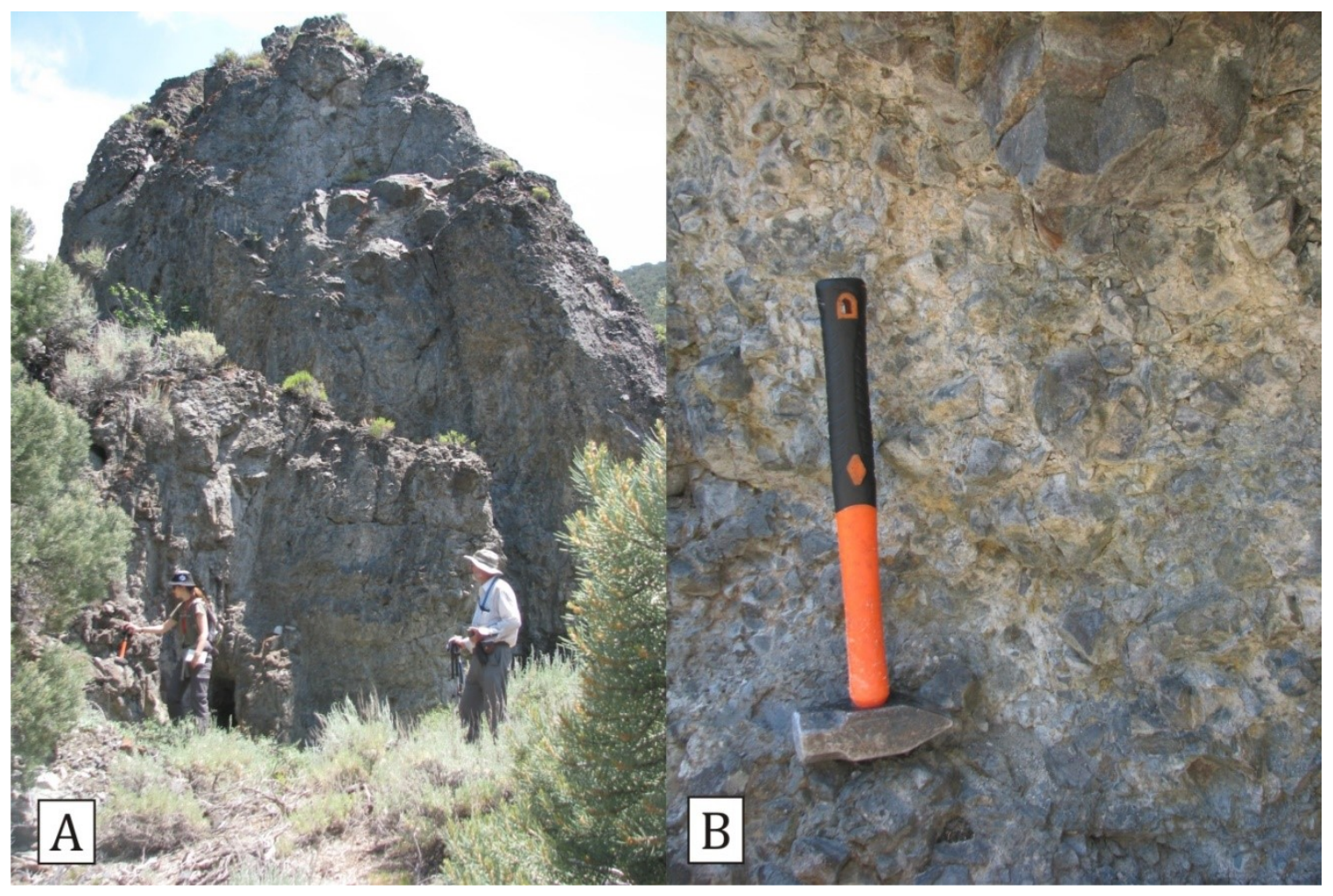

Figure 4.11: (A) A Pablo Formation outcrop in Barrett Canyon (geologists for scale). The Pablo Formation was often present as blocks and spires sitting unconformably on top of the Bonita Canyon Formation. (B) A close-up photo of the Pablo Formation outcrop (hammer for scale). The unit was variably altered and brecciated (photos from Brian Cousens). 


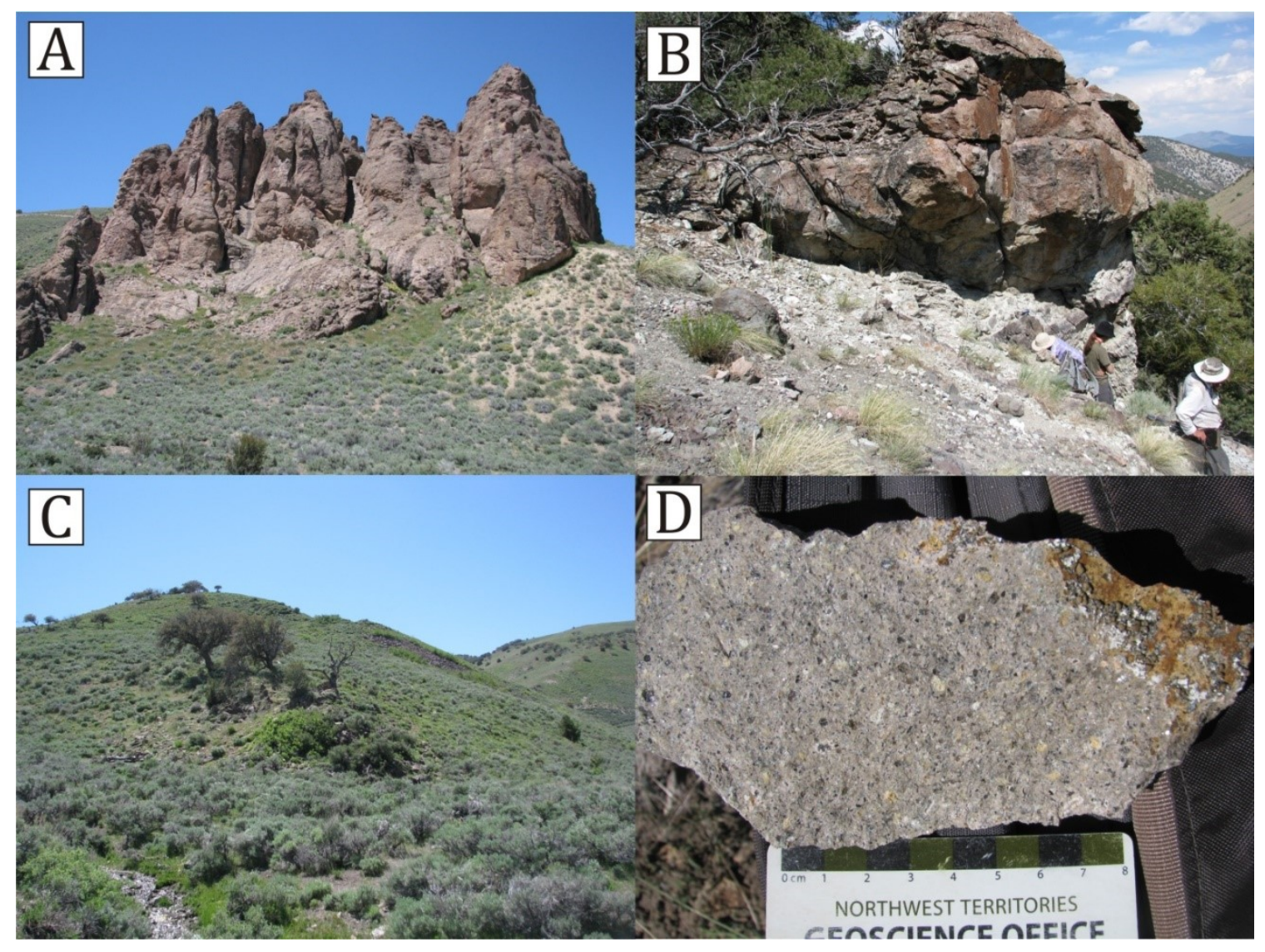

Figure 4.12: (A) Large spires of a quartz-feldspar-biotite tuff deposited on the Bonita Canyon Formation which are megabreccia blocks of the tuff of Arc Dome from the caldera wall that fell inwards into the caldera during collapse. (B) A large block of tuff of Arc Dome overlying the Bonita Canyon formation in the Barrett Canyon (geologists for scale). (C) A small outcrop of the quartz-feldspar-biotite tuff from where a megabreccia sample was taken. (D) A sample of porphyritic quartz-feldspar-biotite tuff proposed to be megabreccia from the wall rock of the caldera collected from the small outcrop (C) (photos from Brian Cousens). 


\section{Intrusions and dykes}

A dacite porphyry dyke was sampled in Devil's Gate Canyon and was distinguished by its high proportion of feldspars (30-40\%) and minor biotite. Fine grained intrusions were observed within the porphyritic texture of the intermediate dyke. The contact of the dacite dyke with the Underdown Tuff trends east to west. Rhyolite intrusions sampled in Idlewild Canyon had a similar mineral assemblage as the surrounding Bonita Canyon Formation and Unnamed tuff (quartz, feldspar and biotite). 


\subsection{Methods}

\subsection{Samples}

41 rock samples were collected in July 2017 and prepared for petrographic, geochemical and isotopic analysis. Unaltered, non-weathered in-situ pumice and whole rock samples were collected, where possible, from intracaldera and potential outflow tuff units. Pumice fragments were collected in locations where the pumice could be separated from the matrix, and whole rock samples were collected with an effort to minimize the amount of lithic fragments. These samples were added to an existing collection of 70 samples from the same region collected by K. Klausen, B. Cousens, and C. Henry (Nevada Bureau of Mines and Geology) in June 2016. These samples from 2016 were previously prepared as thin sections by K. Klausen.

Polished thin sections were produced from 37 of the 41 collected samples at the Carleton University Thin Section Laboratory. The thin sections were analyzed using a Leica petrographic transmitted light microscope, and photomicrographs were taken using a petrographic microscope with a Nikon camera and Jenoptik software.

\subsection{Major and Trace element analyses}

Sample preparation was done at the Carleton University rock preparation lab. A diamond-bladed rock saw was used to cut samples into slabs and remove any weathered surfaces and lithic fragments. Pumice was removed from the whole rock matrix where possible. A Bico Chipmunk jaw-crusher was used to crush each sample 
until the particle size was reduced to $(<1 \mathrm{~mm})$. A small amount of sample was used to pre-contaminate the jaw-crusher before each sample was crushed, that was discarded after crushing, reducing the possibility of contamination from the steel plates. The steel plate and inside of the jaw-crusher was scrubbed with a wire brush and cleaned with ethanol and compressed air between each sample. A Rocklabs ring mill with a chromesteel head was used to reduce each sample to a fine powder. The ring mill was cleaned between samples with water, compressed air, and ethanol. The ring mill was then precontaminated with a small amount of crushed sample which was then discarded. The steel head only adds $\mathrm{Cr}$ to the crushed powder, based on comparison analyses between tuffs crushed in an agate and the steel head.

Whole rock major and trace element concentrations were determined at the ALS Laboratory in North Vancouver, British Columbia. Major element concentrations were obtained using inductively coupled plasma atomic emission spectroscopy (ICP-AES), and trace element concentrations were measured by inductively coupled plasma mass spectrometry (ICP-MS). ICP-AES measures concentrations in weight percent (wt. \%) for the following oxides; $\mathrm{Al}_{2} \mathrm{O}_{3}, \mathrm{BaO}, \mathrm{CaO}, \mathrm{Cr}_{2} \mathrm{O}_{3}, \mathrm{Fe}_{2} \mathrm{O}_{3}, \mathrm{~K} 2 \mathrm{O}, \mathrm{MgO}, \mathrm{MnO}, \mathrm{Na}_{2} \mathrm{O}, \mathrm{P}_{2} \mathrm{O}_{5}, \mathrm{SiO}_{2}$, $\mathrm{SrO}$ and $\mathrm{TiO}_{2}$. The loss-on-ignition (LOI), which is the weight loss of volatiles $\left(\mathrm{H}_{2} \mathrm{O}, \mathrm{CO}_{2}, \mathrm{~S}\right.$, and other trace gases) during fusion, was also measured. Trace element concentrations were determined by ICP-MS for the following elements; $\mathrm{Ag}, \mathrm{Ba}, \mathrm{Cd}, \mathrm{Ce}, \mathrm{Cs}, \mathrm{Cu}, \mathrm{Dy}, \mathrm{Er}$, Eu, Ga, Gd, Hf, Ho, La, Li, Lu, Mo, Nb, Nd, Pb, Pr, Rb, Sm, Sn, Sr, Ta, Tb, Th, Tm, U, W, Y, 
$\mathrm{Yb}$, and $\mathrm{Zr}$. Concentrations of the metals $\mathrm{Co}, \mathrm{Cr}, \mathrm{Ni}, \mathrm{Pb}, \mathrm{Sc}, \mathrm{V}$, and $\mathrm{Zn}$ were determined by ICP-OES (inductively coupled plasma optical emission spectrometry).

Analysis of the rare earth element (REE) characteristics of some samples showed that their REE abundances have been modified. In an attempt to determine if the REE addition to some samples was due to alteration, five grams of powder was acid-washed in $2.5 \mathrm{~N} \mathrm{HCl}$ on a hotplate at $80^{\circ} \mathrm{C}$ for five days, then rinsed several times in ultrapure $\mathrm{H}_{2} \mathrm{O}$. A fraction of the acid-washed sample was sent to ALS Laboratories for major and trace element analysis, and isotopic determinations were performed on the acidwashed powder.

\subsection{Radiogenic Isotope Methods}

22 samples were chosen for $\mathrm{Sr}$ and $\mathrm{Nd}$ isotopic analysis by thermal ionization mass spectrometry (TIMS) and $\mathrm{Pb}$ isotopic analysis by multi-collector inductively coupled plasma mass spectrometry (MC-ICP-MS) at the Isotope Geochemistry and Geochronology Research Centre (IGGRC), Carleton University. Approximately 100 mg of powdered sample was dissolved in $15 \mathrm{~mL}$ Savillex Teflon beakers using $3 \mathrm{~mL}$ of a concentrated $\mathrm{HF}: \mathrm{HNO}_{3}$ mixture (at an approximately 1:2 ratio). The beakers were left on a $130^{\circ} \mathrm{C}$ for 2 days before being opened and evaporated until dry. The dried precipitate was re-dissolved using 1-2 drops of concentrated $\mathrm{HNO}_{3}$ and dried down once more. $6 \mathrm{~N}$ $\mathrm{HCl}$ was then added to the dried residue and the closed Sallivex beakers were placed on a $130^{\circ} \mathrm{C}$ hotplate. After 2 days, the lids were removed from the beakers and the samples were left to evaporate, before $1 \mathrm{~N} \mathrm{HBr}$ was added to the dried sample for $\mathrm{Pb}$ column 
chromatography. Elemental separation from the same dissolution was in the order $\mathrm{Pb}$, Sr, and Nd.

\section{Pb Isotope Analysis}

$\mathrm{Pb}$ separation was completed using a 2 pass procedure. Samples dissolved in $3.0 \mathrm{~mL}$ of 1.0N $\mathrm{HBr}$ were loaded using a pipette into Bio-Rad 10-mL polyethylene Econo columns containing $0.6 \mathrm{~mL}$ of cleaned and conditioned AG1-8X anion resin. After adding the sample to the column, a $2.0 \mathrm{~mL}$ wash of $\mathrm{HBr}$ was added to the column and both were collected in clean Teflon beakers for $\mathrm{Sr}$ and $\mathrm{Nd}$ chemistry. $2.0 \mathrm{~mL}$ of $1.0 \mathrm{~N} \mathrm{HBr}$ and $0.5 \mathrm{~mL}$ of $2.0 \mathrm{~N} \mathrm{HCl}$ were passed through the columns and discarded. $5.0 \mathrm{~mL}$ of $6.0 \mathrm{~N} \mathrm{HCl}$ was used to elute the $\mathrm{Pb}$ into clean snap-cap Teflon beakers which was then dried completely. $0.5 \mathrm{~mL}$ of $1.0 \mathrm{~N} \mathrm{HBr}$ was added to the dried $\mathrm{Pb}$ in preparation for the second column pass. The dissolved sample was pipetted into columns loaded with $0.2 \mathrm{~mL}$ of conditioned AG1-8X anion resin. $2.0 \mathrm{~mL}$ of $1.0 \mathrm{~N} \mathrm{HBr}$ and $0.3 \mathrm{~mL}$ of $1.5 \mathrm{~N} \mathrm{HCl}$ were added sequentially to the columns, and the $\mathrm{Pb}$ separate was eluted using $3.0 \mathrm{~mL}$ of $6.0 \mathrm{~N} \mathrm{HCl}$, and then dried down. $0.5 \mathrm{~mL}$ of $7.0 \mathrm{~N} \mathrm{HNO}_{3}$ was added to the dried $\mathrm{Pb}$ residue to drive off any bromides. A $90 \% \mathrm{~Pb}$ yield was measured from the columns, based on calibration of $\mathrm{Pb}$ eluted from the column.

The $\mathrm{Pb}$ separate was dissolved in $10 \mu \mathrm{L}$ of $\mathrm{HNO}_{3}$ for 10 minutes, whereas the acidwashed samples were dissolved in $20 \mu \mathrm{L} \mathrm{HNO}_{3} .2 \mathrm{~mL}$ of $\mathrm{HNO}_{3}$ and $20 \mu \mathrm{L}$ (only $15 \mu \mathrm{L}$ for acid-washed samples) of thallium (TI) spike were added to a clean polyethylene centrifuge tube. A fraction of the dissolved sample was then pipetted into the centrifuge 
tube and the samples were centrifuged for three minutes to remove any particulate matter. The amount of sample added to the tube was calculated based on an assumed $90 \%$ column yield, and based on the following equation:

$$
\mu L_{\text {sol }}=\frac{\mu L_{\mathrm{HNO}_{3}} \times 0.3 \mu g}{\mu g_{\text {sample }}}
$$

Where $\mu \mathrm{L}_{\text {sol }}$ is the volume of solution added to the centrifuge tube, $\mu \mathrm{L}_{\mathrm{HNO}}$ is the volume of $\mathrm{HNO}_{3}$, and $0.3 \mu \mathrm{g}$ represents the weight of the $\mathrm{HNO}_{3}$. The centrifuge tubes were loaded into the autosampler of a Thermo-Finnigan NEPTUNE multi-collector induction coupled plasma mass spectrometer (MC-ICP-MS). 7 blocks of 10 ratios were taken for each sample, and BCR-2 and NBS981 were run as standards along with the samples. All samples were corrected for mass fractionation using the TI spike and using the NBS981 standard which has long term laboratory averages of ${ }^{206} \mathrm{~Pb} /{ }^{204} \mathrm{~Pb}=16.9316 \pm 0.0015$, ${ }^{207} \mathrm{~Pb} /{ }^{204} \mathrm{~Pb}=15.4853 \pm 0.0014$, and ${ }^{208} \mathrm{~Pb} /{ }^{204} \mathrm{~Pb}=36.6789 \pm 0.0041$ (24 runs; August 2018-June 2019). BCR-2 has laboratory averages of ${ }^{206} \mathrm{~Pb} /{ }^{204} \mathrm{~Pb}=18.7628 \pm 0.0008$, ${ }^{207} \mathrm{~Pb} /{ }^{204} \mathrm{~Pb}=15.6130 \pm 0.0008$, and ${ }^{208} \mathrm{~Pb} /{ }^{204} \mathrm{~Pb}=38.7218 \pm 0.0020$ (4 runs; October 2018-June 2019).

\section{Sr Isotope Analysis}

The LILE/REEs-bearing $\mathrm{HBr}$ solution was dried down, subsequently dissolved in $1.0 \mathrm{~mL}$ of 7.0 $\mathrm{HNO}_{3}$, and was dried down again. The dried residue was taken up in $2.5 \mathrm{~N} \mathrm{HCl}$ and was pipetted into borosilicate glass columns containing $\sim 3 \mathrm{~mL}$ Dowex AG50-X8 cation resin. The columns were washed using $18.0 \mathrm{~mL}$ of $2.5 \mathrm{~N} \mathrm{HCl}$, and $\mathrm{Sr}$ was then collected 
using $6.0 \mathrm{~mL}$ of $2.5 \mathrm{~N} \mathrm{HCl}$. Rare earth elements were then eluted using $6.0 \mathrm{~N} \mathrm{HCl} . \sim 2.5 \mu \mathrm{g}$ of $\mathrm{Sr}$, diluted using weak $\mathrm{HNO}_{3}$, were loaded onto single tantalum filaments with $3 \mu \mathrm{L}$ of $\mathrm{H}_{3} \mathrm{PO}_{4}$ and run in a Thermo-Finnigan TRITON thermal ionization mass spectrometer (TIMS). 10 blocks of 10 ratios were taken for each sample, for a total of 100 ratios. NBS987 was run as a standard and yielded an average value of ${ }^{87} \mathrm{Sr} /{ }^{86} \mathrm{Sr}=0.710242 \pm$ 0.000013. The long term lab average for NBS987 standard is ${ }^{87} \mathrm{Sr} /{ }^{86} \mathrm{Sr}=0.710242 \pm$ 0.000014 (17 runs; June 2018-August 2019). The long term lab average for BCR-2 is $0.704998 \pm 0.000018$ (5 runs; June 2018-March 2019). Initial age-corrected ${ }^{87} \mathrm{Sr} /{ }^{86} \mathrm{Sr}$ ratios were calculated using ${ }^{40} \mathrm{Ar} /{ }^{39} \mathrm{Ar}$ ages provided by C. Henry (Appendix I, Table I).

\section{Nd Isotope Analysis}

The REE-bearing fraction collected from the Sr columns was dried down and then taken up in $0.26 \mathrm{~N} \mathrm{HCl}$. The solution was pipetted into Eichrom Ln spec columns containing Teflon powder coated with HDEHP (di(2-ethylhexl)) orthophosphoric acid. $6.5 \mathrm{~mL}$ of 0.26 $\mathrm{N} \mathrm{HCl}$ was used to wash the columns, after which the $\mathrm{Nd}$ was eluted using $5 \mathrm{~mL}$ of $0.26 \mathrm{~N}$ $\mathrm{HCl}$ and was then dried down. $\sim 0.5 \mu \mathrm{g}$ of $\mathrm{Nd}$ and $1 \mu \mathrm{L}$ of $\mathrm{H}_{3} \mathrm{PO}_{4}$ was loaded onto a double rhenium filament and run in the TRITON TIMS. Initial ${ }^{143} \mathrm{Nd} /{ }^{144} \mathrm{Nd}$ ratios were calculated using ${ }^{40} \mathrm{Ar} /{ }^{39} \mathrm{Ar}$ ages provided by C. Henry (Appendix I, Table I), Sm and Nd concentrations from the whole-rock ICP-MS analyses, and a ${ }^{147} \mathrm{Sm}$ decay constant $\lambda=6.54 * 10^{-12}$. Initial epsilon values $\left(\varepsilon \mathrm{Nd}_{\mathrm{i}}\right)$ were calculated with ${ }^{143} \mathrm{Nd} /{ }^{144} \mathrm{Nd}_{\mathrm{CHUR}}=$ 0.512638 and ${ }^{147} \mathrm{Sm} /{ }^{144} \mathrm{Nd} d_{\text {CHUR }}=0.1967$. An internal laboratory standard (Nd Std) was analysed with the other samples and yielded an average ratio of ${ }^{143} \mathrm{Nd} /{ }^{144} \mathrm{Nd}=0.511814$ 
\pm 0.000009 . The long term lab average of $\mathrm{Nd} \mathrm{Std}$ is ${ }^{143} \mathrm{Nd} /{ }^{144} \mathrm{Nd}=0.511815 \pm 0.000009(7$ runs; June 2018-May 2019). Based on comparative analyses between the Nd Std and La Jolla standards, this average value corresponds to a La Jolla standard value of 0.511845 . The average ${ }^{143} \mathrm{Nd} /{ }^{144} \mathrm{Nd}$ obtained for the BCR-2 international standard is $0.512536 \pm$ 0.000023 (2-sigma, $\mathrm{n}=21$ runs). 


\subsection{Results}

\subsection{Petrography}

Thin sections were analyzed to determine the mineral and glass phases in the samples and to characterize the textures of the units. Full thin section descriptions are listed in Appendix I, Table III.

\section{Pablo Formation}

The Pablo Formation, interpreted to be basement to the Underdown caldera (Bonham, $1970)$, is an andesite with a mineral assemblage of plagioclase + amphibole \pm pyroxene, and contains trace amounts of Fe-Ti oxides and biotite. One sample appears to contain secondary quartz, and pyrite is visible in one hand sample, therefore some opaque minerals are assumed to be pyrite. Pyroxene crystals are being replaced by amphibole and contain opaque inclusions. Plagioclase is the dominant mineral phase and is commonly partially altered to sericite and/or calcite. Plagioclase phenocrysts are up to $2.5 \mathrm{~mm}$, while smaller grains which make up the groundmass are $\sim 0.10 \mathrm{~mm}$. Amphibole phenocrysts are $1.5-3.0 \mathrm{~mm}$ and commonly contain opaque inclusions $0.10-0.25 \mathrm{~mm}$. Crystals are euhedral to subhedral in shape.

\section{The tuff of Gabbs Valley}

The tuff of Gabbs Valley is an ash flow tuff containing approximately $<20 \%$ phenocrysts. The unit is composed of plagioclase + quartz + sanidine, and contains variable to trace amounts of biotite, amphibole, opaque minerals, Fe-Ti oxides and monazite. Whole rock 
samples contain different proportions of plagioclase, quartz, and sanidine. Welded samples have matrices containing glass shards and banding that wraps around phenocrysts. Both banded and white pumice are observed to be phyric and contain spherulites. Plagioclase crystals show some zoning, resorption, and alteration to calcite and sericite. Plagioclase phenocrysts are variable in size, ranging from $0.30-3.0 \mathrm{~mm}$ in different samples. Quartz phenocrysts range in size from $0.10-2.0 \mathrm{~mm}$, sanidine range in size from 0.75-2.25 mm, biotite are $\sim 0.4-2.25 \mathrm{~mm}$, amphibole are $<0.2 \mathrm{~mm}$, and opaque minerals are $<0.5 \mathrm{~mm}$. Phenocrysts are subhedral in shape.

\section{The tuff of Arc Dome}

The tuff of Arc Dome is an ash flow tuff containing $10-25 \%$ phenocrysts. Pumice is less crystal rich (10\%) than the whole rock samples (15-25\%). The unit is composed of plagioclase + quartz + sanidine + biotite, and contains trace amounts of amphibole, opaque minerals, Fe-Ti oxides, monazite and pyroxene. Some samples have a matrix containing spherulites, and the pumice is also spherulitic. Some feldspars and matrices show alteration to calcite. Plagioclase, quartz and sanidine have relatively equal abundances across the samples with some exceptions. No quartz was observed in whole rock 17-SM-20 which was found to contain 15\% pyroxene. Plagioclase phenocrysts are generally around $1.5-2.5 \mathrm{~mm}$, but in one sample they are up to $5.0 \mathrm{~mm}$. Quartz phenocrysts are $1.0-2.5 \mathrm{~mm}$, and sanidine phenocrysts are generally $0.50-3.0 \mathrm{~mm}$ with one sample up to $4.0 \mathrm{~mm}$. Biotite phenocrysts are $0.75-2.5 \mathrm{~mm}$, amphibole are $1.5-2.0$ $\mathrm{mm}$, and opaque minerals are $<0.4 \mathrm{~mm}$. Phenocrysts are subhedral in shape. 


\section{The tuff of Brunton Pass}

The Tuff of Brunton Pass is a crystal poor ash flow tuff with approximately $<5 \%$ phenocrysts. The unit is composed of sanidine + quartz, and trace amounts of plagioclase, biotite, opaque minerals and Fe-Ti oxides. Microcrystalline lithic fragments are found in both samples. The matrices are glassy, altered, and spherulitic. Both white and banded fiamme are found in 17-SM-13A. The matrix of 17-SM-13B contains glass shards, and areas of glassy pumice are completely spherulitic. Calcite alteration is found in the matrix is 17-SM-13B. Plagioclase phenocrysts are small in both samples, $0.50-0.75$ $\mathrm{mm}$, while quartz and sanidine phenocrysts are 1.25-2.0 mm. Biotite phenocrysts are $0.25-0.50 \mathrm{~mm}$, and opaque minerals are $<0.5 \mathrm{~mm}$. Phenocrysts are subhedral in shape.

\section{Underdown Tuff}

The Underdown Tuff is an ash flow tuff that contains $\sim 5-25 \%$ phenocrysts in whole rock samples, $10-20 \%$ phenocrysts in porphyritic pumice samples, and $<10 \%$ phenocrysts in white pumice samples. The Underdown Tuff contains plagioclase + quartz + sanidine, and contains minor and trace amounts of biotite, amphibole, opaque minerals, Fe-Ti oxides, and monazite. The more common white pumice contains quartz, sanidine and secondary calcite. Matrices of porphyritic pumice are dark brown, glassy and altered. Generally, porphyritic pumice has a relatively equal proportion of plagioclase, quartz and sanidine phenocrysts. Biotite and amphibole are only found in one porphyritic pumice sample and both appear to be altered to chlorite. Whole rock matrices are variably welded with some containing spherulites and banding which wraps around 
phenocrysts (Fig. 6.1). Whole rock samples have variable proportions of plagioclase, quartz and sanidine, and trace amounts of biotite and hornblende that appear to be altered to chlorite (Fig. 6.2). Some matrices also show sericite alteration. Plagioclase phenocrysts in whole rock samples are 1.0-3.0 mm, quartz phenocrysts are 1.0-2.5 mm and commonly show embayments, and sanidine phenocrysts are 0.50-3.5 mm. Most biotite crystals are $\sim 0.10 \mathrm{~mm}$, amphibole phenocrysts are up to $0.50-1.50 \mathrm{~mm}$, and opaque minerals are $<0.1 \mathrm{~mm}$. Phenocrysts are subhedral in shape.

\section{The tuff of Clipper Gap}

The tuff of Clipper Gap is an ash flow tuff that contains $~ 5-20 \%$ phenocrysts in whole rock samples and $15-25 \%$ phenocrysts in porphyritic pumice. White pumice contains fewer phenocrysts of quartz and sanidine than the porphyritic pumice ( $3-10 \%)$. The tuff of Clipper Gap contains plagioclase + quartz + sanidine and trace amounts of biotite, amphibole, opaque minerals, Fe-Ti oxides, and monazite. The matrices of porphyritic pumice are dark brown, glassy and heavily altered, and some contain glass shards (Fig. 6.1). Whole rock matrices are glassy, altered and some contain spherulites. Unaltered samples have matrices composed of glass shards. Porphyritic pumice has no identifiable quartz and a higher abundance of sanidine then plagioclase. Whole rock samples generally also have a higher proportion of sanidine than plagioclase and quartz, and in some cases do not contain any identifiable quartz. Biotite is not present in porphyritic pumice and only exists in trace amounts in whole rock samples (Fig. 6.2). A trace amount of amphibole is present in one porphyritic pumice sample and some of the 
whole rock samples. Generally, biotite and amphibole appear altered in whole rock samples. In the porphyritic pumice, plagioclase phenocrysts are $1.0-2.5 \mathrm{~mm}$ and sanidine phenocrysts are 1.0-4.5 mm. In whole rock samples, plagioclase phenocrysts are 0.50-2.5 mm with some smaller crystals $\sim 0.10 \mathrm{~mm}$, quartz phenocrysts are 1.0-2.0 $\mathrm{mm}$, and sanidine phenocrysts are 1.0-4.0 mm. Biotite and amphibole crystals are typically 0.10-0.75 mm with some larger crystals $1.0-2.0 \mathrm{~mm}$, and opaque minerals are 0.1-0.5 mm. Phenocrysts are subhedral in shape.

\section{The Terrill Mountains tuffs}

The Terrill Mountains tuffs are a series of ignimbrites with $\sim 5 \%$ phenocrysts. The unit contains plagioclase + quartz + sanidine and trace amounts of biotite, opaque minerals, Fe-Ti oxides, and possible pyroxene. The samples have a higher abundance of quartz and sanidine than plagioclase. White and banded fiamme are aphyric and phyric, respectively, and the matrices of the samples are generally densely welded. One sample shows possible alteration in the matrix, while the others are composed of fresh glass and glass shards. Plagioclase phenocrysts are generally small, ranging from $0.25-1.0 \mathrm{~mm}$, and sanidine phenocrysts are similarly sized between $1.0-1.50 \mathrm{~mm}$. Quartz phenocrysts are larger and are $\sim 1.50-1.75 \mathrm{~mm}$. Biotite phenocrysts are $0.25-0.5 \mathrm{~mm}$, and opaque minerals are $<0.1 \mathrm{~mm}$. Phenocrysts are subhedral in shape.

\section{Bonita Canyon Formation}


The Bonita Canyon Formation contains 5-15\% phenocrysts. The unit is composed of plagioclase + quartz + sanidine + biotite and trace amounts of amphibole, opaque minerals, Fe-Ti oxides, and monazite. The unit also contains a large proportion of lithic fragments composed of quartz and feldspar, up to $10 \%$ in some samples. Biotite is more common than amphibole in this unit, as amphibole was only identified in one sample (Fig. 6.2). Generally, quartz is slightly more abundant in the whole rock samples, however all phenocryst phases are present in low percentages. Matrices of white pumice samples are composed of glass and glass shards, and appear heavily altered by a green alteration phase. Plagioclase phenocrysts are $0.50-2.5 \mathrm{~mm}$, quartz phenocrysts are 0.50-2.5 mm and commonly show embayments (Fig. 6.1), and sanidine crystals are 0.50-2.0 $\mathrm{mm}$. Biotite phenocrysts are $0.25-2.0 \mathrm{~mm}$ and are generally unaltered, however one phenocryst was observed to be heavily resorbed. Opaque minerals are $<0.1 \mathrm{~mm}$. Phenocrysts are either subhedral to anhedral in shape or are broken fragments of crystals.

\section{Dacite Dyke}

The dacite dyke is an intermediate intrusive rock composed primarily of plagioclase with small amounts of biotite, opaque minerals, Fe-Ti oxides, and monazite. Plagioclase crystals appear to be partially altered to calcite, and the matrix appears to be partially altered to sericite. Plagioclase is present in two sizes, a larger size up to $5.0 \mathrm{~mm}$, and a smaller groundmass size $<0.50 \mathrm{~mm}$. Biotite crystals appear to be filling spaces between 
plagioclase crystals and range from $0.50-1.75 \mathrm{~mm}$, and opaque minerals are $<0.2 \mathrm{~mm}$. Crystals are subhedral to euhedral in shape.

\section{Rhyolite Intrusions}

The rhyolite intrusions are composed of plagioclase + quartz + sanidine + biotite, and trace amounts of opaque minerals, Fe-Ti oxides and monazite. Crystals tend to be present in clusters and the matrices of the samples appear partly composed of microcrystalline quartz. Plagioclase crystals are $1.5-3.0 \mathrm{~mm}$, tend to be present in a lower abundance than both quartz and sanidine, and show resorption in the centre of the crystals. Quartz crystals have embayments and are 1.5-2.5 mm. Sanidine crystals are 1.75-2.5 $\mathrm{mm}$ and show no alteration. Biotite crystals are $0.75-2.0 \mathrm{~mm}$ and are commonly replaced by opaque minerals $<0.25 \mathrm{~mm}$. Crystals are subhedral in shape.

\section{The Unnamed tuff}

The Unnamed tuff is a sequence of ash flow tuffs with $10-30 \%$ phenocrysts. The unit contains plagioclase + quartz + sanidine + biotite + amphibole, and trace amounts of opaque minerals, Fe-Ti oxides, and monazite. Biotite is present in all samples, and amphibole is present in all but two (Fig. 6.2). Two samples contain lithic fragments composed of microcrystalline material, and most samples have a highly welded, glassy brown matrix. Aphyric fiamme are common throughout the unit, as well as large fractured phenocrysts (Fig. 6.1). Some pumice and matrix appear microcrystalline and are possibly silicified. Occasionally, fractures will radiate out from phenocrysts into the 
glassy matrix. Quartz phenocrysts commonly show embayments. Generally, plagioclase, quartz, and sanidine are present in relatively equal abundances. Plagioclase phenocrysts are 1.0-1.5 mm, quartz phenocrysts are 1.5-3.0 $\mathrm{mm}$, and sanidine are generally 2.0-4.0 $\mathrm{mm}$. Biotite phenocrysts are $\sim 0.25-1.75 \mathrm{~mm}$, and amphibole phenocrysts are $\sim 0.10-2.5$ $\mathrm{mm}$. Biotite and hornblende show possible alteration to chlorite and some phenocrysts have yellow rims of alteration. Opaque minerals are $<0.25 \mathrm{~mm}$. Phenocrysts are subhedral in shape. 

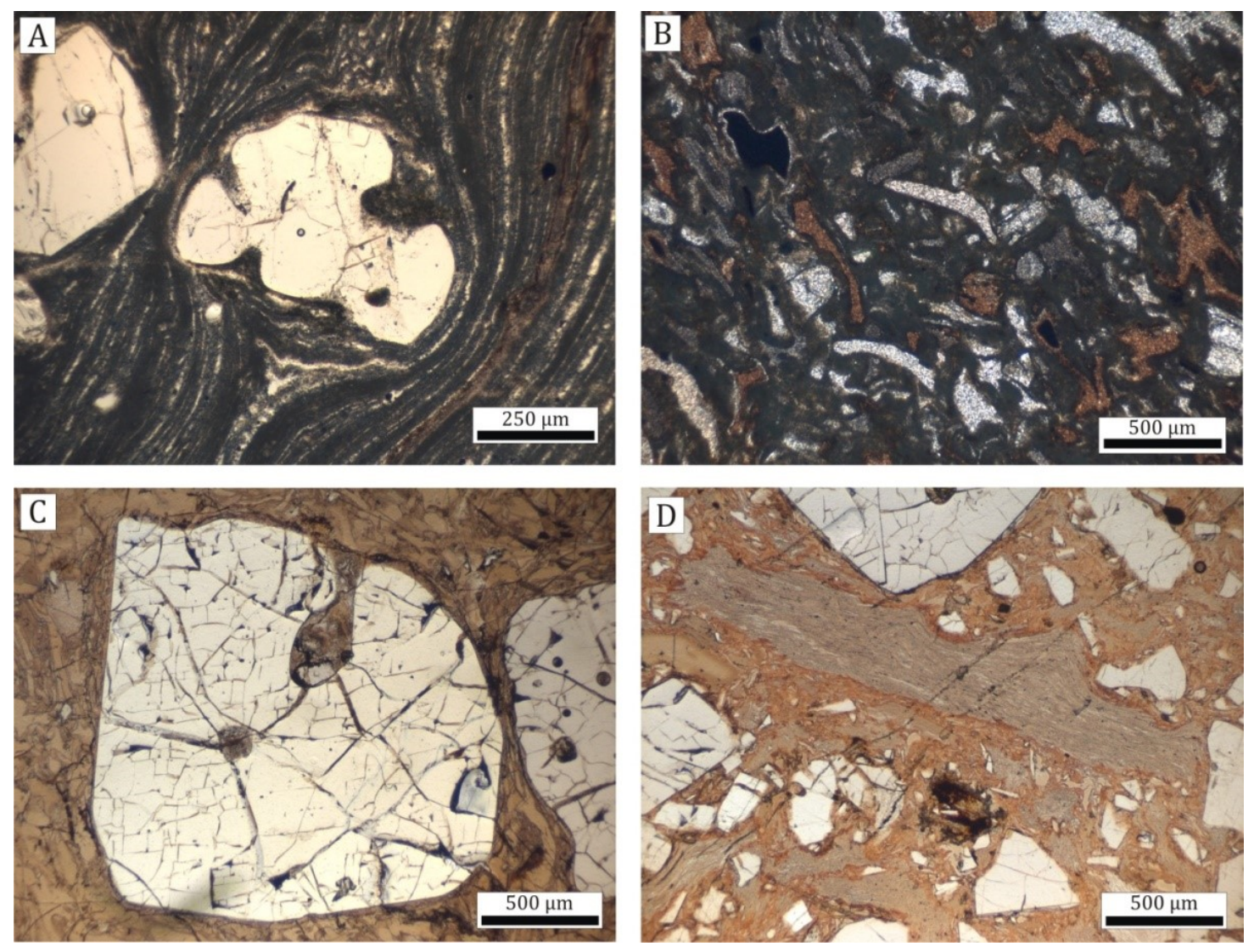

Figure 6.1: Photomicrographs of major ignimbrites showing commonly observed textures. (A) Underdown Tuff - Quartz eye phenocryst with a heavily banded matrix that wraps around the phenocrysts (sample 16-SM-50). (B) Tuff of Clipper Gap showing a densely welded matrix composed of glass shards (sample 17-SM-22). (C) Bonita Canyon Formation - a vitrophyre sample with a glassy matrix and large, fractured and embayed quartz phenocryst (sample 16-SM-03). (D) Unnamed Tuff - A typical Unnamed tuff sample shows a high degree of welding. Fractured phenocrysts can be seen alongside large flattened, aphyric pumice (sample 16-SM-06D). 

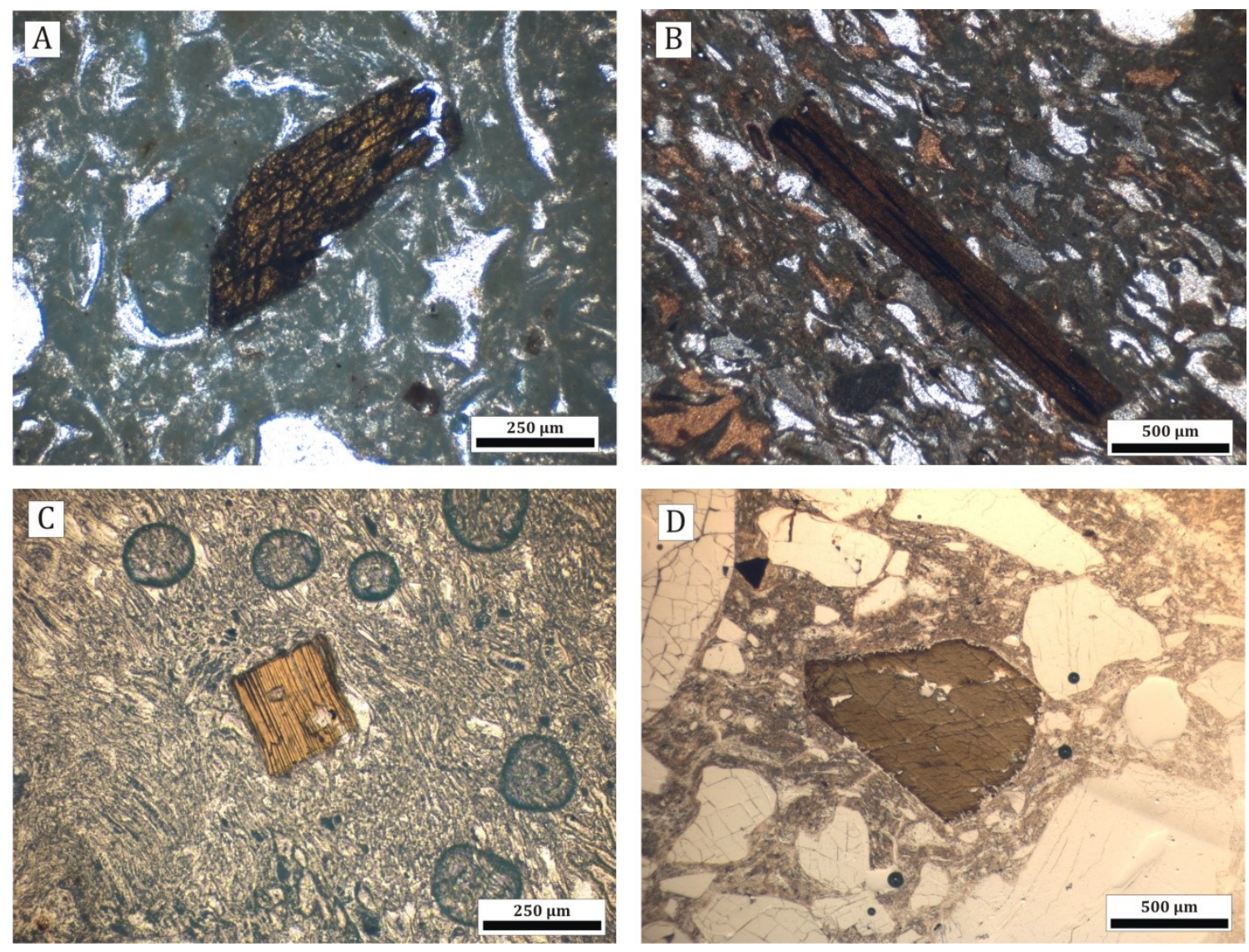

Figure 6.2: Photomicrographs of major ignimbrites showing hydrous phases (hornblende and biotite). (A) Underdown Tuff - an example of hornblende viewed in the Underdown Tuff. Distinctive cleavage can be seen on the dark brown crystal (sample 17SM-27). (B) Tuff of Clipper Gap - A biotite crystal seen in the Tuff of Clipper Gap (sample 17-SM-22). (C) Bonita Canyon Formation - A biotite crystal in the Bonita Canyon formation. The matrix of this unit is far less welded than the vitrophyre which is typical for this unit (sample 16-SM-21B). (D) Unnamed Tuff - An amphibole crystal in the Unnamed tuff. Distinctive cleavage can be seen (sample 16-SM-39). 


\subsection{Geochemistry}

All data from the Underdown Caldera Complex are shown in Figure 6.3, a total alkalissilica (TAS) classification diagram (Le Maitre et al., 1989). The Oligocene tuffs plot in both the rhyolite and trachyte fields. Trachyte samples include pumice samples from the Underdown Tuff, tuff of Clipper Gap, and Bonita Canyon Formation as well as the dacite dyke sample which is likely a trachydacite. Both the Underdown Tuff and tuff of Clipper Gap plot in a trend from rhyolite to trachyte. The trachyte tuff of Clipper Gap pumice samples as well as some of the rhyolitic pumice and whole rock samples exhibit negative and positive Ce anomalies that are not observed in other samples that largely plot in the rhyolite field (Fig. 6.4). These samples, as well as the origin of the Ce anomalies will be discussed separately from the rest of the data (section 7.2). Other samples that will not be interpreted with the main group of data are samples with high loss on ignition (LOI) of over 6 weight percent. These samples have been removed from the major and trace element diagrams as they are interpreted to be altered and therefore the geochemistry does not reflect the original characteristics of the unit. The high LOI samples which have been removed include samples from the tuff of Clipper Gap, Bonita Canyon Formation,

and Terrill Mountains tuffs. Acid-washed tuff of Clipper Gap samples with anomalous REEs are plotted in the isotope geochemistry section but not in the major and trace element geochemistry sections as acid washing has removed some primary phases (apatite, Fe-oxides) which alter the major and trace element geochemistry. 


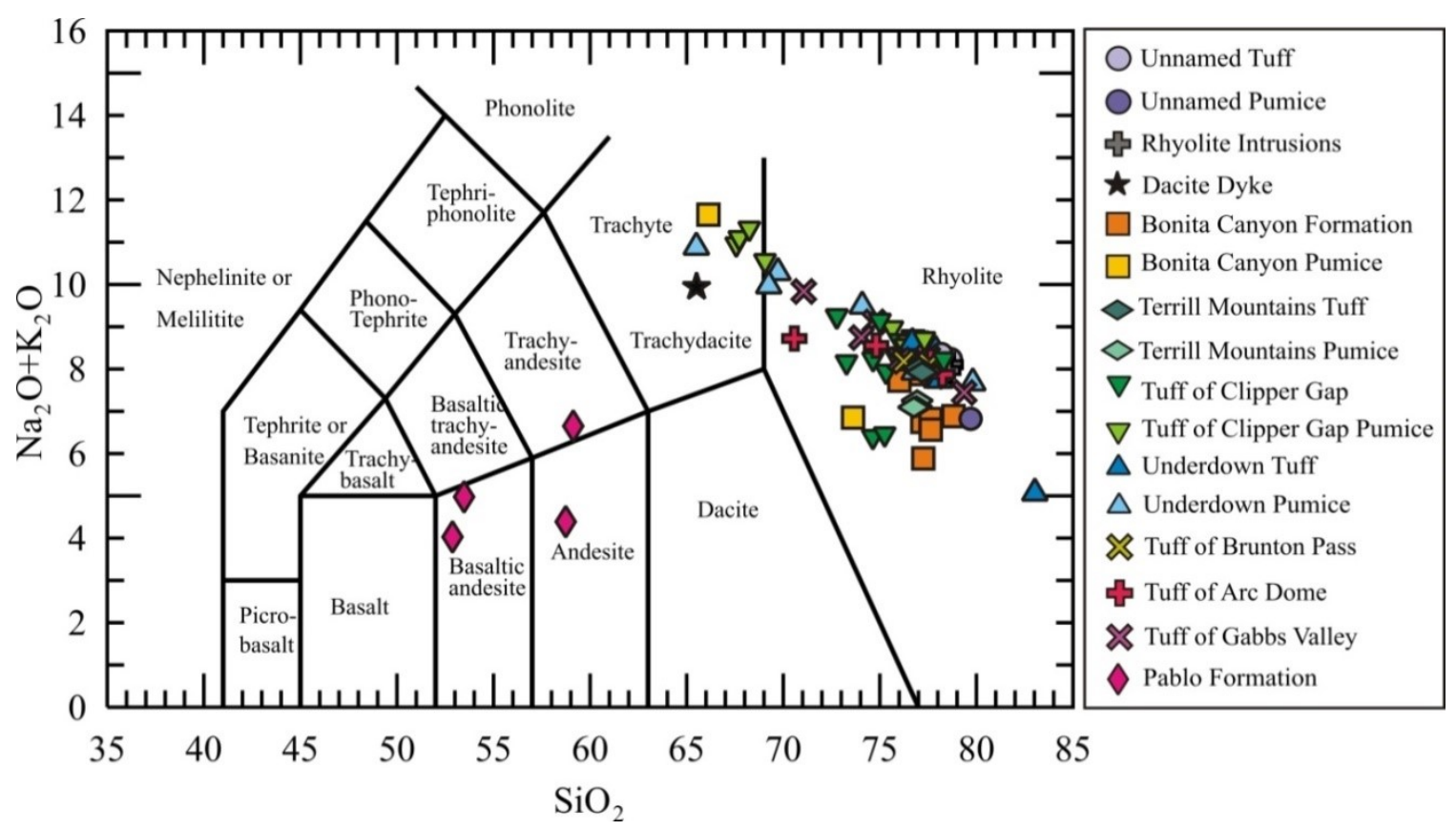

Figure 6.3: Total alkalis-silica diagram (Le Maitre et al., 1989) of all data from the Underdown Caldera Complex. Most felsic samples plot in the rhyolite field of the diagram, while a few samples plot in the trachyte field. Both the Underdown Tuff and the tuff of Clipper Gap show a trend from rhyolite towards trachyte, particularly in their pumice. 


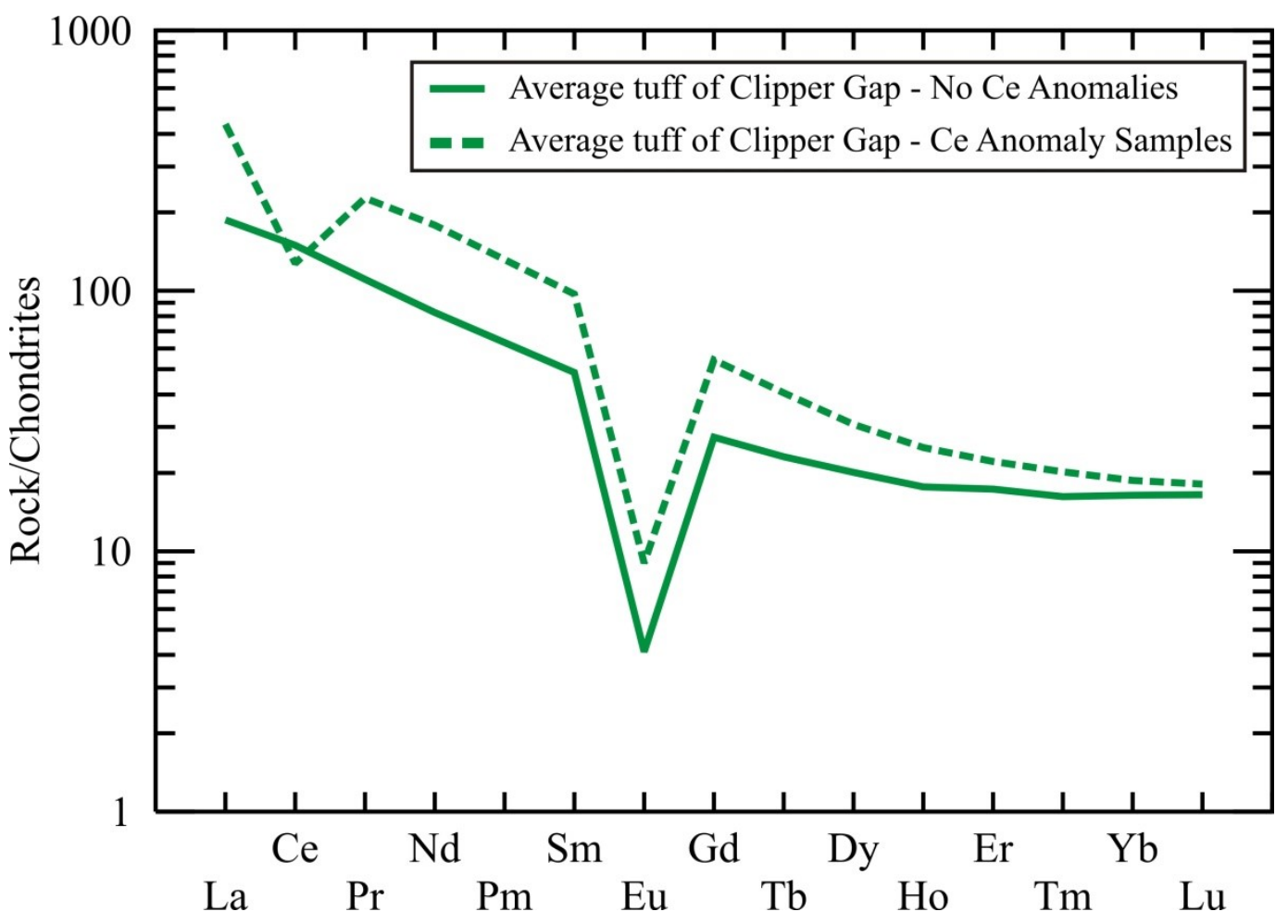

Figure 6.4: Average chondrite normalized rare earth element patterns of the Tuff of Clipper Gap samples with no Ce anomalies and those with Ce anomalies (normalization factors of Sun and McDonough, 1989).

\subsubsection{Major element geochemistry}

Major element compositions are reported in Appendix I, Table IV. All values are recalculated to $100 \%$ anhydrous compositions for plotting. As these are mainly felsic rocks, the concentrations of $\mathrm{MgO}$ and $\mathrm{MnO}$ were very low in all Oliogcene tuffs and therefore are not presented in this section for these units. All units have been plotted as fields on a total alkalis-silica (TAS) diagram in Figure 6.5 (Le Maitre et al., 1989), and have subsequently been divided two different TAS diagrams to better view the Oligocene tuff units. 


\section{Pablo Formation}

The Pablo formation is intermediate in composition and plots in the basaltic-andesite, andesite, and trachy-andesite fields of a TAS diagram (Fig. 6.6, Le Maitre, 1989). The Pablo Formation shows positive trends in $\mathrm{Al}_{2} \mathrm{O}_{3}$ and $\mathrm{Na}_{2} \mathrm{O}$ with increasing $\mathrm{SiO}_{2}$ content, and a negative trend in all other major elements with increasing $\mathrm{SiO}_{2}$ content except $\mathrm{K}_{2} \mathrm{O}$ which shows a scatter.

\section{Oligocene tuffs}

The Oligocene tuffs plot mainly in the rhyolite field of a TAS diagram (Le Maitre et al., 1989), as previously mentioned, with some samples plotting as a trend into the trachyte field. However, after the anomalous-REE tuff of Clipper Gap samples and the high LOI Bonita Canyon pumice samples have been removed, the Underdown pumice samples are the sole Oligocene tuffs which plot in the trachyte field. The tuff of Gabbs Valley and tuff of Arc Dome also show a trend towards the trachyte field but remain in the rhyolite field of the diagram (Fig. 6.6).

The Oligocene tuffs show relatively similar trends in major element oxide data when compared to increasing $\mathrm{SiO}_{2}$ content. These trends and characteristics will be discussed in the next paragraph. However, for the tuff of Brunton Pass and the Terrill Mountains tuffs, the number of samples from each unit (two samples from each) causes there to be no observable trend in the data. The Unnamed tuff samples are also homogeneous and 
plot as a cluster for all major element oxides. Major ignimbrites, including the Underdown Tuff, Bonita Canyon Formation, tuff of Clipper Gap, and the Unnamed tuff were plotted on major element bivariate diagrams on Figure 6.9. The other tuffs, including the tuff of Gabbs Valley, tuff of Arc Dome, tuff of Brunton Pass, and Terrill Mountains tuffs were plotted on Figure 6.10 along with the Underdown Tuff and Bonita Canyon Formation data for comparison.

The Oligocene tuffs show a strong negative trend in $\mathrm{Al}_{2} \mathrm{O}_{3}$ with increasing $\mathrm{SiO}_{2}$ content. Both the major ignimbrites from the Underdown Caldera, the Tuff of Clipper Gap, and the other tuffs show a similar trend. The Underdown Tuff shows the most variation in $\mathrm{Al}_{2} \mathrm{O}_{3}$ content, with the pumice samples generally containing a higher concentration of $\mathrm{Al}_{2} \mathrm{O}_{3}$ than the whole rock samples. The Terrill Mountains tuffs, tuff of Brunton Pass, and the Unnamed tuff all plot as a cluster at the end of the trend (excluding the highest Underdown Tuff whole rock).

Many of the Oligocene tuffs show a negative trend in $\mathrm{CaO}$ with increasing $\mathrm{SiO}_{2}$ content. In detail, the Underdown pumice samples with low $\mathrm{SiO}_{2}$ contents show a negative trend while the whole rock samples and some pumice with higher $\mathrm{SiO}_{2}$ contents plot more as a cluster. Like the Underdown tuff, the Bonita Canyon Formation tuffs show a slightly scattered negative correlation between $\mathrm{CaO}$ and increasing $\mathrm{SiO}_{2}$. The Tuff of Clipper Gap shows the most variation in $\mathrm{CaO}$ as the whole rock and pumice samples generally plot as a cluster near the Underdown Tuff samples, with a few whole rock samples showing a strong decrease from high CaO contents. The tuff of Gabbs Valley and tuff of Arc Dome 
show negative trends similar to the Underdown Tuff, the tuff of Brunton Pass plots as a scatter, and the Unnamed tuff is clustered.

A trend of decreasing $\mathrm{Fe}_{2} \mathrm{O}_{3}$ with increasing $\mathrm{SiO}_{2}$ is also observed in the Underdown Tuff. Similar to $\mathrm{Al}_{2} \mathrm{O}_{3}$ and $\mathrm{CaO}$, the Underdown pumice plot in a strong negative correlation between decreasing $\mathrm{Fe}_{2} \mathrm{O}_{3}$ and increasing $\mathrm{SiO}_{2}$ and the Underdown whole rock samples plot as a cluster with the Bonita Canyon Formation and the tuff of Clipper Gap. The tuff of Gabbs Valley shows the most variation in $\mathrm{Fe}_{2} \mathrm{O}_{3}$ content and plots as a scatter with little change in the $\mathrm{Fe}_{2} \mathrm{O}_{3}$ concentration. In contrast, the tuff of Arc Dome plots in a strong negative correlation between decreasing $\mathrm{Fe}_{2} \mathrm{O}_{3}$ and increasing $\mathrm{SiO}_{2}$, similar to the Underdown pumice. The Terrill Mountains tuffs, tuff of Brunton Pass, and the Unnamed tuff all plot as a cluster with the other clustered major ignimbrites.

The Underdown tuff shows a scattered pattern in both the whole rock and pumice samples. One outlying sample contains very little $\mathrm{K}_{2} \mathrm{O}$ and plots along with samples from the Bonita Canyon Formation which shows a scatter. The tuff of Clipper Gap shows a slight decrease in $\mathrm{K}_{2} \mathrm{O}$ content with increasing $\mathrm{SiO}_{2}$ content, but with more scatter than the Underdown Tuff. Both the tuff of Gabbs Valley and tuff of Arc Dome show a very slight decrease in $\mathrm{K}_{2} \mathrm{O}$ that is less steep than the Underdown Tuff samples. The Terrill Mountains tuffs, tuff of Brunton Pass, and the Unnamed tuff are clustered with a majority of the major ignimbrite samples.

Out of all major element oxides, $\mathrm{Na}_{2} \mathrm{O}$ shows the most scatter among ignimbrite units. The Underdown Tuff, Bonita Canyon Formation, and tuff of Clipper Gap all plot as a 
scatter with increasing $\mathrm{SiO}_{2}$ content, and the Underdown Tuff shows the largest variation in $\mathrm{Na}_{2} \mathrm{O}$ content. The tuff of Gabbs Valley and tuff of Arc Dome plot in similar linear trends with little $\mathrm{Na}_{2} \mathrm{O}$ variation with increasing $\mathrm{SiO}_{2}$. The Terrill Mountains tuffs, tuff of Brunton Pass, and Unnamed tuff generally plot as clusters, although one Unnamed tuff sample plots as an outlier at a much lower $\mathrm{Na}_{2} \mathrm{O}$ content than the other samples.

Negative correlations between $\mathrm{P}_{2} \mathrm{O}_{5}$ and increasing $\mathrm{SiO}_{2}$ content exist in the Underdown Tuff, Bonita Canyon Formation and tuff of Clipper Gap. The tuff of Gabbs Valley shows a negative correlation between decreasing $\mathrm{P}_{2} \mathrm{O}_{5}$ and increasing $\mathrm{SiO}_{2}$ content that is less steep than the Underdown Tuff, while the tuff of Arc Dome shows a strongly negative correlation between decreasing $\mathrm{P}_{2} \mathrm{O}_{5}$ and $\mathrm{SiO}_{2}$ similar to the Underdown Tuff. The Terrill Mountains tuffs, the tuff of Brunton Pass, and the Unnamed tuff show a large scatter.

A negative correlation between decreasing $\mathrm{TiO}_{2}$ and increasing $\mathrm{SiO}_{2}$ is observed in the Underdown Tuff and the Bonita Canyon Formation. The Underdown tuff shows the largest variation in $\mathrm{TiO}_{2}$ content, mostly in the pumice which forms most of the decreasing pattern. The Underdown Tuff whole rocks generally plot as a cluster, with one outlier at a high $\mathrm{SiO}_{2}$ content. The tuff of Clipper Gap has more scatter in $\mathrm{TiO}_{2}$ content in both the whole rock and pumice samples, but plots close to the cluster of Underdown Tuff samples. The tuff of Gabbs Valley and tuff of Arc Dome also show negative trends in $\mathrm{TiO}_{2}$ content with increasing $\mathrm{SiO}_{2}$. The tuff of Arc Dome shows a correlation between $\mathrm{TiO}_{2}$ and $\mathrm{SiO}_{2}$ similar to the Underdown pumice samples, while the 
tuff of Gabbs Valley shows more scatter between decreasing $\mathrm{TiO}_{2}$ and increasing $\mathrm{SiO}_{2}$ content. The Terrill Mountains tuffs, tuff of Brunton Pass, and Unnamed tuff all plot as clusters near the Underdown Tuff whole rock samples.

\section{Intrusive Rocks}

The dacite dyke is felsic in composition and plots in the trachy-dacite field on the TAS diagram (Fig 6.6, Le Maitre et al., 1989). The dacite dyke has a relatively similar concentration of all major element oxides as the Underdown Tuff pumice samples except for $\mathrm{CaO}$ (Fig. 6.9). For $\mathrm{CaO}$, the dacite dyke has a much higher concentration (2.8 wt. \%) than the Underdown Tuff pumice samples (0.14-1.4 wt. \%).

The rhyolite intrusive rocks collected from the Underdown Caldera are felsic in composition and plot in the rhyolite field on a TAS diagram (Fig. 6.6, Le Maitre et al., 1989). In major element variation diagrams, the rhyolite intrusions plot as a cluster with other major ignimbrites and show the most similarity to the Unnamed tuff samples. As there are only two samples from this unit, no fractionation trends are observed in the data, however the samples typically plot in the most evolved end of the major element fractionation trends observed in the other major ignimbrites (Underdown Tuff, Bonita Canyon, tuff of Clipper Gap) (Fig. 6.9). 


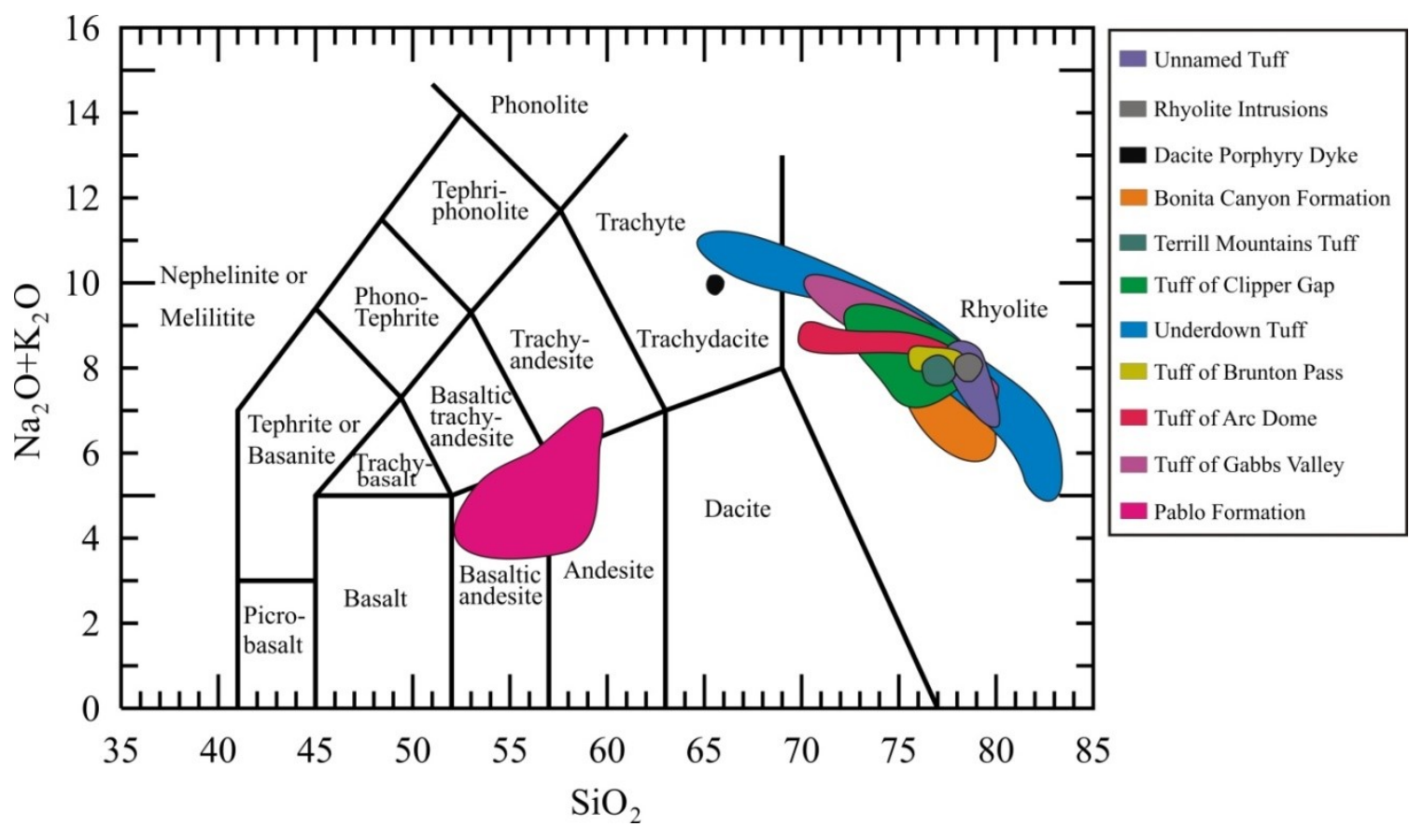

Figure 6.5: Total alkalis-silica diagram (Le Maitre et al., 1989) showing the fields of all units collected within and outside of the Underdown Caldera. The Underdown Tuff and Bonita Canyon formation show a trend of samples into the trachyte field, while other units plot within the rhyolite field. The dacite dyke plots as a point (black circle) in the trachydacite field. The Pablo Formation plots as a field extending between the basaltic andesite, andesite and trachy-andesite fields. 


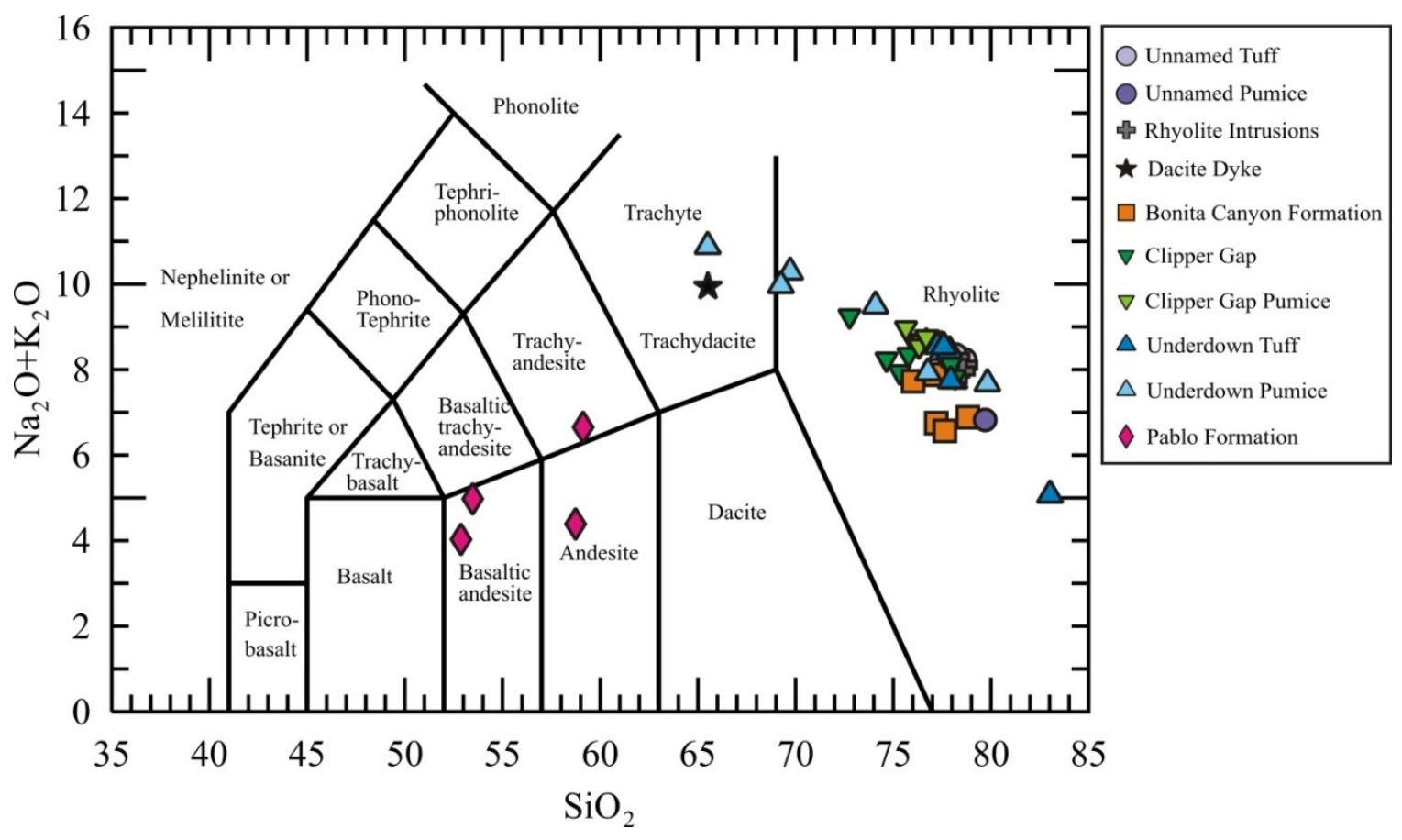

Figure 6.6: Total alkalis-silica diagram (Le Maitre et al., 1989) showing the major ignimbrite units (Underdown Tuff, tuff of Clipper Gap, Bonita Canyon Formation, and Unnamed tuff - without anomalous REE or high LOI samples), mafic to intermediate basement rocks (Pablo Formation), dacite dyke, and rhyolite intrusions collected from the Underdown Caldera. Most ignimbrite and intrusive samples are rhyolitic in composition, with some Underdown pumice samples plotting in a trend into the trachyte field. 


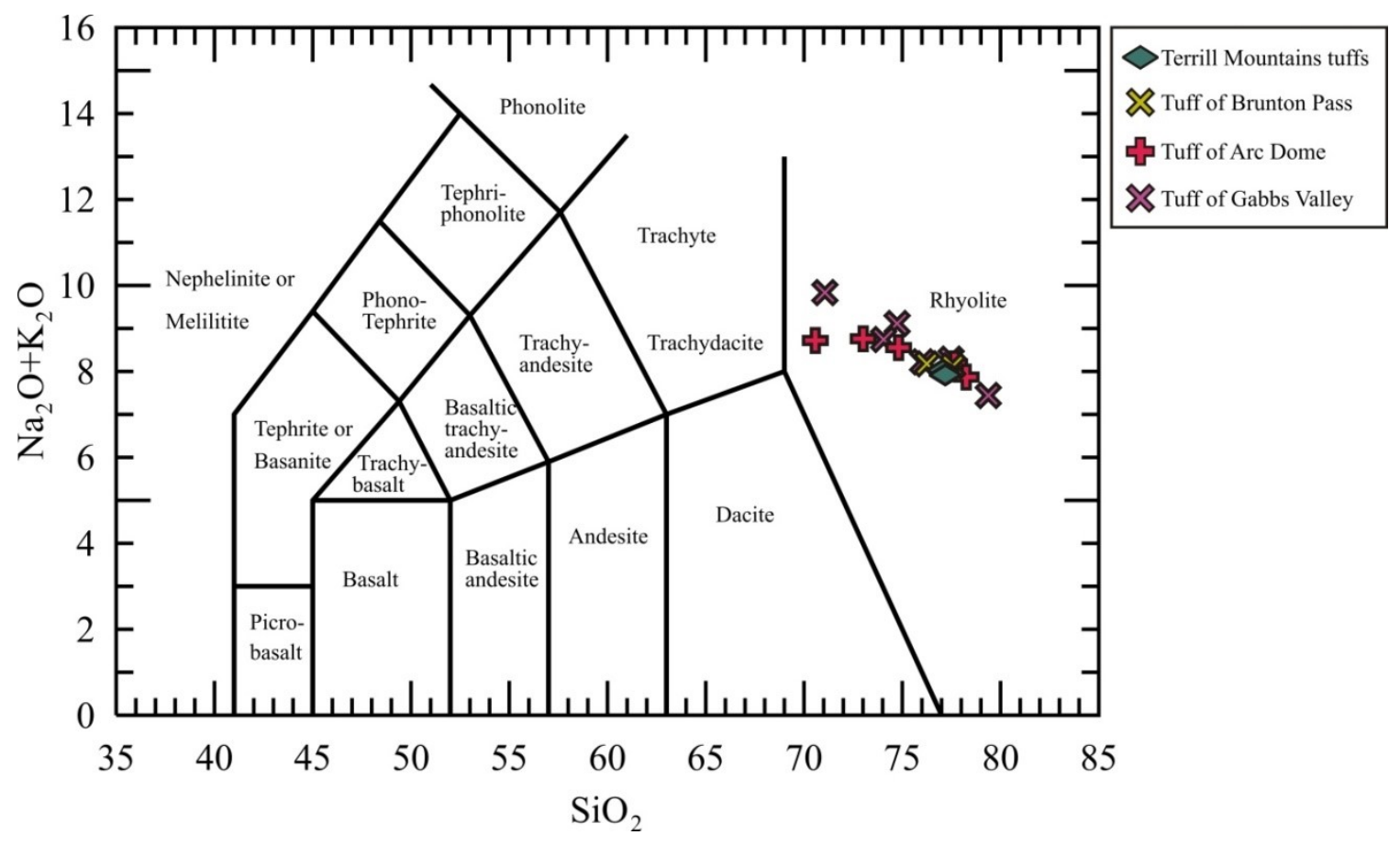

Figure 6.7: Total alkalis-silica diagram (Le Maitre et al., 1989) showing the other ignimbrite units (tuff of Gabbs Valley, tuff of Arc Dome, tuff of Brunton Pass) and the Terrill Mountains tuffs that are close in age to the Underdown tuff. All samples plot within the rhyolite field. 

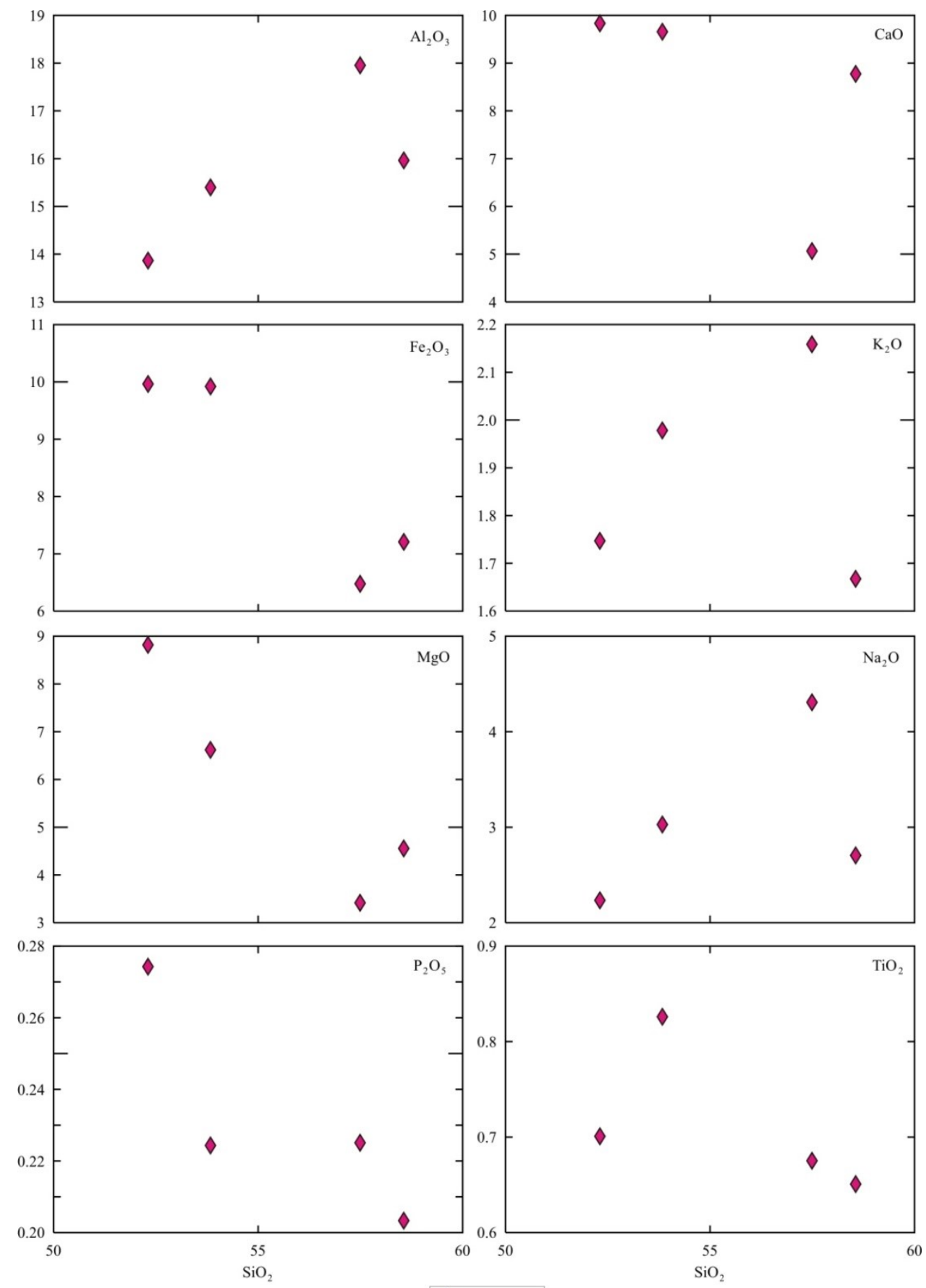

Pablo Fm

Figure 6.8: Major element variation diagrams of the Pablo Formation. $\mathrm{CaO}, \mathrm{Fe} 2 \mathrm{O} 3$, $\mathrm{MgO}$, and $\mathrm{P} 2 \mathrm{O} 5$ show decreasing trends with increasing $\mathrm{SiO} 2$ content. $\mathrm{TiO} 2$ increases between 52-54 wt.\% SiO2 and then shows a decreasing trend. Al2O3, K2O and Na2O show positive trends with increasing SiO2 content until 57 wt. \%. 

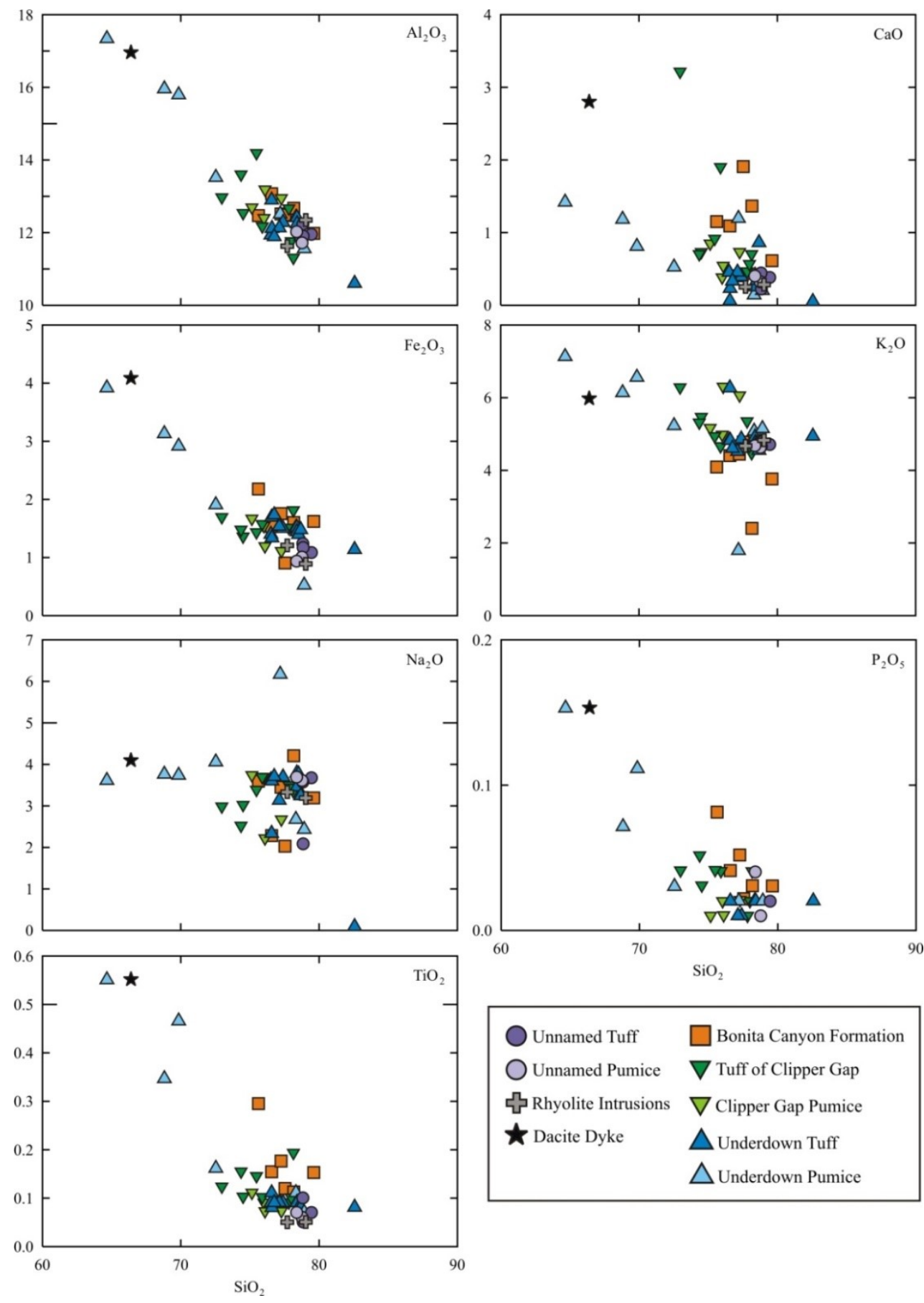

Figure 6.9: Major element variation diagrams of the major ignimbrites and the rhyolite intrusions of the Underdown Caldera complex. All major element oxides show a decreasing trend with increasing $\mathrm{SiO} 2$ content except for $\mathrm{Na2O}$. Al2O3 and $\mathrm{Fe} 2 \mathrm{O} 3$ show tight negative trends with increasing $\mathrm{SiO} 2$, while other major element oxides show more of a variation in steepness between the units. 

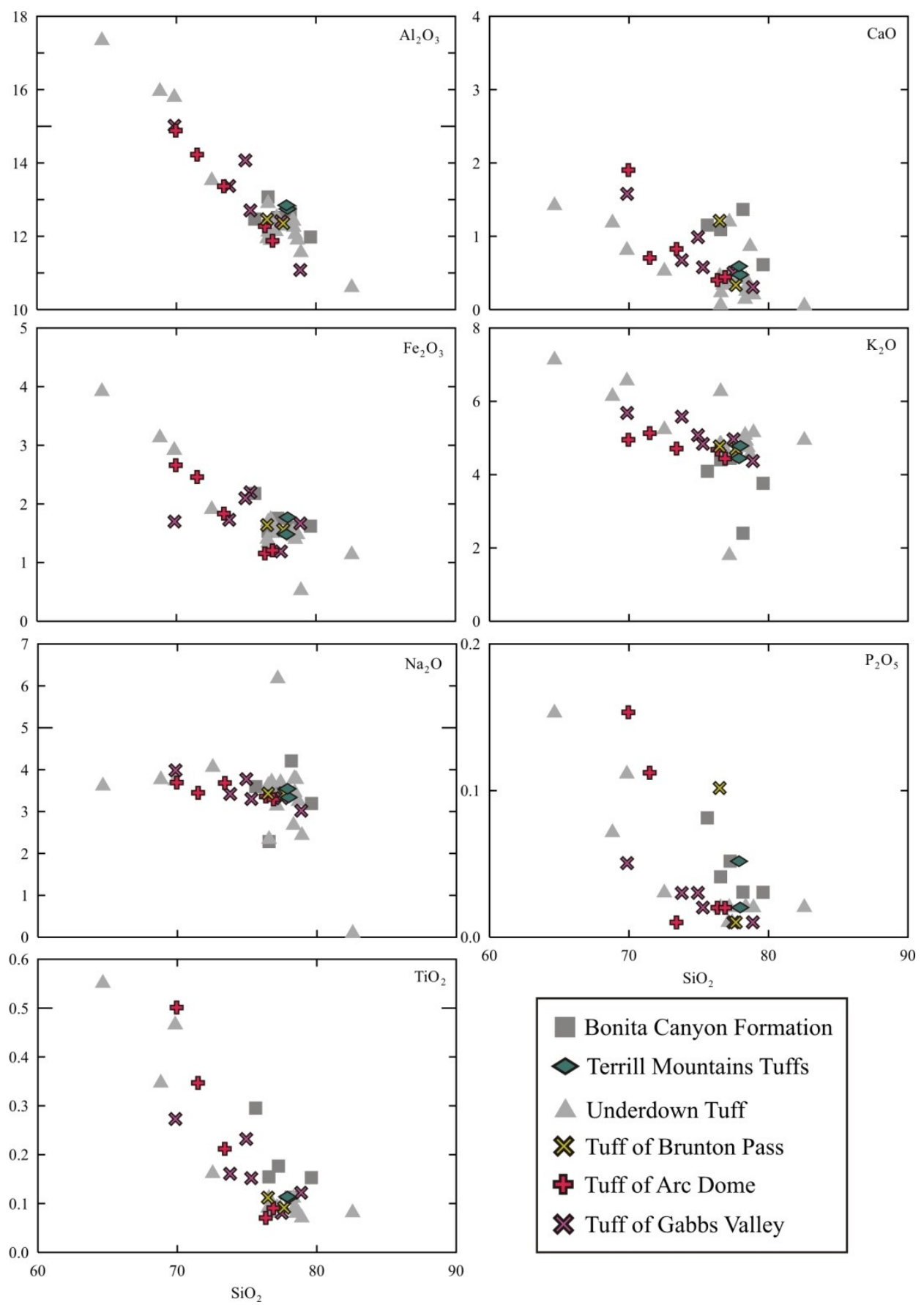

$\mathrm{SiO}_{2}$

Bonita Canyon Formation

Terrill Mountains Tuffs

$\triangle$ Underdown Tuff

Tuff of Brunton Pass

\& Tuff of Arc Dome

Tuff of Gabbs Valley

Figure 6.10: Major element variation diagrams of the other tuffs (tuff of Gabbs Valley, tuff of Arc Dome, and tuff of Brunton Pass) and the Terrill Mountains tuffs. All major element oxides show a decreasing trend with increasing $\mathrm{SiO} 2$ content. $\mathrm{K} 2 \mathrm{O}, \mathrm{MgO}$ and $\mathrm{Na} 2 \mathrm{O}$ show the weakest negative trends with increasing $\mathrm{SiO} 2$ content. 


\subsubsection{Trace element geochemistry}

Trace element results are reported in Appendix I, Table VI. Zirconium concentrations are highly variable, and therefore have been left out of the primitive mantle normalized trace element diagrams. The variation in $\mathrm{Zr}$ may reflect whether Zircon is a stable crystallizing phase in the ignimbrites. Zirconium abundances can be seen in the bivariate (trace element versus $\mathrm{SiO}_{2}$ content) diagrams.

\section{Pablo Formation}

$\mathrm{Cr}, \mathrm{Eu}$, and $\mathrm{Tb}$ appear to be incompatible elements in the Pablo Formation as they show positive correlations with increasing $\mathrm{SiO}_{2}$ content. Lu and $\mathrm{Y}$ show positive correlations until $\sim 65$ wt. $\% \mathrm{SiO}_{2}$ where the concentration appears to decrease. Other trace elements, $\mathrm{La}, \mathrm{Nb}, \mathrm{Sm}, \mathrm{Pb}, \mathrm{Sr}$, Th, and $\mathrm{Zr}$ show scattered patterns which may be a result of sample size (Fig 6.11).

On a chondrite normalized rare earth element diagram, the Pablo Formation shows enrichment in the LREEs relative to the HREEs and a flattening pattern in the HREEs (Fig. 6.14). On a primitive mantle normalized trace element diagram, positive anomalies are observed in $\mathrm{Ba}, \mathrm{U}, \mathrm{Pb}$ and $\mathrm{Sr}$, and a negative $\mathrm{Nb}$-Ta anomaly is observed (Fig. 6.17).

\section{Oligocene Tuffs}

Trace element bivariate plots show which trace elements behave as compatible elements and which behave as incompatible elements. Compatible trace elements are preferentially incorporated into crystallizing phases in the rock. This is shown by a 
decrease in trace element concentration with increasing magma evolution $\left(\mathrm{SiO}_{2}\right.$ content). In the Oligocene tuffs, $\mathrm{Ba}, \mathrm{Eu}, \mathrm{Pb}, \mathrm{Sr}$, and $\mathrm{Zr}$ behave as compatible elements. All of these trace elements show correlation between decreasing concentration of the trace element and increasing $\mathrm{SiO}_{2}$ content. $\mathrm{Nb}$ and Th behave as incompatible elements in the Oligocene tuffs. Both of these trace elements show a positive correlation between increasing $\mathrm{Nb}$ and Th concentration and increasing $\mathrm{SiO}_{2}$ content. Little correlation is observed between $\mathrm{Y}$ concentration and increasing $\mathrm{SiO}_{2}$ content. Similar to the major element oxides, the sample size of the Terrill Mountains tuffs and tuff of Brunton Pass make inferring trends difficult, but their clustering also indicates more homogeneity than is observed in the other Oligocene tuffs.

Chondrite normalized rare earth element diagrams show that the Oligocene tuffs show enrichment in the LREEs relative to the HREEs, and have a flattened pattern in the HREEs. A negative Eu anomaly is observed in every Oligocene tuff unit, the largest of which exists in the Unnamed tuff and the smallest of which exists in the tuff of Gabbs Valley and tuff of Arc Dome. However, individual samples from the Underdown Tuff and the Bonita Canyon Formation also show very small negative Eu anomalies. Small positive Ce anomalies are observed in a few samples in units including the Underdown Tuff and the Unnamed tuff, and a small negative Ce anomaly is observed in one sample from the Tuff of Brunton Pass (Fig. 6.15, Fig. 6.16). Primitive mantle normalized trace element diagrams show that the Oligocene tuffs have patterns typical of convergent margin rocks. Negative anomalies are observed in $\mathrm{Ba}, \mathrm{Sr}$, and $\mathrm{Eu}$ in all units; however the $\mathrm{Ba}$ 
anomaly is more variable in the tuffs of Gabbs Valley and Arc Dome. A positive anomaly is observed in Pb. Overall, the pattern shows flattening in the HREEs, similar to what was observed on the chondrite normalized REE diagram (Fig. 6.18. Fig. 6.19). Samples were normalized to chondrite and primitive mantle using data from Sun and McDonough (1989).

\section{Intrusive Rocks}

The dacite dyke is similar chemically to the major ignimbrite units, occasionally along trends of other units, such as the Underdown Tuff. For example, the dacite dyke plots close to the Underdown Tuff in $\mathrm{Eu}, \mathrm{Nb}, \mathrm{Pb}, \mathrm{Th}$, and $\mathrm{Zr}$. The dacite dyke also contains a higher concentration of $\mathrm{Ba}$ and $\mathrm{Sr}$ than the major ignimbrites (Underdown Tuff, Bonita Canyon Formation, and tuff of Clipper Gap), and shows little relation to the major ignimbrite units in Y. Overall, the dacite dyke shows concentrations of compatible and incompatible trace elements which would be expected for a more primitive, related feeder. Similar to the major element geochemistry, the rhyolite intrusions plot similarly to the Unnamed tuff samples and typically plot at the most evolved end of compatible and incompatible trends observed in the major ignimbrites (Underdown Tuff, Bonita Canyon Formation, and tuff of Clipper Gap). The rhyolite intrusion samples are scattered in $Y$, similar to the other major ignimbrite units of the Underdown Caldera complex.

On a chondrite normalized REE plot, the dacite dyke shows a pattern similar to the Pablo Formation, however has a higher enrichment of LREEs. A flattening pattern is observed in the dacite dyke as well as no negative Eu anomaly, also similar to the Pablo 
Formation, which distinguishes it from the ignimbrites (Fig. 6.14). A similar pattern to the Pablo Formation is also observed on the primitive mantle normalized trace element diagram for the dacite dyke (Fig. 6.17). The rhyolite intrusions show less enrichment in the LREEs than the other Oligocene tuffs, and show less decrease towards the HREEs on a chondrite normalized REE plot (Fig. 6.15). A large Eu anomaly exists in the rhyolite intrusions, however, there is also depletion in $\mathrm{Pr}, \mathrm{Nd}$, and $\mathrm{Sm}$ in one sample compared to the other. On a primitive mantle normalized trace element diagram, the rhyolite intrusions show a similar pattern to the Oligocene tuffs, however the negative Ba and positive $\mathrm{Pb}$ anomalies appear to be larger in the rhyolite intrusions (Fig. 6.16). All samples were normalized to chondrite and primitive mantle using data from Sun and McDonough (1989). 

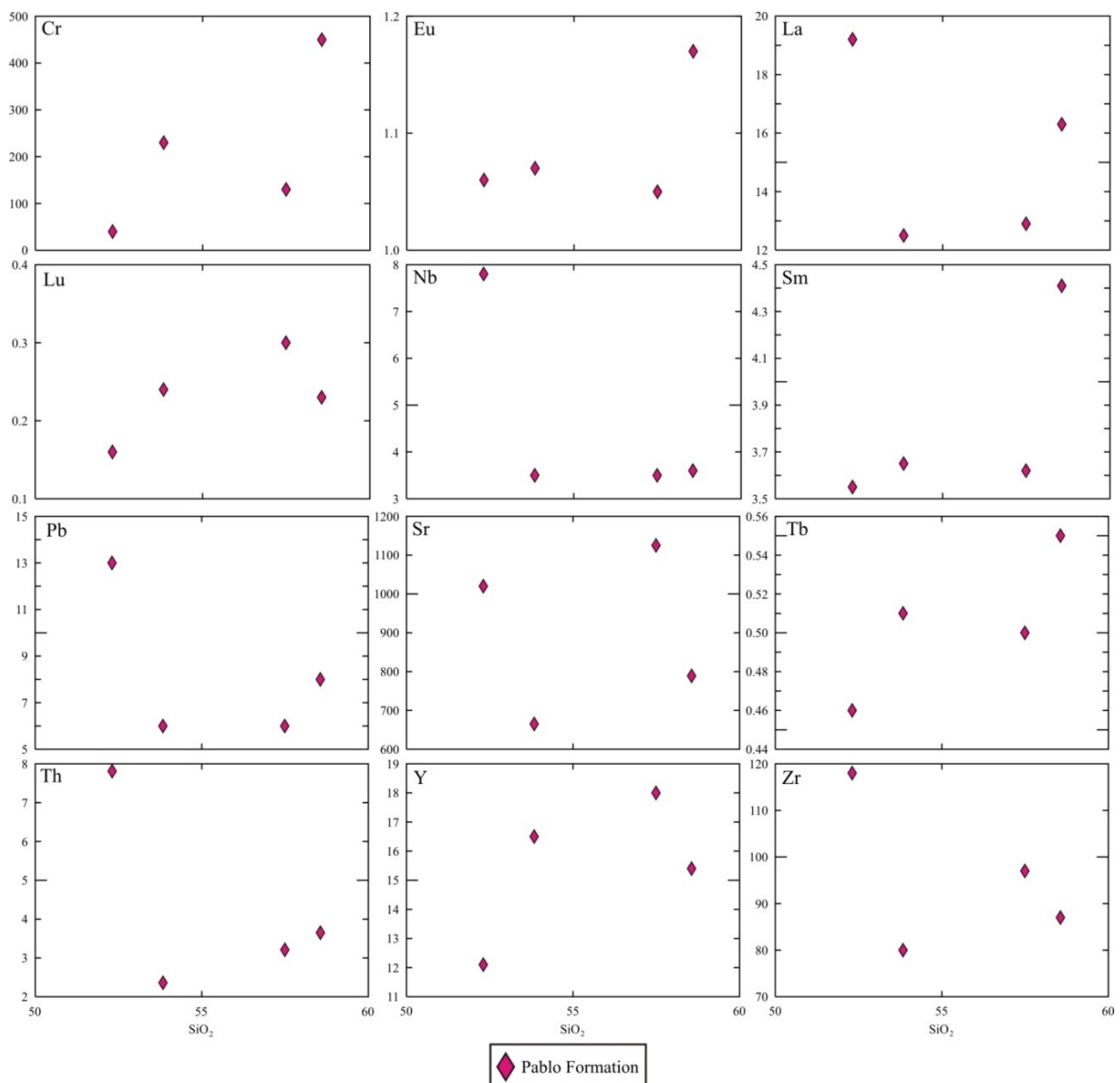

Figure 6.11: Trace element variation diagrams of the Pablo Formation and the dacite dyke. Typical compatible elements in andesite and dacite melts appear to be incompatible in these rocks, except for Sr. 

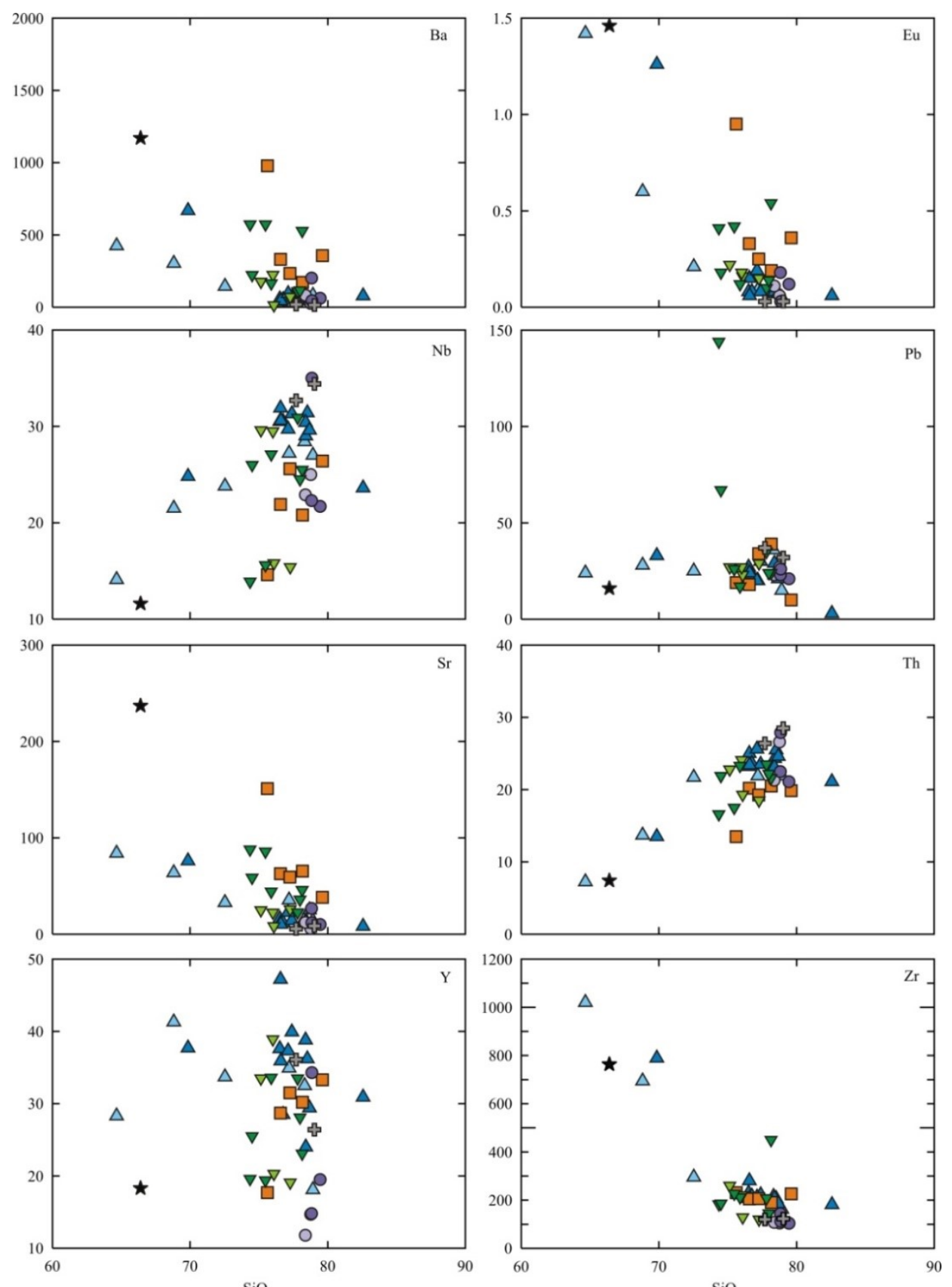

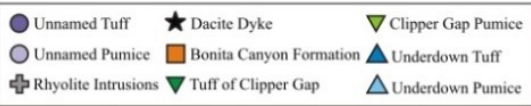

Figure 6.12: Trace element variation diagrams of the major ignimbrites and the rhyolite intrusions of the Underdown Caldera complex. Ba, Eu, $\mathrm{Sr}$, and $\mathrm{Zr}$ are behaving as compatible elements in these units as they show a negative correlation with increasing $\mathrm{SiO}_{2}$ content. The rhyolite intrusions show no observable trend due to the sample size. 

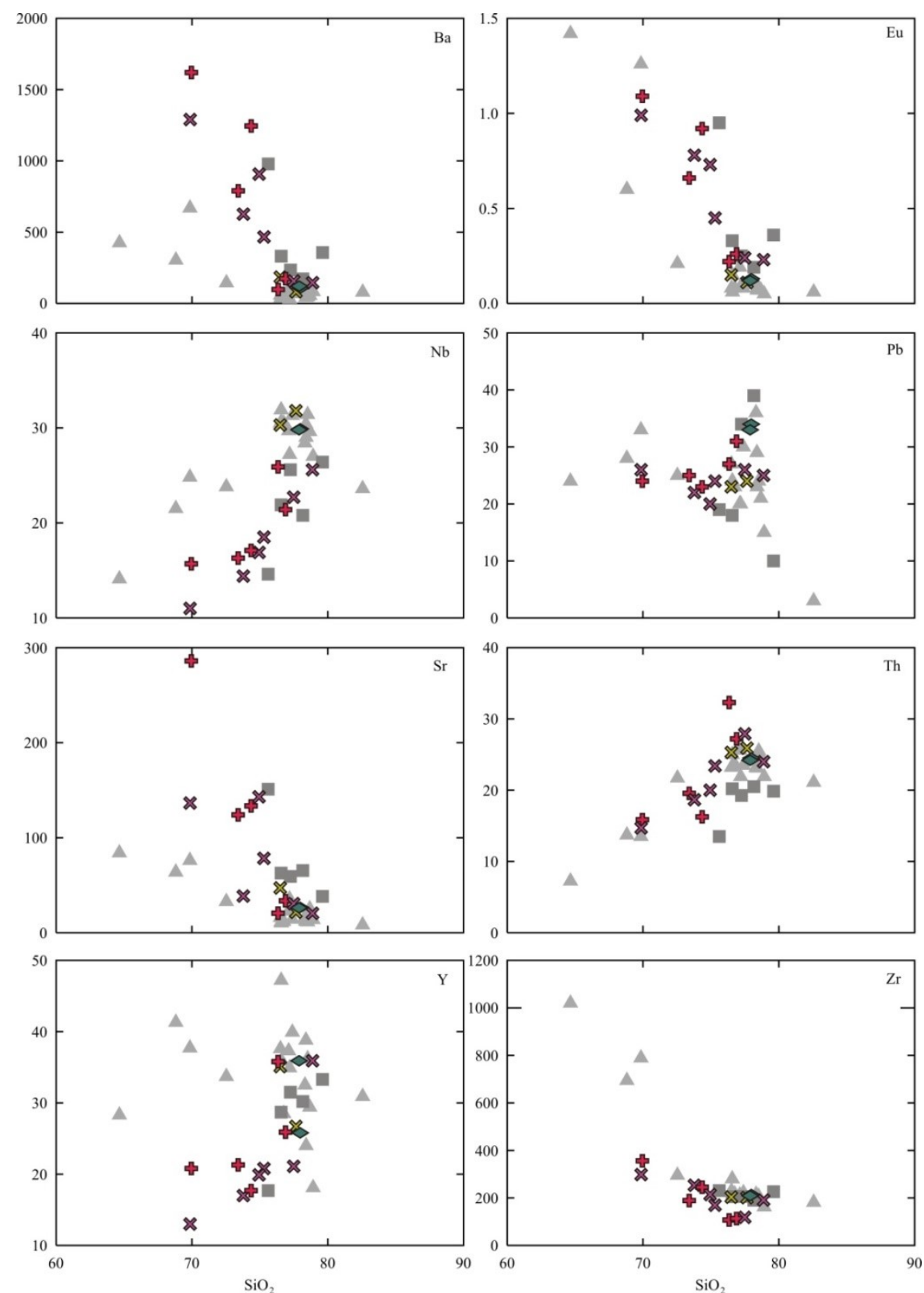

Bonita Canyon Formation $\Delta$ Underdown Tuff

$\diamond$ Terrill Mountains Tuffs

Tuff of Brunton Pass $\$ Tuff of Gabbs Valley

Figure 6.13: Trace element variation diagrams of the other tuffs (tuff of Gabbs Valley, tuff of Arc Dome, and tuff of Brunton Pass) and the Terrill Mountains tuff. Ba, Eu, Sr, and $\mathrm{Zr}$ are behaving as compatible elements in these units as they show a negative correlation with increasing $\mathrm{SiO}_{2}$ content. $\mathrm{Ba}, \mathrm{Eu}$, and $\mathrm{Sr}$ show a stronger negative trend than $\mathrm{Zr}$ with increasing $\mathrm{SiO}_{2}$. The Terrill Mountains tuffs plot as a cluster in $\mathrm{Ba}$, Eu, and $\mathrm{Zr}$, but show a strong negative correlation between $\mathrm{Sr}$ and $\mathrm{SiO}_{2}$. 

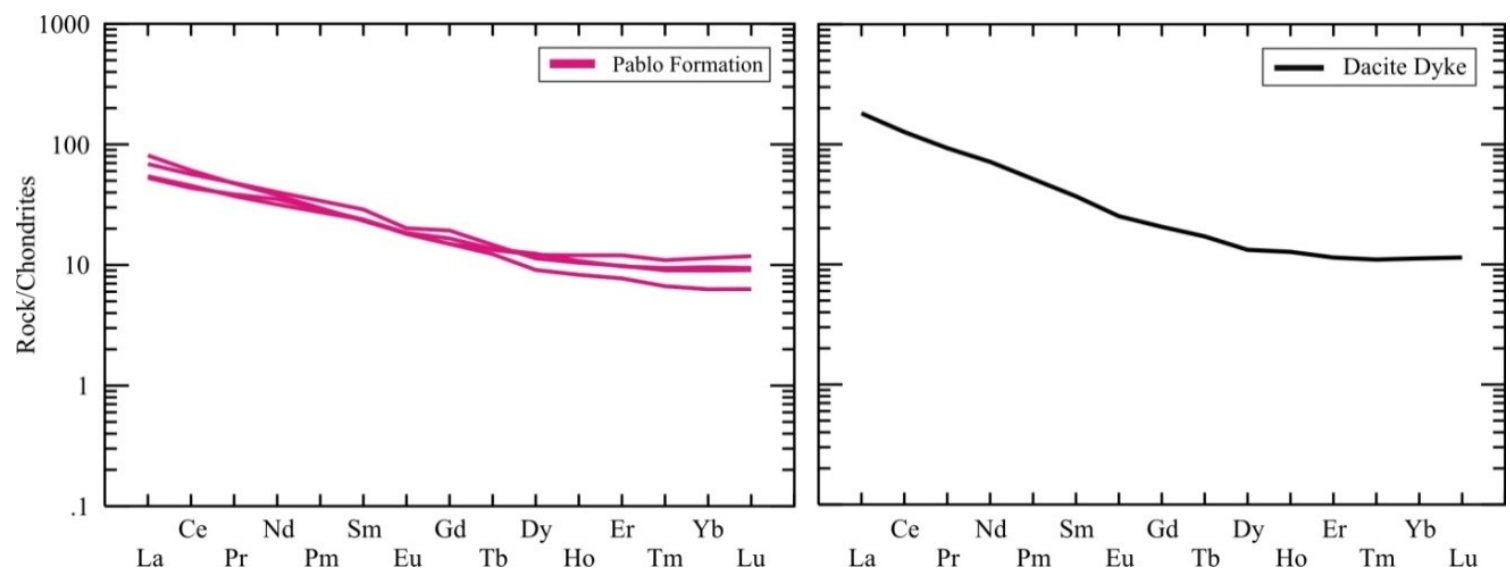

Figure 6.14: Chondrite normalized (Sun and McDonough, 1989) rare earth element diagrams for the Pablo Formation and the dacite dyke. Dacite dyke samples show a larger enrichment in LREEs relative to HREEs than the Pablo Formation. Both units show a flattening pattern in the HREEs and no negative Eu anomaly. 


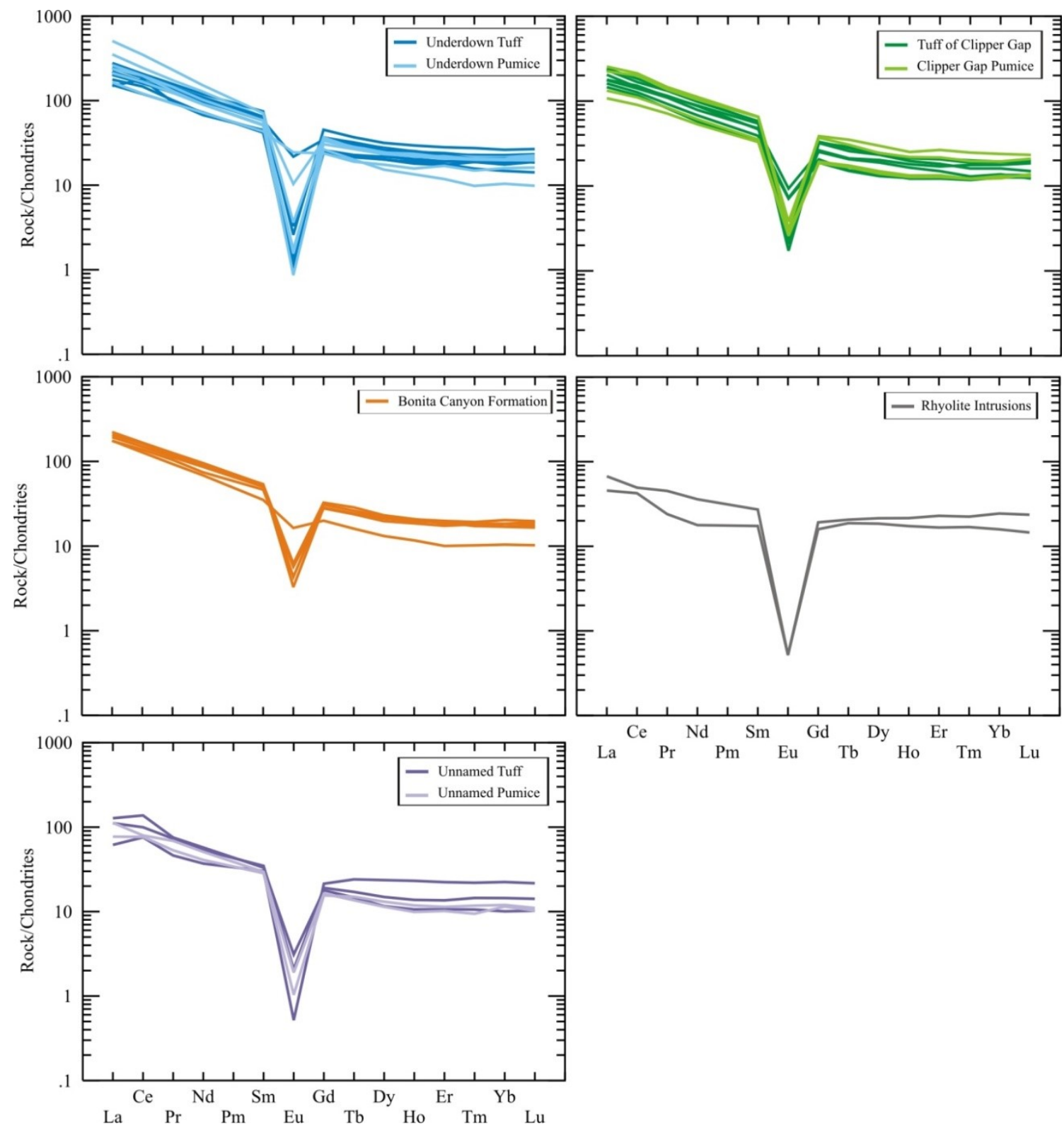

Figure 6.15: Chondrite normalized (Sun and McDonough, 1989) rare earth element diagrams for the major ignimbrites of the Underdown Caldera complex (Underdown Tuff, tuff of Clipper Gap, Bonita Canyon Formation and the Unnamed tuff) and the rhyolite intrusions. Samples show enrichment in LREEs relative to HREEs and a flattened slope in the HREEs, as well as a large negative Eu anomaly. All the major ignimbrites show a similar pattern, however the rhyolite intrusions and the Unnamed tuff show less LREE enrichment and a larger variation in the HREEs. 

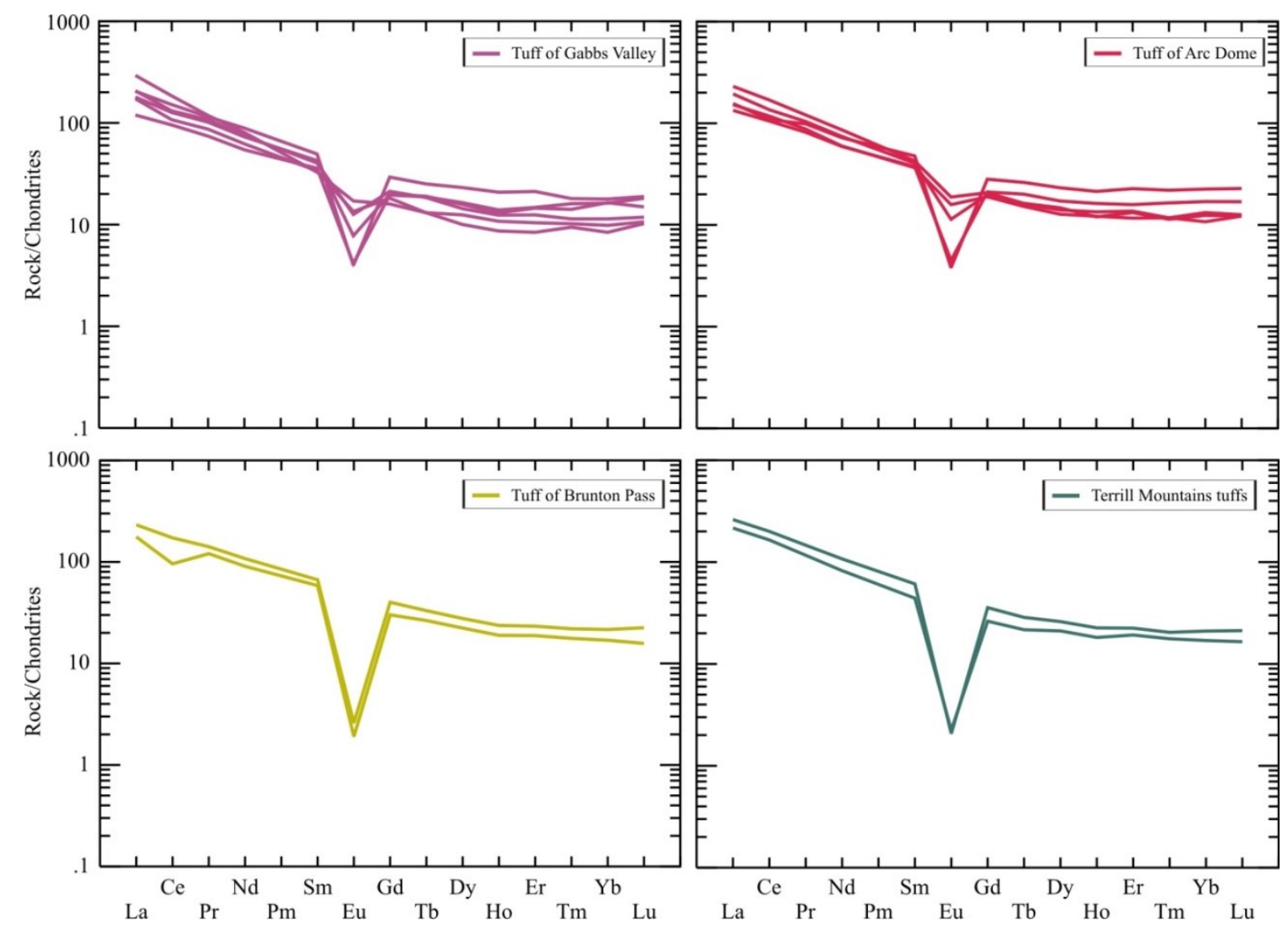

Figure 6.16: Chondrite normalized (Sun and McDonough, 1989) rare earth element diagrams for the slightly older Oligocene tuffs (tuff of Gabbs Valley, tuff of Arc Dome, tuff of Brunton Pass) and the Terrill Mountains tuffs. Samples show enrichment in LREEs relative to HREEs and a flattened slope in the HREEs, as well as a large negative Eu anomaly. 

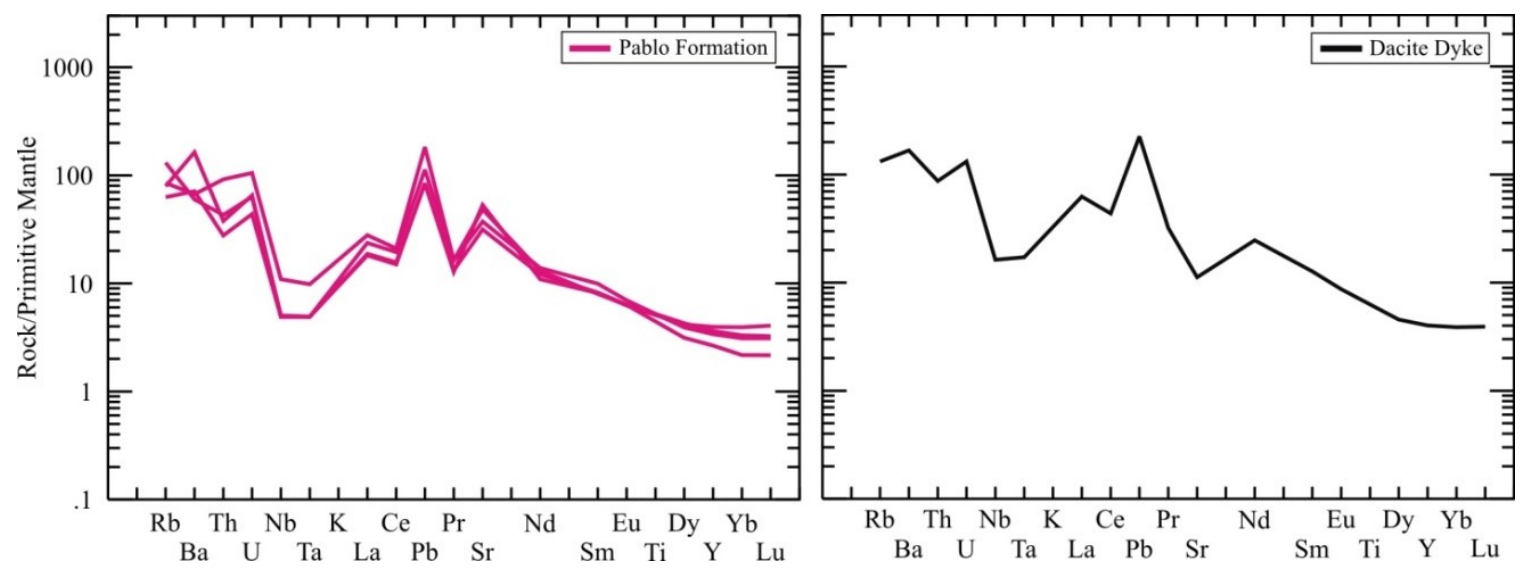

Figure 6.17: Primitive mantle normalized (Sun and McDonough, 1989) trace element diagram for the Pablo Formation and dacite dyke. In the Pablo Formation, positive anomalies exist in $\mathrm{Pb}$ and $\mathrm{Sr}$. In the dacite dyke, there is a positive anomaly in $\mathrm{Pb}$ and a negative anomaly in $\mathrm{Sr}$. Both units also show a $\mathrm{Nb}-\mathrm{Ta}$ anomaly. 

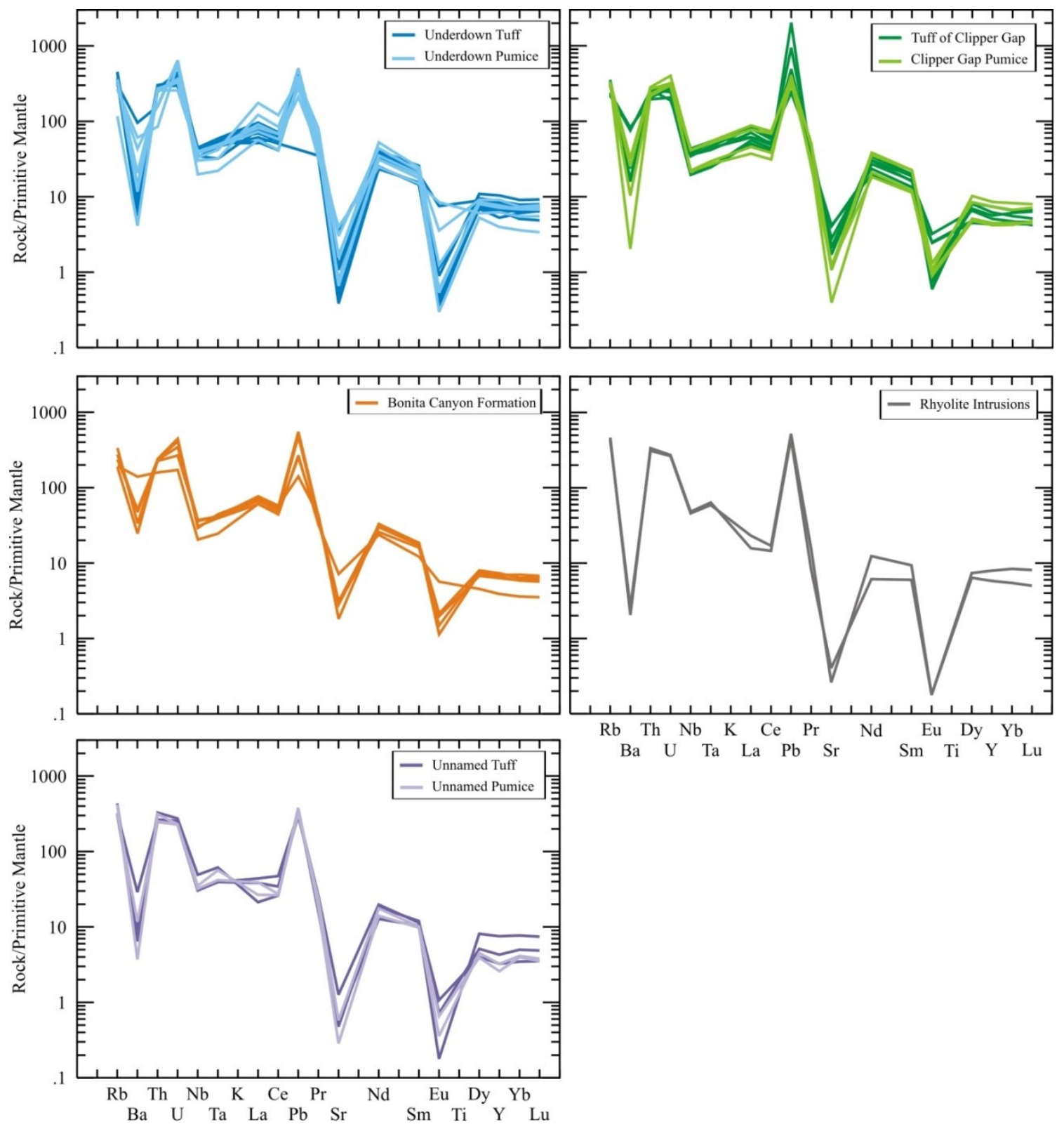

Figure 6.18: Primitive mantle normalized (Sun and McDonough, 1989) trace element diagram for the major ignimbrites of the Underdown Caldera complex (Underdown Tuff, Tuff of Clipper Gap, Bonita Canyon Formation, and Unnamed tuff) and the rhyolite intrusions. Positive anomalies exist in $\mathrm{Th}$ and $\mathrm{Pb}$, and negative anomalies exist in $\mathrm{Ba}, \mathrm{Sr}$, and Eu. 

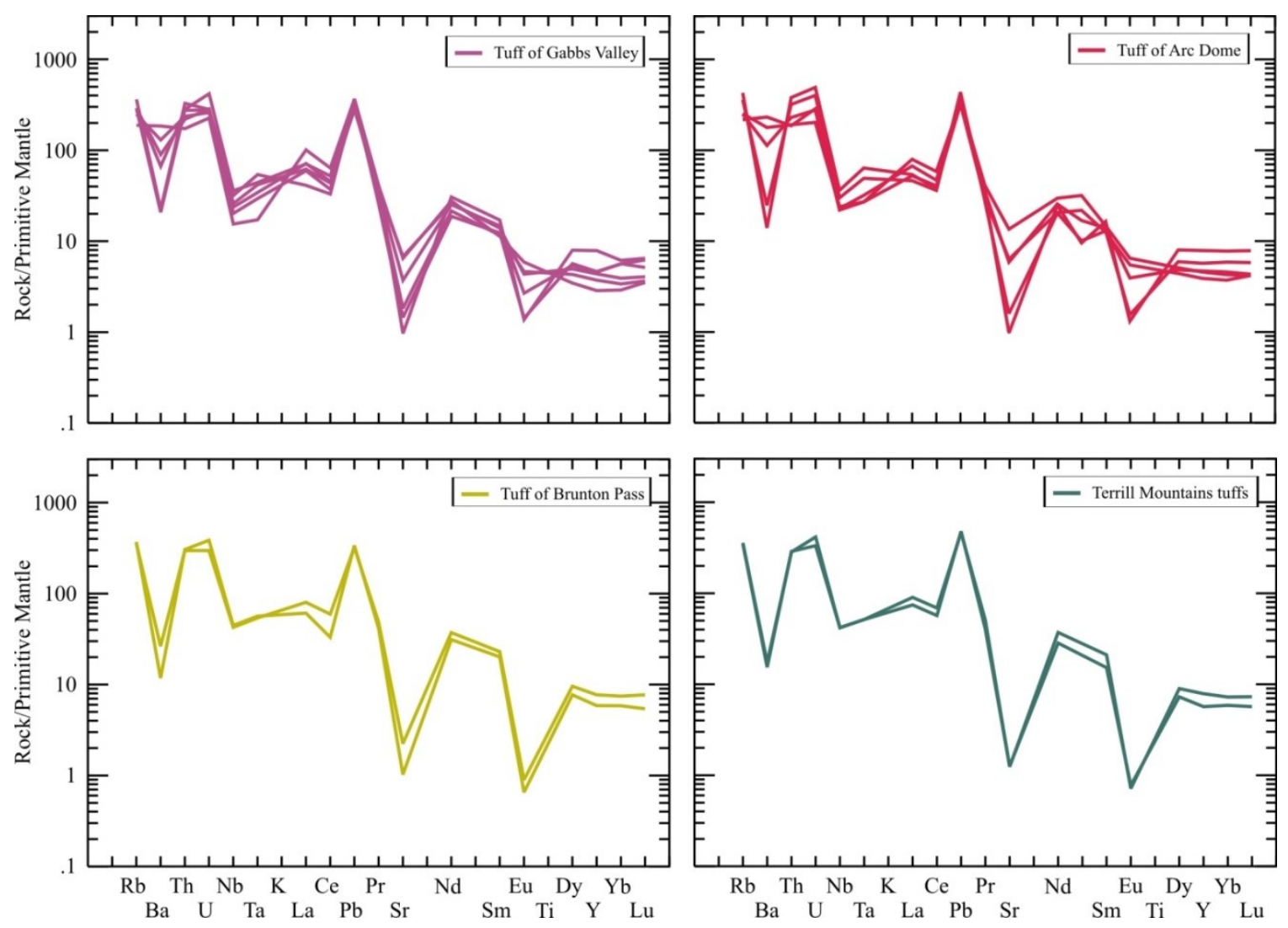

Figure 6.19: Primitive mantle normalized (Sun and McDonough, 1989) trace element diagram for the other tuffs (tuff of Gabbs Valley, tuff of Arc Dome, and tuff of Brunton Pass) and the Terrill Mountains tuff. Positive anomalies exist in $\mathrm{Th}$ and $\mathrm{Pb}$, and negative anomalies exist in $\mathrm{Ba}, \mathrm{Sr}$, and $\mathrm{Eu}$. 


\subsubsection{Isotope geochemistry}

Isotopic results are listed in Appendix I, Table VIII. The selection of samples for isotopic analysis was limited by very low concentrations of $\mathrm{Sr}$ in most of the ignimbrite units. Generally, samples selected for isotopic analysis contained over 40 ppm of Sr. However, two samples have concentrations below $40 \mathrm{ppm}$; a whole rock and a pumice sample from the Unnamed tuff (26.7 and $12.2 \mathrm{ppm} \mathrm{Sr}$, respectively). These two samples were analyzed in spite of their low $\mathrm{Sr}$ concentrations as they contained the highest concentrations of $\mathrm{Sr}$ in any of the Unnamed tuff samples. No rhyolite intrusion samples were analyzed due to their low $\mathrm{Sr}$ concentration (8.8 and $5.5 \mathrm{ppm}$ ). Samples from the tuff of Arc Dome, tuff of Gabbs Valley, and dacite dyke contained much higher $\mathrm{Sr}$ concentrations (above $120 \mathrm{ppm}$ ) than the Oligocene tuffs from the Underdown Caldera.

Radiogenic isotope analyses were completed on a range of samples including the Pablo Formation, tuff of Gabbs Valley, tuff of Arc Dome, Underdown Tuff, tuff of Clipper Gap, Bonita Canyon Formation, the dacite dyke, the Unnamed tuff, and the Terrill Mountains tuffs. The results for ${ }^{87} \mathrm{Sr} /{ }^{86} \mathrm{Sr},{ }^{144} \mathrm{Nd} /{ }^{143} \mathrm{Nd},{ }^{204} \mathrm{~Pb} /{ }^{206} \mathrm{~Pb},{ }^{207} \mathrm{~Pb} /{ }^{206} \mathrm{~Pb}$ and ${ }^{208} /{ }^{206} \mathrm{~Pb}$ are listed in Appendix I, Table VIII. All data plotted below are initial, age-corrected ratios unless otherwise stated. The Pablo Formation has been age corrected to $24.9 \mathrm{Ma}$ for comparison with the other Underdown Caldera tuffs. Miocene-aged lavas from the Underdown Caldera margin analyzed by Tennant (2018) have been plotted with the Underdown Caldera complex data for comparison. Acid-washed tuff of Clipper Gap 
samples are plotted in the isotope geochemistry section to show what is believed to be "fresh" isotopic ratios for those samples.

All isotope data are plotted in Figure 6.20A. This includes samples with REE anomalies and high LOI. The REE anomaly samples will be interpreted separately from the main group of data, and were therefore subsequently removed from the main group of data. The remaining samples were plotted on Figure 6.20B. The high LOI samples (including the tuff of Clipper Gap, Bonita Canyon Formation, and Terrill Mountains tuffs) appear to have $\varepsilon N d$ values that are similar to the main group of data however, the ${ }^{87} \mathrm{Sr}^{186} \mathrm{Sr}$ ratios are either higher or lower than the main group of data. In particular, the Terrill Mountains tuffs have variable ${ }^{87} \mathrm{Sr} /{ }^{86} \mathrm{Sr}$ ratios despite originating from the same unit. The Terrill Mountains whole rock sample plots to the left of the bulk earth line away from a continental signature, one pumice sample from the same unit has an ${ }^{87} \mathrm{Sr} /{ }^{86} \mathrm{Sr}$ value around 0.7050 , and the second pumice sample has an ${ }^{87} \mathrm{Sr} /{ }^{86} \mathrm{Sr}$ value around 0.7075. Based on the suspect age corrected ${ }^{87} \mathrm{Sr} /{ }^{86} \mathrm{Sr}$ ratios of the high LOI samples, those samples were removed and the remaining samples were plotted on Figure 6.20C. The remaining group of data mainly plots between ${ }^{87} \mathrm{Sr} /{ }^{86} \mathrm{Sr}$ values of 0.705 to 0.706 , with one outlying tuff of Clipper Gap sample which has an $\varepsilon N d$ value closer to zero and an ${ }^{87} \mathrm{Sr} /{ }^{86} \mathrm{Sr}$ value over 0.707. Acid-washed tuff of Clipper Gap samples were plotted for comparison in Figure 6.20D. All acid-washed tuff of Clipper Gap samples are pumice. These samples have $\varepsilon N d$ and ${ }^{87} \mathrm{Sr} /{ }^{86} \mathrm{Sr}$ values similar to the main group of non-acidwashed Underdown Caldera complex data and plot closer to the main group of data 
than the remaining tuff of Clipper Gap sample (17-SM-07). The Miocene-aged lavas have isotopic compositions similar to the Oligocene tuffs in the $\varepsilon N d$ versus ${ }^{87} \mathrm{Sr} /{ }^{86} \mathrm{Sr}$ diagram. Four of the Miocene-aged lava samples plot close to the mantle array while two lava samples have higher ${ }^{87} \mathrm{Sr} /{ }^{86} \mathrm{Sr}$ values which are closer to the Underdown Tuff and dacite dyke samples. At the time of ignimbrite formation, the Pablo Formation samples plot far away from the Underdown Caldera complex data in the mantle array and do not appear to be related to the Oligocene tuffs. As a potential mantle source, the Miocene lavas appear more similar to the Oligocene tuffs of the Underdown Caldera than the Pablo Formation. The Pablo Formation has been ignored and only the Miocene aged lavas have been plotted with the Underdown Caldera data on all subsequent isotope diagrams. 

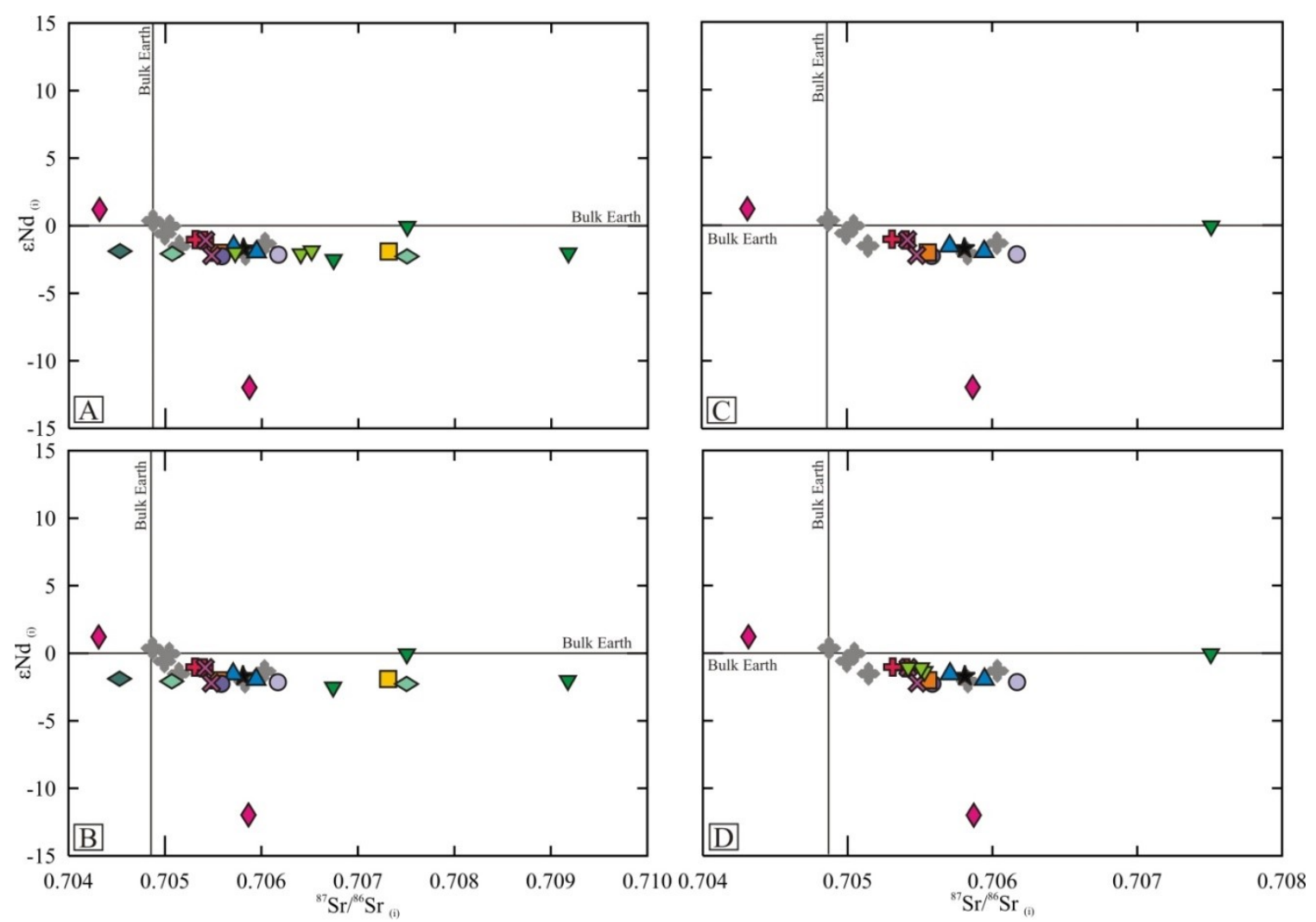

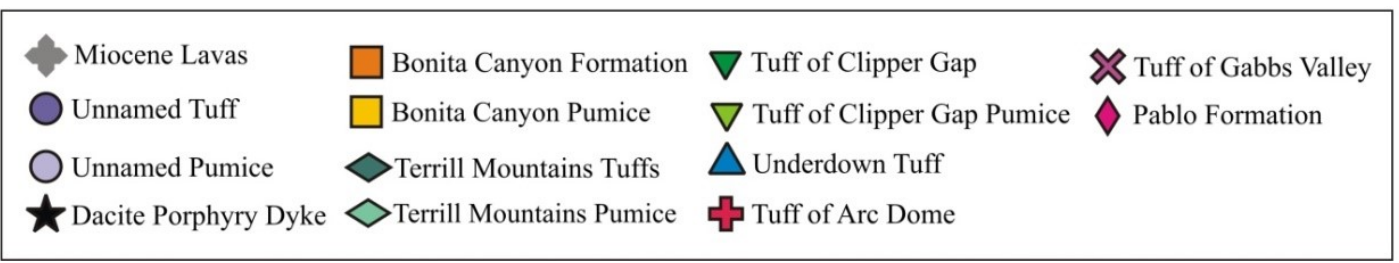

Figure 6.20: (A) Initial $\varepsilon N d$ versus ${ }^{87} \mathrm{Sr} /{ }^{86} \mathrm{Sr}$ with all Underdown Caldera complex data. (B) Same as in (A), but samples with negative Ce anomalies have been removed. (C) Same as in (B), but high LOI (> 6\%) samples have been removed. (D) Same as in (C), but acid-washed tuff of Clipper Gap samples are added for comparison. 
The removal of the Pablo Formation shows more detail on an $\varepsilon N d$ versus ${ }^{87} \mathrm{Sr} /{ }^{86} \mathrm{Sr}$ diagram. While there appears to be no observable trend when all of the data is plotted, the removal of the anomalous REE and high LOI samples shows a correlation between increasing ${ }^{87} \mathrm{Sr} /{ }^{86} \mathrm{Sr}$ and decreasing $\varepsilon \mathrm{Nd}$ in the remaining "fresh" and acid-washed samples (Fig. 6.21). In this $\varepsilon N d$ vs. ${ }^{87} \mathrm{Sr} /{ }^{86} \mathrm{Sr}$ diagram, the ignimbrite samples appear to be related to the Miocene-aged mafic to intermediate lavas, however the lavas collected from the Underdown Caldera margin have much higher Sr concentrations than the Oligocene tuffs. There is also a slight positive correlation between decreasing $\mathrm{Sr}$ concentration and increasing ${ }^{87} \mathrm{Sr} /{ }^{86} \mathrm{Sr}$ ratios in the "fresh" samples (Fig. 6.22). Sample 17-SM-07 (tuff of Clipper Gap) appears to be an outlier with a much higher ${ }^{87} \mathrm{Sr} /{ }^{86} \mathrm{Sr}$ ratio than the other Oligocene tuffs, while the acid-washed tuff of Clipper Gap samples plot with the main group of data. The Unnamed tuff has a much lower Sr concentration than the other Oligocene tuffs and there is a large difference in Sr concentration between the whole rock sample and the pumice sample of the Unnamed tuff. There appears to be no correlation between ${ }^{87} \mathrm{Sr} /{ }^{86} \mathrm{Sr}$ ratios and the $\mathrm{SiO}_{2}$ content of the samples, as the data is scattered (Fig. 6.23). The "fresh" and acid-washed samples show little variation in ${ }^{87} \mathrm{Sr} /{ }^{86} \mathrm{Sr}$ ratios with increasing $\mathrm{SiO}_{2}$ but show a larger amount of variation in ${ }^{87} \mathrm{Sr} /{ }^{86} \mathrm{Sr}$ ratios at high $\mathrm{SiO}_{2}$ content.

When analyzing $\mathrm{Nd}$ isotopic ratios, there appears to be little to no correlation between $\varepsilon \mathrm{Nd}$ values and $\mathrm{Nd}$ concentration or $\mathrm{SiO}_{2}$ content. On an age corrected $\varepsilon \mathrm{Nd}$ versus $1 / \mathrm{Nd}$ concentration diagram, the "fresh" and acid-washed samples appear to show a similar 
correlation between decreasing $\mathrm{Nd}$ concentration and increasing $\varepsilon \mathrm{Nd}$ value as the Miocene lavas (Fig. 6.24). On an $\varepsilon \mathrm{Nd}$ versus $\mathrm{SiO}_{2}$ diagram, there is a large scatter in the data in the "fresh" samples and the acid-washed tuff of Clipper Gap samples (Fig. 6.25).

"Fresh" and acid-washed samples plot in steep positive trends in both the ${ }^{207} \mathrm{~Pb} /{ }^{204} \mathrm{~Pb}$ and ${ }^{208} \mathrm{~Pb} /{ }^{204} \mathrm{~Pb}$ versus ${ }^{206} \mathrm{~Pb} /{ }^{204} \mathrm{~Pb}$ diagrams. ${ }^{207} \mathrm{~Pb} /{ }^{204} \mathrm{~Pb}$ versus ${ }^{206} \mathrm{~Pb} /{ }^{204} \mathrm{~Pb}$ shows a similar slope as the Miocene aged lavas but at a higher ${ }^{206} \mathrm{~Pb} /{ }^{204} \mathrm{~Pb}$ ratio (Fig. 6.26). However the Miocene aged lavas and the Oligocene tuffs plot in one tight trend when comparing ${ }^{208} \mathrm{~Pb} /{ }^{204} \mathrm{~Pb}$ to ${ }^{206} \mathrm{~Pb} /{ }^{204} \mathrm{~Pb}$ (Fig. 6.27). In the $\mathrm{Pb}$ isotope diagrams, $17-\mathrm{SM}-07$ is much less radiogenic than all of the other Oligocene tuffs, while the acid-washed tuff of Clipper Gap samples are some of the most radiogenic samples in the arrays. Within specific units, pumice samples tend to be more radiogenic than their whole rock equivalents. Older units such as the tuffs of Gabbs Valley and Arc Dome are some of the least radiogenic samples, but are more radiogenic than $17-\mathrm{SM}-07$. When comparing the ${ }^{208} \mathrm{~Pb} /{ }^{204} \mathrm{~Pb}$ ratios to increasing $\mathrm{SiO}_{2}$ and magma evolution, the "fresh" and acid-washed samples plot in a scattered, negative trend (Fig. 6.28). When comparing ${ }^{208} \mathrm{~Pb} /{ }^{204} \mathrm{~Pb}$ ratios to $\mathrm{Pb}$ concentration, the samples show a scattered positive correlation, where higher $\mathrm{Pb}$ content is associated with more radiogenic $\mathrm{Pb}$ isotope ratios (Fig. 6.29). 


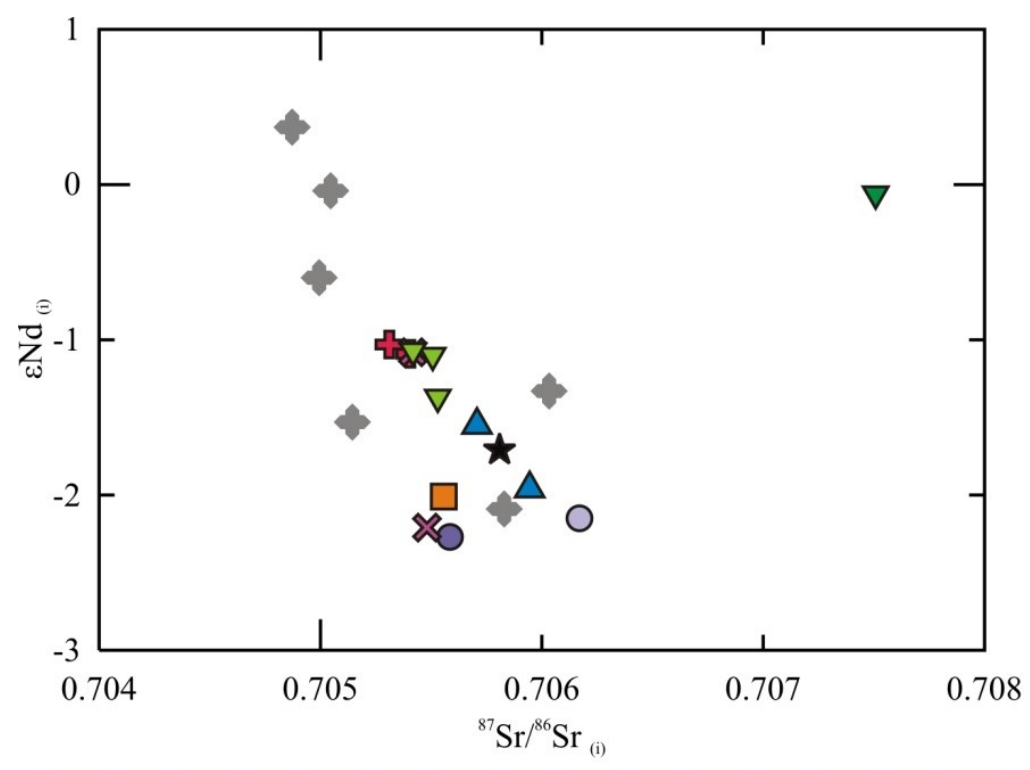

Miocene Lavas

Unnamed Tuff

Bonita Canyon Formation

$\nabla$ Tuff of Clipper Gap

Tuff of Arc Dome

Wuff of Gabbs Valley

Unnamed Pumice

$\nabla$ Tuff of Clipper Gap Pumice

T Dacite Porphyry Dyke

$\triangle$ Underdown Tuff

Figure 6.21: "Fresh" and acid-washed data plotted on an initial $\varepsilon N d$ versus ${ }^{87} \mathrm{Sr} /{ }^{86} \mathrm{Sr}$ diagram without the Pablo Formation. Samples show a negative correlation between $\varepsilon N d$ values and increasing ${ }^{87} \mathrm{Sr} /{ }^{86} \mathrm{Sr}$ ratios. The Miocene lavas form the low-Sr and high$\mathrm{Nd}$ isotope ratio endmember. Sample 17-SM-07, a tuff of Clipper Gap whole rock, plots as an outlier at a very high ${ }^{87} \mathrm{Sr} /{ }^{86} \mathrm{Sr}$ ratio. Acid-washed tuff of Clipper Gap samples plot within the "fresh" samples without anomalous REEs. 


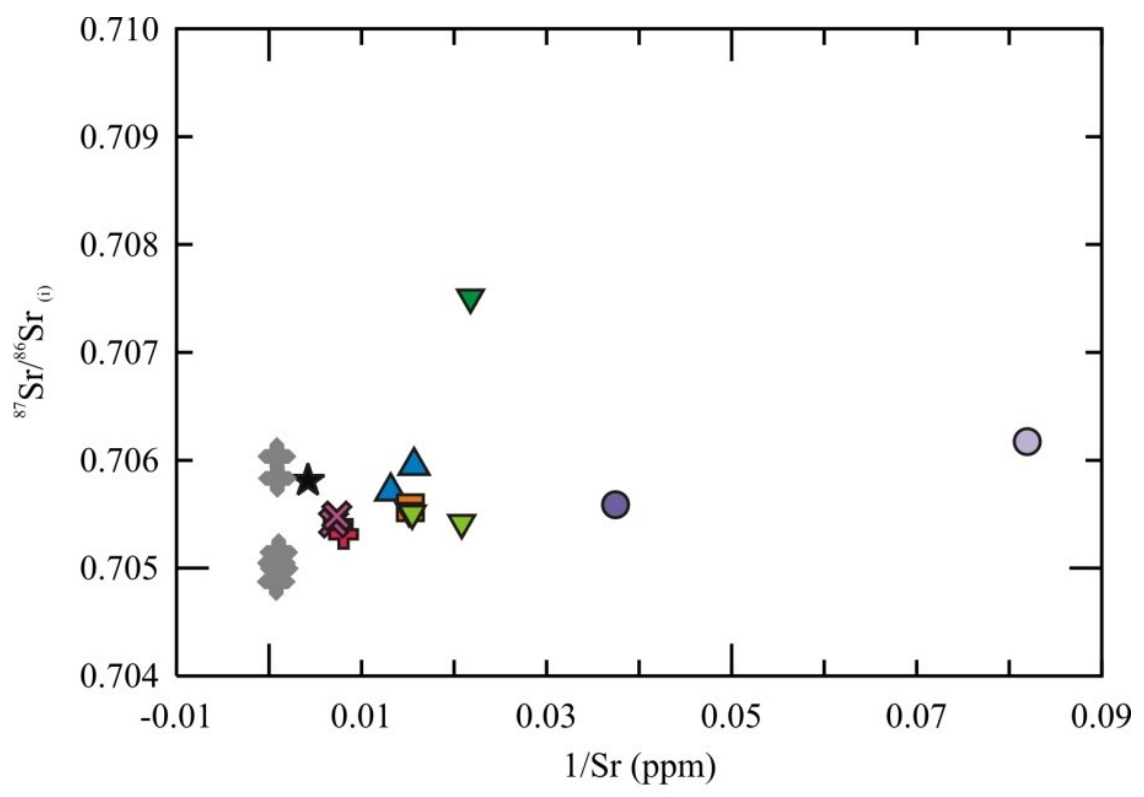

$\begin{array}{lll}\text { Miocene Lavas } & \square \text { Bonita Canyon Formation } & \text { S Tuff of Arc Dome } \\ \text { Unnamed Tuff } & \nabla \text { Tuff of Clipper Gap } & \text { Tuff of Gabbs Valley } \\ \text { Unnamed Pumice } & \nabla \text { Tuff of Clipper Gap Pumice } & \\ \text { Dacite Porphyry Dyke } & \Delta \text { Underdown Tuff }\end{array}$

Figure 6.22: Initial ${ }^{87} \mathrm{Sr} /{ }^{86} \mathrm{Sr}$ versus $1 / \mathrm{Sr}$ (ppm) plot showing the relation between $\mathrm{Sr}$ concentration and ${ }^{87} \mathrm{Sr} /{ }^{86} \mathrm{Sr}$ isotopic ratios. The "fresh" samples show near-constant ${ }^{87} \mathrm{Sr} /{ }^{86} \mathrm{Sr}$ ratios that overlap with ${ }^{87} \mathrm{Sr} /{ }^{86} \mathrm{Sr}$ isotope ratios in the Miocene mafic to intermediate lavas. Similar to the previous diagram, 17-SM-07 appears to be an outlier at a much higher ${ }^{87} \mathrm{Sr} /{ }^{86} \mathrm{Sr}$ value, and the acid washed tuff of Clipper Gap data plot close "fresh" samples. The Unnamed tuff whole rock and pumice have a much lower $\mathrm{Sr}$ concentration than the rest of the "fresh" samples. 


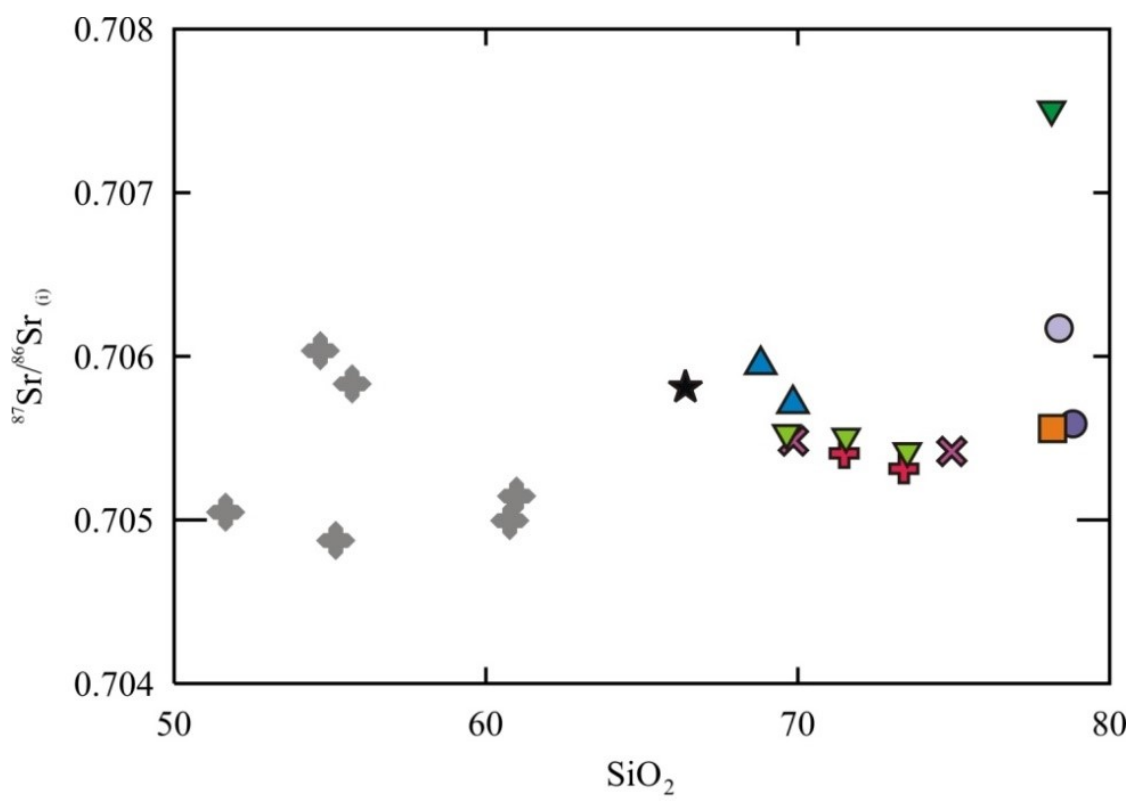

\begin{tabular}{|lll}
\hline Miocene Lavas & $\square$ Bonita Canyon Formation & Un Tuff of Arc Dome \\
Unnamed Tuff & $\nabla$ Tuff of Clipper Gap & Tuff of Gabbs Valley \\
Unnamed Pumice & $\nabla$ Tuff of Clipper Gap Pumice & \\
W Dacite Porphyry Dyke & $\Delta$ Underdown Tuff
\end{tabular}

Figure 6.23: Initial ${ }^{87} \mathrm{Sr} /{ }^{86} \mathrm{Sr}$ versus $\mathrm{SiO}_{2}$ content showing the relationship between $\mathrm{Sr}$ isotopic values and increasing $\mathrm{SiO}_{2}$ content. "Fresh" samples without anomalous REEs and acid-washed samples show a scattered pattern between increasing $\mathrm{SiO}_{2}$ content and $\mathrm{Sr}$ isotopic ratio. Acid-washed tuff of Clipper Gap samples plot more similarly to the "fresh" samples than the 17-SM-07 tuff of Clipper Gap sample which has a much higher ${ }^{87} \mathrm{Sr} /{ }^{86} \mathrm{Sr}$ ratio. In particular, the acid-washed samples show large similarities to the tuff of Gabbs Valley, tuff of Arc Dome, and Underdown Tuff samples. More variation in ${ }^{87} \mathrm{Sr} /{ }^{86} \mathrm{Sr}$ ratios is observed at high $\mathrm{SiO}_{2}$ content. 


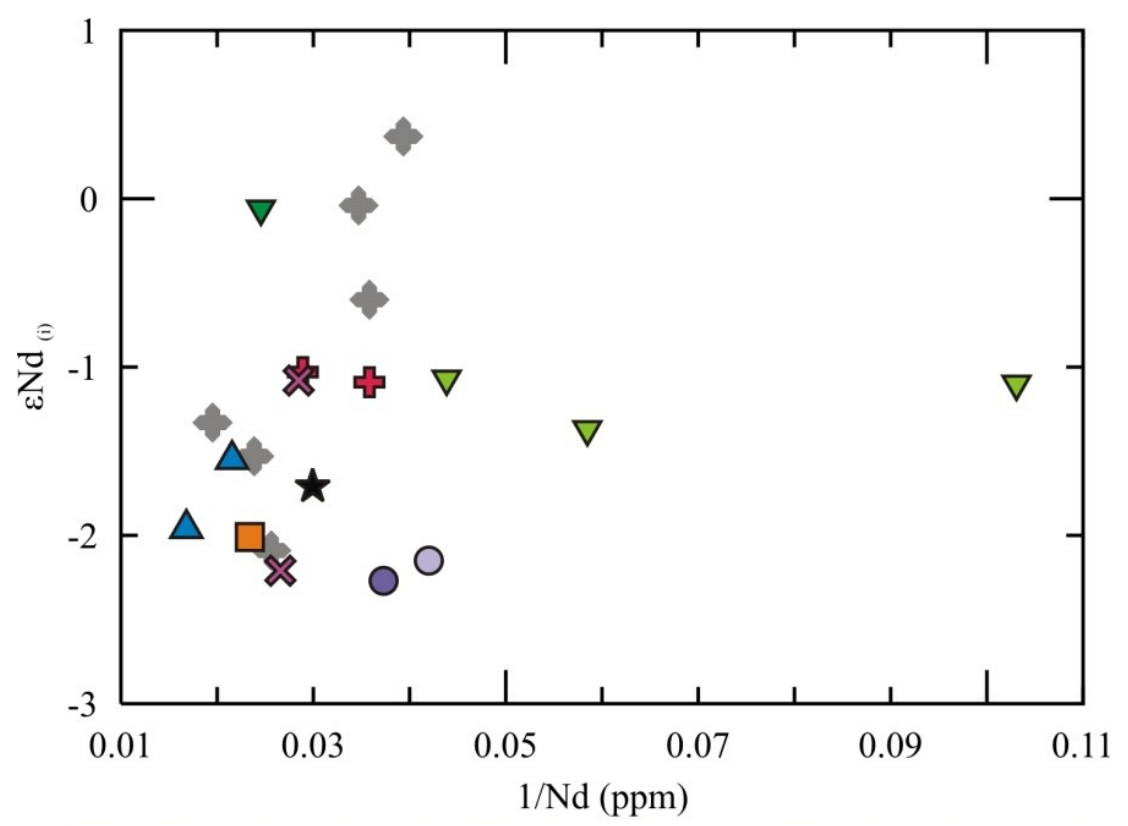

$\begin{array}{lll}\text { Miocene Lavas } & \square \text { Bonita Canyon Formation } & \text { ל Tuff of Arc Dome } \\ \text { Unnamed Tuff } & \nabla \text { Tuff of Clipper Gap } & \text { Tuff of Gabbs Valley } \\ \text { Unnamed Pumice } & \nabla \text { Tuff of Clipper Gap Pumice }\end{array}$

Figure 6.24: Initial $\varepsilon N d$ versus $1 / N d(p p m)$ showing the relation between epsilon $\mathrm{Nd}$ values and Nd concentration. The "fresh" samples show an increasing scatter between increasing $\varepsilon N d$ value and decreasing Nd concentration. Note that the Miocene lavas extend to higher $\varepsilon N d$ values than most of the Oligocene ignimbrites. The acid-washed tuff of Clipper Gap samples have a much lower Nd concentration than a majority of the other samples which may be a result of the acid washing process. 


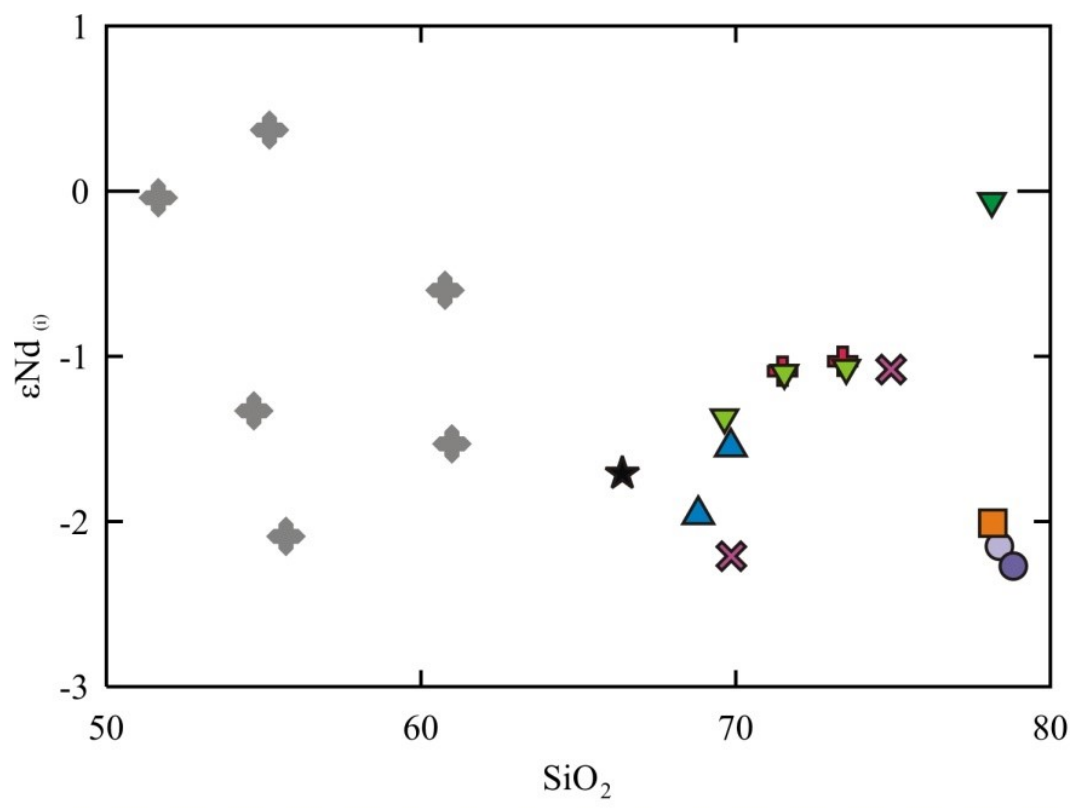

$\begin{array}{lll}\text { Miocene Lavas } & \square \text { Bonita Canyon Formation } & \text { Un Tuff of Arc Dome } \\ \text { Unnamed Tuff } & \nabla \text { Tuff of Clipper Gap } & \\ \text { Unnamed Pumice } & \nabla \text { Tuff of Clipper Gap Pumice }\end{array}$

Figure 6.25: Initial $\varepsilon N d$ versus $\mathrm{SiO}_{2}$ weight percentage showing the comparison between epsilon $\mathrm{Nd}$ values and increasing $\mathrm{SiO}_{2}$ content. The samples appear scattered and there appears to be no correlation between increasing $\mathrm{SiO}_{2}$ content and $\varepsilon N d$ value. The acid-washed tuff of Clipper Gap data plots more similarly to the "fresh" samples than 17-SM-07 (tuff of Clipper Gap) which has an $\varepsilon N d$ value closer to zero than any other sample. 


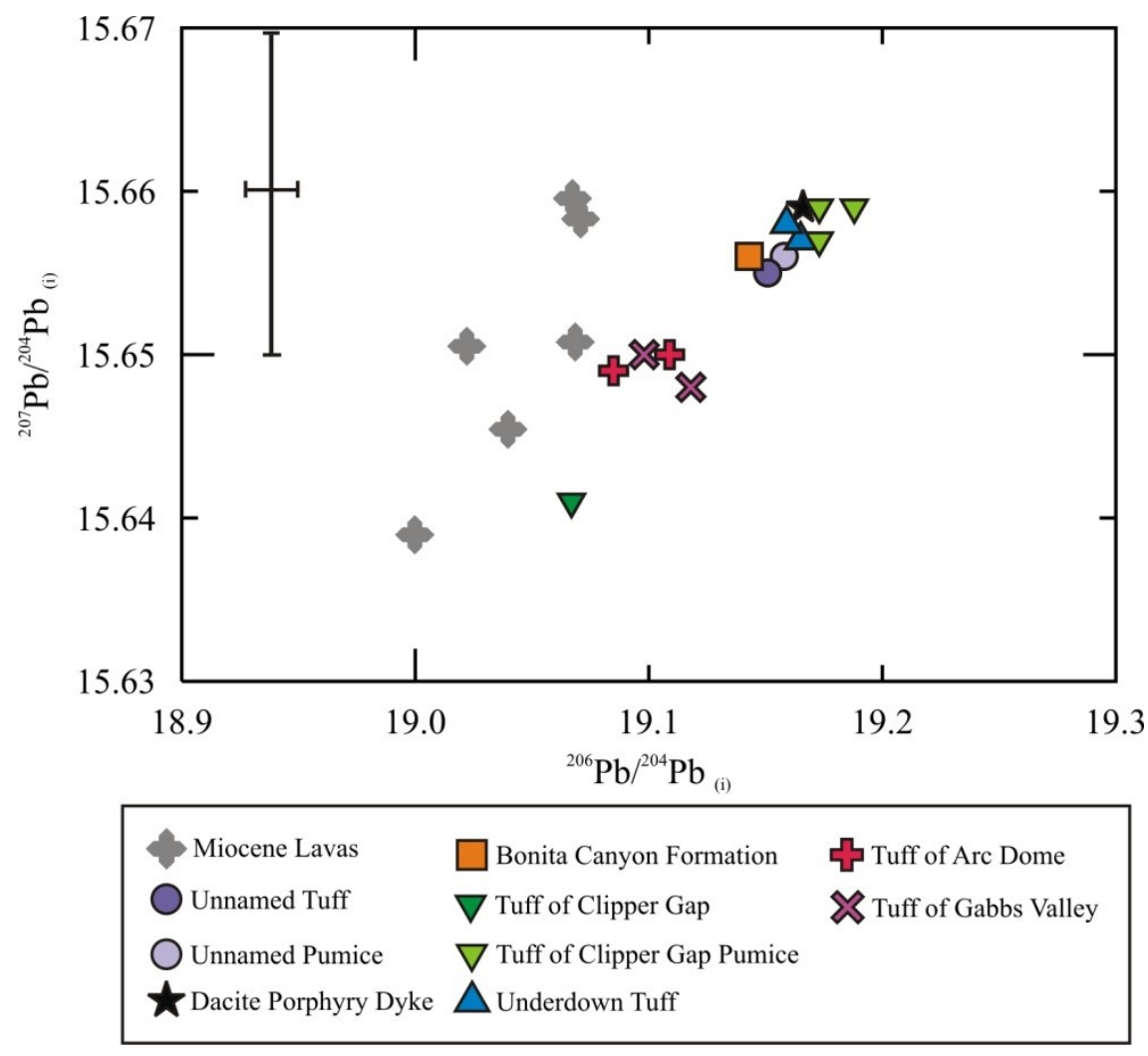

Figure 6.26: Initial ${ }^{207} \mathrm{~Pb} /{ }^{204} \mathrm{~Pb}$ versus ${ }^{206} \mathrm{~Pb} /{ }^{204} \mathrm{~Pb}$. The Underdown Caldera complex data plots as a fairly tight positive correlation that is similar to the Miocene lavas, but at a higher ${ }^{206} \mathrm{~Pb} /{ }^{204} \mathrm{~Pb}$ ratio (which may be explained by differences in analytic techniques). Sample 17-SM-07 (tuff of Clipper Gap) is the least radiogenic sample in the trend, while the acid-washed samples are the most radiogenic in the group. Note that the Miocene lavas were analyzed by TIMS whereas the ignimbrite samples were analyzed by MC-ICP-MS, which likely explains the greater scatter in the Miocene lava data. An error bar in the top left corner represents the error for the each Miocene lava sample. Error bars for MC-ICP-MS runs are the size of the symbols. 


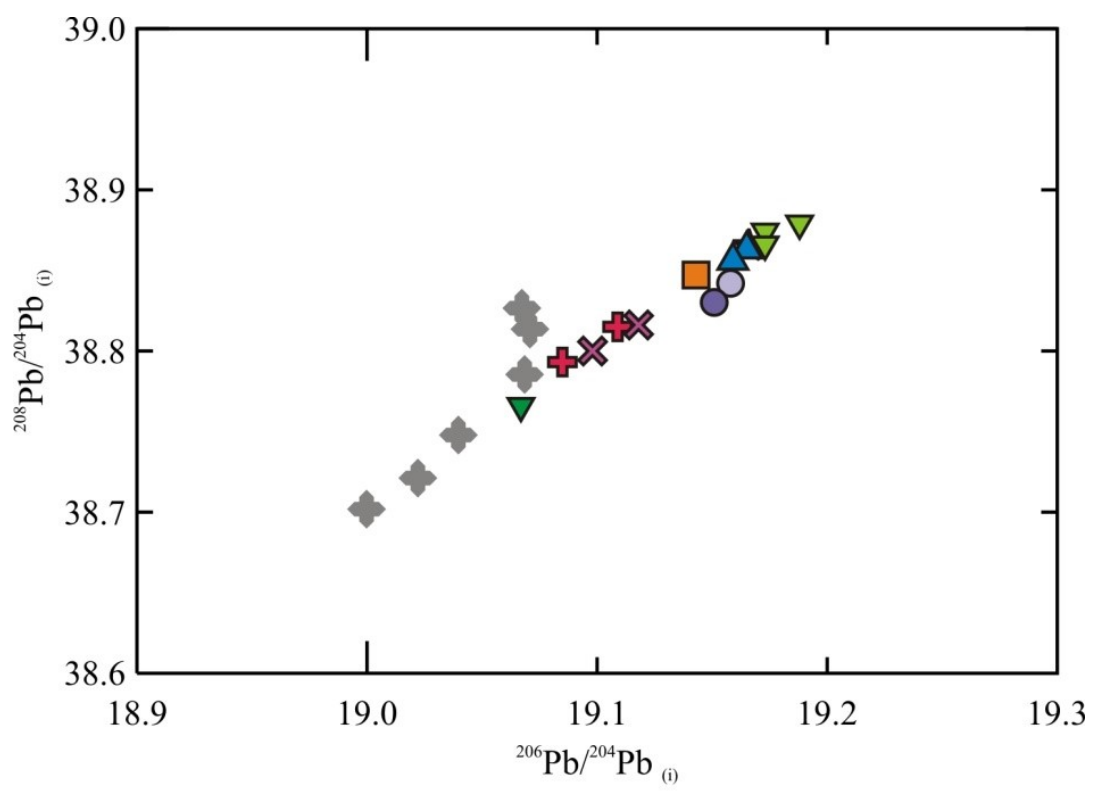

$\begin{array}{lll}\text { Miocene Lavas } & \square \text { Bonita Canyon Formation } & \text { S Tuff of Arc Dome } \\ \text { Unnamed Tuff } & \nabla \text { Tuff of Clipper Gap } & \text { Tuff of Gabbs Valley } \\ \text { Unnamed Pumice } & \nabla \text { Tuff of Clipper Gap Pumice } & \\ \text { Dacite Porphyry Dyke } & \Delta \text { Underdown Tuff }\end{array}$

Figure 6.27: Initial ${ }^{208} \mathrm{~Pb} /{ }^{204} \mathrm{~Pb}$ versus ${ }^{206} \mathrm{~Pb} /{ }^{204} \mathrm{~Pb}$ showing the correlation between increasing ${ }^{206} \mathrm{~Pb} /{ }^{204} \mathrm{~Pb}$ and increasing ${ }^{208} \mathrm{~Pb} /{ }^{204} \mathrm{~Pb}$. Similar to the ${ }^{207} \mathrm{~Pb} /{ }^{204} \mathrm{~Pb}$ versus ${ }^{206} \mathrm{~Pb} /{ }^{204} \mathrm{~Pb}$ comparison, the acid-washed tuff of Clipper Gap samples are much more radiogenic than tuff of Clipper Gap sample 17-SM-07, which is less radiogenic than the tuff of Gabbs Valley and tuff of Arc Dome. In general, the Miocene lavas are less radiogenic than the Oligocene tuffs but generally plot in the same correlation as the Oligocene tuffs. 


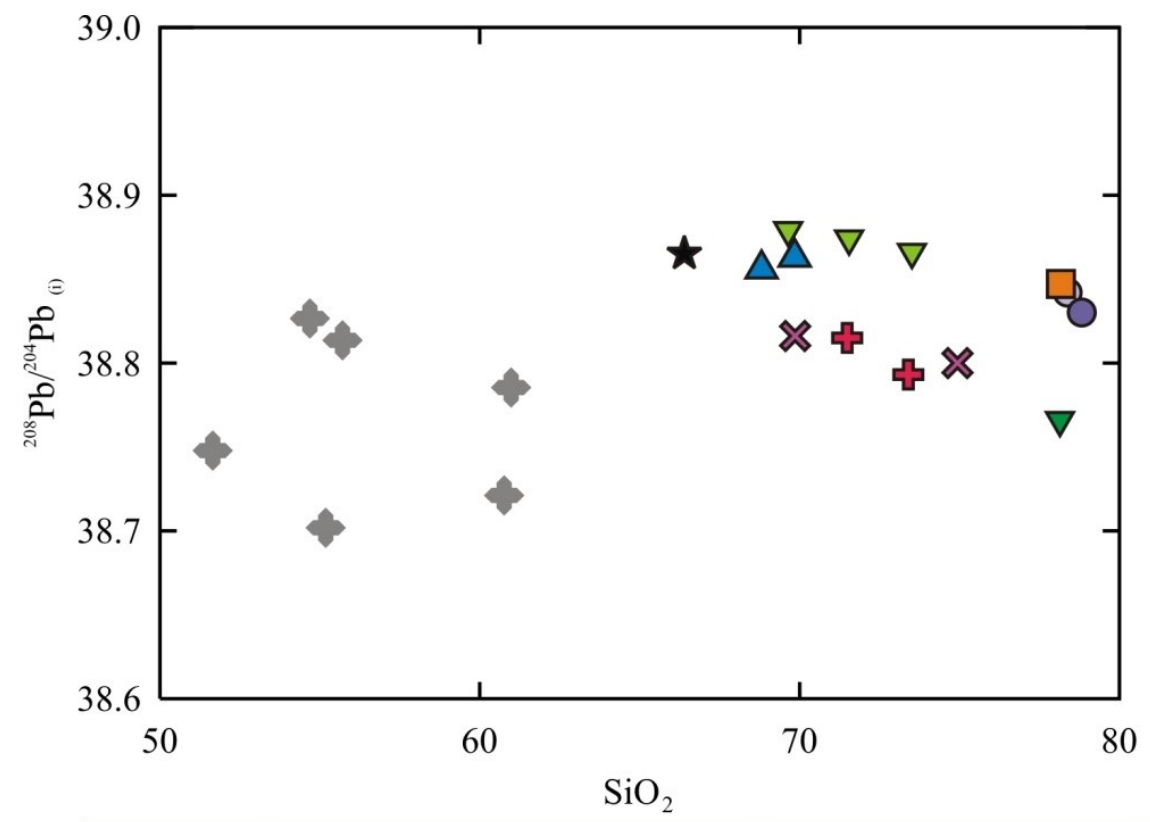

$\begin{array}{lll}\text { Miocene Lavas } & \square \text { Bonita Canyon Formation } & \text { Un Tuff of Arc Dome } \\ \text { Unnamed Tuff } & \nabla \text { Tuff of Clipper Gap } & \text { \uff of Gabbs Valley } \\ \text { Unnamed Pumice } & \nabla \text { Tuff of Clipper Gap Pumice } & \\ \text { ฟ Dacite Porphyry Dyke } & \Delta \text { Underdown Tuff } & \end{array}$

Figure 6.28: Initial ${ }^{208} \mathrm{~Pb} /{ }^{204} \mathrm{~Pb}$ versus $\mathrm{SiO}_{2}$ weight percentage showing the comparison between ${ }^{208} \mathrm{~Pb} /{ }^{204} \mathrm{~Pb}$ and increasing $\mathrm{SiO}_{2}$ content. The "fresh" samples and acid-washed samples show a scattered decrease with increasing $\mathrm{SiO}_{2}$ content. 


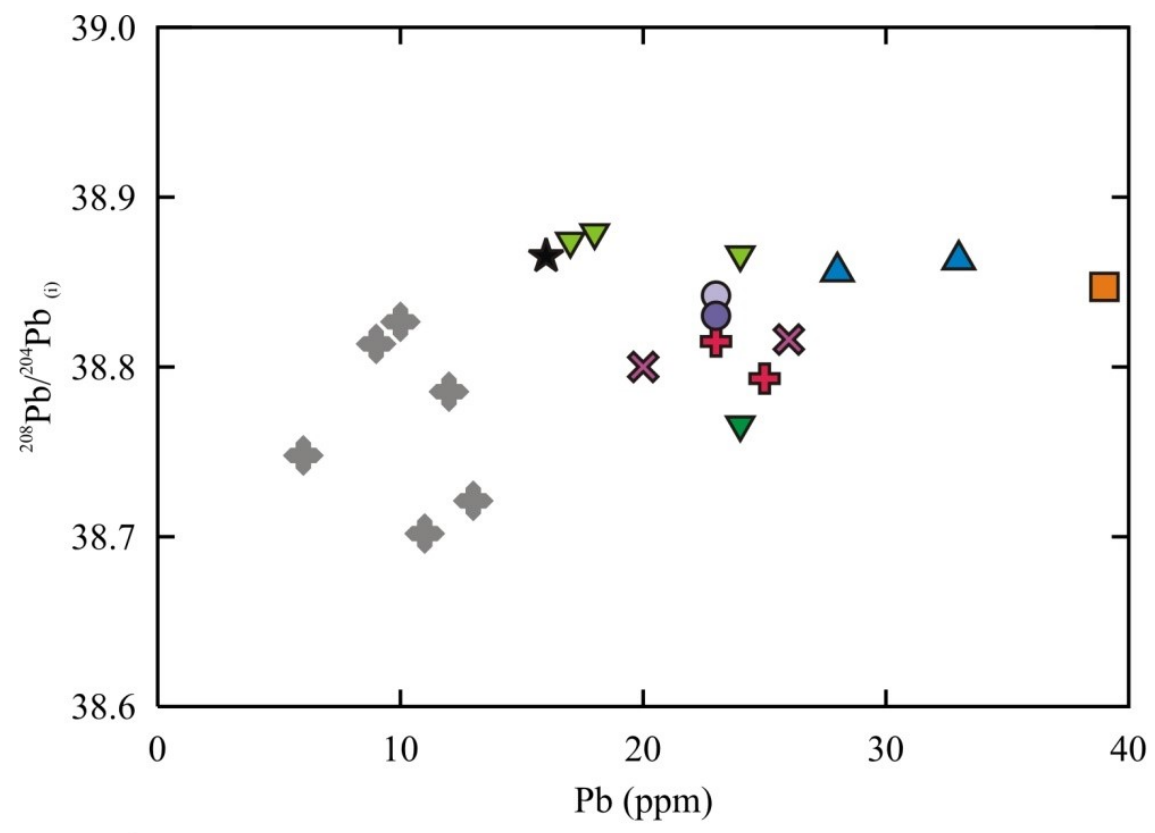

\begin{tabular}{|lll|}
\hline Miocene Lavas & $\square$ Bonita Canyon Formation & گ Tuff of Arc Dome \\
Unnamed Tuff & $\nabla$ Tuff of Clipper Gap & \uff of Gabbs Valley \\
Onnamed Pumice & $\nabla$ Tuff of Clipper Gap Pumice & \\
†Dacite Porphyry Dyke & $\Delta$ Underdown Tuff & \\
\hline
\end{tabular}

Figure 6.29: Initial ${ }^{208} \mathrm{~Pb} /{ }^{204} \mathrm{~Pb}$ versus $\mathrm{Pb}(\mathrm{ppm})$ showing the comparison between $\mathrm{Pb}$ isotopic values and $\mathrm{Pb}$ concentration. The "fresh" samples and acid-washed samples show a scattered positive correlation between ${ }^{208} \mathrm{~Pb} /{ }^{204} \mathrm{~Pb}$ ratios and $\mathrm{Pb}$ concentration. 


\subsection{Discussion}

\subsection{Establishing Primary Characteristics}

This section discusses the petrography and geochemistry of the intracaldera tuffs of the Underdown Caldera complex and the tuff of Clipper Gap to establish the primary characteristics of the units. The isotopic results will be compared to Miocene lavas collected from the margin of the caldera to investigate possible magma sources for the Oligocene tuffs.

\subsubsection{Petrographic characteristics}

The Oligocene tuffs of the Underdown Caldera complex are determined to be "Great Basin" style ignimbrites due to the presence of hydrous phases; biotite, hornblende, and Fe-Ti oxides (Christiansen, 2005). A combination of one or more of these minerals was observed in every ignimbrite unit. Phenocryst assemblages of two feldspars, quartz, and biotite and/or hornblende were standard across the caldera forming and extracaldera ignimbrites. Many quartz and feldspar phenocrysts in the ignimbrites were observed to be fractured, which is likely a result of the flow of pyroclastic material at the time of eruption. Some of the quartz and feldspar phenocrysts were also observed to be partially resorbed suggesting a reaction between the phenocrysts and a melt of changing composition. As expected, the Underdown Tuff and tuff of Clipper Gap were petrographically similar. In particular, the presence of two different pumice types, purple porphyritic pumice and white aphyric pumice, made these units distinct. The 
potential origin of the porphyritic pumice will be discussed in a subsequent section (section 7.4). The Bonita Canyon Formation contained the most sedimentary characteristics of any of the caldera forming ignimbrites. For example, this unit contained a higher proportion of lithic fragments than was observed in the other Oligocene tuffs. These lithic fragments are composed of quartz and feldspar, and likely originate from the Underdown Tuff or other tuffs located in proximity to the caldera. It is possible that this unit is a reworked unit of the upper Underdown Tuff or an unwelded upper section of the Underdown Tuff. The Unnamed tuff appears to be more welded than the other Oligocene tuffs from this study. This difference is highly noticeable, as the matrix of the Unnamed tuff is completely glassy in nearly all studied samples. The higher degree of welding in this sample may be a result of higher melt temperatures at the time of eruption. Many of the ignimbrite samples, particularly porphyritic pumice samples, show a high degree of weathering or alteration, despite the fact that samples appeared fresh when collected in the field.

\subsubsection{Geochemical characteristics}

\section{Major element geochemistry}

The Oligocene tuffs from the Underdown Caldera complex follow the same major element fractionation trends as other ignimbrites from the WNVF (Henry and John, 2013). $\mathrm{Na}_{2} \mathrm{O}$ shows the most scatter of all major element oxides when compared to increasing $\mathrm{SiO}_{2}$ content, likely due to the bulk partition coefficient of $\mathrm{Na}$ being close to 1 and/or the susceptibility of $\mathrm{Na}$ to weathering. As many of the samples appeared to be 
weathered and/or altered under petrographic observation, it is possibly a combination of the two. The trend of Underdown and tuff of Clipper Gap samples (particularly pumice) between the rhyolite and trachyte fields on the TAS diagram is likely a result of weathering which has decreased the $\mathrm{SiO}_{2}$ content and increasing the alkali content. $\mathrm{A}$ similar weathering signature was observed in the Fish Creek Mountains tuffs (Cousens et al., 2019). Therefore, this observed range in $\mathrm{SiO}_{2}$ content is not interpreted to be a primary geochemical characteristic of these units. One Underdown Tuff sample with a $\mathrm{SiO}_{2}$ content of approximately 83 weight percent is interpreted to have undergone postdeposition silicification. The same sample has only 0.09 weight percentage $\mathrm{Na}_{2} \mathrm{O}$, suggesting that it has also lost $\mathrm{Na}$ due to weathering.

\section{Trace Element Geochemistry}

Barium, $\mathrm{Eu}, \mathrm{Sr}$, and $\mathrm{Zr}$ are interpreted to behave as compatible elements in the Oligocene tuffs based on their negative correlations with $\mathrm{SiO}_{2}$ content observed in the trace element bivariate plots. Based on partition coefficients compiled from GERM (Appendix I, Table XII), Ba is likely being preferentially included into potassium feldspar and biotite. Europium may be incorporated into plagioclase feldspar, potassium feldspar, and amphibole. Strontium is preferentially included into plagioclase feldspar, and Zr may be incorporated into zircon. Niobium appears to be an incompatible element in the Oligocene tuffs based on its correlation between increasing $\mathrm{Nb}$ concentration and increasing $\mathrm{SiO}_{2}$ content. Based on its partition coefficient, biotite preferentially incorporates $\mathrm{Nb}$ into its structure, and biotite was observed to be present in all of the 
ignimbrite units, which contradicts the observed incompatible trend. However, despite biotite being present in all units, it was not present in all individual samples, and was found in a small abundance (typically trace-2\%) when present. The observed incompatibility in $\mathrm{Nb}$ could suggest that other minerals which don't incorporate $\mathrm{Nb}$ are dominating the crystallizing sequence. There may therefore be more $\mathrm{Nb}$ left in the melt than is incorporated into the small amount of crystallizing biotite as the magma evolves. $\mathrm{Pb}$ is partitioning variably into each ignimbrite unit as shown by the $\mathrm{Pb}$ bivariate plot which shows a clustered correlation between $\mathrm{Pb}$ concentration and $\mathrm{SiO}_{2}$ content. While $\mathrm{Pb}$ may be incorporating into potassium feldspar, making it a compatible element, other minerals which do not incorporate $\mathrm{Pb}$ may be dominating the crystallizing sequence, causing it to appear incompatible in some units, similar to $\mathrm{Nb}$. Thorium is also interpreted to behave as an incompatible element, and based on partition coefficient is not preferentially incorporated into any of the phenocryst phases in the ignimbrite units. The scatter of $\mathrm{Y}$ when compared to increasing $\mathrm{SiO}_{2}$ content makes it impossible to determine whether the element is behaving compatibly or incompatibly. Yttrium has a positive partition coefficient for biotite, apatite, and zircon, however there is no correlation between $\mathrm{Y}$ and increasing magma evolution that suggests it is being preferentially incorporated into any of these phases.

The Pablo Formation and dacite dyke samples show very similar chondrite normalized REE and primitive mantle normalized trace element patterns, suggesting that the dacite dyke could be originating from a partial melt of the Pablo Formation. However, the Sr 
and $\mathrm{Nd}$ isotopic values for these two units are quite different, making this scenario unlikely.

As observed on the chondrite normalized REE plots (Fig 6.15 and 6.16) most of the felsic units show enrichment in the LREEs compared to the HREEs, except for the rhyolite intrusions and the Unnamed tuff. Those two units show very little enrichment in the LREEs compared to the HREEs, and in the case of the rhyolite intrusions, a nearly flat pattern is observed from the LREEs to the HREEs. Similar chondrite normalized REE patterns are observed in pumice and fiamme from the base of the lower cooling unit of the Fish Creek Mountains tuff (Varve, 2013). The flatter patterns are proposed to be due to allanite fractionation, which preferentially removes the LREE from the melt (Mahood and Hildreth, 1983). The rhyolite intrusions and Unnamed tuff fiamme are interpreted to be early-erupted material from the most evolved part of the magma chamber that has undergone allanite fractionation. As magmatism continued, the eruption drew deeper into the magma reservoir, tapping less evolved magma that has not undergone allanite fractionation, causing a rotation in the REE pattern as $\mathrm{La} / \mathrm{Yb}$ increases, resulting in enrichment in the LREEs compared to the HREEs.

The 24.9 Ma Underdown Tuff, tuff of Clipper Gap, and Bonita Canyon Formation do not show the flattened pattern between the LREEs to the HREEs. The rhyolite intrusions and the Unnamed tuff were dated at $24.774 \pm 0.051$ and $24.755 \pm 0.037 \mathrm{Ma}$, respectively (C. Henry, pers. comm., 2018). Based on their ages, the rhyolite intrusions may mark a recharge event of magma into the Underdown Caldera complex, after a time when the 
magma chamber was allowed to rest and the magma evolved in composition, resulting in the emplacement of more evolved material than was erupted during the formation of the Underdown Tuff, tuff of Clipper Gap, and Bonita Canyon Formation. The rhyolite intrusions may mark the beginning of a new stage of magmatism, as their REE patterns are flatter than the Unnamed tuff which shows some small rotation to more enriched LREE patterns. However, this may also indicate that this region was a long lived center of felsic magmatism lasting from the eruption of the oldest ignimbrite (tuff of Gabbs Valley, $25.15 \pm 0.06 \mathrm{Ma}$ ) (Henry and John, 2013) to the youngest ignimbrite (Unnamed Tuff, $24.774 \pm 0.051 \mathrm{Ma}$ ) (C. Henry, pers. comm., 2018). It is possible that the cooling units marking the beginning of eruption of the Underdown Tuff also shows this REE signature; however the base of the Underdown Tuff is believed to be buried (Bonham, 1970). Therefore no samples were collected from the actual base of the Underdown Tuff, and no rotation in the chondrite normalized REE data is observed in the Underdown Tuff.

The crystallization of an LREE phase, such as allanite, may be responsible for the flattened chondrite normalized REE patterns in the rhyolite intrusions and the Unnamed tuff. Allanite has a high affinity for the LREEs (La-Sm), and a less high affinity for the HREEs and the high field strength elements (HFSEs), therefore the crystallization of this phase from a melt would fractionate LREEs to a high degree, and the La/Yb ratio would be lowered. The crystallization of allanite is an indication of high degrees of magma evolution (Mahood and Hildreth, 1983). Allanite exists in both the lower flows of the 
24.7 Ma Fish Creek Mountains tuff and throughout the 34.0 Ma Caetano Tuff (Cousens

et al., 2019; Watts et al., 2016). The very low affinity for the HFSEs (which includes Nb and $\mathrm{Ta}$ ) in allanite compared to the LREEs would also result in the higher abundances of $\mathrm{Nb}$ and Ta observed in the rhyolite intrusions and the Unnamed tuff than in magmas which have not fractionated allanite (Fig. 6.18 and 6.19). The highly evolved, basal pumice from the Fish Creek Mountains tuff also shows a larger negative Eu anomaly than the pumice from the overlying cooling unit. The largest negative Eu anomalies in the felsic rocks of the Underdown Caldera complex are observed in the rhyolite intrusions and Unnamed tuff, similar to what is observed in the Fish Creek Mountains tuff.

\subsubsection{Potential alteration of isotopic ratios}

Samples with higher than 6 weight percent LOI were not included in the isotope diagrams of the results section due to the potential that those samples have been altered which could affect their age-corrected isotopic ratios. Sr isotopic ratios of highLOI samples appear to show higher variance than those of the "fresh" samples, whereas $\varepsilon N d$ values appear to be similar to those of the "fresh" samples (Fig. 7.1). Pb isotope ratios of the high-LOI samples also are similar to the "fresh" samples, since they plot in the array of $\mathrm{Pb}$ isotopic ratios formed by the "fresh" samples and Miocene lavas (Fig. 7.2). Therefore any alteration on the high-LOI samples is assumed to have affected $\mathrm{Sr}$ isotopic ratios to a higher degree than $\mathrm{Nd}$ or $\mathrm{Pb}$ isotopic ratios. 
Anomalous REE-rich samples were also withheld from the isotope diagrams of the results section based on similar suspicions of alteration. Anomalous REE samples are those which appear to have elevated overall REE abundances as well as negative and positive Ce anomalies. The isotopic data from the anomalous REE samples were plotted along with isotopic data from the same samples after acid washing, as well as the "fresh" samples (Fig. 7.3). Sr isotopic ratios of acid-washed anomalous REE samples are lower, more uniform, and more similar to the "fresh" samples than their non-acidwashed equivalents, while $\varepsilon N d$ values become slightly higher and remain consistent with the "fresh" samples. Pb isotopic ratios are nearly unchanged after acid washing (Fig. 7.4). Nevertheless, the isotopic ratios of the acid-washed samples are interpreted to be more correct, i.e., closer to magmatic values, than of their un-acid-washed equivalents.

Due to the low concentration of $\mathrm{Sr}$ in most samples collected from the Underdown Caldera complex, it is likely that the Sr isotopic ratios have been altered, resulting in the age corrections of some samples becoming over or under age corrected. Suspect $\mathrm{Sr}$ isotopic ratios were also investigated in silicic ignimbrites from Gran Canaria, Canary Islands where $\mathrm{Rb}$ and $\mathrm{Sr}$ were determined to be mobile elements during low temperature, post emplacement interactions with groundwater (Cousens et al., 1993). This mobilization of $\mathrm{Rb}$ and $\mathrm{Sr}$ resulted in inaccurate initial ${ }^{87} \mathrm{Sr} /{ }^{86} \mathrm{Sr}$ isotopic ratios. It is suspected that low temperature groundwater alteration is also causing the apparent unusual range in calculated initial Sr isotopic ratios in the Underdown Caldera complex 
ignimbrites. $\mathrm{Pb}$ and $\mathrm{Nd}$ have much higher concentrations in the Underdown Caldera complex rocks and it is therefore much less likely that these isotopic ratios have been altered. 

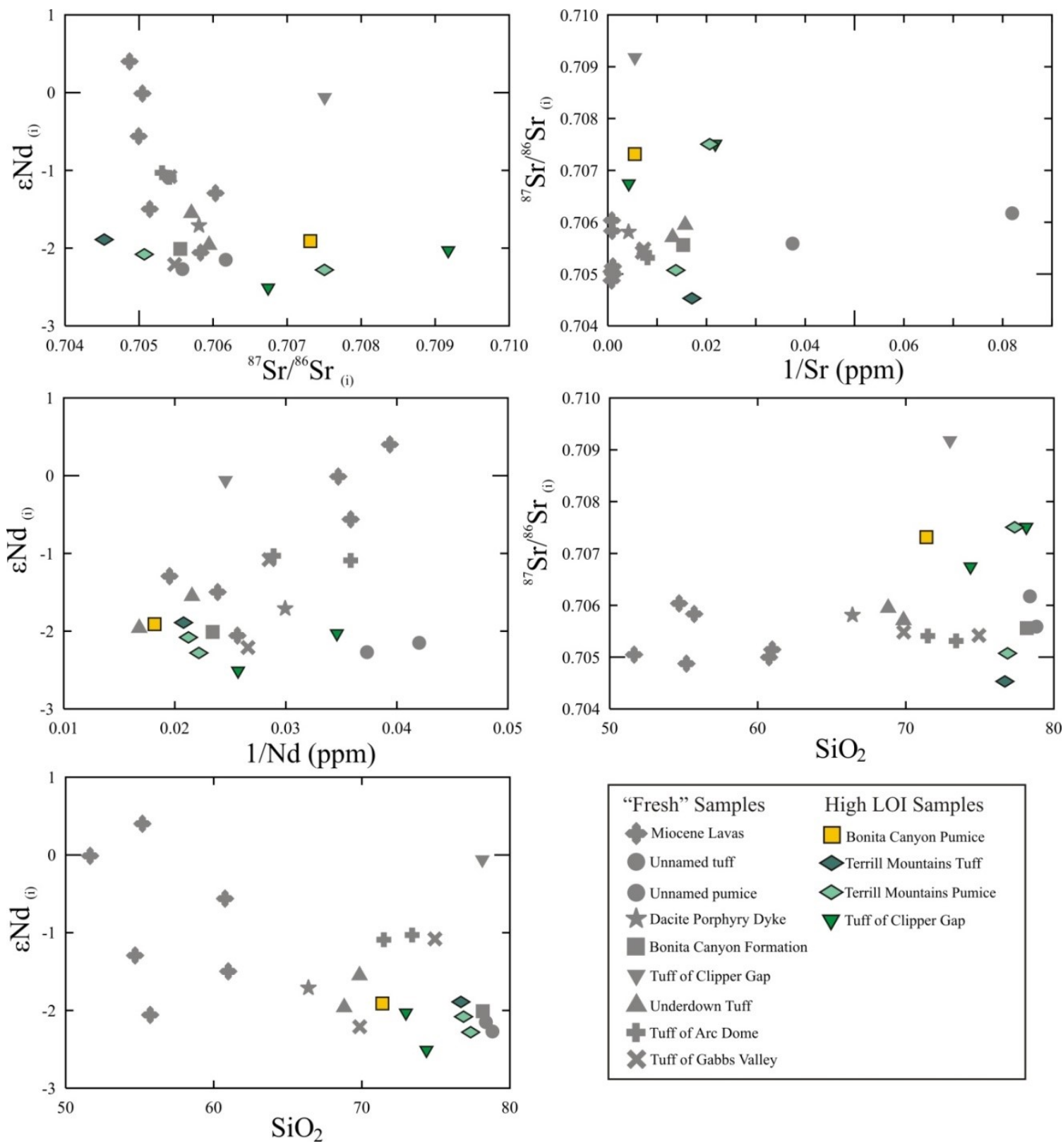

Figure 7.1: Initial $\mathrm{Sr}$ and $\mathrm{Nd}$ isotopic data showing the comparison between the high LOI samples and the "fresh" samples. High LOI samples show the most variance from "fresh" samples in their Sr isotopic data, while their $\varepsilon N d$ values remain similar to those of the "fresh" samples. 

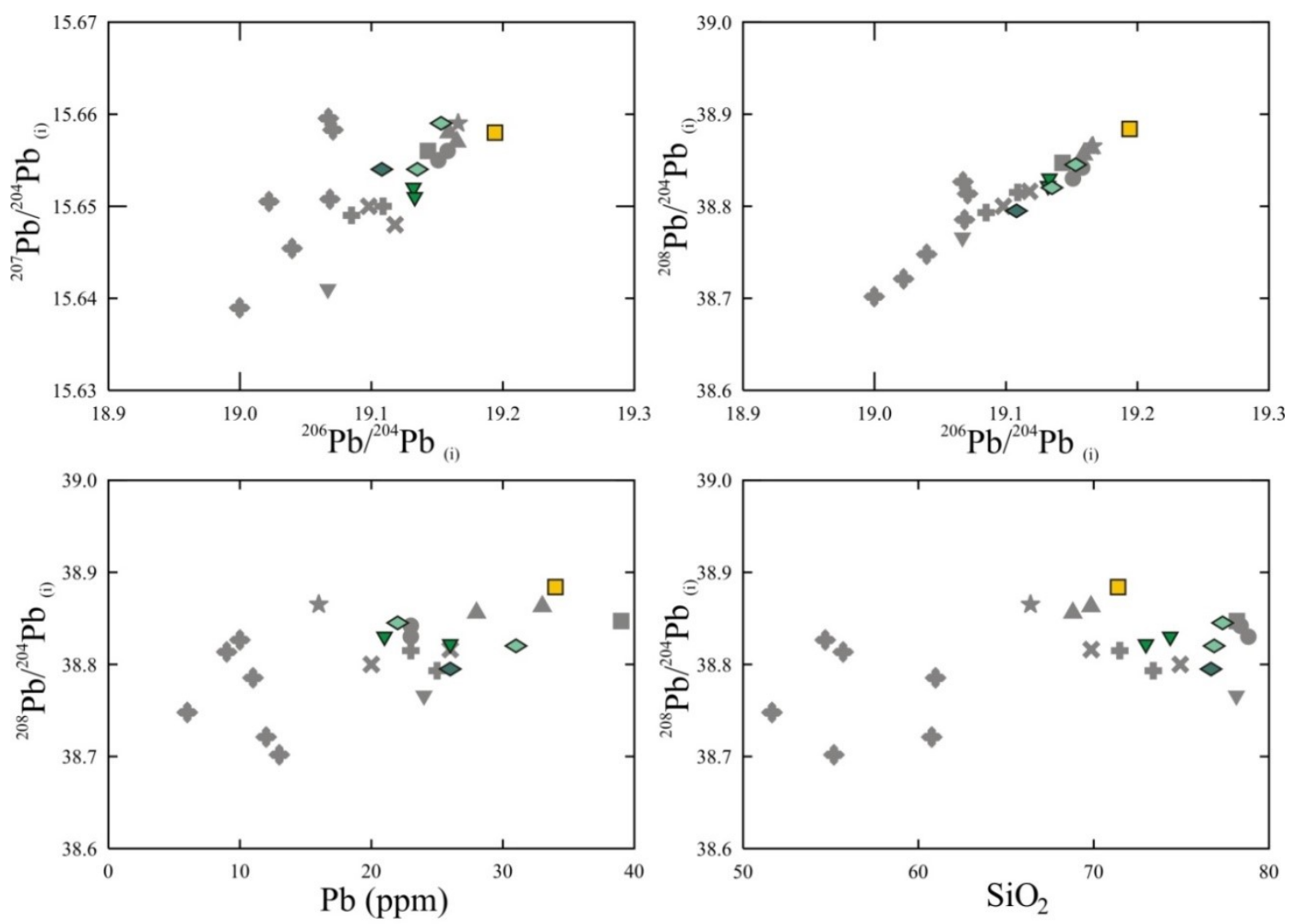

\begin{tabular}{|ll|}
\hline "Fresh" Samples & High LOI Samples \\
Miocene Lavas & $\square$ Bonita Canyon Pumice \\
Unnamed tuff & $\diamond_{\text {Terrill Mountains Tuff }}$ \\
Unnamed pumice & $\diamond_{\text {Terrill Mountains Pumice }}$ \\
$\star$ Dacite Porphyry Dyke & $\nabla$ Tuff of Clipper Gap \\
Bonita Canyon Formation & \\
$\nabla_{\text {Tuff of Clipper Gap }}$ & \\
Underdown Tuff & \\
Tuff of Arc Dome & \\
X Tuff of Gabbs Valley & \\
\hline
\end{tabular}

Figure 7.2: Initial $\mathrm{Pb}$ isotopic diagrams showing the comparison between the high LOI samples and the "fresh" samples. High LOI samples show very little difference in $\mathrm{Pb}$ isotopic data to the "fresh" samples, as the high LOI samples plot with the "fresh" samples in positive correlations in the ${ }^{207} \mathrm{~Pb} /{ }^{204} \mathrm{~Pb}$ vs. ${ }^{206} \mathrm{~Pb} /{ }^{204} \mathrm{~Pb}$ and ${ }^{208} \mathrm{~Pb} /{ }^{204} \mathrm{~Pb}$ vs. ${ }^{206} \mathrm{~Pb} /{ }^{204} \mathrm{~Pb}$ diagrams. 

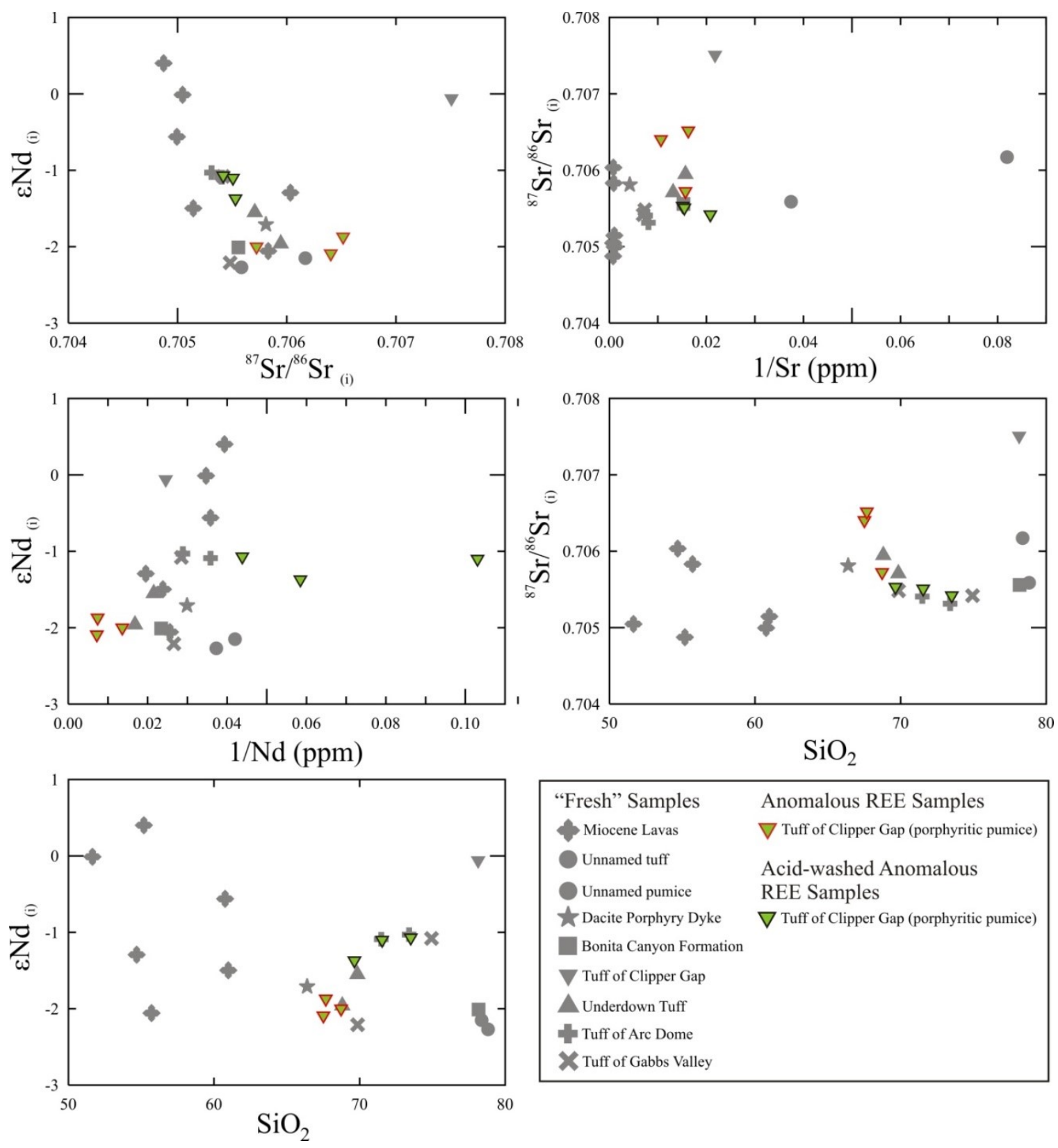

$\begin{array}{ll}\text { "Fresh" Samples } & \text { Anomalous REE Samples } \\ \text { Miocene Lavas } & \nabla \text { Tuff of Clipper Gap (porphyritic pumice) } \\ \text { Unnamed tuff } & \text { Acid-washed Anomalous } \\ \text { Unnamed pumice } & \text { REE Samples } \\ \text { ¿ Dacite Porphyry Dyke } & \nabla \text { Tuff of Clipper Gap (porphyritic pumice) } \\ \text { Bonita Canyon Formation } & \\ \text { Tuff of Clipper Gap } & \\ \text { Underdown Tuff } & \\ \text { Tuff of Arc Dome } & \\ \text { * Tuff of Gabbs Valley } & \end{array}$

Figure 7.3: Initial $\mathrm{Sr}$ and $\mathrm{Nd}$ isotopic diagrams showing the comparison between the anomalous REE samples, their acid-washed equivalents, and the "fresh" samples. Sr isotopic ratios show less variation from the "fresh" samples than the high LOI samples, while their $\varepsilon N d$ values become less negative after acid washing. 

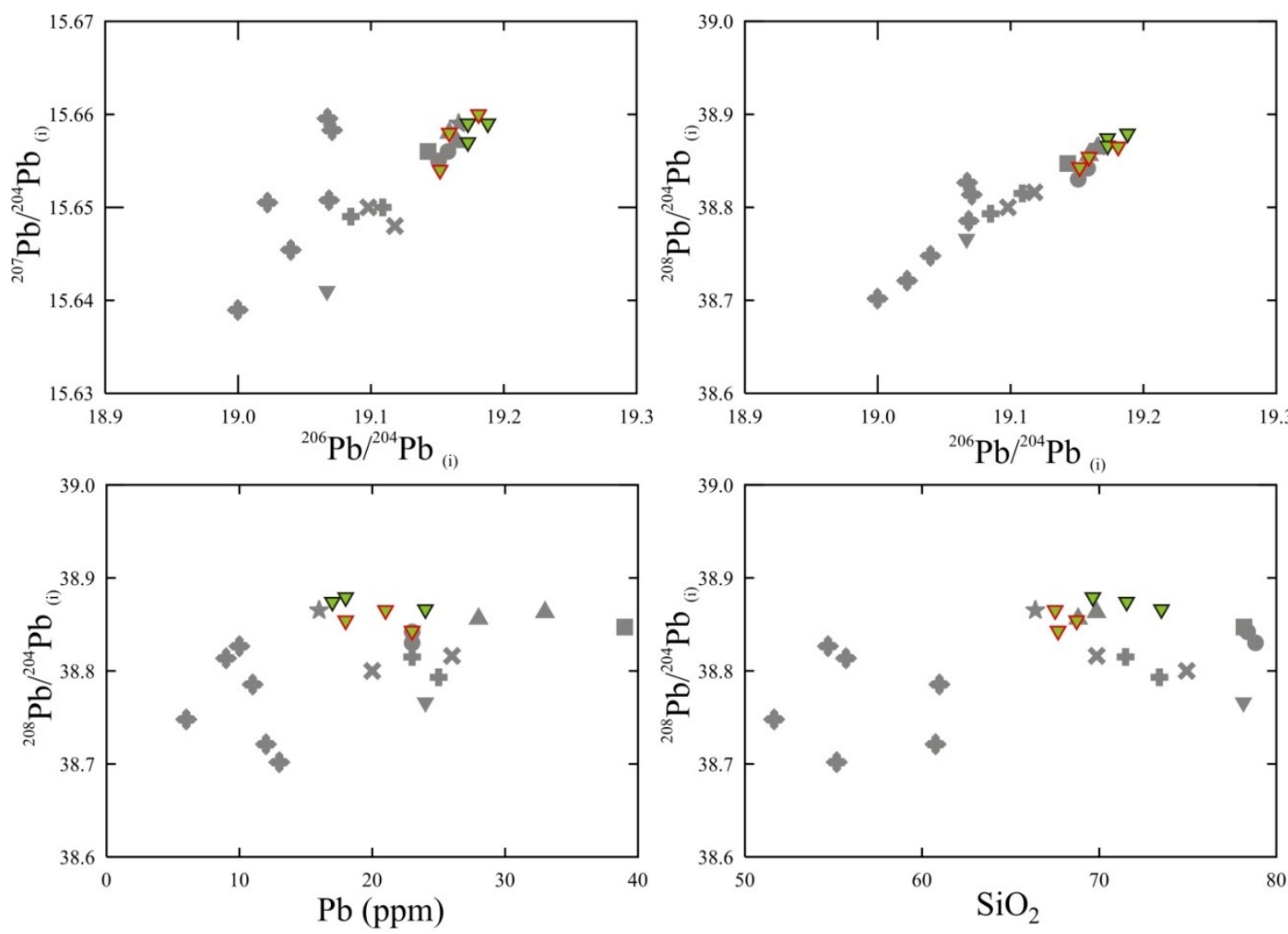

$\begin{array}{ll}\text { "Fresh" Samples } & \text { Anomalous REE Samples } \\ \text { Miocene Lavas } & \nabla \text { Tuff of Clipper Gap (porphyritic pumice) } \\ \text { Unnamed tuff } & \text { Acid-washed Anomalous } \\ \text { Unnamed pumice } & \text { REE Samples } \\ \text { Dacite Porphyry Dyke } & \nabla \text { Tuff of Clipper Gap (porphyritic pumice) } \\ \text { Bonita Canyon Formation } & \\ \text { Tuff of Clipper Gap } & \\ \text { Underdown Tuff } & \\ \text { Tuff of Arc Dome } & \\ \text { Tuff of Gabbs Valley }\end{array}$

Figure 7.4: Initial $\mathrm{Pb}$ isotopic diagrams showing the comparison between the anomalous REE samples, their acid-washed equivalents, and the "fresh" samples. $\mathrm{Pb}$ isotopic ratios of the anomalous REE samples appear relatively unchanged after acid washing. 


\subsubsection{Potential sources of the Oligocene tuffs}

The Oligocene tuffs most likely originate from a multi-component system. One component is suspected to have differentiated from a mantle derived melt, due to the similarity of the $\mathrm{Sr}$ and $\mathrm{Nd}$ isotopic compositions in the tuffs to those of the slightly younger Miocene mafic to intermediate lavas. Tennant (2018) proposed that the Miocene lavas originated from a subcontinental lithospheric mantle source, coupled with minor assimilation and/or contamination by the overlying Phanerozoic crust. Scattered relationships between isotopic ratios $\left(\mathrm{Sr}, \mathrm{Nd}\right.$, and $\mathrm{Pb}$ ) with $\mathrm{SiO}_{2}$ content suggests that the mantle derived source was contaminated by a crustal component, as

pure fractionation does not fractionate isotopes, and progressive assimilation of a crustal component would produce a tighter trend between the isotopic ratios and increasing $\mathrm{SiO}_{2}$ content, as opposed to a scatter. During the Oligocene, the thick lithosphere of the Nevadaplano dominated what is now the Western Great Basin (Colgan and Henry, 2009). The exceptionally thick crust likely prevented most mantle derived melts from reaching the surface, causing them to pool in the crust. If the Oligocene tuffs were derived from a mostly mantle melt, pooling in a MASH (melting, assimilation, storage and homogenization) zone within the crust would allow ample opportunity for assimilation or contamination with the surrounding continental crust (Putirka and Busby, 2007).

The source of the Oligocene tuffs appears to originate from a shallower depth than the melt of the Miocene lavas which appear to originate from the garnet stability field ( $>80$ 
$\mathrm{km}$ depth) (Winter. 2001). Primitive mantle normalized $\mathrm{Gd} / \mathrm{Yb}$ represents the slope from the middle REEs to the heavy REEs, signifying the retention of heavy REEs in garnet during partial melting of the mantle. Whereas the Miocene lavas have a $\mathrm{Gd} / \mathrm{Yb}$ ratio between 2 and 3, the Oligocene tuffs have a Gd/Yb ratio between 1 and 2, suggesting their source melt originates from a shallower depth (above the garnet-peridotite stability field) (Rollinson, 1993). However, the difference in $\mathrm{Gd} / \mathrm{Yb}$ ratio between the two groups could also be a result of fractionation of middle to heavy REE-loving mineral phases from the melt. For example, allanite, apatite, amphibole, or zircon could be responsible for the shift in $\mathrm{Gd} / \mathrm{Yb}$ ratios. Alternatively, the assimilation of a shallow crustal component containing no garnet into the melt could also be responsible for the shift in $\mathrm{Gd} / \mathrm{Yb}$ ratios to lower values (Fig. 7.5). 


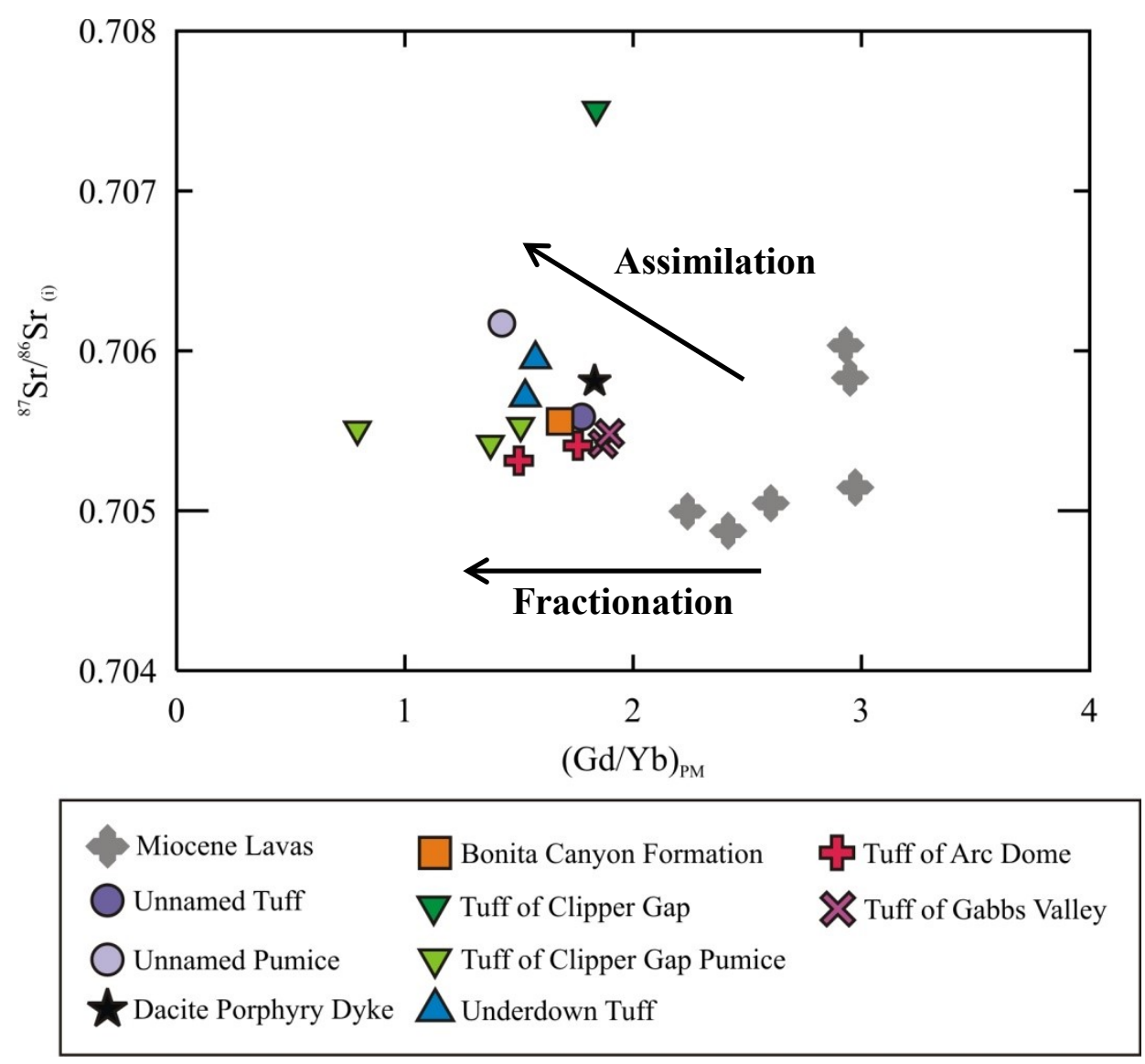

Figure 7.5: Age corrected ${ }^{87} \mathrm{Sr} /{ }^{86} \mathrm{Sr}$ vs. primitive mantle normalized $\mathrm{Gd} / \mathrm{Yb}$ comparing the "fresh" Oligocene tuffs and the acid-washed tuff of Clipper Gap samples with the Miocene lavas. $\mathrm{Gd} / \mathrm{Yb}$ is a slope estimate for the middle to heavy REEs which suggests a depth of melting of the source of mantle derived rocks. The Miocene lavas plot between a $\mathrm{Gd} / \mathrm{Yb}$ ratio of 2-3, and the Oligocene tuffs mostly plot between a $\mathrm{Gd} / \mathrm{Yb}$ ratio of 1-2. Fractionation of a middle to heavy REE-loving phase, or assimilation of a garnet-absent crustal rock into the melt could explain the shift in $\mathrm{Gd} / \mathrm{Yb}$ observed from the Miocene lavas to the Oligocene tuffs. 
The Miocene lavas were determined to be from two suites, a mildly alkaline suite and a sub-alkaline suite (Tennant, 2018). Miocene lavas with higher ${ }^{87} \mathrm{Sr} /{ }^{86} \mathrm{Sr}$ isotopic ratios (from the mildly alkaline suite) were interpreted to include more crustal components than those from the sub-alkaline suite which plot closer to the mantle array at lower ${ }^{87} \mathrm{Sr} /{ }^{86} \mathrm{Sr}$ ratios. The mildly alkaline samples have $\mathrm{Sr}$ isotopic ratios nearly identical to the Underdown Tuff and the dacite dyke (Fig. 7.6). In a plot of crustal addition (primitive mantle normalized Th/La vs. $\mathrm{SiO}_{2}$ ), the Miocene lavas, "fresh" Oligocene tuffs, and acidwashed tuff samples exhibit an increase in Th/La with increasing $\mathrm{SiO}_{2}$ content (Fig. 7.7). This suggests that as $\mathrm{SiO}_{2}$ content increases, more Th-rich continental crust is added to the magmas. The dacite dyke sample has the lowest Th/La and has suffered the least amount of crustal assimilation out of the Underdown Caldera complex felsic samples. The Oligocene tuffs are mostly clustered in two groups; the first group between about 65-75 weight percent $\mathrm{SiO}_{2}$, and the second between about 75-79 weight percent $\mathrm{SiO}_{2}$. The Unnamed tuff samples which plot at much higher Th/La at similar $\mathrm{SiO}_{2}$ content as the Bonita Canyon Formation and tuff of Clipper Gap are interpreted to have fractionated allanite, thus increasing the Th/La ratio (based on the Th and La concentration measured in allanite by Mahood and Hildreth (1983)). A similar fractionation trend was observed in the Caetano and Fish Creek Mountains Tuffs (Cousens et al., 2019). Based on Figure 7.7, the most assimilation of crustal material appears to occur between the high silica dacites and the low silica rhyolites. 


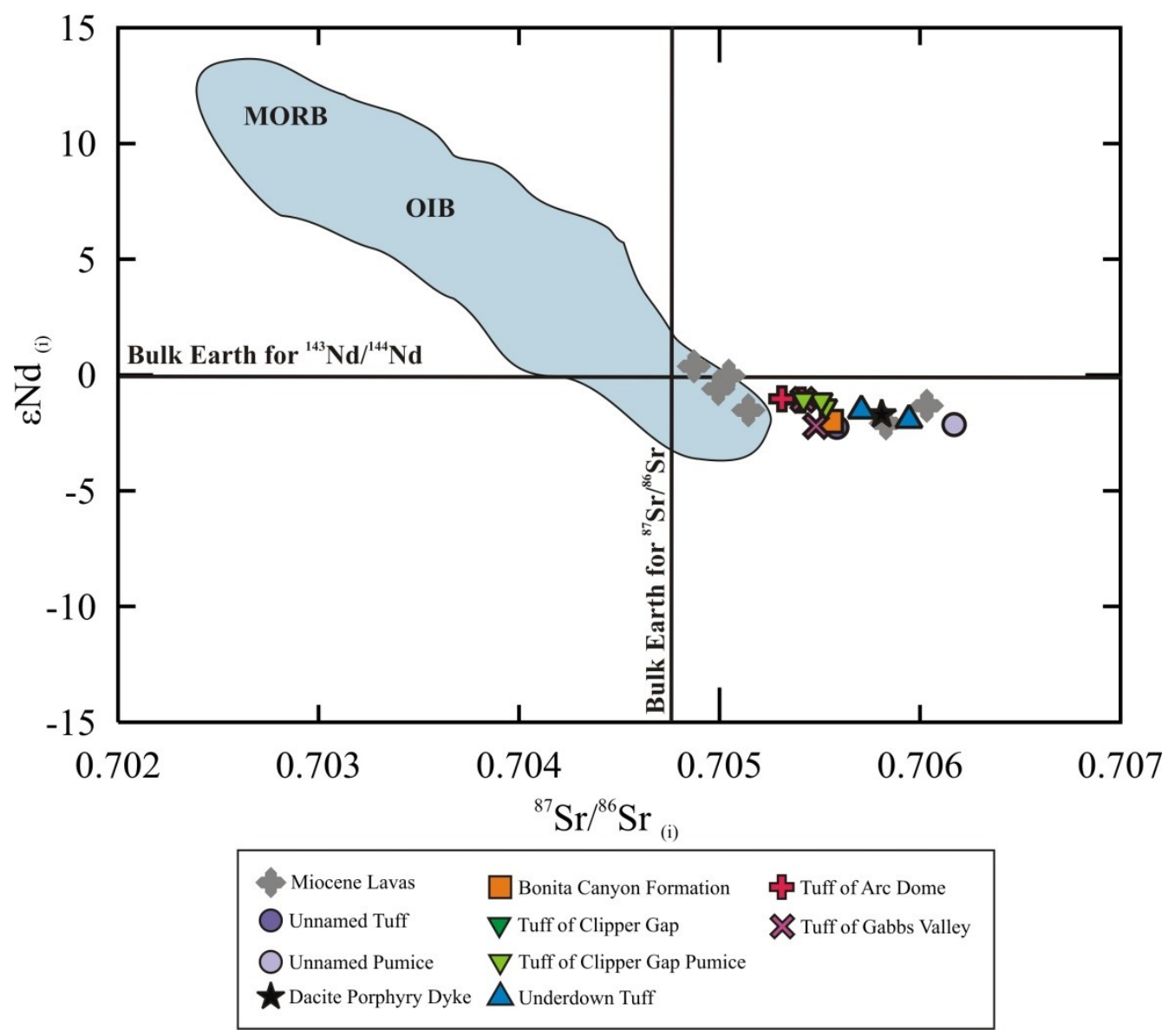

Figure 7.6: $\varepsilon N d$ vs. ${ }^{87} \mathrm{Sr} /{ }^{86} \mathrm{Sr}$ after Allègre (2008) showing the "fresh" samples, acidwashed tuff of Clipper Gap samples, and Miocene lavas. Miocene lavas from the subalkaline suite plot with the mantle array, while two samples from the mildly alkaline suite have higher ${ }^{87} \mathrm{Sr} /{ }^{86} \mathrm{Sr}$ ratios that are nearly identical to the dacite dyke and Underdown Tuff. 


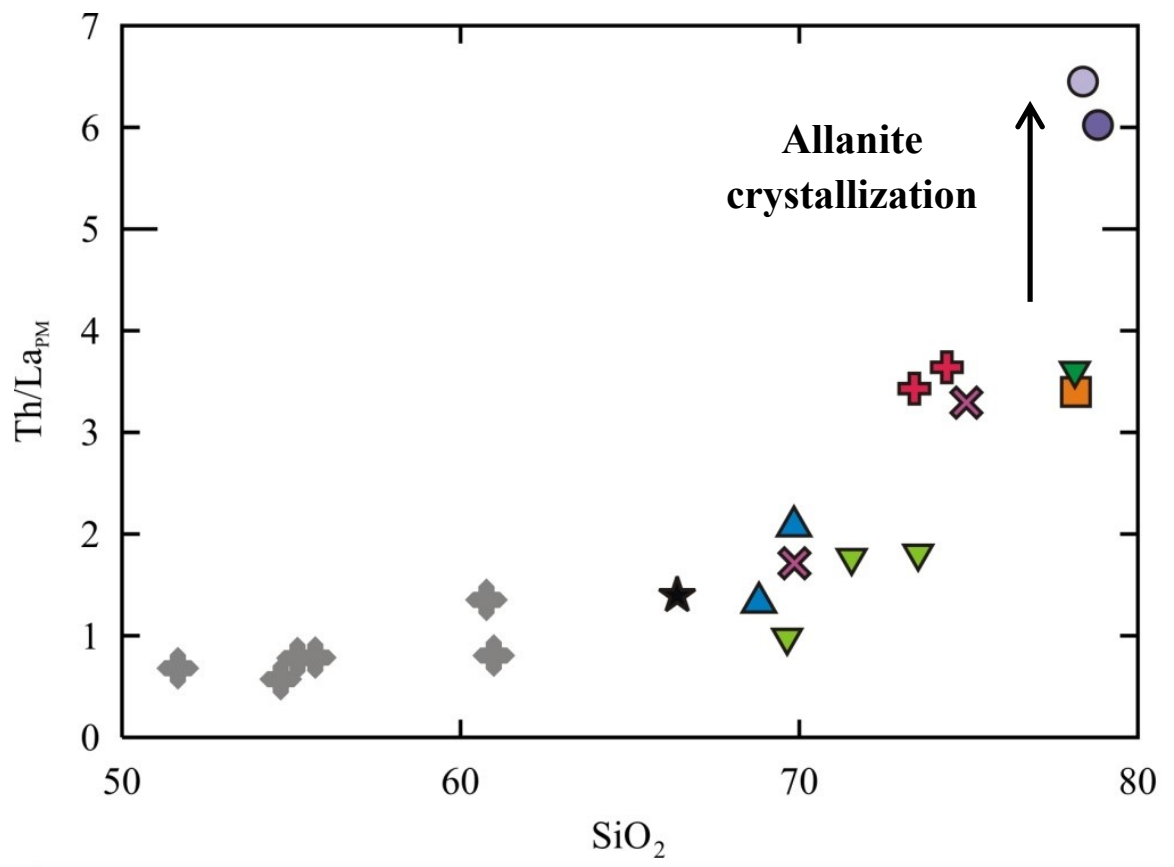

Miocene Lavas

Unnamed Tuff

Bonita Canyon Formation

$\nabla$ Tuff of Clipper Gap

Tuff of Arc Dome

\ Tuff of Gabbs Valley

Unnamed Pumice

Dacite Porphyry Dyke

$\nabla$ Tuff of Clipper Gap Pumice

$\triangle$ Underdown Tuff

Figure 7.7: Primitive mantle normalized (Sun and McDonough, 1989) Th/La versus $\mathrm{SiO}_{2}$ content of the "fresh" Oligocene tuffs, acid-washed tuff of Clipper Gap samples, and Miocene lavas showing potential crustal addition with increasing magma evolution. The Miocene lavas and Oligocene tuffs show a positive correlation between Th/La and $\mathrm{SiO}_{2}$ content. The plot suggests that the Oligocene tuffs have assimilated more crustal material than the andesitic Miocene lavas. Unnamed tuff samples are interpreted to have fractionated allanite, resulting in much higher Th/La ratios. 
$\mathrm{Pb}$ isotope diagrams also suggest crustal addition to the Underdown magmas. On a ${ }^{207} \mathrm{~Pb} /{ }^{204} \mathrm{~Pb}$ versus ${ }^{206} \mathrm{~Pb} /{ }^{204} \mathrm{~Pb}$ diagram (modified after Allègre, 2008), the Miocene lavas and Oligocene tuffs fall on the overlap between continental granites and oceanic basalts (Fig. 7.8). Both the Miocene lavas and the Oligocene tuffs plot above the Northern Hemisphere Reference Line (NHRL), a best-fit line through modern oceanic basalts from the Northern Hemisphere, indicating they do not originate from an asthenospheric source (Hart, 1984). Based on the presented geochemical data and the observed relationship between the Miocene lavas and the Oligocene tuffs, it is postulated that the lavas found around the margin of the caldera may represent a potential parental magma of the Oligocene tuffs. This would require the melting of isotopically-similar lithospheric mantle at the time of both magmatic events. 


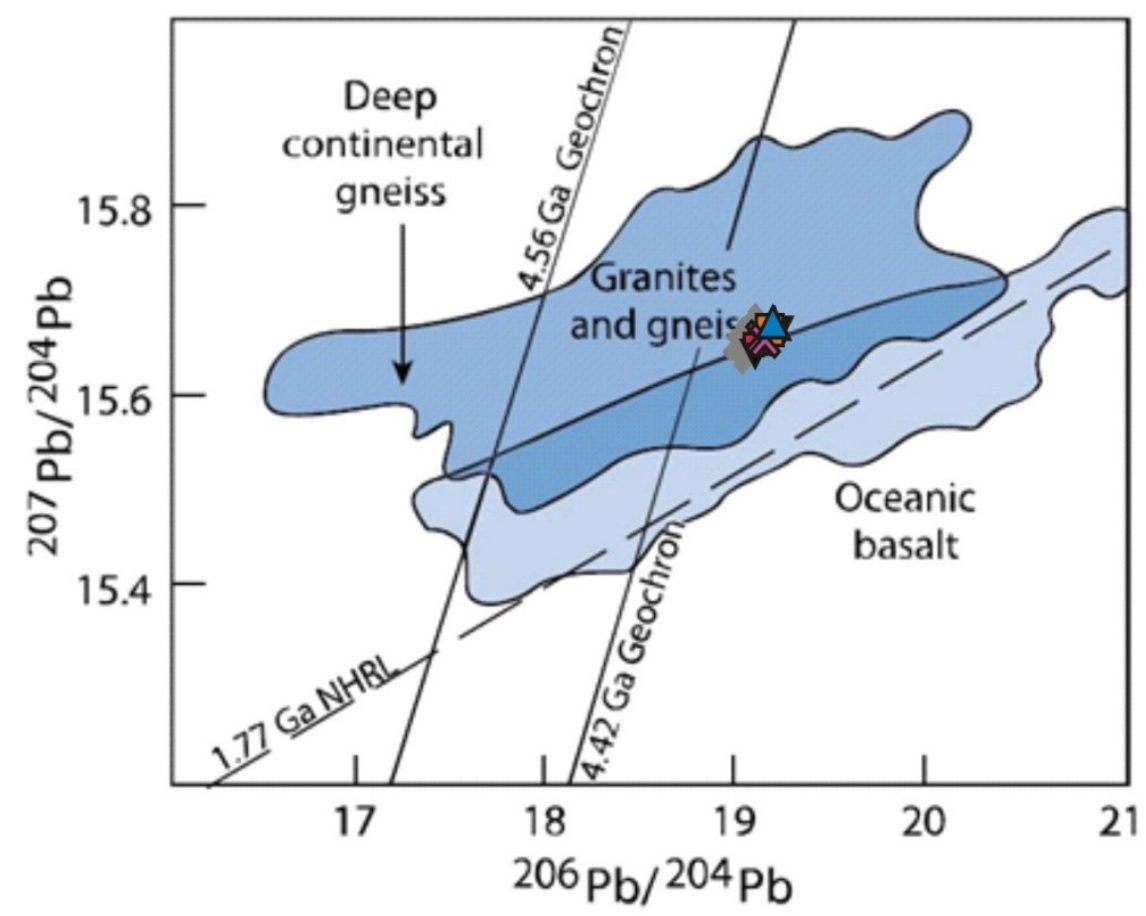

Figure 7.8: Initial ${ }^{207} \mathrm{~Pb} /{ }^{204} \mathrm{~Pb}$ versus ${ }^{206} \mathrm{~Pb} /{ }^{204} \mathrm{~Pb}$ diagram modified after Allègre (2008). The Oligocene tuffs from the Underdown Caldera complex and the Miocene lavas plot on an overlap zone between continental rocks and oceanic basalt, above the Northern Hemisphere Reference Line (Hart, 1984).

Due to suspect $\mathrm{Sr}$ isotopic ratios, $\mathrm{Pb}$ isotopes were used to model potential mixing lines for the Underdown Caldera complex ignimbrites. The primitive end-member used in the mixing line is a sample of the Miocene lavas from the caldera margin (17-SML-11) and will be referred to as the mantle derived magma. Exhaustive options for a crustal source included the upper, middle, lower, and average continental crust (Rudnick and Fountain, 1995), granitic basement from the Stillwater range (Stepner, 2017), and the Carico Lake Pluton (Watts et al., 2016). The two "crustal melt" end-members which fit the mixing line relatively well were (A) an average of Paleozoic sedimentary rocks from the Stillwater Range and Clan Alpine Mountains northwest of the Underdown region 
(Stepner, 2017), and (B) a late Eocene pluton from the Northern Shoshone Range (Cousens et al., 2019). The average sedimentary samples include shale, calcareous shale, and limestone. While the mixing line utilizing the average sedimentary "crustal melt" end-member is not a perfect match to the Underdown Caldera complex ignimbrites, it suggests that the Oligocene tuffs may originate from a mix of a mafic component from the mantle beneath the caldera and a local sedimentary unit (Fig. 7.9). However, it appears as though the ignimbrites are closer in composition to the mantle-derived magma. The individual sedimentary samples used for the "crustal melt" end-member average (also plotted on the mixing line diagram) show how the $\mathrm{Pb}$ isotopic data varies between the sedimentary samples, and suggests that any combination of local sedimentary sources could be responsible for the crustal component in the melt. On the mixing line using the late Eocene pluton as the "crustal melt", the samples plot in two groups; one group between $60-70 \%$ mantle component, and a second larger group between $30-40 \%$ mantle component (Fig. 7.10). Based on the proposed mixing lines and isotopic similarities to the Miocene lavas, it is possible that the Underdown Caldera ignimbrites originated from a mantle derived source beneath the caldera, and are not the product of a purely crustal melt. Mixing lines suggest that the source of the Oligocene tuffs may be a mixture between a mantle source (similar to that of the Miocene lavas) and either a local sedimentary unit, or a local granitoid. 


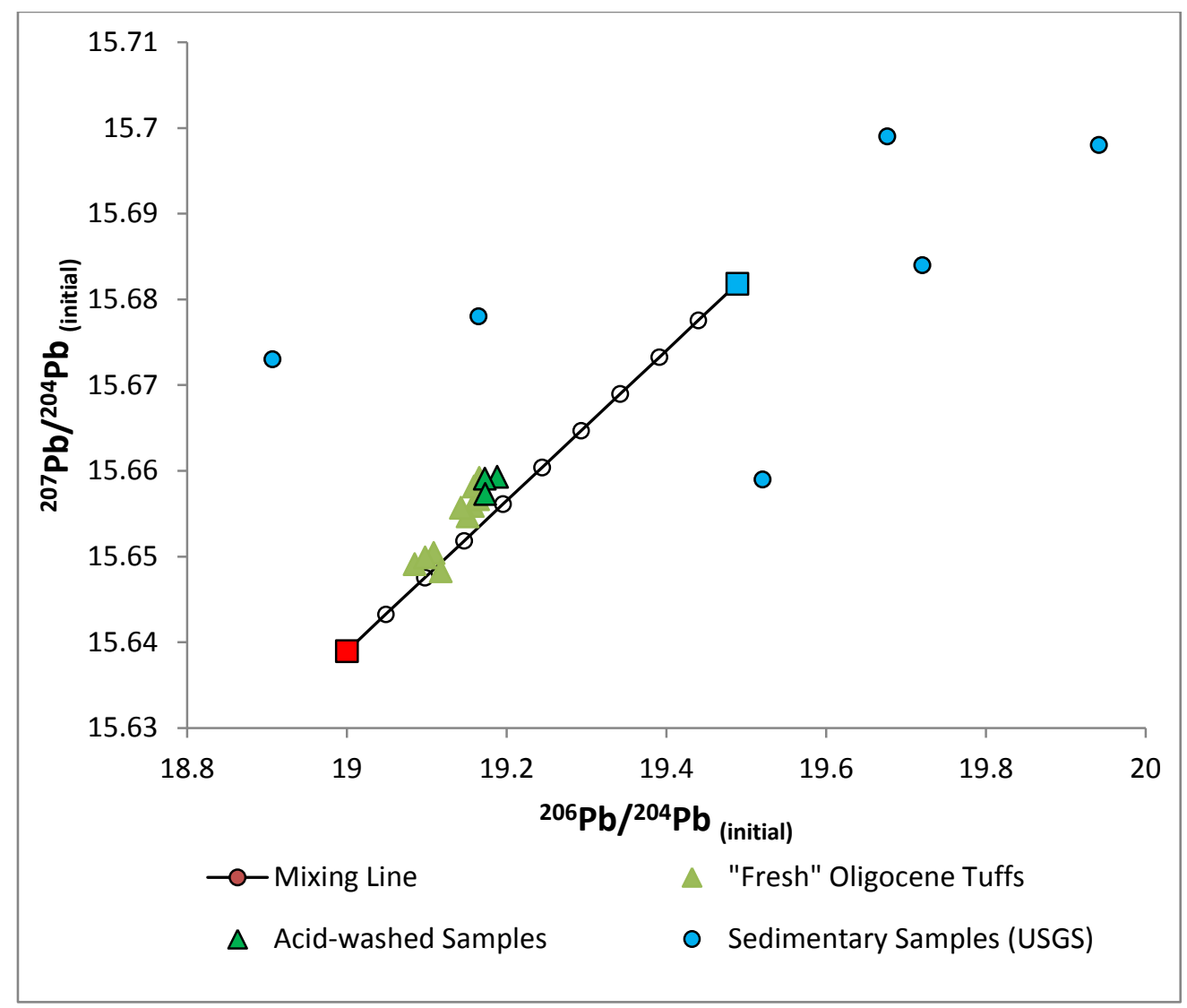

Figure 7.9: Initial ${ }^{207} \mathrm{~Pb} /{ }^{204} \mathrm{~Pb}$ vs. ${ }^{206} \mathrm{~Pb} /{ }^{204} \mathrm{~Pb}$ for the Underdown Caldera ignimbrites compared to mixing between a Miocene lava (red square) (17-SML-11) and an average of selected Paleozoic sedimentary rocks (blue square) (Stepner, 2017). The individual sedimentary rocks which make up the average sedimentary composition are plotted to show the variance in $\mathrm{Pb}$ isotopic data for the sedimentary samples. Each open circle represents $10 \%$ increments of mixing. The mixing line represents purely binary mixing between the "mantle derived magma" and "crustal melt" and is one of the best obtained mixing lines with available data. The ignimbrites appear to be closer in composition to the mantle derived magma end-member. 


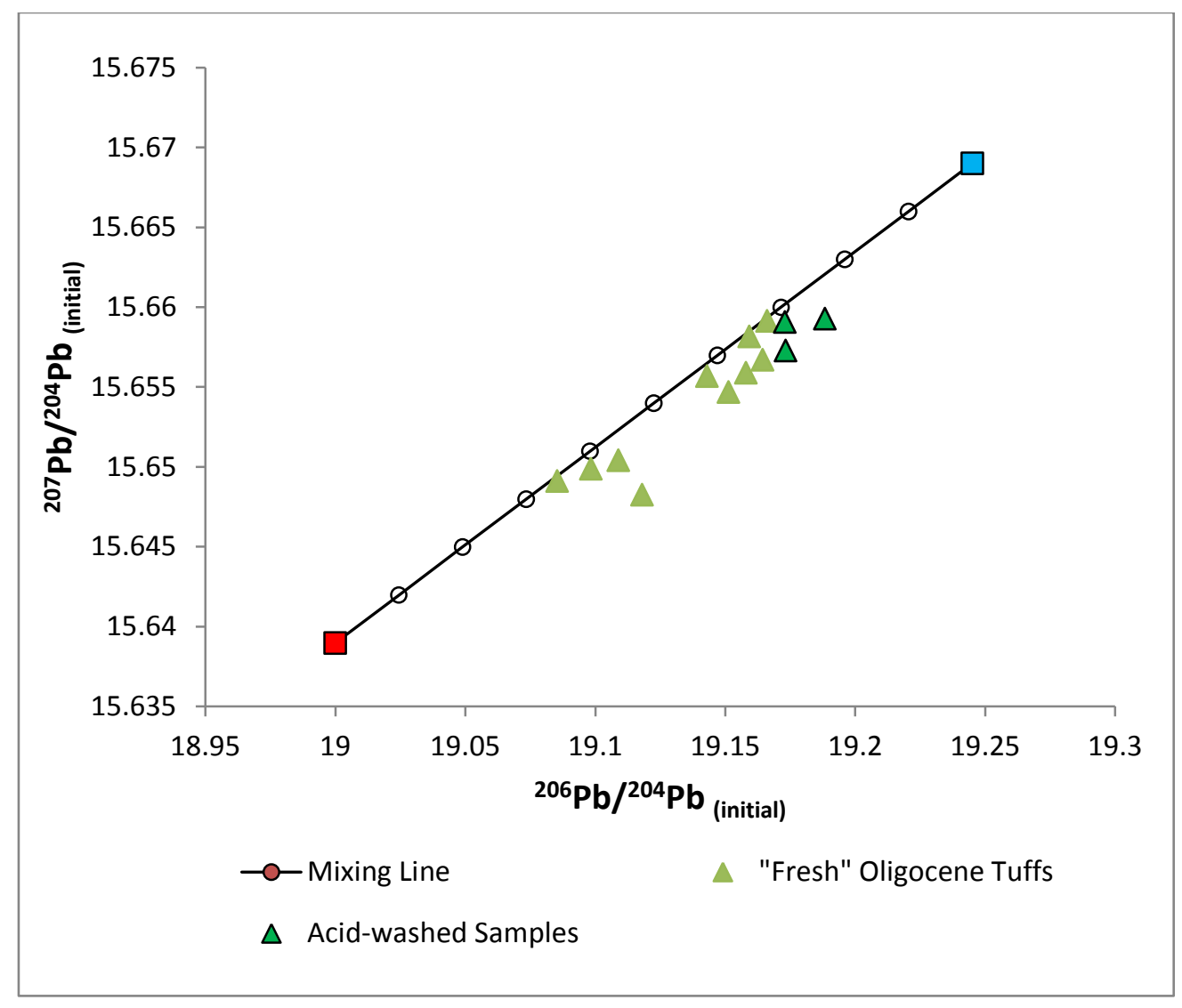

Figure 7.10: Initial ${ }^{207} \mathrm{~Pb} /{ }^{204} \mathrm{~Pb}$ vs. ${ }^{206} \mathrm{~Pb} /{ }^{204} \mathrm{~Pb}$ for the Underdown Caldera ignimbrites compared to mixing between a Miocene lava (red square) (17-SML-11) and a late Eocene pluton from the Northern Shoshone Range (blue square) (Cousens et al., 2019). Each open circle represents $10 \%$ increments of mixing. The mixing line represents purely binary mixing between the "mantle derived magma" and "crustal melt" and is the best obtained mixing line with available granitoid data. The Oligocene tuffs are assumed to originate from a melt which mixes material from a mantle derived source beneath the caldera and a local crustal unit. The ignimbrites plot in two groups along the mixing line. The first group plots between approximately $60-70 \%$ mantle component, and the second group plots between approximately 30-40\% mantle component. 


\subsubsection{Relationship of the Underdown Tuff, tuff of Clipper Gap, and Bonita Canyon Formation}

While it has been suggested that, based on its sedimentary textures, the Bonita Canyon Formation may be a reworked unit of the upper Underdown Tuff, isotopic results as well as the Th/La vs. $\mathrm{SiO}_{2}$ plot showing potential crustal addition (Fig. 7.7) suggest that the Bonita Canyon Formation and the Underdown Tuff are separate, related units. If the Bonita Canyon Formation was composed of reworked Underdown Tuff, the isotopic results between the two units would be identical which is not observed. Sr isotopic analysis of the Bonita Canyon pumice was affected by high LOI; however, as observed in Figures 7.1 and 7.2, the Bonita Canyon pumice appears more similar to the Underdown Tuff than the Bonita Canyon whole rock sample in the $\mathrm{Nd}$ and $\mathrm{Pb}$ isotopic systems. Based on the major element, trace element, and isotopic data of "fresh" samples, the Underdown Tuff and the Bonita Canyon Formation appear to be distinct units, however, new isotopic analyses of acid-washed Bonita Canyon pumice could provide a stronger comparison.

The tuff of Clipper Gap is interpreted to be related to the Underdown Tuff phase of volcanism in the Underdown Caldera Complex. The isotopic values of the Underdown Tuff, Bonita Canyon Formation, and the acid-washed tuff of Clipper Gap appear similar in most isotopic comparisons. However, the acid-washed tuff of Clipper Gap samples are more similar to the Underdown Tuff than the Bonita Canyon Formation. These isotopic similarities, as well as the unique presence of porphyritic pumice in the Underdown Tuff 
and tuff of Clipper Gap which is not observed in the Bonita Canyon Formation, supports the hypothesis that the tuff of Clipper Gap is correlative outflow of the Underdown Tuff.

\subsubsection{Identity of the Unnamed tuff}

The $24.755 \pm 0.037$ Ma Unnamed tuff (Henry, pers. comm., 2018), which as previously stated was mapped as the Tuff of Toiyabe by Bonham (1970), was compared to the true Tuff of Toiyabe with geochemical data from John (1974). A published age of the Tuff of Toiyabe is $23.31 \pm 0.05 \mathrm{Ma}$ (Henry and John, 2013), making the Tuff of Toiyabe notably younger than the Unnamed tuff from the Underdown Caldera complex.

While the samples from the Unnamed tuff and true Tuff of Toiyabe have similar petrographic descriptions (densely welded, phenocryst rich, phenocryst assemblage of plagioclase, sanidine, quartz and minor biotite and hornblende), and are both rhyolitic (Le Maitre et al., 1989), the Unnamed tuff has a higher $\mathrm{SiO}_{2}$ content than the Tuff of Toiyabe (Fig. 7.11). While major element bivariate plots show that the Tuff of Toiyabe and Unnamed tuff generally plot on the same trends between major element oxides and increasing $\mathrm{SiO}_{2}$ content, nearly all ignimbrites in the WNVF show these fractionation trends (Fig. 7.12) (Henry and John, 2013). The Tuff of Toiyabe also appears to show more compositional variation than the Unnamed tuff which generally appears relatively homogeneous. 


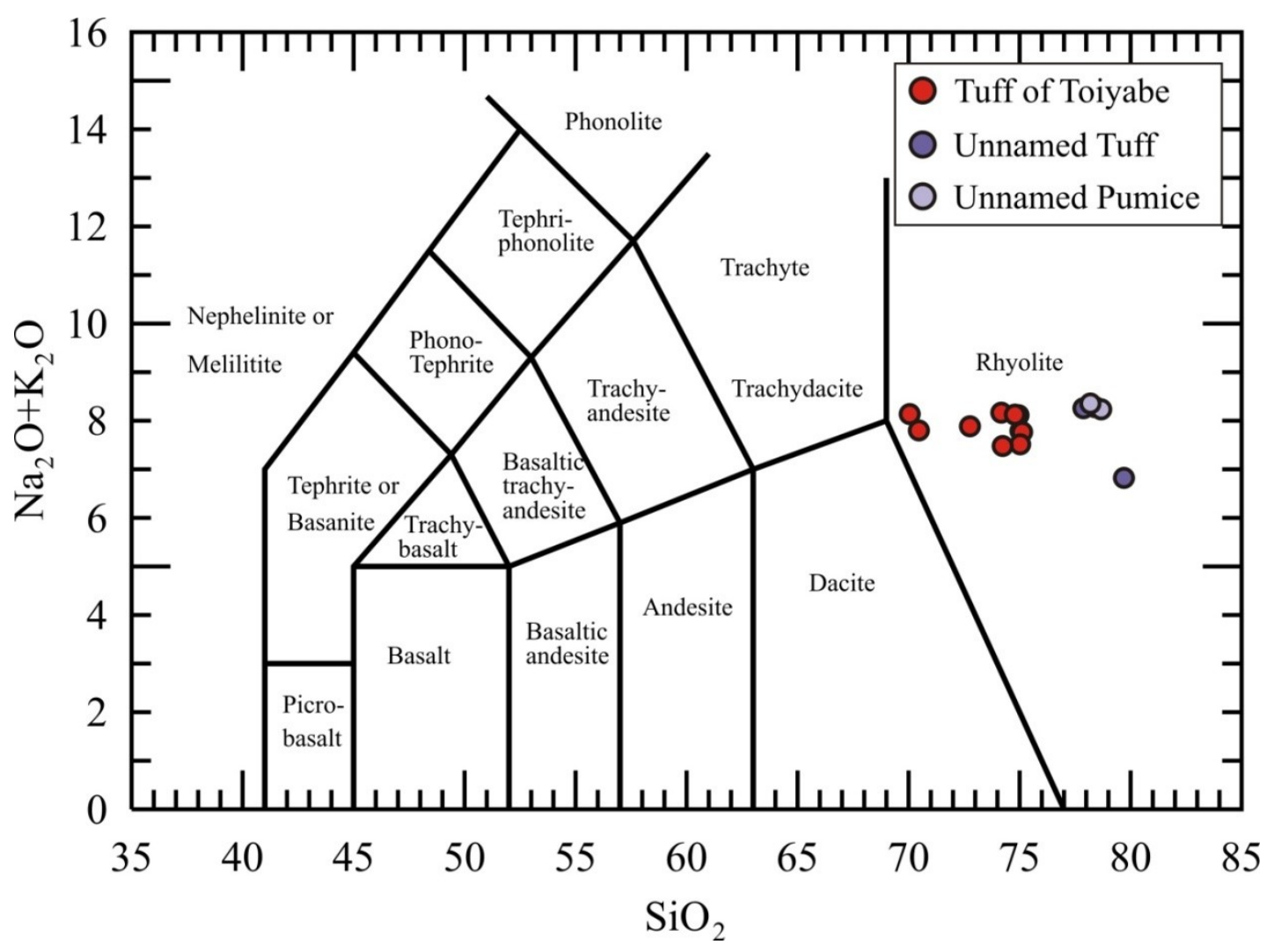

Figure 7.11: Total alkalis-silica diagram (Le Maitre et al., 1989) of the Unnamed tuff and the Tuff of Toiyabe (with data from John, 1974). Both groups of samples plot in the rhyolite field, however the Unnamed tuffs have higher $\mathrm{SiO}_{2}$ contents than the Tuff of Toiyabe. 

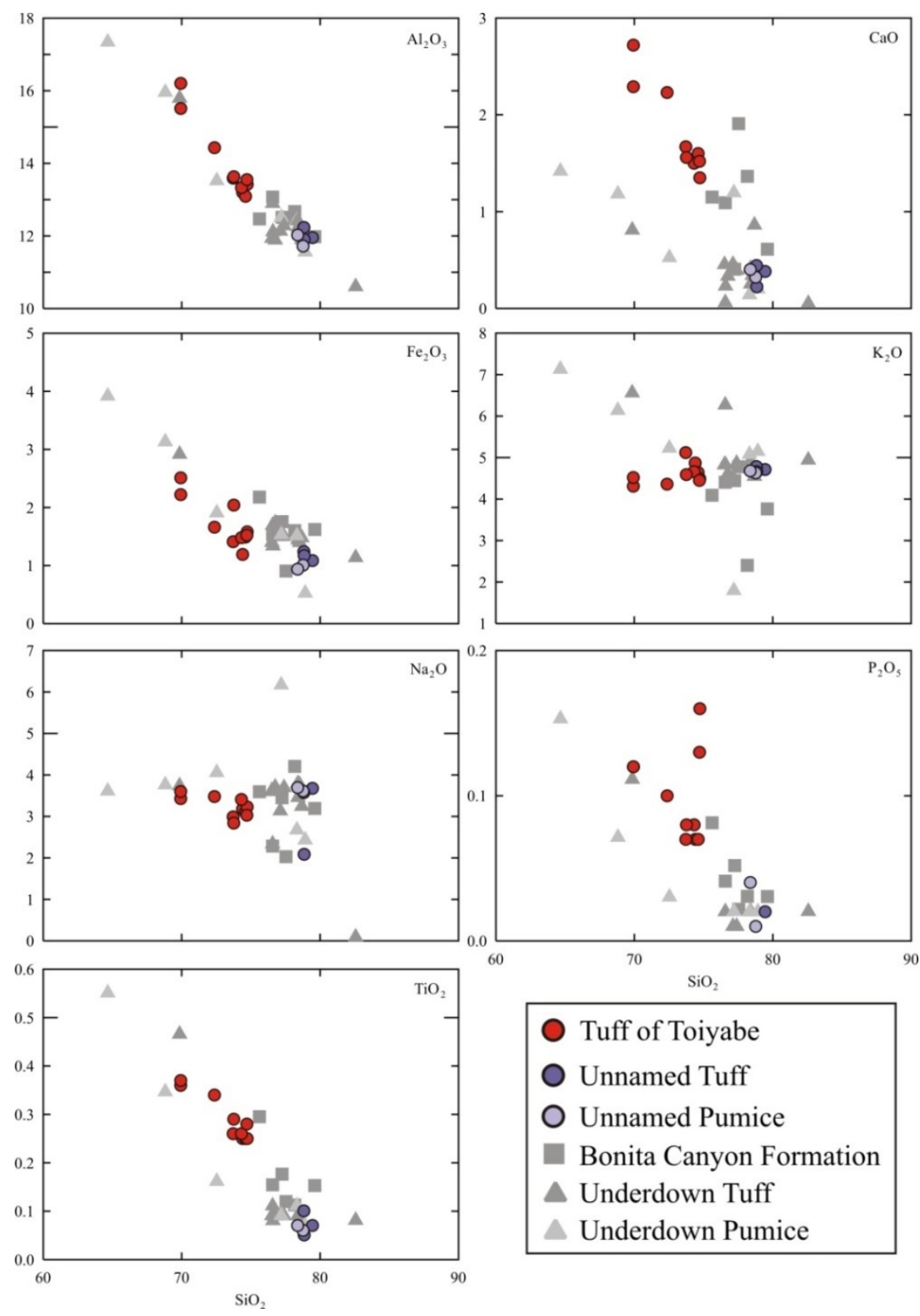

O Tuff of Toiyabe

O Unnamed Tuff

O Unnamed Pumice

Bonita Canyon Formation

$\triangle$ Underdown Tuff

Underdown Pumice

Figure 7.12: Major element variation diagrams comparing the Unnamed tuff with the Tuff of Toiyabe (with data from John, 1974), as well as the Underdown Tuff and Bonita Canyon Formation for reference. The Unnamed tuff and Tuff of Toiyabe plot in similar fractionation trends in all major element oxides, however these trends are similar for most ignimbrites in the Western Nevada Volcanic Field (Henry and John, 2013), as well as in the Underdown Tuff and Bonita Canyon Formation. The Tuff of Toiyabe appears to show more compositional variation than the Unnamed tuff in most major element oxides. 
Trace element data from the Unnamed tuff shows some similarities to the Tuff of Toiyabe. Only Ba, Ce, La, Nb, Sr, Y, and $\mathrm{Zr}$ trace element values were published for the Tuff of Toiyabe (John, 1974) as data collection was completed using XRF (x-ray fluorescence), therefore trace element variation diagrams were made based on those elements (Fig. 7.13). With increasing $\mathrm{SiO}_{2}$ content, $\mathrm{Ba}$ and $\mathrm{Sr}$ decrease, $\mathrm{Nb}$ increases, and $\mathrm{Ce}, \mathrm{La}, \mathrm{Sr}, \mathrm{Y}$, and $\mathrm{Zr}$ show a combination of scattering and clustering. For trace elements that show a trend with $\mathrm{SiO}_{2}$, the Unnamed tuff does show trends in common with the Tuff of Toiyabe. However, due to the difference in $\mathrm{SiO}_{2}$ content, compositional gaps exist between the two units. As observed in the major element bivariate diagrams, the Tuff of Toiyabe appears to show more compositional variation than the Unnamed tuff in Ba and Sr.

Averages of the Unnamed tuff, Unnamed tuff pumice and Tuff of Toiyabe were plotted on a primitive mantle normalized trace element diagram along with the average Underdown Tuff for comparison, with primitive mantle data from Sun and McDonough (1989) (Fig. 7.14). The primitive mantle normalized pattern of the Unnamed tuff shows more similarity to the average Underdown Tuff than the average Tuff of Toiyabe. In particular, the Tuff of Toiyabe lacks characteristic negative anomalies in Ba and Sr that are observed in all of the Underdown Caldera ignimbrites. The Unnamed tuff also has a more similar $\mathrm{Nb}$ concentration to the Underdown Tuff which is characteristically high in the Underdown Tuff and tuff of Clipper Gap compared to most Great Basin ignimbrite units (> 20 ppm; Henry and John, 2013). 

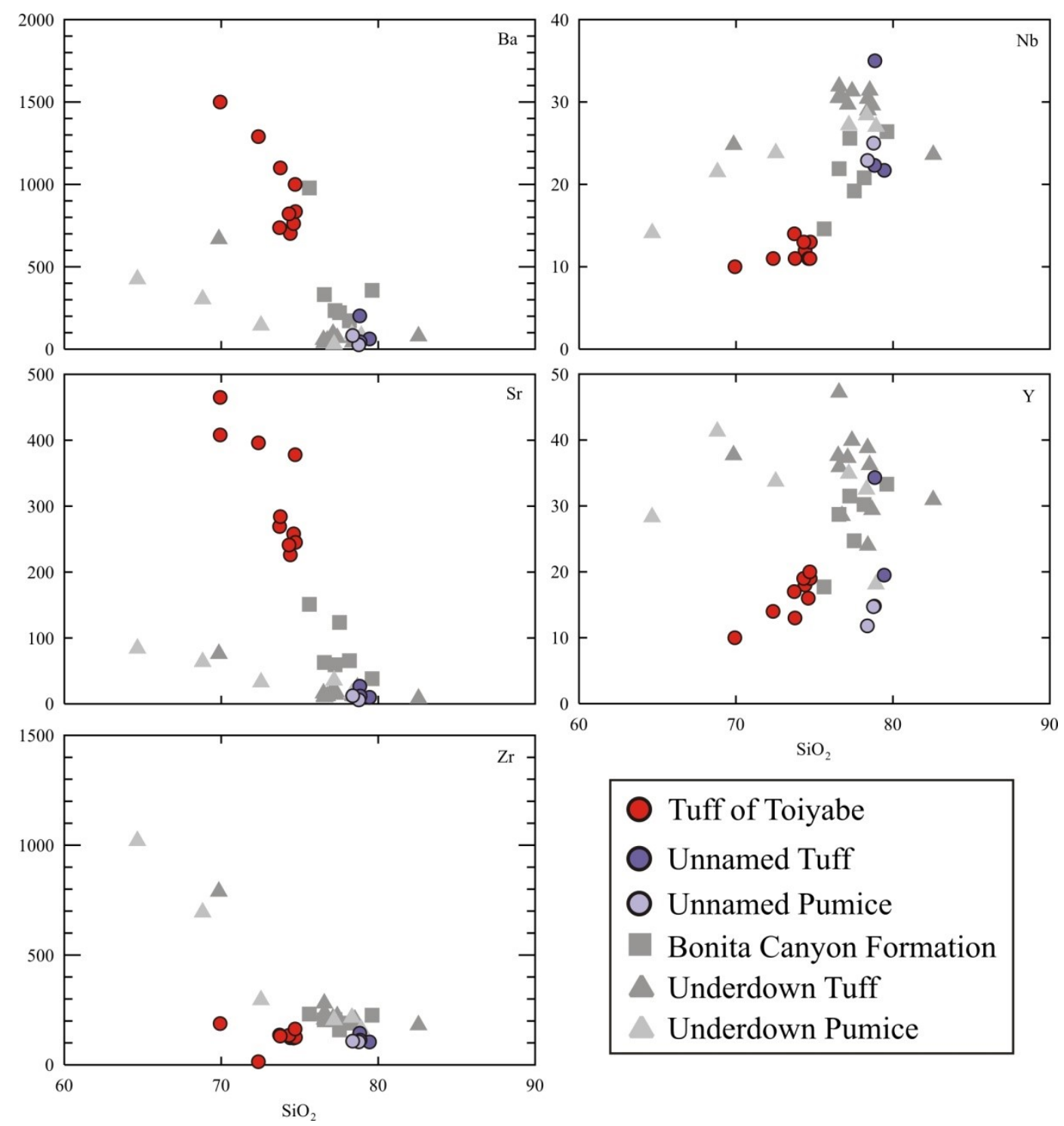

O Tuff of Toiyabe

O Unnamed Tuff

O Unnamed Pumice

Bonita Canyon Formation

Underdown Tuff

Underdown Pumice

Figure 7.13: Trace element variation diagrams comparing the Unnamed tuff with the Tuff of Toiyabe (with data from John, 1974), as well as the Underdown Tuff and Bonita Canyon Formation for reference. The Unnamed tuff could plot on a fractionation trend with the Tuff of Toiyabe in Ba and Sr, but appears to plot differently in all other trace elements. The Tuff of Toiyabe shows more compositional variation in Ba and Sr. 


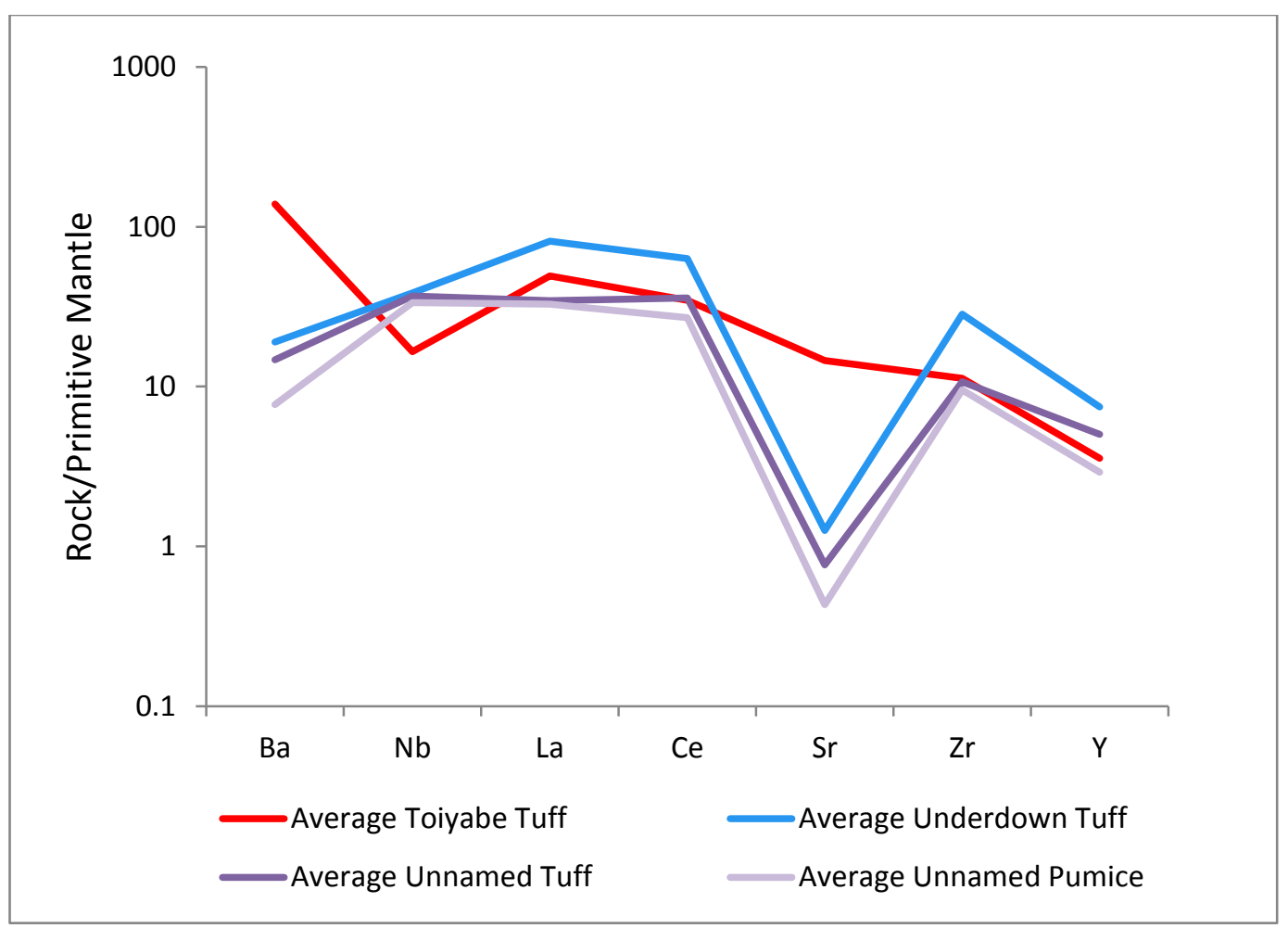

Figure 7.14: Primitive mantle normalized trace element diagram (Sun and McDonough, 1989) of the average trace element concentrations of the Tuff of Toiyabe, Unnamed tuff, Unnamed pumice, and Underdown Tuff, using a limited amount of trace element data available from John (1974). The Unnamed tuff and pumice show more similarity to the Underdown Tuff than the Tuff of Toiyabe. The average Tuff of Toiyabe lacks characteristic negative $\mathrm{Ba}$ and $\mathrm{Sr}$ anomalies in the Unnamed tuff and Underdown Tuff, and contains less $\mathrm{Nb}$. 
Strontium isotope data for the Tuff of Toiyabe were plotted with the "fresh" ignimbrites from the Underdown Caldera complex as well as acid-washed tuff of Clipper Gap samples and the Miocene lavas (Fig. 7.15). Only Sr isotope data were available from John (1974), therefore the data were plotted in initial ${ }^{87} \mathrm{Sr} /{ }^{86} \mathrm{Sr}$ versus $1 / \mathrm{Sr}$ concentration and initial ${ }^{87} \mathrm{Sr} /{ }^{86} \mathrm{Sr}$ versus $\mathrm{SiO}_{2}$ content comparisons. In both diagrams, the Tuff of Toiyabe and the Unnamed tuff appear to be distinct however, both overlap the Underdown Caldera ignimbrites in when comparing ${ }^{87} \mathrm{Sr} /{ }^{86} \mathrm{Sr}$ versus $\mathrm{SiO}_{2}$ content. Due to very low $\mathrm{Sr}$ concentration for the Unnamed Tuff, the isotope comparison is likely inconclusive.

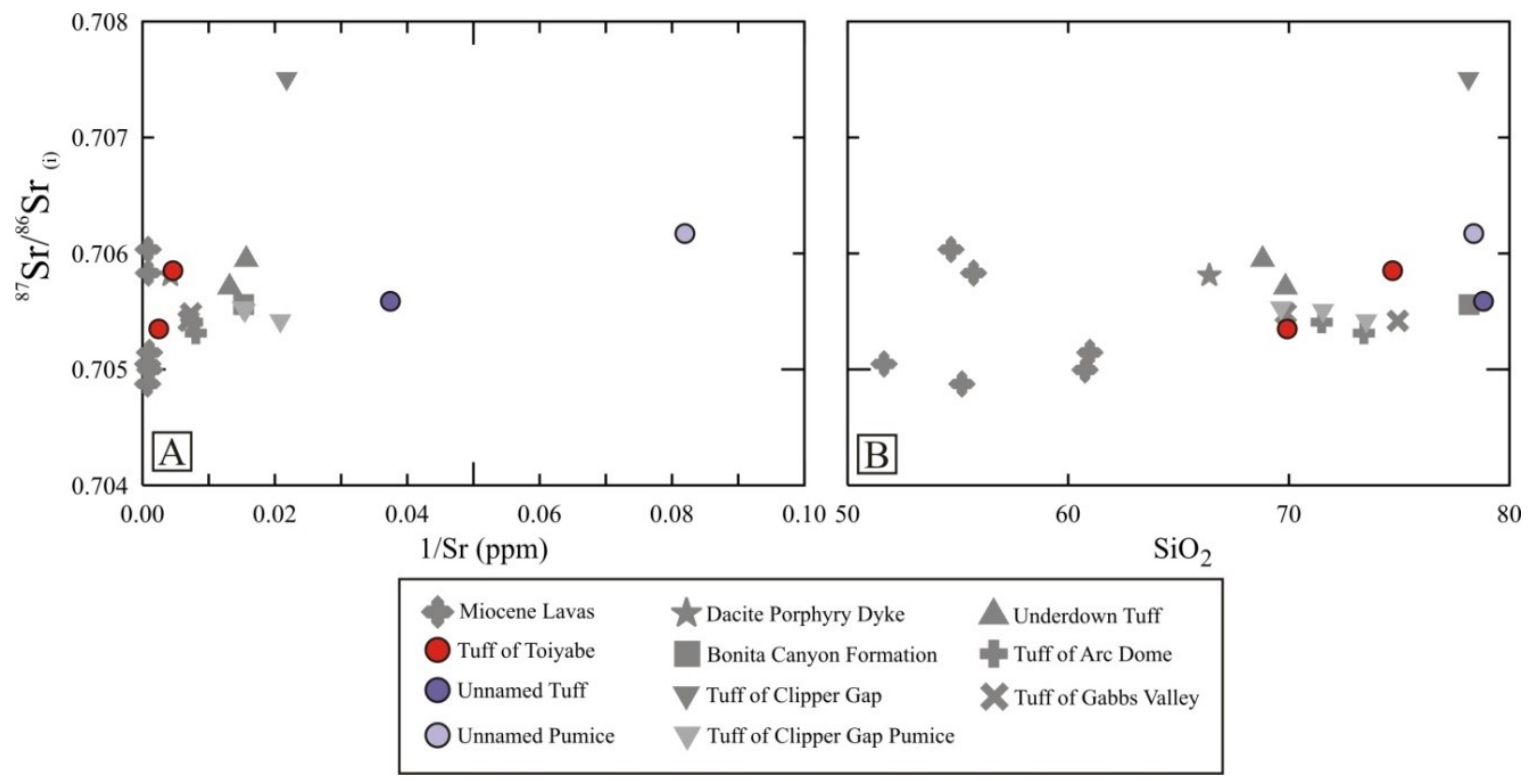

Figure 7.15: Initial ${ }^{87} \mathrm{Sr} /{ }^{86} \mathrm{Sr}$ versus $1 / \mathrm{Sr}$ concentration (A) and $\mathrm{SiO}_{2}$ content (B) showing the $\mathrm{Sr}$ isotope data for the Tuff of Toiyabe and Unnamed tuff (with isotope data from John, 1974). The "fresh" ignimbrites have also been plotted along with acid-washed tuff of Clipper Gap samples and the Miocene lavas. The Sr isotopic ratios of the Unnamed Tuff do not overlap with the Tuff of Toiyabe, and appear more similar to the Bonita Canyon Formation in panel (B). However, the Unnamed tuff suffers from low $\mathrm{Sr}$ concentration, therefore the $\mathrm{Sr}$ isotopic ratios may be questionable. 
Based on the differences in geochemistry, as well as the notable age difference, and the opposite paleomagnetic polarity of the Unnamed tuff to the Tuff of Toiyabe (Best et al., 2013), the Unnamed tuff is likely a distinct ash flow tuff unit of the Underdown Caldera as opposed to a unit from the Tuff of Toiyabe. While the degree of welding and the mineral assemblage of the Unnamed tuff does bear similarities to what is described in the Tuff of Toiyabe, the units are most likely two different ash flow tuff units in the WNVF. 


\subsection{Cerium Anomalies in the tuff of Clipper Gap}

In earlier sections, samples from the tuff of Clipper Gap that have a negative or positive Ce anomaly were removed from the dataset. This section will investigate these samples and the potential cause of the Ce anomaly. Most samples that contain a Ce anomaly are from the Tuff of Clipper Gap, however, there is one sample of the tuff of Brunton Pass which also shows a negative Ce anomaly. This section will focus on samples from the Tuff of Clipper Gap as they provide a closely comparable suite of samples to study. Rock samples with Ce anomalies are termed "anomalous REE samples", and include whole rock and porphyritic pumice samples.

\subsubsection{REE chemistry of the anomalous samples}

As the REEs in the anomalous samples are what make them questionable, they will be discussed first. In a chondrite normalized rare earth element plot, the anomalous REE samples show more enrichment in the LREEs relative to the HREEs than was observed in the average non-anomalous whole rock sample (Fig. 7.16A). The patterns show negative Ce anomalies in most samples, a positive Ce anomaly in one sample, and large negative Eu anomalies in all samples. Most anomalous REE porphyritic pumice samples are more enriched in LREEs than the anomalous REE whole rock samples (except one porphyritic pumice), and show a steeper slope to the HREEs than the anomalous REE whole rock and other anomalous REE porphyritic pumice sample which show flattened patterns. In an extended primitive mantle normalized trace element plot, the samples are enriched in LILEs, show large negative anomalies in Ba and $\mathrm{Sr}$, and large positive anomalies in La 
and $\mathrm{Pb}$ (Fig. 7.16B). Differences in $\mathrm{Nb}-\mathrm{Ta}$ anomalies exist between the anomalous REE porphyritic pumice, anomalous REE whole rock samples, and the average nonanomalous whole rock sample.
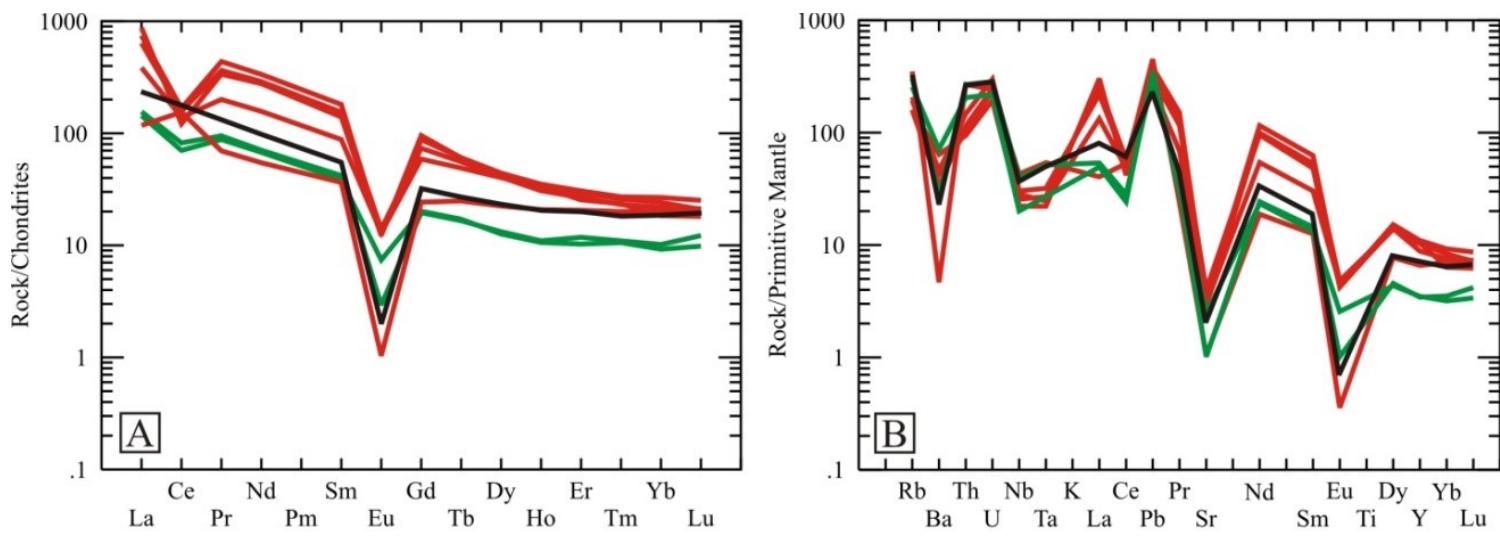

- Anomalous REE Tuff of Clipper Gap (whole rock)

- Anomalous REE Tuff of Clipper Gap porphyritic pumice

- Non-anomalous REE Tuff of Clipper Gap (whole rock - 17-SM-11)

Figure 7.16: (A) Chondrite normalized rare earth element diagram for the anomalous REE samples. Either a positive or negative Ce anomaly can be seen in the whole rock and porphyritic pumice samples, as well as the typical Eu anomaly observed in the nonanomalous tuff of Clipper Gap samples. The porphyritic pumice samples with negative Ce anomalies appear to be more enriched in most REEs than the whole rock samples and porphyritic pumice sample with a positive Ce anomaly. (B) Primitive mantle normalized trace element diagram. Porphyritic pumice samples with negative $\mathrm{Ce}$ anomalies have much higher La concentrations than the whole rock samples and porphyritic pumice sample with a positive Ce anomaly. In both diagrams, a nonanomalous REE sample is plotted for comparison (chondrite and primitive mantle normalizing values from Sun and McDonough, 1989). 


\subsubsection{Major element geochemistry of the anomalous samples}

In a TAS diagram, the anomalous REE samples plot in two groups in the rhyolite and trachyte fields (Fig. 7.17, Le Maitre et al., 1989). The porphyritic pumice samples with negative Ce anomalies plot in the trachyte field. The whole rock samples and porphyritic pumice sample with a positive $\mathrm{Ce}$ anomaly plot in the rhyolite field at higher $\mathrm{SiO}_{2}$ and lower alkali contents than the porphyritic pumice in the trachyte field.

Major element oxides of the anomalous REE samples were plotted in comparison to the non-anomalous Underdown Tuff and tuff of Clipper Gap samples (Fig. 7.18). While the anomalous REE whole rock samples and rhyolitic anomalous REE porphyritic pumice plot with the cluster of non-anomalous whole rock samples from the Underdown Tuff and tuff of Clipper Gap, the rest of the anomalous REE porphyritic pumice generally plot with the non-anomalous Underdown pumice samples (specifically, Underdown porphyritic pumice). The anomalous porphyritic pumice samples with negative Ce anomalies plot as a cluster, except for in $\mathrm{Al}_{2} \mathrm{O}_{3}, \mathrm{Fe}_{2} \mathrm{O}_{3}$, and $\mathrm{P}_{2} \mathrm{O}_{5}$ where more scatter is observed. 


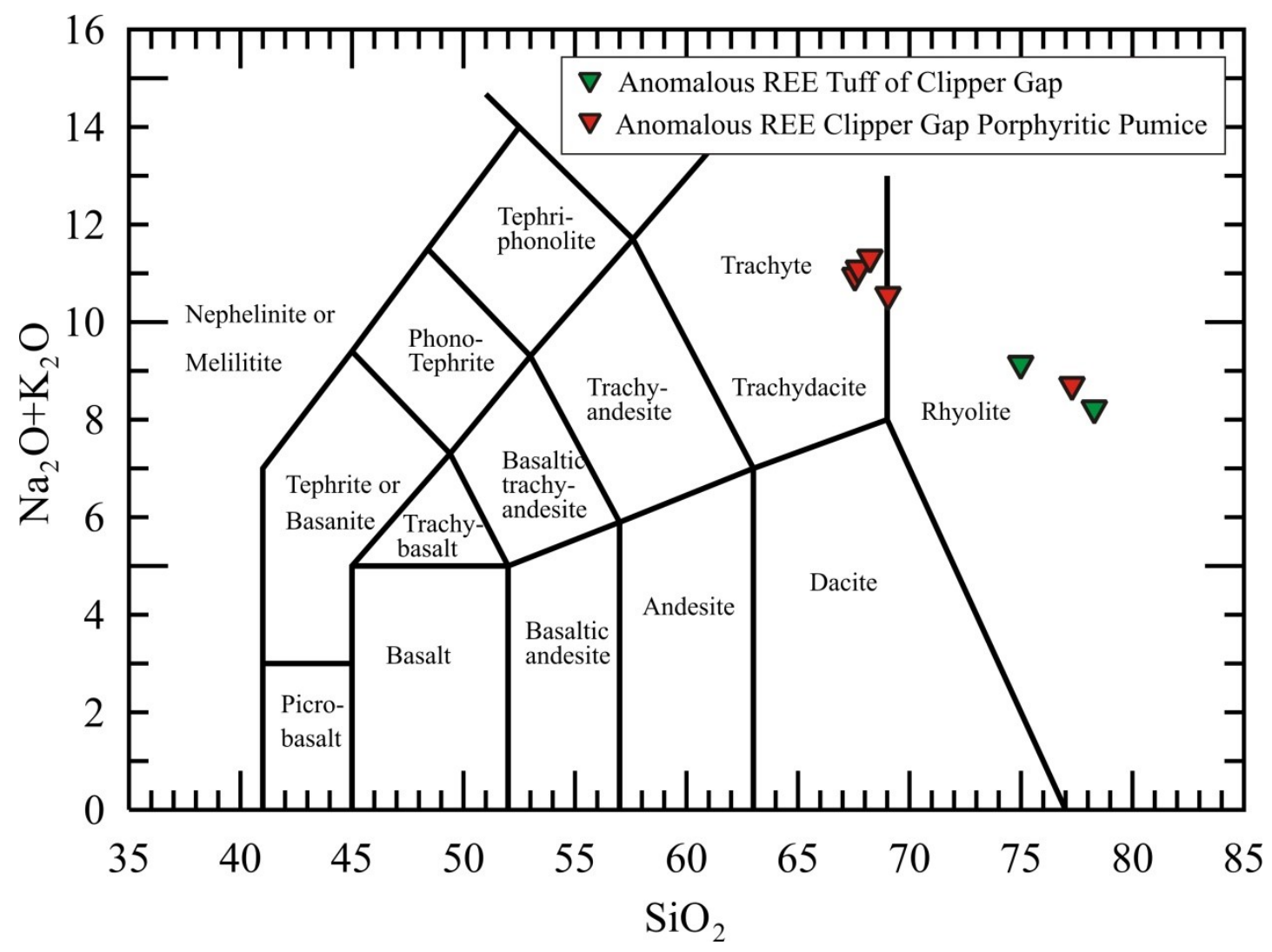

Figure 7.17: Total alkalis-silica diagram (Le Maitre et al., 1989) of the anomalous-REE samples from the Tuff of Clipper Gap shows the samples plotting in two groups in the rhyolite and trachyte fields, with the whole rock samples plotting exclusively in the rhyolite field and the porphyritic pumice samples plotting in both the trachyte and rhyolite fields. One sample of porphyritic pumice (with a positive Ce anomaly) plots in the rhyolite field with the whole rock samples while the rest of the porphyritic pumice samples (with negative $\mathrm{Ce}$ anomalies) plot exclusively in the trachyte field. 

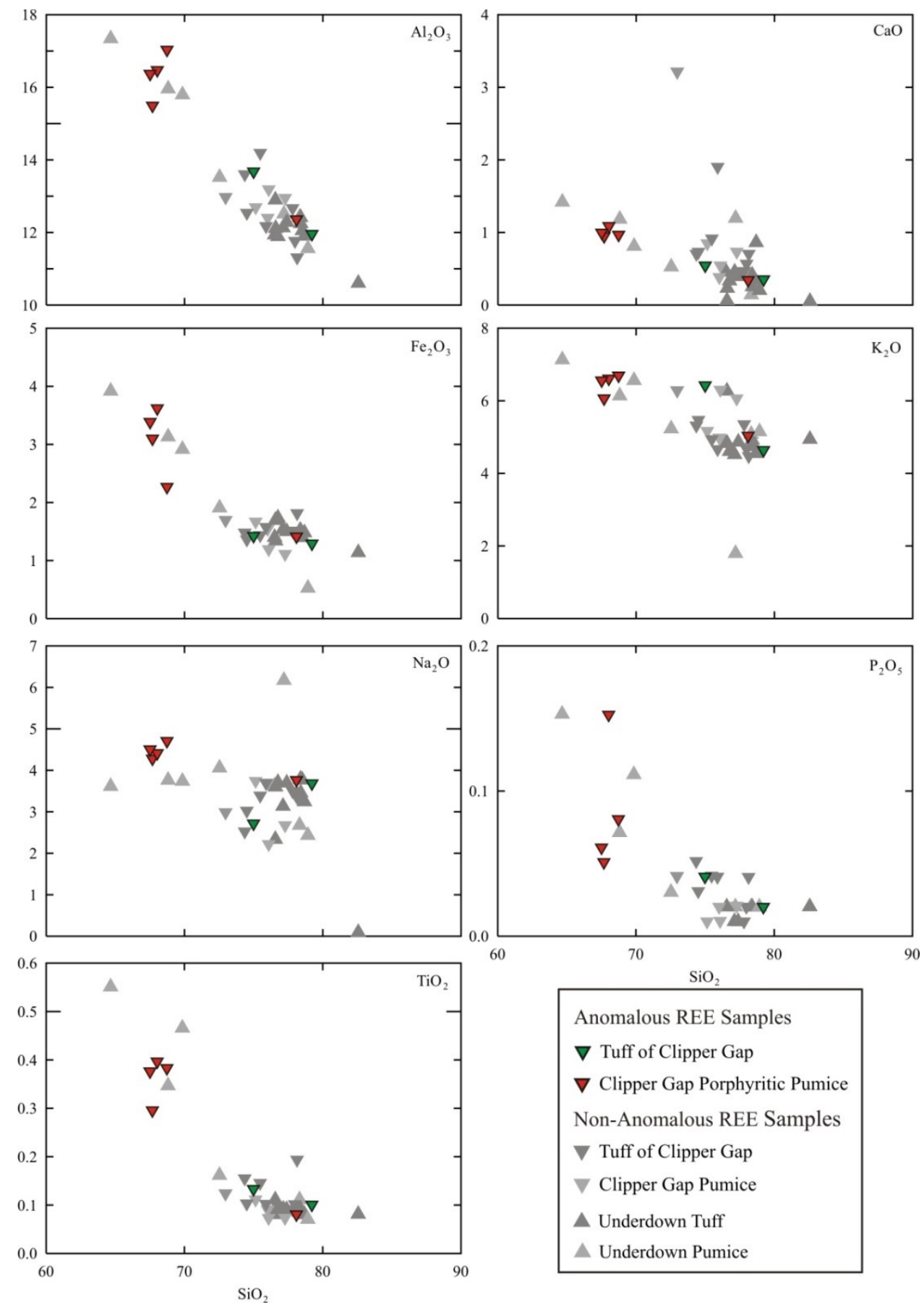

Anomalous REE Samples

$\boldsymbol{\nabla}$ Tuff of Clipper Gap

$\nabla$ Clipper Gap Porphyritic Pumice

Non-Anomalous REE Samples

$\nabla$ Tuff of Clipper Gap

$\nabla$ Clipper Gap Pumice

$\Delta$ Underdown Tuff

Anderdown Pumice

Figure 7.18: Major element oxides plotted versus $\mathrm{SiO}_{2}$ show that the trachyte samples plot as a cluster in half of the comparisons $\left(\mathrm{CaO}, \mathrm{K}_{2} \mathrm{O}\right.$, and $\left.\mathrm{Na}_{2} \mathrm{O}\right)$ and a scatter in the other half $\left(\mathrm{Al}_{2} \mathrm{O}_{3}, \mathrm{Fe}_{2} \mathrm{O}_{3}, \mathrm{P}_{2} \mathrm{O}_{5}\right.$, and $\left.\mathrm{TiO}_{2}\right)$. The rhyolitic porphyritic pumice sample which plots more similarly to the anomalous REE whole rock samples contains a positive $\mathrm{Ce}$ anomaly. 


\subsubsection{Trace element geochemistry of the anomalous samples}

The anomalous REE samples of the tuff of Clipper Gap were plotted in comparison to the Underdown Tuff and non-anomalous tuff of Clipper Gap samples on trace element bivariate diagrams versus $\mathrm{SiO}_{2}$. Similar to the major element oxide bivariate diagrams, the anomalous REE porphyritic pumice samples plot close to the Underdown Tuff porphyritic pumice and the anomalous REE whole rock samples and anomalous REE rhyolitic porphyritic pumice sample plot with the cluster of Underdown Tuff and tuff of Clipper Gap whole rock data (Fig. 7.19). 

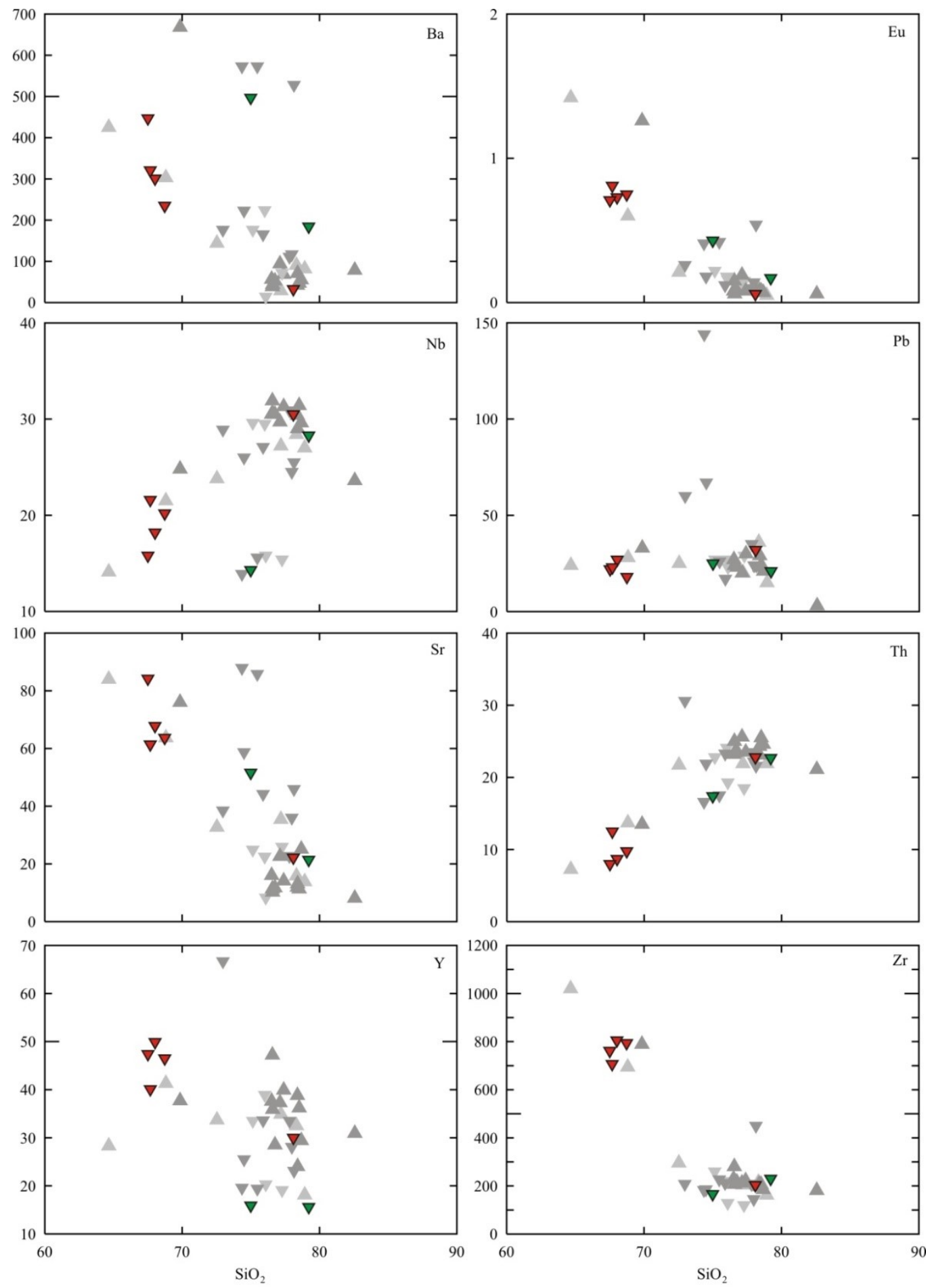

\begin{tabular}{|ll|}
\hline Anomalous REE Samples & Non-Anomalous REE Samples \\
$\nabla$ Tuff of Clipper Gap & $\nabla$ Tuff of Clipper Gap $\Delta$ Underdown Tuff \\
$\nabla$ Clipper Gap Porphyritic Pumice & $\nabla$ Clipper Gap Pumice $\quad \Delta$ Underdown Pumice \\
\hline
\end{tabular}


Figure 7.19: Trace element variation diagrams for the anomalous REE samples from the tuff of Clipper Gap, as well as the non-anomalous Underdown Tuff and tuff of Clipper Gap samples for comparison. Similar to the major element bivariate diagrams, the anomalous REE rhyolitic porphyritic pumice sample plots closer to the anomalous REE whole rock samples than the anomalous REE trachyte porphyritic pumice samples. 


\subsubsection{Effects of acid washing on anomalous REE samples}

Acid washing with $2.5 \mathrm{~N}$ hydrochloric acid $(\mathrm{HCl})$ for five days at 80 degrees Celsius was performed on a selection of the anomalous REE samples to determine whether the REE enrichment and observed Ce anomalies are geochemical characteristics of the tuff of Clipper Gap or are caused by the presence of a secondary phase in the rocks. These secondary phases would be removed by the acid washing process, however it is important to note that primary phases may also be removed by acid washing (eg. apatite, Fe-Ti oxides). Three samples without anomalous REEs were included in the selection of samples along with four anomalous REE samples to compare the effect of the acid washing process on non-anomalous samples. Table 7.1 lists the samples that were acid-washed and whether they show a negative, positive, or no Ce anomaly.

\begin{tabular}{cccc}
\hline \multicolumn{4}{c}{ Table 7.1: Clipper Gap samples selected for acid washing } \\
\hline Sample Number & Unit & Sample Type & Ce Anomaly \\
\hline 16-SM-13C & Tuff of Clipper Gap & Whole Rock & None \\
16-SM-14 & Tuff of Clipper Gap & Porphyritic Pumice & Positive \\
16-SM-16 & Tuff of Clipper Gap & Porphyritic Pumice & Negative \\
17-SM-21A & Tuff of Clipper Gap & Porphyritic Pumice & Negative \\
17-SM-22 & Tuff of Clipper Gap & Vitrophyre & None \\
17-SM-26A & Tuff of Clipper Gap & White Pumice & None \\
17-SM-26C & Tuff of Clipper Gap & Porphyritic Pumice & Negative \\
\hline
\end{tabular}

Table 7.1: Samples selected for the acid washing process, including porphyritic pumice, white pumice, whole rock and vitrophyre samples. Three anomalous REE-enriched porphyritic pumice samples show a negative $\mathrm{Ce}$ anomaly while one shows a positive $\mathrm{Ce}$ anomaly. Non-anomalous samples selected for the acid washing process include a whole rock, vitrophyre, and white pumice samples. 


\section{Geochemical Results}

Geochemical analyses of the acid-washed samples have been compared to the geochemical data for the same unwashed samples to show the effect of acid washing on major and trace element concentrations, as well as isotopic values.

\section{Major Elements}

Major element data for the acid-washed samples is listed in Appendix I, Table IV. Major element oxide contents in the acid-washed samples were normalized to the same major element contents in the unwashed samples and plotted by major element oxide for each sample (Fig. 7.20). This shows how the weight percentage of the major element oxide has changed due to the acid washing process. This analysis does not assume that any major element oxide is completely immobile. Major element oxides plotting at 1.0 showed no change in the concentration after acid washing.

After acid washing, $\mathrm{Al}_{2} \mathrm{O}_{3}, \mathrm{~K}_{2} \mathrm{O}, \mathrm{Na}_{2} \mathrm{O}$, and $\mathrm{SiO}_{2}$ remained unchanged in all samples. The percentage of $\mathrm{CaO}$ which was removed from samples shows the most variation of all major element oxides and ranges between $10-70 \% . \mathrm{Fe}_{2} \mathrm{O}_{3}$ was removed from all samples and shows a decrease of $60-70 \% . \mathrm{P}_{2} \mathrm{O}_{5}$ was heavily depleted in all samples except 16 SM-13C, with decreases in concentration ranging from $70-100 \%$. $\mathrm{TiO}_{2}$ showed a depletion of $5-25 \%$ in the samples. 


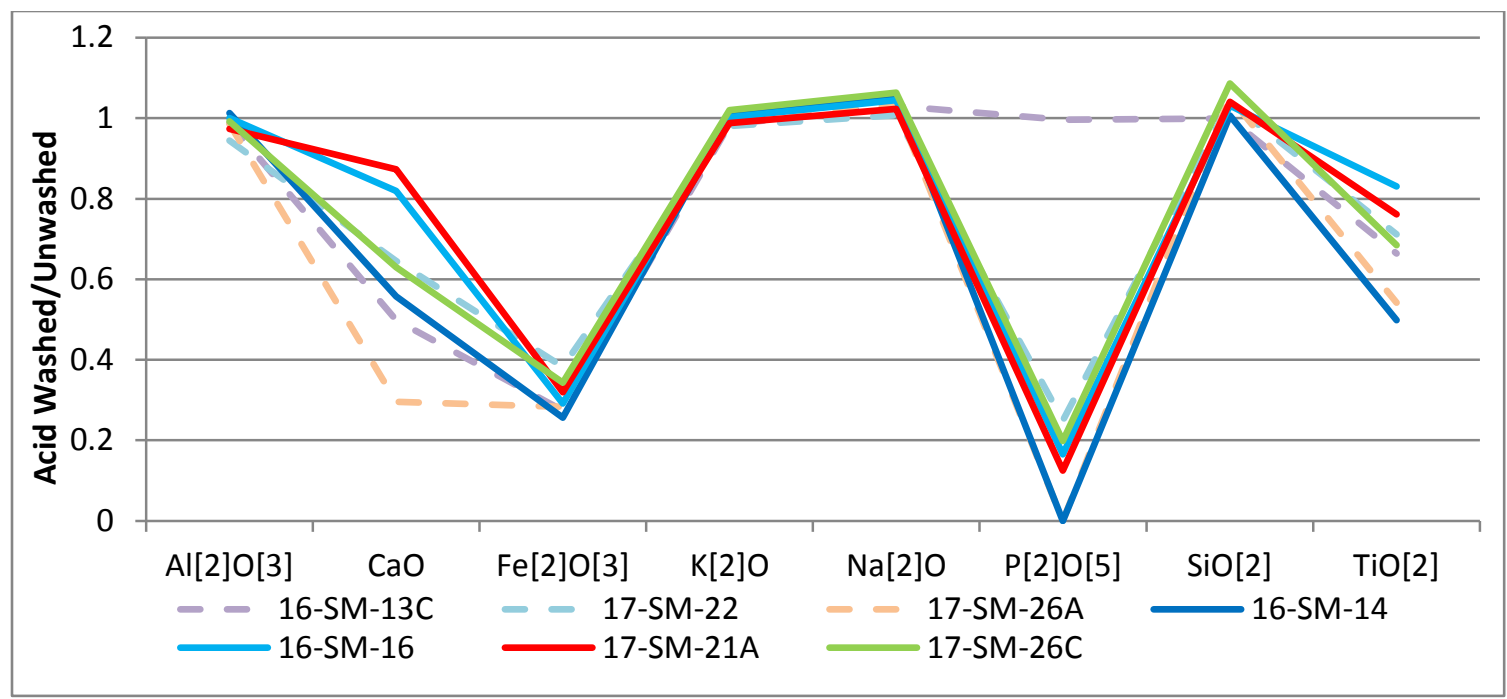

Figure 7.20: A line diagram showing the effect of acid washing on the major element oxides of the anomalous REE samples and non-anomalous REE samples. Non-anomalous REE samples are represented by dashed lines while anomalous REE samples are represented by solid lines. $\mathrm{Al}_{2} \mathrm{O}_{3}, \mathrm{~K}_{2} \mathrm{O}, \mathrm{Na}_{2} \mathrm{O}$, and $\mathrm{SiO}_{2}$ largely remained the same after acid washing. However, $\mathrm{CaO}, \mathrm{Fe}_{2} \mathrm{O}_{3}$, and $\mathrm{P}_{2} \mathrm{O}_{5}$ show large decreases in concentration after acid washing. $\mathrm{TiO}_{2}$ shows a small to moderate decrease in concentration after acid washing. 


\section{Trace Elements}

Trace element data for the acid-washed samples is listed in Appendix I, Table VI. In a chondrite normalized REE diagram, acid washing has caused the LREEs in the acidwashed samples to become depleted relative to the LREEs in the unwashed samples (Fig. 7.21). A decreasing slope towards the HREEs still exists, however the middle REEs are being strongly depleted which has caused a concave-upward curve in the middle to heavy REEs. The negative Ce anomaly is completely removed from almost all samples after acid washing, except for sample 16-SM-16 which still shows a small negative anomaly. The positive Ce anomaly in sample 16-SM-14 has also been removed by acid washing. After acid washing, the negative Eu anomaly generally becomes smaller, and in some samples, the negative Eu anomaly has disappeared or become slightly positive. However, the actual normalized value of Eu in most samples remains unchanged from before acid washing. Certain trace element concentrations in the acid-washed samples were also normalized to the trace element concentrations of the unwashed samples and plotted on a line graph for comparison (Fig. 7.22). Neodymium, Y, Yb, Sr, Sm, U and Th show a decrease in concentration after acid washing. Zirconium and Rb show little to no decrease in concentration. 

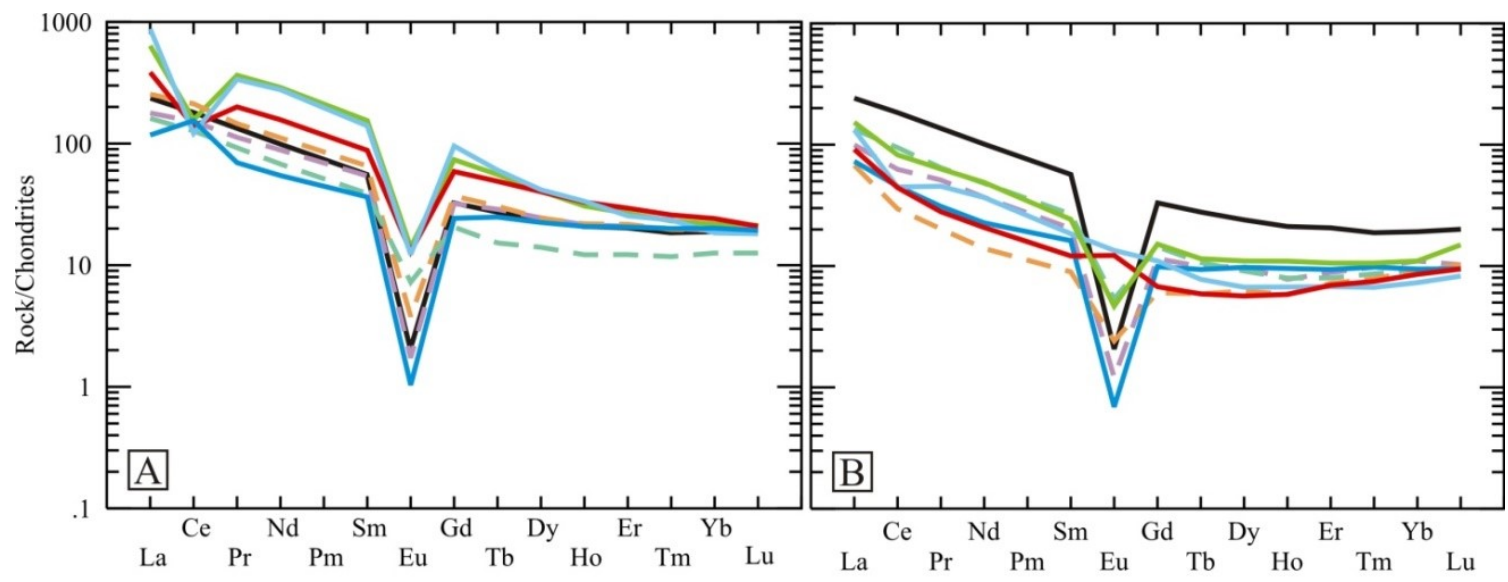

\begin{tabular}{|lll}
\hline Anomalous REE samples & Non-anomalous REE samples & $\begin{array}{l}\text { Un-acid-washed Non- } \\
\text { anomalous REE sample }\end{array}$ \\
\hline 16-SM-14 & $--16-$ SM-13C & $-16-S M-11$ \\
16-SM-16 & $--17-S M-22$ & \\
17-SM-21A & $--17-S M-26 \mathrm{~A}$ & \\
\hline 17-SM-26C & & \\
\hline
\end{tabular}

Figure 7.21: Chondrite normalized REE diagrams for the acid-washed samples before (A) and after acid washing (B). The acid washing process has removed the Ce anomaly almost entirely, except for sample 16-SM-16 which still shows a small negative anomaly. A concave-upward curvature is observed in the middle to heavy REEs, suggesting that a middle REE-loving phase is being removed during acid washing (likely apatite due to the complete loss of $\mathrm{P}_{2} \mathrm{O}_{5}$ during acid washing). The Eu anomaly also appears to become smaller after acid washing (normalizing values from Sun and McDonough, 1989). 


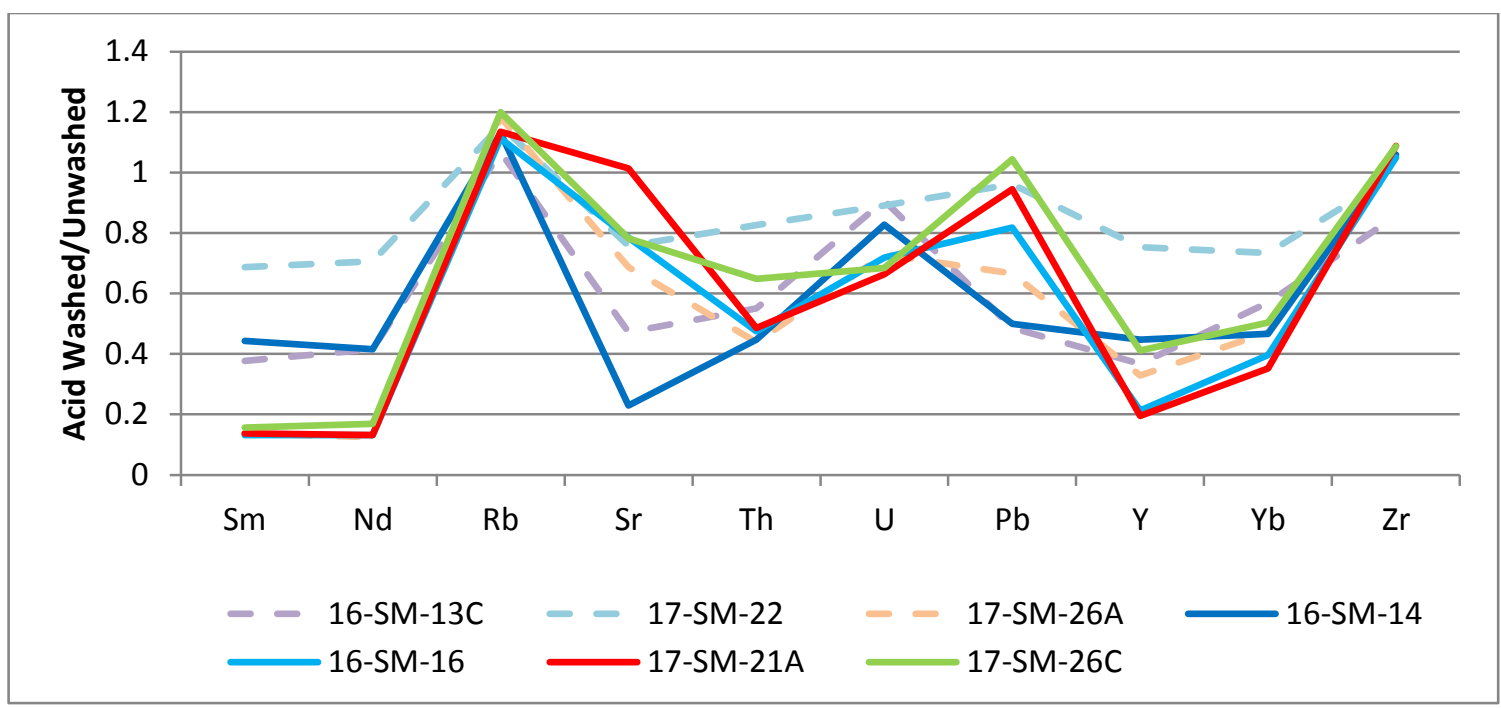

Figure 7.22: A line diagram showing the change in trace element concentration after the acid washing process. Non-anomalous REE samples are represented by dashed lines while anomalous REE samples are represented by solid lines. The anomalous REE and non-anomalous REE samples show little to no depletion of $\mathrm{Rb}$ and $\mathrm{Zr}$. The most highly depleted trace elements in the anomalous REE samples are $\mathrm{Sm}, \mathrm{Nd}, \mathrm{Y}$, and $\mathrm{Yb}$. The anomalous REE samples are depleted to various degrees in $\mathrm{Sr}$ and $\mathrm{Pb}$, with $\mathrm{Sr}$ showing the most variation between anomalous REE samples. The anomalous REE samples are moderately depleted in Th and $U$. The non-anomalous REE samples are moderately depleted in most trace elements, however the degree of depletion varies among individual samples. In some trace elements, the non-anomalous REE samples are depleted to the same degree as the anomalous REE samples. Of the anomalous REE samples, the three porphyritic pumice with negative Ce anomalies (16-SM-16, 17-SM21A, 17-SM-26C) show similar patterns of trace element depletion, while sample 16-SM14 (anomalous REE porphyritic pumice with a positive Ce anomaly) shows a different pattern of depletion. 


\section{Isotope Geochemistry}

Isotopic data for the acid-washed samples is listed in Appendix I, Table VIII. Four acidwashed samples were analyzed isotopically, and the initial isotopic values were compared to the initial isotopic values for the same unwashed samples to observe any changes in isotopic ratio after acid washing. When comparing initial ${ }^{87} \mathrm{Sr} /{ }^{86} \mathrm{Sr}$ isotopic values to the concentration of $\mathrm{Sr}$, there is a negative correlation seen in all samples except for 17-SM-21A in which the isotopic value decreases but the Sr concentration shows no change (Fig. 7.23). After acid washing, the samples have consistently lower initial ${ }^{87} \mathrm{Sr} /{ }^{86} \mathrm{Sr}$ isotopic ratios which decrease to approximately the same ratio for all samples. This new isotopic value is closer to the bulk earth ${ }^{87} \mathrm{Sr} /{ }^{86} \mathrm{Sr}$ ratio, and is similar to the ${ }^{87} \mathrm{Sr} /{ }^{86} \mathrm{Sr}$ ratios of non-anomalous samples from the other Oligocene tuffs.

When comparing the initial $\varepsilon N d$ value and the concentration of $\mathrm{Nd}$, there is a strong decrease in $\mathrm{Nd}$ concentration and an increase in the $\varepsilon \mathrm{Nd}$ values after acid washing (Fig. 7.24). The $\varepsilon N d$ value increases to values closer to the bulk earth $\varepsilon N d$ value in all samples. The original $\mathrm{Nd}$ concentration varies between the samples, with 16-SM-16 and 17-SM-26C containing a Nd concentration of nearly double that in 17-SM-21A. However, all samples experience a decrease in Nd concentration to a relatively similar value which is more similar to $\mathrm{Nd}$ concentrations in non-anomalous REE samples.

Both ${ }^{208} \mathrm{~Pb} /{ }^{204} \mathrm{~Pb}$ and ${ }^{206} \mathrm{~Pb} /{ }^{204} \mathrm{~Pb}$ ratios increase after acid washing (Fig. 7.25). When comparing the ${ }^{208} \mathrm{~Pb} /{ }^{204} \mathrm{~Pb}$ isotopic values and the $\mathrm{Pb}$ concentrations for the acidwashed and unwashed samples, the change in $\mathrm{Pb}$ concentration is variable between the 
samples (Fig. 7.26). The acid-washed samples experience much less change in $\mathrm{Pb}$ concentration than is observed in $\mathrm{Sr}$ and Nd. Sample 17-SM-26C is interpreted to not change at all, as it appears to increase by $1 \mathrm{ppm}$, however this is close to the analytical uncertainty for Pb by ICP-MS.

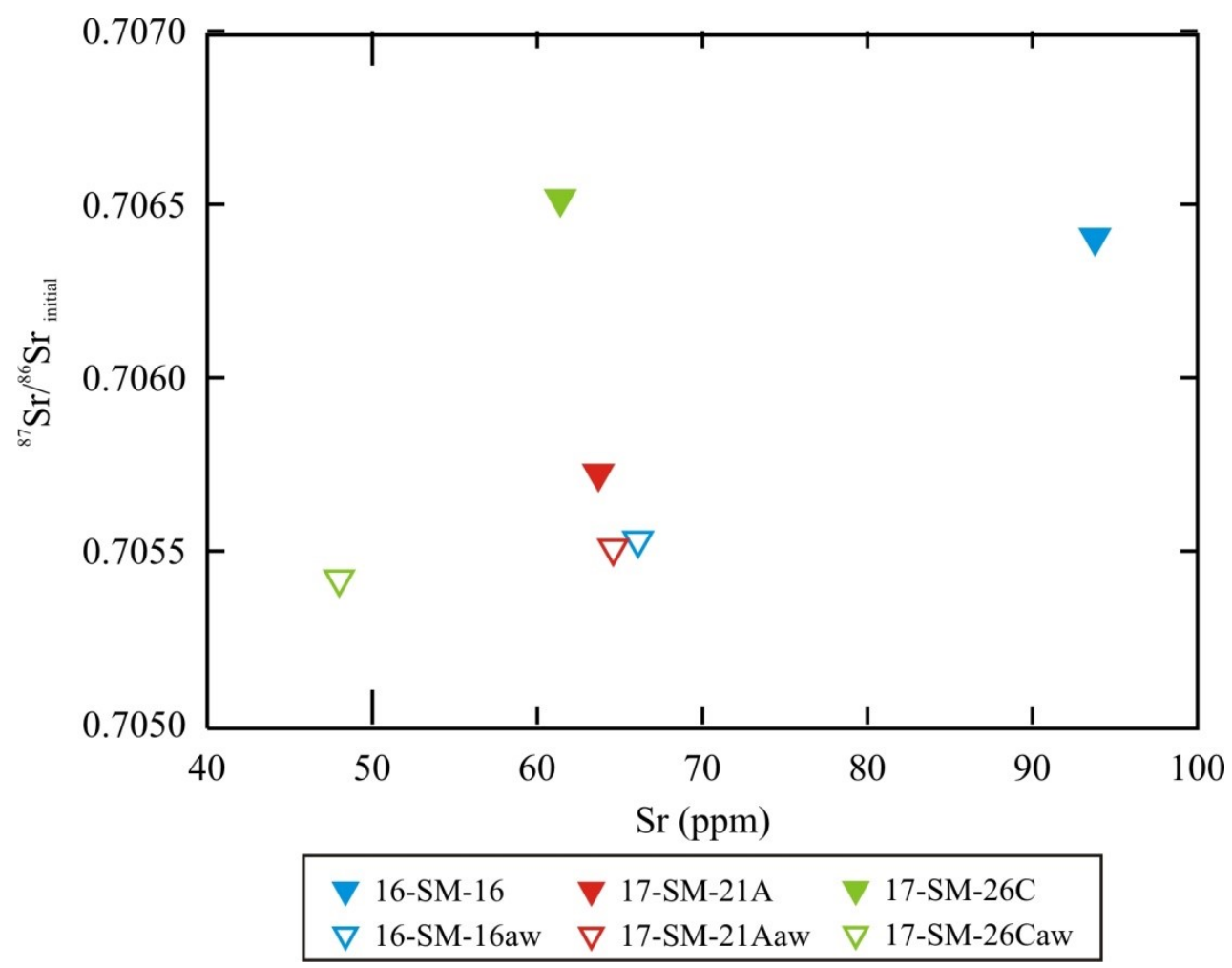

Figure 7.23: Initial ${ }^{87} \mathrm{Sr} /{ }^{86} \mathrm{Sr}$ ratios plotted against $\mathrm{Sr}$ concentration for acid-washed and unwashed anomalous REE samples. All samples show a decrease in both ${ }^{87} \mathrm{Sr} /{ }^{86} \mathrm{Sr}$ isotopic value and $\mathrm{Sr}$ concentration after acid washing except for sample 17-SM-21A which shows only small changes in both. 


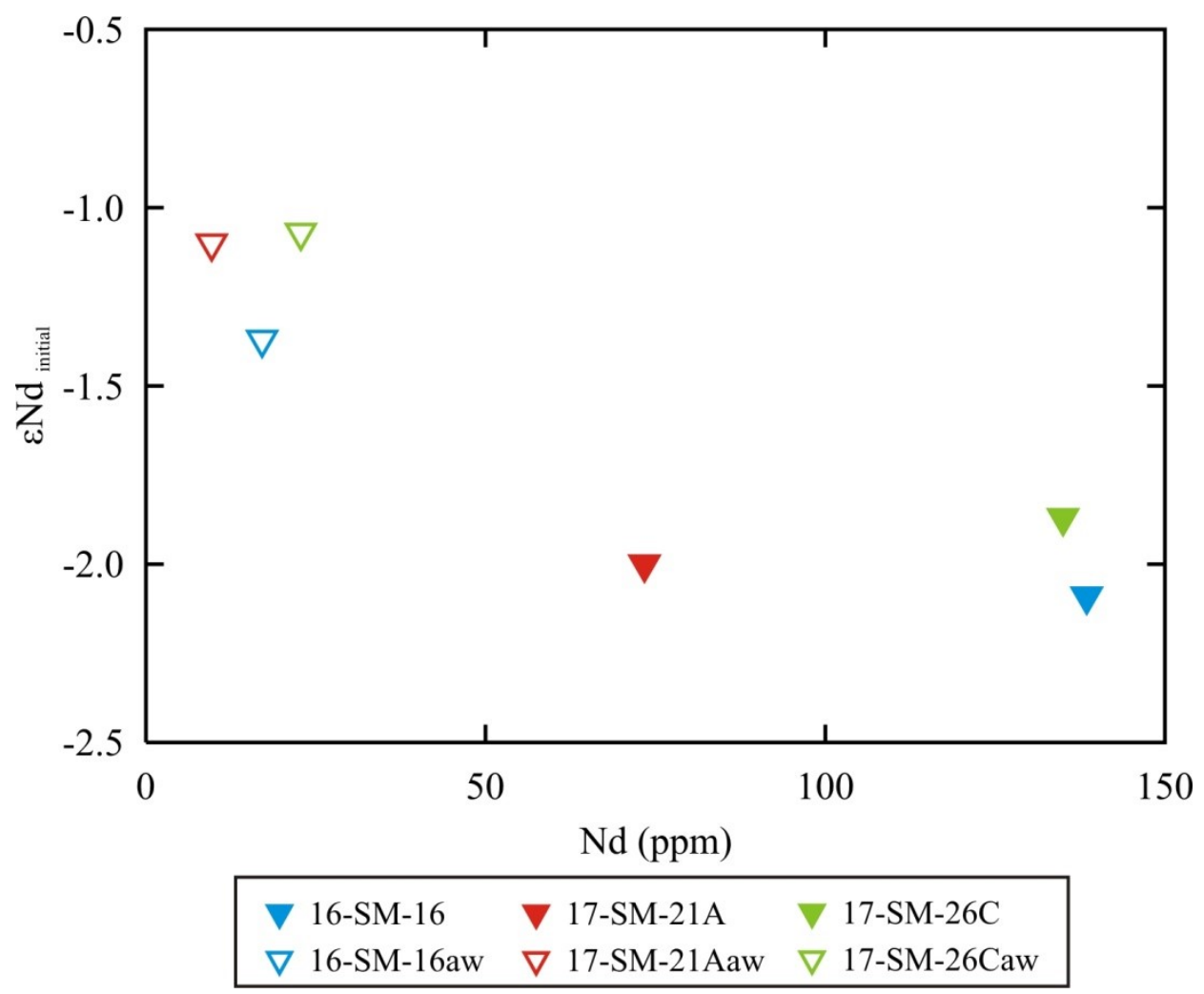

Figure 7.24: Initial $\varepsilon N d$ plotted against $\mathrm{Nd}$ concentration for the acid-washed and unwashed anomalous REE samples from the tuff of Clipper Gap. After acid washing, the samples show a decrease in both $\varepsilon N d$ isotopic value (less negative values) and $\mathrm{Nd}$ concentration. 


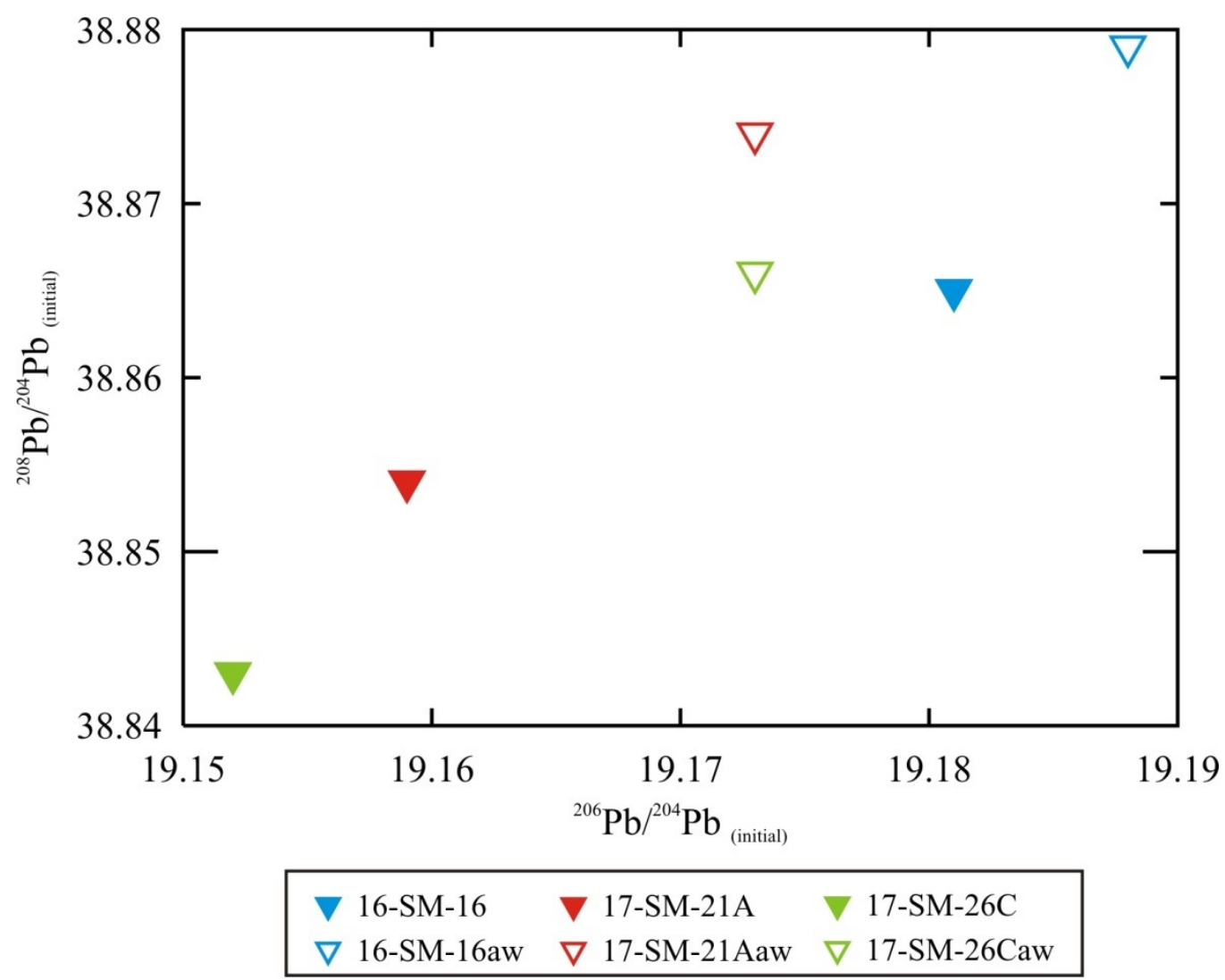

Figure 7.25: Initial ${ }^{208} \mathrm{~Pb} /{ }^{204} \mathrm{~Pb}$ vs. ${ }^{206} \mathrm{~Pb} /{ }^{204} \mathrm{~Pb}$ showing the change in isotopic ratio after acid washing. Both ${ }^{208} \mathrm{~Pb} /{ }^{204} \mathrm{~Pb}$ and ${ }^{206} \mathrm{~Pb} /{ }^{204} \mathrm{~Pb}$ ratios increase after acid washing. After acid washing, $17-\mathrm{SM}-21 \mathrm{~A}$ and $17-\mathrm{SM}-26 \mathrm{C}$ appear to have the same ${ }^{206} \mathrm{~Pb} /{ }^{204} \mathrm{~Pb}$ ratios. 


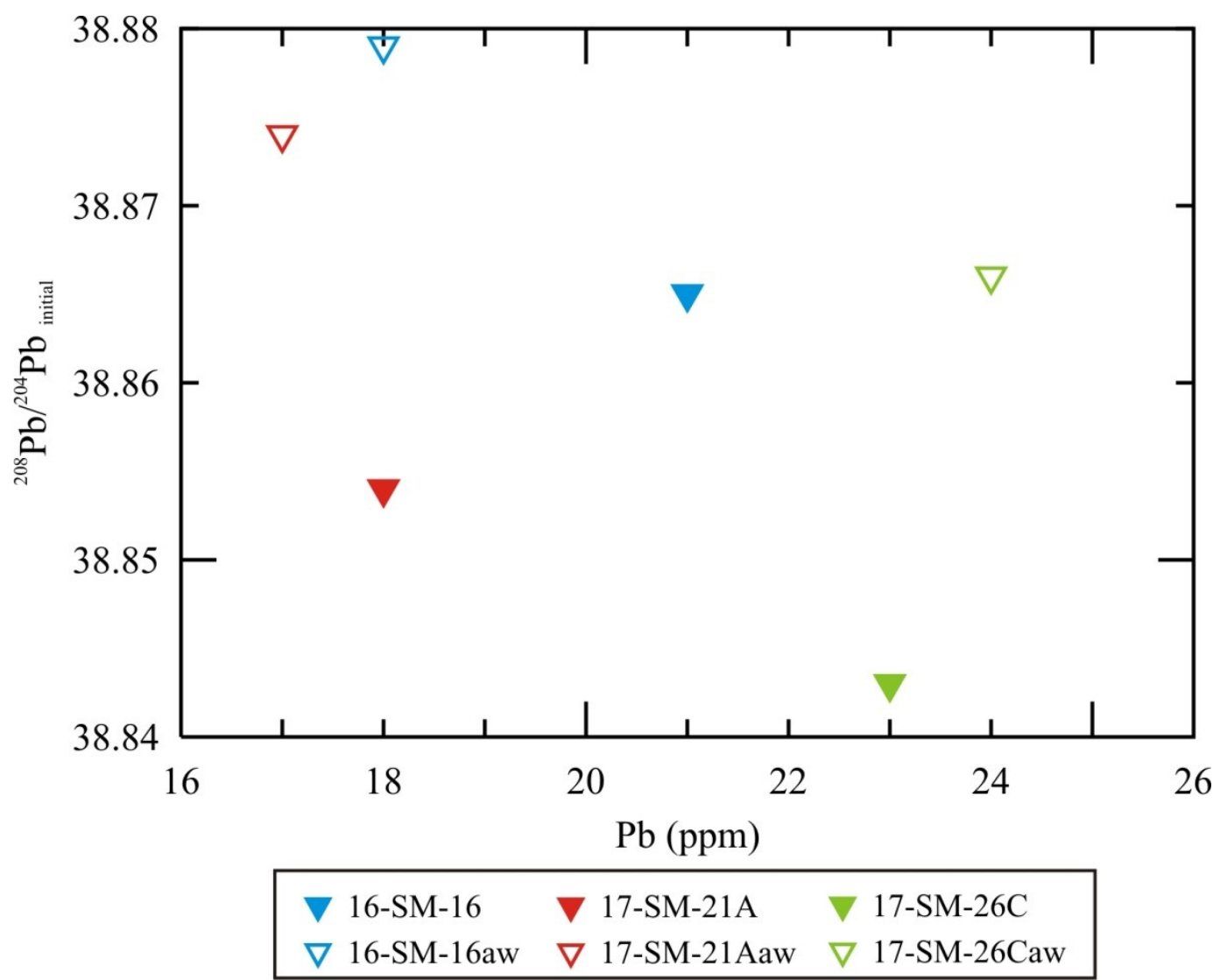

Figure 7.26: Initial ${ }^{208} \mathrm{~Pb} /{ }^{204} \mathrm{~Pb}$ isotopic ratios plotted against $\mathrm{Pb}$ concentrations showing the change in isotopic ratio and $\mathrm{Pb}$ concentrations after acid washing. All samples show an increase in $\mathrm{Pb}$ isotopic ratios after acid washing, while $\mathrm{Pb}$ concentrations decrease in samples $16-\mathrm{SM}-16$ and $17-\mathrm{SM}-21 \mathrm{~A}$. The $\mathrm{Pb}$ concentration in 17-SM-26C is interpreted to experience no change as $1 \mathrm{ppm}$ is close to analytical uncertainty for Pb by ICP-MS. 


\subsubsection{Potential sources of Ce anomalies and REE enrichment}

\section{Apatite}

The effects of the acid washing process suggest that the Ce anomalies could be caused by a secondary phase, and are not a geochemical characteristic of the unit. Acid washing with $\mathrm{HCl}$ strips away surface bonds but leaves internal bonds, such as $\mathrm{SiO}_{2}$ bonds, intact. As observed in the normalized major element line plots, the $\mathrm{SiO}_{2}$ content of the samples did not change after acid washing, however major element oxides such as $\mathrm{CaO}, \mathrm{Fe}_{2} \mathrm{O}_{3}$, $\mathrm{P}_{2} \mathrm{O}_{5}$, and $\mathrm{TiO}_{2}$ experienced significant changes in abundance. The removal of $\mathrm{Fe}-\mathrm{Ti}$ oxides from the samples accounts for the loss of both $\mathrm{Fe}_{2} \mathrm{O}_{3}$ and $\mathrm{TiO}_{2}$. It is possible that $\mathrm{P}_{2} \mathrm{O}_{5}$ and $\mathrm{CaO}$ are being depleted by the removal of apatite, perhaps secondary, from the samples. Apatite, $\mathrm{Ca}_{5}\left(\mathrm{PO}_{4}\right)_{3}$ has a high affinity for all the REEs, and especially partitions the middle REEs. Therefore, the removal of this phase could account for the concave-upward curvature in the middle and heavy REEs observed after acid washing. Although there is only a small amount of $\mathrm{P}_{2} \mathrm{O}_{5}$ present in these samples to begin with, only a small concentration is required to crystallize apatite (Watson and Capobianco, 1981). The apatite in these rocks may be a secondary phase precipitated by fluids altering the rocks. However, the loss of apatite does not explain the loss of the $\mathrm{Ce}$ anomalies, since apatite does not preferentially partition Ce into its structure relative to La or Pr. 


\section{Amphibole}

Amphibole also shows a high affinity for middle REEs. The fractionation of amphibole before and after acid washing was investigated in Figure 7.27. Dy/Yb was used as an indicator for the formation of hornblende, as amphibole has a high partition coefficient for Dy and a lower one for $\mathrm{Yb}$ (11.3 and 1.8, respectively, Appendix I, Table VII). Concentrations of these trace elements and the $\mathrm{SiO}_{2}$ content before and after acid washing were compared to observe whether amphibole is removed during acid washing. While the concentration of $\mathrm{Dy} / \mathrm{Yb}$ decreases after acid washing, the $\mathrm{SiO}_{2}$ content in the samples increases. However, this increase is due to the low amount of $\mathrm{SiO}_{2}$ in amphibole ( $\left.50 \%\right)$. The removal of apatite by acid washing would also have a similar effect on the $\mathrm{SiO}_{2}$ abundance and concentrations of Dy and $\mathrm{Yb}$, as Dy and $\mathrm{Yb}$ also have high partition coefficients in apatite (16.9 and 9.4, respectively, Appendix I, Table XII). As apatite has a higher affinity for heavy REEs than amphibole, it would preferentially incorporate heavy REEs relative to light REEs to a higher degree than amphibole. While this suggests that the removal of apatite or amphibole could be responsible for the observed pattern in the REEs after acid washing, the complete removal of $\mathrm{P}_{2} \mathrm{O}_{5}$ after acid washing (Fig. 7.20) would not be a result of the removal of amphibole, and would rather be a result of the removal of apatite. As well, the crystallization of amphibole would not cause the observed Ce anomalies in the samples, due to the low $(<1)$ partition coefficient for Ce in amphibole (Appendix I, Table XII). Based on these observations, it is unlikely that the removal of amphibole would cause 
the observed trend in the REEs after acid washing, and the removal of apatite is a more likely culprit.

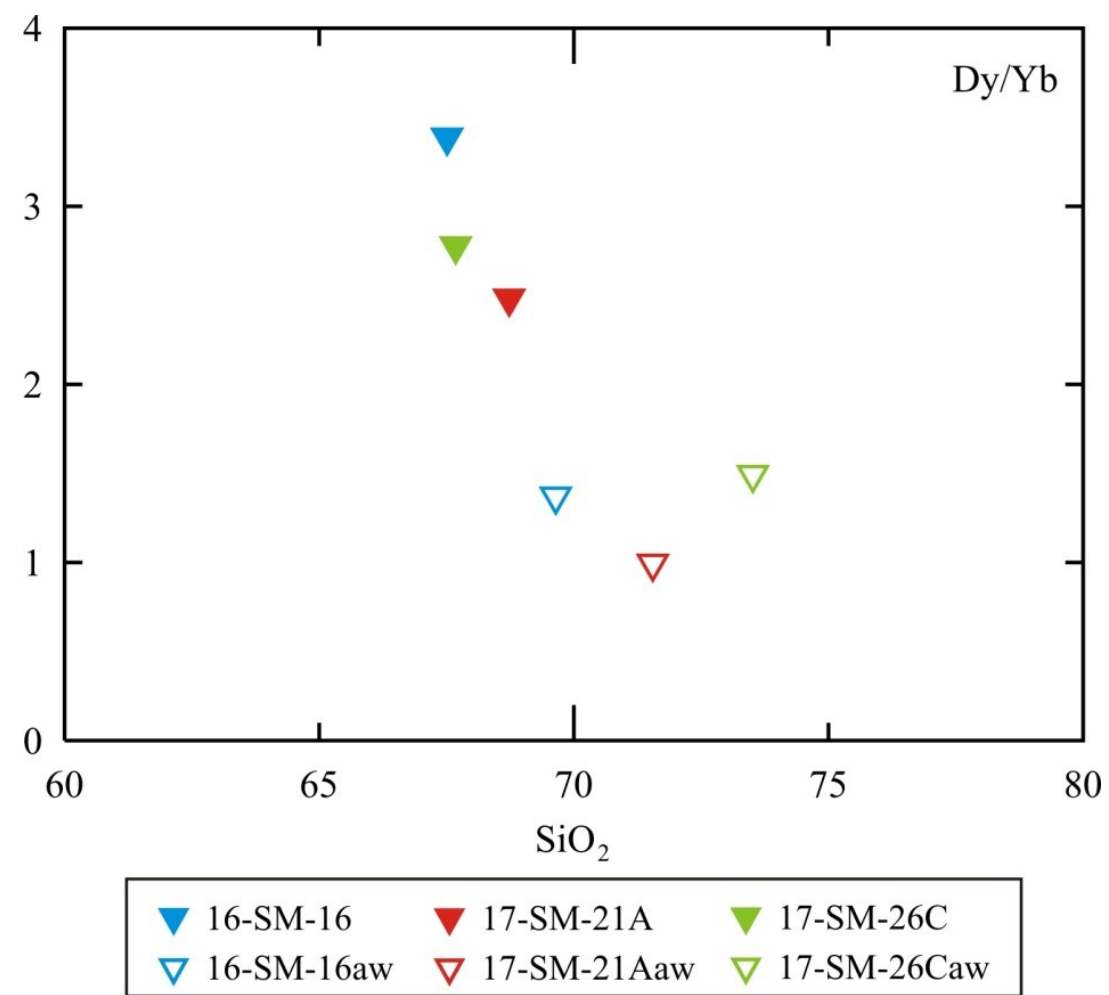

Figure 7.27: The fractionation of amphibole before and after the acid washing process. $\mathrm{Dy} / \mathrm{Yb}$ is used to represent the formation of amphibole as amphibole preferentially partitions Dy into its structure, but takes in much less $\mathrm{Yb}$. As the Dy/Yb decreased after acid washing, the $\mathrm{SiO}_{2}$ content increased. An increase in the $\mathrm{SiO}_{2}$ content can be explained by the low amount of $\mathrm{SiO}_{2}$ in amphibole ( $\left.\sim 50 \%\right)$. 


\section{REE enriched clays}

Another weathering phase which could be causing the Ce anomalies is REE enriched clays. Fresh and weathered dolerites from Karoo were analysed by Marsh (1991) and were observed to have both negative and positive $\mathrm{Ce}$ anomalies in all weathered samples. All REEs and $\mathrm{Y}$ were found to be enriched in weathered rinds in the samples, and negative Ce anomalies were also found in these REE enriched samples. The geochemical trends in the weathered dolerites were found to reflect the production of clays, particularly kaolinite, from the alteration of silicate minerals through the leaching of groundwater. Leached REEs and $\mathrm{Y}$ from the weathering product were taken up by the rocks that were subsequently altered by the REE enriched fluids. This caused an enrichment of REEs and $Y$ in the altered rocks; more specifically an enrichment of LREEs relative to HREEs, and a negative Ce anomaly. In oxidizing environments, $\mathrm{Ce}^{3+}$ can be oxidized to $\mathrm{Ce}^{4+}$ and remain stable as $\mathrm{CeO}_{2}$. Due to this immobility of $\mathrm{Ce}$, the REEs in the weathered sample would show a negative Ce anomaly due to the enrichment of all of the other REEs. The positive Ce anomaly observed in the weathering product would be caused by the immobility of the $\mathrm{Ce}$ in the rock from which the REEs and $\mathrm{Y}$ are being leached. This positive Ce anomaly and REE depletion has also been observed in felsic rocks (Boulange et al., 1990; Braun et al., 1990).

The uptake of these REEs and $Y$ into weathering rinds or zones in the tuff of Clipper Gap samples could account for the observed geochemical trends in the REEs. For example, the higher REE enrichment in the porphyritic pumice with large negative Ce anomalies 
compared to the non-anomalous tuff of Clipper Gap. This suggests that mobility of the other REEs is the culprit behind the Ce anomalies, rather than a depletion or enrichment of Ce. The negative Ce anomalies present in these samples could therefore be caused by the interaction of the rock with groundwater containing REEs and $Y$ from another source, causing enrichment in those elements but not in Ce. The overall depletion in all REEs after acid washing could therefore be caused by the removal of an REE bearing weathering phase from the samples, and not a Ce bearing phase. More evidence for this also exists in the observed change in the Eu anomaly after acid washing. The large negative Eu anomaly observed in most samples appears to become smaller after acid washing, however, the actual abundance of Eu stays relatively the same while the rest of the REEs are depleted. This is likely causing the Eu anomaly to appear smaller, however, the actual amount of Eu in the sample remains relatively constant. Since Eu is incorporated into silicate minerals, such as plagioclase and potassium feldspar, they are less likely to be removed by acid washing. This heavy depletion in REEs may also account for why sample 17-SM-21A appears to gain a positive Eu anomaly after acid washing. Ba and $\mathrm{Sr}$ also show very large negative anomalies in these rocks, and while these phases are incorporated into feldspars, their depletion could also be due to weathering as is seen in the Karoo samples (Marsh, 1991). Further evidence for this mechanism can be observed in the line diagram depicting the change in concentration of trace elements after acid washing as the removal of $Y$ out of most of the samples by acid washing suggests that it could be part of a secondary phase removed by acid washing. 
Formation of the enriched anomalous REEs by groundwater is also supported by the isotopic data. As observed in the isotope diagrams before and after acid washing, the anomalous REE samples experienced changes in initial values for ${ }^{87} \mathrm{Sr} /{ }^{86} \mathrm{Sr}$, $\varepsilon N d$, ${ }^{206} \mathrm{~Pb} /{ }^{204} \mathrm{~Pb}$, and ${ }^{208} \mathrm{~Pb} /{ }^{204} \mathrm{~Pb}$. In particular, all acid-washed samples experienced decreases in their ${ }^{87} \mathrm{Sr} /{ }^{86} \mathrm{Sr}$ ratios, and while the samples did not all decrease by the same amount, they did decrease to relatively similar initial ratios as the "fresh" Underdown Caldera complex ignimbrites. Since the samples have such a small concentration of $\mathrm{Sr}$, it is possible that a fluid rich in $\mathrm{Sr}$ could have easily altered the $\mathrm{Sr}$ isotopic ratios of the samples after deposition. Probable addition of $\mathrm{Nd}$ from other rocks via groundwater likely also decreased the ${ }^{143} \mathrm{Nd} /{ }^{144} \mathrm{Nd}$ ratios in the anomalous REE samples.

Based on observations from field work, the anomalous REE samples were commonly found in upper and lower sections of the sampled units. For example, at the Moore's Canyon Road outcrop, the anomalous REE samples were located at the very top of the exposure, while samples collected from the unwelded base and middle cooling units were not found to contain any REE enrichment or Ce anomalies. Similarly, samples collected from Butler Ranch in Monitor Valley which show negative Ce anomalies were collected from the base of the exposure, beneath a vitrophyre and columnar jointed section. Finally, anomalous REE samples collected in the 2016 field season were found at the top of an outcrop as well as in a subcrop located beneath the main outcrop. Sample 16-SM-14, which exhibits a positive Ce anomaly, was collected from the unit directly 
below sample 16-SM-15A (a sample of porphyritic pumice with a large negative Ce anomaly). The location of these samples on the outer margins of the section could cause them to be more susceptible to weathering by groundwater than the inner rocks. Field notes from these locations state that the rocks and porphyritic pumice from these units show alteration and appear to be vapour phase altered. Under petrographic observation, all of the porphyritic pumice samples appeared highly altered, especially in the matrices.

Based on the evidence of REE enrichment, and the presence of both positive and negative Ce anomalies in these Clipper Gap samples, we postulate that the Ce anomalies in the tuff of Clipper Gap may be caused by the presence of REE enriched clays. These clays were not observed during petrographic analysis; however the fine grained, altered matrix of these samples may have made their identification in regular microscopy impossible. The clays may exist as rinds around other grains, and could contain phases like secondary apatite. Analysis by scanning electron microscope and electron microprobe would be necessary to determine their presence in the samples. 


\subsection{Other potentially related exposures}

While section 7.1 focused on the characteristics of the intracaldera tuffs and the tuff of Clipper Gap, this section investigates some of the slightly older ignimbrites sampled outside of the Underdown Caldera, as well as new potential outflow units to the west of the caldera, to determine whether these units have any relation to the Underdown Caldera magmatic event.

\subsubsection{The tuff of Gabbs Valley}

Henry and John (2013) question a previously interpreted caldera at Fissure Ridge which was proposed to be a source for the tuffs of Gabbs Valley (originally proposed by Ekren and Byers, 1976 and 1986). This fissure is now interpreted to be a canyon which was eroded into two older tuffs of Gabbs Valley, TgV1 and TgV2. In this situation, TgV2 and the uppermost unit, $\operatorname{TgV} 3$, would likely have been outflow tuffs deposited into a paleovalley, rather than ignimbrite deposits formed in a caldera as originally proposed, based on the lack of lithic fragments and megabreccia deposits commonly seen in intracaldera tuffs (Henry and John, 2013, and references therein). It is proposed that the eroded valley has been filled with the youngest tuff unit, TgV3. Both TgV2 and TgV3 were sampled as potential outflow tuffs from the Underdown Caldera.

While these units are currently identified as the tuff of Gabbs Valley (TgV), a widespread, sparsely porphyritic ash-flow tuff in the Western Nevada Volcanic Field (Henry and John, 2013; John, 1974), TgV2 is much more porphyritic than the tuff of 
Gabbs Valley. In the field TgV2 was observed to have $20-25 \%$ phenocrysts in the poorly welded base and up to $35 \%$ phenocrysts in the densely welded upper portion, both of which are also more porphyritic than the Underdown Tuff and the tuff of Clipper Gap. Samples were collected from the poorly welded base (17-SM-28), the moderately welded middle (17-SM-29), and densely welded top (17-SM-30) of TgV2. Above the vitrophyre that separates $\mathrm{TgV} 2$ and $\mathrm{TgV} 3, \mathrm{TgV} 3$ was observed to have far fewer phenocrysts than $\operatorname{TgV} 2$ and dark porphyritic pumice were observed in a moderately welded matrix. The porphyritic pumice was sampled for geochemical analysis (17-SM31). Based on the field observations, it is more likely that $\operatorname{TgV} 3$ is an Underdown-Clipper Gap equivalent than is $\operatorname{TgV} 2$. TgV2 has been determined to be slightly too old to be an Underdown Caldera outflow tuff ( $25.109 \pm 0.080 \mathrm{Ma}$, C. Henry, pers. comm., 2018), but is similar in age to the tuff of Arc Dome (25.19 $\pm 0.04 \mathrm{Ma}$, C. Henry, pers. comm., 2018). However, the age of $\operatorname{TgV} 3(24.875 \pm 0.048 \mathrm{Ma}$, C. Henry, pers. comm., 2018) suggests that it could be a possible Underdown Caldera outflow tuff. Therefore TgV2 will be compared to the tuff of Arc Dome, and TgV3 will be compared to the Underdown Tuff.

In chondrite normalized REE and primitive mantle normalized trace element diagrams, samples of TgV2 show the same patterns as the tuff of Arc Dome (Fig. 7.28). Primitive mantle normalized trace element patterns for the tuff of Arc Dome have large variations in negative $\mathrm{Ba}, \mathrm{Sr}$, and Eu anomalies which are also observed in the TgV2 samples. In particular, sample 17-SM-30 from the welded upper section of TgV2 shows the same 
patterns as tuff of Arc Dome samples 16-SM-09 and 17-SM-14 on both the chondrite normalized REE and primitive mantle normalized trace element diagrams (Fig. 7.29).

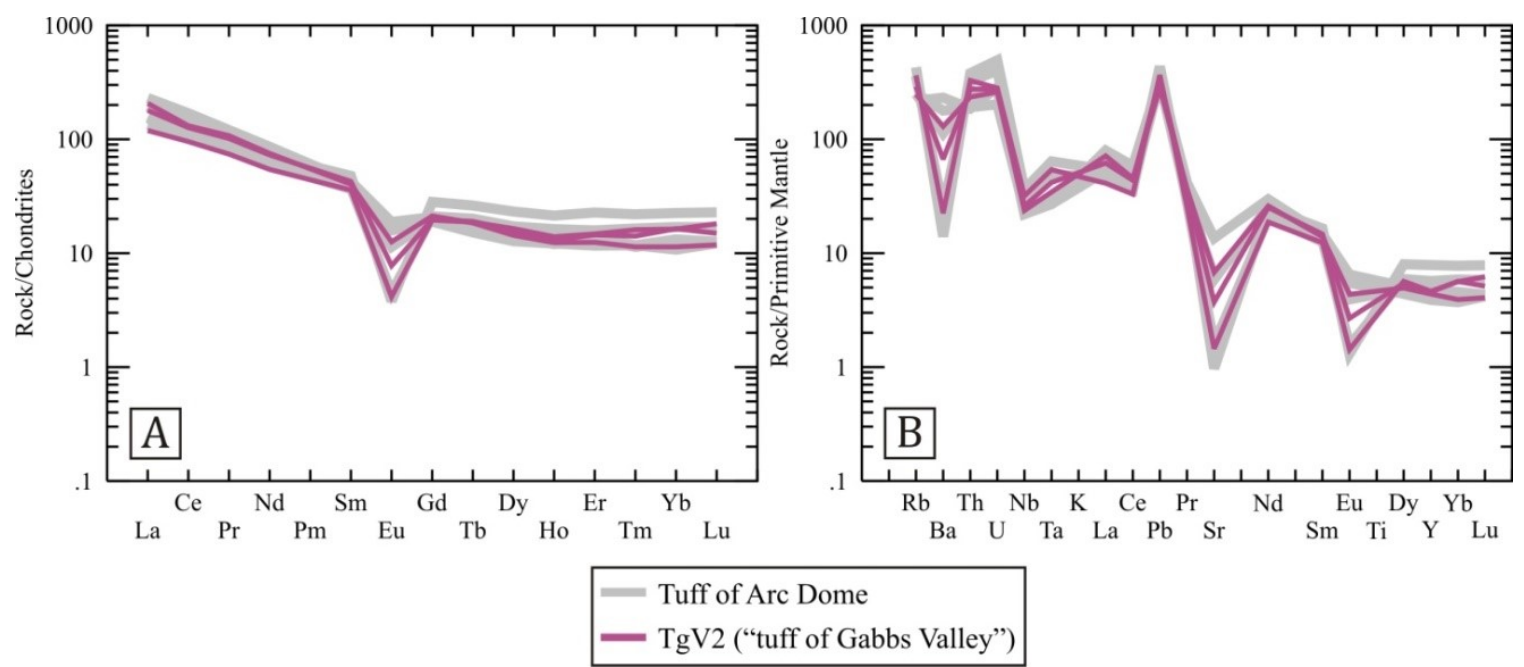

Figure 7.28: (A) Chondrite normalized REE and (B) primitive mantle normalized trace element diagrams comparing TgV2 ("tuff of Gabbs Valley") and the tuff of Arc Dome. In both diagrams, TgV2 appears to be nearly identical to the tuff of Arc Dome, showing the same enrichment in LREEs and flattening to HREEs, and identical ranges of $\mathrm{Ba}$, $\mathrm{Sr}$, and $\mathrm{Eu}$ anomalies (normalizing data from Sun and McDonough, 1989). 

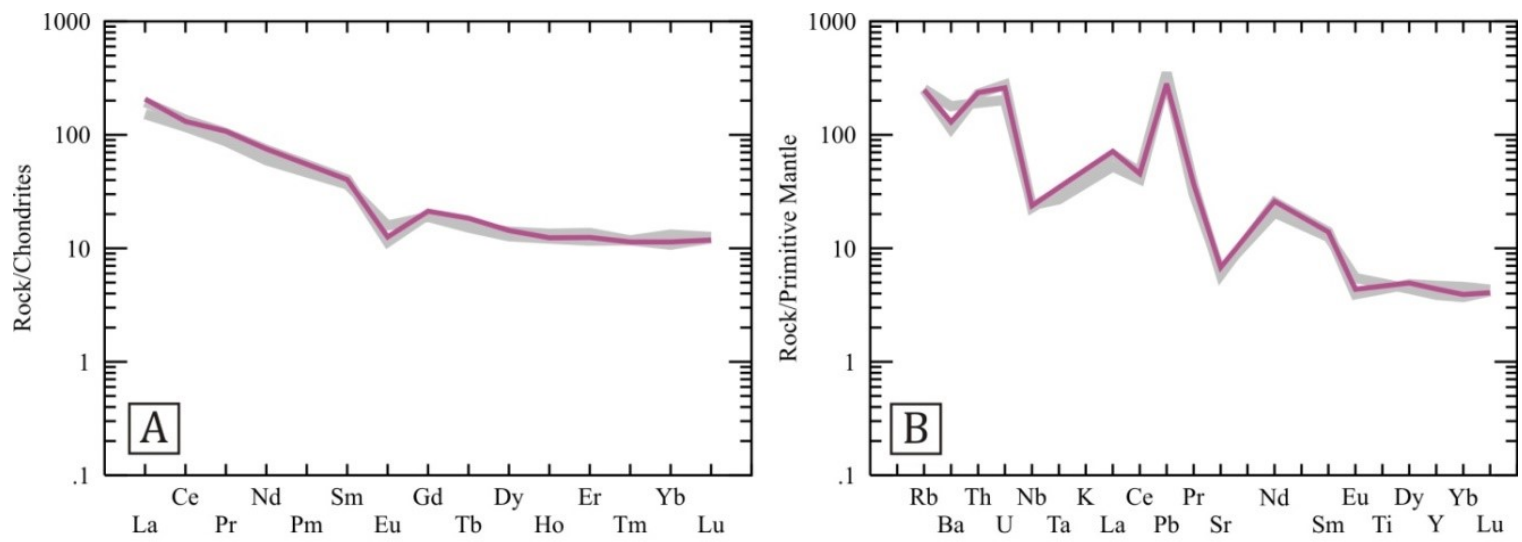

- TgV2 "tuff of Gabbs Valley" (17-SM-30)

- Tuff of Arc Dome (16-SM-09, 17-SM-14)

Figure 7.29: (A) Chondrite normalized REE and (B) primitive mantle normalized trace element diagrams comparing all samples from TgV2 ("tuff of Gabbs Valley") and two samples (17-SM-14, 16-SM-09) from the tuff of Arc Dome. The two tuff of Arc Dome samples plot nearly identical to the sample from TgV2 (normalizing data from Sun and McDonough, 1989).

TgV3 porphyritic pumice was compared to the porphyritic pumice from the Underdown Tuff (Fig. 7.30). Despite both being porphyritic pumice samples, TgV3 porphyritic pumice has a much more depleted HREE signature on a chondrite normalized REE diagram and lacks the characteristic negative $\mathrm{Ba}$ and $\mathrm{Eu}$ anomalies observed in most of the Underdown porphyritic pumice on the primitive mantle normalized trace element diagram. Chondrite normalized REE and primitive mantle normalized trace element patterns of TgV3 show more similarity to a whole rock sample from the Bonita Canyon Formation (16-SM-26) (Fig. 7.31). These samples were plotted with the lone sample of porphyritic pumice (17-SM-17C) from the Underdown Tuff which also shows no negative Eu anomaly. On the chondrite normalized REE diagram, TgV3 appears to be slightly more enriched in LREEs, and show a slightly steeper pattern to the HREEs than the 
Bonita Canyon Formation and the Underdown porphyritic pumice. The Bonita Canyon Formation shows the most similarity in HREE depletion to TgV3. TgV3 also appears more similar to the Bonita Canyon Formation in the primitive mantle normalized trace element diagram. Both TgV3 and the Bonita Canyon Formation samples lack the negative $\mathrm{Ba}$ anomaly that is observed in the Underdown porphyritic pumice. TgV3 shows slightly stronger depletion in $\mathrm{Nb}$ and $\mathrm{Ta}$, and higher enrichment in La than both the Underdown Tuff and Bonita Canyon Formation.
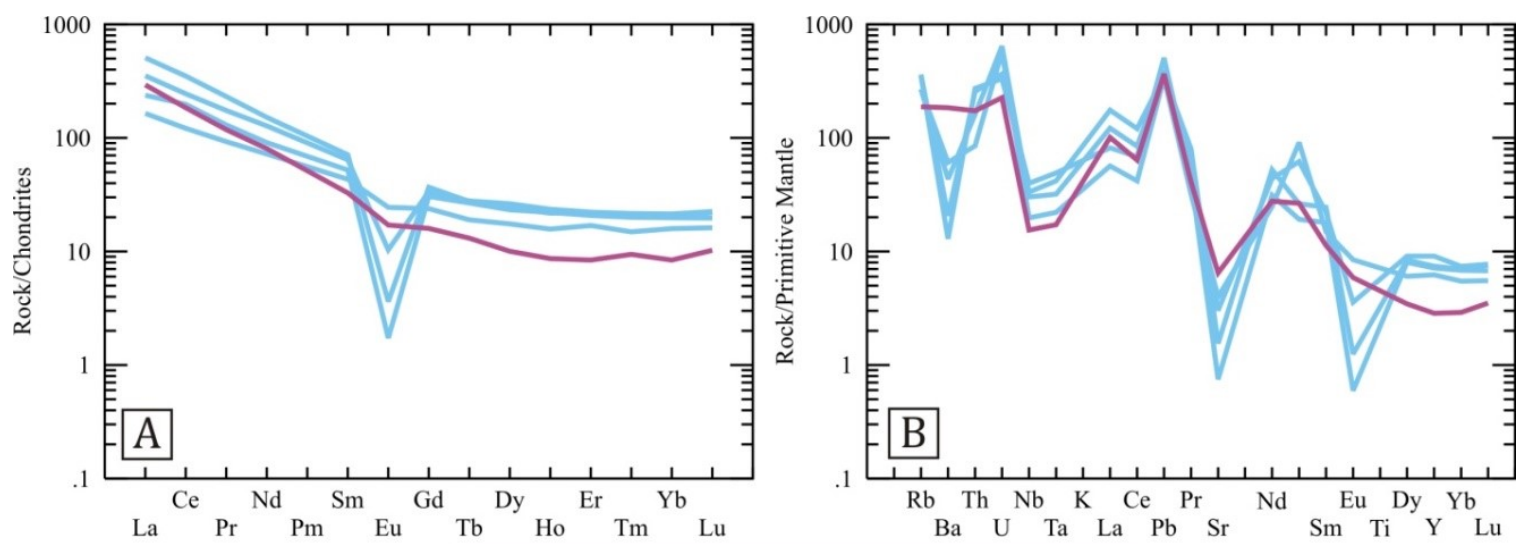

— TgV3 "tuff of Gabbs Valley" porphyritic pumice - Underdown porphyritic pumice

Figure 7.30: (A) Chondrite normalized REE and (B) primitive mantle normalized trace element diagrams comparing TgV3 ("tuff of Gabbs Valley" porphyritic pumice) to the Underdown porphyritic pumice samples. On panel (A) TgV3 shows a steeper pattern from the LREEs to the HREEs than the Underdown porphyritic pumice, as well as no negative Eu anomaly. TgV3 also lacks a negative Ba anomaly which is observed in all Underdown porphyritic pumice samples (B) (normalizing data from Sun and McDonough, 1989). 

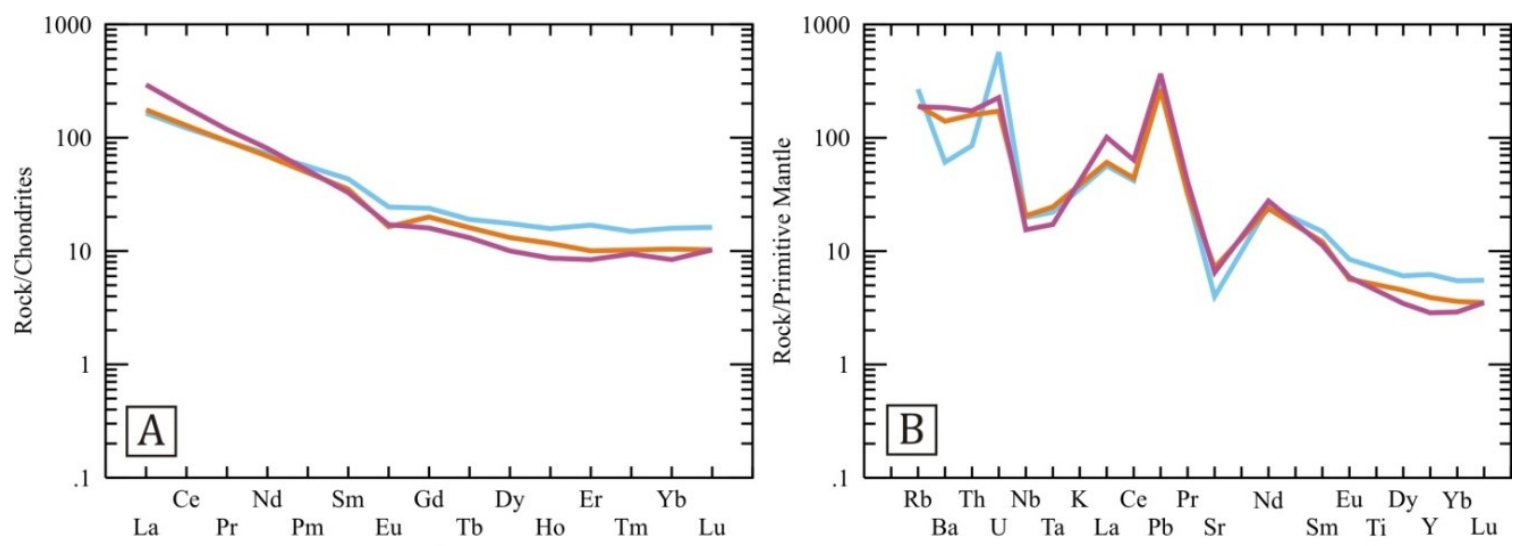

- Bonita Canyon Formation (16-SM-26)

— TgV3 ("tuff of Gabbs Valley") porphyritic pumice

- Underdown Porphyritic Pumice (17-SM-17C)

Figure 7.31: Chondrite normalized rare earth element plot $(A)$ and primitive mantle normalized trace element plot (B) comparing TgV3 with the Bonita Canyon Formation and the Underdown Tuff (porphyritic pumice). While the chondrite normalized pattern of TgV3 appears similar to both units on panel (A), TgV3 shows the most similarity to the Bonita Canyon Formation whole rock when normalized to primitive mantle. Like the Bonita Canyon Formation sample, $\mathrm{TgV} 3$ is lacking a negative $\mathrm{Ba}$ anomaly which is observed in the Underdown porphyritic pumice sample (B) (normalizing data from Sun and McDonough, 1989). 
Isotopic values for $\mathrm{TgV} 2$ and $\mathrm{TgV} 3$ are fairly similar in the $\mathrm{Sr}$ and $\mathrm{Pb}$ isotopic systems, as observed in the isotope result diagrams in Section 6.0 (Fig. 6.21-6.29). However, differences exist between them in their $\varepsilon N d$ values which give clues as to their identities (Fig. 7.32). TgV2 appears to be most similar to the tuff of Arc Dome, while TgV3 shows the most similarities to the Bonita Canyon Formation. In the $\mathrm{Sr}$ and $\mathrm{Pb}$ isotopic systems, TgV2 and TgV3 typically plot in a cluster with the tuff of Arc Dome. When comparing initial $\varepsilon N d$ to ${ }^{87} \mathrm{Sr} /{ }^{86} \mathrm{Sr}$ and $\varepsilon N d$ to $\mathrm{Nd}$ concentration, $\mathrm{TgV} 2$ and the tuff of Arc Dome appear isotopically identical. 

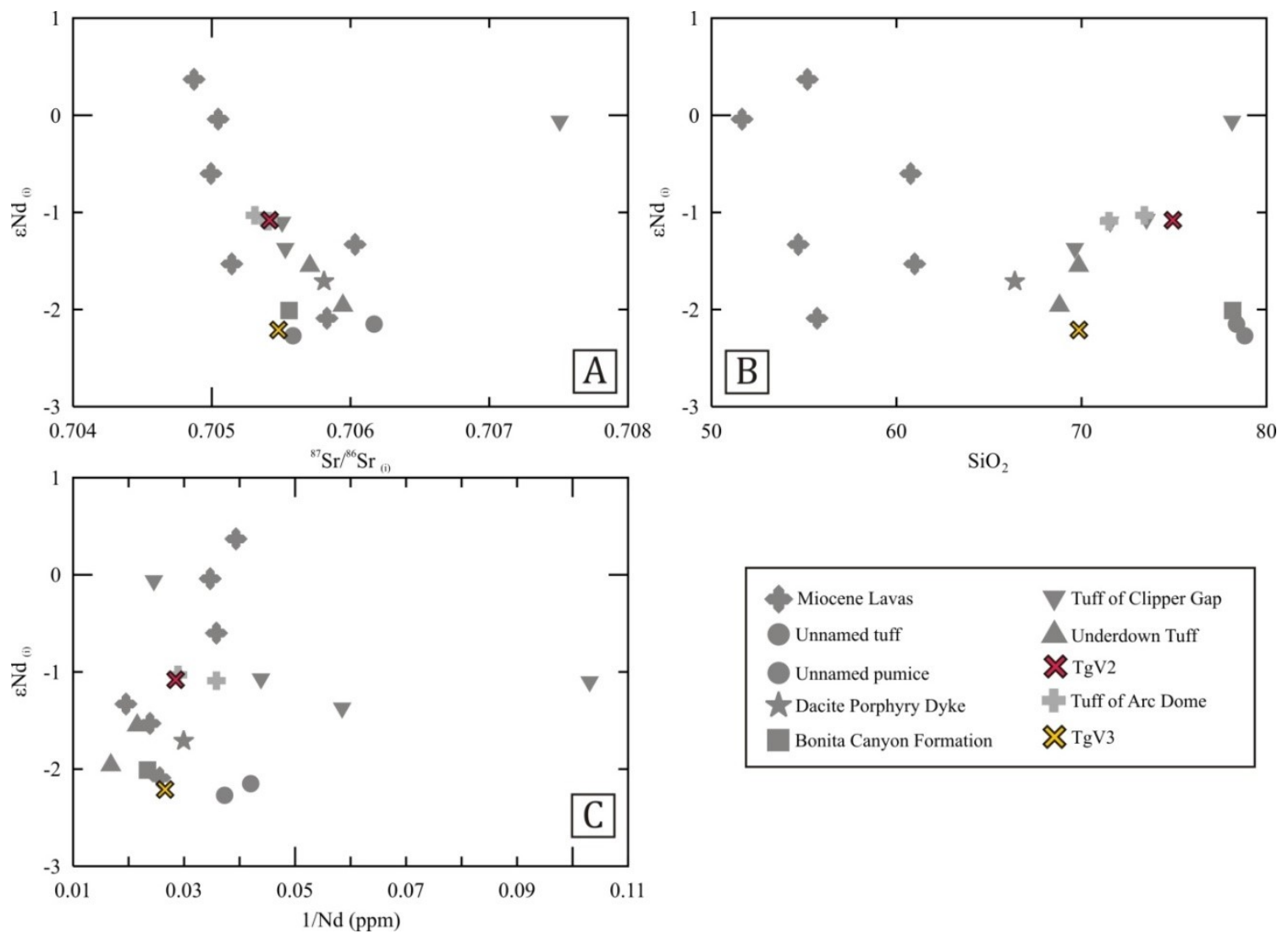

\begin{tabular}{|ll|}
\hline Miocene Lavas & $\nabla$ Tuff of Clipper Gap \\
Unnamed tuff & Underdown Tuff \\
Unnamed pumice & TgV2 \\
Wacite Porphyry Dyke & Tuff of Arc Dome \\
Bonita Canyon Formation & \TgV3
\end{tabular}

Figure 7.32: $\mathrm{Nd}$ isotopic diagrams showing the difference in initial $\varepsilon N d$ values between TgV2 and TgV3. Panel (A) shows the comparison between initial $\varepsilon N d$ values and ${ }^{87} \mathrm{Sr} /{ }^{86} \mathrm{Sr}$ ratios, and the similarities between TgV2 and the tuff of Arc Dome, while TgV3 appears more similar to the Bonita Canyon Formation and the Unnamed Tuff. Panel (B) shows the comparison between initial $\varepsilon N d$ values and $\mathrm{SiO}_{2}$ content. Again, $\mathrm{TgV} 2$ is more similar to the tuff of Arc Dome while TgV3 is less evolved and appears similar to the Underdown Tuff. Panel (C) shows the comparison between initial $\varepsilon N d$ values and $\mathrm{Nd}$ concentration. As observed in panels (A) and (C), TgV2 overlaps the tuff of Arc Dome while TgV3 shows the most similarity to the Bonita Canyon Formation. 
In summary, based on its crystal-rich texture, age and geochemistry, TgV2 from Fissure Ridge is interpreted to be equivalent to the tuff of Arc Dome. Based on field observations, TgV3 shows similarity to the Underdown Tuff and tuff of Clipper Gap. However, geochemically, $\mathrm{TgV} 3$ shows the most similarity to the Bonita Canyon Formation. These observations and the age of the unit suggest that $\operatorname{TgV} 3$ may represent a phase of outflow tuff correlative to the Bonita Canyon Formation. Both TgV2 and TgV3 are not correlative to be the tuff of Gabbs Valley is they were previously interpreted.

\subsubsection{The tuff of Arc Dome}

The megabreccia block and tuff of Arc Dome have been dated at $25.19 \pm 0.04 \mathrm{Ma}$ (C. Henry, pers. comm., 2018) and $25.18 \pm 0.06 \mathrm{Ma}$ (Henry and John, 2013), respectively. Therefore the sampled megabreccia block from the Underdown Caldera complex is similar in age to the tuff of Arc Dome. Chondrite normalized and primitive mantle normalized spider patterns show that the megabreccia block has patterns similar to those of the tuff of Arc Dome (Fig. 7.33). The megabreccia block sample was analyzed isotopically along with one tuff of Arc Dome whole rock sample (16-SM-09 and 17-SM14, respectively). As observed in the isotopic results, both the samples have similar isotopic ratios in all three isotopic systems (Fig. 6.21-6.29). The isotopic similarities between the samples support the suggestion that the megabreccia block is a large piece of the tuff of Arc Dome based on the date by C. Henry (pers. comm., 2018). Large blocks and spires of the tuff of Arc Dome found within the caldera may represent pieces of caldera wall rock that fell inwards during caldera collapse. 


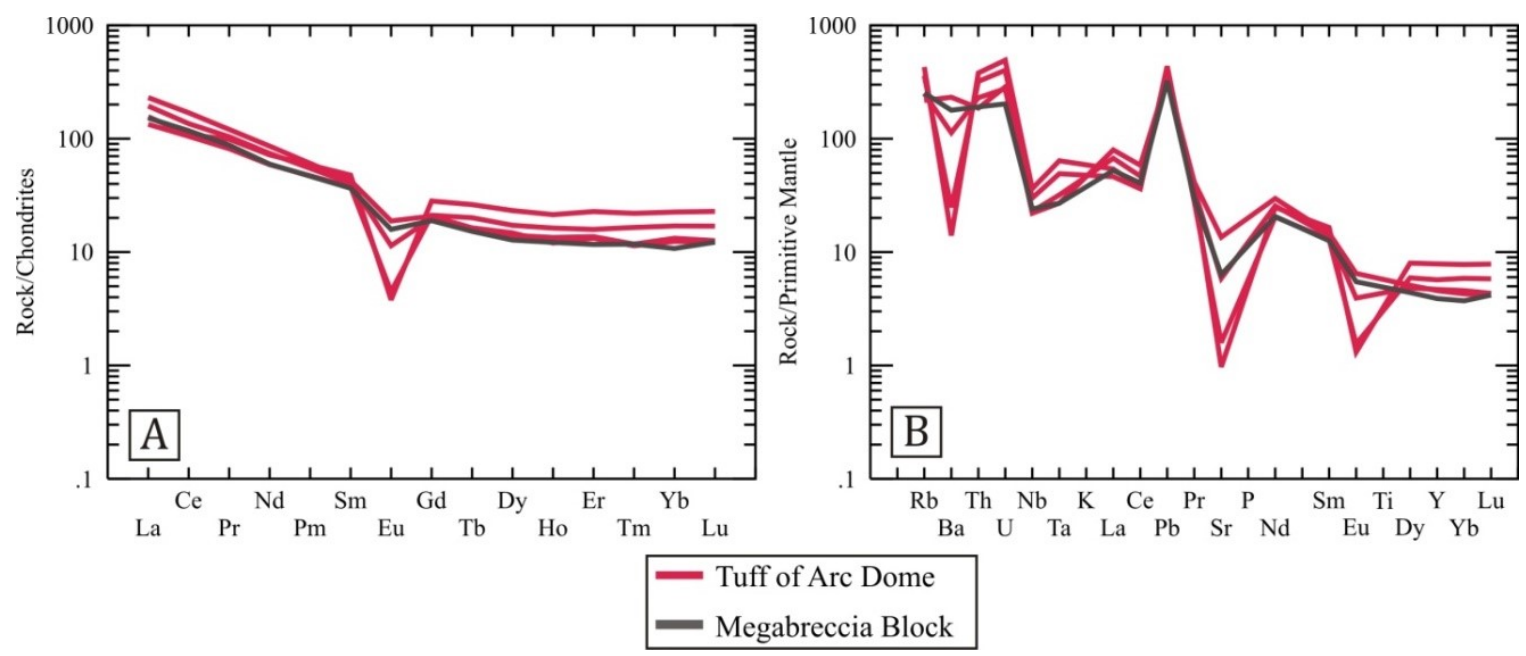

Figure 7.33: Chondrite normalized rare earth element diagram $(A)$ and primitive mantle normalized trace element diagram (B) showing the comparison between the Tuff of Arc Dome and the megabreccia block sampled from the Underdown Caldera. The megabreccia block shows the same trace element arc signature as the other samples of the tuff of Arc Dome collected from outside of the caldera (normalizing data from Sun and McDonough, 1989).

\subsubsection{The tuff of Brunton Pass}

The tuff of Brunton Pass collected from the margins of the Underdown Caldera complex has been dated at $24.892 \pm 0.053 \mathrm{Ma}$ (C. Henry, pers. comm., 2018), while Henry and John (2013) dated another sample of the tuff of Brunton Pass at $25.12 \pm 0.06 \mathrm{Ma}$. The two samples collected from the tuff of Brunton Pass included a welded (17-SM-13A) and an unwelded (17-SM-13B) whole rock. As observed in the major and trace element bivariate diagrams (Fig. 6.10, 6.13) the tuff of Brunton Pass plots within the same fractionation trends as the other Oligocene tuffs, but appears to be relatively homogeneous in composition (however, the few number of samples may be responsible 
for this apparent homogeneity). In chondrite normalized REE and primitive mantle normalized trace element diagrams, the tuff of Brunton Pass appears to have patterns similar to the Underdown Tuff (Fig. 7.34). However, the welded sample shows a small negative Ce anomaly in the chondrite normalized REE plot, similar to what has been observed in the anomalous REE-enriched samples of the tuff of Clipper Gap (however the sample with a Ce anomaly does not have enriched REEs compared to the sample without a Ce anomaly). The LREE enrichment in the welded tuff of Brunton Pass is similar to the LREE enrichment in the anomalous REE-enriched whole rock tuff of Clipper Gap samples, but is less than the LREE enrichment in the anomalous REE tuff of Clipper Gap porphyritic pumice (Fig. 7.35). On a primitive mantle normalized Th/La vs. $\mathrm{SiO}_{2}$ diagram, the tuff of Brunton Pass samples plot within the increasing correlation showing possible crustal addition formed by the Miocene lavas and the Oligocene tuffs, suggesting similar mixing endmembers for these units (Fig. 7.36). 

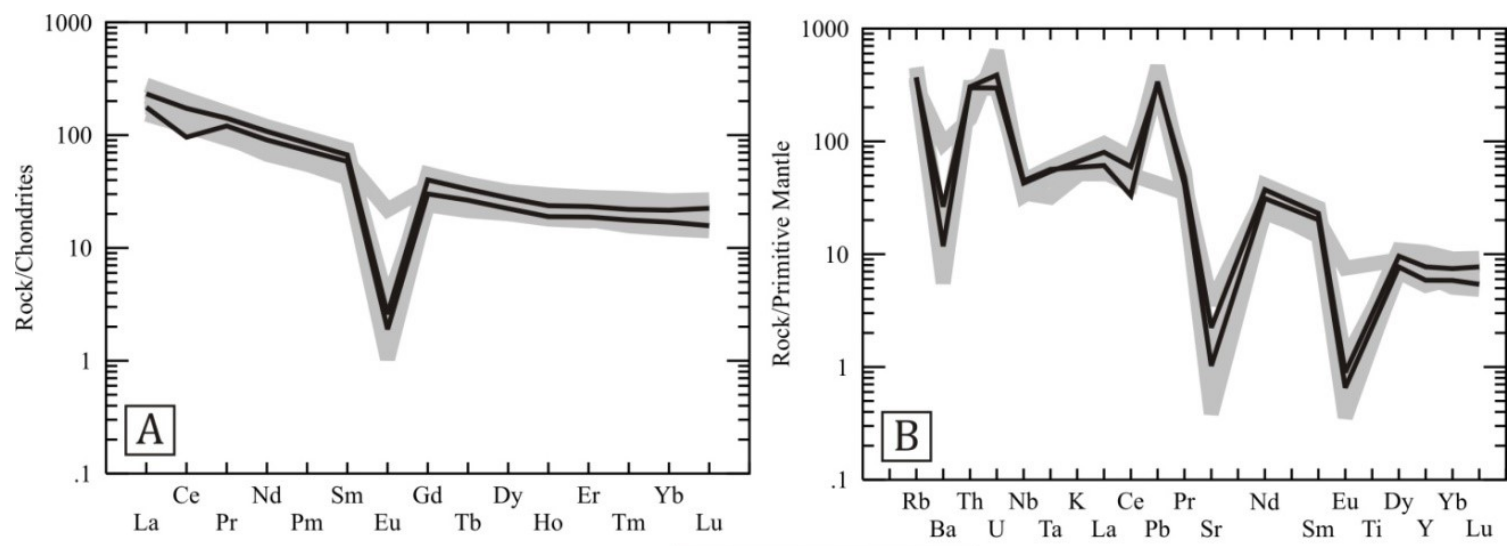

- Underdown Tuff

Tuff of Brunton Pass

Figure 7.34: Chondrite normalized REE (A) and primitive mantle normalized trace element (B) diagrams showing similar patterns in both the Underdown Tuff and the tuff of Brunton Pass. The welded whole rock sample from the tuff of Brunton Pass shows a small negative Ce anomaly, however, there doesn't appear to be the same enrichment in LREEs compared to the non-anomalous whole rock sample that is present in the anomalous REE tuff of Clipper Gap samples (normalizing data from Sun and McDonough, 1989). 


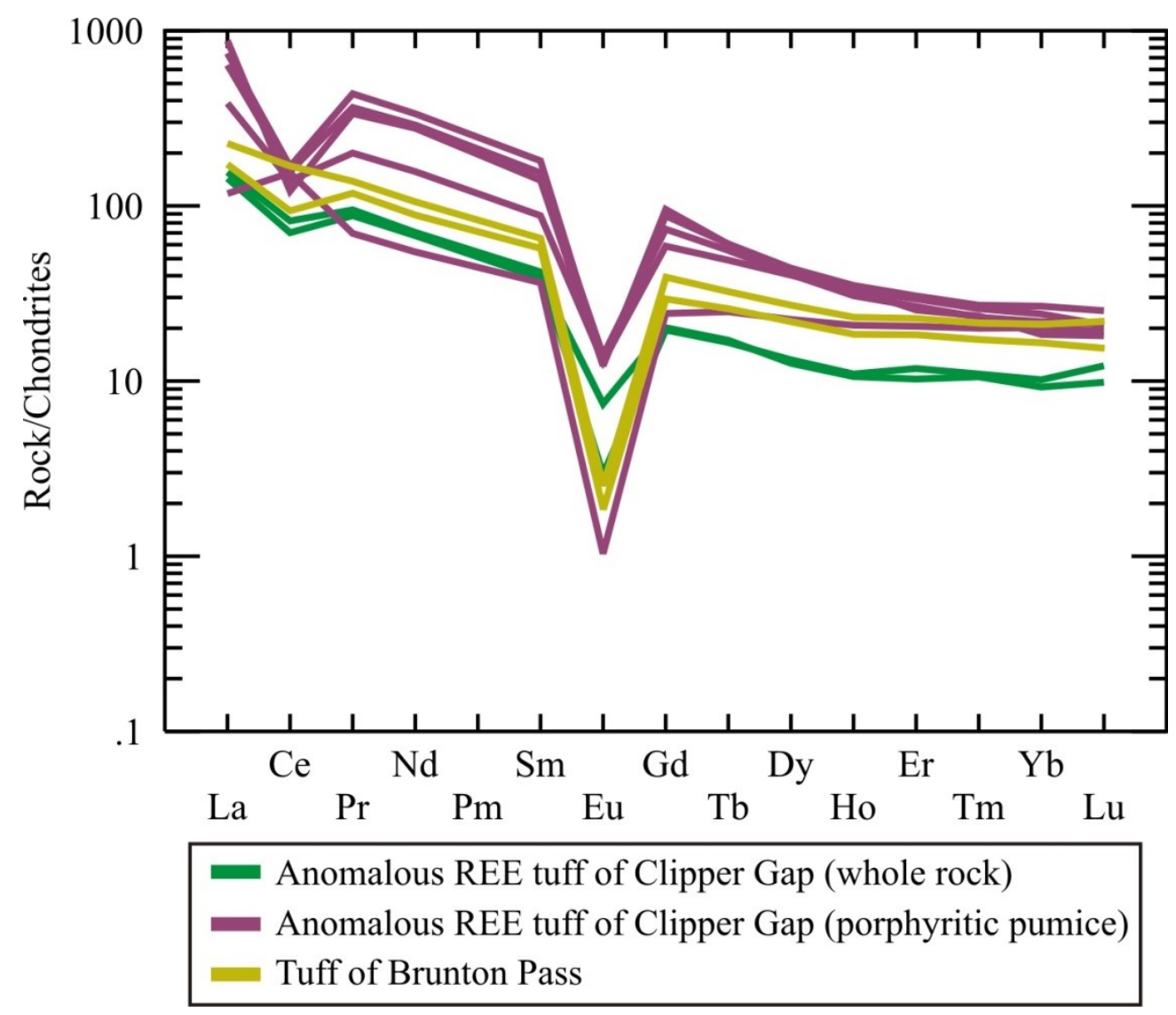

Figure 7.35: Chondrite normalized REE diagram showing the comparison between the anomalous REE Clipper Gap whole rock and porphyritic pumice samples to the tuff of Brunton Pass. The welded tuff of Brunton Pass sample with a small negative Ce anomaly shows less LREE enrichment than the anomalous REE Clipper Gap porphyritic pumice, but slightly more LREE enrichment than in the anomalous REE Clipper Gap whole rock samples (normalizing data from Sun and McDonough, 1989). 


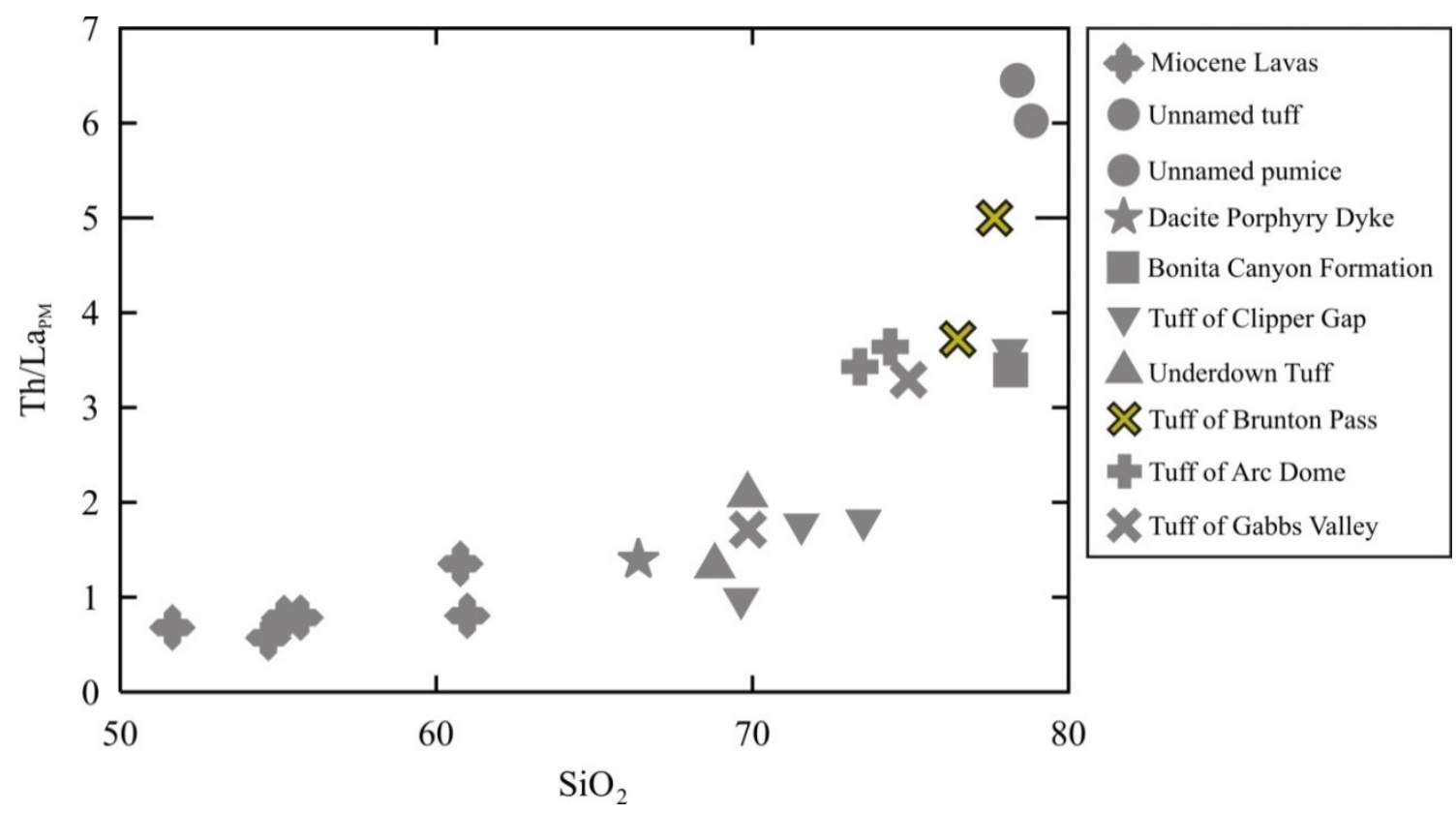

Figure 7.36: Primitive mantle normalized Th/La vs. $\mathrm{SiO}_{2}$ content indicating crustal addition into the Oligocene tuffs and Miocene lavas. The tuff of Brunton Pass samples plot along this curve, suggesting they may be derived from the same sources as the Oligocene tuffs and the Miocene lavas (primitive mantle normalizing values from Sun and McDonough, 1989).

The age of the tuff of Brunton Pass samples collected from the margins of the Underdown Caldera, in addition to its sparsely porphyritic texture, anomalous REEs observed in the welded sample, and similarity of the Th/La ratios to the other evolved (high-SiO ${ }_{2}$ ) Oligocene tuffs suggests that this unit may be from the tuff of Clipper Gap, as opposed to the tuff of Brunton Pass as it is currently identified. 


\subsubsection{The Terrill Mountains tuffs}

While the current mapped exposures of the tuff of Clipper Gap are primarily to the east of the caldera (Best et al., 2013), a series of ignimbrites of similar age have recently been found to the west of the caldera in the Terrill Mountains (Carlson, 2018) and were sampled for comparison. This unit was originally identified as the tuff of Gabbs Valley, however it has an age of $24.95 \pm 0.02 \mathrm{Ma}$, which is younger than the tuff of Gabbs Valley (Carlson, 2018).

As observed in Figures 6.10 and 6.13, the Terrill Mountains tuffs plot as a cluster at the most evolved (highest $\mathrm{SiO}_{2}$ ) end of the fractionation trends of the Oligocene tuffs on major element and trace element bivariate diagrams. However, as has already been discussed, most of the ignimbrites in the WNVF plot along these same major element fractionation trends, therefore other comparisons must be used to determine their relationship to the Underdown Tuff and tuff of Clipper Gap. Chondrite normalized REE and primitive mantle normalized trace element diagrams show how the Terrill Mountains tuffs have normalized patterns identical to the Underdown Tuff whole rock samples (Fig. 7.37). In a Th/La (normalized to primitive mantle) versus $\mathrm{SiO}_{2}$ diagram, the Terrill Mountains tuffs plot along the correlation formed by the Miocene lavas and Oligocene tuffs (Fig. 7.38). In this plot, the Terrill Mountains tuffs cluster with the tuff of Arc Dome, TgV2, Bonita Canyon Formation and tuff of Clipper Gap samples. This suggests that the Terrill Mountains tuffs (24.95 $\pm 0.02 \mathrm{Ma}$, Carlson, 2018) may be 
related to the Underdown Caldera ignimbrites with which they cluster, and that they may originate from the same sources as the Miocene lavas and the Oligocene tuffs.

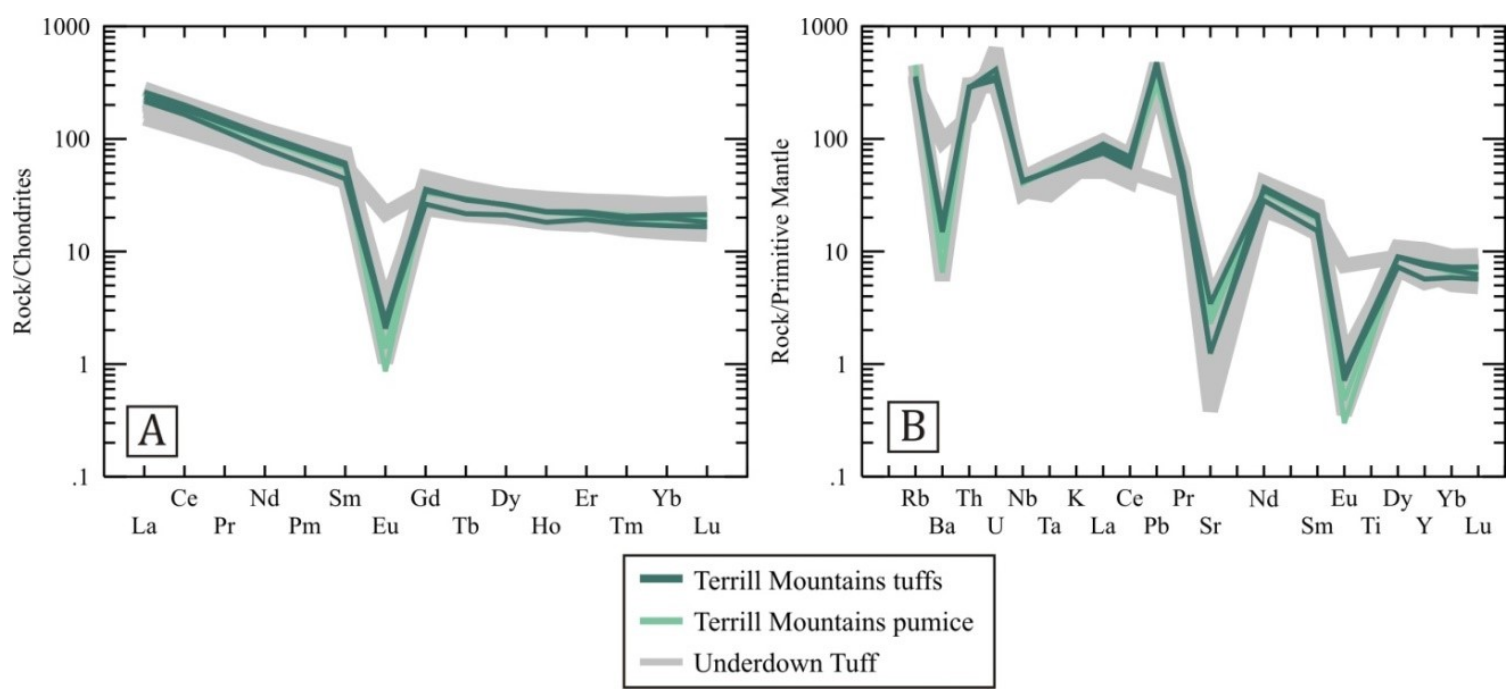

Figure 7.37: (A) Chondrite normalized REE and (B) primitive normalized trace element diagrams showing the comparison between the Underdown Tuff (whole rock samples), the Terrill Mountains tuffs and the Terrill Mountains pumice. The Terrill Mountains tuffs and pumice show normalized patterns nearly identical to the Underdown Tuff in both diagrams (normalizing data from Sun and McDonough, 1989). 


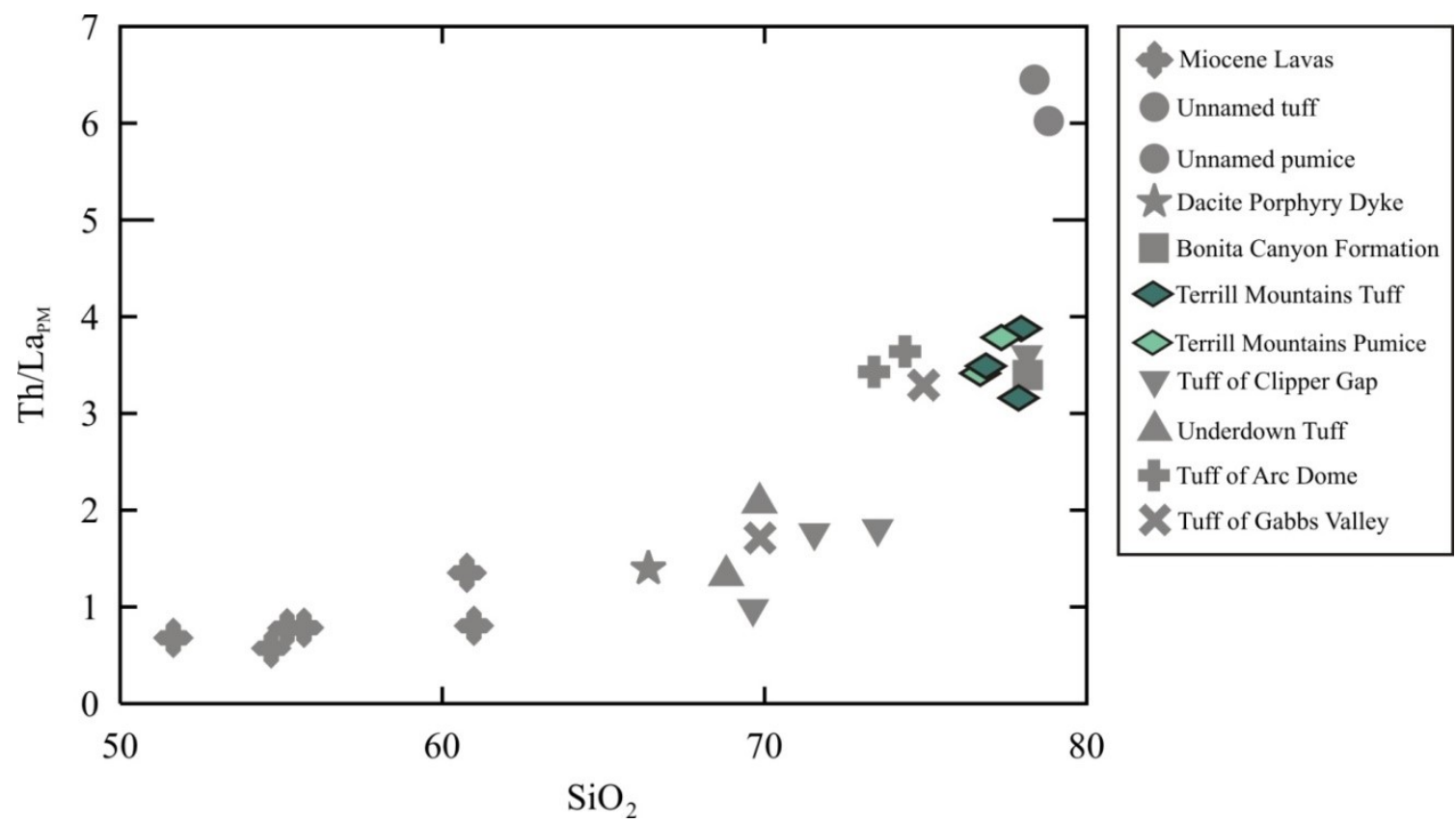

Figure 7.38: Primitive mantle normalized Th/La vs. $\mathrm{SiO}_{2}$ content indicating crustal addition into the Oligocene tuffs and Miocene lavas. The Terrill Mountains tuffs plot along this curve, suggesting they may be mixtures of the same sources for the Oligocene tuffs (primitive mantle normalizing values from Sun and McDonough, 1989).

As shown in Figure 7.1, the Sr isotopic data for the Terrill Mountains tuffs are suspect. Therefore, $\mathrm{Nd}$ and $\mathrm{Pb}$ isotopes were used to compare the Terrill Mountains tuffs with the ignimbrites from the Underdown Caldera (data for the tuff of Clipper Gap is from the acid-washed samples). On an initial $\varepsilon N d$ versus ${ }^{206} \mathrm{~Pb} /{ }^{204} \mathrm{~Pb}$ diagram, the Terrill Mountains tuffs show the most isotopic similarity to the Unnamed Tuff, Bonita Canyon Formation, Underdown Tuff and TgV3 (now assumed to be a Bonita Canyon Formation outflow tuff), while the acid-washed tuff of Clipper Gap samples plot at higher $\varepsilon N d$ values (Fig. 7.39A). On a ${ }^{208} \mathrm{~Pb} /{ }^{204} \mathrm{~Pb}$ versus ${ }^{206} \mathrm{~Pb} /{ }^{204} \mathrm{~Pb}$ diagram, the Terrill Mountains tuffs show the most similarity to the same units as the previous comparison (Unnamed 
tuff, Bonita Canyon Formation, Underdown Tuff) (Fig. 7.39B). However, the whole rock sample from the Terrill Mountains tuffs is more similar to TgV2 and the tuff of Arc Dome samples. Once again, the Terrill Mountains tuffs plot away from the acid-washed tuff of Clipper Gap samples. 


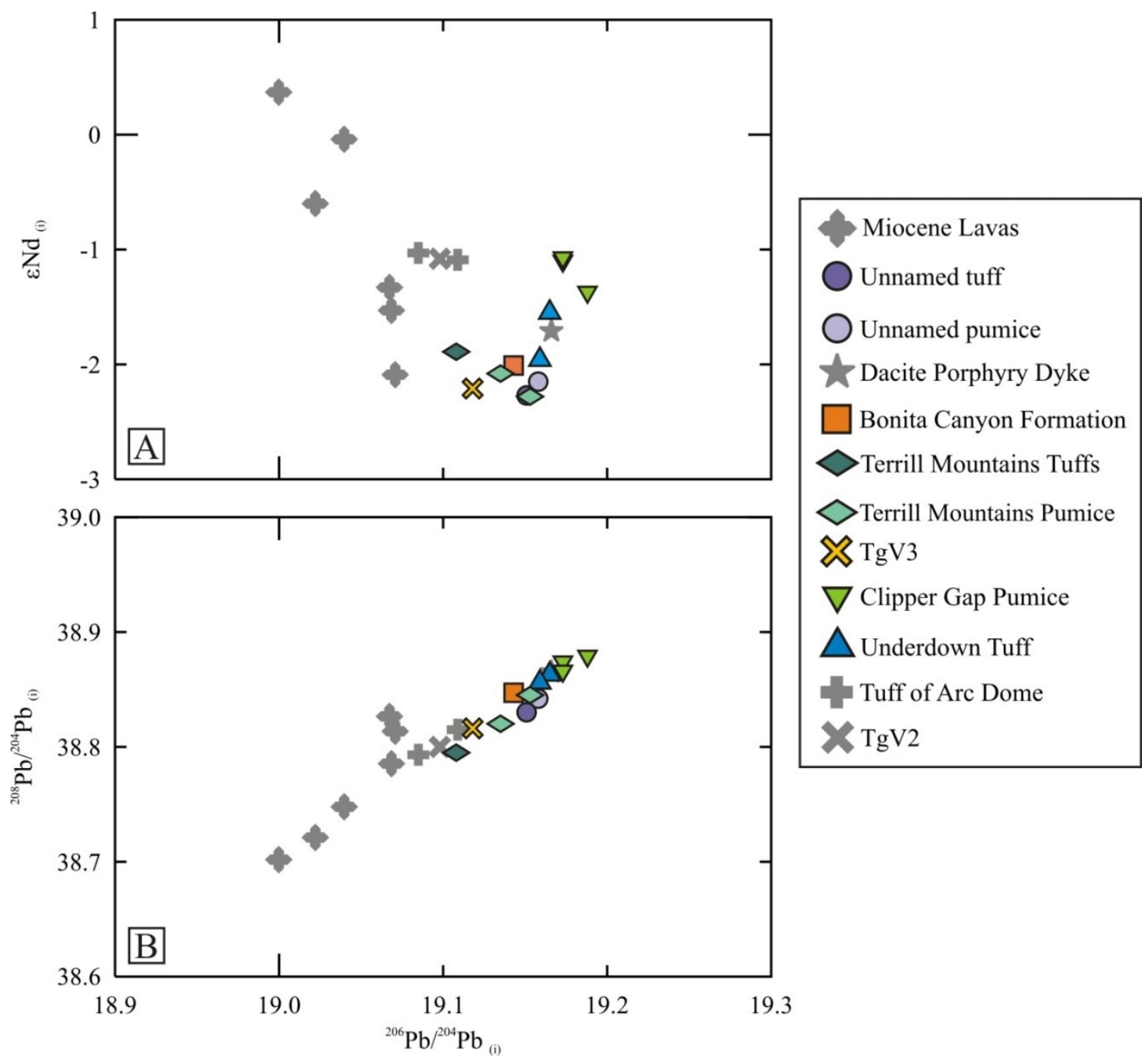

Figure 7.39: (A) Initial $\varepsilon N d$ versus ${ }^{206} \mathrm{~Pb} /{ }^{204} \mathrm{~Pb}$ and (B) initial ${ }^{208} \mathrm{~Pb} /{ }^{204} \mathrm{~Pb}$ versus ${ }^{206} \mathrm{~Pb} /{ }^{204} \mathrm{~Pb}$ showing the comparison between the Terrill Mountains tuffs and the other Oligocene tuffs from the Underdown Caldera complex. The $\mathrm{Nd}$ and $\mathrm{Pb}$ isotopic data of the Terrill Mountains tuffs show similarity to the Unnamed tuff, Bonita Canyon Formation, and $\mathrm{TgV} 3$, as well as the Underdown tuff in the $\mathrm{Pb}$ isotopic comparison. The samples show fewer isotopic similarities to the acid-wash tuff of Clipper Gap samples than the other ignimbrites. 
In summary, based on the age and geochemical characteristics of the Terrill Mountains tuffs, the ignimbrites are postulated to be outflow tuffs from the Underdown Caldera complex, and the position of the Terrill Mountains tuffs along the Th/La crustal addition curve suggests a similar origin as the other Oligocene tuffs. The Terrill Mountains tuffs isotopic data suggest that these units are most similar to the Bonita Canyon Formation. While the Unnamed tuff shows isotopic similarities to the Terrill Mountains tuffs (24.95 $\pm 0.02 \mathrm{Ma}$, Carlson, 2018) on the isotopic diagrams, the age of the Unnamed tuff (24.755 $\pm 0.037 \mathrm{Ma}, \mathrm{C}$. Henry, pers. comm., 2018), rules out that these two units are correlative. The identification of these units suggests that there are potentially more exposures of Underdown Caldera outflow tuff which exists to the west of the caldera complex, expanding the current range, and that the Bonita Canyon Formation may have a correlative tuff outside of the Underdown Caldera Complex. 


\subsubsection{Young Sierra Nevada tuffs}

Ignimbrites from the Sierra Nevada Mountains in California of similar age to the Underdown Caldera event are postulated to represent more outflow tuff from the Underdown Caldera, and will be referred to as the Young Sierra Nevada tuffs. The Young Sierra Nevada tuffs were found overlying the Nine Hill Tuff and have been dated at $24.888 \pm 0.015 \mathrm{Ma}$ (C. Henry, pers. comm., 2018) which is similar to the Underdown Tuff. The Young Sierra Nevada tuffs have been compared to the Underdown Tuff to investigate their possible relationship. Major and trace element geochemistry was provided by C. Henry (personal communication, 2018).

\section{Major Element Geochemistry}

Major element data of the Young Sierra Nevada tuffs are listed in Appendix I, Table IV. The Young Sierra Nevada tuffs are felsic in composition and plot within the rhyolite field in a TAS diagram (Le Maitre et al., 1989) within a cluster of Underdown Tuff samples (Fig. 7.40). On major element bivariate diagrams, the Young Sierra Nevada tuffs plot as a cluster with the cluster of Underdown Tuff whole rock samples for all major element oxides (Fig. 7.41). 


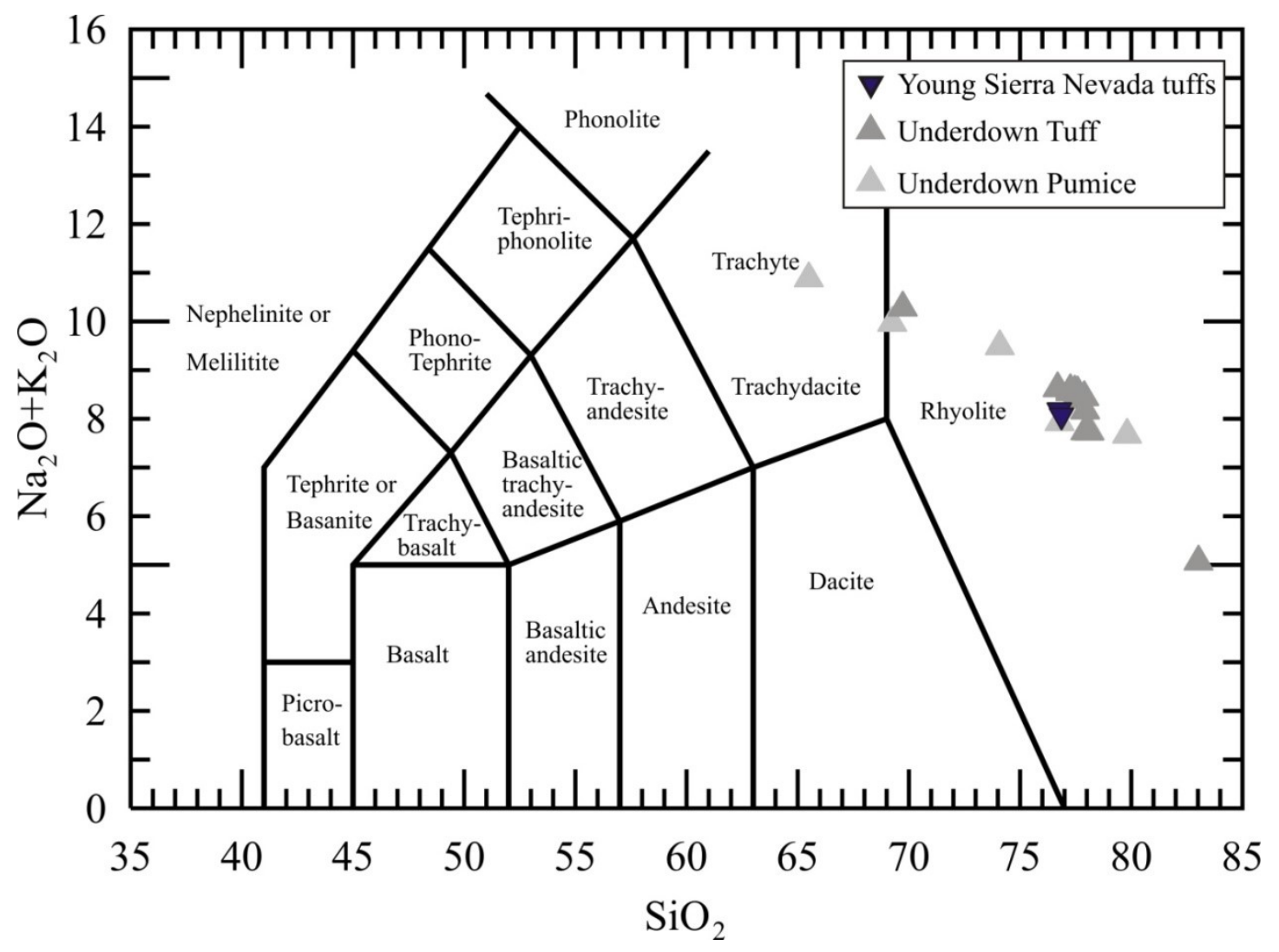

Figure 7.40: Total alkalis-silicate diagram (Le Maitre et al., 1989) comparing the Young Sierra Nevada tuffs to the Underdown Tuff. The Young Sierra Nevada tuffs are felsic in composition and plot in the rhyolite field with a cluster of the Underdown Tuff whole rock samples. 

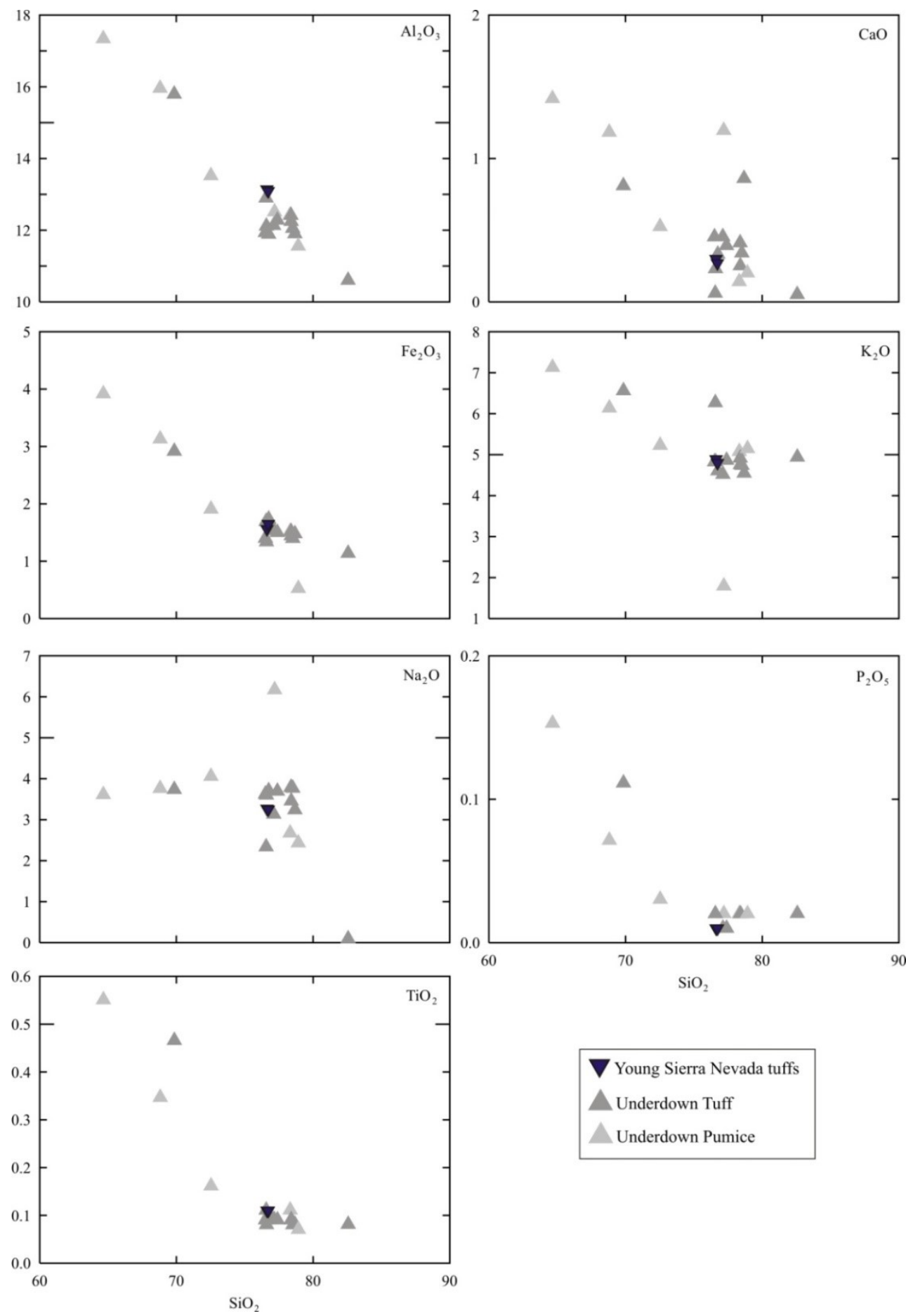

$\nabla$ Young Sierra Nevada tuffs

Underdown Tuff

Underdown Pumice

Figure 7.41: Major element variation diagrams comparing the Young Sierra Nevada tuffs with the Underdown Tuff. The Young Sierra Nevada tuffs show similar major element oxide abundances as clusters of the Underdown Tuff whole rocks in all major element oxides. 


\section{Trace Element Geochemistry}

Trace element data for the Young Sierra Nevada tuffs are listed in Appendix I, Table VI. Similar to the major element bivariate diagrams, the Young Sierra Nevada tuffs show similar trace element concentrations as whole rock samples from the Underdown Tuff. In all trace element versus $\mathrm{SiO}_{2}$ comparisons the Young Sierra Nevada tuffs plot as a cluster with the Underdown Tuff whole rock samples (Fig. 7.42).

In a chondrite normalized rare earth element diagram, the Young Sierra Nevada tuffs shows the same enrichment in LREEs and flattening pattern to the HREEs as the Underdown Tuff whole rock samples (Fig. 7.43). The negative Eu anomaly observed in the Young Sierra Nevada tuffs is also identical to the negative Eu anomaly observed in the Underdown Tuff. Similarly, in a primitive mantle trace element diagram, the Young Sierra Nevada tuffs show a pattern nearly identical to the Underdown Tuff whole rock samples (Fig 7.43). The same negative anomalies are observed in $\mathrm{Ba}, \mathrm{Sr}$, and $\mathrm{Eu}$, as well as the same positive $\mathrm{Pb}$ anomaly. In addition, the Young Sierra Nevada tuffs lack a negative $\mathrm{Nb}$-Ta anomaly which is also mostly absent from the Underdown Tuff.

The Young Sierra Nevada tuffs were also plotted with the Oligocene tuffs and Miocene lavas on a Th/La (normalized to primitive mantle) versus $\mathrm{SiO}_{2}$ diagram (Fig. 7.44). The Young Sierra Nevada tuffs plot within the correlation formed by the Miocene lavas and Oligocene tuffs, suggesting that they have a similar input of crustal addition into their melt as ignimbrites from the Underdown Caldera complex, and may originate from the same sources as the Miocene lavas and the Underdown Caldera ignimbrites. 

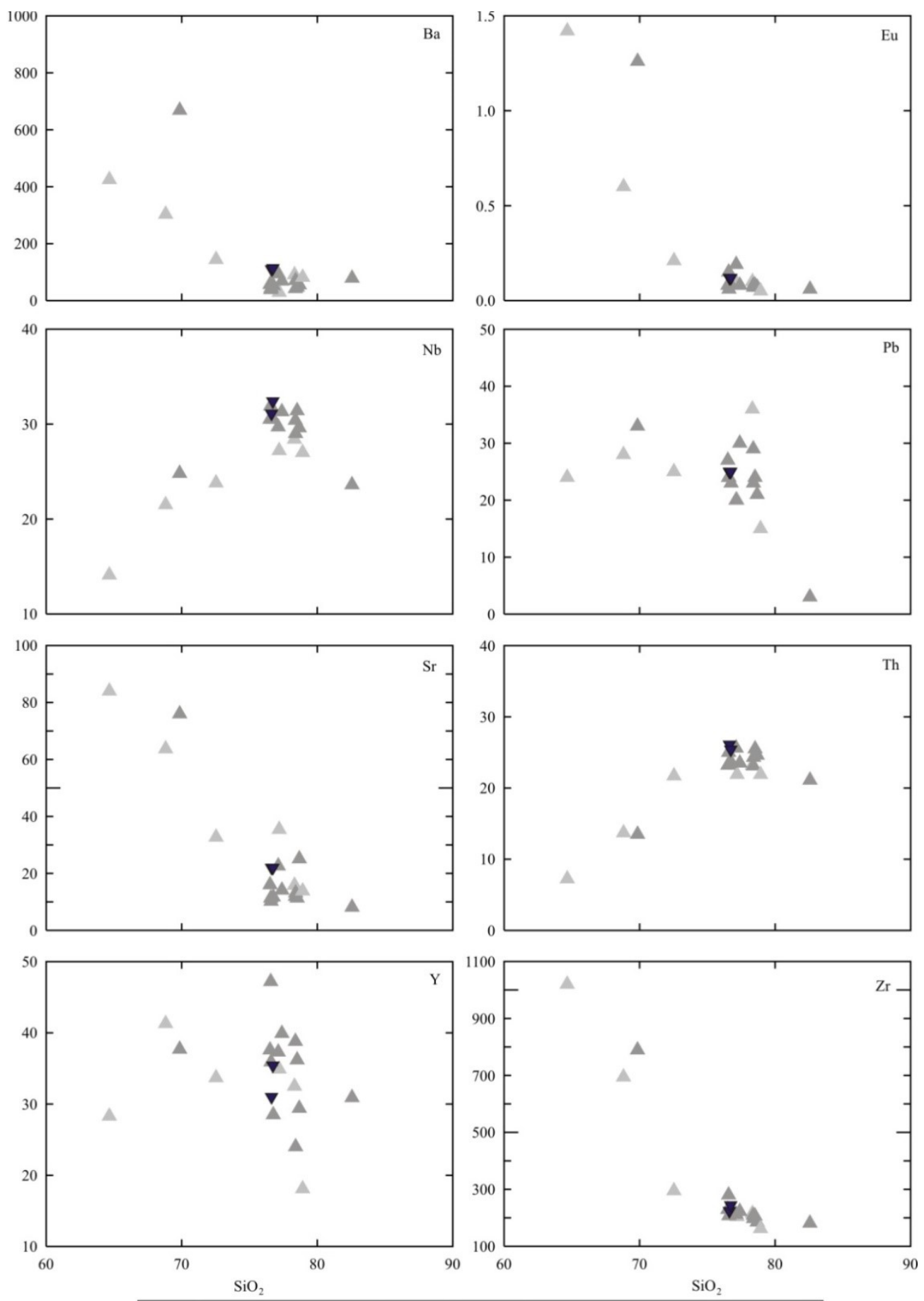

Young Sierra Nevada tuffs

Underdown Tuff

Underdown Pumice

Figure 7.42: Trace element bivariate diagrams comparing the Young Sierra Nevada tuffs to the Underdown Tuff. The Young Sierra Nevada tuffs plot as a cluster with the Underdown Tuff whole rock samples in all trace element comparisons except for $Y$ which appears scattered in both units. 

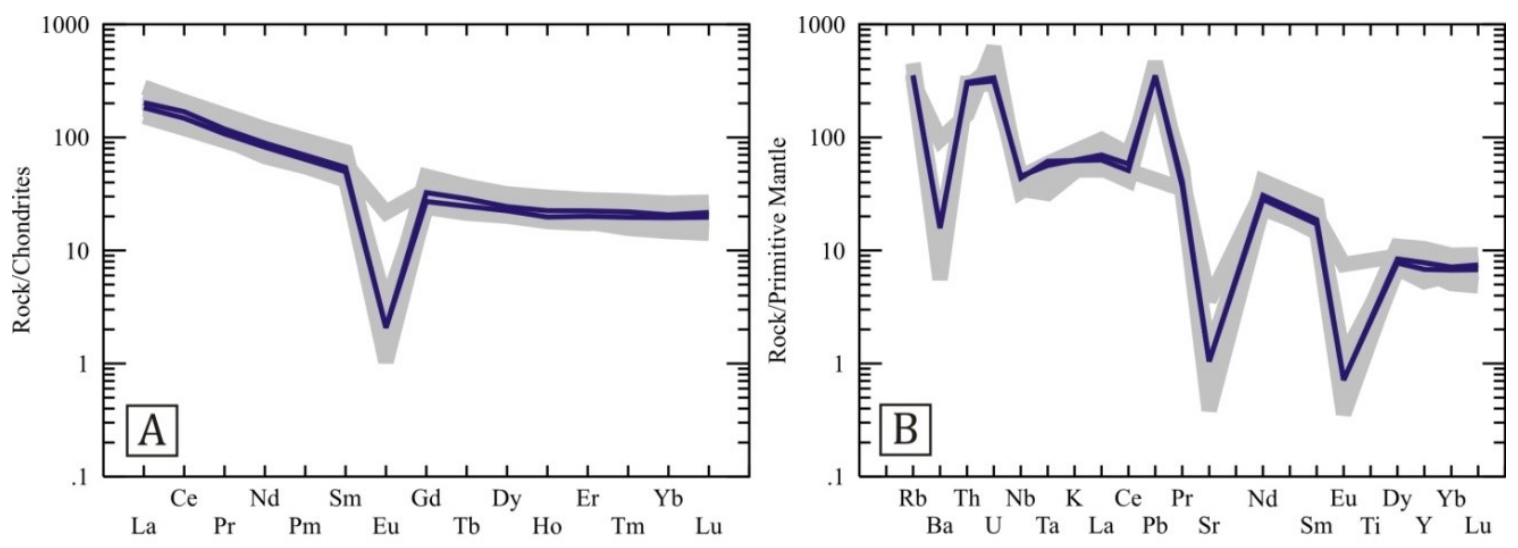

- Young Sierra Nevada tuffs

- Underdown Tuff

Figure 7.43: (A) Chondrite normalized REE and (B) primitive mantle normalized trace element diagrams comparing the Young Sierra Nevada tuffs with the Underdown Tuff. In panel (A) the Young Sierra Nevada tuffs show the same enrichment in LREEs and flattening pattern to the HREEs as the Underdown Tuff, as well as a similar negative Eu anomaly. In panel (B) the Young Sierra Nevada tuffs shows the same sized negative anomalies in $\mathrm{Ba}, \mathrm{Sr}$, and $\mathrm{Eu}$, and the same sized positive $\mathrm{Pb}$ anomaly. The unit also lacks a negative $\mathrm{Nb}$-Ta anomaly which is also observed in the Underdown Tuff (normalizing data from Sun and McDonough, 1989). 


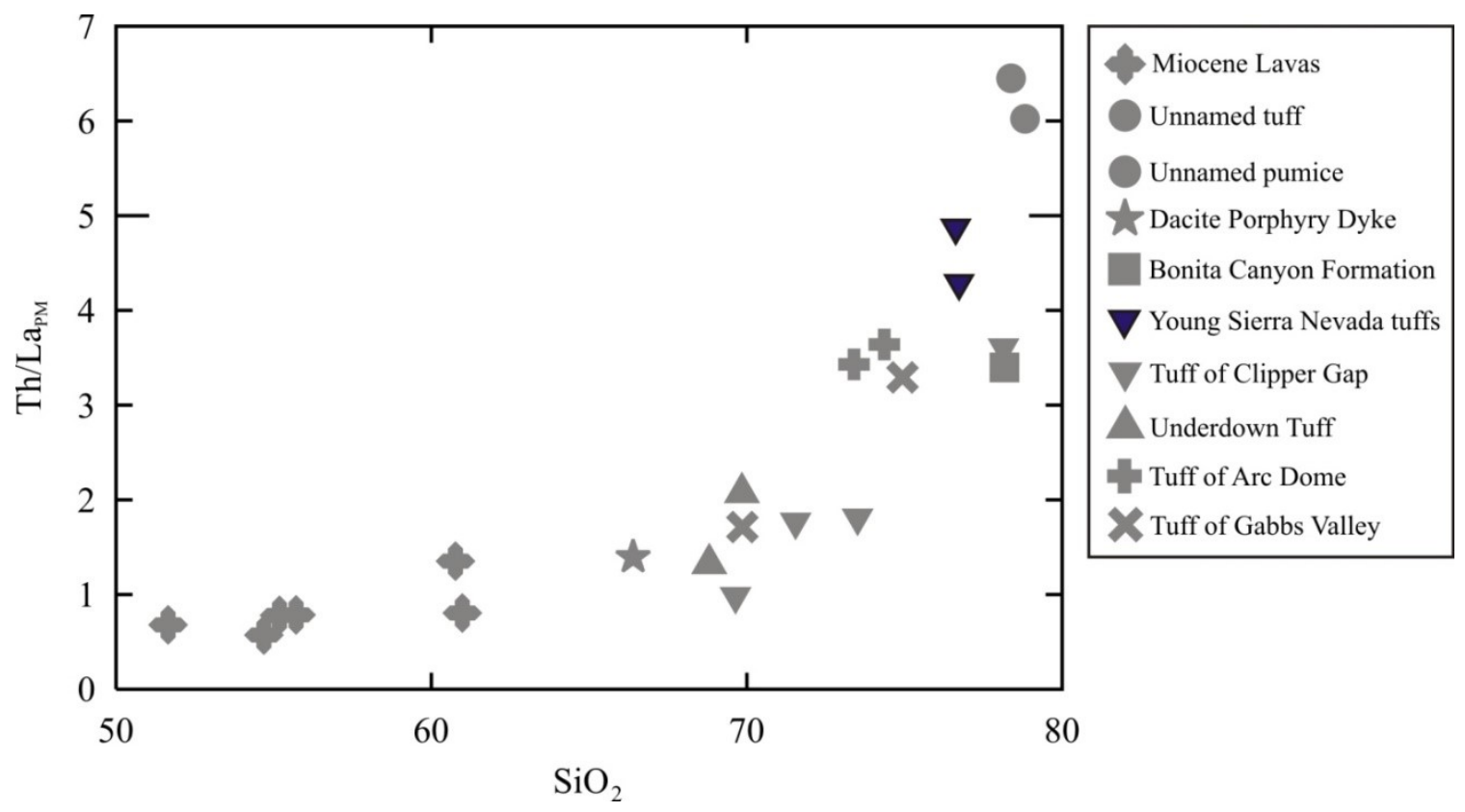

Figure 7.44: Primitive mantle normalized Th/La vs. $\mathrm{SiO}_{2}$ content indicating crustal addition into the Oligocene tuffs and Miocene lavas. The Young Sierra Nevada tuffs plot along this curve, suggesting they may be derived from the same sources as the Oligocene tuffs and the Miocene lavas (primitive mantle normalizing values from Sun and McDonough, 1989). 
On the crustal addition diagram (Fig. 7.44), the Young Sierra Nevada tuffs appear to show more similarity to the Bonita Canyon Formation than the Underdown Tuff. To further investigate this comparison, the Young Sierra Nevada tuffs and Bonita Canyon Formation were plotted on chondrite normalized REE and primitive mantle normalized trace element diagrams (Fig. 7.45). On these plots, the Young Sierra Nevada tuffs appear similar to the Bonita Canyon Formation (especially the most chemically evolved Bonita Canyon Formation samples), however do not show the identical normalized patterns which were observed when compared to the Underdown Tuff (Fig. 7.43).

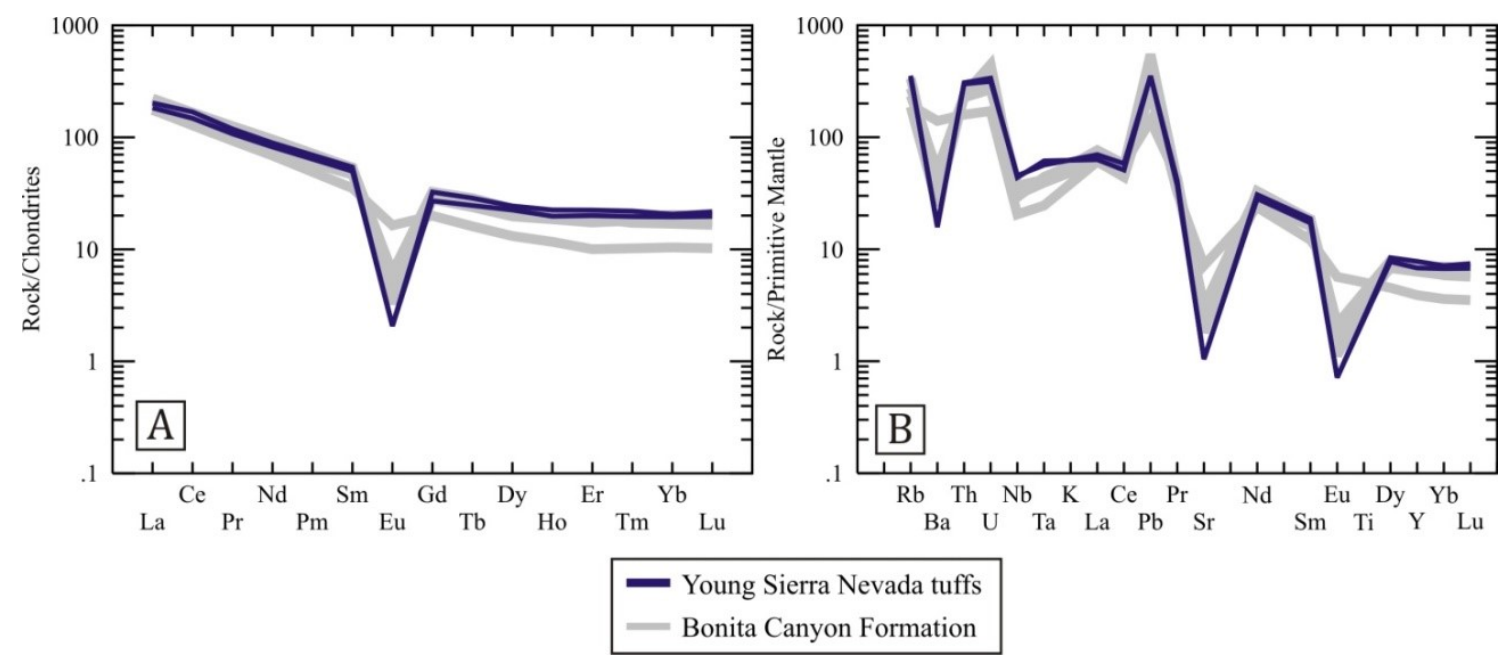

Figure 7.45: (A) Chondrite normalized REE and (B) primitive mantle normalized trace element diagrams showing the comparison between the Young Sierra Nevada tuffs and the Bonita Canyon Formation. While the normalized patterns are similar in both units, they are not identical as was observed when the Young Sierra Nevada tuffs were compared to the Underdown Tuff. The Young Sierra Nevada tuffs appear to have higher enrichments of $\mathrm{Th}, \mathrm{Nb}$ and $\mathrm{Ta}$ than the Bonita Canyon Formation, as well as slightly larger negative Sr and Eu anomalies (normalizing data from Sun and McDonough, 1989). 
As the Young Sierra Nevada tuffs appear, with the available major and trace element data, to be nearly indistinguishable from the Underdown Tuff, it is possible that they may represent an exposure of outflow tuff in California, far to the west of the Underdown Caldera complex. However, the diagram of crustal addition suggests a higher crustal component in the Young Sierra Nevada Tuffs than in the Underdown Tuff, which is more similar to the Bonita Canyon Formation. Comparison using isotopic data would be imperative to fully determine the identity of the Yong Sierra Nevada tuffs.

Paleovalleys would have played an integral role in the distribution of outflow tuff from the Underdown Caldera, depositing the Terrill Mountains tuffs, the Young Sierra Nevada tuffs, and likely other unidentified exposures of outflow tuff in western Nevada and the Sierra Nevada Mountains. At the time of the Underdown Caldera magmatic event, the Sierra Nevada Mountains were not the topographic barrier they are today, as the region had not yet been affected by Great Basin extension. Henry and John (2013) illustrate the location and flow direction of paleovalleys in the Western Great Basin, however all identified western outflow tuffs on this map are related to the Nine Hill Tuff and tuff of Campbell Creek (Fig. 7.46). However, this isn't to say that there are no western outflow tuffs from the Underdown Caldera complex, as indicated by the Terrill Mountains tuffs and the Young Sierra Nevada tuffs. Based on the presented geochemical data, it is possible that these two western outflow units could be related; however, additional data for each unit, as well as isotopic data for the Young Sierra Nevada tuffs, would enable a more complete comparative study. 


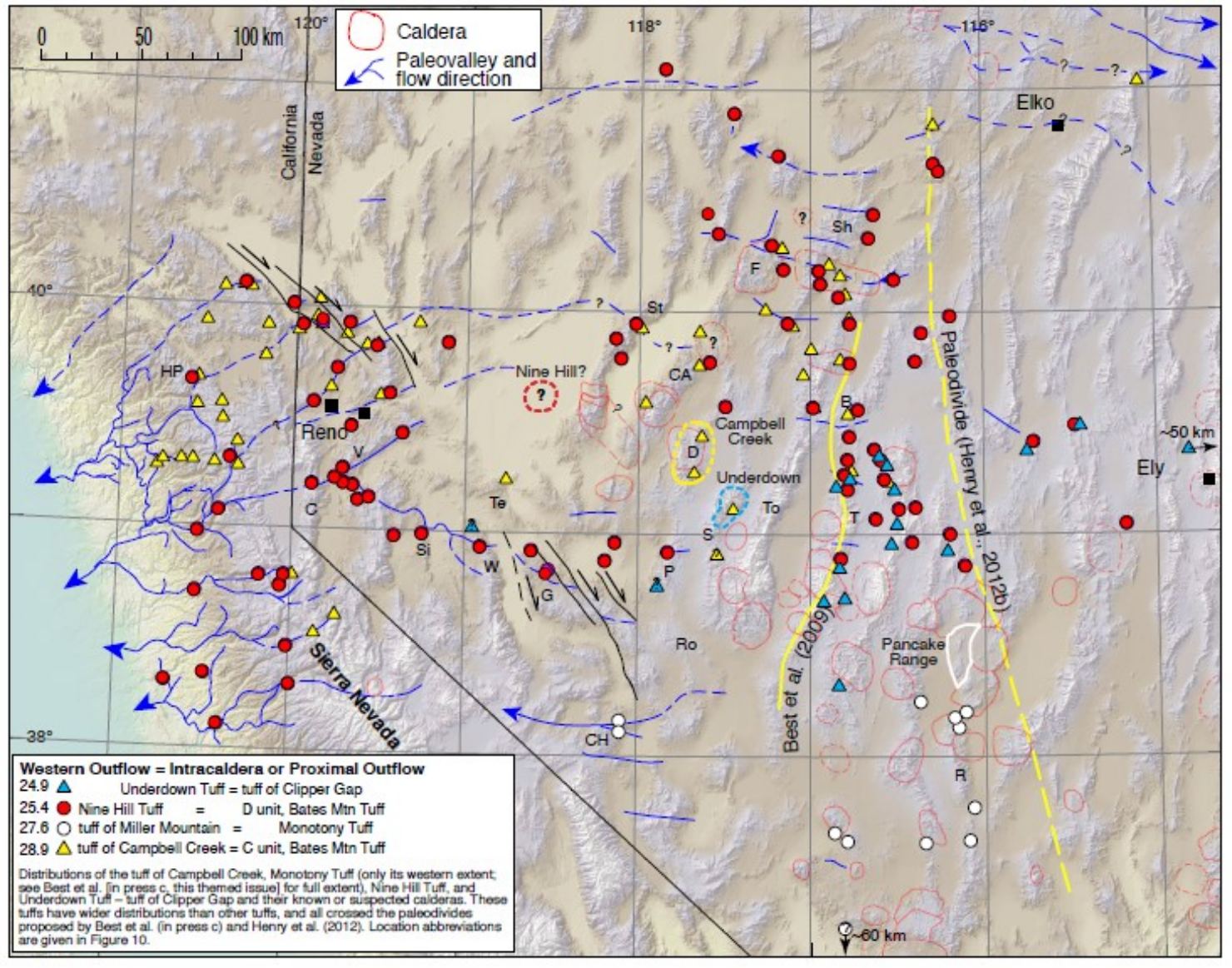

Figure 7.46: Map of the Western Great Basin, showing the location of the Underdown Tuff (light blue dashed circle) and the placement and flow direction of paleovalleys. The high concentration of paleovalleys travelling across the Nevadaplano and through what is now the Sierra Nevada Mountains would have funneled outflow tuffs from the Underdown Caldera to the west of the paleodivide (from Henry and John, 2013). 


\subsection{The Origin of Porphyritic Pumice in the Underdown Tuff}

Porphyritic pumice was present in two ignimbrite units in the Underdown caldera complex; the Underdown Tuff and the tuff of Clipper Gap. This crystal rich pumice is a stark contrast to the white, aphyric pumice which is found in the vast majority of Underdown Tuff and tuff of Clipper Gap exposures. The question of where these two pumice types originate from is the focus of this section. All samples of porphyritic pumice from the tuff of Clipper Gap contain anomalous REE abundances and therefore only the porphyritic pumice from the Underdown Tuff will be discussed.

\subsubsection{Field Observations and Petrography}

In the field, the porphyritic pumice had a characteristic dark purple colour and was observed to contain phenocrysts of two feldspars and quartz. The pumice ranged in shape from very small and flattened to very large (Fig. 7.47). In general, the porphyritic pumice appeared highly altered under petrographic observation. This included alteration in the glassy matrix and alteration of the phenocrysts. The porphyritic pumice samples were determined to contain plagioclase + sanidine + quartz \pm trace amounts of biotite and hornblende. 


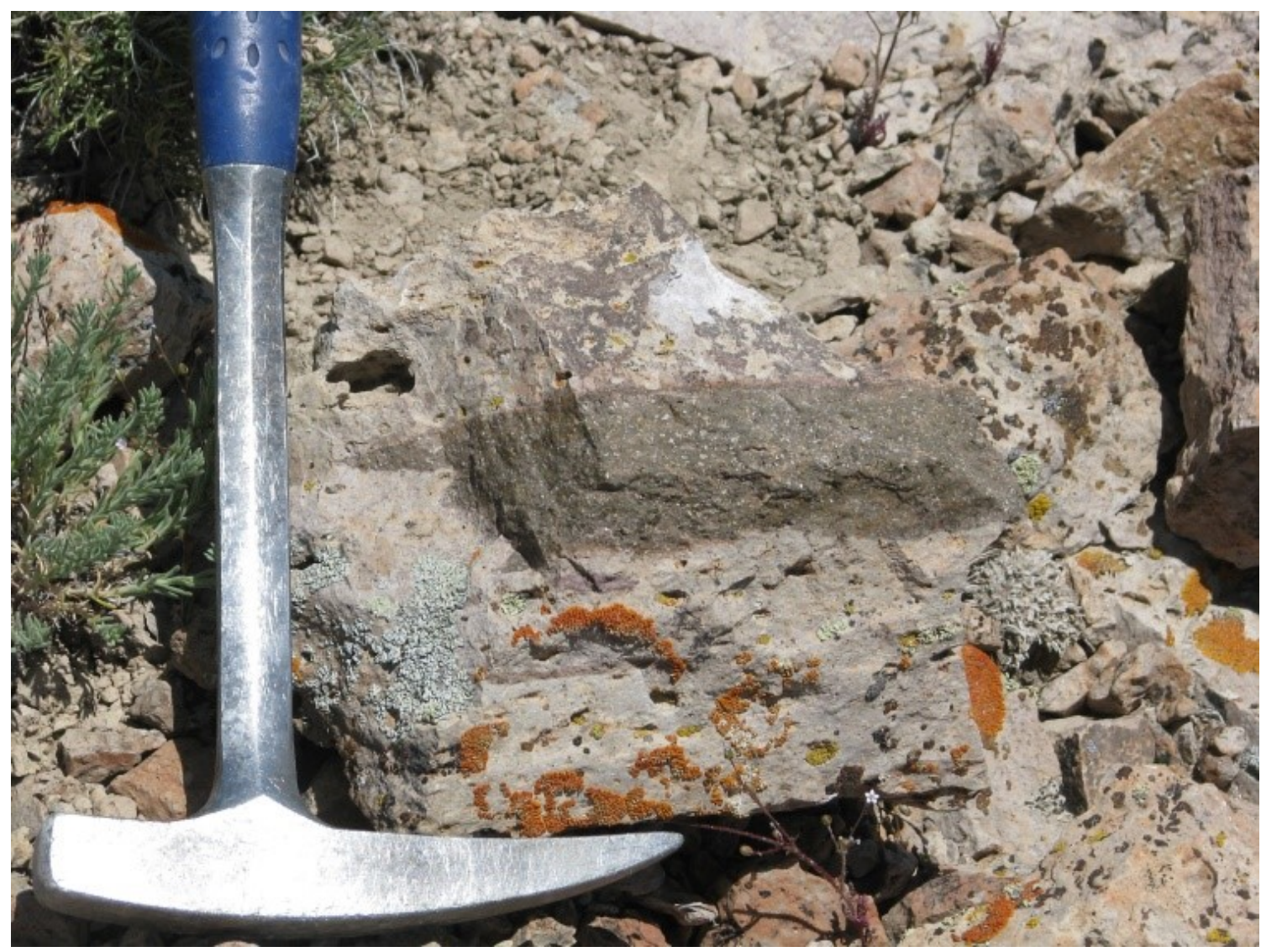

Figure 7.47: Field photograph of a porphyritic pumice from the Underdown Tuff. Porphyritic pumices observed in the field in the Underdown Tuff and the tuff of Clipper Gap are purple and contain quartz and feldspar phenocrysts. The hammer head is $18 \mathrm{~cm}$ long. 


\subsubsection{Major Element Geochemistry}

The porphyritic pumice of the Underdown Tuff plots in a trend from rhyolite to trachyte on a TAS diagram (Fig. 7.48, Le Maitre, 1989). The Underdown Tuff whole rock samples generally plot as a cluster between 75-80 weight percent in the rhyolite field with one outlying high silica rhyolite sample. The outlying sample is interpreted to have undergone post-deposition silicification, and will be removed from the remainder of the discussion. Two porphyritic pumice samples plot with the cluster of whole rock data in the rhyolite field. Major element oxide concentrations in the porphyritic pumice samples show more compositional variation than in the Underdown Tuff whole rock samples (Fig. 7.49). Generally, the porphyritic pumice have a lower $\mathrm{SiO}_{2}$ content than whole rock samples however, two porphyritic pumice samples plot in a cluster with whole rock and the white pumice. 


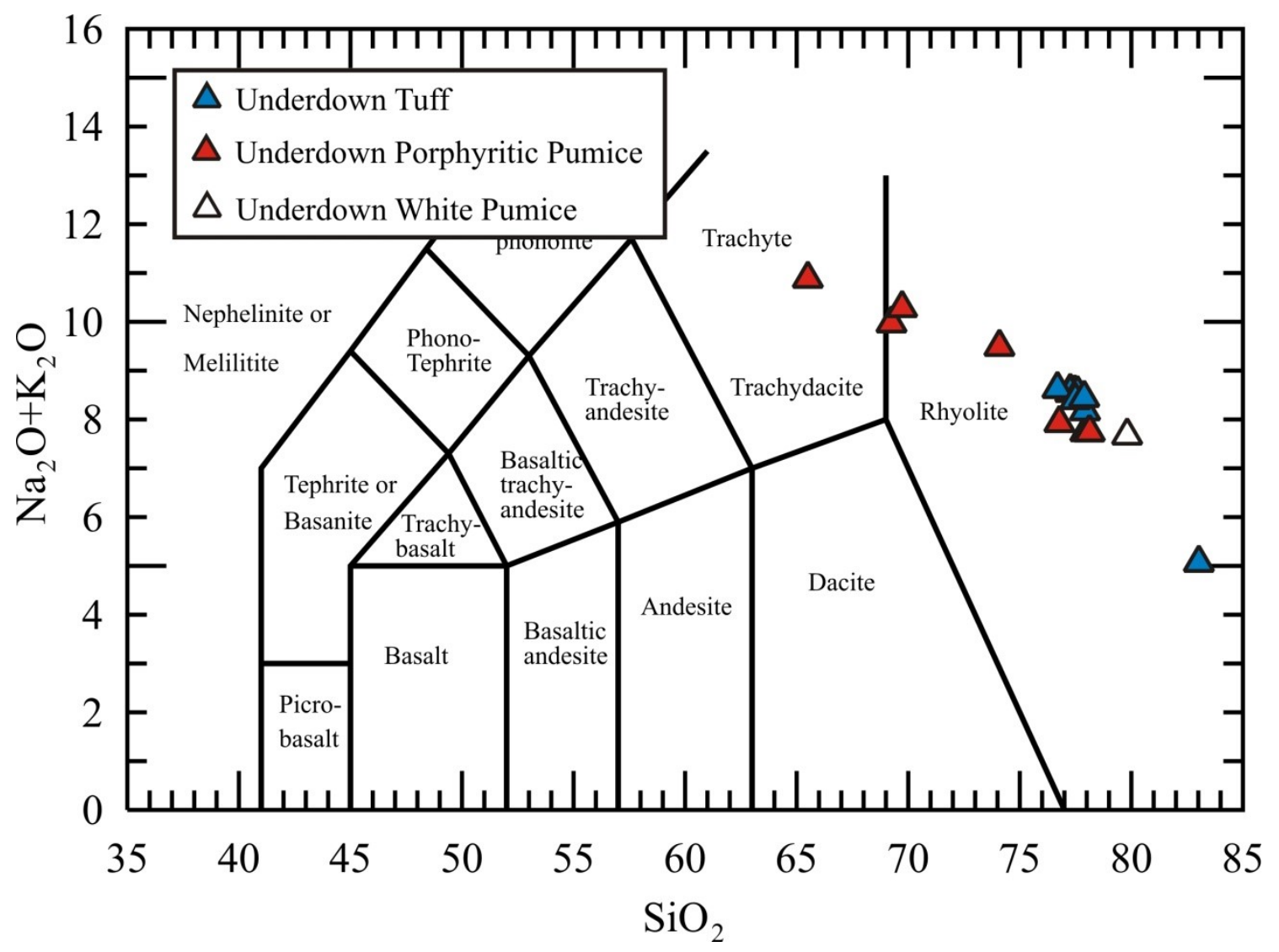

Figure 7.48: Total alkalis-silica diagram (Le Maitre et al., 1989) of the Underdown Tuff, porphyritic pumice and white pumice. The porphyritic pumice plots in a trend from rhyolite into the trachyte field while the Underdown whole rock samples plot as a cluster in the rhyolite field with one outlying high silica rhyolite sample. The white pumice is rhyolitic in composition. The high-silica rhyolite outlier $\left(\sim 83 \% \mathrm{SiO}_{2}\right)$ is interpreted to have undergone post-deposition silicification. 

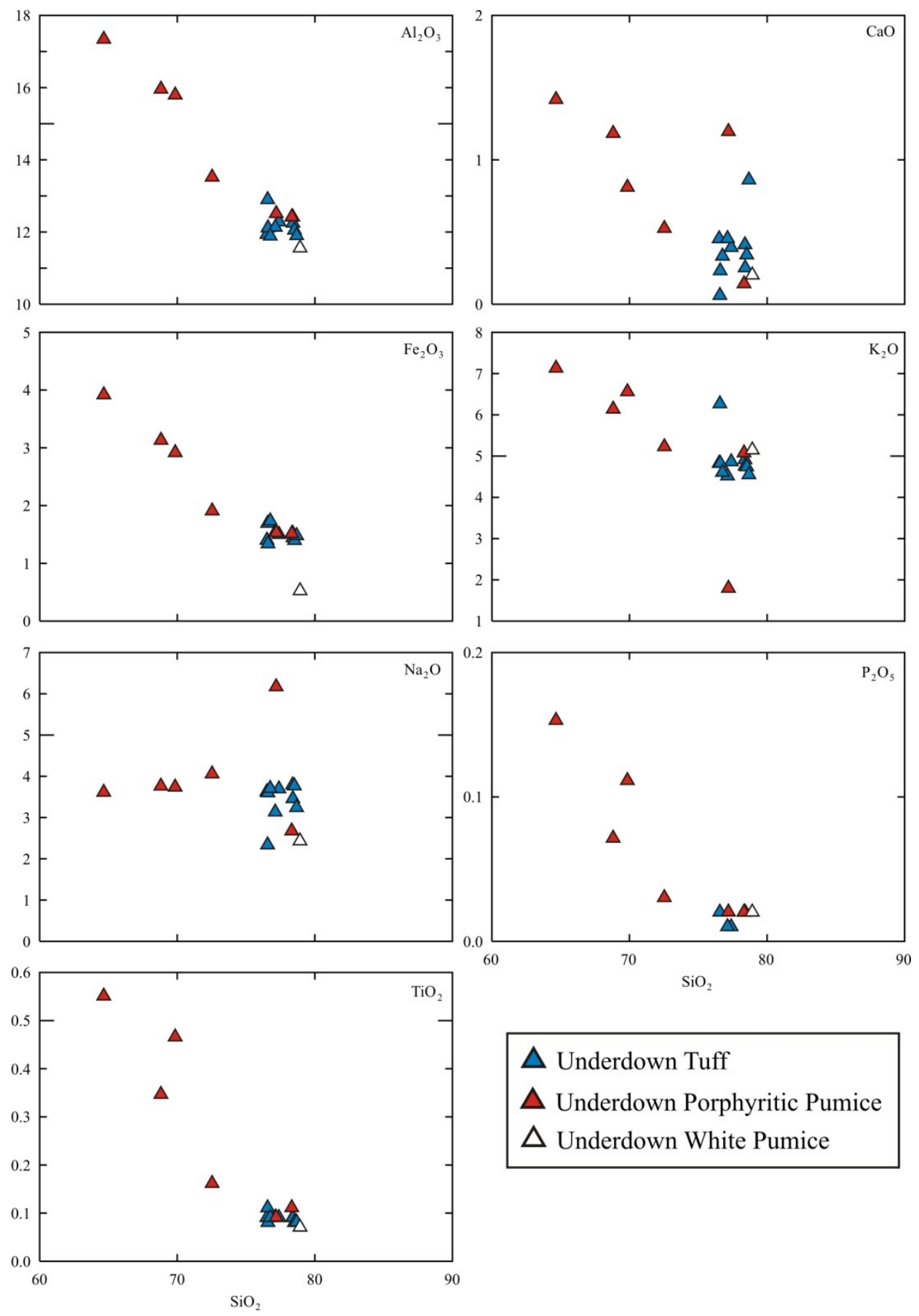

$\Delta$ Underdown Tuff

$\Delta$ Underdown Porphyritic Pumice

$\triangle$ Underdown White Pumice

Figure 7.49: Major element oxide versus $\mathrm{SiO}_{2}$ content diagrams for the Underdown Tuff. Porphyritic pumice is generally more primitive than the whole rock and white pumice of the Underdown Tuff, with two exceptions. The porphyritic pumice show more compositional variation between the samples than the whole rock samples which generally cluster between 75-80 weight percent. 


\subsubsection{Trace Element Geochemistry}

Barium, $\mathrm{Eu}, \mathrm{Sr}$, and $\mathrm{Zr}$ behave as compatible elements in the Underdown porphyritic pumice while $\mathrm{Nb}$ and Th behave as incompatible elements. $\mathrm{Pb}$ and $\mathrm{Y}$ show scattered abundances in the porphyritic pumice data. The Underdown Tuff whole rock samples plot as a cluster in all trace elements except for $\mathrm{Pb}$ and $\mathrm{Y}$ where the samples show more scatter (Fig. 7.50).

A chondrite normalized rare earth element diagram (Fig. 7.51A) comparing average whole rock, average porphyritic pumice and white pumice from the Underdown Tuff shows that whole rock, white pumice, and porphyritic pumice are enriched in LREEs relative to the HREEs, while the porphyritic pumice appears to be slightly more enriched in the LREEs compared to the whole rock samples. The whole rock and white pumice samples have similar large negative Eu anomalies that are larger than those in the porphyritic pumices. The average porphyritic pumice and whole rock samples show a flattened pattern in the HREEs, while the white pumice shows a more depleted pattern in the HREEs. On a primitive mantle normalized trace element diagram (Fig. 7.51B) the whole rock and white pumice samples show similar patterns except in the HREEs. The average porphyritic pumice shows smaller negative anomalies in $\mathrm{Ba}, \mathrm{Sr}$, and $\mathrm{Eu}$ than are

observed in the whole rock and white pumice. The porphyritic pumices also include a lower Th and higher $\mathrm{U}$ enrichment than the whole rock and white pumice, and have a more pronounced $\mathrm{Nb}$-Ta anomaly. 
The most evolved and least evolved porphyritic pumice samples were plotted on chondrite normalized REE and primitive mantle normalized trace element diagrams with the average whole rock samples and white pumice sample to illustrate the variation in trace element abundance across the porphyritic pumices (Fig. 7.52). In both diagrams, the most evolved porphyritic pumice (16-SM-29A) shows a similar pattern of LREE enrichment and HREE flattening as the average whole rock. However, the least evolved porphyritic pumice (17-SM-17C) shows a much smaller Eu anomaly on the chondrite normalized REE plot. When normalized to primitive mantle, the least evolved porphyritic pumice shows differences in the $\mathrm{Ba}, \mathrm{Sr}$, and $\mathrm{Eu}$ anomalies (all are smaller negative anomalies), lower enrichment in Th, higher enrichment in $\mathrm{U}$, and a more negative $\mathrm{Nb}-\mathrm{Ta}$ anomaly. 

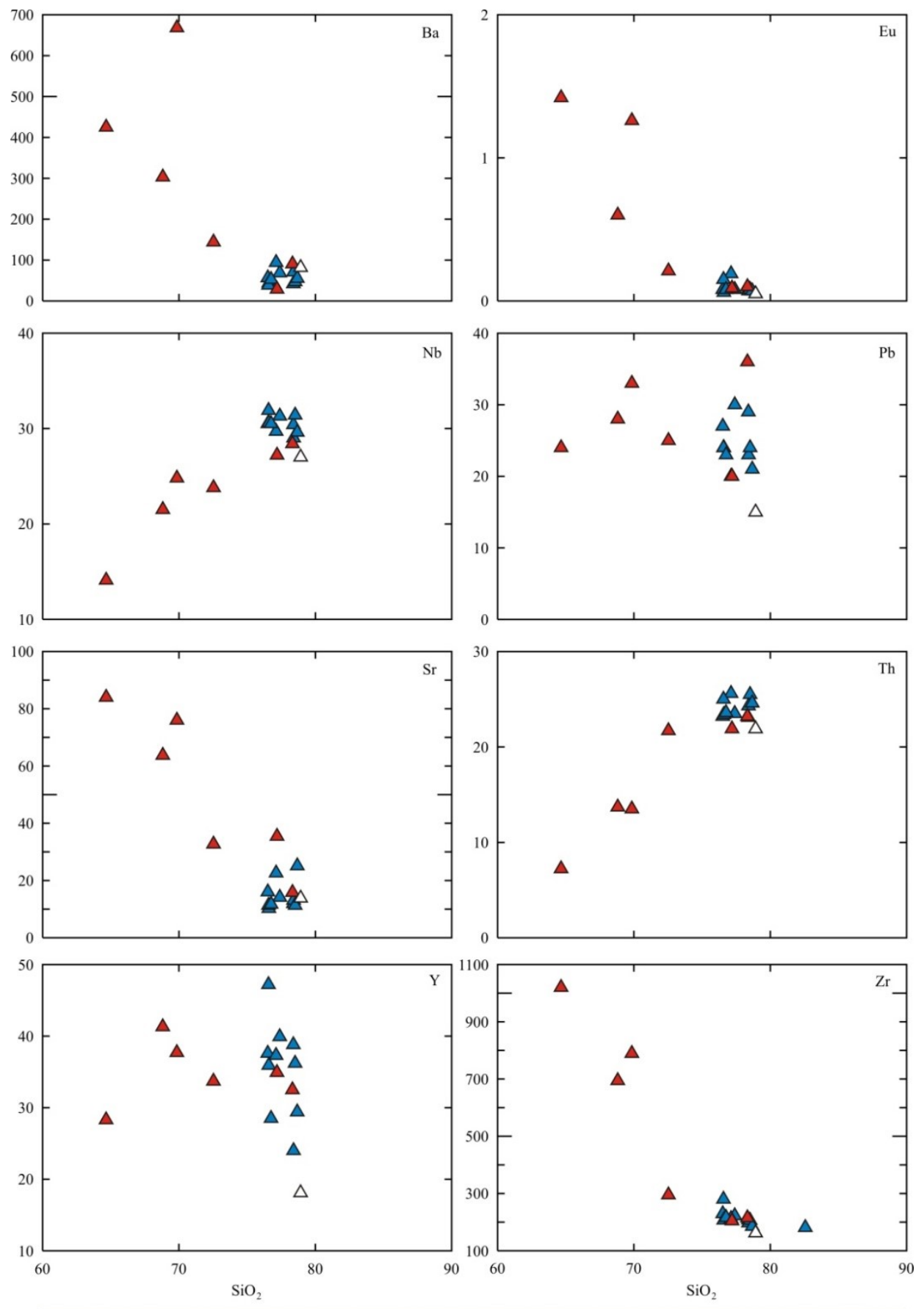

$\Delta$ Underdown Tuff $\Delta$ Underdown Porphyritic Pumice $\Delta$ Underdown White Pumice

Figure 7.50: Trace element bivariate diagrams showing the compatibility of trace elements in the Underdown Tuff whole rock, porphyritic pumice and white pumice. Similar to the major element oxides, the porphyritic pumice show more compositional variation than the whole rock samples. 


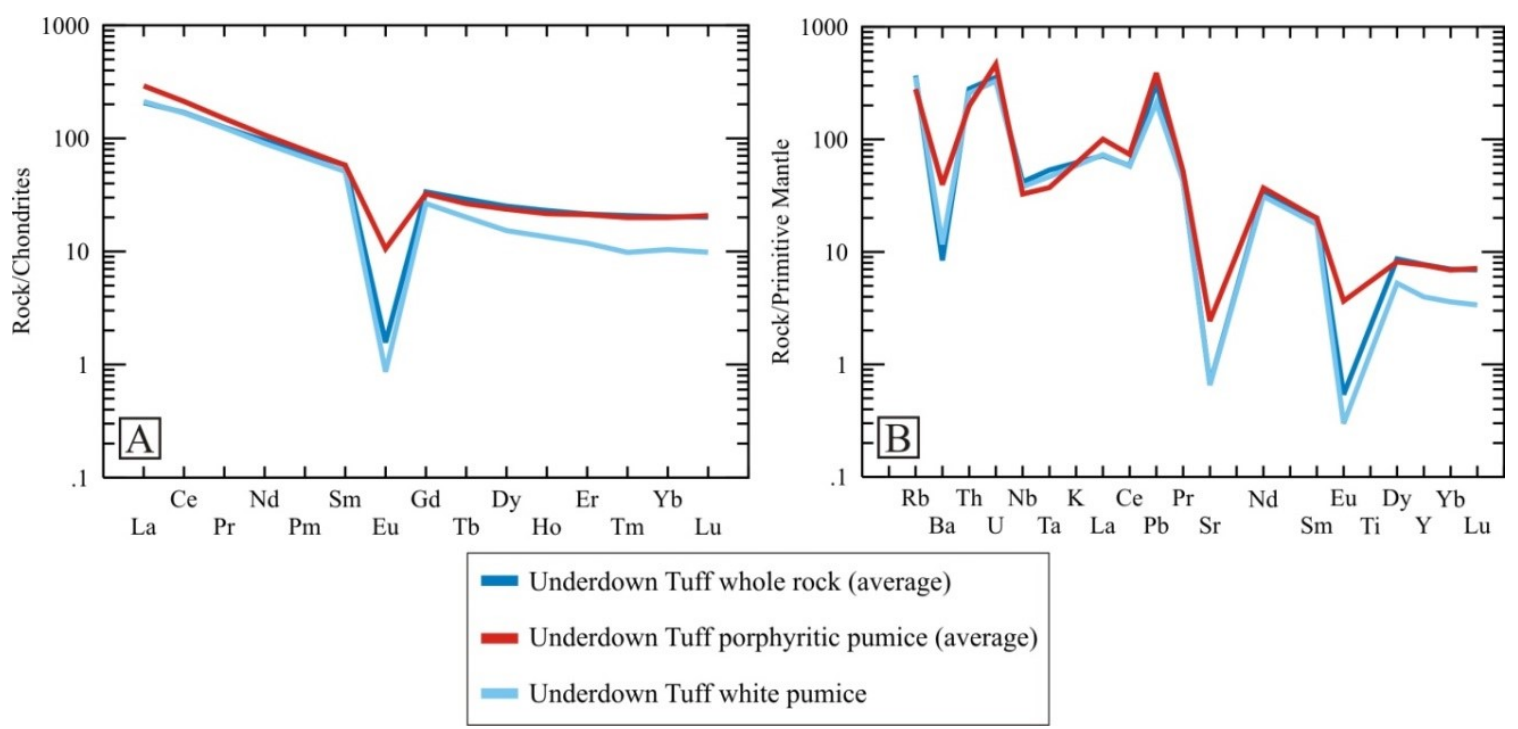

Figure 7.51: (A) Chondrite normalized rare earth element plot and (B) primitive mantle normalized trace element plot of the average Underdown Tuff whole rock, average porphyritic pumice, and white pumice samples (normalizing data from Sun and McDonough, 1989). 


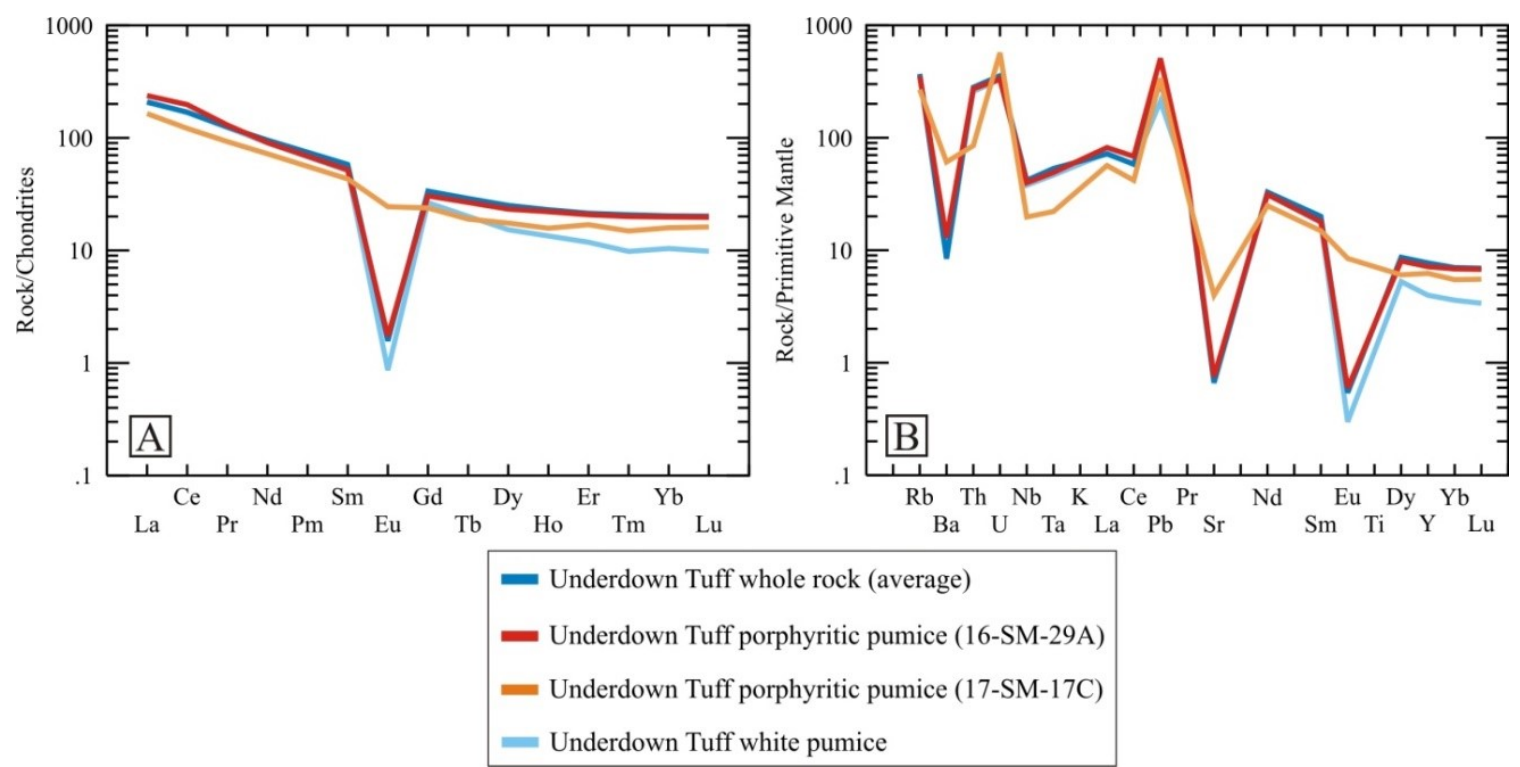

Figure 7.52: $(A)$ Chondrite normalized rare earth element plot and (B) primitive mantle normalized trace element plot of the average Underdown Tuff whole rock sample, most evolved porphyritic pumice sample (16-SM-29A), least evolved porphyritic pumice sample (17-SM-17C), and white pumice sample (16-SM-29B) (normalizing data from Sun and McDonough, 1989).

\subsubsection{Source of the Porphyritic Pumice}

Despite some differences in geochemistry between the porphyritic pumice and whole rock samples of the Underdown Tuff, the porphyritic pumice likely originates from a similar source as the Underdown Tuff. The more primitive geochemistry of many of the porphyritic pumice samples is likely a result of weathering which has removed $\mathrm{SiO}_{2}$ and increased the alkali content in the pumice, causing the samples to plot in a trend from the rhyolite to trachyte fields. A similar trend is observed in the tuff of Clipper Gap porphyritic pumice samples, and in the pumice of the Fish Creek Mountains tuff (Varve, 2013). Two porphyritic pumice samples plot with the group of whole rock Underdown 
data on the TAS diagram and in the major and trace element bivariate diagrams. These two samples are interpreted to not be weathered. If the porphyritic pumice were from a more primitive source than the whole rock and white pumice, they would likely all plot at a more primitive $\mathrm{SiO}_{2}$ content in the subalkaline field, rather than in a trend towards alkaline rocks. On the normalized REE and trace element plots, the average porphyritic pumice appears to have differences in anomaly size compared to the average whole rock and white pumice samples. This is likely a result of the variation in trace element concentration between the samples, as made evident by the trace element bivariate plots and the normalized REE and trace element diagrams. The most evolved (highest $\mathrm{SiO}_{2}$ ) porphyritic pumice sample used for this comparison (16-SM-29A) was collected from the same unit as the white pumice sample. The sample plots with the group of whole rock samples on the TAS, major element bivariate plots, and trace element bivariate plots, and is interpreted to be less weathered than other porphyritic pumice samples. The least evolved, lowest $\mathrm{SiO}_{2}$ porphyritic pumice sample was collected from float at the base of a large Underdown Tuff outcrop in Barrett Canyon. This sample plots in the trachyte field of the TAS diagram and has the lowest $\mathrm{SiO}_{2}$ content of all the porphyritic pumice samples. This comparison shows that the porphyritic pumice which is potentially fresh appears to be from the same source as the whole rock sample, and the least evolved porphyritic pumice sample has a trace element signature which is likely a result of weathering that has removed certain trace element containing phases from the rock. Based on the geochemical data, the porphyritic pumice in the Underdown Tuff is interpreted to be from a similar source as the whole rock and white 
pumice samples, and observed differences in geochemistry are a result of weathering. In addition to the geochemical data, the shape of the porphyritic pumice suggests that they are not fragments of rock broken off of another source and incorporated into the magma, for example from wall rock in a magma chamber.

Since the porphyritic pumice is much more crystal rich than the whole rock of the Underdown Tuff and the aphyric white pumice (which is interpreted to represent the pure magma which formed the ignimbrite), the porphyritic pumice must originate from a more crystal rich liquid than the melt forming the bulk of the ignimbrite. It is possible that the magma reservoir from which the Underdown Tuff originates tapped a more crystalline liquid source, such as a magma mush, and blobs of crystal rich material were incorporated into the melt. A magma mush zone consists mainly of crystals surrounded by an interconnected network of melt which may make up as little as one percent of the material in the magma mush (Bachmann and Bergantz, 2008; Winter, 2001). The erupted blobs of crystal mush may represent the purple porphyritic pumice observed in the Underdown Tuff. It is assumed that the same processes are responsible for the formation of the porphyritic pumice in the tuff of Clipper Gap. However, the presence of purple porphyritic pumice is not restricted to the Underdown Tuff and tuff of Clipper Gap. Similar porphyritic pumice was observed in the tuff of Campbell Creek, a 28.9 Ma ash flow tuff in the WNVF (Henry and John, 2013) (Fig. 7.53). The presence of the large, porphyritic pumice in a tuff unit unrelated to the Underdown event suggests that their presence may be more common in Great Basin ignimbrites than previously thought. 


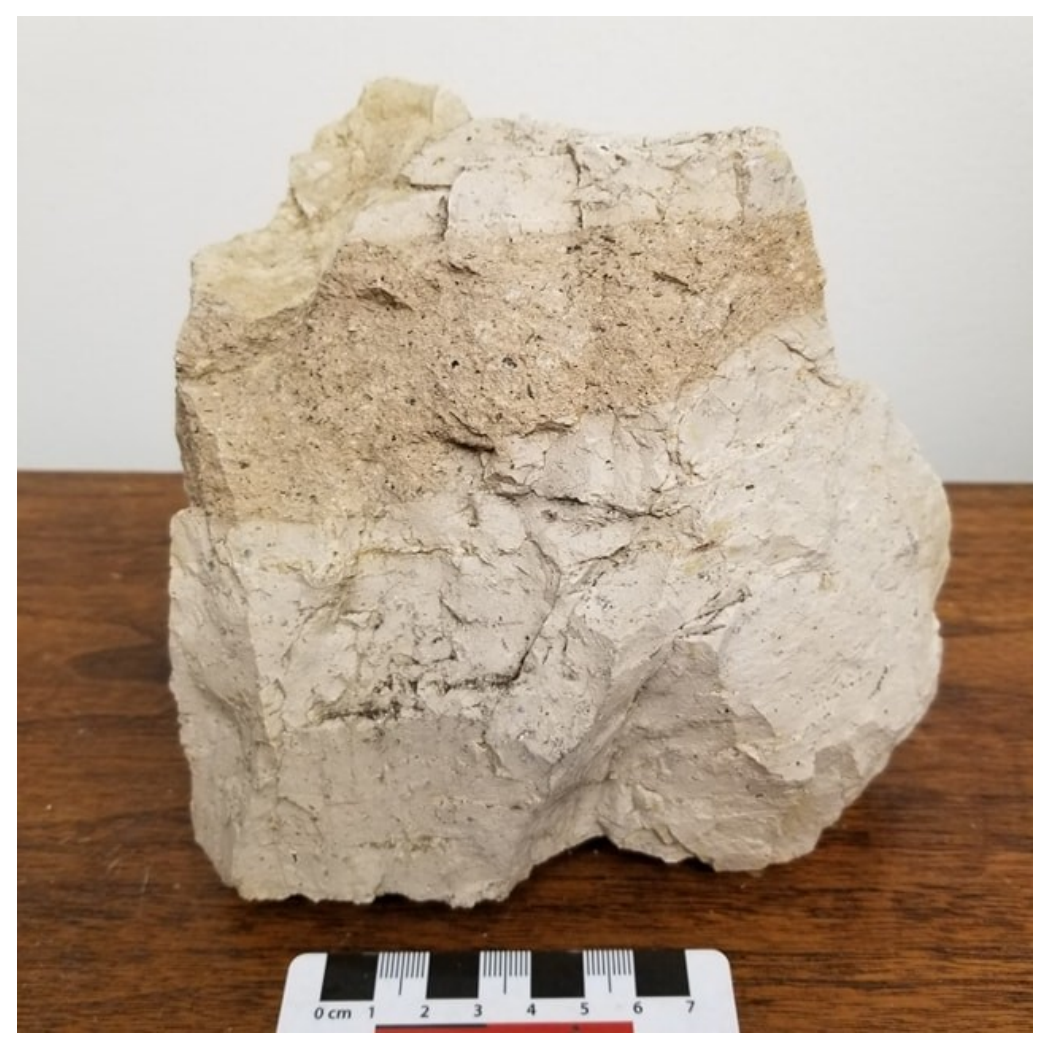

Figure 7.53: Porphyritic pumice in the Tuff of Campbell Creek. The observation of porphyritic pumice in a crystal poor ash flow tuff outside of the Underdown Caldera suggests that the presence of porphyritic pumice in Great Basin ignimbrites may be more common than previously thought. 


\subsection{Conclusions}

\subsection{The Underdown Caldera Complex}

The Oligocene tuffs of the Underdown Caldera complex are "Great Basin" style ignimbrites. Isotopic data supports a common primary magma source as the Miocene lavas located on the margin of the caldera; potentially a mixture of the sub-continental lithospheric mantle and local crustal source. The rocks of the Underdown Caldera complex have undergone post-deposition alteration by groundwater which has altered some initial $\mathrm{Sr}$ isotopic ratios. Measured negative $\mathrm{Ce}$ anomalies in several ignimbrite samples are the result of enrichment of rare earth elements produced by groundwater alteration which appears to have more strongly affected porphyritic pumice of the tuff of Clipper Gap than in other units. Porphyritic pumice may originate from a crystal mush beneath the caldera, and may be more common in the Western Nevada Volcanic Field than previously thought. The Bonita Canyon Formation appears to be a distinct ignimbrite unit overlying the Underdown Tuff, and the Unnamed tuff is likely not an

exposure of the Tuff of Toiyabe as it is currently mapped. The Unnamed tuff is more likely a younger ignimbrite unit of the Underdown Caldera complex which may represent a later stage of caldera forming volcanism. Spires of the older tuff of Arc Dome and Pablo Formation found within the Underdown caldera margins are postulated to represent pieces of wall rock of the Underdown Caldera which fell inwards during caldera collapse. Outflow tuff from the Underdown Caldera complex is not restricted to the east of the caldera, however outflow to the west and the south may 
not necessarily be correlative to just the Underdown Tuff. Two ignimbrites exposed in Gabbs Valley (TgV2 and TgV3) are more likely the tuff of Arc Dome and Bonita Canyon outflow tuff, as opposed to the tuff of Gabbs Valley. The similarities between the Bonita Canyon Formation and newly identified outflow tuffs suggest there may be more than one outflow unit from the Underdown Caldera complex.

\subsection{Future Work}

In the future, any new samples collected from the Underdown Caldera ignimbrites should be acid-washed before isotopic analysis, as multiple samples in this study were affected by alteration. Blocks mapped as Pablo Formation on the Bonham map (1970) should be re-mapped as their correct units. An extension of mapping to the north and south of the range of Bonham's map could also provide more information about the extent of the Underdown Caldera. New Sr isotopic data for the Terrill Mountains tuffs would allow for a more confident comparison of the potential outflow unit to the Underdown Caldera ignimbrites. As well, scanning electron microscope (SEM) analysis of the anomalous REE samples could identify the presence of REE enriched clays that are postulated to be responsible for apparent $\mathrm{Ce}$ anomalies. Finally, isotopic data from the Young Sierra Nevada tuffs would allow for a more complete comparison of this unit to the Underdown Tuff or Bonita Canyon Formation. 


\section{References}

Aitcheson, S.J., Harmon, R.S., Moorbath, S., Schneider, A., Soler, P., Soria-Escalante, E., Steele, G., Swainbank, I. and Wörner, G., 1995, Pb isotopes define basement domains of the Altiplano, central Andes. Geology, v. 23(6), p. 555-558.

Allègre, C.J., 2008, Isotope geology (p. 512). Cambridge: Cambridge University Press.

Annen, C., Sparks, R.S.J., 2002, Effects of repetitive emplacement of basaltic intrusions on thermal evolution and melt generation in the crust: Earth and Planetary Science Letters, v. 203, p. 927-955

Annen, C., Blundy, J.D., Sparks, R.S.J., 2006, The Genesis of Calcalkaline Intermediate and Silicic Magmas in Deep Crustal Hot Zones: Journal of Petrology v. 47, p. 505-539.

Annen, C., Blundy, J.D., Sparks R.S.J., 2008, The sources of granitic melt in Deep Hot Zones: Transactions of the Royal Society of Edinburgh: Earth Sciences, v. 97(4), p. 297309.

Armstrong, L.R., Ward, P., 1991, Evolving geographic patterns of Cenozoic magmatism in the North American Cordillera: The temporal and spatial association of magmatism and metamorphic core complexes: Journal of Geophysical Research: Solid Earth, v. 96(B8), p. 13201-13224.

Atwater, T, 1970, Implications of plate tectonics for the Cenozoic tectonic evolution of western North America: Geological Society of America Bulletin, v. 81(12), p. 3513-3536.

Bachmann, O., Bergantz, G.W., 2008, Rhyolites and their source mushes across tectonic settings: Journal of Petrology, v. 49, n. 12, p. 2277-2285, doi:

10.1093/petrology/egn068.

Best, M.G., Armstrong, R.L., Graustein, W.C., Embree, G.F., and Ahlborn, F.C., 1974, Mica granites of the Kern Mountains pluton, eastern White Pine County, Nevada: Remobilized basement of the Cordilleran miogeosyncline: Geological Society of America Bulletin, v. 85, p. 1277-1286, doi: 10.1130/0016-7606(1974)85

Best, M.G., Gromme, S., Deino, A.L., Christiansen, E.H., Hart, G.L., Tingey, D.G., 2013, The 36-18 Ma Central Nevada ignimbrite field and calderas, Great Basin, USA: Multicyclic super-eruptions: Geosphere, v. 9, p. 1562-1636, doi: 10.1130/GES00945.1. 
Best, M.G., Christiansen, E.H., de Silva, S., Lipman, P.W., 2016, Slab-rollback ignimbrite flareups in the southern Great Basin and other Cenozoic American arcs: A distinct style of arc volcanism: Geosphere, v. 12(4), p. 1097-1135, doi: 10.1130/GES01285.1.

Bohnam, H.F., 1970, Geologic map and sections of a part of the Shoshone Mountains, Lander and Nye counties, Nevada. Nevada Bureau of Mines.

Boulange, B., Muller J.P., Sigolo, J.B., 1990, Behaviour of the rare earth elements in a lateritic bauxite from syenite (Brasil): Geochemistry of the Earth's surface of mineral formation, Spec. Issue Chem. Geol., v. 84, p. 350-351.

Braun, J.J., Pagel, M., Muller, J.P., Bilong, P., Michard, A., Guillet, B., 1990, Cerium anomalies in lateritic profiles: Geochimica et Cosmochimica Acta, v. 54, p. 781-796.

Cadek, O., Fleitout, L., 2003, Effect of lateral viscosity variation in the top $300 \mathrm{~km}$ on the geoid and dynamic topography: Geophysical Journal International, v. 152(3), p. 566-580.

Camp, V.E., Pierce, K.L. and Morgan, L.A., 2015, Yellowstone plume trigger for Basin and Range extension, and coeval emplacement of the Nevada-Columbia Basin magmatic belt. Geosphere 11, doi: 10.1130/GES01051.1.

Carlson, C.W., 2018, Geological Map of the Terrill Mountains Quadrangle, Churchill and Mineral Counties, Nevada: Nevada Bureau of Mines and Geology Map 187.

Chamberlin, R.M., 1983, Cenozoic domino-style crustal extension in the Lemitar Mountains, New Mexico: A summary. In Guidebook, 34th Field Conference, Socorro Region II (V. 34, p. 111-118). New Mexico Geological Society Socorro, New Mexico.

Christiansen, E.H., 2005, Contrasting processes in silicic magma chambers: evidence from very large volume ignimbrites: Geology, v.142, n.6, p. 669-681, doi:

$10.1017 /$ S0016756805001445.

Clemens, J.D. and Stevens, G., 2012, What controls chemical variation in granitic magmas?: Lithos, 134, p. 317-329.

Colgan, J.P., and Henry, C.D., 2009, Rapid middle Miocene collapse of the Sevier orogenic plateau in north-central Nevada: International Geology Review, v. 51, p. 920961.

Colgan, J.P., Watts, K.W., Henry, C., and John, D., 2013, Characterizing geographic variability in magma composition and eruptive style during voluminous mid-Tertiary magmatism in the northern Great Basin using zircon U-Pb geochronology and 
phenocryst O isotopic data: Washington, D.C., American Geophysical Union, Fall Meeting, abstract V33E-2831.

Coney, P.J., 1978, Mesozoic-Cenozoic Cordilleran plate tectonics, in Smith, R.B., and Eaton, G.P., eds., Cenozoic Tectonics and Regional Geophysics of the Western Cordillera: Geological Society of America Memoir 152, p. 33-50.

Cousens, B.L., Spera, F.J., Dobson, P.F., 1993, Post-eruptive alteration of silicic ignimbrites and lavas, Gran Canaria, Canary Islands: Strontium, neodymium, lead, and oxygen isotopic evidence: Geochimica et Cosmochimica Acta, v. 57, p. 631-640.

Cousens, B.L., Prytulak, J., Henry, C.D., Alcazar, A. and Brownrigg, T., 2008, The geology, geochronology and geochemistry of the Miocene-Pliocene Ancestral Cascades Arc, northern Sierra Nevada, California/Nevada: The roles of the upper mantle, subducting slab, and the Sierra Nevada lithosphere: Geosphere, v. 4(5): 829-853.

Cousens, B.L., Henry, C.D., and Gupta, V., 2012, Distinct mantle sources for Pliocene Quaternary volcanism beneath the modern Sierra Nevada and adjacent Great Basin, northern California and western Nevada, USA. Geosphere, v. 8, p. 562-580.

Cousens, B.L., Henry, C.D., Stevens, C., Varve, S., John, D.A., Wetmore, S., 2019, Igneous rocks in the Fish Creek Mountains and enrivons, Battle Mountains area, north-central Nevada: A microcosm of Cenozoic igneous activity in the northern Great Basin, Basin and Range Province, USA: Earth-Science Reviews, v. 192, p. 403-444, doi: 10.1016/j.earscirev.2019.03.013

Davidson, J., 1985, Mechanisms of contamination in Lesser Antilles island arc magmas from radiogenic and oxygen isotope relationships: Earth and Planetary Science Letters, v. 72 , p. 163-174.

Decelles, P.G., 2004, Late Jurassic to Eocene evolution of the Cordilleran thrust belt and foreland basin system, western USA: American Journal of Science, v. 304, p. 105-168.

DePaolo, D.J., 1981, Trace element and isotopic effects of combined wallrock assimilation and fractional crystallization. Earth and Planetary science letters, v. 53(2), p. 189-202.

de Silva, S., 2008, Arc magmatism, calderas, and supervolcanoes: Geology, v. 36, p. 671672.

Dickin, A.P., 2005, Radiogenic isotope geology (p. 492). Cambridge University Press. 
Dickinson, W.R., 2006, Geotectonic evolution of the Great Basin: Geosphere, v. 2, p. 353-368.

Engebretson, D.C., Cox, A., Gordon, R.G, 1985, Relative motions between oceanic and continental plates in the Pacific basin: Geological Society of America Special Papers, 206, p. 1-60.

Farmer, G.L., DePaolo, D.J., 1983, Origin of Mesozoic and Tertiary granite in the western United States and implications for Pre-Mesozoic crustal structure: 1. Nd and Sr isotopic studies in the geocline of the Northern Great Basin: Journal of Geophysical Research, v. 88(B4), p. 3379-3401, doi: 10.1029/JB088iB04p03379.

Geist D. Richards M., 1993, Origin of the Columbia Plateau and Snake River Plain: Deflection of the Yellowstone plume: Geology, v. 21, p. 789-792.

Hart, S.R., 1984, A large-scale isotope anomaly in the Southern Hemisphere mantle. Nature, v. 309(5971), p. 753-757.

Henry, C.D., John, D.A., 2013, Magmatism, ash-flow tuff and calderas of the ignimbrite flareup in the western Nevada volcanic field, Great Basin, USA: Geosphere v. 9(3), p. 951-1008.

Hildreth, W., 1981, Gradients in silicic magma chambers: Implications for lithospheric magmatism: Journal of Geophysical Research, v. 86, p. 10,153-10,192.

Hildreth, W., and Moorbath, S., 1988, Crustal contributions to arc magmatism in the Andes of central Chile: Contributions to Mineralogy and Petrology, v. 98, p. 455-489.

Humphreys, E., 2009, Relation of flat subduction to magmatism and deformation in the western United States: Geological Society of America Memoirs, v. 204, p. 85-98.

Hutton, J., 1794, II. Observations on Granite: Transaction of the Royal Society of Edinburg, v. 3 (02), p. 77-85.

Jarrard, R.D., 1986, Relations among subduction parameters: Reviews of Geophysics, v. 24(2), p. 217-284.

John, D. A., 1974, Stratigraphy, regional distribution, and reconnaissance geochemistry of Oligocene and Miocene volcanic rocks in the Paradise Range and northern Pactolus hills, Nye County, Nevada: U.S. Geological Survey Bulletin, v. 67, doi: 10.3133/b1974. 
John, D.A., Wallace, A.R., Ponce, D.A., Fleck, R.B. and Conrad, J.E., 2000, New perspectives on the geology and origin of the northern Nevada Rift. In: J.K. Cluer, J.G. Price, E.M. Struhsacker, R.F. Hardyman and C.L. Morris (Editors), Geology and Ore Deposits 2000: The Great Basin and Beyond, Symposium Proceedings. Geological Society of Nevada, pp. 127-154.

Le Maitre, R.W.B., Dudek, P., Keller, A., Lameyre, J., Le Bas, J., Sabine, M.J., Schmid, P.A., Sorensen, R., Streckeisen, H., Woolley, A. and Zanettin, A.R., 1989, A classification of igneous rocks and glossary of terms: Recommendations of the International Union of Geological Sciences, Subcommission on the Systematics of Igneous Rocks (No. 552.3 CLA). International Union of Geological Sciences.

Lee, D.E., Christiansen, E.H., 1983, The granite problem as exposed in the southern Snake Range, Nevada: Contributions to Mineralogy and Petrology, v. 83(1-2), p. 99-116, doi: 10.1007/BF00373083.

Lipman, P.W., Prostka, H.J., and Christiansen, R.L., 1972, Cenozoic volcanism and plate tectonic evolution of western United States, Part 1: Early and middle Cenozoic: Philosophical Transactions of the Royal Society of London, Series A, v. 271, p. 217-248, doi:10.1098/rsta.1972.0008.

Lipman, P.W., Prostka, P.J., and Christiansen, R.L., 1992, A discussion on volcanism and the structure of the Earth-Cenozoic volcanism and plate tectonic evolution of the western United Stated. 1. Early and middle Cenozoic, Philosophical Transactions of the Royal Society A, v. 271(1213), doi: 10.1098/rsta1972.0008.

Mahood, G. A. and Hildreth, W., 1983, Large partition coefficients for trace elements in high-silica rhyolites. Geochemica et Cosmochimica Acta, v. 47, p. 11-30.

Marsh, J.S., 1991, REE fractionation and Ce anomalies in weathered Karoo dolerite: Chemical Geology, v. 90, p. 189-194

McKee, E.H., 1971, Tertiary igneous chronology of the Great Basin of the western United States-Implications for tectonic models: Geological Society of America Bulletin, v. 82, p. 3497-3502.

Noble, D.C., 1972, Some observations on the Cenozoic volcano-tectonic evolution of the Great Basin, western United States: Earth and Planetary Science Letters, v. 17, p. 142150, doi: 10.1016/0012-821X(72)90269-5. 
O’Driscoll, L.J., Humphreys, E.D., Saucier, F., 2009, Subduction adjacent to deep continental roots: Enhanced negative pressure in the mantle wedge, mountain building and continental motion: Earth and Planetary Science Letters, v. 280(1), p. 61-70.

Parsons, T., McCarthy, J., Kohlery, W.M., Ammon, C.J., Benz, H.M., Hole J.A., Criley, E.E., 1996, Crustal structure of the Colorado Plateau, Arizona: Application of new long-offset seismic data analysis techniques: Journal of Geophysical Research: Solid Earth, v. 101(B5), p. 11,173-11,194.

Perry, F.V., DePaolo, D.J. and Baldridge, W.S., 1993, Neodymium isotopic evidence for decreasing crustal contributions to Cenozoic ignimbrites of the western United States: Implications for the thermal evolution of the Cordilleran crust: Geological Society of America Bulletin, v. 105(7), p. 872-882.

Proffett, J.M., Jr., 1977, Cenozoic geology of the Yerington district, Nevada, and implications for the nature and origin of Basin and Range faulting: Geological Society of America Bulletin, v. 88, p. 247-266.

Putirka, K. and Busby, C.J., 2007, The tectonic significance of high-K2O volcanism in the Sierra Nevada, California. Geology, v. 35(10), p. 923-926.

Rollinson, H.R., 1993, Using geochemical data: evaluation, presentation, interpretation (p. 352): Essex: Pearson Education Limited.

Rudnick, R.L., Fountain, D.M., 1995, Nature and composition of the continental crust: A lower crustal perspective: Reviews of Geophysics, v. 33, p. 267-309. doi:

10.1029/95RG01302

Siebel, W., Schnurr, W.B., Hahne, K., Kraemer, B., Trumbull, R.B., van den Bogaard, P. and Emmermann, R., 2001, Geochemistry and isotope systematics of small-to mediumvolume Neogene-Quaternary ignimbrites in the southern central Andes: evidence for derivation from andesitic magma sources. Chemical Geology, v. 171(3), p. 213-237.

Smith, R.L., 1979, Ash-flow magmatism: Geological Society of America Special Paper 180, p. 5-27.

Solano, J.M.S., Jackson, M.D., Sparks, R.S.J., Blundy, J.D. and Annen, C., 2012, Melt segregation in deep crustal hot zones: a mechanism for chemical differentiation, crustal assimilation and the formation of evolved magmas. Journal of Petrology, v. 53(10), p. 1999-2026. 
Sparks, R.S.J., Self, S., Walker, G.P.L., 1973, Products of ignimbrite eruptions: Geology, v. 1, p. 115-118.

Stepner, D., 2017, Source and Magma Evolution of the tuff of Elevenmile Canyon, Stillwater Range, Clan Alpine and northern Desatoya Mountains, western Nevada (Masters of Science thesis). University of Ottawa, Ottawa, Ontario.

Sun, S.S. and McDonough, W.S., 1989, Chemical and isotopic systematics of oceanic basalts: implications for mantle composition and processes. Geological Society, London, Special Publications, v. 42(1), p. 313-345.

Tennant, E., 2018, Geochemistry and origin of mafic to intermediate lava flows in the Shoshone Mountains, Nevada, USA (Bachelor of Science Thesis). Carleton University, Ottawa, Ontario.

Timmermans, A.C., 2015, A Geochemical Study of Cenozoic Magmatism Along an EastWest Transect from Central Great Basin, Nevada to the Ancestral Cascade Arc, California - A Compositional Journey Over Space and Time (Doctoral Dissertation).Carleton University, Ottawa, Ontario.

Varve, S., 2013, Stratigraphy, Geochemistry, and Origin of the Fish Creek Mountains Tuff, Battle Mountain Area, North-Central Nevada, U.S.A (Master of Science Thesis). Carleton University, Ottawa, Ontario.

van Hunen, J., Van Den BERG, A.P., Vlaar, N.J., 2002, On the role of subducting oceanic plateaus in the development of shallow flat subduction: Tectonophysics, v. 352(3), p. 317-333.

Watts, K.E., John, D.A., Colgan, J.P., Henry, C.D., Bindeman, I.N., Schmitt, A.K., 2016, Probing the volcanic-plutonic connection and the genesis of crystal-rich rhyolite in a deeply dissected supervolcano in the Nevada Great Basin: Source of the Late Eocene Caetano Tuff: Journal of Petrology, v. 57(18), p. 1599-1644, doi:

10.1093/petrology/egw051.

Winter, J.D., 2001, An Introduction to igneous and metamorphic petrology (p. 697): New York: Prentice Hall. 


\section{Appendix I: Supporting Tables}

Table I: ${ }^{40} \mathrm{Ar} /{ }^{39} \mathrm{Ar}$ Ages provided by C. Henry

\begin{tabular}{cccc}
\hline Sample No. & Unit Name & ${ }^{40} \mathbf{A r} /{ }^{39}$ Ar Age & $\mathbf{2 \sigma}$ \\
\hline $16-S M-32$ & Underdown Tuff & 24.897 & 0.041 \\
$17-S M-26$ & Underdown Tuff & 24.905 & 0.072 \\
$17-S M-21$ & Underdown Tuff & 24.902 & 0.060 \\
$16-S M-21$ & Bonita Canyon Formation & 24.999 & 0.043 \\
H09-85 & tuff of Clipper Gap & 24.87 & 0.10 \\
$16-S M-16$ & tuff Clipper Gap & 24.981 & 0.036 \\
H17-46 & tuff Clipper Gap & 24.917 & 0.048 \\
H01-136 & Unnamed Tuff & 24.72 & 0.05 \\
$16-S M-06$ & Unnamed Tuff & 24.755 & 0.037 \\
$17-S M-20$ & Tuff of Arc Dome Vitrophyre & 24.688 & 0.055 \\
$16-S M-09$ & Megabreccia block & 25.19 & 0.04 \\
$17-S M-13$ & tuff of Brunton Pass & 24.892 & 0.053 \\
H00-97 & tuff of Brunton Pass & 25.12 & 0.06 \\
$16-S M-33$ & Dacite dyke & 24.949 & 0.046 \\
$16-S M-53$ & Rhyolite Intrusive & 24.774 & 0.051 \\
H12-33 & Tgv1 & 25.094 & 0.009 \\
H12-34 & Tgv1 below H12-33 & 25.094 & 0.007 \\
H13-82 & Tgv1 below H12-34 & 25.100 & 0.012 \\
$17-S M-29$ & Tgv2 & 25.109 & 0.080 \\
H17-50 & Tgv3 & 24.875 & 0.048 \\
H12-32 & Tgv3 vitrophyre & 24.898 & 0.009 \\
H18-SN6 & Young Sierra Nevada tuff & 24.888 & 0.015 \\
\hline
\end{tabular}




\section{Table II: Sample Locations}

\begin{tabular}{|c|c|c|c|c|c|c|c|}
\hline Sample No. & Unit & $\mathbf{N}$ & $\mathbf{w}$ & Zone & E & $\mathbf{N}$ & Elevation ( $\mathrm{ft}$ ) \\
\hline \multicolumn{8}{|l|}{ NAD 27} \\
\hline 16-SM-01 & Bonita Canyon Formation & 39.1642 & 117.4012 & $11 \mathrm{~S}$ & 465340 & 4334870 & 7201 \\
\hline $16-S M-02$ & Bonita Canyon Formation & 39.1649 & 117.4022 & $11 \mathrm{~S}$ & 465249 & 4334948 & 7347 \\
\hline 16-SM-03 & Bonita Canyon Formation & 39.1642 & 117.4014 & $11 \mathrm{~S}$ & 465325 & 4334864 & 7216 \\
\hline $16-S M-04$ & Underdown Tuff & 39.1548 & 117.4337 & $11 \mathrm{~S}$ & 462530 & 4338831 & 7900 \\
\hline 16-SM-05 & Bonita Canyon Formation & 39.2358 & 117.3560 & $11 \mathrm{~S}$ & 469278 & 4342800 & 6467 \\
\hline $16-S M-06 A$ & Unnamed Tuff & 39.0757 & 117.5444 & $11 \mathrm{~S}$ & 452906 & 4325110 & 8813 \\
\hline 16-SM-06B & Unnamed Tuff & 39.0757 & 117.5444 & $11 \mathrm{~S}$ & 452906 & 4325110 & 8813 \\
\hline $16-S M-06 C$ & Unnamed Tuff & 39.0757 & 117.5444 & $11 S$ & 452906 & 4325110 & 8813 \\
\hline 16-SM-06D & Unnamed Tuff & 39.0757 & 117.5444 & $11 \mathrm{~S}$ & 452906 & 4325110 & 8813 \\
\hline 16-SM-06E & Unnamed Tuff & 39.0757 & 117.5444 & $11 \mathrm{~S}$ & 452906 & 4325110 & 8813 \\
\hline $16-S M-06 F$ & Unnamed Tuff & 39.0757 & 117.5444 & $11 \mathrm{~S}$ & 452906 & 4325110 & 8813 \\
\hline 16-SM-07 & Bonita Canyon Formation & 39.0729 & 117.5422 & $11 S$ & 453096 & 4324795 & 8282 \\
\hline 16-SM-08 & Bonita Canyon Formation & 39.0832 & 117.5418 & $11 \mathrm{~S}$ & 453139 & 4325937 & 8017 \\
\hline 16-SM-09 & Tuff of Arc Dome & 39.0822 & 117.5419 & $11 \mathrm{~S}$ & 453132 & 4325825 & 7955 \\
\hline $16-S M-10$ & Qtz-feld porphyritic tuff & 39.2198 & 116.8544 & $11 \mathrm{~S}$ & 512567 & 4340971 & 6513 \\
\hline $16-S M-11$ & Tuff of Campbell Creek & 39.2203 & 116.8528 & $11 S$ & 512711 & 4341024 & 6606 \\
\hline $16-S M-12$ & Nine Hill Tuff & 39.2211 & 116.8512 & $11 \mathrm{~S}$ & 512850 & 4341114 & 6826 \\
\hline 16-SM-12B & Nine Hill Tuff & 39.2211 & 116.8512 & $11 S$ & 512850 & 4341114 & 6826 \\
\hline $16-S M-13 A$ & Tuff of Clipper Gap & 39.2216 & 116.8499 & $11 S$ & 512956 & 4341171 & 7009 \\
\hline 16-SM-13B & Tuff of Clipper Gap & 39.2216 & 116.8499 & $11 S$ & 512956 & 4341171 & 7009 \\
\hline $16-S M-13 C$ & Tuff of Clipper Gap & 39.2216 & 116.8499 & $11 S$ & 512956 & 4341171 & 7009 \\
\hline $16-S M-14$ & Tuff of Clipper Gap & 39.2212 & 116.8495 & $11 S$ & 512995 & 4341130 & 7018 \\
\hline $16-S M-15 A$ & Tuff of Clipper Gap & 39.2218 & 116.8495 & $11 \mathrm{~S}$ & 512988 & 4341191 & 7068 \\
\hline 16-SM-15B & Tuff of Clipper Gap & 39.2218 & 116.8495 & $11 \mathrm{~S}$ & 512988 & 4341191 & 7068 \\
\hline $16-S M-16$ & Tuff of Clipper Gap & 39.2225 & 116.8500 & $11 S$ & 512948 & 4341274 & 7036 \\
\hline $16-S M-17$ & Tuff of Clipper Gap & 39.2231 & 116.8502 & $11 S$ & 512933 & 4341335 & 7067 \\
\hline $16-S M-18$ & Tuff of Clipper Gap & 39.2207 & 116.8569 & $11 \mathrm{~S}$ & 512353 & 4341070 & 6414 \\
\hline 16-SM-19 & Pablo Formation & 39.1049 & 117.5413 & $11 \mathrm{~S}$ & 453196 & 4328349 & 8627 \\
\hline $16-S M-20 A$ & Pablo Formation & 39.1090 & 117.5460 & $11 S$ & 452790 & 4328807 & 9252 \\
\hline $16-S M-20 B$ & Pablo Formation & 39.1090 & 117.5460 & $11 S$ & 452790 & 4328807 & 9252 \\
\hline $16-S M-20 C$ & Pablo Formation & 39.1090 & 117.5460 & $11 S$ & 452790 & 4328807 & 9252 \\
\hline $16-S M-21 \mathrm{~A}$ & Bonita Canyon Formation & 39.1109 & 117.5362 & $11 S$ & 453643 & 4329016 & 9156 \\
\hline $16-S M-21 B$ & Bonita Canyon Formation & 39.1109 & 117.5362 & $11 S$ & 453643 & 4329016 & 9156 \\
\hline $16-S M-21 C$ & Bonita Canyon Formation & 39.1109 & 117.5362 & $11 S$ & 453643 & 4329016 & 9156 \\
\hline $16-S M-22$ & Bonita Canyon Formation & 39.1101 & 117.5334 & $11 S$ & 453883 & 4328917 & 9060 \\
\hline $16-S M-23$ & Bonita Canyon Formation & 39.1067 & 117.5289 & $11 S$ & 454270 & 43285437 & 8948 \\
\hline
\end{tabular}


Table II: Sample Locations Cont.

\begin{tabular}{|c|c|c|c|c|c|c|c|}
\hline Sample No. & Unit & $\mathbf{N}$ & $\mathbf{W}$ & Zone & $\mathbf{E}$ & $\mathbf{N}$ & Elevation $(\mathrm{ft})$ \\
\hline \multicolumn{8}{|l|}{ NAD 27} \\
\hline $16-S M-24$ & Bonita Canyon Formation & 39.1045 & 117.4247 & $11 S$ & 454628 & 4328294 & 8805 \\
\hline $16-S M-25$ & Bonita Canyon Formation & 39.1143 & 117.5199 & $11 S$ & 455049 & 4329377 & 8766 \\
\hline $16-S M-26$ & Bonita Canyon Formation & 39.0967 & 117.5274 & $11 S$ & 454390 & 4327430 & 7925 \\
\hline $16-S M-27$ & Bonita Canyon Formation & 39.0974 & 117.5242 & $11 S$ & 454671 & 4327503 & 7892 \\
\hline $16-S M-28$ & Underdown Tuff & 39.0927 & 117.4638 & $11 S$ & 459893 & 4326962 & 6984 \\
\hline $16-S M-29 A$ & Underdown Tuff & 39.0936 & 117.4644 & $11 S$ & 459839 & 4327057 & 7056 \\
\hline $16-S M-29 B$ & Underdown Tuff & 39.0936 & 117.4644 & $11 S$ & 459839 & 4327057 & 7056 \\
\hline $16-S M-30$ & Bonita Canyon Formation & 39.1067 & 117.4707 & $11 S$ & 459299 & 4328514 & 7227 \\
\hline $16-S M-31$ & Underdown Tuff & 39.1056 & 117.4707 & $11 S$ & 459304 & 4328392 & 7277 \\
\hline $16-S M-32 A$ & Underdown Tuff & 39.0965 & 117.4935 & $11 S$ & 457321 & 4327391 & 7292 \\
\hline $16-S M-32 B$ & Underdown Tuff & 39.0965 & 117.4935 & $11 S$ & 457321 & 4327391 & 7292 \\
\hline $16-S M-32 C$ & Underdown Tuff & 39.0965 & 117.4935 & $11 S$ & 457321 & 4327391 & 7292 \\
\hline 16-SM-32D & Underdown Tuff & 39.0965 & 117.4935 & $11 S$ & 457321 & 4327391 & 7292 \\
\hline $16-S M-33 A$ & Dacite Porphyry Dyke & 39.1785 & 117.3743 & $11 S$ & 467669 & 4336444 & 6614 \\
\hline 16-SM-33B & Dacite Porphyry Dyke & 39.1785 & 117.3743 & $11 S$ & 467669 & 4336444 & 6614 \\
\hline $16-S M-34$ & Underdown Tuff & 39.0230 & 117.5252 & $11 S$ & 454539 & 4319249 & 7616 \\
\hline $16-S M-35$ & Underdown Tuff & 39.0238 & 117.5257 & $11 \mathrm{~S}$ & 454491 & 4319345 & 7775 \\
\hline $16-S M-36$ & Underdown Tuff & 39.0235 & 117.5251 & $11 S$ & 454543 & 4319304 & 7708 \\
\hline $16-S M-37$ & Bonita Canyon Formation & 39.2011 & 117.5165 & $11 S$ & 455404 & 4339010 & 6925 \\
\hline $16-S M-38 A$ & Unnamed tuff & 39.2010 & 117.5170 & $11 S$ & 455360 & 4339000 & 7053 \\
\hline 16-SM-38B & Unnamed tuff & 39.2010 & 117.5170 & $11 S$ & 455360 & 4339000 & 7053 \\
\hline $16-S M-39$ & Unnamed tuff & 39.1998 & 117.5178 & $11 S$ & 455286 & 4338866 & 7187 \\
\hline $16-S M-40$ & Unnamed pumice & 39.2001 & 117.5164 & $11 S$ & 455407 & 4338900 & 6978 \\
\hline $16-S M-41$ & Unnamed tuff & 39.1688 & 117.5506 & $11 S$ & 452436 & 4335393 & 6901 \\
\hline $16-S M-42$ & Unnamed tuff & 39.1575 & 117.5441 & $11 S$ & 452987 & 4334182 & 7086 \\
\hline $16-S M-43$ & Unnamed tuff & 39.1336 & 117.5659 & $11 S$ & 451087 & 4331544 & 7287 \\
\hline $16-S M-44$ & Pablo Formation & 39.1285 & 117.5629 & $11 S$ & 451348 & 4330975 & 7559 \\
\hline $16-S M-45$ & Underdown Tuff & 39.1582 & 117.3871 & $11 S$ & 466553 & 4334190 & 6747 \\
\hline $16-S M-46$ & Underdown Tuff & 39.1589 & 117.3872 & $11 S$ & 466548 & 4334275 & 6931 \\
\hline $16-S M-47$ & Underdown Tuff & 39.1590 & 117.3873 & $11 S$ & 466541 & 4334284 & 6938 \\
\hline $16-S M-48$ & Underdown Tuff & 39.1597 & 117.3876 & $11 \mathrm{~S}$ & 466512 & 4334367 & 7023 \\
\hline $16-S M-49$ & Underdown Tuff & 39.1604 & 117.3878 & $11 S$ & 466497 & 4334440 & 7060 \\
\hline $16-S M-50$ & Underdown Tuff & 39.1610 & 117.3882 & $11 S$ & 466461 & 4334501 & 7105 \\
\hline $16-S M-51$ & Underdown Tuff & 39.1618 & 117.3887 & $11 \mathrm{~S}$ & 466417 & 4334595 & 7163 \\
\hline $16-S M-52$ & Rhyolite Intrusions & 39.0156 & 117.5889 & $11 S$ & 449013 & 4318469 & 7473 \\
\hline $16-S M-53$ & Rhyolite Intrusions & 39.0158 & 117.5882 & $11 S$ & 449074 & 4318484 & 7568 \\
\hline $16-S M-54$ & Bonita Canyon Formation & 39.0151 & 117.5900 & $11 \mathrm{~S}$ & 448923 & 4318410 & 7477 \\
\hline $16-S M-55$ & Unnamed Tuff & 39.0236 & 117.5881 & $11 S$ & 449094 & 4319355 & 7626 \\
\hline $16-S M-56$ & Rhyolite Intrusions & 39.0214 & 117.5840 & $11 S$ & 449444 & 4319102 & 7893 \\
\hline
\end{tabular}


Table II: Sample Locations Cont.

\begin{tabular}{|c|c|c|c|c|c|c|c|}
\hline Sample No. & Unit & $\mathbf{N}$ & $\mathbf{W}$ & Zone & $E$ & $\mathbf{N}$ & Elevation (ft) \\
\hline \multicolumn{8}{|l|}{ NAD 83} \\
\hline 17-SM-01 & Terrill Mountains tuffs & 39.0298 & -118.6917 & $11 \mathrm{~S}$ & 353570 & 4321441 & 4798 \\
\hline 17-SM-02 & Terrill Mountains tuffs & 39.0290 & -118.6916 & $11 S$ & 353578 & 4321353 & 4703 \\
\hline 17-SM-03A & Terrill Mountains tuffs & 39.0290 & -119.6916 & $11 \mathrm{~S}$ & 353578 & 4321353 & 4703 \\
\hline 17-SM-03B & Terrill Mountains tuffs & 39.0290 & -119.6916 & $11 S$ & 353578 & 4321353 & 4703 \\
\hline 17-SM-03C & Terrill Mountains tuffs & 39.0290 & -119.6916 & $11 S$ & 353578 & 4321353 & 4703 \\
\hline 17-SM-04 & Underdown Tuff & 39.3735 & -115.7458 & & & & \\
\hline 17-SM-05 & Nine Hill Tuff & 39.3748 & -115.7511 & & & & \\
\hline 17-SM-06 & Tuff of Clipper Gap & 39.4888 & -115.4297 & & & & \\
\hline 17-SM-07 & Tuff of Clipper Gap & 39.4888 & -115.4298 & & & & \\
\hline 17-SM-08 & Tuff of Clipper Gap & 39.4889 & -115.4299 & & & & \\
\hline 17-SM-09 & Tuff of Clipper Gap & 39.4892 & -115.4300 & & & & \\
\hline 17-SM-10 & Tuff of Clipper Gap & 39.4897 & -115.4297 & & & & \\
\hline $17-S M-11$ & Tuff of Clipper Gap & 39.4898 & -115.4298 & & & & \\
\hline 17-SM-12 & Tuff of Clipper Gap & 39.4912 & -115.4299 & & & & \\
\hline 17-SM-13A & Tuff of Brunton Pass & 38.8752 & -117.7375 & $11 S$ & 436027 & 4303189 & 6560 \\
\hline 17-SM-13B & Tuff of Brunton Pass & 38.8752 & -117.7375 & $11 \mathrm{~S}$ & 436027 & 4303189 & 6560 \\
\hline 17-SM-14 & Tuff of Arc Dome & 38.8767 & -117.7382 & $11 S$ & 435966 & 4303356 & 6490 \\
\hline 17-SM-15A & Tuff of Arc Dome & 38.8968 & -117.7832 & $11 S$ & 432084 & 4305620 & 6907 \\
\hline 17-SM-15B & Tuff of Arc Dome & 38.8968 & -117.7832 & $11 S$ & 432084 & 4305620 & 6907 \\
\hline 17-SM-16A & Gabbs Valley Tuff & 38.8989 & -117.7900 & $11 S$ & 431498 & 4305856 & 7015 \\
\hline 17-SM-16B & Gabbs Valley Tuff & 38.8989 & -117.7900 & $11 \mathrm{~S}$ & 431498 & 4305856 & 7015 \\
\hline 17-SM-17A & Underdown Tuff & 39.1610 & -117.3902 & $11 S$ & 466288 & 4334717 & 7049 \\
\hline 17-SM-17B & Underdown Tuff & 39.1610 & -117.3902 & $11 S$ & 466288 & 4334717 & 7049 \\
\hline 17-SM-17C & Underdown Tuff & 39.1610 & -117.3902 & $11 S$ & 466288 & 4334717 & 7049 \\
\hline 17-SM-18 & Pablo Formation & 39.1097 & -117.5047 & $11 S$ & 456369 & 4329070 & 7572 \\
\hline 17-SM-19 & Bonita Canyon Formation & 39.1113 & -117.5100 & $11 S$ & 455906 & 4329253 & 7861 \\
\hline $17-S M-20$ & Tuff of Arc Dome & 39.1589 & -117.3256 & $11 S$ & 471873 & 4334460 & 6535 \\
\hline $17-S M-21 A$ & Clipper Gap Tuff & 39.0547 & -116.5085 & $11 \mathrm{~S}$ & 542529 & 4322963 & 7756 \\
\hline 17-SM-21B & Clipper Gap Tuff & 39.0547 & -116.5085 & $11 S$ & 542529 & 4322963 & 7756 \\
\hline $17-S M-22$ & Clipper Gap Tuff & 39.0545 & -116.5084 & $11 S$ & 542536 & 4322941 & 7714 \\
\hline $17-S M-23$ & Clipper Gap Tuff & 38.8550 & -116.8353 & $11 S$ & 514293 & 4300699 & 7242 \\
\hline $17-S M-24$ & Clipper Gap Tuff & 38.8557 & -116.8352 & $11 S$ & 514297 & 4300779 & 7369 \\
\hline $17-S M-25$ & Clipper Gap Tuff & 38.8565 & -116.8359 & $11 \mathrm{~S}$ & 514238 & 4300864 & 7530 \\
\hline $17-S M-26 A$ & Clipper Gap Tuff & 38.8568 & -116.8359 & $11 S$ & 514238 & 4300900 & 7587 \\
\hline 17-SM-26B & Clipper Gap Tuff & 38.8568 & -116.8359 & $11 S$ & 514238 & 4300900 & 7587 \\
\hline 17-SM-26C & Clipper Gap Tuff & 38.8568 & -116.8359 & $11 S$ & 514238 & 4300900 & 7587 \\
\hline 17-SM-27 & Clipper Gap Tuff & 38.8549 & -116.8355 & $11 \mathrm{~S}$ & 514273 & 4300693 & 7193 \\
\hline $17-S M-28$ & Gabbs Valley Tuff & 38.8941 & -118.1865 & $11 S$ & 397108 & 4305696 & 4550 \\
\hline
\end{tabular}


Table II: Sample Locations Cont.

\begin{tabular}{cccccccc}
\hline Sample No. & Unit & N & W & Zone & E & N & Elevation (ft) \\
\hline NAD 83 & & & & & & & \\
\hline 17-SM-29 & Gabbs Valley Tuff & 38.8922 & -118.1832 & 11 S & 397324 & 4305473 & 4522 \\
17-SM-30 & Gabbs Valley Tuff & 38.8924 & -118.1834 & 11 S & 397370 & 4305502 & 4642 \\
17-SM-31 & Gabbs Valley Tuff & 38.8929 & -118.1832 & 11 S & 397390 & 4305550 & 4642 \\
H18-SN6 & Young Sierra & 39.1028 & -120.4192 & & & & \\
& Nevada tuff & & & & & & \\
H18-SN15 & Young Sierra & 39.0660 & -120.4596 & & & & \\
& Nevada tuff & & & & & & \\
\hline
\end{tabular}


Table III: Thin Section Descriptions

\begin{tabular}{|c|c|c|c|c|}
\hline $\begin{array}{c}\text { Sample Number } \\
\text { Unit } \\
\text { Lithology } \\
\text { \% Phenocrysts }\end{array}$ & $\begin{array}{c}\text { 16-SM-01 } \\
\text { Bonita Canyon } \\
\text { Whole Rock } \\
8 \% \\
\end{array}$ & $\begin{array}{c}\text { 16-SM-02 } \\
\text { Bonita Canyon } \\
\text { Pumice } \\
16 \% \\
\end{array}$ & $\begin{array}{c}\text { 16-SM-03 } \\
\text { Bonita Canyon } \\
\text { Vitrophyre } \\
10 \% \\
\end{array}$ & $\begin{array}{c}\text { 16-SM-04 } \\
\text { Underdown Tuff } \\
\text { Whole rock } \\
8 \% \\
\end{array}$ \\
\hline Plagioclase & $\begin{array}{c}2 \% \text {, up to } 1.0 \mathrm{~mm} \text {, phenocrysts } \\
\text { with polysynthetic twinning, some } \\
\text { are altered and are sieve textured, } \\
\text { some are fresh }\end{array}$ & $\begin{array}{l}5 \%, \sim 1.5 \mathrm{~mm} \text {, fractured, unaltered } \\
\text { phenocrysts with polysynthetic } \\
\text { twinning }\end{array}$ & $\begin{array}{l}2 \% \text {, up to } 1.0 \mathrm{~mm} \text {, fractured, unaltered } \\
\text { phenocrysts with polysynthetic twinning, } \\
\text { some show chemical zoning }\end{array}$ & None identifiable \\
\hline Quartz & $\begin{array}{l}4 \% \text {, up to } 1.5 \mathrm{~mm} \text {, quartz eyes with } \\
\text { embayments, fractured unevenly }\end{array}$ & $\begin{array}{l}5 \%, 1.5-2.0 \mathrm{~mm} \text {, quartz eyes with } \\
\text { embayments, fractured unevenly }\end{array}$ & $\begin{array}{c}6 \% \text {, up to } 2.5 \mathrm{~mm} \text {, quartz eyes with } \\
\text { embayments, unevenly fractured and opaque } \\
\text { inclusions }\end{array}$ & $\begin{array}{c}2 \%, 2.0 \mathrm{~mm} \text {, fractured, quartz eyes with } \\
\text { embayments }\end{array}$ \\
\hline Sanidine & $\begin{array}{l}1 \%,<1.0 \mathrm{~mm} \text {, phenocrysts with } \\
\text { Carlsbad twinning, unaltered }\end{array}$ & $\begin{array}{c}5 \%, \sim 1.5 \mathrm{~mm} \text {, fractured, unaltered } \\
\text { phenocrysts }\end{array}$ & $\begin{array}{l}1 \% \text {, very small phenocryst with Carlsbad } \\
\text { twinning }\end{array}$ & $\begin{array}{c}6 \%, 1.0 \mathrm{~mm} \text {, crystals are relatively fresh, } \\
\text { show carlsbad twinning, and have uneven } \\
\text { fractures }\end{array}$ \\
\hline Biotite & $\begin{array}{c}1 \%, 0.25 \mathrm{~mm} \text {, unaltered, } \\
\text { phenocrysts in matrix and lithic } \\
\text { fragment }\end{array}$ & $\begin{array}{l}1 \%, 0.25-0.5 \mathrm{~mm} \text { long, unaltered, bent } \\
\text { phenocrysts }\end{array}$ & $1 \%,<0.25 \mathrm{~mm}$, unaltered phenocryst & None identifiable \\
\hline Amphibole & None identifiable & None identifiable & $\begin{array}{c}\text { Trace, } 0.5 \mathrm{~mm} \text {, hexagonal crystal with } \\
\text { fracturing }\end{array}$ & Trace, altered by chlorite \\
\hline $\begin{array}{l}\text { Accessory } \\
\text { Phases }\end{array}$ & $\begin{array}{l}1 \% \text {, opaque minerals, }<0.1 \mathrm{~mm} \\
\text { Trace, microcrystalline Ti-oxides } \\
\text { throughout matrix } \\
\text { Trace, monazite }\end{array}$ & $\begin{array}{l}1 \% \text {, opaque minerals throughout } \\
\text { matrix } \\
\begin{array}{c}1 \% \text {, rutile, microcrystalline grains in } \\
\text { matrix } \\
\text { Trace, monazite }\end{array}\end{array}$ & $\begin{array}{l}\text { Trace, opaque minerals } \\
\text { Trace, Fe-Ti oxides }\end{array}$ & $\begin{array}{l}\text { Opaque minerals are very small and are } \\
\text { found throughout matrix }\end{array}$ \\
\hline Lithics & $\begin{array}{l}\text { 10\%, altered, most contain quartz } \\
\text { and feldspar, one is dark red with } \\
\text { abundant plagioclase laths, up to } \\
\quad 2.0 \mathrm{~mm}\end{array}$ & $\begin{array}{l}2 \% \text {, fully altered clast with large altered } \\
\text { feldspar inside, up to } 2.0 \mathrm{~mm}\end{array}$ & $\begin{array}{l}5 \% \text {, most composed of quartz and plagioclase } \\
\text { feldspar, some altered, one porphyritic, one } \\
\text { microcrystalline, up to } 2.0 \mathrm{~mm}\end{array}$ & $\begin{array}{l}1 \% \text {, very altered, composition looks } \\
\text { similar to the groundmass, up to } 2.0 \mathrm{~mm}\end{array}$ \\
\hline Textures & $\begin{array}{l}\text { Matrix of highly altered glass } \\
\text { shards with veins of silicification }\end{array}$ & $\begin{array}{l}\text { Matrix has glass bubble shards, is } \\
\text { phenocryst rich }\end{array}$ & $\begin{array}{l}\text { Matrix is welded, fresh, light brown glass, } \\
\text { glass shards throughout matrix } \\
\text { Fiamme are entirely glass and are lighter than } \\
\text { matrix }\end{array}$ & $\begin{array}{l}\text { Matrix is composed of brown, welded } \\
\text { glass which shows banding that wraps } \\
\text { around phenocrysts, no pumice. }\end{array}$ \\
\hline Alteration & $\begin{array}{c}\text { Possible chlorite alteration in } \\
\text { matrix }\end{array}$ & Matrix is altered heavily by chlorite & None identifiable & $\begin{array}{l}\text { Large areas of quartz silicification (10\%), } \\
\text { chlorite alteration in matrix (1\%) }\end{array}$ \\
\hline
\end{tabular}




\begin{tabular}{|c|c|c|c|c|}
\hline $\begin{array}{c}\text { Sample Number } \\
\text { Unit } \\
\text { Lithology } \\
\text { \% Phenocrysts } \\
\end{array}$ & $\begin{array}{c}\text { 16-SM-05 } \\
\text { Bonita Canyon } \\
\text { Whole Rock } \\
13 \% \\
\end{array}$ & $\begin{array}{c}\text { 16-SM-06 } \\
\text { Unnamed Tuff } \\
\text { Whole Rock } \\
31 \% \\
\end{array}$ & $\begin{array}{c}\text { 16-SM-07 } \\
\text { Bonita Canyon } \\
\text { Whole Rock } \\
6 \% \\
\end{array}$ & $\begin{array}{c}\text { 16-SM-08 } \\
\text { Bonita Canyon } \\
\text { Whole Rock } \\
7 \% \\
\end{array}$ \\
\hline Plagioclase & $\begin{array}{l}5 \%, \sim 0.5 \mathrm{~mm} \text {, phenocrysts with } \\
\text { polysynthetic twinning, fractured } \\
\text { and chemically zoned } \\
1 \%, \sim 1.5 \mathrm{~mm} \text {, xenocryst, heavily } \\
\text { sieved }\end{array}$ & $\begin{array}{l}10 \% \text {, up to } 1.5 \mathrm{~mm} \text {, phenocrysts } \\
\text { with polysynthetic twinning, } \\
\text { fractured and unaltered }\end{array}$ & $\begin{array}{c}1 \%,<1.0 \mathrm{~mm} \text {, very altered } \\
\text { phenocryst with polysynthetic } \\
\text { twinning }\end{array}$ & $\begin{array}{c}1 \%, \sim 0.25 \mathrm{~mm} \text {, unaltered } \\
\text { phenocrysts with polysynthetic } \\
\text { twinning }\end{array}$ \\
\hline Quartz & $\begin{array}{l}5 \% \text {, up to } 1.5 \mathrm{~mm} \text {, phenocrysts with } \\
\text { rounded corners and embayments, } \\
\text { fractured }\end{array}$ & $\begin{array}{l}10 \% \text {, up to } 3.0 \mathrm{~mm} \text {, phenocrysts } \\
\text { with rounded corners and } \\
\text { embayments, very fractured }\end{array}$ & $\begin{array}{l}5 \% \text {, up to } 1.5 \mathrm{~mm} \text {, phenocrysts } \\
\text { with rounded edges and } \\
\text { embayments, unevenly fractured }\end{array}$ & $5 \%$, up to $0.5 \mathrm{~mm}$, phenocrysts \\
\hline Sanidine & $\begin{array}{l}2 \%, \sim 0.5 \mathrm{~mm} \text {, phenocrysts with } \\
\text { Carlsbad twinning, highly fractured }\end{array}$ & $\begin{array}{l}10 \% \text {, up to } 4.0 \mathrm{~mm} \text {, unaltered } \\
\text { phenocrysts with Carlsbad twinning }\end{array}$ & None identifiable & None identifiable \\
\hline Biotite & $\begin{array}{l}1 \% \text {, up to } 0.5 \mathrm{~mm} \text { long, thin, } \\
\text { unaltered, bent phenocrysts }\end{array}$ & $\begin{array}{l}1 \%, 0.5 \mathrm{~mm} \text {, relatively fresh } \\
\text { phenocrysts with opaque rims }\end{array}$ & None identifiable & $\begin{array}{l}1 \% \text {, up to } 1.0 \mathrm{~mm} \text { long, } \\
\text { phenocryst altered slightly by } \\
\text { chlorite }\end{array}$ \\
\hline Amphibole & None identifiable & $\begin{array}{c}\text { Trace, }<0.1 \mathrm{~mm} \text {, unaltered } \\
\text { phenocryst } \\
1 \% \text {, opaque minerals, most } \leq 0.1\end{array}$ & None identifiable & None identifiable \\
\hline $\begin{array}{l}\text { Accessory } \\
\text { Phases }\end{array}$ & $\begin{array}{l}\text { Trace, rutile, disseminated grains in } \\
\text { matrix }\end{array}$ & $\begin{array}{c}\mathrm{mm} \text {, up to } 0.2 \mathrm{~mm} \\
\text { Trace, Fe-Ti oxides, } \sim 0.25 \mathrm{~mm} \\
\text { Trace, monazite }\end{array}$ & $\begin{array}{c}\text { Trace, rutile, disseminated red to } \\
\text { opaque oxides }\end{array}$ & Trace, monazite \\
\hline Lithics & $\begin{array}{l}5 \%, \text { mostly quartz and feldspar, up } \\
\text { to } 2.0 \mathrm{~mm}\end{array}$ & $\begin{array}{c}5 \% \text {, one up to } 3 \mathrm{~mm}, \\
\text { microcrystalline and patchy, most } \\
\text { are } \sim 1.0 \mathrm{~mm} \text { with small plagioclase } \\
\text { laths }\end{array}$ & None identifiable & $\begin{array}{c}1 \% \text {, up to } 1.5 \mathrm{~mm} \text {, composed } \\
\text { mostly of quartz }\end{array}$ \\
\hline Textures & Matrix is green, altered glass & $\begin{array}{l}\text { Matrix is orange-brown glass and } \\
\text { welded, pumice is light brown and } \\
\text { either aphyric or phyric with large } \\
\text { phenocrysts, phenocrysts are highly } \\
\text { fractured, phenocrysts in pumice } \\
\text { have radiating cracks going into } \\
\text { glassy pumice }\end{array}$ & $\begin{array}{l}\text { Matrix is altered, } \\
\text { microcrystalline, and silicified } \\
\text { Pumice likely completely } \\
\text { replaced by patchy alteration }\end{array}$ & $\begin{array}{c}\text { Matrix is altered, unwelded, and } \\
\text { vesicular }\end{array}$ \\
\hline Alteration & $\begin{array}{l}3 \%, \text { wispy sericite alteration in } \\
\text { matrix }\end{array}$ & $\begin{array}{l}\text { Some phenocrysts have light yellow } \\
\text { rims of alteration }\end{array}$ & $\begin{array}{l}2 \% \text { veiny yellow alteration in } \\
\text { matrix }\end{array}$ & $2 \%$ calcite alteration in matrix \\
\hline
\end{tabular}




\begin{tabular}{|c|c|c|c|c|}
\hline $\begin{array}{c}\text { Sample Number } \\
\text { Unit } \\
\text { Lithology } \\
\text { \% Phenocrysts } \\
\end{array}$ & $\begin{array}{c}\text { 16-SM-09 } \\
\text { Tuff of Arc Dome } \\
\text { Mega Breccia Block } \\
\sim 17 \%\end{array}$ & $\begin{array}{c}16-S M-10 \\
\text { Tuff of Clipper Gap } \\
\text { Whole Rock } \\
14 \% \\
\end{array}$ & $\begin{array}{c}\text { 16-SM-11 } \\
\text { Tuff of Campbell Creek } \\
\text { Whole rock } \\
\sim 4 \% \\
\end{array}$ & $\begin{array}{c}\text { 16-SM-13C } \\
\text { Tuff of Clipper Gap } \\
\text { Whole rock } \\
\sim 6 \% \\
\end{array}$ \\
\hline Plagioclase & $\begin{array}{c}10 \% \text {, up to } 1.5 \mathrm{~mm} \text {, altered phenocrysts } \\
\text { with polysynthetic twinning, partially } \\
\text { resorbed }\end{array}$ & $\begin{array}{l}7 \% \text {, up to } 2.0 \mathrm{~mm} \text {, unaltered, fractured } \\
\text { phenocrysts with polysynthetic } \\
\text { twinning, some show chemical zoning }\end{array}$ & $\begin{array}{c}2 \% \text {, up to } 2.0 \mathrm{~mm} \text {, fractured } \\
\text { phenocrysts with polysynthetic } \\
\text { twinning, some are resorbed or } \\
\text { plucked }\end{array}$ & $\begin{array}{c}1 \%, 0.1-1.0 \mathrm{~mm} \text {, unaltered } \\
\text { phenocrysts with polysynthetic } \\
\text { twinning }\end{array}$ \\
\hline Quartz & $\begin{array}{l}10 \% \text {, up to } 2.5 \mathrm{~mm} \text {, phenocrysts with } \\
\text { rounded corners and embayments }\end{array}$ & $10 \%$, microcrystalline quartz in matrix & None identifiable & $\begin{array}{l}2 \%, 1.75-2.0 \mathrm{~mm} \text {, fractured } \\
\text { phenocrysts with rounded corners } \\
\text { and embayments }\end{array}$ \\
\hline Sanidine & $\begin{array}{c}\sim 5 \% \text {, up to } 1.0 \mathrm{~mm} \text {, altered phenocrysts } \\
\text { with Carlsbad twinning, partially } \\
\text { resorbed }\end{array}$ & $\begin{array}{l}7 \% \text {, up to } 2.0 \mathrm{~mm} \text {, unaltered, fractured } \\
\text { phenocrysts with Carlsbad twinning, one } \\
\text { crystal has been completely sieved }\end{array}$ & $\begin{array}{l}2 \% \text {, up to } 2.0 \mathrm{~mm} \text {, fractured } \\
\text { phenocrysts with Carlsbad twinning }\end{array}$ & $\begin{array}{c}3 \%, 1.0-2.0 \mathrm{~mm} \text {, fractured, unaltered } \\
\text { phenocrysts, some with Carlsbad } \\
\text { twinning }\end{array}$ \\
\hline Biotite & $\begin{array}{c}2 \% \text {, up to } 1.0 \mathrm{~mm} \text {, phenocrysts with } \\
\text { opaque rims }\end{array}$ & $\begin{array}{c}\text { Trace, up to } 0.75 \mathrm{~mm} \text {, altered } \\
\text { phenocryst }\end{array}$ & $\begin{array}{c}\text { Trace, up to } 0.5 \mathrm{~mm} \text {, crystals have } \\
\text { opaque rims }\end{array}$ & $\begin{array}{c}\text { Trace- } 1 \%, 0.1-0.25 \mathrm{~mm} \text {, phenocrysts, } \\
\text { some slightly bent }\end{array}$ \\
\hline Amphibole & None identifiable & None identifiable & None identifiable & None identifiable \\
\hline Accessory Phases & $2 \%$, opaque minerals, up to $0.4 \mathrm{~mm}$ & $\begin{array}{l}\text { 1\%, opaque minerals, } \leq 0.2 \mathrm{~mm} \\
\text { Trace, Fe-Ti oxides, }<0.1 \mathrm{~mm} \text {, } \\
\text { disseminated grains in matrix, larger } \\
>0.1 \mathrm{~mm} \text { around plucked out minerals }\end{array}$ & $\begin{array}{l}\text { Trace-1\%, opaque minerals, up to } 0.5 \\
\mathrm{~mm} \\
\text { Trace-1\%, pyroxene, up to } 0.75 \mathrm{~mm}\end{array}$ & $\begin{array}{c}\text { 3-4\%, opaque minerals, up to } 0.2 \mathrm{~mm} \text {, } \\
\text { some rim phenocrysts, Trace, Fe-Ti } \\
\text { oxides, } 0.1-1.0 \mathrm{~mm} \text {, Trace, pyroxene?, } \\
\sim 1.0 \mathrm{~mm} \text {, pink, slightly fractured, } \\
\text { unaltered }\end{array}$ \\
\hline Lithics & $1 \%$, up to $3.5 \mathrm{~mm}$, microcrystalline & None identifiable & $\begin{array}{c}1 \%, 2.0 \mathrm{~mm} \text {, brown, very altered, } \\
\text { possibly looks spherulitic under } \\
\text { alteration }\end{array}$ & None identifiable \\
\hline Textures & $\begin{array}{l}\text { Matrix is brown and spherulitic, with } \\
\text { some microcrystalline quartz ( } \sim 5 \%)\end{array}$ & $\begin{array}{l}\text { Matrix is glassy, has some } \\
\text { microcrystalline quartz, unwelded, some } \\
\text { areas of spherulites }\end{array}$ & $\begin{array}{l}\text { Matrix is highly welded, colourless, } \\
\text { composed of glass shards, some glass } \\
\text { shards are light brown } \\
\text { White and banded fiamme are both } \\
\text { mostly aphyric, one large sanidine } \\
\text { crystal on edge that may be in matrix }\end{array}$ & Matrix is composed of glass shards \\
\hline Alteration & Brown alteration in matrix & None identifiable & None identifiable & Slight alteration in matrix \\
\hline
\end{tabular}




\begin{tabular}{|c|c|c|c|c|c|}
\hline $\begin{array}{c}\text { Sample Number } \\
\text { Unit } \\
\text { Lithology } \\
\text { \% Phenocrysts } \\
\end{array}$ & $\begin{array}{c}\text { 16-SM-14 } \\
\text { Tuff of Clipper Gap } \\
\text { Pumice } \\
\sim 10 \% \\
\end{array}$ & $\begin{array}{c}\text { 16-SM-15A } \\
\text { Tuff of Clipper Gap } \\
\text { Porphyritic pumice } \\
13 \% \\
\end{array}$ & $\begin{array}{c}\text { 16-SM-15B } \\
\text { Tuff of Clipper Gap } \\
\text { Whole rock } \\
13 \% \\
\end{array}$ & $\begin{array}{c}\text { 16-SM-16 } \\
\text { Tuff of Clipper Gap } \\
\text { Porphyritic Pumice } \\
\text { 25\% } \\
\end{array}$ & $\begin{array}{c}\text { 16-SM-17 } \\
\text { Tuff of Clipper Gap } \\
\text { Porphyritic pumice } \\
\text { 13\% } \\
\end{array}$ \\
\hline Plagioclase & $\begin{array}{c}\text { Trace, } \leq 0.2 \mathrm{~mm} \text {, } \\
\text { unaltered phenocrysts } \\
\text { with polysynthetic } \\
\text { twinning, }\end{array}$ & $\begin{array}{l}\quad 3 \%, 1.0-2.5 \mathrm{~mm} \text {, } \\
\text { phenocrysts with } \\
\text { polysynthetic twinning, } \\
\text { alteration on rims, and } \\
\text { sieve texture }\end{array}$ & None identifiable & $\begin{array}{c}10 \%, 1.0-2.5 \mathrm{~mm} \text {, partially } \\
\text { altered phenocrysts with } \\
\text { polysynthetic twinning, some } \\
\text { chemical zoning }\end{array}$ & $\begin{array}{l}3 \% \text {, up to } 2.5 \mathrm{~mm} \text {, } \\
\text { phenocrysts with } \\
\text { polysynthetic twinning, } \\
\text { alteration on rims, and } \\
\quad \text { sieve texture }\end{array}$ \\
\hline Quartz & $\begin{array}{c}2 \%, 1.25-2.0 \mathrm{~mm}, \\
\text { unevenly fractured } \\
\text { phenocrysts with rounded } \\
\text { corners and embayments, }\end{array}$ & None identifiable & $\begin{array}{l}10 \% \text { microcrystalline } \\
\text { quartz in matrix }\end{array}$ & None identifiable & None identifiable \\
\hline Sanidine & $\begin{array}{c}5 \%, 1.0-2.5 \mathrm{~mm}, \\
\text { fractured, unaltered } \\
\text { phenocrysts, some show } \\
\text { Carlsbad twinning }\end{array}$ & $\begin{array}{l}10 \% \text {, up to } 3.0 \mathrm{~mm} \text {, altered, } \\
\text { rectangular crystals }\end{array}$ & $\begin{array}{l}3 \% \text {, up to } 1.5 \mathrm{~mm}, \\
\text { unaltered, fractured } \\
\text { phenocrysts }\end{array}$ & $\begin{array}{c}15 \%, 1.0-4.5 \mathrm{~mm} \text {, fractured, } \\
\text { partially altered phenocrysts, } \\
\text { some show simple twinning }\end{array}$ & $\begin{array}{c}10 \% \text {, up to } 3.0 \mathrm{~mm} \text {, } \\
\text { altered, rectangular } \\
\text { crystals }\end{array}$ \\
\hline Biotite & $\begin{array}{l}\text { Trace, } 0.1-0.25 \mathrm{~mm} \text {, } \\
\text { generally thin, unaltered }\end{array}$ & None identifiable & $\begin{array}{l}\text { Trace, } \sim 0.75 \mathrm{~mm}, \\
\text { altered, dark red to } \\
\text { opaque on edges and } \\
\text { partially resorbed }\end{array}$ & None identifiable & None identifiable \\
\hline Amphibole & None identifiable & None identifiable & None identifiable & None identifiable & None identifiable \\
\hline Accessory Phases & $\begin{array}{l}\text { Trace, opaque minerals, } \\
\sim 0.1 \mathrm{~mm} \text {, blocky, Trace, } \\
\text { Fe-Ti oxides, } \leq 0.25 \mathrm{~mm} \text {, } \\
\text { blocky, } 2 \% \text {, pyroxene?, } \\
0.5-1.75 \mathrm{~mm} \text {, unaltered, } \\
2^{\text {nd }} \text { order interference }\end{array}$ & $\begin{array}{c}2 \% \text {, Fe-Ti oxides, clustered, } \\
0.5-1 \mathrm{~mm} \\
1 \% \text {, opaque minerals, } 0.25- \\
0.5 \mathrm{~mm} \\
\text { Trace, monazite }\end{array}$ & $\begin{array}{c}\text { Trace, opaque minerals, } \\
\leq 0.1 \mathrm{~mm} \\
\text { Trace, monazite }\end{array}$ & $\begin{array}{l}2 \% \text {, Fe-Ti oxides, } \sim 1.0 \mathrm{~mm} \text {, } \\
\text { blocky clusters, } 1 \% \text {, opaque } \\
\text { minerals, } \leq 0.25 \mathrm{~mm} \text {, blocky } \\
\text { Trace, monazite }\end{array}$ & $\begin{array}{c}\text { 2\%, Fe-Ti oxides, clustered, } \\
0.5-1 \mathrm{~mm} \\
1 \% \text {, opaque minerals, } 0.25- \\
0.5 \mathrm{~mm} \\
\text { Trace, monazite }\end{array}$ \\
\hline Lithics & None identifiable & None identifiable & None identifiable & None identifiable & None identifiable \\
\hline Textures & $\begin{array}{c}\text { Matrix is altered and } \\
\text { spherulitic, one area of } \\
\text { matrix is orange and more } \\
\text { glassy }\end{array}$ & $\begin{array}{l}\text { Matrix is reddish, opaque, } \\
\text { altered glass, very } \\
\text { porphyritic }\end{array}$ & $\begin{array}{l}\text { Matrix is altered glass, } \\
\text { part of matrix is } \\
\text { microcrystalline quartz, } \\
\text { little evidence of welding }\end{array}$ & $\begin{array}{c}\text { Matrix is brown, altered, } \\
\text { patchy glass }\end{array}$ & $\begin{array}{c}\text { Matrix is reddish, opaque, } \\
\text { altered glass, very } \\
\text { porphyritic }\end{array}$ \\
\hline Alteration & Some matrix alteration & Alteration in matrix & Alteration in matrix & Alteration in matrix & Alteration in matrix \\
\hline
\end{tabular}




\begin{tabular}{|c|c|c|c|c|}
\hline $\begin{array}{c}\text { Sample Number } \\
\text { Unit } \\
\text { Lithology } \\
\text { \% Phenocrysts }\end{array}$ & $\begin{array}{c}\text { 16-SM-18 } \\
\text { Tuff of Clipper Gap } \\
\text { Whole rock } \\
17 \%\end{array}$ & $\begin{array}{c}\text { 16-SM-19 } \\
\text { Pablo Formation } \\
\text { Whole Rock } \\
\text { - }\end{array}$ & $\begin{array}{c}\text { 16-SM-20B } \\
\text { Pablo Formation } \\
\text { Whole Rock } \\
\text { - }\end{array}$ & $\begin{array}{c}\text { 16-SM-21A } \\
\text { Bonita Canyon } \\
\text { Whole Rock } \\
10 \%\end{array}$ \\
\hline Plagioclase & $\begin{array}{l}7 \% \text {, up to } 2.5 \mathrm{~mm} \text {, phenocrysts with } \\
\text { polysynthetic twinning, slightly altered } \\
\text { and fractured, some show chemical } \\
\text { zoning and sieve texture }\end{array}$ & $\begin{array}{c}60 \%, 0.1-2.5 \mathrm{~mm} \text {, phenocrysts and } \\
\text { matrix material with polysynthetic } \\
\text { and simple twinning, altered by } \\
\text { sericite }\end{array}$ & $\begin{array}{c}40 \%, 0.1-1.5 \mathrm{~mm} \text {, large crystals are } \\
\text { heavily altered by sericite, small } \\
\text { crystals are fresh }\end{array}$ & $\begin{array}{c}2 \% \text {, up to } 0.5 \mathrm{~mm} \text {, unaltered, fractured, } \\
\text { phenocrysts }\end{array}$ \\
\hline Quartz & None identifiable & $\begin{array}{l}5 \%, \text { up to } 0.5 \mathrm{~mm} \text {, secondary, } \\
\text { mostly microcrystalline in veins, one } \\
\text { large crystal is being eaten away at } \\
\text { edges }\end{array}$ & None identifiable & $\begin{array}{c}4 \% \text {, up to } 2.0 \mathrm{~mm} \text {, phenocrysts with } \\
\text { rounded corners and embayments } \\
\text { Smaller grains are in silicified areas of } \\
\text { matrix }\end{array}$ \\
\hline Sanidine & $\begin{array}{l}\text { 7\%, up to } 4.0 \mathrm{~mm} \text {, unaltered, fractured } \\
\text { phenocrysts, some with Carlsbad } \\
\text { twinning }\end{array}$ & None identifiable & None identifiable & $\begin{array}{l}2 \% \text {, up to } 2.0 \mathrm{~mm} \text {, unaltered, fractured, } \\
\text { phenocrysts }\end{array}$ \\
\hline Biotite & $\begin{array}{c}1 \% \text {, up to } 2.0 \mathrm{~mm} \text {, altered phenocrysts, } \\
\text { opaque dehydration rim around edges } \\
\text { of crystals }\end{array}$ & $\begin{array}{c}\text { Trace, up to } 0.5 \mathrm{~mm} \text {, altered, bent } \\
\text { phenocrysts }\end{array}$ & None identifiable & $\begin{array}{l}2 \% \text {, up to } 0.5 \mathrm{~mm} \text {, unaltered, bent, } \\
\text { phenocrysts }\end{array}$ \\
\hline Amphibole & $\begin{array}{l}2 \% \text {, up to } 2 \mathrm{~mm} \text {, altered by chlorite, } \\
\text { opaque dehydration rim around edges } \\
\text { of crystals }\end{array}$ & $\begin{array}{l}\text { 32\%, up to } 1.5 \mathrm{~mm} \text {, elongate and } \\
\text { hexagonal crystals altered by } \\
\text { chlorite, some opaque inclusions } \\
\text { and simple twinning }\end{array}$ & $\begin{array}{l}30 \% \text {, up to } ~ 3.0 \mathrm{~mm} \text {, elongate and } \\
\text { hexagonal crystals altered by chlorite, } \\
\text { some opaque inclusions and simple } \\
\text { twinning }\end{array}$ & None identifiable \\
\hline Accessory Phases & $\begin{array}{c}1 \% \text {, Fe-Ti oxides, }<0.1 \mathrm{~mm} \text {, red to } \\
\text { opaque }\end{array}$ & $3 \%$, opaque minerals, up to $0.5 \mathrm{~mm}$ & $\begin{array}{l}\text { 1\%, pyrite, } \sim 1.75 \mathrm{~mm} \\
\text { Trace, Fe-Ti oxides, up to } \sim 0.1 \mathrm{~mm}\end{array}$ & $\begin{array}{c}\text { Trace, monazite } \\
\text { Trace, opaque minerals, disseminated in } \\
\text { matrix }\end{array}$ \\
\hline Lithics & Trace, opaque minerals $<0.1 \mathrm{~mm}$ & None identifiable & None identifiable & $\begin{array}{c}\text { Trace, Fe-Ti oxides in matrix, }<0.1 \mathrm{~mm} \\
5 \% \text {, lithics with different compositions from } \\
\text { different sources; red opaque with quartz, } \\
\text { spherulitic lithics, completely altered } \\
\text { lithics, microcrystalline quartz, up to } 2.5 \\
\mathrm{~mm}\end{array}$ \\
\hline Textures & $\begin{array}{l}\text { Welded, altered, glassy matrix, glass } \\
\text { shards, banding of matrix around } \\
\text { phenocrysts }\end{array}$ & $\begin{array}{l}\text { Matrix is split in two halves, one } \\
\text { more altered and one with } \\
\text { microcrystalline matrix }\end{array}$ & $\begin{array}{l}\text { Matrix is } 20 \% \text { microcrystalline } \\
\text { material (too small to be identified) }\end{array}$ & $\begin{array}{l}\text { Matrix is fresh, glassy, with glass shards, } \\
\text { pumice is not flattened }\end{array}$ \\
\hline Alteration & Sericite alteration in matrix & Chlorite and sericite & $\begin{array}{l}5 \% \text {, calcite alteration in matrix, crystals } \\
\text { up to } \sim 1.75 \mathrm{~mm} \\
\text { Sericite alteration of plagioclase }\end{array}$ & Wispy yellow alteration in matrix \\
\hline
\end{tabular}




\begin{tabular}{|c|c|c|c|c|}
\hline $\begin{array}{l}\text { Sample Number } \\
\text { Unit } \\
\text { Lithology } \\
\text { \% Phenocrysts }\end{array}$ & $\begin{array}{c}\text { 16-SM-21B } \\
\text { Bonita Canyon } \\
\text { White Pumice } \\
11 \%\end{array}$ & $\begin{array}{c}\text { 16-SM-21C } \\
\text { Bonita Canyon } \\
\text { Whole Rock } \\
17 \%\end{array}$ & $\begin{array}{c}\text { 16-SM-22-1 } \\
\text { Bonita Canyon } \\
\text { Whole Rock } \\
16 \%\end{array}$ & $\begin{array}{c}\text { 16-SM-23 } \\
\text { Bonita Canyon } \\
\text { Whole Rock } \\
16 \%\end{array}$ \\
\hline Plagioclase & $\begin{array}{l}4 \%, \sim 1.5 \mathrm{~mm} \text {, rectangular phenocrysts } \\
\text { with polysynthetic twinning, unaltered, } \\
\text { some show chemical zoning }\end{array}$ & $\begin{array}{l}5 \%, \leq 0.5 \mathrm{~mm} \text {, phenocrysts with } \\
\text { polysynthetic twinning, unaltered } \\
\text { and unevenly fractured }\end{array}$ & $\begin{array}{l}3 \% \text {, up to } 0.75 \mathrm{~mm} \text {, phenocrysts with } \\
\text { polysynthetic twinning, fractured and } \\
\text { chemically zoned } \\
2 \% \text { feldspar xenocrysts, } 0.25-0.5 \mathrm{~mm} \text {, } \\
\text { with only rim of crystals remaining }\end{array}$ & $\begin{array}{l}3 \% \text {, up to } 0.75 \mathrm{~mm} \text {, phenocrysts with } \\
\text { polysynthetic twinning, fractured and } \\
\text { chemically zoned } \\
\begin{array}{c}2 \% \text { feldspar xenocrysts, } 0.25-0.5 \mathrm{~mm} \text {, with } \\
\text { only rim of crystals remaining }\end{array}\end{array}$ \\
\hline Quartz & $\begin{array}{c}3 \% \text {, up to } 2.0 \mathrm{~mm} \text {, phenocrysts with } \\
\text { rounded edges and embayments, } \\
\text { unevenly fractured }\end{array}$ & $\begin{array}{l}10 \%, 0.5-1.5 \mathrm{~mm} \text {, phenocrysts with } \\
\text { some rounded edges, unfractured }\end{array}$ & $\begin{array}{l}3 \% \text {, up to } 2.0 \mathrm{~mm} \text {, phenocrysts with } \\
\text { rounded corners, very fractured }\end{array}$ & $\begin{array}{l}3 \% \text {, up to } 2.0 \mathrm{~mm} \text {, phenocrysts with } \\
\text { rounded corners, very fractured }\end{array}$ \\
\hline Sanidine & $\begin{array}{l}2 \%, \text { up to } 1.5 \mathrm{~mm} \text {, unaltered } \\
\text { phenocrysts with no visible twinning }\end{array}$ & $\begin{array}{c}10 \%, 0.5-1.5 \mathrm{~mm} \text {, rectangular } \\
\text { phenocrysts with fractures, one } \\
\text { crystal is zoned }\end{array}$ & $\begin{array}{l}3 \% \text {, up to } 1.5 \mathrm{~mm} \text {, rectangular } \\
\text { phenocrysts, fractured }\end{array}$ & $\begin{array}{c}3 \% \text {, up to } 1.5 \mathrm{~mm} \text {, rectangular phenocrysts, } \\
\text { fractured }\end{array}$ \\
\hline Biotite & $\begin{array}{l}2 \% \text {, up to } 0.5 \mathrm{~mm} \text {, bent, unaltered } \\
\text { phenocrysts }\end{array}$ & $\begin{array}{l}2 \% \text {, most } 0.5-0.1 \mathrm{~mm} \text {, largest up to } \\
1-1.5 \mathrm{~mm} \text { long, unaltered, bent } \\
\text { phenocrysts }\end{array}$ & $\begin{array}{l}5 \%,<0.5 \mathrm{~mm} \text {, unaltered, bent } \\
\text { phenocrysts with red opaque } \\
\text { inclusions } \\
\text { One phenocryst up to } 2.5 \mathrm{~mm} \text { being } \\
\text { resorbed in the middle }\end{array}$ & $\begin{array}{c}5 \%,<0.5 \mathrm{~mm} \text {, unaltered, bent phenocrysts } \\
\text { with red opaque inclusions } \\
\text { One phenocryst up to } 2.5 \mathrm{~mm} \text { being } \\
\text { resorbed in the middle }\end{array}$ \\
\hline Amphibole & Trace, possible & None identifiable & None identifiable & None identifiable \\
\hline Accessory Phases & $\begin{array}{c}\text { Trace, opaque minerals } \\
\text { microcrystalline in matrix, }<0.1 \mathrm{~mm} \\
\text { Trace, Fe-Ti oxides, microcrystalline in } \\
\text { matrix, }<0.1 \mathrm{~mm}\end{array}$ & $\begin{array}{l}\text { Trace, opaque minerals, }<0.1 \mathrm{~mm} \text { in } \\
\text { matrix } \\
\text { Trace, Fe-Ti oxides, }<0.1 \mathrm{~mm} \text { in } \\
\text { matrix } \\
\text { 3\%, } 1.0-1.5 \mathrm{~mm} \text {, mostly }\end{array}$ & $\begin{array}{c}\text { Trace, Fe-Ti oxides, }<0.1 \mathrm{~mm} \text {, square } \\
\text { Trace, opaque minerals, }<0.1 \mathrm{~mm}, \\
\text { disseminated in matrix and inclusions } \\
\text { Trace, monazite }\end{array}$ & $\begin{array}{l}\text { Trace, Fe-Ti oxides, }<0.1 \mathrm{~mm} \text {, square } \\
\text { Trace, opaque minerals, }<0.1 \mathrm{~mm} \text {, } \\
\text { disseminated in matrix and inclusions } \\
\text { Trace, monazite }\end{array}$ \\
\hline Lithics & None identifiable & $\begin{array}{l}\text { microcrystalline clasts that look } \\
\text { similar in composition, two altered } \\
\text { completely }\end{array}$ & $\begin{array}{l}2 \%, 2.0 \mathrm{~mm} \text {, red opaque, } \\
\text { microcrystalline }\end{array}$ & $2 \%, 2.0 \mathrm{~mm}$, red opaque, microcrystalline \\
\hline Textures & Matrix made up of glass shards & $\begin{array}{l}\text { Matrix is fresh glass, pumice is not } \\
\text { flattened, } \sim 5 \% \text { vesicles }\end{array}$ & $\begin{array}{l}\text { Matrix is glassy and relatively fresh, } \\
\text { unwelded-poorly welded }\end{array}$ & $\begin{array}{l}\text { Matrix is glassy and relatively fresh, } \\
\text { unwelded-poorly welded }\end{array}$ \\
\hline Alteration & Chlorite alteration in matrix? & None identifiable & Slightly altered aphyric pumice & Slightly altered aphyric pumice \\
\hline
\end{tabular}




\begin{tabular}{|c|c|c|c|c|}
\hline $\begin{array}{l}\text { Sample Number } \\
\text { Unit } \\
\text { Lithology } \\
\text { \% Phenocrysts }\end{array}$ & $\begin{array}{c}16-S M-24 \\
\text { Bonita Canyon } \\
\text { Whole Rock } \\
14 \% \\
\end{array}$ & $\begin{array}{c}\text { 16-SM-26 } \\
\text { Tuff of Arc Dome } \\
\text { Mega Breccia Block } \\
23 \%\end{array}$ & $\begin{array}{c}\text { 16-SM-27 } \\
\text { Bonita Canyon } \\
\text { Whole rock } \\
5 \% \\
\end{array}$ & $\begin{array}{c}\text { 16-SM-30 } \\
\text { Bonita Canyon } \\
\text { Whole Rock } \\
11 \% \\
\end{array}$ \\
\hline Plagioclase & $\begin{array}{l}3 \% \text {, up to } 0.5 \mathrm{~mm} \text {, phenocrysts with } \\
\text { polysynthetic twinning, sieve texture, } \\
\text { slightly altered and fractured }\end{array}$ & $\begin{array}{l}10 \% \text {, up to } 5.0 \mathrm{~mm} \text {, phenocrysts with } \\
\text { polysynthetic twinning, some } \\
\text { inclusions, altered by sericite and } \\
\text { calcite }\end{array}$ & None identifiable & $\begin{array}{c}1 \%, 0.25 \mathrm{~mm} \text {, unaltered phenocryst with } \\
\text { polysynthetic twinning }\end{array}$ \\
\hline Quartz & $\begin{array}{l}6 \%, \text { up to } 2.0 \mathrm{~mm} \text {, phenocrysts with } \\
\text { rounded corners and embayments, } \\
\text { highly fractured }\end{array}$ & $\begin{array}{l}7 \% \text {, up to } 2.0 \mathrm{~mm} \text {, rounded } \\
\text { phenocrysts with embayments, highly } \\
\text { to slightly fractured }\end{array}$ & $\begin{array}{c}5 \%, 2.5 \mathrm{~mm} \text {, phenocrysts with rounded } \\
\text { corners and embayments } \\
90 \%, \text { microcrystalline qtz in matrix }\end{array}$ & $\begin{array}{l}5 \% \text {, up to } 1.5 \mathrm{~mm} \text {, phenocrysts with } \\
\text { rounded corners and embayments } \\
50 \%, \sim 0.1 \mathrm{~mm} \text {, crystals in silicified veins }\end{array}$ \\
\hline Sanidine & $\begin{array}{c}2 \%, 0.5 \mathrm{~mm} \text {, phenocryst with Carlsbad } \\
\text { twinning, with sieve texture and } \\
\text { alteration }\end{array}$ & $\begin{array}{l}5 \% \text {, up to } 4.0 \mathrm{~mm} \text {, phenocrysts with } \\
\text { Carlsbad twinning, heavily altered }\end{array}$ & None identifiable & $\begin{array}{c}5 \%, 0.5 \mathrm{~mm} \text {, phenocrysts altered and } \\
\text { sieved }\end{array}$ \\
\hline Biotite & $\begin{array}{l}3 \%, 0.1-0.5 \mathrm{~mm} \text {, largest up to } 1 \mathrm{~mm}, \\
\text { bent phenocrysts }\end{array}$ & $\begin{array}{c}1 \% \text {, up to } 1.5 \mathrm{~mm} \text {, altered phenocrysts } \\
\text { with opaque rims, some completely } \\
\text { replaced }\end{array}$ & None identifiable & None identifiable \\
\hline Amphibole & $\begin{array}{l}\text { Trace, } 1 \mathrm{~mm} \text {, completely replaced by } \\
\text { chlorite }\end{array}$ & $\begin{array}{c}\text { Trace, } \sim 0.2 \mathrm{~mm} \text {, very altered, opaque } \\
\text { rim }\end{array}$ & None identifiable & None identifiable \\
\hline $\begin{array}{l}\text { Accessory } \\
\text { Phases }\end{array}$ & $\begin{array}{c}\text { Trace, opaque minerals, } 0.1 \mathrm{~mm} \text { in } \\
\text { matrix } \\
\text { Trace, Fe-Ti oxides, }<0.1 \mathrm{~mm} \\
\text { inclusions }\end{array}$ & $\begin{array}{l}2 \% \text {, opaque minerals, most } \leq 0.1 \mathrm{~mm} \text {, } \\
\text { largest up to } 1.0 \mathrm{~mm}\end{array}$ & $\begin{array}{l}3 \% \text {, calcite, up to } 1.5 \mathrm{~mm} \text { crystals filling } \\
\text { voids where feldspars are altered out, } \\
\text { some found in matrix } \\
\text { Trace, opaque minerals, }<0.1 \mathrm{~mm} \text {, } \\
\text { disseminated throughout matrix }\end{array}$ & $\begin{array}{l}\text { Trace, opaque minerals, }<0.1 \mathrm{~mm} \\
\text { Trace, monazite, }<0.1 \mathrm{~mm}\end{array}$ \\
\hline Lithics & $\begin{array}{l}10 \%, 3.0 \mathrm{~mm} \text {, most composed of } \\
\text { altered quartz and feldspar, } \\
\text { spherulites, one is microcrystalline qtz } \\
\text { and rich in Ti-oxides }\end{array}$ & None identifiable & None identifiable & $\begin{array}{l}5 \%, 2.5 \mathrm{~mm} \text {, composed of } \\
\text { microcrystalline quartz }\end{array}$ \\
\hline Textures & $\begin{array}{l}\text { Relatively unaltered, unwelded matrix, } \\
5 \% \text { vesicles }\end{array}$ & $\begin{array}{l}\text { Matrix is altered, contains } \\
\text { microcrystalline quartz and is slightly } \\
\text { spherulitic }\end{array}$ & $\begin{array}{c}\text { Matrix is completely silicified, composed } \\
\text { of microcrystalline quartz, spherulites } \\
\text { throughout matrix }\end{array}$ & Matrix is heavily silicified \\
\hline Alteration & Slightly altered aphyric pumice & $\begin{array}{l}8 \% \text {, calcite alteration on feldspars and } \\
\text { in matrix }\end{array}$ & Calcite alteration and silicification & $1 \%$ green, chlorite alteration in matrix \\
\hline
\end{tabular}




\begin{tabular}{|c|c|c|c|c|}
\hline $\begin{array}{c}\text { Sample Number } \\
\text { Unit } \\
\text { Lithology } \\
\text { \% Phenocrysts } \\
\end{array}$ & $\begin{array}{l}\text { 16-SM-31 } \\
\text { Underdown Tuff } \\
\text { Whole Rock } \\
\sim 20 \% \\
\end{array}$ & $\begin{array}{c}\text { 16-SM-32A } \\
\text { Underdown Tuff } \\
\text { Porphyritic pumice } \\
\sim 10 \% \\
\end{array}$ & $\begin{array}{l}\text { 16-SM-32B } \\
\text { Underdown Tuff } \\
\text { Whole Rock } \\
12 \% \\
\end{array}$ & $\begin{array}{l}\text { 16-SM-32C } \\
\text { Underdown Tuff } \\
\text { Whole Rock } \\
\sim 10 \% \\
\end{array}$ \\
\hline Plagioclase & $\begin{array}{c}10 \%, 2.0-3.0 \mathrm{~mm} \text {, phenocrysts } \\
\text { show sieve texture and are } \\
\text { very altered }\end{array}$ & $\begin{array}{c}10 \%, 2.0 \mathrm{~mm} \text {, phenocrysts } \\
\text { showing polysynthetic twinning } \\
\text { are highly altered by sericite and } \\
\text { some calcite, with some small } \\
\text { inclusions }\end{array}$ & $\begin{array}{c}3 \% \text {, up to } 1.5 \mathrm{~mm} \text {, phenocrysts } \\
\text { almost completely replaced by } \\
\text { calcite }\end{array}$ & $\begin{array}{l}5 \% \text {, up to } 2.5 \mathrm{~mm} \text {, altered feldspar } \\
\text { phenocrysts, calcite and sericite } \\
\text { alteration, some small crystals with } \\
\text { polysynthetic twins on edges of voids } \\
\text { where quartz and calcite are found }\end{array}$ \\
\hline Quartz & $\begin{array}{c}10 \%, \text { up to } 2.0 \mathrm{~mm} \text {, quartz } \\
\text { eyes with embayments, are } \\
\text { fractured }\end{array}$ & $\begin{array}{l}5 \%, 0.5 \mathrm{~mm} \text {, small grains in } \\
\text { matrix, a result of silicification }\end{array}$ & $\begin{array}{c}5 \% \text {, up to } 2.0 \mathrm{~mm} \text {, quartz eye } \\
\text { phenocrysts with embayments, } \\
\text { yellow-red inclusions } \\
40 \% \text {, microcrystalline silicification }\end{array}$ & $\begin{array}{c}5 \% \text {, up to } 1.0 \mathrm{~mm} \text {, fractured quartz } \\
\text { eyes }\end{array}$ \\
\hline Sanidine & $\begin{array}{l}1 \% \text {, up to } 1.0 \mathrm{~mm} \text {, phenocrysts } \\
\text { showing carlsbad twinning }\end{array}$ & $\begin{array}{l}10 \% \text {, up to } 1.5 \mathrm{~mm} \text {, phenocrysts } \\
\text { showing recrystallization around } \\
\text { the edges of the crystal }\end{array}$ & $\begin{array}{l}\text { 3\%, up to } 1.5 \mathrm{~mm} \text {, phenocrysts with } \\
\text { Carlsbad twinning have sericite } \\
\text { alteration on the edges }\end{array}$ & $\begin{array}{c}1 \% \text {, up to } 1.5 \mathrm{~mm} \text {, relatively fresh } \\
\text { phenocrysts }\end{array}$ \\
\hline Biotite & None identifiable & $2 \%, 0.1 \mathrm{~mm}$, altered by chlorite & $\begin{array}{l}1 \% \text {, up to } 0.1 \mathrm{~mm} \text {, completely } \\
\text { replaced by chlorite }\end{array}$ & None identifiable \\
\hline Amphibole & None identifiable & $2 \%, 0.1 \mathrm{~mm}$, altered by chlorite & $\begin{array}{l}\text { Trace, completely replaced by } \\
\text { chlorite, up to } 0.1 \mathrm{~mm}\end{array}$ & None identifiable \\
\hline Accessory Phases & $\begin{array}{l}1 \% \text { opaque minerals in matrix, } \\
\text { trace Fe-Ti oxides, }<0.1 \mathrm{~mm}\end{array}$ & $\begin{array}{l}1 \% \text { calcite alteration, } 1 \% \text { very } \\
\text { small opaques thoughout matrix } \\
\text { and as inclusions in feldspar } \\
\text { phenocrysts, }<0.1 \mathrm{~mm}\end{array}$ & $\begin{array}{c}1 \% \text {, up to } 0.1 \mathrm{~mm} \text {, opaque minerals in } \\
\text { matrix and as inclusions in } \\
\text { phenocrysts } \\
\text { Trace, monazite, }<0.1 \mathrm{~mm}\end{array}$ & $\begin{array}{l}\text { Calcite crystals between } 1.5-2.0 \mathrm{~mm} \\
\text { fill voids in matrix }\end{array}$ \\
\hline Lithics & None identifiable & None identifiable & None identifiable & None identifiable \\
\hline Textures & $\begin{array}{l}\text { Matrix has grey glassy areas } \\
\text { and microcrystalline quartz, } \\
\text { banding of matrix wraps } \\
\text { around phenocrysts, } \\
\text { spherulitic areas }\end{array}$ & $\begin{array}{l}\text { Matrix is made of brown altered } \\
\text { glass, phenocryst rich }\end{array}$ & $\begin{array}{l}\text { Matrix has grey glassy areas and } \\
\text { microcrystalline quartz, banding of } \\
\text { matrix wraps around phenocrysts, } \\
\text { spherulitic areas }\end{array}$ & Matrix is spherulitic \\
\hline Alteration & $\begin{array}{l}\text { Calcite alteration on feldspar } \\
\text { phenocrysts }\end{array}$ & Calcite and chlorite alteration & Calcite alteration on feldspars & Chlorite alteration in matrix \\
\hline
\end{tabular}




\begin{tabular}{|c|c|c|c|c|}
\hline $\begin{array}{c}\text { Sample Number } \\
\text { Unit } \\
\text { Lithology } \\
\text { \% Phenocrysts } \\
\end{array}$ & $\begin{array}{c}\text { 16-SM-32D } \\
\text { Underdown Tuff } \\
\text { Whole Rock } \\
\text { 7\% } \\
\end{array}$ & $\begin{array}{c}\text { 16-SM-33A } \\
\text { Dacite Dyke } \\
\text { Whole rock } \\
26 \% \\
\end{array}$ & $\begin{array}{c}\text { 16-SM-33B } \\
\text { Dacite Dyke } \\
\text { Whole rock } \\
14 \% \\
\end{array}$ & $\begin{array}{c}\text { 16-SM-34 } \\
\text { Underdown Tuff } \\
\text { Whole Rock } \\
28 \% \\
\end{array}$ \\
\hline Plagioclase & $\begin{array}{c}3 \% \text {, up to } 2.5 \mathrm{~mm} \text {, phenocrysts } \\
\text { altered heavily by sericite and have } \\
\text { sieve texture }\end{array}$ & $\begin{array}{l}25 \% \text {, up to } 5.0 \mathrm{~mm} \text {, phenocrysts with } \\
\text { polysynthetic twinning, sericite } \\
\text { alteration, some chemical zoning } \\
\sim 65 \%, \leq 0.1 \mathrm{~mm} \text {, fine grained in matrix }\end{array}$ & $\begin{array}{c}14 \% \text {, up to } 2.25 \mathrm{~mm} \text {, phenocrysts with } \\
\text { polysynthetic twinning heavily altered by } \\
\text { sericite, opaque inclusions } \\
70 \%, 0.1-0.5 \mathrm{~mm} \text {, small plag laths in matrix }\end{array}$ & $\begin{array}{l}10 \% \text {, up to } 2.5 \mathrm{~mm} \text {, feldspar, } \\
\text { heavily altered and sieved, } \\
\text { heavily resorbed }\end{array}$ \\
\hline Quartz & $\begin{array}{l}2 \% \text {, between } 1.0-2.0 \mathrm{~mm} \text {, quartz eye } \\
\text { phenocrysts with embayments with } \\
\text { some small opaque inclusions } \\
20 \%, \sim 0.5 \mathrm{~mm} \text {, crystals filling voids }\end{array}$ & None identifiable & None identifiable & $\begin{array}{l}12 \% \text {, between } 2.5-3.0 \mathrm{~mm} \text {, } \\
\text { largest phenocryst up to } 5 \mathrm{~mm} \text {, } \\
\text { quartz eyes with embayments } \\
\text { are fractured irregularly, with } \\
\text { resorbed edges } \\
50 \% \text {, microcrystalline in matrix }\end{array}$ \\
\hline Sanidine & $\begin{array}{c}2 \% \text {, between } 1.0-0.5 \mathrm{~mm} \\
\text { phenocrysts with Carlsbad twinning } \\
\text { altered by sericite }\end{array}$ & None identifiable & None identifiable & $\begin{array}{l}3 \% \text {, up to } 1.5 \mathrm{~mm} \text {, phenocrysts } \\
\text { with Carlsbad twinning have } \\
\text { sericite alteration on the edges }\end{array}$ \\
\hline Biotite & None identifiable & $\begin{array}{l}1 \% \text {, up to } 1.75 \mathrm{~mm} \text {, filling voids, last to } \\
\text { crystallize or secondary, unaltered }\end{array}$ & $\begin{array}{l}\text { Trace, } \sim 0.5 \mathrm{~mm} \text {, filling voids, last to } \\
\text { crystallize or secondary, unaltered }\end{array}$ & None identifiable \\
\hline Amphibole & None identifiable & None identifiable & None identifiable & None identifiable \\
\hline Accessory Phases & 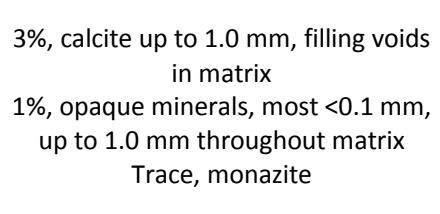 & $\begin{array}{l}3 \% \text {, opaque minerals, most }<0.1 \mathrm{~mm} \text { in } \\
\text { matrix, largest up to } 0.5 \mathrm{~mm}\end{array}$ & $\begin{array}{c}3 \% \text {, opaque minerals, up to } 0.2 \mathrm{~mm} \text {, some } \\
\text { elongate opaque needles }<0.1 \mathrm{~mm} \\
\text { Trace- } 1 \% \text {, Fe-Ti oxides, }<<0.1 \mathrm{~mm} \\
\text { Trace, monazite }\end{array}$ & $\begin{array}{c}2 \% \text {, opaque minerals, }<0.1-1.0 \\
\mathrm{~mm} \text {, throughout matrix and in } \\
\text { groupings } \\
\text { Trace, Fe-Ti oxides are inclusions } \\
\text { in quartz, }<0.1 \mathrm{~mm} \\
\text { Trace, monazite }\end{array}$ \\
\hline Lithics & None identifiable & None identifiable & None identifiable & None identifiable \\
\hline Textures & $\begin{array}{c}\text { Matrix is completely spherulitic with } \\
\text { areas of quartz silicification and } \\
\text { calcite }\end{array}$ & $\begin{array}{c}\text { Matrix is fine grained plagioclase, } \\
\text { altered }\end{array}$ & $\begin{array}{c}\text { Matrix is microcrystalline plag, all } \\
\text { phenocrysts are altered, some completely } \\
\text { replaced }\end{array}$ & $\begin{array}{l}\text { Matrix is silicified, } \\
\text { microcrystalline, and altered }\end{array}$ \\
\hline Alteration & $\begin{array}{l}\text { Sericite alteration on feldspars, and } \\
\text { secondary calcite in matrix }\end{array}$ & $\begin{array}{l}5 \% \text {, sericite, up to } 0.5-1.0 \mathrm{~mm} \text {, fully } \\
\text { replacing another mineral, radial looking } \\
\text { in XPL, } \\
2 \% \text {, calcite, up to } 0.5 \mathrm{~mm} \text {, fully replacing } \\
\text { another mineral or filling a void }\end{array}$ & $\begin{array}{c}\begin{array}{c}10 \%, \text { calcite, alteration on feldspars and in } \\
\text { matrix, }\end{array} \\
\begin{array}{c}1 \% \text {, chlorite alteration, green, spherulite } \\
\text { looking }\end{array}\end{array}$ & $3 \%$, sericite alteration in matrix \\
\hline
\end{tabular}




\begin{tabular}{|c|c|c|c|c|}
\hline $\begin{array}{c}\text { Sample Number } \\
\text { Unit } \\
\text { Lithology } \\
\text { \% Phenocrysts }\end{array}$ & $\begin{array}{c}\text { 16-SM-35 } \\
\text { Underdown Tuff } \\
\text { Whole Rock } \\
11 \% \\
\end{array}$ & $\begin{array}{c}\text { 16-SM-36 } \\
\text { Underdown Tuff } \\
\text { Whole Rock } \\
11 \% \\
\end{array}$ & $\begin{array}{c}\text { 16-SM-37 } \\
\text { Bonita Canyon } \\
\text { Whole Rock } \\
4 \% \\
\end{array}$ & $\begin{array}{c}\text { 16-SM-38A } \\
\text { Unnamed Tuff } \\
\text { Whole Rock } \\
\sim 30 \% \\
\end{array}$ \\
\hline Plagioclase & $\begin{array}{c}5 \%, \sim 1.5 \mathrm{~mm} \text {, feldspar } \\
\text { phenocrysts, heavily altered by } \\
\text { sericite, some completely } \\
\text { replaced }\end{array}$ & $\begin{array}{l}5 \%, \sim 1.5 \mathrm{~mm} \text {, feldspar } \\
\text { phenocrysts, heavily altered by } \\
\text { sericite, some completely replaced }\end{array}$ & $\begin{array}{c}1 \%, 0.5 \mathrm{~mm} \text {, fractured } \\
\text { phenocrysts with polysynthetic } \\
\text { twinning }\end{array}$ & $\begin{array}{l}10 \% \text {, up to } 1.5 \mathrm{~mm} \text {, unaltered } \\
\text { phenocrysts with polysynthetic twinning, } \\
\text { slightly fractured }\end{array}$ \\
\hline Quartz & $\begin{array}{l}5 \%, \sim 2.0 \mathrm{~mm} \text {, phenocrysts with } \\
\text { rounded edges and embayments, } \\
\text { weakly to very fractured }\end{array}$ & $\begin{array}{l}5 \%, \sim 2.0 \mathrm{~mm} \text {, phenocrysts with } \\
\text { rounded edges and embayments, } \\
\text { weakly to very fractured }\end{array}$ & $\begin{array}{l}3 \% \text {, up to } 0.5 \mathrm{~mm} \text {, unfractured } \\
\text { phenocrysts }\end{array}$ & $\begin{array}{l}10 \% \text {, up to } 2.5 \mathrm{~mm} \text {, phenocrysts with } \\
\text { rounded corners, fractured }\end{array}$ \\
\hline Sanidine & $\begin{array}{l}2 \% \text {, between } 1.0-0.5 \mathrm{~mm} \text {, } \\
\text { phenocrysts with Carlsbad } \\
\text { twinning altered by sericite }\end{array}$ & $\begin{array}{l}2 \% \text {, between } 1.0-0.5 \mathrm{~mm}, \\
\text { phenocrysts with Carlsbad } \\
\text { twinning altered by sericite }\end{array}$ & $\begin{array}{l}\text { Trace, up to } 1.0 \mathrm{~mm} \text {, fragment } \\
\text { of phenocryst, fractured }\end{array}$ & $\begin{array}{l}10 \% \text {, up to } 2.5 \mathrm{~mm} \text {, fractured, unaltered } \\
\text { phenocrysts with Carlsbad twinning }\end{array}$ \\
\hline Biotite & Trace, altered & Trace, altered & $\begin{array}{l}1 \%, 0.5-0.75 \mathrm{~mm} \text { thin, bent } \\
\text { phenocrysts }\end{array}$ & $\begin{array}{l}\text { Trace, up to } 0.75 \mathrm{~mm} \text {, phenocrysts with } \\
\text { opaque rims, altered by chlorite }\end{array}$ \\
\hline Amphibole & $\begin{array}{l}1 \% \text {, up to } 1.5 \mathrm{~mm} \text { long, fully } \\
\text { replaced by chlorite } \\
1 \% \text {, opaque minerals, smallest } \\
\text { found in silicified matrix, larger }\end{array}$ & $\begin{array}{l}1 \% \text {, up to } 1.5 \mathrm{~mm} \text { long, fully } \\
\text { replaced by chlorite } \\
1 \% \text {, opaque minerals, smallest } \\
\text { found in silicified matrix, larger }\end{array}$ & None identifiable & $\begin{array}{l}\text { Trace, up to } 1.0 \mathrm{~mm} \text {, phenocrysts with } \\
\text { opaque rim, altered by chlorite }\end{array}$ \\
\hline Accessory Phases & $\begin{array}{l}\text { crystals in altered and silicified } \\
\text { areas } \\
\text { Trace, monazite, }<0.1 \mathrm{~mm} \\
\text { Trace, rutile }<0.1 \mathrm{~mm}\end{array}$ & $\begin{array}{l}\text { crystals in altered and silicified } \\
\text { areas } \\
\text { Trace, monazite, }<0.1 \mathrm{~mm} \\
\text { Trace, rutile, }<0.1 \mathrm{~mm}\end{array}$ & Trace, monazite & $\begin{array}{l}\text { 1\%, opaque minerals, up to } 0.2 \mathrm{~mm} \\
\text { Trace, Fe-Ti oxides, } \sim 0.2 \mathrm{~mm}\end{array}$ \\
\hline Lithics & None Identifiable & None Identifiable & $\begin{array}{l}2 \%, 2.0 \mathrm{~mm} \text {, composed of } \\
\text { microcrystalline quartz }\end{array}$ & None identifiable \\
\hline Textures & $\begin{array}{l}\text { Matrix is grey and altered, has } \\
\text { large areas of patchy, altered } \\
\text { material, possibly altered pumice }\end{array}$ & $\begin{array}{l}\text { Matrix is grey and altered, has } \\
\text { large areas of patchy, altered } \\
\text { material, possibly altered pumice }\end{array}$ & Matrix is unwelded, $5 \%$ vesicles & $\begin{array}{l}\text { Matrix is glassy and welded, pumice is } \\
\text { recrystallized and microcrystalline }\end{array}$ \\
\hline Alteration & $\begin{array}{l}3 \% \text { sericite alteration in altered } \\
\text { areas of matrix } \\
2 \% \text { chlorite alteration in altered } \\
\text { areas of matrix }\end{array}$ & $\begin{array}{l}3 \% \text { sericite alteration in altered } \\
\text { areas of matrix } \\
\begin{array}{l}2 \% \text { chlorite alteration in altered } \\
\text { areas of matrix }\end{array}\end{array}$ & $\begin{array}{l}\text { Wispy yellow alteration in } \\
\text { matrix }\end{array}$ & $\begin{array}{l}\text { Chlorite alteration on hornblende and } \\
\text { biotite }\end{array}$ \\
\hline
\end{tabular}




\begin{tabular}{|c|c|c|c|}
\hline $\begin{array}{l}\text { Sample Number } \\
\text { Unit } \\
\text { Lithology } \\
\text { \% Phenocrysts }\end{array}$ & $\begin{array}{l}\text { 16-SM-39 } \\
\text { Unnamed Tuff } \\
\text { Whole Rock } \\
27 \%\end{array}$ & $\begin{array}{l}\text { 16-SM-40 } \\
\text { Unnamed Tuff } \\
\text { Whole Rock } \\
\text { 30\% }\end{array}$ & $\begin{array}{l}\text { 16-SM-41 } \\
\text { Unnamed Tuff } \\
\text { Whole Rock } \\
\quad \sim 30 \%\end{array}$ \\
\hline Plagioclase & $\begin{array}{c}8 \% \text {, up to } 1.5 \mathrm{~mm} \text {, unaltered, fractured } \\
\text { phenocrysts with polysynthetic twinning } \\
7 \% \text {, up to } 2.5 \mathrm{~mm} \text {, highly fractured phenocrysts } \\
\text { with rounded corners } \\
40 \% \text {, microcrystalline quartz in matrix }\end{array}$ & $\begin{array}{c}10 \% \text {, up to } 1.5 \mathrm{~mm} \text {, unaltered phenocrysts with } \\
\text { polysynthetic twinning and slight uneven fracturing } \\
\text { 10\%, up to } 3.0 \mathrm{~mm} \text {, unevenly fractured phenocrysts } \\
\text { with rounded corners } \\
50 \% \text {, microcrystalline quartz in matrix }\end{array}$ & $\begin{array}{l}8 \% \text {, up to } 1.5 \mathrm{~mm} \text {, unaltered, fractured, } \\
\text { phenocrysts with polysynthetic twinning } \\
8 \% \text {, up to } 2.5 \mathrm{~mm} \text {, unevenly fractured } \\
\text { phenocrysts with rounded corners } \\
30 \% \text {, microcrystalline quartz in pumice }\end{array}$ \\
\hline Sanidine & $\begin{array}{l}12 \% \text {, up to } 3.0 \mathrm{~mm} \text {, unaltered, fractured } \\
\text { phenocrysts with Carlsbad twinning }\end{array}$ & $\begin{array}{l}10 \% \text {, up to } 3.0 \mathrm{~mm} \text {, highly fractured, unaltered, } \\
\text { phenocrysts with Carlsbad twinning }\end{array}$ & $\begin{array}{l}10 \% \text {, up to } 2.5 \mathrm{~mm} \text {, unaltered, fractured } \\
\text { phenocrysts with Carlsbad twinning } \\
1 \% \text {, up to } 1.0 \mathrm{~mm} \text {, bent, phenocrysts }\end{array}$ \\
\hline Biotite & Trace, up to $0.5 \mathrm{~mm}$, thin phenocrysts & Trace, $\leq 0.1 \mathrm{~mm}$, opaque rim on phenocrysts & $\begin{array}{l}\text { with opaque spots and possible } \\
\text { alteration }\end{array}$ \\
\hline Amphibole & $\begin{array}{c}\text { Trace, up to } 1.0 \mathrm{~mm} \text {, phenocrysts with a } \\
\text { slightly altered rim }\end{array}$ & None identifiable & $\begin{array}{c}2 \% \text {, up to } 2.5 \mathrm{~mm} \text {, relatively fresh } \\
\text { phenocrysts with slightly altered edges } \\
\text { and opaque inclusions concentrated on } \\
\text { edges }\end{array}$ \\
\hline Accessory Phases & $\begin{array}{l}\text { 1\%, opaque minerals, } \leq 0.25 \mathrm{~mm} \\
\text { Trace, monazite, }<0.1 \mathrm{~mm}\end{array}$ & $\begin{array}{c}\text { 1\%, opaque minerals, } \leq 0.25 \mathrm{~mm} \\
\text { Trace, Fe-Ti oxides, most } \leq 0.1 \mathrm{~mm} \text {, largest up to } 0.5 \\
\mathrm{~mm} \\
\begin{array}{c}1 \%, \text { monazite, } \\
\text { material in cracks of feldspars and in groupings } \\
\text { around voids }\end{array}\end{array}$ & $\begin{array}{l}\text { 1\%, opaque minerals, } \leq 0.25 \mathrm{~mm} \\
\text { Trace, monazite, }<0.1 \mathrm{~mm}\end{array}$ \\
\hline Lithics & $\begin{array}{c}2 \%, 2.0 \mathrm{~mm} \text {, composed of microcrystalline qtz } \\
\text { or feldspar, altered by sericite }\end{array}$ & None identifiable & None identifiable \\
\hline Textures & $\begin{array}{c}\text { Matrix is brown and glassy, relatively } \\
\text { unaltered, pumice silicified to microcrystalline } \\
\text { quartz }\end{array}$ & $\begin{array}{c}\text { Matrix composed of microcrystalline quartz, } \\
\text { brownish matrix has some banding around } \\
\text { phenocrysts }\end{array}$ & $\begin{array}{l}\text { Matrix is glassy, pumice has been } \\
\text { silicified and is microcrystalline quartz }\end{array}$ \\
\hline Alteration & Possible chlorite alteration on hornblende & None identifiable & $\begin{array}{l}\text { Possible chlorite alteration on } \\
\text { hornblende and biotite }\end{array}$ \\
\hline
\end{tabular}




\begin{tabular}{|c|c|c|c|c|}
\hline $\begin{array}{c}\text { Sample Number } \\
\text { Unit } \\
\text { Lithology } \\
\text { \% Phenocrysts } \\
\end{array}$ & $\begin{array}{c}\text { 16-SM-42 } \\
\text { Unnamed Tuff } \\
\text { Whole Rock } \\
\sim 26 \% \\
\end{array}$ & $\begin{array}{c}\text { 16-SM-43 } \\
\text { Unnamed Tuff } \\
\text { Whole Rock } \\
30 \% \\
\end{array}$ & $\begin{array}{l}\text { 16-SM-44 } \\
\text { Pablo Formation } \\
\text { Whole Rock } \\
\text { - }\end{array}$ & $\begin{array}{c}\text { 16-SM-45 } \\
\text { Underdown Tuff } \\
\text { Whole Rock } \\
13 \% \\
\end{array}$ \\
\hline Plagioclase & $\begin{array}{l}8 \% \text {, up to } 1.5 \mathrm{~mm} \text {, unaltered phenocrysts } \\
\text { with polysynthetic twinning }\end{array}$ & $\begin{array}{l}\text { 7\%, up to } 1.5 \mathrm{~mm} \text {, unaltered } \\
\text { phenocrysts with polysynthetic } \\
\text { twinning }\end{array}$ & $\begin{array}{c}60 \%, 0.1-2.5 \mathrm{~mm} \text {, phenocrysts with } \\
\text { polysynthetic twinning, very altered } \\
\text { by calcite and sericite, some show } \\
\text { chemical zoning }\end{array}$ & $\begin{array}{l}2 \% \text {, up to } 2.5 \mathrm{~mm} \text {, phenocrysts } \\
\text { with polysynthetic twinning, } \\
\text { altered and sieve textured }\end{array}$ \\
\hline Quartz & $\begin{array}{l}5 \% \text {, up to } 1.5 \mathrm{~mm} \text {, pieces of phenocrysts } \\
\text { with rounded corners } \\
30 \% \text {, microcrystalline quartz in matrix }\end{array}$ & $\begin{array}{l}5 \% \text {, up to } 2.0 \mathrm{~mm} \text {, unevenly fractured } \\
\text { phenocrysts with rounded corners } \\
40 \% \text {, microcrystalline quartz in pumice }\end{array}$ & None identifiable & $\begin{array}{l}5 \% \text {, up to } 2.5 \mathrm{~mm} \text {, rounded edged } \\
\text { phenocrysts with embayments, } \\
\text { unevenly fractured, with inclusions } \\
\text { of rutile } \\
70 \% \text {, microcrystalline quartz, in } \\
\text { matrix, larger crystals in veins }\end{array}$ \\
\hline Sanidine & $\begin{array}{l}12 \% \text {, up to } 2.0 \mathrm{~mm} \text {, unaltered, fractured } \\
\text { phenocrysts, some with Carlsbad twinning }\end{array}$ & $\begin{array}{l}15 \% \text {, up to } 2.5 \mathrm{~mm} \text {, unaltered, } \\
\text { unevenly fractured phenocrysts with } \\
\text { Carlsbad twinning }\end{array}$ & None identifiable & $\begin{array}{l}\text { 6\%, up to } 1.5 \mathrm{~mm} \text {, phenocrysts } \\
\text { with Carlsbad twins, slightly } \\
\text { altered and sieve textured }\end{array}$ \\
\hline Biotite & $\begin{array}{l}\text { Trace, up to } 0.5 \mathrm{~mm} \text {, slightly altered, and } \\
\text { bent phenocrysts }\end{array}$ & $\begin{array}{l}1 \% \text {, up to } 1.75 \mathrm{~mm} \text {, bent, unaltered } \\
\text { phenocrysts }\end{array}$ & None identifiable & None identifiable \\
\hline Amphibole & $\begin{array}{l}1 \% \text {, up to } 1.5 \mathrm{~mm} \text {, phenocrysts with } \\
\text { altered rims and opaque inclusions in rims }\end{array}$ & $\begin{array}{l}2 \% \text {, up to } 1.0 \mathrm{~mm} \text {, phenocrysts with } \\
\text { alteration on rim }\end{array}$ & $\begin{array}{c}15 \% \text {, up to } 1.75 \mathrm{~mm} \text {, elongate and } \\
\text { hexagonal crystals with some opaque } \\
\text { inclusions } \\
15 \% \text {, pyroxene, }<0.1-1.75 \mathrm{~mm} \text {, }\end{array}$ & Trace, $\sim 0.5 \mathrm{~mm}$, fully replaced \\
\hline Accessory Phases & $\begin{array}{c}\text { Trace, opaque minerals, } \leq 0.25 \mathrm{~mm} \\
\text { Trace, monazite, }<0.1 \mathrm{~mm}\end{array}$ & $1 \%$, opaque minerals, up to $1.0 \mathrm{~mm}$ & $\begin{array}{l}\text { phenocrysts and groundmass with } \\
\text { some chemical zoning and simple } \\
\text { twinning } \\
\text { 5\%, opaque minerals, some are blocky }\end{array}$ & $\begin{array}{l}3 \% \text {, rutile, reddish alteration on } \\
\text { feldspar and found throughout } \\
\text { matrix, }<0.1 \mathrm{~mm}\end{array}$ \\
\hline & & & $\begin{array}{c}\text { (<0.1 mm), some fill voids (up to } \sim 3.0 \\
\mathrm{~mm} \text { ) } \\
\text { Trace, Fe-Ti oxides, }<0.1 \mathrm{~mm}\end{array}$ & $\begin{array}{l}1 \% \text {, very small opaque minerals, } \\
\text { thoughout matrix, }<<0.1 \mathrm{~mm}\end{array}$ \\
\hline Lithics & None identifiable & None identifiable & None identifiable & None identifiable \\
\hline Textures & $\begin{array}{c}\text { Matrix is brown and glassy, pumice has } \\
\text { been recrystallized to microcrystalline } \\
\text { pumice }\end{array}$ & $\begin{array}{c}\text { Matrix is brown and glassy, pumice has } \\
\text { been silicified with microcrystalline } \\
\text { quartz }\end{array}$ & Matrix is microcrystalline & $\begin{array}{c}\text { Matrix is microcrystalline quartz, } \\
\text { primary banding of matrix is } \\
\text { preserved and wrapped around } \\
\text { matrix }\end{array}$ \\
\hline Alteration & $\begin{array}{l}\text { Possible chlorite alteration on rims of } \\
\text { hornblende }\end{array}$ & $\begin{array}{l}\text { Possible chlorite alteration on } \\
\text { hornblende }\end{array}$ & $\begin{array}{l}5 \% \text {, calcite alteration on plagioclase } \\
\text { and pyroxene (?), up to } \sim 1.5 \mathrm{~mm}\end{array}$ & \\
\hline
\end{tabular}




\begin{tabular}{|c|c|c|c|c|c|}
\hline $\begin{array}{c}\text { Sample Number } \\
\text { Unit } \\
\text { Lithology } \\
\text { \% Phenocrysts } \\
\end{array}$ & $\begin{array}{c}\text { 16-SM-46 } \\
\text { Underdown Tuff } \\
\text { Whole Rock } \\
9 \% \\
\end{array}$ & $\begin{array}{c}\text { 16-SM-47 } \\
\text { Underdown Tuff } \\
\text { Whole Rock } \\
13 \% \\
\end{array}$ & $\begin{array}{c}\text { 16-SM-48 } \\
\text { Underdown Tuff } \\
\text { Whole Rock } \\
10 \% \\
\end{array}$ & $\begin{array}{c}\text { 16-SM-49 } \\
\text { Underdown Tuff } \\
\text { Whole Rock } \\
13 \% \\
\end{array}$ & $\begin{array}{c}\text { 16-SM-50-1 } \\
\text { Underdown Tuff } \\
\text { Porphyritic pumice } \\
20 \% \\
\end{array}$ \\
\hline Plagioclase & $\begin{array}{c}1 \% \text {, up to } 1.0 \mathrm{~mm} \text {, phenocryst } \\
\text { completely altered by sericite } \\
\text { shows some polysynthetic } \\
\text { twinning }\end{array}$ & $\begin{array}{l}2 \% \text {, up to } 2.5 \mathrm{~mm} \text {, phenocrysts } \\
\text { with polysynthetic twinning, } \\
\text { altered and sieve textured }\end{array}$ & Trace & $\begin{array}{l}2 \% \text {, up to } 2.5 \mathrm{~mm} \text {, phenocrysts } \\
\text { with polysynthetic twinning, } \\
\text { altered and sieve textured }\end{array}$ & $\begin{array}{c}10 \% \text {, up to } 2.0 \mathrm{~mm} \text {, } \\
\text { phenocrysts altered } \\
\text { heavily by sericite and } \\
\text { calcite, show polysynthetic } \\
\text { twinning }\end{array}$ \\
\hline Quartz & $\begin{array}{l}3 \% \text {, up to } 1.0 \mathrm{~mm} \text {, quartz eye } \\
\text { phenocrysts with embayments }\end{array}$ & $\begin{array}{l}5 \% \text {, up to } 2.5 \mathrm{~mm} \text {, rounded } \\
\text { edged phenocrysts with } \\
\text { embayments, unevenly } \\
\text { fractured, with inclusions of } \\
\text { rutile } \\
70 \% \text {, microcrystalline quartz, in } \\
\text { matrix, larger crystals in veins }\end{array}$ & $\begin{array}{c}3 \% \text {, up to } 2.5 \mathrm{~mm} \text {, quartz eye } \\
\text { phenocrysts with embayments } \\
15 \% \text {, quartz silicification in } \\
\text { veins }\end{array}$ & $\begin{array}{l}5 \% \text {, up to } 2.5 \mathrm{~mm} \text {, rounded } \\
\text { edged phenocrysts with } \\
\text { embayments, unevenly } \\
\text { fractured, with inclusions of } \\
\text { rutile } \\
70 \% \text {, microcrystalline quartz, in } \\
\text { matrix, larger crystals in veins }\end{array}$ & $\begin{array}{l}10 \% \text {, up to } 0.5 \mathrm{~mm} \text {, small } \\
\text { grains in silicified veins }\end{array}$ \\
\hline Sanidine & $\begin{array}{l}5 \% \text {, up to } 3.5 \mathrm{~mm} \text {, fractured } \\
\text { phenocrysts with sieve texture }\end{array}$ & $\begin{array}{l}6 \% \text {, up to } 1.5 \mathrm{~mm} \text {, phenocrysts } \\
\text { with Carlsbad twins, slightly } \\
\text { altered and sieve textured }\end{array}$ & $\begin{array}{l}7 \% \text {, up to } 1.5 \mathrm{~mm} \text {, phenocrysts } \\
\text { are fractured and show } \\
\text { Carlsbad twinning }\end{array}$ & $\begin{array}{l}6 \% \text {, up to } 1.5 \mathrm{~mm} \text {, phenocrysts } \\
\text { with Carlsbad twins, slightly } \\
\text { altered and sieve textured }\end{array}$ & $\begin{array}{l}10 \% \text {, up to } 1.5 \mathrm{~mm}, \\
\text { phenocrysts altered by } \\
\text { yellow alteration }\end{array}$ \\
\hline Biotite & None identifiable & None identifiable & None identifiable & None identifiable & None identifiable \\
\hline Amphibole & None identifiable & Trace, $\sim 0.5 \mathrm{~mm}$, fully replaced & None identifiable & Trace, $\sim 0.5 \mathrm{~mm}$, fully replaced & None identifiable \\
\hline Accessory Phases & $\begin{array}{l}1 \% \text {, small opaque minerals in } \\
\text { matrix, some larger are square } \\
\text { and round }<0.1 \mathrm{~mm} \\
\text { Trace, microcrystalline Ti-oxides, } \\
\quad<<0.1 \mathrm{~mm}\end{array}$ & $\begin{array}{l}3 \% \text {, rutile, reddish alteration on } \\
\text { feldspar and found throughout } \\
\text { matrix }<0.1 \mathrm{~mm} \\
1 \% \text {, very small opaque minerals, } \\
\text { thoughout matrix, }<<0.1 \mathrm{~mm}\end{array}$ & $\begin{array}{c}\text { Trace, opaques throughout } \\
\text { matrix, }<0.1 \mathrm{~mm} \\
\text { Trace, Fe-Ti oxides throughout } \\
\text { matrix, }<0.1 \mathrm{~mm}\end{array}$ & $\begin{array}{c}3 \% \text {, rutile, reddish alteration on } \\
\text { feldspar and found throughout } \\
\text { matrix, }<0.1 \mathrm{~mm} \\
1 \% \text {, very small opaque minerals, } \\
\text { thoughout matrix, }<<0.1 \mathrm{~mm}\end{array}$ & $\begin{array}{c}2 \% \text { opaque minerals are } \\
\text { included in feldspars and } \\
\text { larger grains in } \\
\text { groundmass, up to } 0.1 \\
\text { mm, trace monazite, }<0.1 \\
\text { mm }\end{array}$ \\
\hline Lithics & None identifiable & None identifiable & $1 \%$, heavily altered & None identifiable & None identifiable \\
\hline Textures & $\begin{array}{l}\text { Matrix is microcrystalline, } \\
\text { possibly quartz, little to no glass, } \\
\text { some relict banding visible that } \\
\text { slightly wraps phenocrysts }\end{array}$ & $\begin{array}{c}\text { Matrix is microcrystalline quartz, } \\
\text { primary banding of matrix is } \\
\text { preserved and wrapped around } \\
\text { matrix }\end{array}$ & $\begin{array}{l}\text { Matrix is glassy, has silicified } \\
\text { veins, and banding that wraps } \\
\text { around phenocrysts }\end{array}$ & $\begin{array}{l}\text { Matrix is microcrystalline } \\
\text { quartz, primary banding of } \\
\text { matrix is preserved and } \\
\text { wrapped around matrix }\end{array}$ & $\begin{array}{l}\text { Matrix is brown altered } \\
\text { glass }\end{array}$ \\
\hline Alteration & $\sim 1 \%$ chlorite alteration in matrix & None identifiable & Chlorite alteration in matrix & None identifiable & $1 \%$ calcite alteration \\
\hline
\end{tabular}




\begin{tabular}{|c|c|c|c|c|}
\hline $\begin{array}{c}\text { Sample Number } \\
\text { Unit } \\
\text { Lithology }\end{array}$ & $\begin{array}{l}\text { 16-SM-50-2 } \\
\text { Underdown Tuff } \\
\text { Whole Rock }\end{array}$ & $\begin{array}{l}\text { 16-SM-51 } \\
\text { Underdown Tuff } \\
\text { Whole Rock }\end{array}$ & $\begin{array}{l}\text { 16-SM-52 } \\
\text { Rhyolite Intrusive } \\
\text { Whole rock }\end{array}$ & $\begin{array}{l}\text { 16-SM-53 } \\
\text { Rhyolite Intrusive } \\
\text { Whole rock }\end{array}$ \\
\hline \% Phenocrysts & $15 \%$ & $8 \%$ & - & - \\
\hline Plagioclase & $\begin{array}{l}2 \% \text {, up to } 2.0 \mathrm{~mm} \text {, fractured, } \\
\text { unaltered phenocrysts }\end{array}$ & None identifiable & $\begin{array}{c}10 \% \text {, up to } 3.0 \mathrm{~mm} \text {, phenocrysts with } \\
\text { polysynthetic twinning, some altered } \\
\text { and resorbed }\end{array}$ & $\begin{array}{l}5 \% \text {, up to } 1.75 \mathrm{~mm} \text {, fractured phenocrysts } \\
\text { with polysynthetic twinning }\end{array}$ \\
\hline Quartz & $\begin{array}{l}3 \% \text {, up to } 2.0 \mathrm{~mm} \text {, fractured, } \\
\text { unaltered phenocrysts } \\
5 \% \text {, up to } 0.5 \mathrm{~mm} \text {, small grains of } \\
\text { quartz in silicified veins }\end{array}$ & $\begin{array}{l}3 \% \text {, up to } 1.5 \mathrm{~mm} \text {, fractured, quartz } \\
\text { eye phenocrysts with embayments }\end{array}$ & $\begin{array}{l}15 \%, \text { up to } 1.5 \mathrm{~mm} \text {, fractured } \\
\text { phenocrysts with rounded corners } \\
\text { and embayments }\end{array}$ & $\begin{array}{l}8 \% \text {, up to } 2.5 \mathrm{~mm} \text {, fractured phenocrysts } \\
\text { with rounded corners and embayments } \\
35 \%, \leq 0.5 \mathrm{~mm} \text {, in matrix }\end{array}$ \\
\hline Sanidine & $\begin{array}{l}8 \% \text {, up to } 1.5 \mathrm{~mm} \text {, fractured, } \\
\text { mildly altered phenocrysts show } \\
\text { Carlsbad twinning and small } \\
\text { opaque inclusions }\end{array}$ & $\begin{array}{l}5 \% \text {, up to } 1.5 \mathrm{~mm} \text {, altered and } \\
\text { fractured phenocrysts }\end{array}$ & $\begin{array}{l}15 \% \text {, up to } 1.75 \mathrm{~mm} \text {, fractured } \\
\text { phenocrysts with Carlsbad twinning }\end{array}$ & $\begin{array}{l}8 \% \text {, up to } 2.5 \mathrm{~mm} \text {, fractured phenocrysts, } \\
\text { some with Carlsbad twinning }\end{array}$ \\
\hline Biotite & $\begin{array}{c}1 \% \text {, up to } 0.5 \mathrm{~mm} \text {, altered by } \\
\text { chlorite }\end{array}$ & $\begin{array}{l}\text { Trace, } 0.1 \mathrm{~mm} \text {, appears relatively } \\
\text { fresh }\end{array}$ & $\begin{array}{l}5 \% \text {, up to } 2.0 \mathrm{~mm} \text {, generally fresh } \\
\text { phenocrysts, some bent, some } \\
\text { replaced by opaque minerals }\end{array}$ & $\begin{array}{c}\text { Trace, } 1.0 \mathrm{~mm} \text {, almost completely replaced } \\
\text { by opaque minerals }\end{array}$ \\
\hline Amphibole & $\begin{array}{l}1 \% \text {, up to } 0.5 \mathrm{~mm} \text {, altered by } \\
\text { chlorite }\end{array}$ & $\begin{array}{l}\text { Trace, } 0.1 \mathrm{~mm} \text {, fully replaced by } \\
\text { chlorite }\end{array}$ & None identifiable & None identifiable \\
\hline Accessory Phases & $\begin{array}{c}\text { Trace small Fe-Ti oxides are bright } \\
\text { red and disseminated throughout } \\
\text { groundmass, }<0.1 \mathrm{~mm}, \\
\text { Trace opaque minerals, }<0.1 \mathrm{~mm}, \\
\text { found throughout groundmass }\end{array}$ & $\begin{array}{l}1 \% \text {, small square grains, possibly } \\
\text { magnetite, }<0.1 \mathrm{~mm}\end{array}$ & $\begin{array}{l}\text { Trace, opaque minerals, up to } 0.25 \\
\text { mm } \\
\text { Trace, Fe-Ti oxides, up to } 0.5 \mathrm{~mm} \\
\text { Trace, monazite, in matrix and } \\
\text { inclusion in biotite }\end{array}$ & $\begin{array}{c}\text { 1\%, opaque minerals, most }<<0.1 \mathrm{~mm} \text {, } \\
\text { largest up to } 0.25 \mathrm{~mm} \\
\text { Trace, Fe-Ti oxides, most }<<0.1 \mathrm{~mm} \text {, largest } \\
\text { up to } 0.5 \mathrm{~mm} \\
\text { Trace, monazite, }<0.1 \mathrm{~mm}\end{array}$ \\
\hline Lithics & None identifiable & None identifiable & None identifiable & None identifiable \\
\hline Textures & $\begin{array}{c}\text { Matrix is brown altered glass that } \\
\text { shows banding which wraps } \\
\text { around phenocrysts. Phenocryst } \\
\text { poor }\end{array}$ & $\begin{array}{l}\text { Matrix is glassy, and has banding and } \\
\text { wraps around phenocrysts }\end{array}$ & Microcrystalline quartz in matrix & Microcrystalline quartz in matrix \\
\hline Alteration & $\begin{array}{l}\text { Some chlorite alteration in the } \\
\text { matrix }\end{array}$ & $\begin{array}{l}\text { Chlorite alteration of amphibole, } \\
\text { matrix alteration }\end{array}$ & None identifiable & None identifiable \\
\hline
\end{tabular}




\begin{tabular}{|c|c|c|c|c|}
\hline $\begin{array}{l}\text { Sample Number } \\
\text { Unit } \\
\text { Lithology } \\
\text { \% Phenocrysts }\end{array}$ & $\begin{array}{c}\text { 16-SM-54 } \\
\text { Bonita Canyon } \\
\text { Whole Rock } \\
6 \%\end{array}$ & $\begin{array}{c}\text { 16-SM-55 } \\
\text { Unnamed Tuff } \\
\text { Whole Rock } \\
\sim 12 \%\end{array}$ & $\begin{array}{c}\text { 16-SM-56 } \\
\text { Rhyolite Intrusive } \\
\text { Whole rock } \\
\sim 17 \%\end{array}$ & $\begin{array}{c}\text { 17-SM-01 } \\
\text { Terrill Mountains Tuff } \\
\text { Whole Rock } \\
\sim 5 \%\end{array}$ \\
\hline Plagioclase & $\begin{array}{l}\text { Trace, } 0.1-0.5 \mathrm{~mm} \text {, phenocrysts } \\
\text { with polysynthetic twinning }\end{array}$ & $\begin{array}{l}2 \% \text {, up to } 1.0 \mathrm{~mm} \text {, phenocrysts } \\
\text { with polysynthetic twinning }\end{array}$ & $\begin{array}{l}\text { 3\%, up to } 1.5 \mathrm{~mm} \text {, phenocrysts with } \\
\text { polysynthetic twinning, some } \\
\text { resorption }\end{array}$ & $\begin{array}{l}\text { Trace, } \sim 0.25 \mathrm{~mm} \text {, fractured } \\
\text { phenocryst with polysynthetic } \\
\text { twinning and some opaque } \\
\text { inclusions }\end{array}$ \\
\hline Quartz & $\begin{array}{l}5 \%, \sim 0.25 \mathrm{~mm} \text {, phenocrysts with } \\
\text { rounded corners and } \\
\text { embayments }\end{array}$ & $\begin{array}{l}8 \% \text {, up to } 1.5 \mathrm{~mm} \text {, slightly } \\
\text { unevenly fractured phenocrysts } \\
\text { with rounded corners and } \\
\text { embayments } \\
\sim 70 \% \text { microcrystalline quartz in } \\
\text { matrix }\end{array}$ & $\begin{array}{c}8 \% \text {, up to } 2.25 \mathrm{~mm} \text {, fractured } \\
\text { phenocrysts with rounded corners } \\
\text { and embayments } \\
\sim 35 \%, \leq 0.25 \mathrm{~mm} \text {, in matrix }\end{array}$ & $\begin{array}{c}3 \% \text {, up to } 1.5 \mathrm{~mm} \text {, highly fractured } \\
\text { phenocrysts with rounded corners } \\
\text { and embayments }\end{array}$ \\
\hline Sanidine & None identifiable & $\begin{array}{c}2 \%, \text { up to } 2.0 \mathrm{~mm} \text {, unaltered } \\
\text { phenocrysts some with Carlsbad } \\
\text { twinning }\end{array}$ & $\begin{array}{c}5 \% \text {, up to } 1.75 \mathrm{~mm} \text {, fractured } \\
\text { phenocrysts with some Carlsbad } \\
\text { twinning }\end{array}$ & $\begin{array}{c}1 \%, \sim 1.5 \mathrm{~mm} \text {, fractured } \\
\text { phenocrysts, some with Carlsbad } \\
\text { twinning }\end{array}$ \\
\hline Biotite & $\begin{array}{l}1 \% \text {, up to } 0.5 \mathrm{~mm} \text { long, thin, } \\
\text { unaltered phenocrysts }\end{array}$ & $\begin{array}{l}\text { Trace, up to } 0.2 \mathrm{~mm} \text {, altered } \\
\text { phenocrysts with opaque rim }\end{array}$ & $\begin{array}{l}\text { Trace- } 1 \% \text {, up to } 0.75 \mathrm{~mm} \text {, almost } \\
\text { completely replaced by opaque } \\
\text { minerals }\end{array}$ & None identifiable \\
\hline Amphibole & None identifiable & None identifiable & None identifiable & None identifiable \\
\hline $\begin{array}{l}\text { Accessory } \\
\text { Phases }\end{array}$ & $\begin{array}{l}\text { Trace, opaque minerals, most } \\
<0.1 \mathrm{~mm} \text {, largest up to } 0.25 \mathrm{~mm} \\
\text { Trace Ti-oxides }<0.1 \mathrm{~mm}\end{array}$ & $\begin{array}{l}\text { Trace, opaque minerals, most }<0.1 \\
\text { mm, largest up to } 0.25 \mathrm{~mm} \\
\text { 1\%, Fe-Ti oxides, up to } 0.2 \mathrm{~mm} \\
\text { completely replaced biotite or } \\
\text { amphibole up to } 2.0 \mathrm{~mm} \text { long }\end{array}$ & $\begin{array}{l}\text { Trace, opaque minerals, most }<0.1 \\
\mathrm{~mm} \text { in matrix, blocky grains up to } 0.2 \\
\mathrm{~mm} \\
\text { Trace, Fe-Ti oxides, most }<0.1 \mathrm{~mm} \text {, } \\
\text { one cluster up to } 0.5 \mathrm{~mm}\end{array}$ & $\begin{array}{l}\text { Trace, opaque minerals, }<<0.1 \mathrm{~mm} \\
\text { Trace, Fe-Ti oxides, }<<0.1 \mathrm{~mm}\end{array}$ \\
\hline Lithics & $\begin{array}{c}1 \%, 1.0 \mathrm{~mm}, \text { composed of } \\
\text { microcrystalline quartz }\end{array}$ & None identifiable & None identifiable & $\begin{array}{l}\text { Trace-1\%, up to } 1.0 \mathrm{~mm} \text {, } \\
\text { microcrystalline and altered }\end{array}$ \\
\hline Textures & $\begin{array}{c}\text { Matrix is unwelded-poorly } \\
\text { welded, } 5 \% \text { vesicles, all } \\
\text { phenocrysts are small fractures of } \\
\text { crystal }\end{array}$ & $\begin{array}{l}\text { Matrix is patchy, altered slightly, } \\
\text { and microcrystalline quartz }\end{array}$ & $\begin{array}{c}\text { Matrix appears patchy, possibly } \\
\text { spherulitic, some microcrystalline } \\
\text { quartz in matrix }\end{array}$ & $\begin{array}{l}\text { Matrix is altered, brown and } \\
\text { microcrystalline, pumice is } \\
\text { spherulitic }\end{array}$ \\
\hline Alteration & None identifiable & None identifiable & None identifiable & Alteration of matrix \\
\hline
\end{tabular}




\begin{tabular}{|c|c|c|c|c|}
\hline $\begin{array}{c}\text { Sample Number } \\
\text { Unit } \\
\text { Lithology } \\
\text { \% Phenocrysts }\end{array}$ & $\begin{array}{c}\text { 17-SM-02 } \\
\text { Terrill Mountains Tuff } \\
\text { Vitrophyre } \\
\sim 5 \%\end{array}$ & $\begin{array}{c}\text { 17-SM-03C } \\
\text { Terrill Mountains Tuff } \\
\text { Whole rock } \\
\sim 5 \%\end{array}$ & $\begin{array}{l}\text { 17-SM-05 } \\
\text { Nine Hill Tuff } \\
\text { Whole rock } \\
\quad \sim 5 \%\end{array}$ & $\begin{array}{c}\text { 17-SM-06 } \\
\text { Tuff of Clipper Gap } \\
\text { Whole rock } \\
\sim 4 \%\end{array}$ \\
\hline Plagioclase & $\begin{array}{l}\text { Trace- } 1 \% \text {, up to } 1.0 \mathrm{~mm} \text {, } \\
\text { fractured phenocrysts with } \\
\text { polysynthetic twinning } \\
2 \%\end{array}$ & $\begin{array}{l}\text { Trace- } 1 \% \text {, up to } 0.75 \mathrm{~mm} \text {, } \\
\text { unaltered, fractured phenocrysts } \\
\text { with polysynthetic twinning }\end{array}$ & $\begin{array}{c}1 \%, \sim 1.0 \mathrm{~mm} \text {, unevenly fractured } \\
\text { and unaltered phenocrysts with } \\
\text { polysynthetic twinning }\end{array}$ & $\begin{array}{c}\text { Trace, }<0.5 \mathrm{~mm} \text {, fractured } \\
\text { phenocrysts with polysynthetic } \\
\text { twinning }\end{array}$ \\
\hline Quartz & $\begin{array}{l}\text { phenocrysts with rounded } \\
\text { corners and embayments }\end{array}$ & $\begin{array}{l}\text { with rounded corners and } \\
\text { embayments }\end{array}$ & None identifiable & None identifiable \\
\hline Sanidine & $\begin{array}{l}2 \%, \sim 0.1 \mathrm{~mm} \text {, highly fractured } \\
\text { phenocrysts with Carlsbad } \\
\text { twinning }\end{array}$ & $\begin{array}{l}2 \%, \text { up to } 1.0 \mathrm{~mm} \text {, unaltered, } \\
\text { fractured phenocrysts }\end{array}$ & $\begin{array}{c}2 \%, \text { up to } 1.5 \mathrm{~mm} \text {, unaltered } \\
\text { phenocrysts, some with chemical } \\
\text { zoning }\end{array}$ & $\begin{array}{l}3 \%, \text { up to } 2.0 \mathrm{~mm} \text {, unaltered, } \\
\text { fractured phenocrysts }\end{array}$ \\
\hline Biotite & $\begin{array}{l}\text { Trace, up to } 0.25 \mathrm{~mm} \text {, unaltered, } \\
\text { bent phenocrysts }\end{array}$ & $\begin{array}{l}\text { Trace, up to } 0.5 \mathrm{~mm} \text {, almost } \\
\text { completely opaque }\end{array}$ & $\begin{array}{c}\text { Trace-1\%, up to } 1.25 \mathrm{~mm} \text {, almost } \\
\text { opaque }\end{array}$ & $\begin{array}{c}1 \% \text {, up to } 0.2 \mathrm{~mm} \text {, phenocrysts } \\
\text { altered by chlorite }\end{array}$ \\
\hline Amphibole & None identifiable & None identifiable & Trace, $\sim 0.2 \mathrm{~mm}$ & None identifiable \\
\hline Accessory Phases & $\begin{array}{l}\text { Trace, possible pyroxene, up to } \\
1.0 \mathrm{~mm} \\
\text { Trace, opaque minerals, }<<0.1 \\
\mathrm{~mm}\end{array}$ & Trace, opaque minerals, $<0.1 \mathrm{~mm}$ & $\begin{array}{l}\text { Trace-1\%, opaque minerals, } \leq 0.2 \\
\text { mm, crystals are singular and } \\
\text { blocky or in clusters } \\
\text { Trace, pyroxene, up to } 0.5 \mathrm{~mm} \text {, } \\
\text { red alteration on edges } \\
\text { Trace, Fe-Ti oxides, }<0.1 \mathrm{~mm}\end{array}$ & $\begin{array}{c}\text { 1\%, opaque minerals, }<0.1 \mathrm{~mm} \text {, one } \\
\text { hexagonal crystal is } \sim 0.5 \mathrm{~mm} \\
1 \% \text {, Fe-Ti oxides, disseminated } \\
\text { grains throughout matrix, }<<0.1 \mathrm{~mm}\end{array}$ \\
\hline Lithics & $\begin{array}{c}5 \%, 2.5 \mathrm{~mm} \text {, green, small } \\
\text { opaques } \\
6.5 \mathrm{~mm} \text {, phenocryst rich with bt, } \\
\text { qtz, and san (might be pumice) }\end{array}$ & None identifiable & $\begin{array}{c}1 \%, \sim 1.75 \mathrm{~mm} \text {, composed of red } \\
\text { opaque material and plagioclase } \\
\text { laths }\end{array}$ & $\begin{array}{l}2 \%, 1.5-2.0 \mathrm{~mm} \text {, brown opaque } \\
\text { with plagioclase laths and opaques, } \\
\text { multiple of the same composition }\end{array}$ \\
\hline Textures & $\begin{array}{l}\text { Matrix is fresh, welded, and } \\
\text { composed of glass shards } \\
\text { White fiamme is generally } \\
\text { aphyric, some fiamme look } \\
\text { banded }\end{array}$ & $\begin{array}{l}\text { Matrix is welded, and composed } \\
\text { of fresh brown glass shards } \\
\text { Fiamme is banded or white and } \\
\text { both phyric and aphyric }\end{array}$ & $\begin{array}{l}\text { Matrix is altered glass, composed } \\
\text { of yellow glass shards, wispy } \\
\text { areas are likely pumice }\end{array}$ & $\begin{array}{c}\text { Matrix is welded and glassy, } \\
\text { contains } ~ 5 \% \text { pumice, and glass } \\
\text { shards, pumice is phyric and either } \\
\text { white or banded }\end{array}$ \\
\hline Alteration & None identifiable & None identifiable & Matrix alteration & Chlorite alteration of biotite \\
\hline
\end{tabular}




\begin{tabular}{|c|c|c|c|c|}
\hline $\begin{array}{c}\text { Sample Number } \\
\text { Unit } \\
\text { Lithology } \\
\text { \% Phenocrysts }\end{array}$ & $\begin{array}{c}\text { 17-SM-07 } \\
\text { Tuff of Clipper Gap } \\
\text { Whole rock } \\
\sim 4 \%\end{array}$ & $\begin{array}{c}\text { 17-SM-10 } \\
\text { Tuff of Clipper Gap } \\
\text { Whole rock } \\
\sim 5 \%\end{array}$ & $\begin{array}{c}\text { 17-SM-11 } \\
\text { Tuff of Clipper Gap } \\
\text { Whole Rock } \\
\sim 10 \%\end{array}$ & $\begin{array}{c}\text { 17-SM-12 } \\
\text { Tuff of Clipper Gap } \\
\text { Whole Rock } \\
\sim 5 \%\end{array}$ \\
\hline Plagioclase & $\begin{array}{c}\text { Trace, }<0.5 \mathrm{~mm} \text {, fractured } \\
\text { phenocrysts with polysynthetic } \\
\text { twinning }\end{array}$ & $\begin{array}{l}1 \% \text {, up to } 1.5 \mathrm{~mm} \text {, phenocrysts } \\
\text { with polysynthetic twinning }\end{array}$ & $\begin{array}{l}3 \% \text {, up to } 1.5 \mathrm{~mm}, 2.5 \mathrm{~mm} \text { in fiamme, } \\
\text { phenocrysts with polysynthetic } \\
\text { twinning, unaltered with some } \\
\text { opaque inclusions }\end{array}$ & $\begin{array}{c}1 \% \text {, up to } 0.5 \mathrm{~mm} \text {, slightly altered } \\
\text { phenocrysts with polysynthetic } \\
\text { twinning }\end{array}$ \\
\hline Quartz & None identifiable & $\begin{array}{l}\text { Trace, up to } 1.5 \mathrm{~mm} \text {, highly } \\
\text { fractured phenocryst with rounded } \\
\text { corners and embayments }\end{array}$ & $\begin{array}{l}3 \% \text {, up to } 1.5 \mathrm{~mm} \text {, phenocrysts with } \\
\text { rounded corners and embayments, } \\
\text { fractured }\end{array}$ & $\begin{array}{l}\text { 1\%, up to } 1.5 \mathrm{~mm} \text {, phenocrysts } \\
\text { with rounded corners and } \\
\text { embayments, fractured }\end{array}$ \\
\hline Sanidine & $\begin{array}{l}3 \% \text {, up to } 2.0 \mathrm{~mm} \text {, unaltered, } \\
\text { fractured phenocrysts }\end{array}$ & $\begin{array}{c}3 \%, \text { up to } 2.0 \mathrm{~mm} \text {, fractured } \\
\text { phenocrysts }\end{array}$ & $\begin{array}{c}2 \%, 1.5 \mathrm{~mm} \text {, fractured, unaltered } \\
\text { phenocrysts }\end{array}$ & $\begin{array}{c}2 \%, \text { up to } 1.0 \mathrm{~mm} \text {, fractured, } \\
\text { unaltered }\end{array}$ \\
\hline Biotite & $\begin{array}{l}1 \% \text {, up to } 0.2 \mathrm{~mm} \text {, phenocrysts } \\
\text { altered by chlorite }\end{array}$ & $\begin{array}{c}\text { Trace, up to } 0.2 \mathrm{~mm} \text {, altered by } \\
\text { chlorite }\end{array}$ & $\begin{array}{c}\text { Trace, up to } 0.5 \mathrm{~mm} \text { in fiamme, up to } \\
0.25 \mathrm{~mm} \text { in matrix, altered } \\
\text { phenocrysts }\end{array}$ & Trace, up to $0.5 \mathrm{~mm}$, altered red \\
\hline Amphibole & None identifiable & None identifiable & $\begin{array}{l}1 \% \text {, up to } 1.0 \mathrm{~mm} \text {, altered and } \\
\text { replaced, in fiamme }\end{array}$ & $\begin{array}{l}\text { Trace, up to } 1.75 \mathrm{~mm} \text {, phenocryst } \\
\text { with thick dehydration rim }\end{array}$ \\
\hline Accessory Phases & $\begin{array}{c}1 \% \text {, opaque minerals, }<0.1 \mathrm{~mm} \text {, } \\
\text { one hexagonal crystal is } \sim 0.5 \\
\mathrm{~mm} \\
\begin{array}{c}1 \%, \text { Fe-Ti oxides, disseminated } \\
\text { grains throughout matrix },<<0.1 \\
\mathrm{~mm}\end{array}\end{array}$ & Trace, opaque minerals, $<0.1 \mathrm{~mm}$ & $\begin{array}{c}\text { Trace, opaque minerals, }<0.1 \mathrm{~mm} \text {, in } \\
\text { fiamme and matrix } \\
\text { Trace, Fe-Ti oxides, }<0.1 \mathrm{~mm} \\
\text { Trace, monazite }\end{array}$ & $\begin{array}{c}\text { Trace, opaque minerals, }<0.1 \mathrm{~mm} \\
\text { Trace, Fe-Ti oxides, }<0.1 \mathrm{~mm} \\
\text { Trace, monazite }\end{array}$ \\
\hline Lithics & $\begin{array}{c}2 \%, 1.5-2.0 \mathrm{~mm} \text {, brown opaque } \\
\text { with plagioclase laths and } \\
\text { opaques, multiple of the same } \\
\text { composition }\end{array}$ & $\begin{array}{c}1 \% \text {, composed of red opaque } \\
\text { material, } 1.0 \mathrm{~mm}\end{array}$ & None identifiable & None identifiable \\
\hline Textures & $\begin{array}{l}\text { Matrix is welded and glassy, } \\
\text { contains } \sim 5 \% \text { pumice, and glass } \\
\text { shards, pumice is phyric and } \\
\text { either white or banded }\end{array}$ & $\begin{array}{c}\text { Matrix is glassy and spherulitic, } \\
\text { appears welded }\end{array}$ & $\begin{array}{l}\text { Matrix is brown, welded and glassy, } \\
\text { voids or pockets of glass are } \\
\text { recrystallized on the edges, dark } \\
\text { brown opaque areas of matrix }\end{array}$ & $\begin{array}{l}\text { Matrix is altered and composed of } \\
\text { glass shards }\end{array}$ \\
\hline Alteration & Chlorite alteration of biotite & Chlorite alteration of biotite & $\begin{array}{l}10 \% \text {, calcite or sericite alteration in } \\
\text { matrix }\end{array}$ & $\begin{array}{c}10 \% \text {, calcite or sericite alteration in } \\
\text { matrix }\end{array}$ \\
\hline
\end{tabular}




\begin{tabular}{|c|c|c|c|c|}
\hline $\begin{array}{c}\text { Sample Number } \\
\text { Unit } \\
\text { Lithology } \\
\text { \% Phenocrysts } \\
\end{array}$ & $\begin{array}{c}\text { 17-SM-13A } \\
\text { Tuff of Brunton Pass } \\
\text { Whole rock } \\
\sim 6 \%\end{array}$ & $\begin{array}{c}\text { 17-SM-13B } \\
\text { Tuff of Brunton Pass } \\
\text { Whole rock } \\
\sim 3 \%\end{array}$ & $\begin{array}{c}\text { 17-SM-14 } \\
\text { Tuff of Arc Dome } \\
\text { Whole Rock } \\
21 \% \\
\end{array}$ & $\begin{array}{c}\text { 17-SM-15A } \\
\text { Tuff of Arc Dome } \\
\text { Pumice } \\
11 \% \\
\end{array}$ \\
\hline Plagioclase & $\begin{array}{l}\text { Trace, up to } 0.75 \mathrm{~mm} \text {, slightly } \\
\text { fractured phenocrysts with } \\
\text { polysynthetic twinning }\end{array}$ & $\begin{array}{l}\text { Trace, up to } 0.5 \mathrm{~mm} \text {, phenocrysts } \\
\text { with polysynthetic twinning }\end{array}$ & $\begin{array}{l}7 \% \text {, up to } 1.5 \mathrm{~mm} \text {, phenocrysts } \\
\text { with polysynthetic twinning }\end{array}$ & $\begin{array}{l}5 \% \text {, up to } 1.5 \mathrm{~mm} \text {, slightly } \\
\text { fractured phenocrysts with } \\
\text { polysynthetic twinning, some are } \\
\text { weakly chemically zoned }\end{array}$ \\
\hline Quartz & $\begin{array}{l}2 \% \text {, up to } 2.0 \mathrm{~mm} \text {, phenocrysts } \\
\text { with rounded corners and } \\
\text { embayments, some have } \\
\text { resorption in the middle }\end{array}$ & $\begin{array}{l}\text { Trace, up to } \sim 1.25 \mathrm{~mm} \text {, unevenly } \\
\text { fractured phenocrysts with rounded } \\
\text { corners and embayments }\end{array}$ & $\begin{array}{l}2 \%, \text { up to } 1.0 \mathrm{~mm} \text {, weakly } \\
\text { fractured, unaltered phenocrysts }\end{array}$ & $\begin{array}{l}5 \% \text {, up to } 2.0 \mathrm{~mm} \text {, fractured } \\
\text { phenocrysts with rounded corners } \\
\sim 30 \% \text { microcrystalline in matrix }\end{array}$ \\
\hline Sanidine & $\begin{array}{l}3 \% \text {, up to } \sim 1.75 \mathrm{~mm} \text {, fractured } \\
\text { phenocrysts, some with Carlsbad } \\
\text { twinning, some have resorption }\end{array}$ & $\begin{array}{c}2 \%, \text { up to } \sim 1.75 \mathrm{~mm} \text {, fractured } \\
\text { phenocrysts, some with Carlsbad } \\
\text { twinning }\end{array}$ & $\begin{array}{c}10 \% \text {, up to } 2.5 \mathrm{~mm} \text {, phenocrysts, } \\
\text { some with Carlsbad twinning and } \\
\text { uneven fractures, some are } \\
\text { weakly chemically zoned }\end{array}$ & $\begin{array}{c}5 \%, 0.5-1.0 \mathrm{~mm} \text {, phenocrysts with } \\
\text { Carlsbad twinning }\end{array}$ \\
\hline Biotite & Trace, $\sim 0.25 \mathrm{~mm}$, altered & Trace, up to $0.5 \mathrm{~mm}$ & $\begin{array}{c}2 \% \text {, up to } 0.75 \mathrm{~mm} \text {, slightly bent } \\
\text { phenocrysts }\end{array}$ & $\begin{array}{c}1 \% \text {, up to } 1.0 \mathrm{~mm} \text {, bent } \\
\text { phenocrysts, some partially } \\
\text { opaque }\end{array}$ \\
\hline Amphibole & None identifiable & None identifiable & $\begin{array}{c}2 \% \text {, up to } 2.0 \mathrm{~mm} \text {, altered edges, } \\
\text { some phenocrysts completely } \\
\text { replaced }\end{array}$ & None identifiable \\
\hline Accessory Phases & $\begin{array}{l}\text { Trace, opaque minerals, up to } 0.4 \\
\text { mm } \\
\text { Trace, Fe-Ti oxides, most }<0.1 \\
\text { mm, one up to } 0.2 \mathrm{~mm}\end{array}$ & $\begin{array}{c}\text { 1\%, opaque minerals, most } \leq 0.1 \\
\text { mm, up to } 0.5 \mathrm{~mm} \\
\text { Trace, Fe-Ti oxides, }<0.1 \mathrm{~mm}\end{array}$ & $\begin{array}{l}\text { 1\%, opaque minerals, up to } 0.2 \\
\text { mm } \\
\text { Trace, monazite, }<0.1 \mathrm{~mm}\end{array}$ & $\begin{array}{c}\text { Trace, opaque minerals, most } \leq 0.1 \\
\mathrm{~mm} \text {, largest up to } 1.0 \mathrm{~mm}\end{array}$ \\
\hline Lithics & $\begin{array}{l}3 \%, \text { up to } \sim 3.0 \mathrm{~mm} \text {, composed of } \\
\text { microcrystalline quartz }\end{array}$ & $\begin{array}{c}\text { 1-2\%, up to } 0.5 \mathrm{~mm} \text {, greenish, } \\
\text { altered, composed of } \\
\text { microcrystalline qtz }\end{array}$ & None identifiable & None identifiable \\
\hline Textures & $\begin{array}{c}\text { Matrix is welded, orange-brown, } \\
\text { composed of spherulitic glass } \\
\text { shards } \\
\text { White and banded fiamme are } \\
\text { spherulitic and aphyric }\end{array}$ & $\begin{array}{l}\text { Matrix is glassy, altered and } \\
\text { spherulitic, doesn't appear as } \\
\text { welded as 17-SM-13B } \\
\text { Matrix has air bubbles with glassy } \\
\text { rims that haven't been compacted } \\
\text { Possible pumice is all spherulitic }\end{array}$ & $\begin{array}{l}\text { Matrix is brown, glassy, and } \\
\text { wraps phenocrysts } \\
\text { Pumice is spherulitic }\end{array}$ & $\begin{array}{c}\text { Matrix is glassy, brown and slightly } \\
\text { banded which wraps phenocrysts, } \\
\text { partially microcrystalline quartz }\end{array}$ \\
\hline Alteration & None identifiable & $\begin{array}{l}\sim 5 \% \text {, calcite or sericite alteration in } \\
\text { matrix }\end{array}$ & None identifiable & None identifiable \\
\hline
\end{tabular}




\begin{tabular}{|c|c|c|c|c|}
\hline $\begin{array}{c}\text { Sample Number } \\
\text { Unit } \\
\text { Lithology } \\
\text { \% Phenocrysts }\end{array}$ & $\begin{array}{c}\text { 17-SM-15B } \\
\text { Tuff of Arc Dome } \\
\text { Whole rock } \\
22 \%\end{array}$ & $\begin{array}{c}\text { 17-SM-16A } \\
\text { Gabbs Valley Tuff } \\
\text { Whole rock } \\
\sim 1 \%\end{array}$ & $\begin{array}{c}\text { 17-SM-16B } \\
\text { Gabbs Valley Tuff } \\
\text { Whole rock } \\
\sim 6 \%\end{array}$ & $\begin{array}{c}\text { 17-SM-17A } \\
\text { Underdown Tuff } \\
\text { Porphyritic pumice } \\
\text { 20\% }\end{array}$ \\
\hline Plagioclase & $\begin{array}{l}5 \% \text {, up to } 1.5 \mathrm{~mm} \text {, phenocrysts with } \\
\text { polysynthetic twinning }\end{array}$ & None identifiable & $\begin{array}{c}1 \%, \sim 0.3-2.0 \mathrm{~mm} \text {, fractured } \\
\text { phenocrysts with polysynthetic } \\
\text { twinning }\end{array}$ & $\begin{array}{c}10 \%, 2.0 \mathrm{~mm} \text {, phenocrysts altered heavily } \\
\text { by sericite and calcite, show polysynthetic } \\
\text { twinning }\end{array}$ \\
\hline Quartz & $\begin{array}{l}8 \%, \text { up to } 2.5 \mathrm{~mm} \text {, fractured } \\
\text { phenocrysts with rounded corners, } \\
\text { many are plucked or resorbed }\end{array}$ & $\begin{array}{l}1 \%, \sim 0.1-0.4 \mathrm{~mm} \text {, possibly secondary, } \\
\text { most are small phenocrysts }\end{array}$ & $\begin{array}{c}1 \% \text {, up to } 2.0 \mathrm{~mm} \text {, fractured } \\
\text { phenocrysts with rounded corners and } \\
\text { embayments }\end{array}$ & $\begin{array}{c}10 \%, 0.5 \mathrm{~mm} \text {, small grains in silicified } \\
\text { veins }\end{array}$ \\
\hline Sanidine & $\begin{array}{l}8 \% \text {, up to } 2.0 \mathrm{~mm} \text {, phenocrysts, some } \\
\text { have Carlsbad twins }\end{array}$ & None identifiable & $\begin{array}{l}2 \%, \text { up to } \sim 2.0 \mathrm{~mm} \text {, fractured } \\
\text { phenocrysts with Carlsbad twinning }\end{array}$ & $\begin{array}{c}10 \%, 2.0 \mathrm{~mm} \text {, phenocrysts altered by } \\
\text { yellow alteration }\end{array}$ \\
\hline Biotite & $\begin{array}{c}1 \% \text {, up to } 1 . / 5 \mathrm{~mm} \text {, phenocrysts with } \\
\text { completely opaque, some partially } \\
\text { resorbed in the middle }\end{array}$ & $\begin{array}{l}\text { Trace, } \sim 1.75 \mathrm{~mm} \text {, fresh, opaque } \\
\text { inclusion, located in pumice }\end{array}$ & $\begin{array}{l}\text { Trace- } 1 \% \text {, up to } ~ 0.4 \mathrm{~mm} \text {, slightly bent } \\
\text { phenocrysts with thin opaque rims }\end{array}$ & None identifiable \\
\hline Amphibole & None identifiable & None identifiable & Trace, $<0.1 \mathrm{~mm}$, small green fragment & None identifiable \\
\hline Accessory Phases & $\begin{array}{c}1 \% \text {, opaque minerals, up to } 0.25 \mathrm{~mm} \\
\text { Trace, monazite }\end{array}$ & Trace, opaque minerals, $\leq 0.1 \mathrm{~mm}$ & $\begin{array}{c}\text { Trace, opaque minerals, } 0.1-0.25 \mathrm{~mm} \\
\text { Trace, mystery blue fragments, } \leq 0.1 \\
\mathrm{~mm}\end{array}$ & $\begin{array}{l}2 \% \text { opaque minerals are included in } \\
\text { feldspars and larger grains in } \\
\text { groundmass, trace monazite }\end{array}$ \\
\hline Lithics & $1 \%$, microcrystalline, $1.0 \mathrm{~mm}$ & None identifiable & $\begin{array}{c}2 \%, \sim 1.75 \mathrm{~mm} \text {, porphyritic with a } \\
\text { microcrystalline matrix }\end{array}$ & None identifiable \\
\hline Textures & $\begin{array}{l}\text { Matrix is brown and glassy, pumice is } \\
\text { spherulitic }\end{array}$ & $\begin{array}{l}\text { Matrix is welded, composed of } \\
\text { orange-brown glass shards } \\
\text { White pumice is aphyric, completely } \\
\text { spherulitic } \\
\text { Dark pumice is phyric, with bt and qtz } \\
\text { phenocrysts, and glass shards } \\
\text { Banded pumice is spherulitic }\end{array}$ & $\begin{array}{l}\text { Matrix is welded, brown, glassy, shows } \\
\text { some glass shards and slight banding } \\
\text { that wraps around phenocrysts } \\
\text { Banded and white pumice are } \\
\text { spherulitic and phryic }\end{array}$ & Matrix is brown altered glass \\
\hline Alteration & None identifiable & None identifiable & None identifiable & $1 \%$ calcite alteration \\
\hline
\end{tabular}




\begin{tabular}{|c|c|c|c|c|}
\hline $\begin{array}{c}\text { Sample Number } \\
\text { Unit } \\
\text { Lithology } \\
\text { \% Phenocrysts } \\
\end{array}$ & $\begin{array}{c}\text { 17-SM-17B } \\
\text { Underdown Tuff } \\
\text { Whole Rock } \\
10 \% \\
\end{array}$ & $\begin{array}{c}\text { 17-SM-17C } \\
\text { Underdown Tuff } \\
\text { Porphyritic pumice } \\
20 \% \\
\end{array}$ & $\begin{array}{c}\text { 17-SM-18 } \\
\text { Pablo Formation } \\
\text { Whole Rock } \\
\text { - } \\
\end{array}$ & $\begin{array}{c}\text { 17-SM-19 } \\
\text { Bonita Canyon } \\
\text { Whole Rock } \\
\sim 10 \% \\
\end{array}$ \\
\hline Plagioclase & $\begin{array}{l}3 \% \text {, up to } 2.5 \mathrm{~mm} \text {, phenocrysts } \\
\text { highly altered by calcite }\end{array}$ & $\begin{array}{c}10 \% \text {, up to } 2.0 \mathrm{~mm} \text {, phenocrysts } \\
\text { altered heavily by sericite and } \\
\text { calcite, show polysynthetic } \\
\text { twinning }\end{array}$ & $\begin{array}{l}68 \% \text {, up to } 1.75 \mathrm{~mm} \text {, phenocrysts } \\
\text { with polysynthetic twinning, } \\
\text { altered by sericite, some show } \\
\text { chemical zoning }\end{array}$ & $\begin{array}{l}3 \% \text {, up to } 2.5 \mathrm{~mm} \text {, most } \sim 1.5 \mathrm{~mm} \text {, } \\
\text { phenocrysts, calcite alteration }\end{array}$ \\
\hline Quartz & $\begin{array}{l}3 \% \text {, up to } 1.5 \mathrm{~mm} \text {, quartz eye } \\
\text { phenocrysts have embayments, } \\
\text { and are slightly fractured } \\
50 \% \text {, microcrystalline quartz in } \\
\text { silicified areas of matrix }\end{array}$ & $\begin{array}{l}10 \% \text {, up to } 2.0 \mathrm{~mm} \text {, small grains } \\
\text { in silicified veins }\end{array}$ & None identifiable & $\begin{array}{l}5 \% \text {, up to } 1.5 \mathrm{~mm} \text {, fractured } \\
\text { phenocrysts with rounded } \\
\text { corners and embayments }\end{array}$ \\
\hline Sanidine & $\begin{array}{c}3 \% \text {, up to } 2.5 \mathrm{~mm} \text {, phenocrysts } \\
\text { have Carlsbad twinning, and sieve } \\
\text { texture }\end{array}$ & $\begin{array}{l}10 \% \text {, up to } 2.0 \mathrm{~mm} \text {, phenocrysts } \\
\text { altered by yellow alteration }\end{array}$ & None identifiable & $\begin{array}{l}2 \%, \sim 1.5 \mathrm{~mm} \text {, highly altered, } \\
\text { sieved, phenocrysts }\end{array}$ \\
\hline Biotite & None identifiable & None identifiable & None identifiable & $\begin{array}{l}\text { Trace, up to } 2.0 \mathrm{~mm} \text { long, thin, } \\
\text { altered, phenocrysts }\end{array}$ \\
\hline Amphibole & $\begin{array}{l}1 \% \text {, up to } 0.5 \mathrm{~mm} \text {, completely } \\
\text { replaced by opaque minerals }\end{array}$ & None identifiable & $\begin{array}{l}30 \% \text {, up to } 1.5 \mathrm{~mm} \text {, unaltered } \\
\text { phenocrysts }\end{array}$ & None identifiable \\
\hline Accessory Phases & $\begin{array}{l}1 \% \text {, opaque minerals are up to } 0.5 \\
\mathrm{~mm} \text { and found throughout matrix }\end{array}$ & $\begin{array}{l}2 \% \text { opaque minerals are included } \\
\text { in feldspars and larger grains in } \\
\text { groundmass, }<0.1 \mathrm{~mm} \\
\text { trace monazite, }<0.1 \mathrm{~mm}\end{array}$ & $\begin{array}{c}2 \% \text {, opaque minerals, blocky, } \\
\text { most } 0.1 \mathrm{~mm} \text {, one up to } 0.25 \\
\mathrm{~mm}\end{array}$ & Trace, opaque minerals, $<0.1 \mathrm{~mm}$ \\
\hline Lithics & None identifiable & None identifiable & None identifiable & $\begin{array}{l}5 \%, \text { size, composed mostly } \\
\text { microcrystalline quartz, are } \\
\text { patchy looking }\end{array}$ \\
\hline Textures & $\begin{array}{l}\text { Matrix is crystalline with some } \\
\text { altered brown glass showing } \\
\text { banding that wraps phenocrysts, } \\
\text { some areas of silicification }\end{array}$ & Matrix is brown altered glass & Matrix is microcrystalline & $\begin{array}{l}\text { Matrix is glassy, has some } \\
\text { microcrystalline quartz }\end{array}$ \\
\hline Alteration & $1 \%$ chlorite alteration in matrix & $1 \%$ calcite alteration & Sericite alteration on plagioclase & $\begin{array}{c}1 \% \text { wispy yellow alteration } \\
\text { (chlorite?) }\end{array}$ \\
\hline
\end{tabular}




\begin{tabular}{|c|c|c|c|c|}
\hline $\begin{array}{c}\text { Sample Number } \\
\text { Unit } \\
\text { Lithology } \\
\text { \% Phenocrysts }\end{array}$ & $\begin{array}{c}17-S M-20 \\
\text { Tuff of Arc Dome } \\
\text { Whole Rock } \\
27 \%\end{array}$ & $\begin{array}{c}\text { 17-SM-21A } \\
\text { Tuff of Clipper Gap } \\
\text { Porphyritic pumice } \\
18 \%\end{array}$ & $\begin{array}{c}\text { 17-SM-21B } \\
\text { Tuff of Clipper Gap } \\
\text { Whole Rock } \\
\sim 6 \%\end{array}$ & $\begin{array}{c}\text { 17-SM-22 } \\
\text { Tuff of Clipper Gap } \\
\text { Whole Rock } \\
\sim 16 \%\end{array}$ \\
\hline Plagioclase & $\begin{array}{l}10 \% \text {, up to } 2.5 \mathrm{~mm} \text {, phenocrysts } \\
\text { with polysynthetic twinning, } \\
\text { some chemically zoned }\end{array}$ & $\begin{array}{c}4 \%, 1.0-1.5 \mathrm{~mm} \text {, fractured } \\
\text { phenocrysts with polysynthetic } \\
\text { twinning, some show chemical } \\
\text { zoning and resorption }\end{array}$ & $\begin{array}{l}1 \% \text {, up to } 1.5 \mathrm{~mm} \text {, most }<0.1 \mathrm{~mm} \text {, } \\
\text { unaltered phenocrysts with } \\
\text { polysynthetic twinning }\end{array}$ & $\begin{array}{l}5 \%, 1.0-1.25 \mathrm{~mm} \text {, fractured } \\
\text { phenocrysts with polysynthetic } \\
\text { twinning, some resorption }\end{array}$ \\
\hline Quartz & None identifiable & None identifiable & $\begin{array}{c}2 \% \text {, up to } 1.0 \mathrm{~mm} \text {, phenocrysts } \\
\text { with rounded corners and } \\
\text { embayments }\end{array}$ & $\begin{array}{l}1 \%, \sim 2.0 \mathrm{~mm} \text {, unevenly fractured } \\
\text { phenocrysts with rounded corners } \\
\text { and embayments }\end{array}$ \\
\hline Sanidine & $\begin{array}{l}10 \% \text {, up to } 3.0 \mathrm{~mm} \text {, fractured } \\
\text { phenocrysts, some with } \\
\text { Carlsbad twinning }\end{array}$ & $\begin{array}{l}12 \%, 1.0-2.5 \mathrm{~mm} \text {, fractured } \\
\text { phenocrysts, some show } \\
\text { chemical zoning and resorption, } \\
\text { some with Carlsbad twinning }\end{array}$ & $\begin{array}{c}3 \% \text {, up to } 2.5 \mathrm{~mm} \text {, unaltered } \\
\text { phenocrysts with Carlsbad } \\
\text { twinning }\end{array}$ & $\begin{array}{l}5 \%, 1.0-1.5 \mathrm{~mm} \text {, unaltered, } \\
\text { fractured phenocrysts, some with } \\
\text { Carlsbad twinning }\end{array}$ \\
\hline Biotite & $\begin{array}{l}3 \% \text {, up to } 2.5 \mathrm{~mm} \text {, unaltered } \\
\text { phenocrysts, some slightly bent }\end{array}$ & None identifiable & $\begin{array}{c}\text { Trace, } \sim 0.25 \mathrm{~mm} \text {, dark and almost } \\
\text { and opaque }\end{array}$ & $\begin{array}{c}2-3 \%, 0.75-1.75 \mathrm{~mm} \text {, unaltered } \\
\text { phenocrysts }\end{array}$ \\
\hline Amphibole & $\begin{array}{l}1 \% \text {, up to } 1.5 \mathrm{~mm} \text {, unaltered } \\
\text { phenocrysts } \\
3 \% \text {, pyroxene, up to } 2.0 \mathrm{~mm} \text {, } \\
\text { phenocrysts with some }\end{array}$ & None identifiable & None identifiable & $\begin{array}{c}2 \%, \sim 1.0 \mathrm{~mm} \text {, unaltered } \\
\text { phenocrysts, elongate or hexagonal }\end{array}$ \\
\hline Accessory Phases & $\begin{array}{l}\text { inclusions of opaque minerals } \\
\text { and Fe-Ti oxides } \\
\begin{array}{c}1 \% \text {, opaque minerals, } 0.5-1.0 \\
\text { mm }\end{array}\end{array}$ & $\begin{array}{c}\text { 1\%, opaque minerals, } \leq 0.2 \mathrm{~mm}, \\
\text { Trace, monazite }\end{array}$ & $\begin{array}{l}\text { Trace, opaque minerals, most } \\
<<0.1 \mathrm{~mm} \text {, one up to } 0.1 \mathrm{~mm}\end{array}$ & $2 \%$, opaque minerals, $\leq 0.2 \mathrm{~mm}$ \\
\hline Lithics & None identifiable & None identifiable & None identifiable & $\begin{array}{l}5 \%, \sim 2.0 \mathrm{~mm} \text {, patchy and } \\
\text { microcrystalline, plagioclase rich }\end{array}$ \\
\hline Textures & Matrix is fresh and glassy & Matrix is glassy and altered & $\begin{array}{l}\text { Matrix is glassy, welded, with } \\
\text { some glass shards, some areas of } \\
\text { spherulites and microcrystalline } \\
\text { quartz, relatively unaltered }\end{array}$ & $\begin{array}{c}\text { Matrix is densely welded, composed } \\
\text { of glass shards, large aphyric } \\
\text { fiamme }\end{array}$ \\
\hline Alteration & None identifiable & Alteration in matrix & None identifiable & None identifiable \\
\hline
\end{tabular}




\begin{tabular}{|c|c|c|c|c|}
\hline $\begin{array}{c}\text { Sample Number } \\
\text { Unit } \\
\text { Lithology } \\
\text { \% Phenocrysts }\end{array}$ & $\begin{array}{c}\text { 17-SM-24A } \\
\text { Tuff of Clipper Gap } \\
\text { Banded Pumice } \\
\text { 3\% }\end{array}$ & $\begin{array}{c}\text { 17-SM-25 } \\
\text { Tuff of Clipper Gap } \\
\text { Whole Rock } \\
6 \%\end{array}$ & $\begin{array}{c}\text { 17-SM-26A } \\
\text { Tuff of Clipper Gap } \\
\text { Whole rock } \\
7 \%\end{array}$ & $\begin{array}{c}\text { 17-SM-26B } \\
\text { Tuff of Clipper Gap } \\
\text { Porphyritic Pumice } \\
\sim 10 \%\end{array}$ \\
\hline Plagioclase & $\begin{array}{l}1 \% \text {, up to } 1.0 \mathrm{~mm} \text {, phenocryst } \\
\text { with polysynthetic twinning }\end{array}$ & $\begin{array}{c}1 \% \text {, up to } 0.2 \mathrm{~mm} \text {, unaltered } \\
\text { phenocrysts with polysynthetic } \\
\text { twinning }\end{array}$ & $\begin{array}{l}\text { 1-2\%, } 1.75 \mathrm{~mm} \text {, unaltered, weakly } \\
\text { fractured phenocrysts with } \\
\text { polysynthetic twinning }\end{array}$ & None identifiable \\
\hline Quartz & None identifiable & None identifiable & $\begin{array}{l}1 \%, 1.0-1.5 \mathrm{~mm} \text {, weakly fractured } \\
\text { phenocrysts with rounded corners } \\
\text { and embayments }\end{array}$ & $\begin{array}{l}5 \% \text {, up to } 2.0 \mathrm{~mm} \text {, phenocrysts } \\
\text { with rounded corners, partially } \\
\text { resorbed in the center }\end{array}$ \\
\hline Sanidine & $\begin{array}{l}2 \% \text {, up to } 2.0 \mathrm{~mm} \text {, fractured, } \\
\text { unaltered phenocrysts }\end{array}$ & $\begin{array}{l}3 \% \text {, up to } 1.5 \mathrm{~mm} \text {, unaltered } \\
\text { phenocrysts }\end{array}$ & $\begin{array}{c}4 \%, 1.0-1.5 \mathrm{~mm} \text {, unaltered, } \\
\text { fractured phenocrysts, some with } \\
\text { Carlsbad twinning }\end{array}$ & $\begin{array}{l}5 \% \text {, up to } 2.0 \mathrm{~mm} \text {, slightly altered, } \\
\text { fractured phenocrysts }\end{array}$ \\
\hline Biotite & None identifiable & $\begin{array}{c}2 \% \text {, up to } 1.5 \mathrm{~mm} \text {, dark, nearly } \\
\text { opaque phenocrysts, some are bent }\end{array}$ & None identifiable & $\begin{array}{l}\text { Trace, up to } 0.5 \mathrm{~mm} \text {, altered, } \\
\text { nearly opaque phenocryst }\end{array}$ \\
\hline Amphibole & None identifiable & None identifiable & $\begin{array}{c}\text { Trace, } \sim 0.5 \mathrm{~mm} \text {, altered with a dark } \\
\text { brown rim } \\
1 \% \text { opaque minerals, } \sim 0.1 \mathrm{~mm}\end{array}$ & $\begin{array}{l}\text { Trace, up to } 0.5 \mathrm{~mm} \text {, phenocryst } \\
\text { completely replaced by chlorite }\end{array}$ \\
\hline Accessory Phases & $\begin{array}{l}\text { Trace, opaque minerals, } \leq 0.1 \\
\text { mm } \\
\text { Trace, Fe-Ti oxides, }<<0.1 \mathrm{~mm}\end{array}$ & $\begin{array}{l}\text { 1\%, opaque minerals, } \leq 0.1 \mathrm{~mm} \\
\text { Trace, monazite, }<0.1 \mathrm{~mm}\end{array}$ & $\begin{array}{c}\text { some blocky, others look like fillers } \\
\text { oxides, }<0.1 \mathrm{~mm} \\
\text { Trace, monazite, }<0.1 \mathrm{~mm}\end{array}$ & $\begin{array}{l}\text { Trace, opaque minerals, up to } 0.2 \\
\text { mm } \\
\text { Trace, Fe-Ti oxides, }<0.1 \mathrm{~mm}\end{array}$ \\
\hline Lithics & None identifiable & $\begin{array}{c}5 \% \text {, microcrystalline clasts, some } \\
\text { with Ti-oxides, ranging from 0.5-5.5 } \\
\text { mm }\end{array}$ & None identifiable & None identifiable \\
\hline Textures & $\begin{array}{l}\text { Matrix is glassy, banded and } \\
\text { wraps around phenocrysts }\end{array}$ & $\begin{array}{c}\text { Matrix is yellow, glassy and welded } \\
\text { with yellow glass shards, pumice is } \\
\text { yellow and banded } \\
5 \% \text { pumice that is spherulitic }\end{array}$ & $\begin{array}{l}\text { Matrix is spherulitic, reddish-brown } \\
\text { areas, some areas of matrix have } \\
\text { smaller pieces of phenocrysts, some } \\
\text { parts of matrix appear to wrap } \\
\text { around phenocrysts }\end{array}$ & $\begin{array}{c}\text { Matrix is altered, red and streaky, } \\
\text { has spherulites and } \\
\text { microcrystalline quartz }\end{array}$ \\
\hline Alteration & None identifiable & Yellow alteration of matrix & Red alteration in matrix & Alteration in matrix \\
\hline
\end{tabular}




\begin{tabular}{|c|c|c|c|c|}
\hline $\begin{array}{c}\text { Sample Number } \\
\text { Unit } \\
\text { Lithology } \\
\text { \% Phenocrysts }\end{array}$ & $\begin{array}{c}\text { 17-SM-26C } \\
\text { Tuff of Clipper Gap } \\
\text { Porphyritic pumice? } \\
\sim 15 \%\end{array}$ & $\begin{array}{c}\text { 17-SM-27 } \\
\text { Tuff of Clipper Gap } \\
\text { Whole rock } \\
\sim 10 \%\end{array}$ & $\begin{array}{c}\text { 17-SM-28 } \\
\text { Gabbs Valley Tuff } \\
\text { Whole rock } \\
\sim 13 \%\end{array}$ & $\begin{array}{c}\text { 17-SM-29 } \\
\text { Gabbs Valley Tuff } \\
\text { Whole rock } \\
22 \%\end{array}$ \\
\hline Plagioclase & $\begin{array}{l}5 \% \text {, up to } 2.0 \mathrm{~mm} \text {, phenocrysts with } \\
\text { polysynthetic twinning, some are } \\
\text { chemically zoned and altered }\end{array}$ & $\begin{array}{l}5 \%, \leq 1.5 \mathrm{~mm} \text {, phenocrysts with } \\
\text { polysynthetic twinning, some are yellow } \\
\text { in XPL, singular or clustered }\end{array}$ & $\begin{array}{l}2 \%, \leq 0.5 \mathrm{~mm} \text {, phenocrysts with } \\
\text { polysynthetic twinning }\end{array}$ & $\begin{array}{c}5 \%, \text { up to } \sim 1.0 \mathrm{~mm} \text {, fractured } \\
\text { phenocrysts with polysynthetic } \\
\text { twinning, some are resorbed in the } \\
\text { centre }\end{array}$ \\
\hline Quartz & None identifiable & $\begin{array}{l}\text { Trace, } \sim 1.25 \mathrm{~mm} \text {, phenocrysts with } \\
\text { rounded corners and embayments, very } \\
\text { fractured }\end{array}$ & $\begin{array}{l}7 \% \text {, up to } 2.0 \mathrm{~mm} \text {, phenocrysts with } \\
\text { rounded corners and embayments }\end{array}$ & $\begin{array}{c}10 \%, \text { up to } \sim 2.5 \mathrm{~mm} \text {, highly fractured } \\
\text { phenocrysts with rounded corners } \\
\text { and embayments, uneven fractures } \\
\text { are brown-reddish }\end{array}$ \\
\hline Sanidine & $\begin{array}{c}10 \%, 1.25-2.0 \mathrm{~mm} \text {, weakly fratured } \\
\text { phenocrysts, some are altered and } \\
\text { show Carlsbad twinning }\end{array}$ & $\begin{array}{l}5 \%, 1.5-2.0 \mathrm{~mm} \text {, slightly fractured } \\
\text { phenocrysts with Carlsbad twinning }\end{array}$ & $\begin{array}{l}3 \% \text {, up to } ~ 1.25 \mathrm{~mm} \text {, slightly fractured } \\
\text { phenocrysts with Carlsbad twinning }\end{array}$ & $\begin{array}{l}5 \% \text {, up to } \sim 1.75 \mathrm{~mm} \text {, fractured } \\
\text { phenocrysts with Carlsbad twinning }\end{array}$ \\
\hline Biotite & None identifiable & $\begin{array}{l}\text { Trace, } \leq 0.5 \mathrm{~mm} \text {, very pleochroic, } \\
\text { possibly slightly altered }\end{array}$ & $\begin{array}{c}1 \% \text {, up to } ~ 0.75 \mathrm{~mm} \text {, bent phenocrysts } \\
\text { with red edges, reddish-orange to } \\
\text { opaque inclusions }\end{array}$ & $\begin{array}{l}2 \%, \text { up to } \sim 1.75 \mathrm{~mm} \text {, bent } \\
\text { phenocrysts }\end{array}$ \\
\hline Amphibole & Trace, $\sim 0.25 \mathrm{~mm}$, altered & $\begin{array}{c}\text { Trace, } \sim 0.75 \mathrm{~mm} \text {, possibly slightly } \\
\text { altered }\end{array}$ & Trace, $\sim 0.2 \mathrm{~mm}$, very altered & None identifiable \\
\hline Accessory Phases & $\begin{array}{c}\text { 1\%, opaque minerals, } \leq 0.25 \mathrm{~mm} \text {, } \\
\text { blocky, Trace, monazite, Trace, Fe-Ti } \\
\text { oxides, yellow, possibly replacing } \\
\text { biotite based on the shape }\end{array}$ & $1 \%$, opaque minerals, $\leq 0.25 \mathrm{~mm}$, blocky & $\begin{array}{c}\text { Trace, opaque minerals, } \leq 0.2 \mathrm{~mm} \\
\text { Trace, Fe-Ti oxides, }<<0.1 \mathrm{~mm} \\
\text { Trace, monazite } \\
\text { Trace, mystery blue fragments, }<<0.1 \\
\mathrm{~mm}\end{array}$ & $\begin{array}{l}\text { Trace-1\%, opaque minerals, up to } \\
\qquad \begin{array}{l}0.25 \mathrm{~mm} \\
\text { Trace, monazite, }<0.1 \mathrm{~mm}\end{array}\end{array}$ \\
\hline Lithics & None identifiable & $\begin{array}{c}3 \%, 1.0-1.5 \mathrm{~mm} \text {, most microcrystalline } \\
\text { with opaque minerals }\end{array}$ & $\begin{array}{l}1 \% \text {, up to } 1.25 \mathrm{~mm} \text {, altered orange- } \\
\text { yellow clast with a yellow rind }\end{array}$ & $1 \%$, microcrystalline, $1.0 \mathrm{~mm}$ \\
\hline Textures & $\begin{array}{l}\text { Matrix is red-orange and nearly } \\
\text { opaque, most altered phenocrysts are } \\
\text { in groupings or vein-like structures, no } \\
\text { banding }\end{array}$ & $\begin{array}{l}\text { Matrix is composed of unaltered glass } \\
\text { shards, fiamme are banded and } \\
\text { generally aphyric }\end{array}$ & $\begin{array}{l}\text { Matrix is microcrystalline, possibly } \\
\text { glassy, poorly welded } \\
\text { Phyric pumice is spherulitic }\end{array}$ & $\begin{array}{l}\text { Matrix is welded, composed of } \\
\text { orange-brown glass shards, banding } \\
\text { wraps around phenocrysts } \\
\text { Some veiny areas of microcrystalline } \\
\text { quartz, and microcrystalline areas of } \\
\text { matrix }\end{array}$ \\
\hline Alteration & Alteration in matrix & None identifiable & None identifiable & None identifiable \\
\hline
\end{tabular}




\begin{tabular}{|c|c|c|}
\hline $\begin{array}{l}\text { Sample Number } \\
\text { Unit } \\
\text { Lithology } \\
\% \text { Phenocrysts }\end{array}$ & $\begin{array}{l}\text { 17-SM-30 } \\
\text { Gabbs Valley Tuff } \\
\text { Whole rock } \\
15 \%\end{array}$ & $\begin{array}{c}\text { 17-SM-31 } \\
\text { Gabbs Valley Tuff } \\
\text { Pumice } \\
16 \%\end{array}$ \\
\hline Plagioclase & $\begin{array}{c}10 \%, \text { up to } ~ 3.0 \mathrm{~mm} \text {, fractured phenocrysts with } \\
\text { polysynthetic twinning, some show chemical zoning, } \\
\text { some resorption in centres }\end{array}$ & $\begin{array}{l}\text { 7\%, up to } 1.5 \mathrm{~mm} \text {, fractured phenocrysts with polysynthetic } \\
\text { twinning, altered by calcite and sericite }\end{array}$ \\
\hline Quartz & $\begin{array}{c}3 \% \text {, up to } \sim 1.25 \mathrm{~mm} \text {, rounded phenocrysts with } \\
\text { embayments }\end{array}$ & None identifiable \\
\hline Sanidine & $\begin{array}{c}10 \% \text {, up to } \sim 3.0 \mathrm{~mm} \text {, fractured phenocrysts with } \\
\text { Carlsbad twinning }\end{array}$ & $\begin{array}{c}7 \% \text {, up to } 2.5 \mathrm{~mm} \text {, fractured phenocrysts with some } \\
\text { resorption }\end{array}$ \\
\hline Biotite & $\begin{array}{c}2 \% \text {, up to } \sim 2.25 \mathrm{~mm} \text {, phenocrysts with opaque } \\
\text { inclusions, some bent }\end{array}$ & $\begin{array}{c}2 \%, \sim 1.25-1.75 \mathrm{~mm} \text {, most phenocrysts look fresh, some } \\
\text { almost completely opaque, some are bent and wrap around } \\
\text { other phenocrysts }\end{array}$ \\
\hline Amphibole & None identifiable & None identifiable \\
\hline Accessory Phases & $\begin{array}{c}\text { 1\%, opaque minerals, up to } 0.5 \mathrm{~mm} \text {, most smaller } \\
\text { Trace, Fe-Ti oxides, }<<0.1 \mathrm{~mm}\end{array}$ & $\begin{array}{l}\text { 1\%, opaque minerals, up to } \sim 0.5 \mathrm{~mm} \\
\text { Trace, Fe-Ti oxides, }<0.1 \mathrm{~mm}\end{array}$ \\
\hline Lithics & None identifiable & None identifiable \\
\hline $\begin{array}{l}\text { Textures } \\
\text { Alteration }\end{array}$ & $\begin{array}{l}\text { Matrix is welded and composed of reddish-orange } \\
\text { glass shards, matrix wraps around phenocrysts } \\
\text { Possible alteration in matrix }\end{array}$ & $\begin{array}{l}\text { Matrix is brown, glassy and spherulitic, banding in matrix } \\
\text { wraps around phenocrysts, phenocrysts have glassy rims } \\
\text { None identifiable }\end{array}$ \\
\hline
\end{tabular}




\section{Table IV: Major Element Oxide Abundances}

\begin{tabular}{|c|c|c|c|c|c|c|c|}
\hline Sample ID & Unit Name & Rock Type & $\mathrm{SiO}_{2}$ & $\mathrm{TiO}_{2}$ & $\mathrm{Al}_{2} \mathrm{O}_{3}$ & $\mathrm{Fe}_{2} \mathrm{O}_{3}$ & Mno \\
\hline 16-SM-02 & Bonita Canyon Formation & pumice & 66.46 & 0.15 & 18.77 & 2.17 & 0.043 \\
\hline 16-SM-04 & Underdown Tuff & tuff & 78.41 & 0.09 & 12.25 & 1.44 & 0.040 \\
\hline 16-SM-08 & Bonita Canyon Formation & tuff & 76.57 & 0.15 & 13.07 & 1.53 & 0.021 \\
\hline 16-SM-09 & Megabreccia block & tuff & 71.49 & 0.35 & 14.23 & 2.46 & 0.031 \\
\hline 16-SM-13A & Tuff of Clipper Gap & tuff & 74.36 & 0.16 & 13.60 & 1.48 & 0.052 \\
\hline 16-SM-13B & Tuff of Clipper Gap & tuff & 74.51 & 0.10 & 12.54 & 1.36 & 0.041 \\
\hline $16-S M-13 C$ & Tuff of Clipper Gap & tuff & 77.82 & 0.09 & 12.67 & 1.51 & 0.051 \\
\hline $16-S M-14$ & Tuff of Clipper Gap & porphyritic pumice & 78.10 & 0.08 & 12.36 & 1.41 & 0.020 \\
\hline 16-SM-15A & Tuff of Clipper Gap & porphyritic pumice & 66.57 & 0.40 & 16.08 & 3.44 & 0.051 \\
\hline 16-SM-15A & Tuff of Clipper Gap & porphyritic pumice & 68.03 & 0.40 & 16.47 & 3.62 & 0.051 \\
\hline $16-S M-16$ & Tuff of Clipper Gap & porphyritic pumice & 67.51 & 0.38 & 16.37 & 3.39 & 0.041 \\
\hline $16-S M-20 B$ & Pablo Formation & andesite & 52.31 & 0.70 & 13.86 & 9.96 & 0.173 \\
\hline $16-S M-20 C$ & Pablo Formation & andesite & 58.56 & 0.65 & 15.96 & 7.21 & 0.122 \\
\hline $16-S M-21 \mathrm{~A}$ & Bonita Canyon Formation & tuff & 77.99 & 0.13 & 12.64 & 1.62 & 0.022 \\
\hline 16-SM-21B & Bonita Canyon Formation & pumice & 71.39 & 0.11 & 14.51 & 0.93 & 0.022 \\
\hline $16-S M-22$ & Bonita Canyon Formation & tuff & 77.26 & 0.18 & 12.51 & 1.75 & 0.052 \\
\hline $16-S M-26$ & Bonita Canyon Formation & tuff & 75.62 & 0.30 & 12.47 & 2.18 & 0.061 \\
\hline 16-SM-29A & Underdown Tuff & porphyritic pumice & 78.33 & 0.11 & 12.42 & 1.51 & 0.061 \\
\hline 16-SM-29B & Underdown Tuff & white pumice & 78.93 & 0.07 & 11.56 & 0.52 & 0.020 \\
\hline $16-S M-30$ & Bonita Canyon Formation & tuff & 79.62 & 0.15 & 11.98 & 1.62 & 0.041 \\
\hline $16-S M-32 A$ & Underdown Tuff & porphyritic pumice & 72.54 & 0.16 & 13.52 & 1.91 & 0.050 \\
\hline $16-S M-32 B$ & Underdown Tuff & tuff & 76.52 & 0.09 & 11.93 & 1.40 & 0.040 \\
\hline 16-SM-32D & Underdown Tuff & banded pumice & 77.19 & 0.09 & 12.51 & 1.53 & 0.142 \\
\hline 16-SM-33A & Dacite Porphyry Dyke & dacite & 66.40 & 0.55 & 16.96 & 4.09 & 0.102 \\
\hline $16-S M-34$ & Underdown Tuff & tuff & 76.57 & 0.11 & 12.90 & 1.69 & 0.020 \\
\hline $16-S M-35$ & Underdown Tuff & tuff & 82.57 & 0.08 & 10.60 & 1.14 & 0.010 \\
\hline $16-S M-37$ & Bonita Canyon Formation & tuff & 77.54 & 0.12 & 12.49 & 0.91 & 0.011 \\
\hline 16-SM-38A & Unnamed tuff & tuff & 79.45 & 0.07 & 11.95 & 1.08 & 0.020 \\
\hline $16-S M-38 B$ & Unnamed tuff & pumice & 78.77 & 0.06 & 11.72 & 1.01 & 0.030 \\
\hline $16-S M-40$ & Unnamed pumice & pumice & 78.38 & 0.07 & 12.02 & 0.94 & 0.020 \\
\hline $16-S M-42$ & Unnamed tuff & tuff & 78.83 & 0.10 & 12.23 & 1.24 & 0.040 \\
\hline $16-S M-44$ & Pablo Formation & andesite & 53.84 & 0.83 & 15.40 & 9.92 & 0.163 \\
\hline $16-S M-45$ & Underdown Tuff & tuff & 76.76 & 0.09 & 11.89 & 1.73 & 0.071 \\
\hline $16-S M-46$ & Underdown Tuff & tuff & 78.52 & 0.08 & 12.05 & 1.40 & 0.020 \\
\hline $16-S M-47$ & Underdown Tuff & tuff & 78.39 & 0.09 & 12.41 & 1.52 & 0.040 \\
\hline $16-S M-48$ & Underdown Tuff & tuff & 77.40 & 0.09 & 12.28 & 1.50 & 0.040 \\
\hline $16-S M-49$ & Underdown Tuff & tuff & 76.59 & 0.08 & 12.11 & 1.34 & 0.030 \\
\hline $16-S M-50$ & Underdown Tuff & tuff & 69.85 & 0.47 & 15.79 & 2.92 & 0.051 \\
\hline $16-S M-51$ & Underdown Tuff & tuff & 78.68 & 0.08 & 11.90 & 1.48 & 0.041 \\
\hline
\end{tabular}




\begin{tabular}{|c|c|c|c|c|c|c|c|c|c|c|}
\hline Sample ID & MgO & $\mathrm{CaO}$ & $\mathrm{Na}_{2} \mathrm{O}$ & $\mathrm{K}_{2} \mathrm{O}$ & $\mathrm{P}_{2} \mathrm{O}_{5}$ & $\mathrm{Cr}_{2} \mathrm{O}_{3}$ & SrO & $\mathrm{BaO}$ & LOI & Total \\
\hline 16-SM-02 & 0.40 & 0.989 & 2.93 & 8.77 & 0.021 & $<0.01$ & 0.011 & 0.032 & 6.41 & 101.16 \\
\hline 16-SM-04 & 0.04 & 0.252 & 3.46 & 4.76 & 0.020 & 0.000 & 0.000 & 0.000 & 0.79 & 100.77 \\
\hline 16-SM-08 & 0.16 & 1.091 & 2.28 & 4.40 & 0.041 & 0.000 & 0.000 & 0.000 & 2.9 & 99.47 \\
\hline 16-SM-09 & 0.21 & 0.704 & 3.45 & 5.13 & 0.112 & 0.000 & 0.000 & 0.000 & 1.95 & 98.36 \\
\hline $16-S M-13 A$ & 0.62 & 0.703 & 2.52 & 5.32 & 0.052 & 0.000 & 0.000 & 0.000 & 3.39 & 99.05 \\
\hline 16-SM-13B & 0.33 & 0.733 & 3.02 & 5.47 & 0.031 & 0.000 & 0.000 & 0.000 & 3.14 & 98.28 \\
\hline $16-S M-13 C$ & 0.16 & 0.466 & 3.50 & 5.35 & 0.010 & $<0.01$ & $<0.01$ & 0.010 & 1.35 & 101.65 \\
\hline $16-S M-14$ & 0.07 & 0.343 & 3.76 & 5.04 & $<0.01$ & $<0.01$ & $<0.01$ & $<0.01$ & 0.92 & 101.2 \\
\hline $16-S M-15 A$ & 0.21 & 1.045 & 4.44 & 6.49 & 0.183 & 0.000 & 0.000 & 0.000 & 1.46 & 98.98 \\
\hline $16-S M-15 A$ & 0.22 & 1.088 & 4.41 & 6.61 & 0.153 & $<0.01$ & 0.010 & 0.031 & 1.71 & 101.13 \\
\hline $16-S M-16$ & 0.22 & 0.996 & 4.50 & 6.56 & 0.061 & $<0.01$ & 0.010 & 0.051 & 1.68 & 100.12 \\
\hline 16-SM-20B & 8.82 & 9.832 & 2.23 & 1.75 & 0.274 & 0.000 & 0.000 & 0.000 & 1.57 & 100.11 \\
\hline $16-S M-20 C$ & 4.55 & 8.774 & 2.70 & 1.67 & 0.203 & 0.010 & 0.122 & 0.051 & 1.68 & 100.62 \\
\hline $16-S M-21 A$ & 0.41 & 2.344 & 1.07 & 4.87 & 0.022 & $<0.01$ & $<0.01$ & 0.022 & 8.17 & 101.8 \\
\hline 16-SM-21B & 0.62 & 2.825 & 0.88 & 5.76 & 0.022 & 0.000 & 0.000 & 0.000 & 10.15 & 98.16 \\
\hline $16-S M-22$ & 0.23 & 0.405 & 3.45 & 4.44 & 0.052 & $<0.01$ & $<0.01$ & 0.031 & 3.86 & 100.51 \\
\hline $16-S M-26$ & 0.15 & 1.150 & 3.59 & 4.09 & 0.081 & $<0.01$ & 0.020 & 0.112 & 1.77 & 99.85 \\
\hline $16-S M-29 A$ & 0.05 & 0.141 & 2.67 & 5.08 & 0.020 & 0.000 & 0.000 & 0.000 & 0.94 & 100.41 \\
\hline 16-SM-29B & 0.04 & 0.202 & 2.43 & 5.15 & 0.020 & 0.000 & 0.000 & 0.000 & 0.92 & 98.96 \\
\hline $16-S M-30$ & 0.16 & 0.612 & 3.19 & 3.76 & 0.031 & $<0.01$ & $<0.01$ & 0.041 & 1.97 & 101.25 \\
\hline $16-S M-32 A$ & 0.08 & 0.525 & 4.06 & 5.23 & 0.030 & 0.000 & 0.000 & 0.000 & 0.87 & 98.12 \\
\hline 16-SM-32B & 0.04 & 0.453 & 3.62 & 4.82 & $<0.01$ & $<0.01$ & $<0.01$ & 0.010 & 0.68 & 98.94 \\
\hline 16-SM-32D & 0.04 & 1.195 & 6.17 & 1.79 & 0.020 & 0.000 & 0.000 & 0.000 & 1.31 & 100.71 \\
\hline 16-SM-33A & 0.63 & 2.799 & 4.10 & 5.98 & 0.153 & $<0.01$ & 0.031 & 0.143 & 2.2 & 101.98 \\
\hline 16-SM-34 & 0.04 & 0.060 & 2.34 & 6.27 & 0.020 & 0.000 & 0.000 & 0.000 & 0.75 & 100.02 \\
\hline $16-S M-35$ & 0.06 & 0.051 & 0.09 & 4.94 & 0.020 & 0.000 & 0.000 & 0.000 & 1.43 & 99.59 \\
\hline $16-S M-37$ & 0.17 & 1.908 & 2.03 & 4.78 & 0.022 & $<0.01$ & 0.011 & 0.033 & 9.13 & 100.84 \\
\hline $16-S M-38 A$ & 0.07 & 0.382 & 3.68 & 4.71 & 0.020 & 0.000 & 0.000 & 0.000 & 0.45 & 101.45 \\
\hline 16-SM-38B & 0.05 & 0.322 & 3.61 & 4.63 & 0.010 & $<0.01$ & $<0.01$ & $<0.01$ & 0.6 & 100.21 \\
\hline $16-S M-40$ & 0.09 & 0.402 & 3.69 & 4.68 & 0.040 & $<0.01$ & $<0.01$ & 0.010 & 0.62 & 100.35 \\
\hline $16-S M-42$ & 0.10 & 0.443 & 3.57 & 4.78 & $<0.01$ & 0.000 & 0.000 & 0.000 & 0.68 & 101.36 \\
\hline $16-S M-44$ & 6.62 & 9.656 & 3.03 & 1.98 & 0.224 & 0.031 & 0.082 & 0.061 & 2 & 101.86 \\
\hline $16-S M-45$ & 0.04 & 0.332 & 3.71 & 4.60 & $<0.01$ & $<0.01$ & $<0.01$ & 0.010 & 0.73 & 99.24 \\
\hline $16-S M-46$ & 0.03 & 0.341 & 3.77 & 4.74 & $<0.01$ & 0.000 & 0.000 & 0.000 & 0.41 & 100.95 \\
\hline $16-S M-47$ & 0.04 & 0.412 & 3.79 & 4.91 & $<0.01$ & $<0.01$ & $<0.01$ & $<0.01$ & 0.51 & 101.61 \\
\hline $16-S M-48$ & 0.05 & 0.393 & 3.69 & 4.86 & 0.010 & $<0.01$ & $<0.01$ & 0.010 & 0.65 & 100.33 \\
\hline 16-SM-49 & 0.03 & 0.231 & 3.60 & 4.82 & $<0.01$ & $<0.01$ & $<0.01$ & $<0.01$ & 0.51 & 98.84 \\
\hline $16-S M-50$ & 0.17 & 0.810 & 3.74 & 6.56 & 0.111 & 0.000 & 0.000 & 0.000 & 1.24 & 100.57 \\
\hline 16-SM-51 & 0.05 & 0.861 & 3.24 & 4.55 & $<0.01$ & 0.000 & 0.000 & 0.000 & 1.27 & 100.9 \\
\hline
\end{tabular}




\begin{tabular}{|c|c|c|c|c|c|c|c|}
\hline Sample ID & Unit Name & Rock Type & $\mathrm{SiO}_{2}$ & $\mathrm{TiO}_{2}$ & $\mathrm{Al}_{2} \mathrm{O}_{3}$ & $\mathrm{Fe}_{2} \mathrm{O}_{3}$ & Mno \\
\hline $16-S M-53$ & Rhyolite Intrusions & rhyolite & 77.71 & 0.05 & 11.63 & 1.21 & 0.020 \\
\hline $16-S M-55$ & Unnamed Tuff & tuff & 78.85 & 0.05 & 11.90 & 1.17 & 0.020 \\
\hline $16-S M-56$ & Rhyolite Intrusions & rhyolite & 79.04 & 0.05 & 12.35 & 0.89 & 0.020 \\
\hline 17-SM-01 & Terrill Mountains tuffs & tuff & 77.97 & 0.11 & 12.74 & 1.77 & 0.020 \\
\hline 17-SM-02 & Terrill Mountains tuffs & tuff & 77.89 & 0.11 & 12.84 & 1.48 & 0.031 \\
\hline 17-SM-03 A & Terrill Mountains tuffs & white pumice & 76.70 & 0.11 & 13.57 & 1.57 & 0.032 \\
\hline 17-SM-03 B & Terrill Mountains tuffs & banded pumice & 77.36 & 0.10 & 13.41 & 1.59 & 0.032 \\
\hline 17-SM-03 C & Terrill Mountains tuffs & tuff & 76.88 & 0.12 & 13.22 & 1.71 & 0.032 \\
\hline 17-SM-06 & Tuff of Clipper Gap & tuff & 72.46 & 0.20 & 13.56 & 2.23 & 0.043 \\
\hline 17-SM-07 & Tuff of Clipper Gap & tuff & 78.15 & 0.19 & 11.31 & 1.81 & 0.031 \\
\hline 17-SM-08 & Tuff of Clipper Gap & tuff & 15.63 & 0.15 & 3.46 & 1.07 & 0.027 \\
\hline 17-SM-09 & Tuff of Clipper Gap & tuff & 72.99 & 0.12 & 13.97 & 1.49 & 0.066 \\
\hline 17-SM-10 & Tuff of Clipper Gap & tuff & 77.99 & 0.10 & 11.76 & 1.51 & 0.020 \\
\hline 17-SM-11 & Tuff of Clipper Gap & tuff & 75.90 & 0.10 & 12.17 & 1.58 & 0.041 \\
\hline 17-SM-12 & Tuff of Clipper Gap & tuff & 72.97 & 0.12 & 12.97 & 1.70 & 0.041 \\
\hline 17-SM-13 A & Tuff of Brunton Pass & tuff & 77.66 & 0.09 & 12.35 & 1.56 & 0.020 \\
\hline 17-SM-13 B & Tuff of Brunton Pass & tuff & 76.50 & 0.11 & 12.46 & 1.64 & 0.061 \\
\hline 17-SM-14 & Tuff of Arc Dome & tuff & 73.41 & 0.21 & 13.36 & 1.84 & 0.040 \\
\hline 17-SM-15 A & Tuff of Arc Dome & tuff & 76.35 & 0.07 & 12.27 & 1.16 & 0.040 \\
\hline 17-SM-15 B & Tuff of Arc Dome & tuff & 76.90 & 0.09 & 11.88 & 1.21 & 0.030 \\
\hline 17-SM-16 A & Tuff of Gabbs Valley & tuff & 78.88 & 0.12 & 11.08 & 1.67 & 0.030 \\
\hline 17-SM-16 B & Tuff of Gabbs Valley & tuff & 73.79 & 0.16 & 13.37 & 1.73 & 0.040 \\
\hline 17-SM-17 A & Underdown Tuff & porphyritic pumice & 68.81 & 0.35 & 15.95 & 3.13 & 0.102 \\
\hline 17-SM-17 B & Underdown Tuff & tuff & 77.12 & 0.09 & 12.13 & 1.54 & 0.030 \\
\hline 17-SM-17 C & Underdown Tuff & porphyritic pumice & 64.66 & 0.55 & 17.34 & 3.92 & 0.082 \\
\hline 17-SM-18 & Pablo Formation & andesite & 57.49 & 0.68 & 17.95 & 6.48 & 0.113 \\
\hline 17-SM-19 & Bonita Canyon Formation & tuff & 78.17 & 0.11 & 12.67 & 1.60 & 0.041 \\
\hline 17-SM-20 & Tuff of Arc Dome & tuff & 69.96 & 0.50 & 14.88 & 2.66 & 0.051 \\
\hline $17-S M-21 \mathrm{~A}$ & Tuff of Clipper Gap & tuff & 68.73 & 0.38 & 17.03 & 2.27 & 0.020 \\
\hline 17-SM-21 B & Tuff of Clipper Gap & tuff & 79.22 & 0.10 & 11.96 & 1.29 & 0.010 \\
\hline $17-S M-22$ & Tuff of Clipper Gap & tuff & 75.48 & 0.15 & 14.19 & 1.43 & 0.052 \\
\hline 17-SM-23 & Tuff of Clipper Gap & white pumice & 77.28 & 0.07 & 12.95 & 1.11 & 0.084 \\
\hline 17-SM-24 & Tuff of Clipper Gap & white pumice & 76.09 & 0.07 & 13.19 & 1.19 & 0.052 \\
\hline 17-SM-25 & Tuff of Clipper Gap & tuff & 75.00 & 0.13 & 13.68 & 1.42 & 0.041 \\
\hline 17-SM-26 A & Tuff of Clipper Gap & white pumice & 75.14 & 0.11 & 12.69 & 1.67 & 0.040 \\
\hline 17-SM-26 B & Tuff of Clipper Gap & tuff & 76.01 & 0.09 & 12.40 & 1.54 & 0.050 \\
\hline $17-S M-26$ C & Tuff of Clipper Gap & tuff & 67.68 & 0.30 & 15.49 & 3.10 & 0.092 \\
\hline $17-S M-27$ & Tuff of Clipper Gap & tuff & 74.37 & 0.17 & 13.45 & 1.78 & 0.022 \\
\hline $17-S M-28$ & TgV2 & tuff & 77.49 & 0.08 & 12.41 & 1.19 & 0.030 \\
\hline 17-SM-29 & TgV2 & tuff & 75.31 & 0.15 & 12.70 & 2.20 & 0.020 \\
\hline
\end{tabular}




\begin{tabular}{|c|c|c|c|c|c|c|c|c|c|c|}
\hline Sample ID & MgO & $\mathrm{CaO}$ & $\mathrm{Na}_{2} \mathrm{O}$ & $\mathrm{K}_{2} \mathrm{O}$ & $\mathrm{P}_{2} \mathrm{O}_{5}$ & $\mathrm{Cr}_{2} \mathrm{O}_{3}$ & SrO & $\mathrm{BaO}$ & LOI & Total \\
\hline 16-SM-53 & 0.03 & 0.252 & 3.33 & 4.67 & $<0.01$ & $<0.01$ & $<0.01$ & $<0.01$ & 0.65 & 98.9 \\
\hline $16-S M-55$ & 0.07 & 0.224 & 2.09 & 4.66 & $<0.01$ & $<0.01$ & $<0.01$ & 0.010 & 1.73 & 99.08 \\
\hline 16-SM-56 & 0.07 & 0.283 & 3.19 & 4.83 & $<0.01$ & $<0.01$ & $<0.01$ & $<0.01$ & 1.21 & 100.73 \\
\hline 17-SM-01 & 0.12 & 0.475 & 3.34 & 4.78 & 0.020 & 0.015 & $<0.01$ & 0.010 & 1.15 & 101.4 \\
\hline 17-SM-02 & 0.06 & 0.590 & 3.54 & 4.44 & 0.052 & 0.019 & $<0.01$ & 0.010 & 3.62 & 101.21 \\
\hline 17-SM-03 A & 0.35 & 0.641 & 2.77 & 4.32 & 0.021 & 0.005 & $<0.01$ & 0.011 & 6.86 & 100.56 \\
\hline 17-SM-03 B & 0.28 & 0.630 & 2.83 & 4.46 & 0.011 & 0.010 & $<0.01$ & 0.011 & 6.93 & 101.19 \\
\hline $17-S M-03 \mathrm{C}$ & 0.29 & 0.786 & 2.79 & 4.31 & $<0.01$ & 0.010 & $<0.01$ & 0.011 & 6.22 & 100.54 \\
\hline 17-SM-06 & 0.90 & 1.608 & 2.32 & 5.76 & 0.032 & 0.009 & $<0.01$ & 0.043 & 7.16 & 99.67 \\
\hline 17-SM-07 & 0.09 & 0.703 & 3.35 & 4.47 & 0.041 & 0.006 & $<0.01$ & 0.061 & 1.89 & 100.26 \\
\hline $17-S M-08$ & 0.78 & 63.486 & 0.60 & 0.62 & 0.055 & 0.005 & 0.027 & 0.041 & 37 & 99.68 \\
\hline 17-SM-09 & 1.23 & 1.764 & 1.98 & 4.27 & 0.044 & 0.011 & 0.022 & 0.088 & 9.49 & 98.96 \\
\hline $17-S M-10$ & 0.11 & 0.568 & 3.44 & 4.68 & 0.020 & 0.008 & $<0.01$ & 0.010 & 1.42 & 100.24 \\
\hline $17-S M-11$ & 0.21 & 1.903 & 3.69 & 4.66 & 0.041 & 0.009 & $<0.01$ & 0.020 & 2.3 & 100.39 \\
\hline $17-S M-12$ & 0.11 & 3.215 & 2.99 & 6.28 & 0.041 & 0.004 & $<0.01$ & 0.021 & 3.38 & 100.58 \\
\hline $17-S M-13 \mathrm{~A}$ & 0.10 & 0.334 & 3.43 & 4.70 & 0.010 & 0.009 & $<0.01$ & 0.010 & 1.25 & 100.29 \\
\hline $17-S M-13$ B & 0.20 & 1.211 & 3.43 & 4.77 & 0.102 & 0.007 & $<0.01$ & 0.020 & 1.74 & 100.55 \\
\hline 17-SM-14 & 0.21 & 0.827 & 3.68 & 4.71 & 0.010 & 0.018 & 0.010 & 0.091 & 0.82 & 98.42 \\
\hline $17-S M-15$ A & 0.07 & 0.402 & 3.36 & 4.68 & 0.020 & 0.017 & $<0.01$ & 0.010 & 0.58 & 98.45 \\
\hline 17-SM-15 B & 0.09 & 0.443 & 3.29 & 4.44 & 0.020 & 0.026 & $<0.01$ & 0.020 & 0.64 & 98.44 \\
\hline $17-S M-16$ A & 0.05 & 0.305 & 3.02 & 4.37 & 0.010 & 0.013 & $<0.01$ & 0.020 & 1.64 & 99.59 \\
\hline $17-S M-16$ B & 0.11 & 0.674 & 3.42 & 5.58 & 0.030 & 0.013 & $<0.01$ & 0.070 & 0.52 & 98.98 \\
\hline 17-SM-17 A & 0.17 & 1.183 & 3.76 & 6.14 & 0.071 & 0.010 & $<0.01$ & 0.031 & 1.94 & 99.75 \\
\hline 17-SM-17 B & 0.07 & 0.455 & 3.13 & 4.52 & 0.010 & 0.022 & $<0.01$ & 0.010 & 1.07 & 99.14 \\
\hline $17-S M-17 \mathrm{C}$ & 0.24 & 1.418 & 3.61 & 7.13 & 0.153 & 0.006 & 0.010 & 0.051 & 1.97 & 99.21 \\
\hline $17-S M-18$ & 3.42 & 5.064 & 4.31 & 2.16 & 0.225 & 0.017 & 0.133 & 0.133 & 2.26 & 98.22 \\
\hline 17-SM-19 & 0.24 & 1.364 & 4.21 & 2.40 & 0.031 & 0.016 & $<0.01$ & 0.021 & 2.61 & 100.94 \\
\hline $17-S M-20$ & 0.63 & 1.902 & 3.69 & 4.95 & 0.153 & 0.015 & 0.031 & 0.184 & 2.27 & 99.67 \\
\hline $17-S M-21 \mathrm{~A}$ & 0.08 & 0.968 & 4.71 & 6.69 & 0.081 & 0.009 & 0.010 & 0.030 & 0.79 & 101.02 \\
\hline $17-S M-21$ B & 0.03 & 0.353 & 3.68 & 4.64 & 0.020 & 0.015 & $<0.01$ & 0.020 & 0.93 & 101.36 \\
\hline $17-S M-22$ & 0.65 & 0.915 & 3.39 & 4.94 & 0.042 & 0.014 & 0.010 & 0.062 & 4.02 & 101.48 \\
\hline $17-S M-23$ & 0.18 & 0.734 & 2.67 & 6.06 & 0.021 & 0.009 & $<0.01$ & 0.010 & 4.92 & 101.42 \\
\hline $17-S M-24$ & 0.15 & 0.544 & 2.22 & 6.30 & 0.010 & 0.012 & $<0.01$ & $<0.01$ & 4.67 & 100.05 \\
\hline $17-S M-25$ & 0.14 & 0.543 & 2.72 & 6.42 & 0.041 & 0.005 & 0.010 & 0.051 & 2.46 & 100.27 \\
\hline $17-S M-26 \mathrm{~A}$ & 0.07 & 0.850 & 3.74 & 5.17 & 0.010 & 0.008 & $<0.01$ & 0.020 & 1.13 & 99.54 \\
\hline $17-S M-26$ B & 0.10 & 0.383 & 3.70 & 4.98 & 0.020 & 0.009 & $<0.01$ & 0.020 & 0.81 & 99.32 \\
\hline $17-S M-26 C$ & 0.34 & 0.948 & 4.28 & 6.06 & 0.051 & 0.008 & 0.010 & 0.031 & 1.9 & 98.43 \\
\hline $17-S M-27$ & 0.59 & 2.214 & 1.44 & 4.95 & 0.022 & 0.003 & 0.033 & 0.044 & 10.7 & 100.22 \\
\hline $17-S M-28$ & 0.12 & 0.504 & 3.32 & 4.96 & 0.010 & 0.023 & $<0.01$ & 0.020 & 0.9 & 100.17 \\
\hline $17-S M-29$ & 0.13 & 0.577 & 3.30 & 4.84 & 0.020 & 0.020 & 0.010 & 0.051 & 1.21 & 99.34 \\
\hline
\end{tabular}




\begin{tabular}{|c|c|c|c|c|c|c|c|c|}
\hline Sample ID & Unit Name & Rock Type & $\mathrm{SiO}_{2}$ & $\mathrm{TiO}_{2}$ & $\mathrm{Al}_{2} \mathrm{O}_{3}$ & $\mathrm{Fe}_{2} \mathrm{O}_{3}$ & MnO & MgO \\
\hline \multicolumn{9}{|c|}{ Table IV: Major Element Oxide Abundances Cont. Underdown Caldera Complex } \\
\hline $17-S M-30$ & $\operatorname{TgV} 2$ & tuff & 74.94 & 0.23 & 14.07 & 2.10 & 0.020 & 0.18 \\
\hline 17-SM-31 & TgV3 & porphyritic pumice & 69.86 & 0.27 & 15.01 & 1.70 & 0.040 & 0.29 \\
\hline \multicolumn{9}{|c|}{ Table IV: Major Element Oxide Abundances Cont. Acid washing samples } \\
\hline 16-SM-13Caw & Tuff of Clipper Gap & tuff & 77.79 & 0.06 & 12.51 & 0.41 & $<0.01$ & 0.05 \\
\hline 16-SM-14aw & Tuff of Clipper Gap & white pumice & 78.64 & 0.04 & 12.52 & 0.36 & $<0.01$ & 0.03 \\
\hline 16-SM-16aw & Tuff of Clipper Gap & porphyritic pumice & 69.65 & 0.31 & 16.38 & 0.99 & 0.010 & 0.03 \\
\hline 17-SM-21Aaw & Tuff of Clipper Gap & porphyritic pumice & 71.55 & 0.29 & 16.58 & 0.72 & 0.010 & 0.03 \\
\hline 17-SM-22aw & Tuff of Clipper Gap & whole rock & 78.46 & 0.10 & 13.40 & 0.55 & 0.021 & 0.32 \\
\hline 17-SM-26Aaw & Tuff of Clipper Gap & whole rock & 79.02 & 0.06 & 12.52 & 0.47 & $<0.01$ & $<0.01$ \\
\hline 17-SM-26Caw & Tuff of Clipper Gap & porphyritic pumice & 73.52 & 0.20 & 15.37 & 1.06 & 0.020 & 0.03 \\
\hline 17-SM-27aw & Tuff of Clipper Gap & whole rock & 84.56 & 0.15 & 9.31 & 0.73 & 0.011 & 0.25 \\
\hline \multicolumn{9}{|c|}{ Table IV: Major Element Oxide Abundances Cont. Young Sierra Nevada tuffs } \\
\hline H18-SN6 & Young Sierra Nevada tuffs & tuff & 76.63 & 0.11 & 13.14 & 1.73 & 0.01 & 0.06 \\
\hline H18-SN15 & Young Sierra Nevada tuffs & tuff & 76.73 & 0.11 & 13.09 & 1.84 & 0.02 & 0.05 \\
\hline
\end{tabular}

\begin{tabular}{|c|c|c|c|c|c|c|c|c|c|}
\hline Sample ID & $\mathrm{CaO}$ & $\mathrm{Na}_{2} \mathrm{O}$ & $\mathrm{K}_{2} \mathrm{O}$ & $\mathrm{P}_{2} \mathrm{O}_{5}$ & $\mathrm{Cr}_{2} \mathrm{O}_{3}$ & SrO & $\mathrm{BaO}$ & LOI & Total \\
\hline \multicolumn{10}{|c|}{ Table IV: Major Element Oxide Abundances Cont. Underdown Caldera Complex } \\
\hline 17-SM-30 & 0.988 & 3.77 & 5.07 & 0.030 & 0.021 & 0.020 & 0.101 & 0.88 & 101.56 \\
\hline $17-S M-31$ & 1.577 & 3.98 & 5.68 & 0.051 & 0.015 & 0.020 & 0.142 & 1.09 & 98.67 \\
\hline \multicolumn{10}{|c|}{ Table IV: Major Element Oxide Abundances Cont. Acid-washed Samples } \\
\hline 16-SM-13Caw & 0.232 & 3.60 & 5.27 & 0.010 & $<0.002$ & $<0.01$ & 0.010 & 0.89 & 99.95 \\
\hline 16-SM-14aw & 0.191 & 3.96 & 5.07 & 0.010 & $<0.002$ & $<0.01$ & $<0.01$ & 0.57 & 100.83 \\
\hline 16-SM-16aw & 0.816 & 4.71 & 6.57 & 0.010 & $<0.002$ & $<0.01$ & 0.030 & 0.79 & 99.51 \\
\hline 17-SM-21Aaw & 0.844 & 4.81 & 6.61 & 0.010 & 0.004 & $<0.01$ & 0.030 & 0.5 & 101.5 \\
\hline 17-SM-22aw & 0.590 & 3.42 & 4.84 & 0.010 & 0.006 & 0.010 & 0.052 & 3.57 & 101.91 \\
\hline 17-SM-26Aaw & 0.251 & 3.86 & 5.22 & $<0.01$ & 0.004 & $<0.01$ & 0.010 & 0.54 & 101.41 \\
\hline 17-SM-26Caw & 0.597 & 4.55 & 6.19 & 0.010 & 0.004 & $<0.01$ & 0.020 & 1.14 & 101.58 \\
\hline 17-SM-27aw & 0.707 & 0.98 & 3.19 & $<0.01$ & 0.002 & 0.011 & 0.033 & 10.5 & 101.03 \\
\hline \multicolumn{10}{|c|}{ Table IV: Major Element Oxide Abundances Cont. Young Sierra Nevada tuffs } \\
\hline H18-SN6 & 0.30 & 3.27 & 4.89 & 0.01 & & & & 1.57 & 101.44 \\
\hline H18-SN15 & 0.27 & 3.25 & 4.80 & 0.01 & & & & 1.58 & 101.46 \\
\hline
\end{tabular}


Table V: Precision of Major Element analyses

\begin{tabular}{llllll}
\hline Element & 10-LT-05 & 10-LT-05 & $\mathbf{1 0 - L T - 0 5}$ & Average & $\mathbf{2 \sigma}$ \\
\hline $\mathrm{SiO}_{2}$ & 48.9 & 49.3 & 47.9 & 48.8 & 1.0 \\
$\mathrm{TiO}_{2}$ & 1.43 & 1.44 & 1.44 & 1.45 & 0.06 \\
$\mathrm{Al}_{2} \mathrm{O}_{3}$ & 17.8 & 18.25 & 18.4 & 18.18 & 0.46 \\
$\mathrm{Fe}_{2} \mathrm{O}_{3}$ & 9.39 & 9.76 & 9.69 & 9.54 & 0.28 \\
$\mathrm{MnO}$ & 0.14 & 0.14 & 0.14 & 0.14 & 0.00 \\
$\mathrm{MgO}$ & 6.45 & 6.66 & 6.62 & 6.61 & 0.20 \\
$\mathrm{CaO}$ & 9.34 & 9.56 & 9.44 & 9.52 & 0.30 \\
$\mathrm{Na}_{2} \mathrm{O}$ & 3.60 & 3.56 & 3.51 & 3.59 & 0.02 \\
$\mathrm{~K}_{2} \mathrm{O}$ & 1.02 & 1.03 & 1.03 & 1.02 & 0.04 \\
$\mathrm{Cr} \mathrm{O}_{3}$ & 0.030 & 0.030 & 0.025 & 0.030 & 0.008 \\
$\mathrm{P}_{2} \mathrm{O}_{5}$ & 0.36 & 0.38 & 0.38 & 0.38 & 0.02 \\
$\mathrm{SrO}$ & 0.11 & 0.11 & 0.11 & 0.11 & 0.00 \\
$\mathrm{BaO}$ & 0.06 & 0.06 & 0.06 & 0.06 & 0.00 \\
$\mathrm{LOI}$ & 0.53 & 0.67 & 0.71 & 0.73 & 0.30 \\
$\mathrm{Total}$ & 99.16 & 100.95 & 99.46 & 100.23 & 1.54 \\
\hline
\end{tabular}

Note: The first three columns of major element data for 10-LT-05 are the results of individual runs obtained with three batches of samples submitted to ALS for geochemical analysis. Averages and standard deviation ( $\sigma$ ) for 10-LT-05 are calculated from 31 analyses by ALS (Nov. 2013-Nov. 2019). 
Table V: Precision of Major Element analyses

\begin{tabular}{ccccccc}
\hline Element & BHVO-2 & BHVO-2 & BHVO-2 & Average & $\mathbf{2 \sigma}$ & USGS Recommended Values \\
\hline $\mathrm{SiO}_{2}$ & 49.7 & 49.2 & 48.5 & 49.4 & 1.4 & 49.9 \\
$\mathrm{TiO}_{2}$ & 2.66 & 2.6 & 2.66 & 2.69 & 0.12 & 2.73 \\
$\mathrm{Al}_{2} \mathrm{O}_{3}$ & 13.2 & 13.3 & 13.6 & 13.4 & 0.4 & 13.5 \\
$\mathrm{Fe}_{2} \mathrm{O}_{3}$ & 12.20 & 12.55 & 12.55 & 12.37 & 0.30 & 12.3 \\
$\mathrm{MnO}$ & 0.17 & 0.17 & 0.16 & 0.17 & 0.00 & - \\
$\mathrm{MgO}$ & 7.11 & 7.28 & 7.25 & 7.27 & 0.22 & 7.23 \\
$\mathrm{CaO}$ & 11.1 & 11.3 & 11.2 & 11.3 & 0.4 & 11.4 \\
$\mathrm{Na}_{2} \mathrm{O}$ & 2.23 & 2.16 & 2.16 & 2.21 & 0.08 & 2.22 \\
$\mathrm{~K}_{2} \mathrm{O}$ & 0.51 & 0.52 & 0.51 & 0.51 & 0.02 & 0.52 \\
$\mathrm{Cr}_{2} \mathrm{O}_{3}$ & 0.04 & 0.04 & 0.04 & 0.04 & 0.00 & - \\
$\mathrm{P}_{\mathbf{2}} \mathrm{O}_{5}$ & 0.25 & 0.25 & 0.26 & 0.26 & 0.02 & 0.27 \\
$\mathrm{SrO}$ & 0.05 & 0.04 & 0.05 & 0.05 & 0.00 & - \\
$\mathrm{BaO}$ & 0.01 & 0.01 & 0.01 & 0.01 & 0.00 & - \\
$\mathrm{LOI}$ & -0.51 & -0.57 & -0.57 & -0.59 & 0.16 & - \\
$\mathrm{Total}$ & 98.72 & 98.85 & 98.38 & 99.19 & 1.9 & 100.07 \\
\hline
\end{tabular}

Note: The first three columns of major element data for BHVO-2 are the results of individual runs obtained with three batches of samples submitted to ALS for geochemical analysis. Averages and standard deviation ( $\sigma$ ) for BHVO-2 are calculated from 9 analyses by ALS (Jan. 2017-Nov. 2019). 
Table VI: Trace Element Concentrations

\begin{tabular}{|c|c|c|c|c|c|c|c|c|c|c|c|c|c|c|c|c|}
\hline Sample ID & Unit Name & Rock Type & $\mathbf{A g}$ & As & $\mathrm{Ba}$ & Cd & $\mathrm{Ce}$ & Co & $\mathrm{Cr}$ & Cs & $\mathrm{Cu}$ & Dy & Er & Eu & Ga & Gd \\
\hline 16-SM-02 & Bonita Canyon Formation & pumice & $<0.5$ & $<5$ & 303 & $<0.5$ & 125 & 1 & $<10$ & 114 & 5 & 8.2 & 4.9 & 0.25 & 26 & 8.95 \\
\hline $16-S M-04$ & Underdown Tuff & tuff & $<0.5$ & $<5$ & 70.6 & $<0.5$ & 109 & $<1$ & $<10$ & 3.87 & 6 & 5.11 & 2.87 & 0.07 & 20.4 & 5.11 \\
\hline $16-S M-08$ & Bonita Canyon Formation & tuff & $<0.5$ & 15 & 331 & $<0.5$ & 84.4 & $<1$ & $<10$ & 9.16 & 4 & 5 & 2.88 & 0.33 & 18.6 & 5.74 \\
\hline 16-SM-09 & Mega-breccia block & tuff & $<0.5$ & 11 & 1245 & $<0.5$ & 72 & 1 & $<10$ & 6.4 & 3 & 3.24 & 1.93 & 0.92 & 17.9 & 3.89 \\
\hline $16-S M-13 A$ & Tuff of Clipper Gap & tuff & $<0.5$ & 6 & 573 & $<0.5$ & 71.6 & 1 & $<10$ & 5.85 & 5 & 3.32 & 2.06 & 0.41 & 16.5 & 3.86 \\
\hline $16-S M-13 B$ & Tuff of Clipper Gap & tuff & $<0.5$ & 13 & 223 & $<0.5$ & 86.2 & $<1$ & 10 & 3.68 & 8 & 5.13 & 2.81 & 0.18 & 18.7 & 5.41 \\
\hline $16-S M-13 C$ & Tuff of Clipper Gap & tuff & $<0.5$ & $<5$ & 111 & $<0.5$ & 92.9 & 1 & $<10$ & 3.4 & 4 & 6.21 & 3.46 & 0.1 & 21.3 & 6.61 \\
\hline $16-S M-14$ & Tuff of Clipper Gap & porphyritic pumice & $<0.5$ & $<5$ & 32.6 & $<0.5$ & 94.5 & $<1$ & $<10$ & 4.73 & 4 & 5.7 & 3.4 & 0.06 & 20.8 & 4.99 \\
\hline $16-S M-15 A$ & Tuff of Clipper Gap & porphyritic pumice & $<0.5$ & 12 & 301 & $<0.5$ & 102.5 & 1 & 10 & 2.69 & 13 & 11.2 & 5.06 & 0.73 & 21.9 & 18 \\
\hline $16-S M-15 A$ & Tuff of Clipper Gap & porphyritic pumice & $<0.5$ & 12 & 303 & $<0.5$ & 106.5 & $<1$ & $<10$ & 2.59 & 12 & 11.1 & 4.94 & 0.69 & 21.4 & 18.2 \\
\hline $16-S M-16$ & Tuff of Clipper Gap & porphyritic pumice & $<0.5$ & 11 & 447 & $<0.5$ & 74.2 & $<1$ & $<10$ & 2.02 & 8 & 10.6 & 4.21 & 0.71 & 20.5 & 19.6 \\
\hline $16-S M-20 B$ & Pablo Formation & andesite & $<0.5$ & $<5$ & 419 & $<0.5$ & 34.6 & 34 & 450 & 14.35 & 100 & 2.88 & 1.63 & 1.17 & 18 & 3.97 \\
\hline $16-S M-20 C$ & Pablo Formation & andesite & $<0.5$ & 6 & 467 & $<0.5$ & 37.3 & 19 & 40 & 6.38 & 19 & 2.31 & 1.28 & 1.06 & 19.2 & 3.07 \\
\hline $16-S M-21 A$ & Bonita Canyon Formation & tuff & $<0.5$ & $<5$ & 179 & $<0.5$ & 93 & 1 & 10 & 5.34 & 8 & 5.99 & 3.19 & 0.2 & 17.7 & 6.65 \\
\hline $16-S M-21 B$ & Bonita Canyon Formation & pumice & $<0.5$ & $<5$ & 178 & $<0.5$ & 128.5 & $<1$ & 10 & 2.99 & 7 & 6.01 & 2.47 & 0.19 & 12.9 & 9.05 \\
\hline $16-S M-22$ & Bonita Canyon Formation & tuff & $<0.5$ & 6 & 234 & $<0.5$ & 91.5 & 2 & 10 & 11.6 & 5 & 5.61 & 3.28 & 0.25 & 18.3 & 6.32 \\
\hline $16-S M-26$ & Bonita Canyon Formation & tuff & $<0.5$ & $<5$ & 978 & $<0.5$ & 78.3 & 2 & 10 & 5.02 & 5 & 3.34 & 1.66 & 0.95 & 12.7 & 4.1 \\
\hline $16-S M-29 A$ & Underdown Tuff & porphyritic pumice & $<0.5$ & $<5$ & 90.4 & $<0.5$ & 121 & 1 & $<10$ & 7.51 & 6 & 5.92 & 3.43 & 0.1 & 19.1 & 6.27 \\
\hline $16-S M-29 B$ & Underdown Tuff & white pumice & $<0.5$ & $<5$ & 81.6 & $<0.5$ & 102.5 & $<1$ & $<10$ & 6.4 & 7 & 3.88 & 1.96 & 0.05 & 16 & 5.45 \\
\hline $16-S M-30$ & Bonita Canyon Formation & tuff & $<0.5$ & 7 & 357 & $<0.5$ & 102 & 1 & 10 & 9.21 & 3 & 5.86 & 3.05 & 0.36 & 18.6 & 6.7 \\
\hline $16-S M-32 A$ & Underdown Tuff & porphyritic pumice & $<0.5$ & $<5$ & 56.5 & $<0.5$ & 114 & 1 & $<10$ & 3.8 & 5 & 6.83 & 3.73 & 0.08 & 21.1 & 7.44 \\
\hline $16-S M-32 B$ & Underdown Tuff & tuff & $<0.5$ & $<5$ & 28.7 & $<0.5$ & 121 & $<1$ & $<10$ & 1.73 & 5 & 6.24 & 3.48 & 0.09 & 21.4 & 7.13 \\
\hline $16-S M-32 D$ & Underdown Tuff & banded pumice & $<0.5$ & 6 & 1170 & $<0.5$ & 77.6 & 2 & 10 & 1.89 & 7 & 3.36 & 1.89 & 1.46 & 18.6 & 4.23 \\
\hline
\end{tabular}


Table VI: Trace Element Concentrations Cont.

\begin{tabular}{|c|c|c|c|c|c|c|c|c|c|c|c|c|c|c|c|c|c|c|c|c|}
\hline Sample ID & $\mathrm{Hf}$ & Ho & La & $\mathbf{L i}$ & Lu & Mo & $\mathrm{Nb}$ & Nd & $\mathrm{Ni}$ & $\mathrm{Pb}$ & $\mathrm{Pr}$ & $\mathbf{R b}$ & Sc & Sm & Sn & $\mathrm{Sr}$ & $\mathrm{Ta}$ & Tb & Th & $\mathrm{TI}$ \\
\hline 16-SM-02 & 9.4 & 1.64 & 65 & 30 & 0.7 & $<1$ & 37.7 & 59 & 2 & 28 & 15.65 & 391 & 2 & 11 & 5 & 82.1 & 2.7 & 1.37 & 29.4 & $<10$ \\
\hline 16-SM-04 & 7.3 & 1.02 & 35 & 30 & 0.5 & 3 & 29 & 32 & 4 & 23 & 9.17 & 213 & 1 & 6.9 & 4 & 13.1 & 2.1 & 0.82 & 24.3 & $<10$ \\
\hline $16-S M-08$ & 6.6 & 1.05 & 41 & 60 & 0.5 & 4 & 21.9 & 35 & 2 & 18 & 9.93 & 175 & 3 & 7.1 & 3 & 62.7 & 1.6 & 0.89 & 20.2 & $<10$ \\
\hline 16-SM-09 & 6.6 & 0.69 & 36 & 100 & 0.3 & 2 & 17.1 & 28 & 4 & 23 & 8.32 & 161 & 5 & 5.6 & 2 & 134 & 1.1 & 0.57 & 16.3 & $<10$ \\
\hline $16-S M-13 A$ & 5.8 & 0.7 & 35 & 40 & 0.3 & $<1$ & 13.9 & 27 & 1 & 144 & 7.82 & 153 & 4 & 5.2 & 12 & 87.9 & 1 & 0.56 & 16.6 & 10 \\
\hline 16-SM-13B & 7.2 & 1.02 & 42 & 30 & 0.5 & $<1$ & 26 & 37 & 3 & 67 & 10.4 & 191 & 2 & 7.3 & 13 & 58.7 & 1.8 & 0.79 & 21.9 & $<10$ \\
\hline $16-S M-13 C$ & 7.3 & 1.22 & 42 & 20 & 0.5 & 2 & 30.9 & 41 & $<1$ & 35 & 10.7 & 225 & 1 & 8.3 & 4 & 22.7 & 2.2 & 1.08 & 23.5 & $<10$ \\
\hline $16-S M-14$ & 7.5 & 1.18 & 28 & 20 & 0.5 & 2 & 30.5 & 26 & 1 & 32 & 6.62 & 222 & 1 & 5.6 & 5 & 22.2 & 2.2 & 0.93 & 22.8 & $<10$ \\
\hline $16-S M-15 A$ & 15.6 & 1.99 & 176 & 50 & 0.6 & 2 & 18.2 & 157 & 5 & 27 & 41.5 & 132 & 10 & 28 & 2 & 67.8 & 1.1 & 2.27 & 8.69 & $<10$ \\
\hline 16-SM-15A & 14.8 & 2 & 161 & 40 & 0.7 & 2 & 17.7 & 152 & 6 & 25 & 42.1 & 130 & 10 & 29 & 3 & 68.9 & 1.1 & 2.19 & 9.44 & $<10$ \\
\hline $16-S M-16$ & 14.3 & 1.9 & 208 & 40 & 0.5 & 2 & 15.8 & 130 & 3 & 22 & 32 & 102 & 10 & 21 & 2 & 84.2 & 0.9 & 2.26 & 8 & $<10$ \\
\hline $16-S M-20 B$ & 2.6 & 0.59 & 16 & 30 & 0.2 & 1 & 3.6 & 19 & 163 & 8 & 4.54 & 83.4 & 29 & 4.4 & 1 & 789 & 0.2 & 0.55 & 3.65 & $<10$ \\
\hline $16-S M-20 C$ & 3.3 & 0.47 & 19 & 30 & 0.2 & 1 & 7.8 & 18 & 28 & 13 & 4.52 & 53.9 & 13 & 3.6 & 1 & 1020 & 0.4 & 0.46 & 7.81 & $<10$ \\
\hline $16-S M-21 \mathrm{~A}$ & 7 & 1.2 & 48 & 30 & 0.5 & 1 & 25.9 & 42 & 1 & 21 & 11.1 & 168 & 2 & 7.9 & 4 & 59.4 & 1.7 & 1.06 & 20 & $<10$ \\
\hline $16-S M-21 B$ & 6.4 & 1.04 & 66 & 10 & 0.3 & $<1$ & 32.1 & 55 & 2 & 34 & 15.15 & 168 & 1 & 11 & 2 & 183 & 1.6 & 1.23 & 19.2 & $<10$ \\
\hline $16-S M-22$ & 6.6 & 1.17 & 46 & 50 & 0.5 & $<1$ & 25.6 & 40 & $<1$ & 34 & 10.65 & 214 & 3 & 7.7 & 4 & 59.2 & 1.7 & 0.98 & 19.3 & $<10$ \\
\hline $16-S M-26$ & 5.8 & 0.66 & 42 & 60 & 0.3 & 1 & 14.6 & 32 & 1 & 19 & 8.87 & 123 & 4 & 5.4 & 1 & 151 & 1 & 0.6 & 13.5 & $<10$ \\
\hline $16-S M-29 A$ & 7.5 & 1.25 & 56 & 20 & 0.5 & 1 & 28.4 & 42 & 3 & 36 & 12.35 & 224 & 2 & 8 & 4 & 15.8 & 2 & 1 & 23.2 & $<10$ \\
\hline $16-S M-29 B$ & 5.4 & 0.76 & 50 & 20 & 0.3 & 1 & 27 & 42 & 4 & 15 & 11.75 & 228 & 1 & 7.8 & 3 & 13.8 & 1.9 & 0.75 & 21.9 & $<10$ \\
\hline $16-S M-30$ & 7 & 1.18 & 53 & 70 & 0.5 & 1 & 26.4 & 45 & 1 & 10 & 11.95 & 150 & 2 & 8.2 & 4 & 38.2 & 1.7 & 1.07 & 19.9 & $<10$ \\
\hline $16-S M-32 A$ & 7.6 & 1.36 & 57 & 20 & 0.5 & 3 & 30.5 & 51 & 1 & 27 & 13.45 & 228 & 1 & 9.6 & 4 & 16 & 2.1 & 1.17 & 23.2 & $<10$ \\
\hline $16-S M-32 B$ & 7 & 1.24 & 62 & 10 & 0.5 & 2 & 27.2 & 48 & 3 & 20 & 13.8 & 74.4 & 1 & 8.9 & 3 & 35.4 & 1.9 & 1.06 & 21.9 & $<10$ \\
\hline $16-S M-32 D$ & 13.6 & 0.72 & 43 & 20 & 0.3 & 2 & 11.6 & 33 & 1 & 16 & 8.83 & 83.8 & 10 & 5.7 & 1 & 237 & 0.7 & 0.64 & 7.41 & $<10$ \\
\hline
\end{tabular}


Table VI: Trace Element Concentrations Cont.

\begin{tabular}{|c|c|c|c|c|c|c|c|c|}
\hline Sample ID & $\mathrm{Tm}$ & $\mathbf{U}$ & $\mathbf{v}$ & w & $Y$ & $\mathrm{Yb}$ & $\mathrm{Zn}$ & $\mathrm{Zr}$ \\
\hline $16-S M-02$ & 0.71 & 9 & 5 & 1 & 44.1 & 4.85 & 112 & 284 \\
\hline 16-SM-04 & 0.48 & 6.6 & $<5$ & 7 & 24 & 2.98 & 72 & 197 \\
\hline $16-S M-08$ & 0.46 & 8.6 & 5 & 2 & 28.7 & 2.9 & 67 & 205 \\
\hline 16-SM-09 & 0.3 & 4.3 & 16 & 4 & 17.7 & 1.83 & 59 & 245 \\
\hline $16-S M-13 A$ & 0.31 & 4.3 & 12 & 2 & 19.6 & 2.29 & 114 & 186 \\
\hline 16-SM-13B & 0.45 & 5.9 & 6 & 2 & 25.5 & 3.01 & 91 & 208 \\
\hline $16-S M-13 C$ & 0.51 & 5.5 & 7 & 3 & 33.5 & 3.28 & 91 & 209 \\
\hline $16-S M-14$ & 0.51 & 5.1 & $<5$ & 4 & 30 & 3.43 & 77 & 204 \\
\hline $16-S M-15 A$ & 0.69 & 5 & 20 & 3 & 49.9 & 4.55 & 139 & 805 \\
\hline $16-S M-15 A$ & 0.73 & 5.2 & 18 & 3 & 49.5 & 4.65 & 132 & 749 \\
\hline 16-SM-16 & 0.6 & 4.1 & 21 & 5 & 47.4 & 3.13 & 88 & 762 \\
\hline $16-\mathrm{SM}-20 \mathrm{~B}$ & 0.23 & 1.3 & 350 & 1 & 15.4 & 1.53 & 94 & 87 \\
\hline $16-S M-20 C$ & 0.17 & 2.2 & 208 & 1 & 12.1 & 1.07 & 69 & 118 \\
\hline $16-S M-21 \mathrm{~A}$ & 0.49 & 6 & 7 & 1 & 31.7 & 3.23 & 78 & 210 \\
\hline $16-S M-21 B$ & 0.38 & 6 & $<5$ & 2 & 27 & 2.13 & 42 & 208 \\
\hline $16-S M-22$ & 0.49 & 5.6 & 15 & 2 & 31.5 & 3.45 & 72 & 206 \\
\hline $16-S M-26$ & 0.26 & 3.6 & 15 & 5 & 17.7 & 1.77 & 53 & 231 \\
\hline $16-S M-29 A$ & 0.51 & 7 & $<5$ & 1 & 32.5 & 3.37 & 81 & 215 \\
\hline 16-SM-29B & 0.25 & 6.9 & $<5$ & 1 & 18.1 & 1.77 & 47 & 162 \\
\hline 16-SM-30 & 0.47 & 7.2 & 7 & 6 & 33.3 & 3.12 & 41 & 226 \\
\hline $16-S M-32 A$ & 0.55 & 8.3 & $<5$ & 1 & 37.6 & 3.62 & 79 & 229 \\
\hline $16-S M-32 B$ & 0.52 & 5.4 & $<5$ & 2 & 34.9 & 3.37 & 85 & 204 \\
\hline $16-S M-32 D$ & 0.28 & 2.8 & 20 & 2 & 18.3 & 1.91 & 76 & 763 \\
\hline
\end{tabular}


Table VI: Trace Element Concentrations Cont.

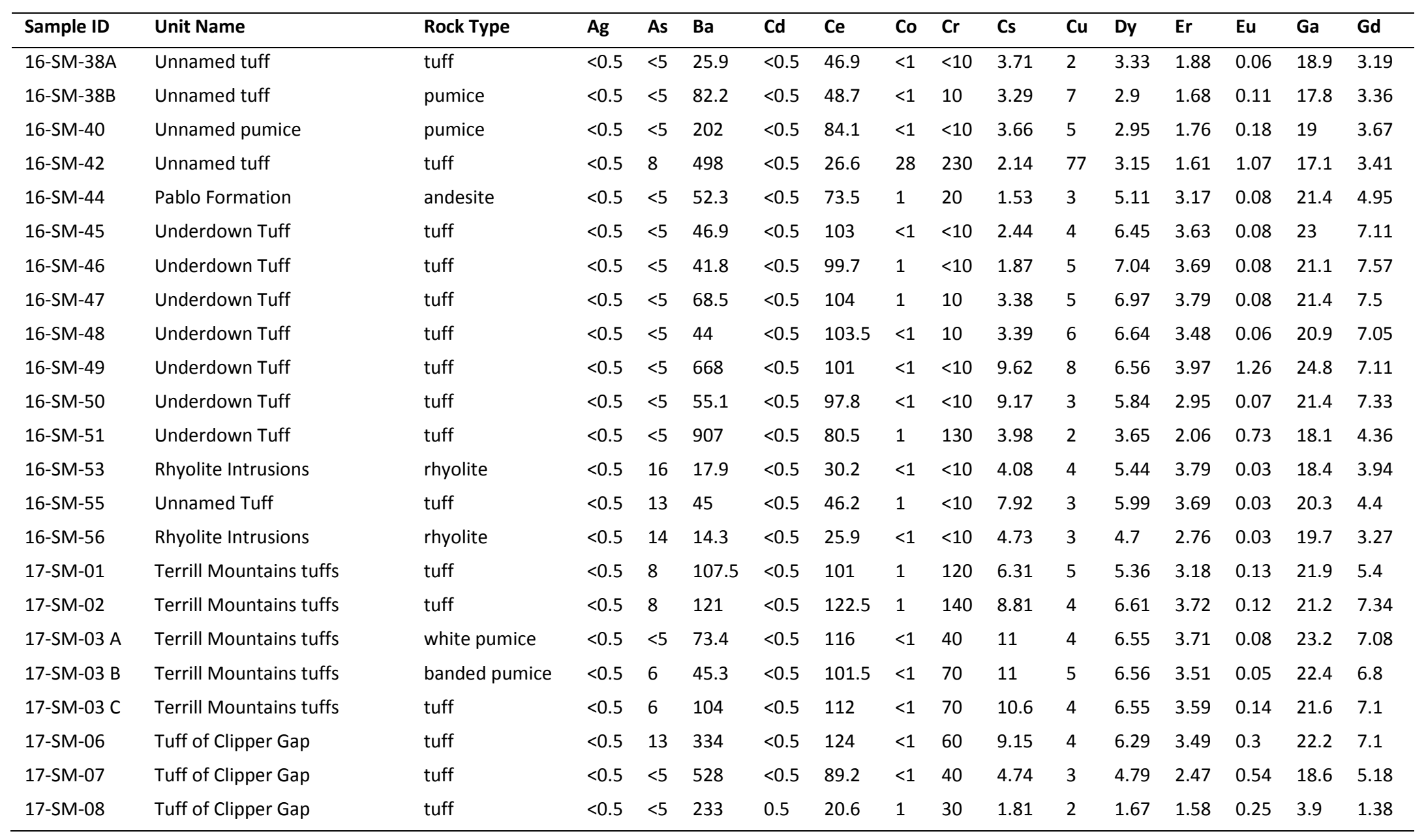


Table VI: Trace Element Concentrations Cont.

\begin{tabular}{|c|c|c|c|c|c|c|c|c|c|c|c|c|c|c|c|c|c|c|c|c|}
\hline Sample ID & $\mathrm{Hf}$ & Ho & La & Li & Lu & Mo & $\mathrm{Nb}$ & Nd & $\mathrm{Ni}$ & $\mathrm{Pb}$ & $\mathrm{Pr}$ & $\mathbf{R b}$ & Sc & Sm & Sn & Sr & $\mathrm{Ta}$ & Tb & Th & TI \\
\hline $16-S M-38 \mathrm{~A}$ & 4.9 & 0.67 & 18 & 70 & 0.3 & 3 & 25 & 19 & 1 & 27 & 5.05 & 266 & 2 & 4.4 & 4 & 6 & 2.3 & 0.56 & 26.6 & $<10$ \\
\hline $16-S M-38 B$ & 4.5 & 0.56 & 27 & 50 & 0.3 & 2 & 22.9 & 24 & 1 & 23 & 6.54 & 207 & 2 & 4.5 & 3 & 12.2 & 1.7 & 0.51 & 21.3 & $<10$ \\
\hline $16-S M-42$ & 2.2 & 0.61 & 13 & 20 & 0.2 & $<1$ & 3.5 & 16 & 58 & 6 & 3.66 & 39.9 & 34 & 3.7 & 1 & 665 & 0.2 & 0.51 & 2.36 & $<10$ \\
\hline $16-S M-44$ & 7.4 & 1.06 & 36 & 20 & 0.5 & 2 & 30.5 & 34 & 1 & 23 & 8.86 & 224 & 1 & 6.4 & 4 & 11.7 & 2.2 & 0.8 & 23.6 & $<10$ \\
\hline $16-S M-45$ & 7.1 & 1.37 & 48 & 10 & 0.5 & 3 & 31.4 & 46 & 3 & 24 & 11.75 & 236 & 1 & 9.2 & 5 & 11.3 & 2.2 & 1.13 & 25.5 & $<10$ \\
\hline $16-S M-46$ & 7 & 1.42 & 49 & 10 & 0.5 & 2 & 30.4 & 47 & $<1$ & 29 & 12.35 & 220 & 1 & 9.3 & 4 & 11.9 & 2.1 & 1.16 & 23.1 & $<10$ \\
\hline $16-S M-47$ & 7.5 & 1.41 & 52 & 20 & 0.6 & 2 & 31.3 & 48 & 2 & 30 & 12.65 & 228 & 1 & 9.5 & 4 & 14.1 & 2.2 & 1.2 & 23.5 & $<10$ \\
\hline $16-S M-48$ & 7.1 & 1.32 & 50 & 20 & 0.5 & 3 & 30.6 & 46 & 2 & 24 & 12.3 & 221 & 1 & 9.2 & 4 & 10.2 & 2.2 & 1.14 & 23.4 & $<10$ \\
\hline $16-S M-49$ & 14.7 & 1.4 & 53 & 30 & 0.6 & 2 & 24.8 & 46 & 2 & 33 & 11.9 & 196 & 7 & 8.9 & 3 & 76 & 1.3 & 1.1 & 13.5 & $<10$ \\
\hline $16-S M-50$ & 6.7 & 1.1 & 48 & 20 & 0.4 & 2 & 29.6 & 47 & 3 & 21 & 11.8 & 223 & 1 & 9.9 & 4 & 25.1 & 2.2 & 1.08 & 24.6 & $<10$ \\
\hline $16-S M-51$ & 6.1 & 0.7 & 49 & 20 & 0.3 & 3 & 16.9 & 35 & 7 & 20 & 10.2 & 158 & 3 & 6.2 & 3 & 143 & 1.4 & 0.69 & 20 & $<10$ \\
\hline $16-S M-55$ & 5.5 & 1.31 & 15 & 410 & 0.6 & 2 & 35 & 17 & $<1$ & 26 & 4.39 & 276 & 2 & 4.6 & 4 & 11.8 & 2.5 & 0.9 & 27.9 & $<10$ \\
\hline $16-S M-56$ & 5.5 & 0.98 & 11 & 70 & 0.4 & 2 & 34.4 & 8.3 & $<1$ & 32 & 2.28 & 295 & 2 & 2.7 & 5 & 8.5 & 2.6 & 0.7 & 28.5 & $<10$ \\
\hline 17-SM-01 & 7.5 & 1.03 & 51 & 30 & 0.4 & 3 & 29.9 & 38 & 7 & 34 & 11.1 & 221 & 2 & 6.8 & 5 & 26.6 & 2.1 & 0.81 & 24.5 & $<10$ \\
\hline 17-SM-02 & 7.4 & 1.28 & 62 & 10 & 0.5 & 5 & 29.8 & 50 & 8 & 33 & 13.9 & 228 & 2 & 9.3 & 5 & 26.2 & 2.1 & 1.07 & 24.2 & $<10$ \\
\hline 17-SM-03 A & 7.9 & 1.25 & 59 & 10 & 0.5 & 3 & 28.9 & 48 & 2 & 26 & 13.3 & 261 & 2 & 8.9 & 5 & 58.6 & 2.1 & 1.09 & 24.7 & $<10$ \\
\hline 17-SM-03 B & 7.4 & 1.25 & 53 & 10 & 0.5 & 4 & 28.7 & 45 & $<1$ & 22 & 12.4 & 288 & 2 & 8.5 & 5 & 48.4 & 2.2 & 1.1 & 25 & $<10$ \\
\hline 17-SM-03 C & 7.4 & 1.27 & 56 & 10 & 0.5 & 4 & 30.2 & 47 & 1 & 31 & 12.9 & 216 & 2 & 8.9 & 5 & 72.5 & 2.1 & 1.09 & 24 & $<10$ \\
\hline 17-SM-06 & 11.9 & 1.23 & 63 & 30 & 0.6 & 4 & 32.9 & 52 & 2 & 39 & 14.25 & 179 & 5 & 9.4 & 4 & 82.8 & 2.2 & 1.09 & 27.1 & $<10$ \\
\hline 17-SM-07 & 8.9 & 0.93 & 48 & 20 & 0.3 & 1 & 25.5 & 41 & $<1$ & 24 & 10.95 & 144 & 4 & 7.1 & 3 & 45.9 & 1.7 & 0.77 & 21.6 & $<10$ \\
\hline 17-SM-08 & 1.5 & 0.41 & 13 & 20 & 0.3 & $<1$ & 4.4 & 9.1 & $<1$ & 2 & 2.57 & 15.2 & 2 & 1.6 & 1 & 209 & 0.3 & 0.26 & 4.25 & $<10$ \\
\hline
\end{tabular}


Table VI: Trace Element Concentrations Cont.

\begin{tabular}{|c|c|c|c|c|c|c|c|c|}
\hline Sample ID & $\mathrm{Tm}$ & $\mathbf{U}$ & $\mathbf{v}$ & $\mathbf{w}$ & $Y$ & $\mathbf{Y b}$ & $\mathrm{Zn}$ & $\mathrm{Zr}$ \\
\hline 16-SM-38A & 0.3 & 4.8 & $<5$ & 2 & 14.7 & 2.04 & 42 & 105 \\
\hline $16-\mathrm{SM}-38 \mathrm{~B}$ & 0.24 & 4.8 & $<5$ & 2 & 11.8 & 1.95 & 47 & 108 \\
\hline $16-S M-40$ & 0.27 & 5.3 & $<5$ & 1 & 14.8 & 1.71 & 47 & 144 \\
\hline $16-S M-42$ & 0.24 & 0.9 & 337 & 1 & 16.5 & 1.63 & 82 & 80 \\
\hline $16-S M-44$ & 0.49 & 7.3 & $<5$ & 1 & 28.5 & 3.26 & 67 & 216 \\
\hline $16-S M-45$ & 0.55 & 6.2 & $<5$ & 1 & 36.2 & 3.49 & 68 & 206 \\
\hline $16-S M-46$ & 0.58 & 7.4 & $<5$ & 1 & 38.8 & 3.81 & 84 & 208 \\
\hline $16-S M-47$ & 0.58 & 8.9 & $<5$ & 2 & 39.9 & 3.85 & 87 & 222 \\
\hline $16-S M-48$ & 0.5 & 9.2 & $<5$ & 1 & 35.9 & 3.4 & 79 & 207 \\
\hline $16-S M-49$ & 0.57 & 13 & $<5$ & 11 & 37.7 & 3.85 & 105 & 789 \\
\hline $16-S M-50$ & 0.4 & 6.3 & $<5$ & 1 & 29.4 & 2.51 & 85 & 185 \\
\hline $16-S M-51$ & 0.29 & 5.5 & $<5$ & 4 & 19.9 & 1.93 & 37 & 214 \\
\hline $16-S M-53$ & 0.57 & 5.6 & $<5$ & 5 & 36.1 & 4.14 & 51 & 120 \\
\hline $16-S M-55$ & 0.56 & 5.8 & $<5$ & 4 & 34.3 & 3.8 & 61 & 112 \\
\hline $16-S M-56$ & 0.43 & 5.7 & $<5$ & 3 & 26.4 & 2.69 & 88 & 123 \\
\hline $17-S M-01$ & 0.45 & 7 & 8 & 5 & 25.8 & 2.89 & 86 & 214 \\
\hline 17-SM-02 & 0.52 & 8.7 & $<5$ & 3 & 35.9 & 3.57 & 85 & 209 \\
\hline 17-SM-03 A & 0.54 & 7.4 & $<5$ & 3 & 35.7 & 3.42 & 85 & 224 \\
\hline 17-SM-03 B & 0.51 & 7.5 & $<5$ & 5 & 34.3 & 3.22 & 86 & 204 \\
\hline 17-SM-03 C & 0.5 & 7.5 & 5 & 4 & 34.2 & 3.37 & 90 & 214 \\
\hline 17-SM-06 & 0.52 & 8.7 & 17 & 4 & 33.6 & 3.53 & 95 & 450 \\
\hline 17-SM-07 & 0.33 & 5.1 & 11 & 1 & 23.1 & 2.33 & 73 & 339 \\
\hline 17-SM-08 & 0.25 & 1 & 16 & 1 & 18.6 & 1.76 & 29 & 70 \\
\hline
\end{tabular}


Table VI: Trace Element Concentrations Cont.

\begin{tabular}{|c|c|c|c|c|c|c|c|c|c|c|c|c|c|c|c|c|}
\hline Sample ID & Unit Name & Rock Type & $\mathbf{A g}$ & As & $\mathrm{Ba}$ & $\mathrm{Cd}$ & $\mathrm{Ce}$ & Co & $\mathrm{Cr}$ & Cs & $\mathrm{Cu}$ & Dy & $\mathrm{Er}$ & Eu & Ga & Gd \\
\hline 17-SM-09 & Tuff of Clipper Gap & tuff & $<0.5$ & $<5$ & 735 & $<0.5$ & 68.6 & $<1$ & 80 & 105.5 & 5 & 3.72 & 2.1 & 0.26 & 18 & 3.86 \\
\hline $17-S M-10$ & Tuff of Clipper Gap & tuff & $<0.5$ & $<5$ & 117 & $<0.5$ & 102.5 & $<1$ & 70 & 5.05 & 2 & 5.92 & 3.01 & 0.14 & 20.6 & 6.59 \\
\hline $17-S M-11$ & Tuff of Clipper Gap & tuff & $<0.5$ & 5 & 165.5 & $<0.5$ & 112.5 & $<1$ & 70 & 6.03 & 9 & 6.1 & 3.41 & 0.12 & 21.4 & 6.8 \\
\hline 17-SM-12 & Tuff of Clipper Gap & tuff & $<0.5$ & 17 & 176.5 & $<0.5$ & 153 & 1 & 30 & 1.61 & 3 & 10.7 & 6.79 & 0.26 & 21.8 & 9.87 \\
\hline $17-S M-13$ A & Tuff of Brunton Pass & tuff & $<0.5$ & $<5$ & 82.1 & $<0.5$ & 58.7 & $<1$ & 70 & 6.21 & 4 & 5.67 & 3.11 & 0.11 & 22.3 & 6.19 \\
\hline 17-SM-13 B & Tuff of Brunton Pass & tuff & $<0.5$ & $<5$ & 184 & $<0.5$ & 105.5 & 1 & 50 & 4.73 & 6 & 7.05 & 3.85 & 0.15 & 21.8 & 8.24 \\
\hline 17-SM-14 & Tuff of Arc Dome & tuff & $<0.5$ & 8 & 790 & $<0.5$ & 83.1 & 1 & 130 & 5.05 & 2 & 3.56 & 2.26 & 0.66 & 17.9 & 4.08 \\
\hline $17-S M-15$ A & Tuff of Arc Dome & tuff & $<0.5$ & 8 & 97.8 & $<0.5$ & 66.5 & $<1$ & 140 & 8.15 & 2 & 5.89 & 3.77 & 0.22 & 19.3 & 5.8 \\
\hline $17-S M-15$ B & Tuff of Arc Dome & tuff & $<0.5$ & 5 & 173 & $<0.5$ & 64.2 & 1 & 200 & 7.88 & 3 & 4.37 & 2.62 & 0.26 & 17.9 & 4.34 \\
\hline $17-S M-16$ A & Tuff of Gabbs Valley & tuff & $<0.5$ & $<5$ & 145.5 & $<0.5$ & 92.5 & $<1$ & 100 & 6.36 & 1 & 5.87 & 3.5 & 0.23 & 18.8 & 6.02 \\
\hline 17-SM-16 B & Tuff of Gabbs Valley & tuff & $<0.5$ & $<5$ & 144 & $<0.5$ & 214 & $<1$ & 10 & 5.25 & 7 & 6.19 & 3.64 & 0.21 & 22.2 & 7.55 \\
\hline 17-SM-17 A & Underdown Tuff & porphyritic pumice & $<0.5$ & 10 & 626 & $<0.5$ & 65.9 & 1 & 100 & 6.82 & 4 & 3.17 & 1.73 & 0.78 & 17.3 & 3.74 \\
\hline 17-SM-17 B & Underdown Tuff & tuff & $<0.5$ & $<5$ & 303 & $<0.5$ & 149.5 & $<1$ & 70 & 9.93 & 4 & 6.69 & 3.67 & 0.6 & 25.2 & 6.92 \\
\hline 17-SM-17 C & Underdown Tuff & porphyritic pumice & $<0.5$ & $<5$ & 93.8 & $<0.5$ & 117 & $<1$ & 160 & 11.05 & 3 & 6.64 & 3.82 & 0.19 & 21.1 & 7.43 \\
\hline $17-S M-18$ & Pablo Formation & andesite & $<0.5$ & $<5$ & 425 & $<0.5$ & 74.3 & 2 & 50 & 13.15 & 4 & 4.45 & 2.8 & 1.42 & 22.4 & 4.9 \\
\hline $17-S M-19$ & Bonita Canyon Formation & tuff & $<0.5$ & 7 & 1145 & $<0.5$ & 27.8 & 14 & 130 & 8.76 & 68 & 3.07 & 1.99 & 1.05 & 20.7 & 3.07 \\
\hline $17-S M-20$ & Tuff of Arc Dome & tuff & $<0.5$ & $<5$ & 172 & $<0.5$ & 98.8 & $<1$ & 120 & 6.5 & 3 & 5.37 & 3.13 & 0.19 & 20.2 & 5.85 \\
\hline $17-S M-21 \mathrm{~A}$ & Tuff of Clipper Gap & tuff & $<0.5$ & 7 & 1620 & $<0.5$ & 103.5 & 4 & 110 & 5.63 & 3 & 3.75 & 2.19 & 1.09 & 18.9 & 4.27 \\
\hline 17-SM-21 B & Tuff of Clipper Gap & tuff & $<0.5$ & $<5$ & 235 & $<0.5$ & 85.4 & $<1$ & 50 & 2.18 & 3 & 10.2 & 4.87 & 0.75 & 22 & 12.1 \\
\hline $17-S M-22$ & Tuff of Clipper Gap & tuff & $<0.5$ & $<5$ & 184.5 & $<0.5$ & 50.3 & $<1$ & 90 & 6.01 & 4 & 3.36 & 1.95 & 0.17 & 19.8 & 4.02 \\
\hline $17-S M-23$ & Tuff of Clipper Gap & white pumice & $<0.5$ & $<5$ & 573 & $<0.5$ & 77.8 & 1 & 70 & 6.2 & 2 & 3.56 & 2.02 & 0.42 & 17.6 & 4.22 \\
\hline $17-S M-24$ & Tuff of Clipper Gap & white pumice & $<0.5$ & 6 & 72 & $<0.5$ & 55.2 & $<1$ & 60 & 6.6 & 2 & 3.55 & 2.11 & 0.15 & 18.7 & 3.83 \\
\hline $17-S M-25$ & Tuff of Clipper Gap & tuff & $<0.5$ & 7 & 14.2 & $<0.5$ & 67.8 & 1 & 70 & 6.08 & 2 & 3.78 & 2.2 & 0.16 & 18.9 & 3.96 \\
\hline 17-SM-26 A & Tuff of Clipper Gap & white pumice & $<0.5$ & $<5$ & 497 & $<0.5$ & 43 & 1 & 30 & 2.57 & 3 & 3.21 & 1.7 & 0.43 & 16.9 & 4.14 \\
\hline
\end{tabular}


Table VI: Trace Element Concentrations Cont.

\begin{tabular}{|c|c|c|c|c|c|c|c|c|c|c|c|c|c|c|c|c|c|c|c|c|}
\hline Sample ID & $\mathrm{Hf}$ & Ho & La & $\mathrm{Li}$ & Lu & Mo & $\mathrm{Nb}$ & $\mathrm{Nd}$ & $\mathrm{Ni}$ & $\mathrm{Pb}$ & $\mathrm{Pr}$ & $\mathbf{R b}$ & Sc & $\mathrm{Sm}$ & Sn & $\mathrm{Sr}$ & $\mathrm{Ta}$ & Tb & Th & TI \\
\hline 17-SM-09 & 5.3 & 0.74 & 35 & 40 & 0.3 & 2 & 15.9 & 29 & 3 & 26 & 8.07 & 133 & 4 & 5.1 & 3 & 182 & 1.2 & 0.57 & 19 & $<10$ \\
\hline 17-SM-10 & 7.2 & 1.11 & 55 & 10 & 0.4 & 1 & 24.5 & 46 & 2 & 24 & 12.55 & 194 & 2 & 8.9 & 3 & 36 & 1.9 & 0.96 & 22.2 & $<10$ \\
\hline 17-SM-11 & 7.5 & 1.2 & 57 & 40 & 0.5 & $<1$ & 27.1 & 47 & 3 & 17 & 12.95 & 215 & 2 & 8.7 & 2 & 44.2 & 2.1 & 1.04 & 23.3 & $<10$ \\
\hline 17-SM-12 & 7.2 & 2.2 & 66 & 30 & 0.9 & 1 & 28.9 & 59 & $<1$ & 60 & 15.7 & 201 & 1 & 12 & 17 & 38.5 & 2.2 & 1.68 & 30.6 & $<10$ \\
\hline $17-S M-13 \mathrm{~A}$ & 7.4 & 1.07 & 42 & 20 & 0.4 & 3 & 31.8 & 42 & 1 & 24 & 11.45 & 235 & 2 & 9 & 4 & 21.6 & 2.3 & 0.99 & 25.9 & $<10$ \\
\hline $17-S M-13$ B & 7.5 & 1.34 & 55 & 30 & 0.6 & 2 & 30.3 & 50 & 5 & 23 & 13.4 & 228 & 2 & 10 & 2 & 47.1 & 2.2 & 1.24 & 25.3 & $<10$ \\
\hline 17-SM-14 & 5.4 & 0.76 & 46 & 20 & 0.3 & 2 & 16.3 & 35 & 1 & 25 & 9.87 & 159 & 3 & 6.2 & 3 & 124 & 1.3 & 0.6 & 19.6 & $<10$ \\
\hline $17-S M-15$ A & 5 & 1.21 & 37 & 70 & 0.6 & 2 & 25.9 & 34 & 2 & 27 & 9.37 & 273 & 2 & 7.3 & 5 & 20.5 & 2.6 & 0.98 & 32.3 & $<10$ \\
\hline 17-SM-15 B & 4.7 & 0.92 & 32 & 50 & 0.4 & 2 & 21.4 & 28 & 3 & 31 & 7.76 & 229 & 1 & 5.7 & 4 & 33.6 & 2 & 0.75 & 27.2 & $<10$ \\
\hline $17-S M-16$ A & 6.3 & 1.18 & 49 & 20 & 0.5 & 2 & 25.6 & 42 & $<1$ & 25 & 10.9 & 184 & 3 & 7.6 & 3 & 20.4 & 1.8 & 0.94 & 24 & $<10$ \\
\hline 17-SM-16 B & 8.8 & 1.23 & 121 & 20 & 0.6 & 2 & 23.8 & 71 & 4 & 25 & 22 & 230 & 3 & 11 & 4 & 32.7 & 1.7 & 1.03 & 21.7 & 10 \\
\hline $17-S M-17$ A & 6.6 & 0.61 & 41 & 20 & 0.3 & 2 & 14.4 & 29 & 2 & 22 & 8.26 & 183 & 3 & 5.2 & 2 & 38.5 & 1.2 & 0.49 & 18.7 & $<10$ \\
\hline 17-SM-17 B & 15.1 & 1.33 & 84 & 30 & 0.6 & 3 & 21.5 & 60 & 1 & 28 & 16.55 & 171 & 8 & 9.8 & 4 & 63.7 & 1.3 & 1.04 & 13.7 & $<10$ \\
\hline $17-S M-17 \mathrm{C}$ & 7.6 & 1.43 & 58 & 20 & 0.5 & 2 & 29.7 & 51 & 1 & 20 & 13.85 & 219 & 1 & 9.9 & 4 & 22.6 & 2.3 & 1.16 & 25.6 & $<10$ \\
\hline 17-SM-18 & 19 & 0.89 & 39 & 30 & 0.4 & 2 & 14.1 & 34 & $<1$ & 24 & 8.81 & 171 & 10 & 6.6 & 2 & 84 & 0.9 & 0.71 & 7.23 & $<10$ \\
\hline 17-SM-19 & 2.7 & 0.68 & 13 & 30 & 0.3 & 1 & 3.5 & 15 & 28 & 6 & 3.54 & 50.3 & 12 & 3.6 & 1 & 1125 & 0.2 & 0.5 & 3.21 & $<10$ \\
\hline $17-S M-20$ & 6.6 & 1.12 & 49 & 40 & 0.4 & 1 & 20.8 & 43 & 2 & 39 & 11.3 & 119 & 2 & 8.2 & 4 & 65.4 & 1.8 & 0.91 & 20.5 & $<10$ \\
\hline $17-S M-21 \mathrm{~A}$ & 8.4 & 0.68 & 55 & 40 & 0.3 & 4 & 15.7 & 40 & 3 & 24 & 11.45 & 138 & 6 & 6.5 & 2 & 286 & 1.1 & 0.61 & 15.9 & $<10$ \\
\hline $17-S M-21$ B & 16 & 1.87 & 91 & 40 & 0.5 & 2 & 20.2 & 73 & $<1$ & 18 & 19 & 101 & 6 & 13 & 2 & 63.7 & 1 & 1.83 & 9.77 & $<10$ \\
\hline $17-S M-22$ & 7.4 & 0.62 & 37 & 30 & 0.3 & 3 & 28.3 & 33 & 2 & 21 & 9 & 193 & 2 & 6.4 & 2 & 21.4 & 2.1 & 0.62 & 22.7 & $<10$ \\
\hline $17-S M-23$ & 5.4 & 0.69 & 38 & 20 & 0.3 & 2 & 15.6 & 32 & 2 & 26 & 8.77 & 139 & 4 & 6 & 2 & 85.8 & 1 & 0.57 & 17.5 & $<10$ \\
\hline $17-S M-24$ & 4.6 & 0.72 & 26 & 10 & 0.4 & 3 & 15.4 & 25 & $<1$ & 29 & 6.76 & 200 & 4 & 5 & 3 & 25.9 & 1.1 & 0.62 & 18.5 & $<10$ \\
\hline 17-SM-25 & 4.9 & 0.75 & 31 & 20 & 0.3 & 3 & 15.8 & 28 & $<1$ & 23 & 7.94 & 212 & 4 & 5.4 & 2 & 8.3 & 1.2 & 0.65 & 19.3 & $<10$ \\
\hline $17-S M-26 \mathrm{~A}$ & 5.3 & 0.6 & 34 & 20 & 0.3 & $<1$ & 14.3 & 32 & 2 & 25 & 8.35 & 162 & 4 & 5.9 & 2 & 51.6 & 1.1 & 0.64 & 17.4 & $<10$ \\
\hline
\end{tabular}


Table VI: Trace Element Concentrations Cont.

\begin{tabular}{|c|c|c|c|c|c|c|c|c|}
\hline Sample ID & $\mathrm{Tm}$ & $\mathbf{U}$ & $\mathbf{v}$ & $\mathbf{w}$ & $\mathbf{Y}$ & $\mathrm{Yb}$ & $\mathrm{Zn}$ & $\mathrm{Zr}$ \\
\hline 17-SM-09 & 0.33 & 4.9 & 11 & 3 & 20.4 & 2.13 & 49 & 145 \\
\hline $17-S M-10$ & 0.41 & 4 & 6 & 2 & 28.1 & 2.73 & 69 & 212 \\
\hline $17-S M-11$ & 0.48 & 6.2 & 8 & 6 & 33.6 & 3.26 & 60 & 227 \\
\hline $17-S M-12$ & 0.92 & 4.9 & 8 & 2 & 66.7 & 6.38 & 76 & 208 \\
\hline $17-S M-13 \mathrm{~A}$ & 0.45 & 8.1 & 5 & 2 & 26.7 & 2.88 & 83 & 201 \\
\hline 17-SM-13 B & 0.56 & 6.2 & 10 & 3 & 35.1 & 3.67 & 83 & 203 \\
\hline $17-S M-14$ & 0.3 & 5.8 & 9 & 2 & 21.3 & 2.25 & 48 & 189 \\
\hline $17-S M-15$ A & 0.56 & 10 & $<5$ & 3 & 35.8 & 3.83 & 39 & 107 \\
\hline 17-SM-15 B & 0.42 & 8.4 & $<5$ & 3 & 25.9 & 2.89 & 45 & 113 \\
\hline $17-S M-16$ A & 0.46 & 8.8 & $<5$ & 2 & 35.9 & 3.03 & 68 & 191 \\
\hline 17-SM-16 B & 0.52 & 7.7 & $<5$ & 2 & 33.7 & 3.45 & 93 & 295 \\
\hline $17-S M-17$ A & 0.26 & 6 & $<5$ & 3 & 17 & 1.67 & 45 & 253 \\
\hline 17-SM-17 B & 0.55 & 14 & 7 & 9 & 41.3 & 3.64 & 93 & 694 \\
\hline $17-S M-17$ C & 0.52 & 7.1 & $<5$ & 1 & 37.3 & 3.5 & 70 & 212 \\
\hline 17-SM-18 & 0.38 & 12 & 6 & 12 & 28.3 & 2.7 & 91 & 1020 \\
\hline 17-SM-19 & 0.28 & 1.4 & 235 & 3 & 18 & 1.94 & 71 & 97 \\
\hline $17-S M-20$ & 0.44 & 9.4 & 9 & 1 & 30.2 & 2.88 & 71 & 190 \\
\hline $17-S M-21 \mathrm{~A}$ & 0.29 & 6 & 31 & 3 & 20.8 & 2.11 & 81 & 356 \\
\hline $17-S M-21$ B & 0.66 & 5.2 & $<5$ & 3 & 46.5 & 4.11 & 87 & 794 \\
\hline $17-S M-22$ & 0.28 & 6 & $<5$ & 3 & 15.6 & 1.73 & 63 & 230 \\
\hline $17-S M-23$ & 0.3 & 5.8 & $<5$ & 3 & 19.4 & 2.14 & 55 & 176 \\
\hline $17-S M-24$ & 0.31 & 6.3 & $<5$ & 3 & 19.1 & 2.09 & 54 & 120 \\
\hline $17-S M-25$ & 0.31 & 6.7 & $<5$ & 3 & 20.3 & 2.22 & 49 & 129 \\
\hline $17-S M-26$ A & 0.27 & 4.6 & $<5$ & 1 & 15.9 & 1.57 & 47 & 166 \\
\hline
\end{tabular}


Table VI: Trace Element Concentrations Cont.

\begin{tabular}{|c|c|c|c|c|c|c|c|c|c|c|c|c|c|c|c|c|}
\hline Sample ID & Unit Name & Rock Type & $\mathrm{Ag}$ & As & $\mathrm{Ba}$ & Cd & $\mathrm{Ce}$ & Co & $\mathrm{Cr}$ & Cs & $\mathrm{Cu}$ & Dy & Er & Eu & $\mathbf{G a}$ & Gd \\
\hline 17-SM-26 B & Tuff of Clipper Gap & tuff & $<0.5$ & 6 & 176.5 & $<0.5$ & 130 & $<1$ & 50 & 5.37 & 5 & 6.2 & 3.58 & 0.22 & 21 & 7.61 \\
\hline 17-SM-26 C & Tuff of Clipper Gap & tuff & $<0.5$ & $<5$ & 224 & $<0.5$ & 122.5 & $<1$ & 60 & 5.98 & 4 & 7.55 & 4.4 & 0.18 & 21.2 & 7.93 \\
\hline $17-S M-27$ & Tuff of Clipper Gap & tuff & $<0.5$ & 6 & 321 & $<0.5$ & 95.9 & 1 & 50 & 4.29 & 9 & 10.3 & 4.41 & 0.81 & 22.4 & 15.15 \\
\hline $17-S M-28$ & TgV2 & tuff & $<0.5$ & $<5$ & 372 & $<0.5$ & 102 & $<1$ & 20 & 7.98 & 3 & 4.39 & 3.03 & 0.35 & 14.8 & 4.7 \\
\hline 17-SM-29 & TgV2 & tuff & $<0.5$ & 6 & 156.5 & $<0.5$ & 58.5 & $<1$ & 140 & 4.71 & 1 & 4.17 & 2.44 & 0.24 & 16.8 & 4.02 \\
\hline $17-S M-30$ & TgV2 & tuff & $<0.5$ & 18 & 466 & $<0.5$ & 77.5 & 1 & 130 & 4.94 & 2 & 4.01 & 2.4 & 0.45 & 17.8 & 4.08 \\
\hline 17-SM-31 & TgV3 & porphyritic pumice & $<0.5$ & 6 & 1290 & $<0.5$ & 113 & 1 & 90 & 5.35 & 2 & 2.55 & 1.39 & 0.99 & 16.5 & 3.28 \\
\hline Sample ID & Unit Name & Rock Type & $\mathrm{Ag}$ & As & $\mathrm{Ba}$ & Cd & $\mathrm{Ce}$ & Co & $\mathrm{Cr}$ & Cs & $\mathrm{Cu}$ & Dy & Er & Eu & Ga & Gd \\
\hline 16-SM-13Caw & Tuff of Clipper Gap & tuff & $<0.5$ & $<5$ & 78.7 & $<0.5$ & 38.4 & 1 & $<10$ & 3.14 & 1 & 2.49 & 1.46 & 0.07 & 21 & 2.36 \\
\hline 16-SM-14aw & Tuff of Clipper Gap & white pumice & $<0.5$ & $<5$ & 21.3 & $<0.5$ & 27.8 & $<1$ & $<10$ & 4.51 & 3 & 2.47 & 1.55 & 0.04 & 23.4 & 2.03 \\
\hline 16-SM-16aw & Tuff of Clipper Gap & porphyritic pumice & $<0.5$ & 6 & 230 & $<0.5$ & 27.4 & 1 & $<10$ & 1.91 & 2 & 1.7 & 1.12 & 0.78 & 22 & 2.26 \\
\hline 17-SM-21Aaw & Tuff of Clipper Gap & porphyritic pumice & $<0.5$ & $<5$ & 226 & $<0.5$ & 27.1 & $<1$ & 30 & 1.94 & $<1$ & 1.44 & 1.15 & 0.71 & 22.1 & 1.39 \\
\hline 17-SM-22aw & Tuff of Clipper Gap & whole rock & $<0.5$ & 6 & 387 & $<0.5$ & 57.8 & $<1$ & 40 & 5.97 & $<1$ & 2.31 & 1.32 & 0.31 & 17.9 & 2.96 \\
\hline 17-SM-26Aaw & Tuff of Clipper Gap & whole rock & $<0.5$ & 5 & 104 & $<0.5$ & 18.1 & $<1$ & 40 & 4.95 & 1 & 1.58 & 1.19 & 0.14 & 22.2 & 1.24 \\
\hline 17-SM-26Caw & Tuff of Clipper Gap & porphyritic pumice & $<0.5$ & 6 & 168.5 & $<0.5$ & 50.4 & 1 & 40 & 4.29 & 1 & 2.79 & 1.75 & 0.27 & 23.6 & 3.11 \\
\hline 17-SM-27aw & Tuff of Clipper Gap & whole rock & $<0.5$ & $<5$ & 249 & $<0.5$ & 40.6 & $<1$ & 20 & 7.76 & 1 & 1.33 & 1.11 & 0.26 & 13.1 & 0.99 \\
\hline Sample ID & Unit Name & Rock Type & Ag & As & $\mathrm{Ba}$ & Cd & $\mathrm{Ce}$ & Co & $\mathrm{Cr}$ & Cs & $\mathrm{Cu}$ & Dy & Er & Eu & Ga & Gd \\
\hline H18-SN6 & Young Sierra Nevada tuffs & tuff & $<0.5$ & 5 & 114 & $<0.5$ & 103.1 & $<1$ & $<10$ & 3.77 & 3 & 6.20 & 3.70 & 0.12 & 22.9 & 6.68 \\
\hline H18-SN15 & Young Sierra Nevada tuffs & tuff & $<0.5$ & $<5$ & 110 & $<0.5$ & 90.5 & $<1$ & $<10$ & 6.04 & 2 & 5.71 & 3.31 & 0.12 & 24.2 & 5.56 \\
\hline
\end{tabular}


Table VI: Trace Element Concentrations Cont.

\begin{tabular}{|c|c|c|c|c|c|c|c|c|c|c|c|c|c|c|c|c|c|c|c|c|}
\hline Sample ID & $\mathrm{Hf}$ & Ho & La & $\mathbf{L i}$ & Lu & Mo & $\mathrm{Nb}$ & $\mathrm{Nd}$ & $\mathrm{Ni}$ & $\mathrm{Pb}$ & $\mathrm{Pr}$ & $\mathbf{R b}$ & Sc & Sm & Sn & $\mathrm{Sr}$ & $\mathrm{Ta}$ & $\mathrm{Tb}$ & Th & TI \\
\hline 17-SM-26 B & 8.1 & 1.24 & 60 & 30 & 0.5 & 3 & 29.6 & 52 & 2 & 27 & 13.85 & 202 & 2 & 10 & 3 & 24.9 & 2.2 & 1.14 & 22.8 & $<10$ \\
\hline $17-S M-26$ C & 8 & 1.42 & 53 & 20 & 0.6 & 2 & 29.5 & 49 & 1 & 27 & 13 & 208 & 2 & 9.9 & 2 & 22.5 & 2.1 & 1.31 & 24.1 & $<10$ \\
\hline $17-S M-27$ & 16.1 & 1.74 & 151 & 30 & 0.5 & 3 & 21.6 & 135 & 3 & 23 & 34.6 & 123 & 9 & 24 & 2 & 61.4 & 1.3 & 2.08 & 12.5 & $<10$ \\
\hline $17-S M-28$ & 5.8 & 0.96 & 53 & 10 & 0.4 & 1 & 14.4 & 39 & 1 & 21 & 11.25 & 172 & 3 & 6.8 & 2 & 235 & 1 & 0.76 & 18.5 & $<10$ \\
\hline $17-S M-29$ & 4.9 & 0.79 & 28 & 50 & 0.5 & 1 & 22.7 & 25 & 2 & 26 & 7.05 & 231 & 2 & 5.5 & 3 & 30.6 & 2.2 & 0.7 & 27.9 & $<10$ \\
\hline $17-S M-30$ & 5.4 & 0.74 & 43 & 40 & 0.4 & 1 & 18.5 & 34 & $<1$ & 24 & 9.67 & 185 & 2 & 6.5 & 3 & 78.3 & 1.7 & 0.71 & 23.4 & $<10$ \\
\hline 17-SM-31 & 6.6 & 0.49 & 69 & 20 & 0.3 & 3 & 11 & 38 & $<1$ & 26 & 11.25 & 120 & 4 & 5 & 1 & 137 & 0.7 & 0.49 & 14.7 & $<10$ \\
\hline Sample ID & $\mathrm{Hf}$ & Ho & La & $\mathbf{L i}$ & Lu & Mo & $\mathrm{Nb}$ & $\mathrm{Nd}$ & $\mathrm{Ni}$ & $\mathrm{Pb}$ & $\operatorname{Pr}$ & $\mathbf{R b}$ & Sc & Sm & Sn & $\mathrm{Sr}$ & $\mathrm{Ta}$ & $\mathrm{Tb}$ & Th & $\mathrm{Tl}$ \\
\hline 16-SM-13Caw & 7.3 & 0.44 & 24 & 10 & 0.3 & 1 & 30.7 & 17 & 1 & 17 & 4.86 & 240 & 1 & 3.1 & 2 & 10.7 & 2.5 & 0.37 & 13 & $<10$ \\
\hline 16-SM-14aw & 7.3 & 0.54 & 17 & 20 & 0.2 & 1 & 32.8 & 11 & 1 & 16 & 2.95 & 251 & 1 & 2.5 & 2 & 5.1 & 2.6 & 0.35 & 10.2 & 10 \\
\hline 16-SM-16aw & 16 & 0.38 & 31 & 40 & 0.2 & 1 & 17.1 & 17 & $<1$ & 18 & 4.32 & 114 & 3 & 2.8 & 1 & 66.1 & 1.1 & 0.29 & 3.8 & $<10$ \\
\hline 17-SM-21Aaw & 17.1 & 0.33 & 22 & 30 & 0.2 & 1 & 18.4 & 9.7 & 1 & 17 & 2.66 & 114 & 2 & 1.9 & 1 & 64.6 & 1.1 & 0.22 & 4.74 & $<10$ \\
\hline 17-SM-22aw & 5.6 & 0.45 & 32 & 20 & 0.3 & 2 & 15.1 & 22 & 1 & 25 & 6.13 & 160 & 3 & 4.1 & 2 & 65 & 1.2 & 0.4 & 14.5 & $<10$ \\
\hline 17-SM-26Aaw & 8.1 & 0.33 & 16 & 30 & 0.3 & 2 & 31.2 & 6.5 & $<1$ & 18 & 1.92 & 239 & 1 & 1.4 & 2 & 17.1 & 2.2 & 0.22 & 10 & $<10$ \\
\hline 17-SM-26Caw & 16.5 & 0.62 & 36 & 30 & 0.4 & 2 & 22.7 & 23 & $<1$ & 24 & 5.99 & 147 & 3 & 3.7 & 1 & 48 & 1.5 & 0.43 & 8.1 & $<10$ \\
\hline 17-SM-27aw & 5.7 & 0.33 & 29 & 10 & 0.2 & 1 & 16 & 13 & $<1$ & 9 & 3.95 & 147 & 1 & 1.5 & 1 & 86.9 & 1.3 & 0.17 & 6.44 & $<10$ \\
\hline Sample ID & $\mathrm{Hf}$ & Ho & La & $\mathbf{L i}$ & Lu & Mo & $\mathrm{Nb}$ & $\mathrm{Nd}$ & $\mathrm{Ni}$ & $\mathrm{Pb}$ & $\operatorname{Pr}$ & $\mathbf{R b}$ & Sc & Sm & Sn & $\mathrm{Sr}$ & $\mathrm{Ta}$ & Tb & Th & TI \\
\hline H18-SN6 & 8.0 & 1.27 & 48.0 & 30 & 0.55 & $<1$ & 32.4 & 41.6 & $<1$ & 25 & 11.26 & 218 & 2 & 8.29 & 3.00 & 22 & 2.3 & 1.07 & 25.4 & $<10$ \\
\hline H18-SN15 & 7.3 & 1.12 & 43.4 & 30 & 0.50 & 1 & 31.1 & 38.3 & 1 & 25 & 10.21 & 225 & 2 & 7.62 & 2.00 & 22 & 2.5 & 0.92 & 26.1 & $<10$ \\
\hline
\end{tabular}


Table VI: Trace Element Concentrations Cont.

\begin{tabular}{lllllllll}
\hline Sample ID & Tm & $\mathbf{U}$ & $\mathbf{V}$ & $\mathbf{W}$ & $\mathbf{Y}$ & $\mathbf{Y b}$ & $\mathrm{Zn}$ & $\mathrm{Zr}$ \\
\hline 17-SM-26 B & 0.5 & 6.7 & $<5$ & 3 & 33.5 & 3.3 & 79 & 260 \\
17-SM-26 C & 0.63 & 8.4 & $<5$ & 5 & 38.9 & 4.05 & 72 & 220 \\
17-SM-27 & 0.59 & 6.3 & $<5$ & 4 & 40.1 & 3.71 & 127 & 707 \\
17-SM-28 & 0.46 & 5 & $<5$ & 1 & 27.5 & 2.88 & 43 & 183 \\
17-SM-29 & 0.41 & 5.9 & $<5$ & 2 & 21.1 & 2.77 & 42 & 118 \\
17-SM-30 & 0.36 & 5.8 & 6 & 3 & 20.8 & 2.79 & 49 & 169 \\
17-SM-31 & 0.24 & 4.8 & $<5$ & 3 & 13 & 1.43 & 50 & 298 \\
\hline Sample ID & $\mathrm{Tm}$ & $\mathbf{U}$ & $\mathbf{V}$ & $\mathbf{W}$ & $\mathbf{Y}$ & $\mathrm{Yb}$ & $\mathrm{Zn}$ & $\mathrm{Zr}$ \\
\hline 16-SM-13Caw & 0.25 & 5 & $<5$ & 2 & 12.3 & 1.87 & 18 & 179 \\
16-SM-14aw & 0.25 & 4.2 & $<5$ & 2 & 13.4 & 1.6 & 20 & 216 \\
16-SM-16aw & 0.17 & 2.9 & $<5$ & 2 & 10.1 & 1.24 & 27 & 800 \\
17-SM-21Aaw & 0.19 & 3.4 & 21 & 2 & 9.1 & 1.45 & 18 & 864 \\
17-SM-22aw & 0.22 & 5.1 & 13 & 2 & 14.6 & 1.57 & 30 & 175 \\
17-SM-26Aaw & 0.2 & 4.9 & $<5$ & 3 & 11 & 1.56 & 22 & 272 \\
17-SM-26Caw & 0.27 & 4.3 & $<5$ & 3 & 16.5 & 1.87 & 40 & 768 \\
17-SM-27aw & 0.2 & 2.9 & 73 & 1 & 12.6 & 1.33 & 21 & 191 \\
\hline Sample ID & Tm & $\mathbf{U}$ & $\mathbf{V}$ & $\mathbf{W}$ & $\mathbf{Y}$ & $\mathrm{Yb}$ & $\mathrm{Zn}$ & $\mathrm{Zr}$ \\
\hline H18-SN6 & 0.56 & 6.61 & 5 & 1 & 35.4 & 3.51 & 75 & 244 \\
H18-SN15 & 0.50 & 7.07 & 5 & 2 & 31.0 & 3.31 & 78 & 224 \\
\hline
\end{tabular}


Table VII: Precision of Trace Element analyses

\begin{tabular}{|c|c|c|c|c|c|}
\hline Element & 10-LT-05 & 10-LT-05 & 10-LT-05 & Average & $2 \sigma$ \\
\hline $\mathrm{Ag}$ & $<0.5$ & $<0.5$ & $<0.5$ & $<0.5$ & - \\
\hline As & $<5$ & $<5$ & $<5$ & $<5$ & - \\
\hline $\mathrm{Ba}$ & 517 & 515 & 554 & 540 & 40 \\
\hline $\mathrm{Cd}$ & $<0.5$ & $<0.5$ & $<0.5$ & 0.63 & 0.26 \\
\hline $\mathrm{Ce}$ & 49.0 & 45.6 & 48.8 & 48.0 & 3.8 \\
\hline Co & 37 & 42 & 37 & 40 & 4 \\
\hline $\mathrm{Cr}$ & 180 & 190 & 160 & 185 & 22 \\
\hline Cs & 0.24 & 0.24 & 0.23 & 0.23 & 0.06 \\
\hline $\mathrm{Cu}$ & 40 & 43 & 40 & 42 & 4 \\
\hline Dy & 3.66 & 3.48 & 3.55 & 3.63 & 0.32 \\
\hline $\mathrm{Er}$ & 1.9 & 1.81 & 1.93 & 1.96 & 0.16 \\
\hline Eu & 1.59 & 1.46 & 1.56 & 1.59 & 0.16 \\
\hline $\mathbf{G a}$ & 19.6 & 18.0 & 19.4 & 19.9 & 1.6 \\
\hline Gd & 4.41 & 4.19 & 4.73 & 4.46 & 0.46 \\
\hline Hf & 3.4 & 3.5 & 3.4 & 3.6 & 0.2 \\
\hline Ho & 0.74 & 0.68 & 0.68 & 0.72 & 0.08 \\
\hline La & 22.6 & 21.2 & 22.3 & 22.4 & 2.0 \\
\hline Li & $<10$ & 10 & 10 & 10 & 0 \\
\hline Lu & 0.23 & 0.21 & 0.25 & 0.25 & 0.04 \\
\hline Mo & 2 & 1 & 1 & 1 & 0 \\
\hline $\mathrm{Nb}$ & 10.8 & 10.5 & 10.7 & 10.9 & 1.0 \\
\hline $\mathrm{Nd}$ & 26.9 & 25.2 & 26.7 & 25.6 & 2.0 \\
\hline $\mathrm{Ni}$ & 115 & 120 & 109 & 116 & 10 \\
\hline $\mathrm{Pb}$ & 2 & 3 & 3 & 4 & 4 \\
\hline $\operatorname{Pr}$ & 6.32 & 5.96 & 6.24 & 6.21 & 0.62 \\
\hline $\mathbf{R b}$ & 12.2 & 12.1 & 11.6 & 12.5 & 0.8 \\
\hline Sc & 17 & 15 & 16 & 17 & 2 \\
\hline Sm & 5.15 & 4.92 & 5.31 & 5.17 & 0.54 \\
\hline Sn & 1 & 1 & 1 & 1 & 0 \\
\hline $\mathrm{Sr}$ & 919 & 864 & 948 & 935 & 48 \\
\hline $\mathrm{Ta}$ & 0.5 & 0.6 & 0.5 & 0.6 & 0.2 \\
\hline $\mathbf{T b}$ & 0.66 & 0.63 & 0.67 & 0.66 & 0.06 \\
\hline Th & 1.99 & 1.80 & 1.94 & 1.99 & 0.24 \\
\hline $\mathrm{TI}$ & $<10$ & $<10$ & $<10$ & 10 & 0.00 \\
\hline $\mathrm{Tm}$ & 0.27 & 0.24 & 0.25 & 0.27 & 0.04 \\
\hline $\mathbf{U}$ & 0.55 & 0.50 & 0.57 & 0.59 & 0.10 \\
\hline
\end{tabular}


Table VII: Precision of Trace Element analyses cont.

\begin{tabular}{cccccc}
\hline Element & $\mathbf{1 0 - L T - 0 5}$ & $\mathbf{1 0 - L T - 0 5}$ & $\mathbf{1 0 - L T - 0 5}$ & Average & $\mathbf{2 \sigma}$ \\
\hline $\mathbf{V}$ & 163 & 165 & 130 & 164 & 20 \\
$\mathbf{W}$ & $<1$ & 1 & 1 & 1 & 0 \\
$\mathbf{Y}$ & 18.5 & 18.0 & 18.2 & 18.7 & 1.5 \\
$\mathbf{Y b}$ & 1.50 & 1.65 & 1.59 & 1.68 & 0.26 \\
$\mathbf{Z n}$ & 91 & 97 & 88 & 93 & 8 \\
$\mathbf{Z r}$ & 149 & 151 & 157 & 151 & 14 \\
\hline
\end{tabular}

Note: The first three columns of trace element data for 10-LT-05 are the results of individual runs obtained with three batches of samples submitted to ALS for geochemical analysis.

Averages and standard deviation $(\sigma)$ for 10-LT-05 are calculated from 31 analyses by ALS (Nov. 2013-Nov. 2019). 
Table VII: Precision of Trace Element analyses cont.

\begin{tabular}{|c|c|c|c|c|c|c|}
\hline Element & BHVO-2 & BHVO-2 & BHVO-2 & Average & $2 \sigma$ & $\begin{array}{c}\text { USGS Recommended } \\
\text { Values }\end{array}$ \\
\hline $\mathrm{Ag}$ & $<0.5$ & $<0.5$ & $<0.5$ & $<0.5$ & - & - \\
\hline As & $<5$ & $<5$ & $<5$ & $<5$ & - & - \\
\hline $\mathrm{Ba}$ & 126 & 128 & 138 & 134 & 14 & 130 \\
\hline Cd & $<0.5$ & $<0.5$ & $<0.5$ & 0.73 & 0.38 & - \\
\hline $\mathrm{Ce}$ & 37.8 & 35.5 & 37.4 & 37.4 & 3.0 & 38 \\
\hline Co & 41 & 45 & 39 & 44 & 6 & 45 \\
\hline $\mathrm{Cr}$ & 300 & 310 & 270 & 304 & 38 & 280 \\
\hline Cs & 0.1 & 0.1 & 0.04 & 0.09 & 0.04 & 0.1 \\
\hline $\mathrm{Cu}$ & 142 & 134 & 128 & 136 & 10 & 127 \\
\hline Dy & 5.07 & 5.02 & 5.3 & 5.28 & 0.52 & - \\
\hline Er & 2.46 & 2.19 & 2.62 & 2.55 & 0.44 & - \\
\hline $\mathrm{Eu}$ & 2 & 1.91 & 1.94 & 2.04 & 0.28 & - \\
\hline Ga & 22.2 & 19.9 & 21.3 & 21.1 & 2.4 & 21.7 \\
\hline Gd & 6.1 & 5.87 & 6.34 & 6.25 & 0.76 & 6.3 \\
\hline Hf & 4.4 & 4.3 & 4.5 & 4.5 & 0.4 & 4.1 \\
\hline Ho & 0.98 & 0.98 & 0.96 & 0.98 & 0.10 & 1.04 \\
\hline La & 15.1 & 14.5 & 14.9 & 15.5 & 2.06 & 15 \\
\hline Li & $<10$ & 10 & $<10$ & 10.00 & 0.00 & - \\
\hline Lu & 0.26 & 0.25 & 0.28 & 0.28 & 0.04 & 0.28 \\
\hline Mo & 2 & 4 & 4 & 3 & 2 & - \\
\hline $\mathrm{Nb}$ & 17.6 & 17.1 & 17.9 & 17.7 & 1.8 & 18 \\
\hline $\mathrm{Nd}$ & 25.5 & 24.5 & 24.5 & 24.9 & 2.4 & 25 \\
\hline $\mathbf{N i}$ & 137 & 124 & 114 & 126 & 14 & 119 \\
\hline $\mathrm{Pb}$ & $<2$ & $<2$ & $<2$ & 4.33 & 4.62 & - \\
\hline $\mathrm{Pr}$ & 5.23 & 5.08 & 5.26 & 5.35 & 0.70 & - \\
\hline $\mathbf{R b}$ & 9.0 & 8.8 & 8.5 & 9.1 & 1.2 & 9.8 \\
\hline Sc & 29 & 30 & 28 & 30 & 2 & 32 \\
\hline Sm & 6.39 & 6.08 & 6.42 & 6.30 & 0.72 & 6.2 \\
\hline Sn & 2 & 2 & 2 & 2 & 0 & 1.9 \\
\hline $\mathrm{Sr}$ & 411 & 386 & 407 & 407 & 34 & 389 \\
\hline Ta & 1.1 & 1.1 & 1 & 1.1 & 0.2 & 1.4 \\
\hline $\mathrm{Tb}$ & 0.91 & 0.89 & 1 & 0.93 & 0.12 & 0.9 \\
\hline Th & 1.24 & 1.15 & 1.19 & 1.24 & 0.18 & 1.2 \\
\hline TI & $<10$ & $<10$ & $<10$ & 10.00 & 0.00 & - \\
\hline $\mathrm{Tm}$ & 0.34 & 0.32 & 0.30 & 0.32 & 0.04 & - \\
\hline $\mathbf{U}$ & 0.43 & 0.41 & 0.40 & 0.42 & 0.06 & - \\
\hline $\mathbf{v}$ & 352 & 331 & 274 & 333 & 56 & 317 \\
\hline w & $<1$ & 1 & 2 & 1 & 0 & - \\
\hline
\end{tabular}


Table VII: Precision of Trace Element analyses

\begin{tabular}{ccccccc}
\hline Element & BHVO-2 & BHVO-2 & BHVO-2 & Average & 2 $\boldsymbol{c}$ & $\begin{array}{c}\text { USGS Recommended } \\
\text { Values }\end{array}$ \\
\hline Y & 24.4 & 23.6 & 23.9 & 24.6 & 2.4 & 26 \\
Yb & 1.87 & 1.77 & 1.93 & 1.98 & 0.28 & 2 \\
Zn & 102 & 107 & 99 & 106 & 10 & 103 \\
Zr & 169 & 172 & 176 & 175 & 16 & 172 \\
\hline
\end{tabular}

Note: The first three columns of trace element data for BHVO-2 are the results of individual runs obtained with three batches of samples submitted to ALS for geochemical analysis. Averages and standard deviation ( $\sigma$ ) for BHVO-2 are calculated from 9 analyses by ALS (Jan. 2017-Nov. 2019). 
Table VIII: Isotopic Results

\begin{tabular}{|c|c|c|c|c|c|c|c|c|c|}
\hline Sample ID & $87 \mathrm{Rb} / 86 \mathrm{Sr}$ & $\begin{array}{l}87 \mathrm{Sr} / 86 \mathrm{Sr} \\
\text { measured }\end{array}$ & $\begin{array}{c}87 \mathrm{Sr} / 86 \mathrm{Sr} \\
\text { initial }\end{array}$ & $2 \sigma$ & $147 \mathrm{Sm} / 144 \mathrm{Nd}$ & $\begin{array}{c}143 \mathrm{Nd} / 144 \mathrm{Nd} \\
\text { measured }\end{array}$ & $\begin{array}{c}143 \mathrm{Nd} / 144 \mathrm{Nd} \\
\text { initial }\end{array}$ & $2 \sigma$ & $\varepsilon N d$ initial \\
\hline 16-SM-09 & 3.48909 & 0.70665 & 0.70541 & 0.000016 & 0.12113 & 0.512570 & 0.512550 & 0.000004 & -1.09 \\
\hline $16-S M-16$ & 3.40854 & 0.70761 & 0.70640 & 0.000012 & 0.20535 & 0.512532 & 0.512499 & 0.000005 & -2.09 \\
\hline $16-S M-20 C$ & 0.15287 & 0.70592 & 0.70587 & 0.000011 & 0.12126 & 0.512023 & 0.512004 & 0.000010 & -12.09 \\
\hline 16-SM-21B & 2.66368 & 0.70826 & 0.70731 & 0.000011 & 0.12256 & 0.512528 & 0.512508 & 0.000005 & -1.91 \\
\hline $16-S M-33 A$ & 1.02292 & 0.70617 & 0.70581 & 0.000012 & 0.10227 & 0.512535 & 0.512518 & 0.000010 & -1.71 \\
\hline $16-S M-40$ & 49.16896 & 0.72343 & 0.70617 & 0.000016 & 0.11456 & 0.512515 & 0.512496 & 0.000004 & -2.15 \\
\hline $16-S M-42$ & 21.90229 & 0.71328 & 0.70559 & 0.000012 & 0.20535 & 0.512523 & 0.512490 & 0.000004 & -2.27 \\
\hline $16-S M-44$ & 0.17355 & 0.70438 & 0.70432 & 0.000016 & 0.20535 & 0.512699 & 0.512666 & 0.000006 & 1.10 \\
\hline $16-S M-50$ & 7.44343 & 0.70834 & 0.70571 & 0.000015 & 0.11583 & 0.512546 & 0.512527 & 0.000006 & -1.55 \\
\hline 17-SM-03A & 15.60657 & 0.71005 & 0.70453 & 0.000015 & 0.11971 & 0.512529 & 0.512509 & 0.000006 & -1.89 \\
\hline 17-SM-03B & 11.49824 & 0.71157 & 0.70751 & 0.000018 & 0.20535 & 0.512522 & 0.512489 & 0.000006 & -2.28 \\
\hline $17-S M-03 C$ & 10.66639 & 0.70884 & 0.70507 & 0.000017 & 0.20535 & 0.512533 & 0.512500 & 0.000007 & -2.08 \\
\hline 17-SM-07 & 9.04856 & 0.71071 & 0.70751 & 0.000015 & 0.10547 & 0.512620 & 0.512603 & 0.000005 & -0.06 \\
\hline 17-SM-09 & 2.12071 & 0.70993 & 0.70918 & 0.000012 & 0.10648 & 0.512519 & 0.512502 & 0.000010 & -2.03 \\
\hline 17-SM-14 & 3.70973 & 0.70663 & 0.70531 & 0.000012 & 0.10816 & 0.512571 & 0.512553 & 0.000006 & -1.03 \\
\hline 17-SM-17A & 7.76804 & 0.70869 & 0.70556 & 0.000015 & 0.20535 & 0.512539 & 0.512506 & 0.000008 & -1.96 \\
\hline 17-SM-19 & 5.26465 & 0.70742 & 0.70595 & 0.000010 & 0.20535 & 0.512536 & 0.512503 & 0.000006 & -2.01 \\
\hline $17-S M-21 \mathrm{~A}$ & 4.56482 & 0.70734 & 0.70572 & 0.000012 & 0.20535 & 0.512537 & 0.512503 & 0.000008 & -2.00 \\
\hline $17-S M-26 C$ & 5.77320 & 0.70856 & 0.70652 & 0.000012 & 0.20535 & 0.512544 & 0.512510 & 0.000004 & -1.87 \\
\hline 17-SM-27 & 2.11770 & 0.70749 & 0.70674 & 0.000011 & 0.20535 & 0.512511 & 0.512477 & 0.000006 & -2.51 \\
\hline 17-SM-30 & 3.19658 & 0.70656 & 0.70542 & 0.000015 & 0.10645 & 0.512568 & 0.512550 & 0.000008 & -1.08 \\
\hline 17-SM-31 & 2.53275 & 0.70638 & 0.70548 & 0.000014 & 0.08056 & 0.512506 & 0.512493 & 0.000006 & -2.21 \\
\hline
\end{tabular}


Table VIII: Isotopic Results Cont.

\begin{tabular}{|c|c|c|c|c|c|c|c|c|c|c|c|c|}
\hline Sample ID & $\underset{(p p m)}{U}$ & $\begin{array}{c}\text { Th } \\
\text { (ppm) }\end{array}$ & $\begin{array}{c}\mathrm{Pb} \\
(\mathrm{ppm})\end{array}$ & $\begin{array}{c}208 \mathrm{~Pb} / 204 \mathrm{~Pb} \\
\text { measured }\end{array}$ & $\begin{array}{c}207 \mathrm{~Pb} / 204 \mathrm{~Pb} \\
\text { measured }\end{array}$ & $\begin{array}{c}206 \mathrm{~Pb} / 204 \mathrm{~Pb} \\
\text { measured }\end{array}$ & $\begin{array}{c}208 \mathrm{~Pb} / 204 \mathrm{~Pb} \\
\text { initial }\end{array}$ & $2 \sigma$ & $\begin{array}{c}207 \mathrm{~Pb} / 204 \mathrm{~Pb} \\
\text { initial }\end{array}$ & $2 \sigma$ & $\begin{array}{c}206 \mathrm{~Pb} / 204 \mathrm{~Pb} \\
\text { initial }\end{array}$ & $2 \sigma$ \\
\hline 16-SM-09 & 4.26 & 16.25 & 23 & 38.873 & 15.653 & 19.156 & 38.815 & 0.002 & 15.650 & 0.001 & 19.109 & 0.001 \\
\hline $16-S M-20 C$ & 2.21 & 7.81 & 13 & 38.706 & 15.619 & 18.935 & 38.657 & 0.001 & 15.617 & 0.000 & 18.893 & 0.001 \\
\hline $16-S M-21 B$ & 6.01 & 19.2 & 34 & 38.930 & 15.660 & 19.238 & 38.884 & 0.001 & 15.658 & 0.000 & 19.194 & 0.001 \\
\hline $16-S M-33 A$ & 2.78 & 7.41 & 16 & 38.903 & 15.661 & 19.210 & 38.865 & 0.001 & 15.659 & 0.000 & 19.166 & 0.001 \\
\hline $16-S M-40$ & 4.82 & 21.3 & 23 & 38.918 & 15.658 & 19.210 & 38.842 & 0.002 & 15.656 & 0.001 & 19.158 & 0.001 \\
\hline $16-S M-42$ & 5.34 & 22.5 & 23 & 38.910 & 15.657 & 19.209 & 38.830 & 0.002 & 15.655 & 0.001 & 19.151 & 0.001 \\
\hline $16-S M-44$ & 0.92 & 2.36 & 6 & 38.443 & 15.585 & 18.784 & 38.411 & 0.002 & 15.583 & 0.001 & 18.746 & 0.001 \\
\hline $16-S M-50$ & 13.25 & 13.5 & 33 & 38.896 & 15.661 & 19.265 & 38.863 & 0.002 & 15.657 & 0.001 & 19.165 & 0.001 \\
\hline 17-SM-03A & 7.37 & 24.7 & 26 & 38.887 & 15.658 & 19.192 & 38.795 & 0.002 & 15.654 & 0.001 & 19.108 & 0.001 \\
\hline 17-SM-03B & 7.46 & 25 & 22 & 38.912 & 15.661 & 19.213 & 38.845 & 0.002 & 15.659 & 0.001 & 19.153 & 0.001 \\
\hline $17-S M-03 C$ & 7.49 & 24 & 31 & 38.896 & 15.657 & 19.207 & 38.820 & 0.002 & 15.654 & 0.001 & 19.135 & 0.001 \\
\hline 17-SM-07 & 5.14 & 21.6 & 24 & 38.840 & 15.644 & 19.120 & 38.766 & 0.002 & 15.641 & 0.001 & 19.067 & 0.001 \\
\hline 17-SM-09 & 4.91 & 19 & 26 & 38.882 & 15.653 & 19.179 & 38.822 & 0.001 & 15.652 & 0.000 & 19.132 & 0.001 \\
\hline 17-SM-14 & 5.81 & 19.55 & 25 & 38.857 & 15.652 & 19.144 & 38.793 & 0.002 & 15.649 & 0.001 & 19.085 & 0.001 \\
\hline 17-SM-17A & 9.37 & 20.5 & 28 & 38.896 & 15.664 & 19.280 & 38.847 & 0.001 & 15.656 & 0.000 & 19.143 & 0.001 \\
\hline 17-SM-19 & 13.5 & 13.7 & 39 & 38.890 & 15.658 & 19.203 & 38.856 & 0.002 & 15.658 & 0.001 & 19.159 & 0.001 \\
\hline $17-S M-21 \mathrm{~A}$ & 5.15 & 9.77 & 18 & 38.899 & 15.661 & 19.230 & 38.854 & 0.002 & 15.658 & 0.001 & 19.159 & 0.002 \\
\hline $17-S M-26 C$ & 6.25 & 12.5 & 23 & 38.888 & 15.657 & 19.220 & 38.843 & 0.001 & 15.654 & 0.001 & 19.152 & 0.001 \\
\hline 17-SM-27 & 4.98 & 18.5 & 21 & 38.902 & 15.654 & 19.192 & 38.830 & 0.001 & 15.651 & 0.000 & 19.133 & 0.001 \\
\hline $17-S M-30$ & 5.46 & 20 & 20 & 38.883 & 15.653 & 19.167 & 38.800 & 0.001 & 15.650 & 0.000 & 19.098 & 0.001 \\
\hline 17-SM-31 & 4.75 & 14.7 & 26 & 38.863 & 15.650 & 19.164 & 38.816 & 0.001 & 15.648 & 0.000 & 19.118 & 0.001 \\
\hline
\end{tabular}


Table VIII: Isotopic Results Cont.

\begin{tabular}{|c|c|c|c|c|c|c|c|c|c|c|c|c|c|c|c|}
\hline \multicolumn{2}{|l|}{ Sample ID } & \multirow[t]{2}{*}{$87 \mathrm{Rb} / 86 \mathrm{Sr}$} & \multicolumn{2}{|c|}{$\begin{array}{l}87 \mathrm{Sr} / 86 \mathrm{Sr} \\
\text { Measured }\end{array}$} & \multicolumn{2}{|c|}{$\begin{array}{c}87 \mathrm{Sr} / 86 \mathrm{Sr} \\
\text { initial }\end{array}$} & 20 & \multicolumn{2}{|c|}{$147 \mathrm{Sm} / 144 \mathrm{Nd}$} & \multicolumn{2}{|c|}{$\begin{array}{c}143 \mathrm{Nd} / 144 \mathrm{Nd} \\
\text { measured }\end{array}$} & \multicolumn{2}{|c|}{$\begin{array}{c}143 \mathrm{Nd} / 144 \mathrm{Nd} \\
\text { initial }\end{array}$} & $2 \sigma$ & $\begin{array}{c}\varepsilon N d \\
\text { initial }\end{array}$ \\
\hline \multicolumn{15}{|c|}{ Acid-washed Samples } & \\
\hline \multicolumn{2}{|c|}{ 16-SM-16aw } & 4.96809 & \multicolumn{2}{|c|}{0.70729} & \multicolumn{2}{|c|}{0.70553} & 0.000012 & \multicolumn{2}{|c|}{0.09970} & \multicolumn{2}{|c|}{0.512552} & \multicolumn{2}{|c|}{0.512536} & 0.000008 & -1.37 \\
\hline \multicolumn{2}{|c|}{ 17-SM-21Aaw } & 5.10585 & \multicolumn{2}{|c|}{0.70731} & \multicolumn{2}{|c|}{0.70551} & 0.00001 & \multicolumn{2}{|c|}{0.11531} & \multicolumn{2}{|c|}{0.512569} & \multicolumn{2}{|c|}{0.512550} & 0.000018 & -1.10 \\
\hline \multicolumn{2}{|c|}{ 17-SM-26Caw } & 8.86186 & \multicolumn{2}{|c|}{0.70855} & \multicolumn{2}{|c|}{0.70542} & 0.00001 & \multicolumn{2}{|c|}{0.09838} & \multicolumn{2}{|c|}{0.512567} & \multicolumn{2}{|c|}{0.512551} & 0.000006 & -1.07 \\
\hline \multicolumn{2}{|c|}{ 17-SM-27aw } & 4.89395 & & 0650 & 0.70 & 477 & 0.0000 & 0.06 & & & 512512 & 0.5125 & & 0.000008 & -2.04 \\
\hline Sample ID & $\begin{array}{c}\mathrm{U} \\
\text { (ppm) }\end{array}$ & $\begin{array}{c}\text { Th } \\
\text { (ppm) }\end{array}$ & $\begin{array}{c}\mathrm{Pb} \\
\text { (ppm) }\end{array}$ & $\begin{array}{r}208 \mathrm{~Pb} \\
\text { mea }\end{array}$ & $\begin{array}{l}4 \mathrm{~Pb} \\
\text { ed }\end{array}$ & $\begin{array}{r}207 \mathrm{P} \\
\mathrm{me}\end{array}$ & $\begin{array}{l}204 \mathrm{~Pb} \\
\text { ured } \\
\end{array}$ & $\begin{array}{c}206 \mathrm{~Pb} / 204 \mathrm{~Pb} \\
\text { measured }\end{array}$ & $\begin{array}{r}208 \mathrm{~Pb} \\
\text { ini }\end{array}$ & $4 \mathrm{~Pb}$ & $2 \sigma$ & $\begin{array}{c}207 \mathrm{~Pb} / 204 \mathrm{~Pb} \\
\text { intial }\end{array}$ & $2 \sigma$ & $\begin{array}{c}206 \mathrm{~Pb} / 204 \mathrm{~Pb} \\
\text { initial }\end{array}$ & $2 \sigma$ \\
\hline & & & & & & & Acic & d-washed Samp & & & & & & & \\
\hline 16-SM-16aw & 2.91 & 3.8 & 18 & 38 & & & 661 & 19.229 & 38 & & 0.003 & 15.659 & 0.001 & 19.188 & 0.001 \\
\hline 17-SM-21Aaw & 3.42 & 4.74 & 17 & 38 & & & 661 & 19.223 & 38 & & 0.002 & 15.659 & 0.001 & 19.173 & 0.001 \\
\hline 17-SM-26Caw & 4.28 & 8.1 & 24 & 38 & & & 659 & 19.218 & 38 & & 0.002 & 15.657 & 0.001 & 19.173 & 0.001 \\
\hline 17-SM-27aw & 2.93 & 6.44 & 9 & 38 & & & 654 & 19.182 & 38 & & 0.002 & 15.650 & 0.001 & 19.101 & 0.001 \\
\hline
\end{tabular}




\section{Table IX: Sr Isotopic Precision}

\begin{tabular}{cccc}
\hline Sample ID & ${ }^{87} \mathrm{Sr} /{ }^{86} \mathrm{Sr}$ & Average & $\mathbf{2 \sigma}$ \\
\hline NBS987 & 0.710238 & & \\
NBS987 & 0.710243 & & \\
NBS987 & 0.710237 & 0.710244 & 0.000016 \\
NBS987 & 0.710237 & & \\
NBS987 & 0.710258 & & \\
NBS987 & 0.710250 & & \\
\hline BCR-2 & 0.704991 & 0.705002 & 0.000018 \\
BCR-2 & 0.705009 & & \\
BCR-2 & 0.705005 & & \\
\hline
\end{tabular}

Note:

a) Recommended value for SRM 987 is ${ }^{87} \mathrm{Sr} /{ }^{86} \mathrm{Sr}=0.710252 \pm 13(2 \sigma)$ (Weis et al., 2006)

b) Recommended value for BCR-2 is ${ }^{87} \mathrm{Sr} /{ }^{86} \mathrm{Sr}=0.705019 \pm 16(2 \sigma)$ (Weis et al., 2006)

\section{Table X: Nd Isotopic Precision}

\begin{tabular}{cccc}
\hline Sample ID & ${ }^{143} \mathrm{Nd} /{ }^{144} \mathrm{Nd}$ & Average & $\mathbf{2 \sigma}$ \\
\hline Nd Std & 0.511814 & & \\
Nd Std & 0.511825 & & \\
Nd Std & 0.511808 & 0.511814 & 0.000014 \\
Nd Std & 0.511810 & & \\
Nd Std & 0.511819 & & \\
Nd Std & 0.511806 & & \\
\hline BCR-2 & 0.512622 & 0.512620 & 0.000008 \\
BCR-2 & 0.512624 & & \\
BCR-2 & 0.512615 & & \\
BCR-2 & 0.512618 & & \\
\hline
\end{tabular}

Note:

a) 38 runs of an internal $\mathrm{Nd}$ metal standard average ${ }^{143} \mathrm{Nd} /{ }^{144} \mathrm{Nd}=0.511827 \pm 15(2 \sigma)(2010-$ 2019), corresponding to a La Jolla value of 0.511857 based on comparative runs. Six runs of the La Jolla standard between 2012 and 2015 yield ${ }^{143} \mathrm{Nd} /{ }^{144} \mathrm{Nd}=0.511860 \pm 9$

b) Recommended value for BCR-2 are ${ }^{143} \mathrm{Nd} /{ }^{144} \mathrm{Nd}=0.512634 \pm 11(2 \sigma)$ (Weis et al., 2006) 


\section{Table XI: Pb Isotopic Precision}

\begin{tabular}{|c|c|c|c|c|c|c|c|c|c|}
\hline $\begin{array}{l}\text { Sample } \\
\text { ID }\end{array}$ & $\begin{array}{c}{ }^{208} \mathrm{~Pb} / \\
{ }^{204} \mathrm{~Pb}\end{array}$ & Average & $2 \sigma$ & $\begin{array}{c}{ }^{207} \mathrm{~Pb} / \\
{ }^{204} \mathrm{~Pb}\end{array}$ & Average & $2 \sigma$ & $\begin{array}{l}{ }^{206} \mathrm{~Pb} / \\
{ }^{204} \mathrm{~Pb}\end{array}$ & Average & $2 \sigma$ \\
\hline NBS981 & 36.709 & \multirow{7}{*}{36.7054} & \multirow{7}{*}{0.0050} & 15.4936 & \multirow{7}{*}{15.4923} & \multirow{7}{*}{0.0020} & 16.9384 & \multirow{7}{*}{16.9367} & \multirow{7}{*}{0.0022} \\
\hline NBS981 & 36.706 & & & 15.4924 & & & 16.9369 & & \\
\hline NBS981 & 36.705 & & & 15.4925 & & & 16.9372 & & \\
\hline NBS981 & 36.707 & & & 15.4931 & & & 16.9373 & & \\
\hline NBS981 & 36.702 & & & 15.4908 & & & 16.9349 & & \\
\hline NBS981 & 36.702 & & & 15.4913 & & & 16.9358 & & \\
\hline NBS981 & 36.706 & & & 15.4926 & & & 16.9365 & & \\
\hline BCR-2 & 38.796 & \multirow{4}{*}{38.7489} & \multirow{4}{*}{1.064} & 15.6207 & \multirow{4}{*}{15.6200} & \multirow{4}{*}{0.0020} & 18.7924 & \multirow{4}{*}{18.7688} & \multirow{4}{*}{0.0542} \\
\hline BCR-2 & 38.793 & & & 15.6201 & & & 18.7917 & & \\
\hline BCR-2 & 38.708 & & & 15.6207 & & & 18.7503 & & \\
\hline BCR-2 & 38.698 & & & 15.6186 & & & 18.7407 & & \\
\hline
\end{tabular}

Note:

a) Recommended values for NBS987 are ${ }^{206} \mathrm{~Pb} /{ }^{204} \mathrm{~Pb}=16.9356,{ }^{207} \mathrm{~Pb} /{ }^{204} \mathrm{~Pb}=15.4891,{ }^{208} \mathrm{~Pb} /{ }^{204} \mathrm{~Pb}$ $=36.7006$ (Todt et al., 1996)

b) Recommended values for BCR-2 are ${ }^{206} \mathrm{~Pb} /{ }^{204} \mathrm{~Pb}=18.7529 \pm 0.0195,{ }^{207} \mathrm{~Pb} /{ }^{204} \mathrm{~Pb}=15.6249 \pm$ $0.0040,{ }^{208} \mathrm{~Pb} /{ }^{204} \mathrm{~Pb}=38.7237 \pm 0.0405$ 
Table XII: Partition Ceofficients

\begin{tabular}{|c|c|c|c|c|c|c|c|c|c|c|c|c|c|c|c|c|c|c|c|}
\hline & Cs & $\mathbf{R b}$ & $\mathbf{K}$ & $\mathrm{Ba}$ & Sr & $\mathrm{Pb}$ & Th & $\mathbf{U}$ & $\mathrm{Zr}$ & $\mathrm{Hf}$ & $\mathrm{Ti}$ & $\mathrm{Ta}$ & $\mathbf{Y}$ & $\mathrm{Nb}$ & Sc & $\mathrm{Cr}$ & $\mathbf{N i}$ & Co & V \\
\hline \multicolumn{20}{|c|}{ Felsic/Acidic Melts } \\
\hline Plagioclase & 0.030 & 0.30 & 0.263 & 0.48 & 4.400 & 1.300 & 0.010 & 0.0315 & 0.200 & 0.030 & & 0.0300 & 0.250 & 0.57 & 0.010 & 0.010 & 1.50 & 0.15 & \\
\hline K-Feldspar & 0.025 & 0.40 & 1.490 & 22.0 & 5.900 & 2.545 & 0.022 & 0.0550 & 0.360 & 0.034 & & 0.0105 & 0.041 & 0.08 & 0.025 & & & & \\
\hline Biotite & 2.800 & 3.20 & 1.010 & 20.8 & 0.410 & 0.850 & 1.135 & 0.8300 & 0.590 & 0.640 & & 1.5500 & 1.200 & 6.75 & 12.45 & 19.65 & & & \\
\hline Amphibole & 0.010 & 0.40 & 24.20 & 0.30 & 1.275 & 0.430 & 0.160 & & 0.430 & 0.520 & 15.8 & 0.4300 & 9.640 & 4.10 & 14.00 & 40.00 & 7.75 & 37.0 & 19.5 \\
\hline Apatite & & & & & & 0.030 & & 43.700 & 0.906 & 0.878 & & & 162.0 & & & & & & \\
\hline Zircon & & & & & & 7.500 & 22.10 & 254.00 & & 971.0 & & 47.500 & 71.40 & & 68.65 & 189.5 & & 16.0 & \\
\hline Allanite & & 0.19 & & & & 0.920 & 484.0 & 15.500 & 0.290 & 18.90 & & 3.1500 & 95.50 & 1.70 & 55.85 & 380.0 & & 42.5 & \\
\hline
\end{tabular}

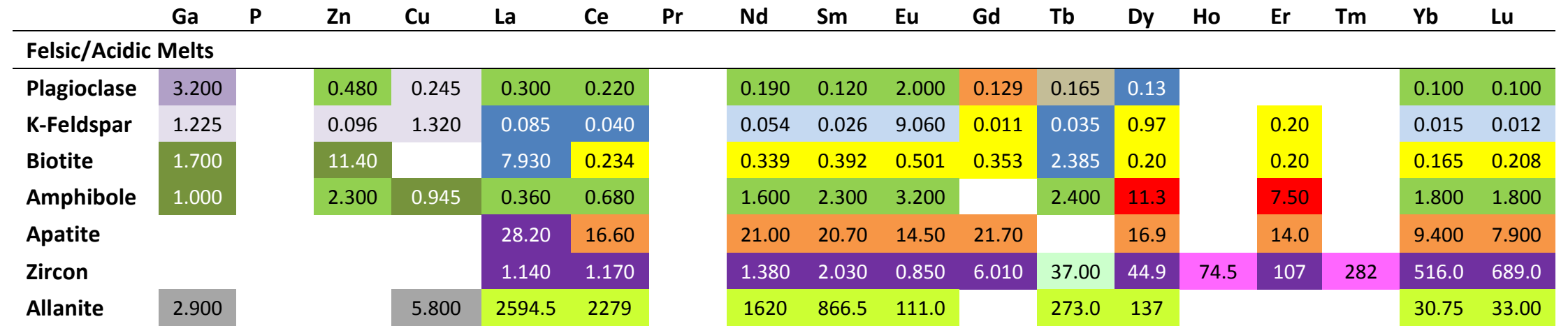




\section{References for Kd values:}

Partition coefficients were aggregated from the GERM Partition Coefficient (Kd) database; specific references are listed below:

$$
\mathrm{Kd}=\mathrm{C}_{\text {mineral element }} / \mathrm{C}_{\text {melt element }}
$$

Where $\mathrm{C}_{\text {mineral element }}$ is the concentration of the trace element in the mineral and $\mathrm{C}_{\text {melt element }}$ is the concentration of the trace element in the melt (both concentrations in ppm or weight percent).

\begin{tabular}{|l|l|}
\hline & Schnetzler, C.C. and Philpotts, J.A. (1970) \\
\hline & Bacon, C.R. and Druitt, T.H. (1988) \\
\hline & Leeman, W.P. and Phelps, D.W. (1981) \\
\hline & Philpotts, J.A. and Schnetzler, C.C. (1970) \\
\hline & Ewart, A. and Griffin, W.L. (1994) \\
\hline & Ewart, A. and Griffin, W.L. (1994) (Calculation from high and low) \\
\hline & Nagasawa, H. and Schnetzler, C.C. (1971) \\
\hline & Nash, W.P. and Crecraft, H.R. (1985) (Calculation from high and low) \\
\hline & Sisson, T.W. (1994) (Calculation from high and low) \\
\hline & Fujimaki, H. (1986) \\
\hline & Bea et al. (1994) \\
\hline & Mahood, G.A. and Hildreth, E.W. (1983) (Calculated from high and low) \\
\hline & Mahood, G.A. and Hildreth, E.W. (1983) \\
\hline
\end{tabular}

